\title{
INITIFi: DEVELOPMENT OF AN ABLATIVE LEADING EDGE FOR THE SPACE SHUTTLE ORBITER
}

\author{
(NASA-CE-132379) INITIAL DEVELOFAENT OF \\ AN ABLATIVE LEADING EDGE FOR THE SPACE \\ SHUTTLE ORBITER Pinal Eeport (Gruman \\ Aerisspace Corp.) 373 p HC $\$ 21.75$
}

$N 74-26317$

CSCL 22B $\quad 63 / 31$

Unclas

39396

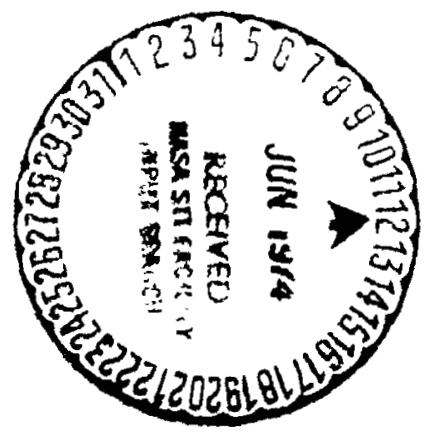



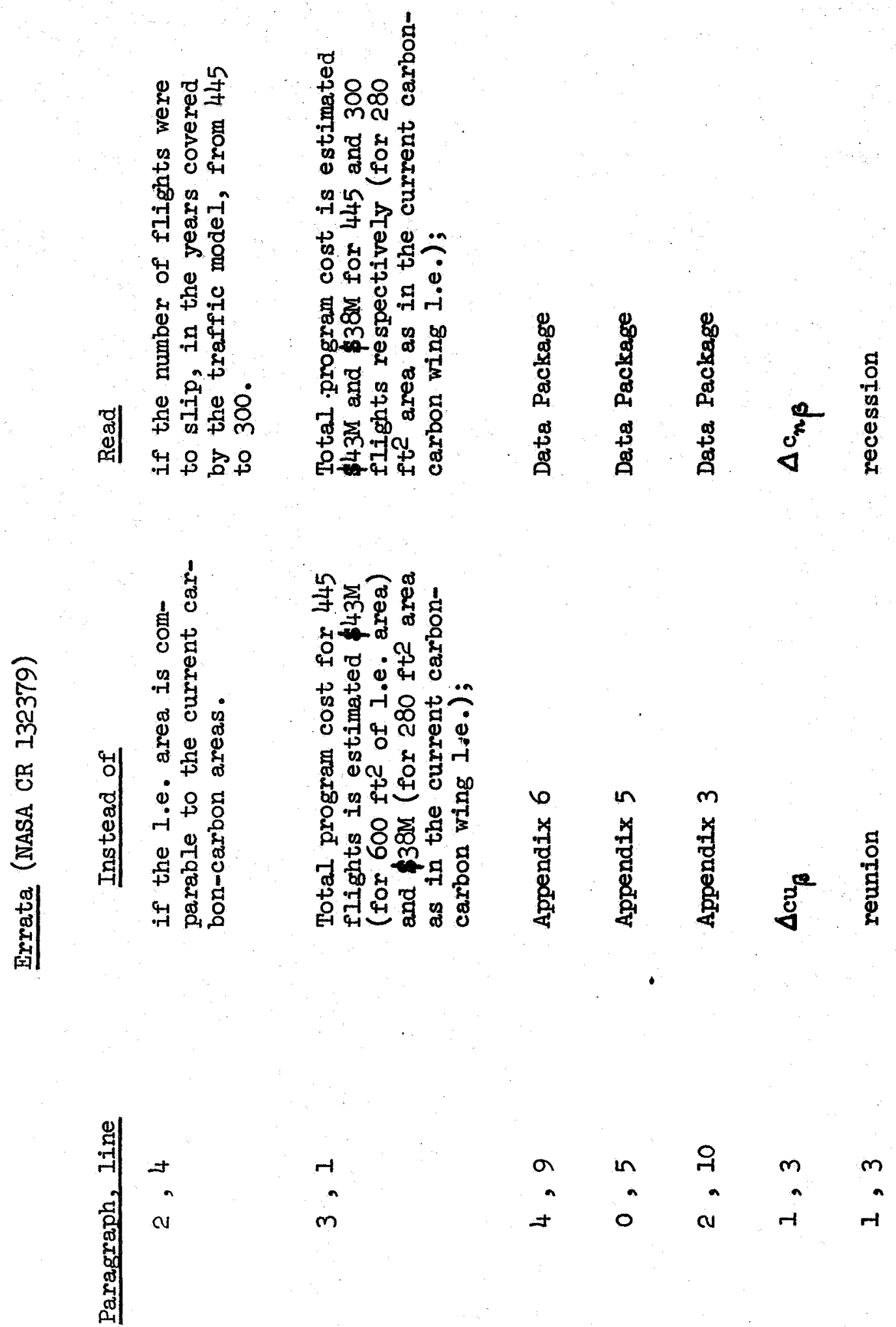

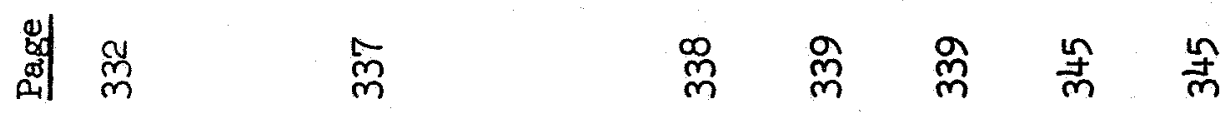




\section{INITIAL DEVELOPMENT OF AN ABLATIVE LEADING EDGE FOR THE SPACE SHUTTLE ORBITER}

by

G. DaForno and L. Fose, Grumman Aerospace Corporation

and

J. Graham and P. Roy, AVCO Systems Division

Prepared under Contract NAS 1-11416

March 1974

Grumman Aerospace Corpcration

Bethpage, New York 11714 


\begin{tabular}{|c|c|c|c|}
\hline $\begin{array}{l}\text { 1. meport No. } \\
\text { NASA CR-132379 }\end{array}$ & 2 Gow nment Actusion No. & \multicolumn{2}{|c|}{3 Accipunt's Covertos No } \\
\hline \multicolumn{2}{|l|}{ A. Trite and Subtille } & \multicolumn{2}{|c|}{5 Acpon Don 1973} \\
\hline \multicolumn{2}{|c|}{$\begin{array}{l}\text { INITIAL DEVELOPMENT OF AN ABL.ITIVE LEADING } \\
\text { EDGE FOR THE SPACE SHUTTLE ORBITER }\end{array}$} & \multicolumn{2}{|c|}{$\begin{array}{l}\text { 6. Porterming Orgemzetion cooce } \\
\text { NONE }\end{array}$} \\
\hline \multicolumn{2}{|c|}{ 7. Muthor(s) } & \multicolumn{2}{|c|}{$\begin{array}{l}\text { 8. Purtorming Orgenizution Report No. } \\
\text { NONE }\end{array}$} \\
\hline \multicolumn{2}{|c|}{ G. DaForno, J. Graham, P. Roy, L. Rose } & \multirow{2}{*}{\multicolumn{2}{|c|}{ 10. Work Unit No. }} \\
\hline \multirow{3}{*}{\multicolumn{2}{|c|}{$\begin{array}{l}\text { 9. Nrorming Orenimation Name and Adtrew } \\
\text { Grumman Aerospace Corporation } \\
\text { Bethpage, N.Y. } \\
\text { AVCO Systems Division } \\
\text { Willungton, Mass. }\end{array}$}} & & \\
\hline & & \multicolumn{2}{|c|}{$\begin{array}{r}11 \text { Contret or Grent No } \\
\text { NAS1 - } 11416\end{array}$} \\
\hline & & \multirow{2}{*}{\multicolumn{2}{|c|}{$\begin{array}{l}13 \text { Tree of Rapore and Period Covered } \\
\text { Final }\end{array}$}} \\
\hline \multirow{2}{*}{\multicolumn{2}{|c|}{$\begin{array}{l}\text { 12. Seonering Amery Nome und Adoress } \\
\text { National Aeronautics and Space Administration } \\
\text { Langley Research Center } \\
\text { Hampton, Virginia } 23365\end{array}$}} & & \\
\hline & & \multicolumn{2}{|c|}{ 14. Spontering Aponcy Code } \\
\hline \multicolumn{4}{|l|}{ 15. Sucodemantery Mots } \\
\hline \multicolumn{4}{|c|}{$\begin{array}{l}\text { 16. Aburat } \\
\text { A state-of-the-art preliminary design for typical wing areas is developed. Seven medium-density } \\
\text { ablators (with/without honeycomb, flown on Apollo, Prime, X15A2) are evaluated. The screening } \\
\text { tests include: 1) leading-edge models sequentially subjected to ascent heating, cold soak, entry heat. } \\
\text { ing, postentry pressure fluctuations, and touchdown shock and, } 2 \text { ) virgin/charred models subjected } \\
\text { to bondline strains. Two honeycomb reinforced } 30 \text { pcf elastomeric ablators were selected. Rough- } \\
\text { ness/recession degradation of low speed aerodynamics appears acceptable. The design. including } \\
\text { attachments, substructure and joints, is presented. }\end{array}$} \\
\hline \multicolumn{4}{|l|}{$\begin{array}{l}\text { 17. Key Word (Suginatod oy Author(s): } \\
\text { Charring Ablators } \\
\text { Shuttle Orbiter } \\
\text { Leading Edges } \\
\text { Thermal Protection System } \\
\text { Leading Edge Roughness }\end{array}$} \\
\hline $\begin{array}{l}\text { 19. Security Gosemit. (of thus report) } \\
\text { Unclassified }\end{array}$ & $\begin{array}{l}20 \text { Security Clesent lof imis posel } \\
\text { Unclassified }\end{array}$ & 21. No of Preps & 22. Price' \\
\hline
\end{tabular}

- For sale by the National Technical Information Service. Springfield. Virginia 22151 


\section{TABLE OF COMTENT'S}

Pege

Sumary . . . . . . . . . . . . . . . . . . . . . . . . 1

Foreword . . . . . . . . . . . . . . . . . . . . . . . 2

. Subject . . . . . . . . . . . . . . . . . . . . . . 4 4

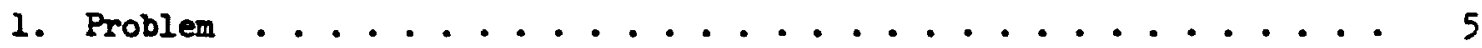

2. Design Ground Rules and Requirements ................. . 7

3. Orbiter L. E. Environment .................... 14

3.1 Thermal . . . . . . . . . . . . . . . . . . 14

3.2 structural ..................... 23

3.2.1 Static Structural Environment . . . . . . . . . 23

3.2.2 Dynamic Structural Environment ............ 28

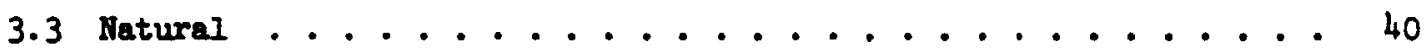

3.4 Aerodynamic . . . . . . . . . . . . . . . . . 44

3.5 Selecticn of Design Enviroment ............... 49

4. Aerodrnamic Characteristics Degradation Due to Roughness and

Recession (Preliminary Study) . . . . . . . . . . . . . 50

4.1 Review of State-of-the-Art ................ 51

4.1.1 Aerodynamic Characteristics Affected . . . . . . . . 51

4.2.2 Importance of Effects .............. 51

4.1 .3 Roughness ......................... 52

4.1.4 Leading Edge Shape Change ............... 64 
4.2 Methods for Determinins Cost Penalties for Aerodynamic Degradation Due to Effects of L. E. Roughness/Recession at Subsonic speede................... 71

4.3 Aerodynamic Degradation vs Koughness ............ 81

4.4 Minimizing Shape Change ................. . 94

4.5 Aerodynamic Degradation vs Recession Uncertaintles........ 94

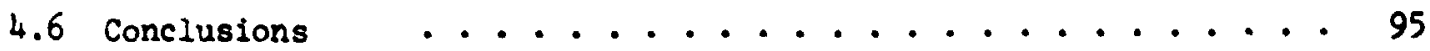

j. Ablator Selection ...................... 97

5.1 Ground Ru'es and Criteria for Selection of Candidate Ablators .................. . . 97

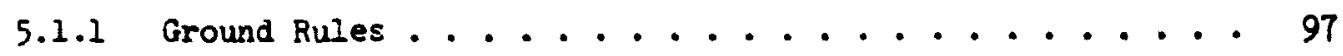

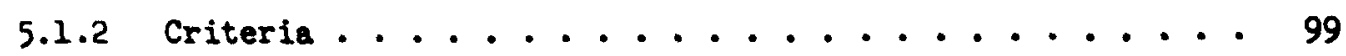

5.2 Selection of Candidate Materials . . . . . . . . . 102

5.2.1 Candidate Materials Selected . . . . . . . . . 102

5.2.2 Key Material Properties .............. 109

5.3 Screening Test Program ... . . . . . . . . . . . 109

5.3.1 Rationale ................. 109

5.3.2 Overview of Tests ................ 112

5.3.3 Ascent Heating of L. E. Models ............ 123

5.3.4 Cold soak of the L. E. Models ............ 131

5.3.5 Entry Heating of the L. E. Models .......... 131

5.3 .6 Vibration of L. E. Models ............ 234

5.3.7 Acceleration Test of L. E. Models .......... 142

5.3.8 Cutting of L. E. Models ............... 142

5.3.9 Flexure of Virgin Strips ............. 148

5.3.10 Charring of Strips............... 148 
5.3.11 Flexure of Charred Strips .............. 152

5.3.12 Cutting of Charred Strips ............. 152

5.4 Evaluation Criteria ................. 152

5.5 Evaluation of the Candidate Ablators ........... 167

5.6 Ablator selection .................. 174

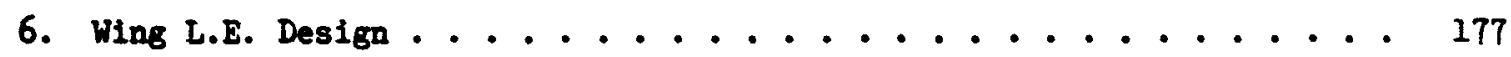

6.1 L.F. Rerurbishment and Design Concept . . . . . . . . . 177

6.1.1 Refurbishment Concepts ............. 177

6.1.2 Weight, Cost and Concepts Evaluation ......... 182

6.1.3 Refurbishment Concept Selection........... 190

6.2 Attachments ..................... 192

6.2.1 Design Ground Rules................ 193

6.2.2 Leading-Edge-to-Wing-Front-Beam Attachment Schemes . . 197

6.2.3 Trade-off Studies of L.E.-to-Front-Beam Attar ment ... 202

6.2.4 Selected L.E.-to-Front-Beam Attachment ........ 208

6.2.5 Selected Segment-to-Segment Attachments ........ 209

6.3 Ablator Design ................. 210

6.3.1 Design Thermal Loads .............. 210

6.3.2 Thickness Predictions Charts ............ 213

6.3.3 Safety Factor Rationale ............. 217

6.3 .4 Single Ablator ................. 223

6.3 .5 Shape optimization .............. 226

6.3.6 Ablator Requirements .............. 230 
Page

6.4 substructure Design .................. 232

6.4.1 Desigr. Eriteriz .............. 232

6.4.2 structirs: crncepts............... 233

6.4 .3 Scope of Structural Analysis ............ 238

0.4 .4 Static Loads \& Criteria for Trade-Off Analysis ..... 238

6.4.5 Development of Candidate Rib Sifffened Designs ..... 242

6.4 .6 Titanium vs Aluminum ............... 252

6.4.7 Tradeoff of Aluminum Designs and Design Selection . . . 252

6.5 Joirts ....................... 253

6.5 .1 Ablator/Ablator Joints ............ 257

6.5 .2 Ablator/RSI Joints .............. 294

6.6 Final Design .................. 310

6.6 .1 Drawing ..................... 310

6.6.2 Characteristics of the Final Design ......... 310

0.6.3 Final Design Weights ............. 316

T. Comments on Wins Special Areas and Fin L.E. . . . . . . . . 320

8. Wing Ablator Leading Edge Costs ... . . . . . . . . . . 322

8.1 Non-Recurring (DDTEE) Costs . . . . . . . . . . 322

8.2 Recurring Costs . . . . . . . . . . . . . 322

3.3 Program Costs .................. 325

9. Prospectives for Cost/Weight Improvements . . . . . . . . 328

9.1 :eided hblators . . . . . . . . . . . . . . . 328

9.2 Alternate Ablator Reinforcement Techniques . . . . . . . 329 
Page

9.3 Multiple Ablator Leading Edge . . . . . . . . . . . . 331

9.4 Honeycomb Ablator Reuse . . . . . . . . . . . . 332

9.5 Estimates for Cost Savings ................ 332

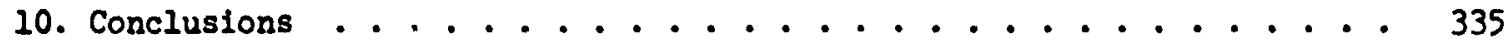

11. Recomendations ................... 338

21.1 Development of the Ablative L.E. . . . . . . . . 338

11.2 Tests with Models Fabricated Under the Present Study . . . . . 338

11.3 Plan for Detailed Study of Aerodynamic

Characteristics Degradation .............. 341

11.3.1 Study Criteria ............... 341

11.3 .2 Test Program ................ 342

11.3.3 Analysis and Comparisons with Data ........ 343

11.3.4 Analysis of Experimental Data and

Extrapolation to Flight ............ 343

11.3.5 Conclusions on Aerodynamic Performance

Degradation and Recommendations for Ablative

Leading Edge Design............... 345

12. References ...................... 346 
Colvyeniss

or

DATA PACKAGE*

1. Properties of Candidate Ablators

2. Detailed Eavironments

3. Test Data Reports for Ablator Screoning Tests

4. Detalled Supporting Data for the Substructure Desion

5. Models for Tests on Joints to be Carried Out by MASA, LRC

5.1 Tests on the Ablator/Ablator Joint

5.1.1 Rationale

5.1.2 Model Design * Test Data Evaluation

5.1.3 Ascent Heating Tests

5.2 Tests on the Ablator-RSI Joint

5.2.1 Rationale

5.2.2 Models Design and Test Data Evaluntion

6. L.E. Models for Planned Tests at MASA, JSC

6.1 Requirements

6.2 Test Environment and Rationale

6.3 Models Design

6.3.1 Thermal Design

6.3.2 Model Fabrication

6.3.3 ModeI Instrumentation

6.4 Prediction of T/C Response

"Detailed information on the leading edge design, aupporting data from teets, etc., on file at MASA, LRC. 
Trajectory and Aerodynamic Environment During Orblter

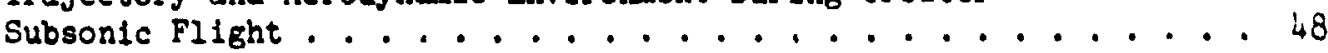

24 Roughness Levels ................... 55

25 Rnughress Levels - Flight/Zunnel ............... . .

26(a) zero Lift Drag Increase Due to LER Effects ......... . 58

26(b) Drag Plateaus for Cambered and Uncambered Wing on $\mathrm{H} 33$

at Moderate Lift .................. 59

Effect of IER on Isteral Stability Derivatives ........61

Recession on H33 Wing Leading Edge ............ 65

Concept for Leading Edge Shape Optimization . . . . . . . . 68

Total Recession of Some Candidate Ablators .......... . 69

Recession Rates of Some Candidate Ablators . . . . . . . 70

Recession Rate Date for Avcoat 5026-39 HC/G . . . . . . . . 72

Relation Between Float Time and $(L / D)_{\text {MAX }} \ldots \ldots 75$

Effects of Roughness on H-33: Correlation Between $\mathcal{C}_{\beta} \& \mathrm{~S}, \ldots 82$

H-33 040-A Lateral Characteristics ...........83

Effect of Elevator Deflection on H-33 Lateral Stability ..... 84

Effect of Foughness on H-33 Directional Stability . . . . . 86

38 High Lift Degradation Due to L. E. Roughness ......... 87

39 Maximum Acceptable Roughness Due to Landing Speed

Requirements for a Typical Orbiter. . . . . . . . . . . 88

$40 \quad \Sigma / D$ Buffer for Gruman 473 orbiter ............. 90

42 Extrapolated Tunnel Data Showing (I/D) Degration due to

L. E. Roughness . . . . . . Max . . . . . . . . 92

i2 Maximum Acceptable Roughness Due to Float Tlme Requirements for a Typical orbiter................... 93

43 Estimated Maximum Acceptable L. E. Roughness for One Orbiter . . 96

44 Key Environments For Sereening Candliate Ablators ........ 111 
45 screening Tests ................... 113

46 Typical Leading Elge Specimen . . . . . . . . . . . 115

47 Une Set of Flexure Models of the Candidate Ablators . . . . . . 115

48 Leading Edge Test Model ................. . 117

49 Flexure Tests Models .................. . 119

50 Comparison of Insulation Efficiency of Candidate Ablators . . . . 220

51 Comparisun of Ablation Histories of Candidate Materials ...... 121

52 Typical Shape Change Roughness of L. E. Models . . . . . . 122

53 Leading Edge Calorimeter Configuration - Rovers ARC Fecility . . 126

54 I. E. Models Appenrance After Ascent Heating . . . . . . . 130

55(a) Environment Maintalned During Cold Soak Test . . . . . . 132

55(b) The L. E. Models in the Cold Soak Chamber ........... 233

56 Shape Change of Leading Edge Models After Entry Heating . . . . . . 237

57 Stagnation Point Backface Temperature History During

Entry Heating of I. E. Nodels .............. g g

58 I. E. Models Appearance before and after Entry Heating (Materfals are: 5026/39HC, Mod 7 He and $3560 \mathrm{HF}$ ) ....... 140

59 Comparison Flight Vs Test Vibration Environment on L. E. Models . . 141

60 Vibration Test on the I. E. Models - the Models installed in the Thermo-acoustic Patigue Pacility ............ 143

61 Vibration Test on the I. E. Models - Detall of the Models Installation. ................... 144

62 Block Dlagram - Shock Test Set-Up for L. E. Models ........ 145

63 Set-Up for Acceleration Tests on the L. E. Models Acceleration In the Spanwise Direction ............... 146

64 Set-Up for Acceleration Test on the L. E. Models - Acceleration in the Chnrd-wise Direction ................ 147 Fl1eht (Eatimated) Vs Test Tensile Strain Comparison . . . . . 150 
Figure

Pare

66

Strip Morlel Mounted on the Olsen Machine........... 151

67 Charring of the Flexure Models - Irstallation in the ROVERS

Arc-Jet Facility . . . . . . . . . . . . . 154

68

Evaluation of the Candidate Ablators - Go/:lo-Go Criteria . . . . 163

69

Relative Contribution of Candidate Ablators to

Stiffness of Substructure. ............... 273

Areas Covered in Wing L. E. Design Study . . . . . . . . . 178

71

Leading Edge Refurbishment Concepts Studied . . . . . . . . 180

Weight and Cost Comparison of Refurbishment Concepts . . . . . 284

Leading Edge Installation Concepts . . . . . . . . . . . . 194

Jemisequential Leading Edge Segment Removel . . . . . . . . 195

Bol.t on External Access. . . . . . . . . . . . . 198

Bolt on $\sim$ Internel Access ............... 199

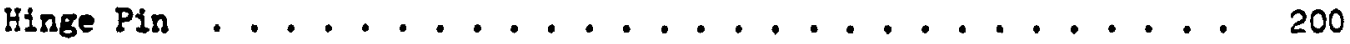

Quick Release (Duel Latch) . . . . . . . . . . . 201

Pres-Loc and Dzus Quick-Release Fasteners in a

Flat Panel Appizcetion ............... 203

80 Nondetachable Forward Structure Mock-Up. Ablator Panels

Attached to Structure ................. 205

8I Detachable Forward Structure Mock-Up . . . . . . . . . 206

82 Atlator Requirements for a Given Maximum

Structure semperature ............... 214

Ablator Weight Requirements for $350^{\circ}$ Maximum Structure

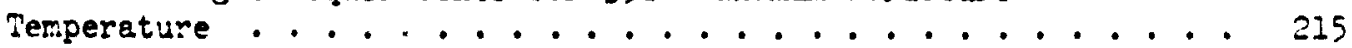

94 Effect of Ascent heatirg on Ablator Thickness . . . . . . . 216

$85^{\circ}$ Ascent Char Data For Leading Fdge ............ 218

86 Ablator Thicksess Requirements . . . . . . . . . . . 219

8T Post Entry Char Jepths . . . . . . . . . . . . . 220

88 Structure Temperature Histeries ............... 222

xiv 
89 Double Ablator Leading Edge Concept

90 L. E. Structural Designs: Integral Stiffened AI.'Slant

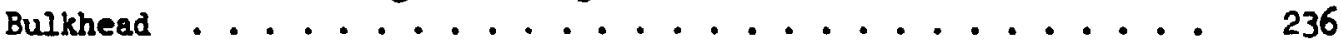

91 Ultimate Static Loads At Midspan Used For Structural Tradeoffs-Max q \& (+) \& \& $(-)$ Condition ........... 240

92 U1timate Static Loads At Midspan Used For Structural Tradeoffs $-2-1 / 2 \mathrm{~g}$ Condition ............. 241

93 L. E. Structural Designs ................ 243

94 L. E. Structure Desigas: AI. Sandwich L. E. Structure . . . . 247

95 Typreal Wing Leading Edge . . . . . . . . . . . . . 255

96 Flight Changes of Gap Width Between L. E. Segments Due to Thermal Environment ............... 259

97 Flight Changes In Gap Width Between L. E. Segments Due to Wing Flexure ................... 261

98 Controlled Gap Width A/A Joints . . . . . . . . . . . 265

99 Compressible Seal Concepts for A/A Joints . . . . . . . . 268

100 Wave Seals For A/A Joint ............... 270

101 Labyrinth Seals for A/A Joints ............... 271

102 Seal Compressibility Test Specinens . . . . . . . . . 273

103 Test Fixture for Seal Compressibility . . . . . . . . . 274

104 Results of Seal Compression Test . . . . . . . . . . 275

105 Compressibility of Silica Felt ............. 278

106 Details of Seal Construction and Instrumentation of

Previous AvCO seel Tests. ................ 280

107(a) AVCO Seal Test Data: Pre-Test V1ew of Specimens

$-1,-2$ and $-4(" 122944 G) \ldots \ldots 281$

107(b) AvCO Seal Test Data: Pre-Test Visw of Specimens

-3 and $-5(n 22944 H) \ldots \ldots 282$

108(a) AVCO Seal Test Data: Post-Test View of Specimens

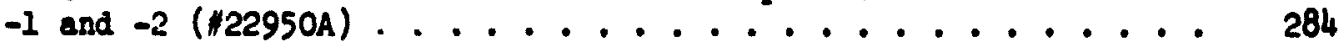


108(b) AVCo Seel Test Data: Post-Test "'iew of Specimens

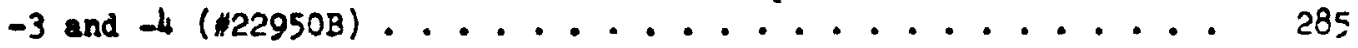

108(c) Avco Seal Test Data: Post-Test View of Reference Ablator Specimen $($ H22950C) . . . . . . . . . . . . 286

109 Rear Surface Temperature Rise on Seal :aterial Tests (Previous AVCO Tests) .................. 287

110 Models Designed for A/A Joint Ivaluation .......... 290

111 Post-Ascent Appearance of A/A Silica Felt Seal Model . . . . . 292

112 Fost-Ascent Appearance of A/A Silicone Foam Seal Model . . . . 293

113 Typical RSI-RSI Joints of Current Interest . . . . . . . 296

114 Ablator/RSI Joint: Controlled Gap with a Mechanically Attached Ablator Strip ............... 298

115 Ablator/RSI Joint: Controlled Gap With An Externally Bolted Ablator Strip (Metal Strip) ...............

116 Ablator/RSI Jo1.: : Controlled Gap With an Bxternally Bolted Ablator Strip (Bond Variant) ................ . 301

117 Ablator/RSI Joint: Sllica Felt Seal . . . . . . . . . . 302

118 Ablator/RSI Joint: Metall1c Wave Seal . . . . . . . . . . 303

119 AblatoriRSI Joint $\sim$ Gap Sealed with RTV Wave Seal . . . . . . 304

120 Ablator/RSI Joint: Gap Sealed W1th Labyrinth SeaI . . . . . 305

121 Ablator/RSI Joint Candidate Designs . . . . . . . . . . . 308

122 Ablator/RSI Arc Test Model. . . . . . . . . . . . . . 309

123 Final Design - Ablator Leading Edge (Sheet 1) . . . . . . . 311

123 Final Design - Ablator Leading Edge (Sheet 2) . . . . . . . . 312

124 Leading EAge Heat Shield Thickness . . . . . . . . . . . . . 317

125 Total fiblator cost for Wing L. E. . . . . . . . . . . . . 324

126 Total Program Cost for Wing L. E. of $600 \mathrm{ft}^{2}$. . . . . . . . 326

127 Totsi Program Cost for Wing L. E. of $280 \mathrm{ft}^{2}$. . . . . . . . . 327

128 Loop Reinforcement Concept . . . . . . . . . . . . . . . 330 
129 Total Progran Cost Savings With Three Concepts Recomnended for Development (a) Full Traffic Model ............ 333 (Cont.) (b) Reduced Traffic Model .......... 334

130 Proposed Tunnel Tests and Flight Conditions .......... 344 


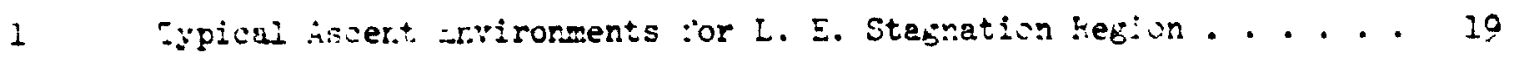

2 Typical Emtry Exvironments for L. E. Etagnatiur. Eegion . . . . 2 20

$3 \quad$ Mpisal Ascent Environments for Windward Joint Region . . . . . 21

4 Typical - try Environnents for Windward Joint Pegion . . . . . 22

5 Critical Conditions for Structural Environment ......... 27

6 Vikration Environments for the wing L. E. . . . . . . . . 41

$7 \quad$ Critical Natural Environments for $040 \mathrm{~A}$ and 473

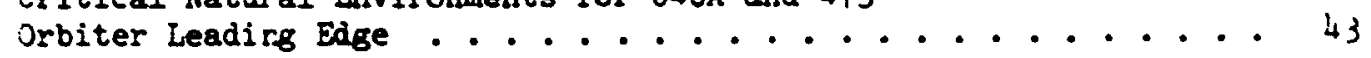

8 Conaitions Mypical for Most Severe Rain Environment for

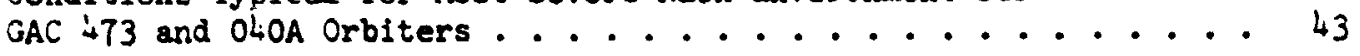

$9 \quad$ Leading Edge Ablators Grouped by Density . . . . . . . . . 98

10 Candidate Ablators Selected for the Orbiter Leading Edges ..... 103

11 Driving Criteria for Selection of the Candidate Ablators ..... 108

12 Material Property Sumary ................. 110

13 Overview of Screening Test Program and Results ......... 114

$14 \mathrm{a}$ Ascent Environments ................ 124

14b ROVERS Arc Test Environment ................. ${ }^{2} 25$

15 Ascent Heating Test Summary for L. E. Models . . . . . . . 128

16a Commerts on Generai Appearance of the L. E. Models
After Ascent Heating . . . . . . . . . . 129

16b Entry Flight vs Simuletion Environment .......... 135

17 Entry Heating Test Surnary for L. E. Models . . . . . . . . 136

18 Observations c: Cut i. E. Sections ............... 149

19 Comparison, Filght vs hrc, of Thermal Environment for

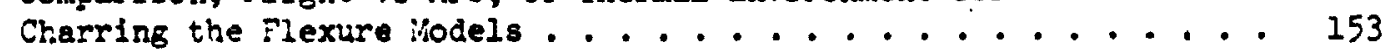



Observations of Cut Charred Flexure Models . . . . . . . . 156

Evaluation of the Tro Best Candidate Ablators, Ratine Criteria .................. 175

Description of Refurbishment Concepts ........... 181

Data for Trade off of Refurbishment Concepts ......... 183

Items Bookkept Under cost ............... 186

Itemized Man-Hours Needed for I. E. Refurbishment . . . . . 187

Boolkkeeping of Welght Itews ...............

Summary of Leading Edge Heating Stagnation ifine of

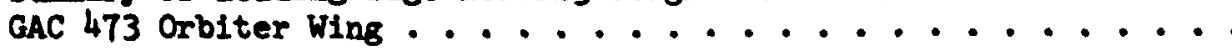

Summary of Heating Distribution at Mid-Span Location

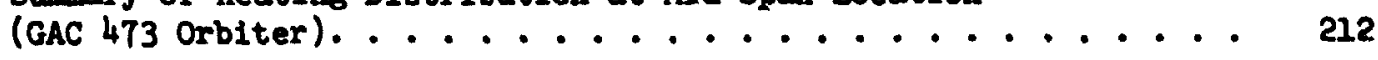

Tradeoffs in Double Ablator System . . . . . . . . . .

Typical ROVERS Arc Test Deta on Mod TM Splash Test - No

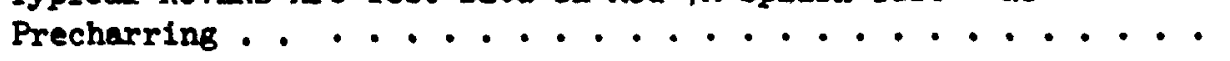

Recession in Ablator Leading Edge Models during Reentry Test

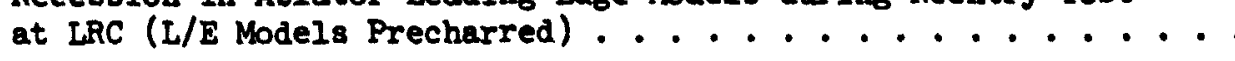

Sumary of Preliminary Design Concepts . . . . . . . . . 249 
Table

Pese

41 Rarurbiebmant oparational Procedure ............. 315

42 Weight summry .................... 318

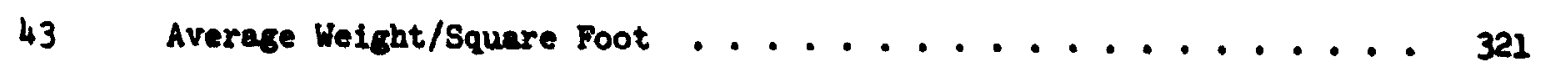

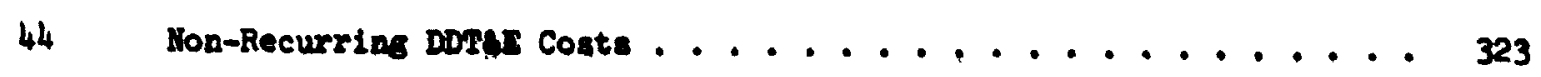


INITIAL DEVELOPMENT OF AN ABLATTVE LEADING EDGE

FOR THE SPACE SHUTTLE ORBITER

G. DeForno and L. Rose, Grumman Aerospace Corp.

J. Graham and P. Roy, AVCO Systems Division

\section{SUMARY}

The work described in this report includes design, testing and related efforts required to determine the feasibility of utilizing ablators on the leading edges of the space shuttle orbiter. The specific tasks involved are: 1) the defiuition of a representative leading edge environment, 2) evaluation of seven candidate ablators under sequential test conditions using leading edge configurations, 3) analysis of the effects of surface roughness on subsonic aerodynamics, 4) trade-off studies to determine the most efficient structural design and ablator to wing attachment scheme, 5) a preliminary design of the leading edge defining selected attachment and seal concepts and, 6) a cost analysis outlining the expenditures required. An additional effort was involved in the fabrication of eight ablator leading edge models which were submitted to NASA for testing in a reentry heating environment at the Johnson Spacecraft Center.

Significant findings are: 1) ablators are feasible TPS for the leading edge areas and are reasonably cost competitive relative to the carbon/carbon system, 2) of available ablators, it appears that only those which use honeycomb reinforcement are acceptable; and, 3) none of the ablators produce surface roughness which will significantly degrade subsonic aerodynamic performance.

of the seven ablators evaluated, two 30 pcf elastomers appear to be most promising (1.e. Avco Mod 7 Hc and Martin ESA $3560 \mathrm{HF}$ ). These materials, both relnforced with honeycomb, are in the state of development where only minimal work would be required to apply them with confidence to the orblter leading edges. 
This report describes the body of the work, while a separate Data Fackape contains supporting data of specialized interest such as the detailed test results and the desigr. of models that have been produced but not usad. The Data Fackare (of some \$50 pages) can be consultec at, or obtained on loan from the rhermal Frotection Branch, Material Division, NASA Langley Research Center.

Part of the work presented in this report was conducted under NASA Contract NAS1-11416 (Narch 1972, vecember 1973), and part under independent development efforts at Gruman and AVCO. Contract MASI-11416 to the Grumman Aerospace Corprration included a subcontract to AVCO for design studies and material testing. Proprietary ablators were procured from the Martin-Marietta Corporation, Denver Divisic!: and the AVCO Corporation, AVCO Systems Division.

The NASA Langley technical monitor was Mr. S. Tompkins, Thermal Protection Branch, Material Division, while D. Curry, ISC was the contact at JSC.

The work described is the result of a tean effort. Other people closely 1avclved were: (at Grumman) F. Peinemann, C. Osonitsch, J. Vaientiae; (at AVCO) H. I.oercher, D. Mosher, R. Brown; (at NASA Langley Research Center) R. Levine and R. Brown. Many tests were consucted in the facilities of the Thermal Protection Branch, NASA Langley. Moreover, for the vibration tests, the NASA Langley Thermoacoustic Facility was used with the cooperation of C. Rucker, Load Division, Acoustic Dynamics Secticr. All these tests are described in this report, including one test conducted by the thermat Protection Branch with one extre model produced under this program. 
As questions arose, this study had the ready cooperation of the Martin Marietta Corporation, Fenver Division in the persons of P. Plank, A. Norton, B. Maccalous and C. Miller. In particular, the Martin Corporation in the persons of A. Norton and B. Maccalous agreed to the purchase of the Prime and X15A2 ablators under the demanding schedule of the stucy.

When, as a result of the screening tests, it became advisable to select two, rather than one, ablators, both ablator houses, AVCO and Martin, displayed exceptional cooperation in fabricating, in a very cost effective fashion, the models for the evaluation of the l.e. design at NASA, JSC.

A short version of this report can be found in the following paper: G. DaForno, J. Gral:am, S. Tompkins, Iritia] Development of an ablative leading edge for the Space Shuttle orbiter, AlAA Paper No. 73-739, presented at the AIAA 8th Thermophysics Conference, Palm Springs, Ca., Juiy 16-18, 1973. Minor refinements in the design were made after that paper was presented and the data in this report are to be regarded as definitive.

All the models, both those used in the program and those not used (in particular the three rain erosion samples) are with the Thermo Protection Branch, NASA Langley, with the exception of eight 1.e. models that are with the Thermal Technology Branch, Structures and Mechanics Division, NASA JSC. 


\section{SURTECT}

The subject of the work presented here is the use of a charring ablator heat shield as a thermal protection system (TPS) for the wing and fin leading edges (1.e.) of the space shuttle orbiter. More specifically, our theme comprises neither a justification for the use of an ablative l.e. nor a comparison with other TPSs envisioned for the orbiter 1.e. Rather, we are dealing with the development of detailed and comprehensive information on an ablative 1.e.

The general expectation during Phase B of the Shuttle program has been that an ablative 1.e. for the orbiter is feasible, but development studies had not been carried out. In particular, no experimental data were arailable on the performance of ablators under a sequence of enviroments representative of this application. Such a sequence includes a novel aspect, nemely, a charring phase during ascent followed by an extended period in cold soak and anly finally by the primary charring during entry. Noreover, characteristics such as weight, cost, etc., had not been based on a systematic effort at a minimum weight and cost design. But of course, estimates for such characteristics were used in trade-off studies during Phase B. Basically the only information available at the start of this study were some (non-sequential) ablator test data (Ref. 1), the design studies on Graham et al. (Ref. 2) and some iritial studies on aerodynamic characteristics degradation due to l.e. roughness on delta wing orbiters (Refs. 3 and 4 ).

The ablative 1.e. can be considered either as a permanent TPS for the entire traffic of the Shuttle or as a mere temporary TPS to reduce risks in the initial orbiter filights and to insure against delays in the availability of a reusable TPS. Bmphasis in this study is on the first alternative even though most of the effort is also applicable to the other. 


\section{PROBLEM}

The problem we have attacked is that of the initial development of an ablative 1.e. for the orbiter, using state-of'.the-art teclinology. 'State-of-the-art' means, amork other things, that the ablator is an off-the-shelf well-developed material, requiring at most, a modest effort in the area of low-cost fabrication. 'Initial development' means that the end result of this effort is to be a preliminary desion for the wing midspan, the design being untested as a whole. However, all the key issues are to be examined at least in a 'first-cut' fashion, key selections (e.g., the ablator) are to be tested and an overall picture is to be formed rapidly of the entire problem. The preliminary design produced should be such that the next step is large scale fabrication and testing.

The steos obviously necessary for this goal are: (i) estublish the design ground rules and the requirements, such as the environment to be withstood, the roughness that can be tolerated, etc; (ii) select an ablator; (iii) evolve the refurbishment procedure and the attachment scheme; (iv) design substructures ablator and joints; $(v)$ draw up a preliminary desiga and determine its characteristics, its cost and the time needed to transform it into qualified hardware. These five steps are discussed in this report with supporting data relegated to a separate Data Package. In addition, the following is also presented: (a) how the wing l.e. design can be adapted to the fin 1.e.; (b) comments $\mathrm{cn}$ what prospectives there are for cost and weight improvericnt; (c) recommendations for tne rext step following this fritial development of an ablative 2.e.; and finaly (i) a description of certair models that have been fabricated but not tested uncer this stuay (these mclels witi evaluate, in small scale, the design). 
Lio special attention is devrted to the rin l.e. The Justi:ization for such an attitude is the fact that KSI is beini consideret udequate is a fir. i.e. IPS and that we expect the 1'is. 1.e. therma: protection $\because$ be a mati infles problem than the wing 1.e. 'ive essential elements of the desifn car be apfiled to the fin by Just scaling ablator thickress tc the reudced hesti::s. 


\section{DESIGN GROUND IRTES AND REQUIRRMIGNTS}

Apart from the obvious ground rule of striking for minimum cost .- the theme of the Shuttle program -- MSA set out importent ground rules for this effort. One ground rule is quite predictable. It requires that:

a) the wing main structure is of alum $3 \mathrm{~mm}$, not of titantum. This means that this study has few points of contact with another detalled study of an ablative 1.e., Ref. 5. Otracusly in the bookkeeping of weight and costs, if the l.e. substructure is of titanium, the l.e. design must be charged $w$. 1 the penalties of reducing the structural temperatur. . $30^{\circ} \mathrm{F}$ at the interface with the wing main structure.

Other ground rules are less predictable. They require:

b) to consider typical delta wing orbiters, maintaining flexibility with respect to the prevailing configurations. In other words this is a technology study not tied to a specific crbiter design. Since it is necessary to be more specitic, e.g. to obtain the design enviroment, typical end-of-Phase-B/be ginningof-Phase-C orbiters were considered. They were the MSA O4OA, the Grumman 473 and the Rockwell ATP, 000089B and 000033 (or 7D) orbiters. For the external geometry, an ad hoc configuration was used with lines that are a compromise between the Grumman 473 and the Rockwell 000033. This compromise is given in figure I (planform and cross section at wing midspan) and 2 (distribution of wing 1.e. radif). The 1.e. shape is almost identical to that of the 473 orbiter except for the characteristic hook at the nose of the 473 . 

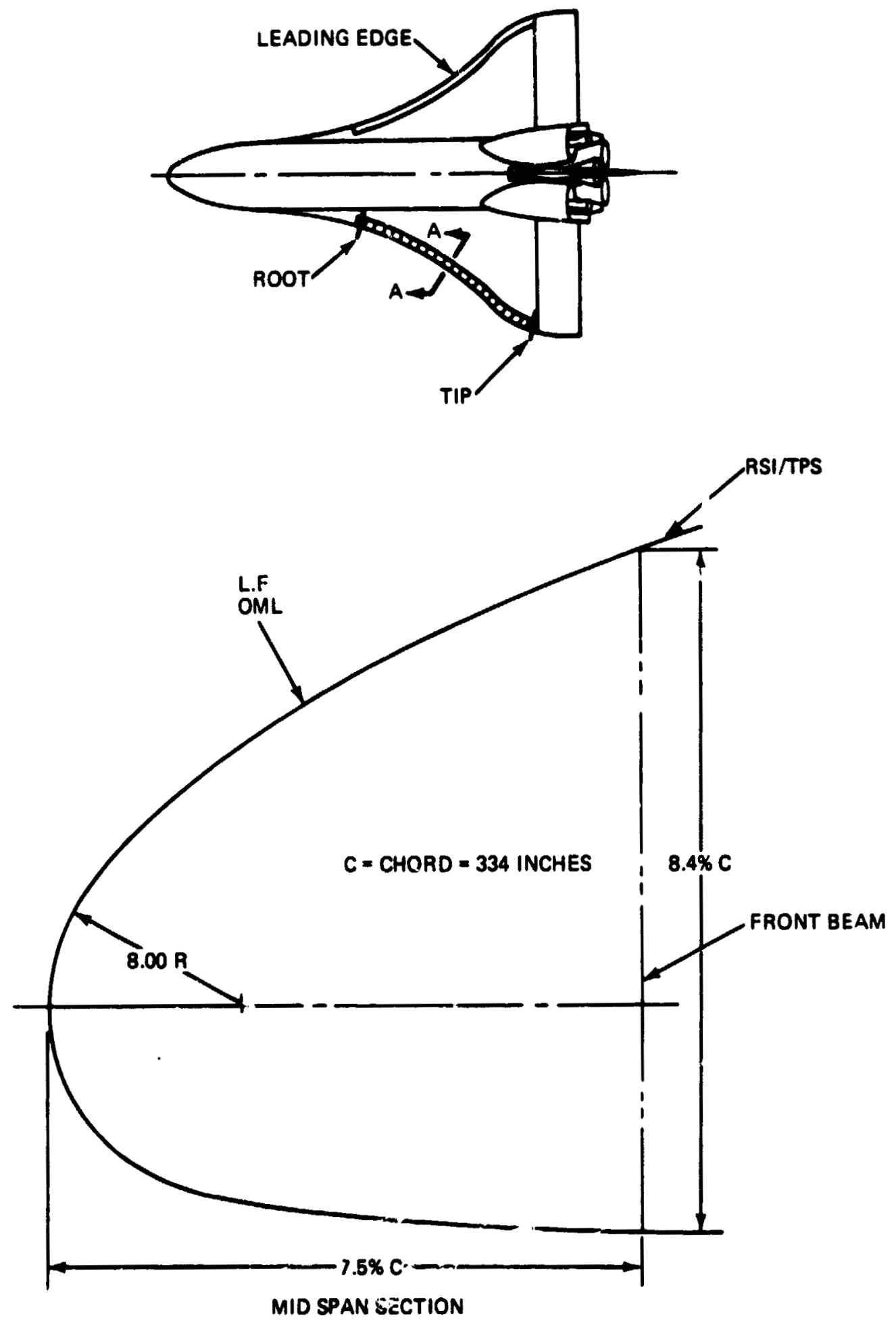

Figure 1 Configuration Unad in the Study 


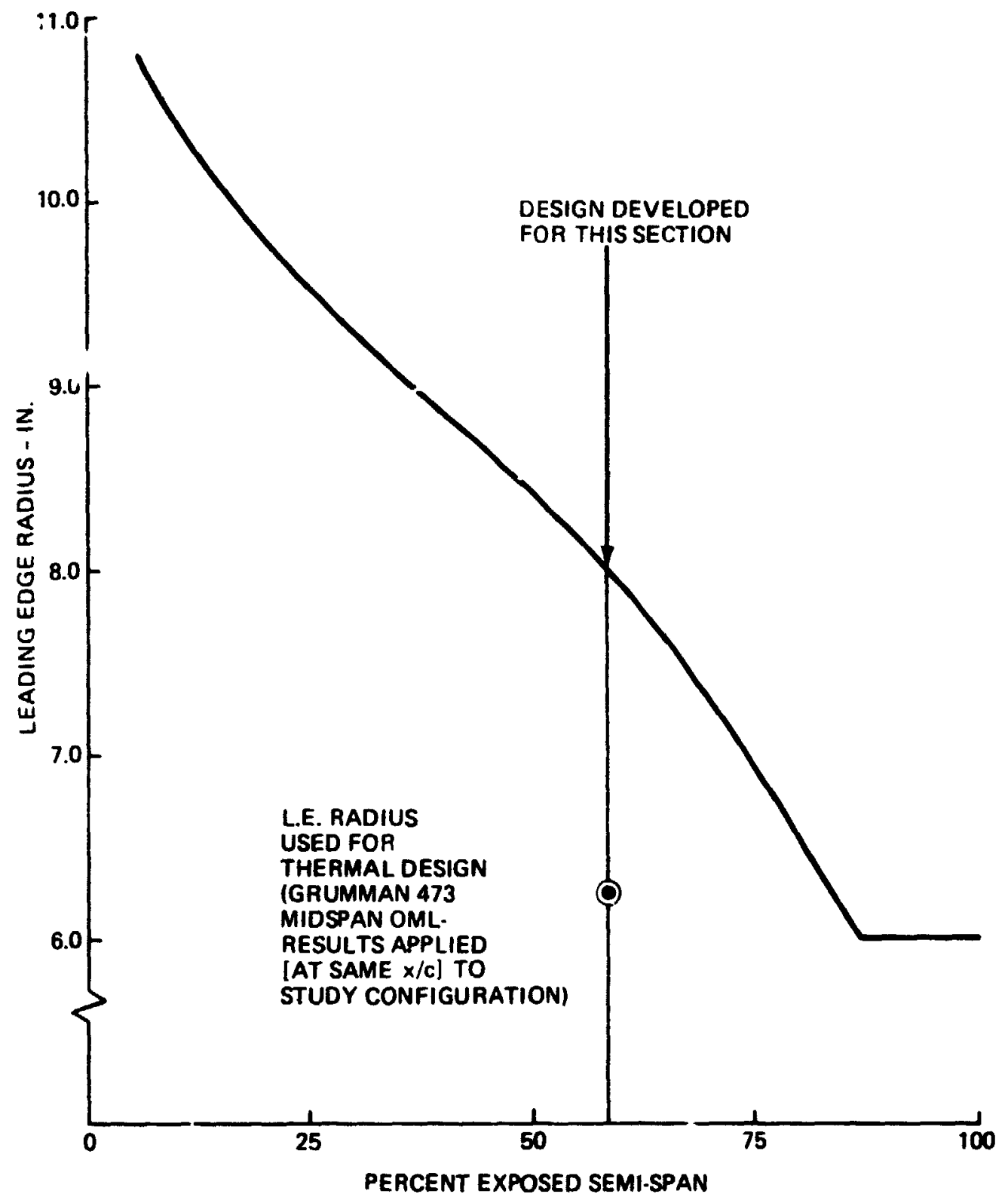

Figure 2. Wing Leading Edy Redius Definition for Configuration Uad 
c) to design a typical wing $m$ dspan section and neglect the special areas, such as fillets, the shock impingement area (if the bow shock is reasonably stationary during entry) or the kink area in double delta desirns.

d) to forgo interchangeability or compatibility with the carboncarbon (CC) system, but strive for an absolute optimum ablative 1.e.

e) to interface with the reusable surface insulation (RSI) and the acreage TPS and uot with o metallic TPS.

f) to protect with ablator the entire region ahead of the wing front bean, even though RSI can be used aneed of the front beam (usurlly at some 8 or 10 f of the chord) at least on the leeward side.

8) to plan for the entire NASA traffic model (Ref. 6) (a total of 447 flights on an appropriate schedule and a fleet of five orbiters). A slightly different traffic model was prescribed for costing the ablative l.e.

h) to take the Shuttle system 'frozen' rather than 'rubber' for trade-offs of components weight versus cost. A 'rubber' system is appropriate for Phase $A$ and $B$ type studies, while the 'frozen' rule should reflect the relevance of this study to a system already in preliminary design.

On the whole these ground rules represent a reasonable compromise between the many constrzints. Perhaps the biggest problem is rule ( $f$ ) that imposes a larger 1.e. area ( $\approx 500 \mathrm{ft}^{2}$ per orbiter) compared to the area that is not 

carried, is desired nc matter whether the shuttle system suffers a we i ilt frowt! or shrinkage. Of course, a critical review of thit point of view is nut relevent here. It follows that if the orbiter undergoes a weight increase (decrease), flisht(s) need to be added (eliminated) to carry the sume tcta: payload over ihs antire trarfic. Frum the costs of these flights, one can easily calsulate the cost of a weight change. We will make the reasonable assumption that number of vehicles, shuttle progran DDT\&T costs, schedu. $e$, turn-around tines, etc. will remain the same. Then, when $\Delta W p$ is the pay: ad that cannot be carried in each flight because of an increase in weight JWp of the orbiter, the cost of the extra flights needed is JWp.Nc $\mathrm{N}_{2}$ in where $N$ is tre number of flights in the traffic model, Wp the payload of the orbiter and $c_{2}$ the (:ecurrent) cost of an operational flight. The value of weight savings is then $\mathrm{Nc}_{2} / \mathrm{Wp}$. For the NASA traffic model, the current payload of $65 \mathrm{~K}$ libs, ind the currently projected cost per flight of $10.5 \mathrm{M} \$$ (Ref. 10), the value of a pound is $72,000 \$ / 1 b$. We tried as much as possible not to use ground rule $(h)$ and the extremely high value of a pound it imposes upon this study.

Turning now to the requirements for the ablative l.e., these are:

(a) First of 411 , to withstand the environments, aerothermal, struc$t$ ural and natural. The data needed to characterize these environments are examined in Section 3.

(b) Touliness and shape change should produce acceptable degradation of the Low speed aerodymamic characteristics of the orbiter. Ul:imately, one would I ike to 'now the maximum 'acceptable' value for roughness levels below the maximum. This question is taken up in a preliminary fashion in Section 4. 
(c) Roughness should produce os shift in boundary layer transition that causes 'acceptable' heating increases in the RSI area: probably much more important than the roughness effect, the ablatior should rause 'acceptabio' contamination of the RSI. Fut no informat ion is available on what is 'acceptable,' nor could the detailed study needed be fitted into our study.

(a) Tne refurbishment of the orbiter l.e. should fit into the vehicle turnaround time which is curreit ly (Tuse 1973) required to be between 150 and 250 elapsec sours. (Ref. 11\%) 


\section{ORBITER LAE, ENVIROMMENT}

This section covers the effort involved in determining the environmental facturs that characterize the environment encountered o ar a typical set of missions. From such data came the desion environments used in this stidy. Full deta:ls are collected in the Datil Fackage.

\subsection{Thermal}

The aerothermal environment (pressure, shear stress and cold wall heat flux) for two shuttle orbiters configurations (GAC 473 and NASA $40 A$ ) and several trajectories (nominal, dispersed, and abort ascent/reentry) were first determined for wing LE, fin LE and nose. A matrix of aerothermal environmental factors was generated. Similar data available of the NAR, MDAC, \& IMSC Phase $B$ orbiters were included in this matrix.

A brief outline of ti:e methods used in the calculaticns of heat flux, shear stress and pressure follows.

Stagnation line/point pressures were calculated usinf the hypersonic relation:

$$
\begin{aligned}
& P_{S I}=1.35 \mathrm{P}_{\infty} M_{\Lambda, E F F}^{2} \quad M_{\Lambda, E F F}=M_{\infty} \cos \Lambda_{E F F} \\
& l_{E F F}=\sin ^{-1}\{\sin \therefore \cos \phi+\cos 1 \sin x \sin i\} \\
& \text { - dihedral } \\
& \text { A l.e. sweep }
\end{aligned}
$$

Pressure distributions normal to the leading edge were calculated usine mod: sied Newtonian theory on the windward and Prandtl-Meyer expansion on the leeside.

heat flux values were calculated by modifying the Fav-Riddell one foot reference sphere values calculated for each trajectory for radius difference at the nose and by swept cy] inder theory on the leading edges, 


$$
\dot{q}_{\mathrm{SI}}=0.7 \mathrm{CT} \quad \dot{q}_{\mathrm{REF}} \sqrt{\frac{R_{\mathrm{REF}}}{R_{:}}} \quad\left(\mathrm{COE} \dot{F F F}_{\mathrm{FF}}\right)^{1 \cdot 2}
$$

$\dot{q}_{\mathrm{REF}}$ is the stagnation point heating on the sphere with radils $Y \mathrm{FEF}_{A}, \mathrm{~A}_{\text {is }}$ the stagnation point z.e. radius evaluated in a plane rormal to the $2 . e$. (subscrint $A$

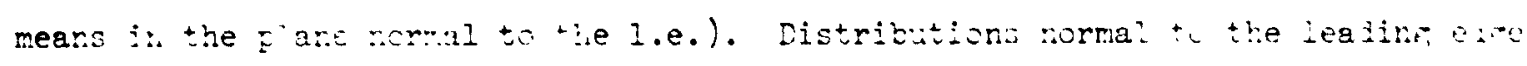

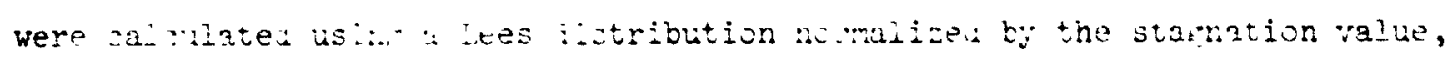

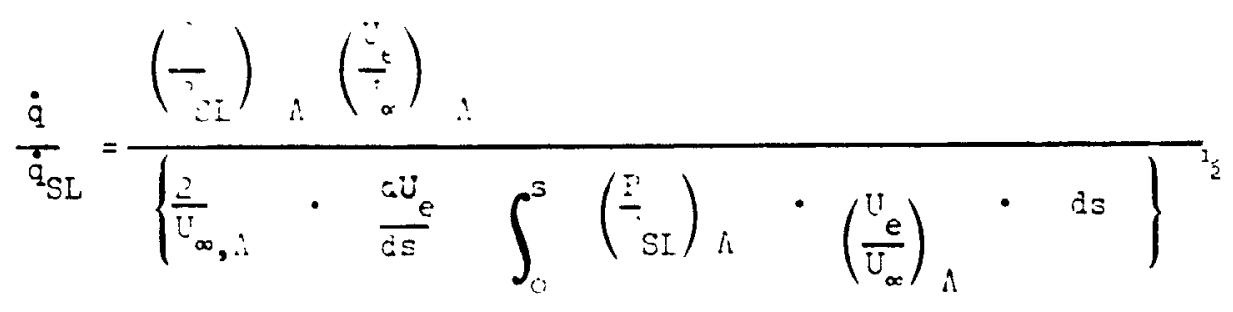

All heat flux are for a cold wall $\left(\mathrm{H}_{w} / \mathrm{H}_{e} \rightarrow 0\right)$. The temperature distributions are at radiation equilibrium conditions. $U_{e}$ is the boundary edge velocity, $\ddot{w}_{\alpha}$ the free stream velcsity, $s$ is the arc length (from the stagnation point) measured in a Elane normal to the l.e. Chear stress was calculated using a Reynolds analogy with the anaiosy factor of 1.24 ,

$$
\tau=\frac{\dot{q} v_{e}}{1 \cdot 24 g\left(H_{r}-H_{w}\right)} \quad H_{r} \gg H_{W}
$$

$$
\begin{aligned}
& v_{e}=\text { boundary layer edge velocity } \\
& g=\text { acceleration of gravity } \\
& H_{r}=\text { recovery enthalpy }
\end{aligned}
$$

Shear stress distributions on the leading edges are normalized by the stagnation line value. On the nose, they are normilized by the maximu value.

Heat flux and pressure amplification on the wing leading edge due to bow shock impingement has been included. The shock envelope was determined through a combiuation of blast wave, shock expansion theories and experimental Schlieren data along the nominal tajectory.

$\mathrm{Jiscid} /$ inviscid interaction corrections at low Reynolds number were applied to heating in regions of attached boundary layers, and found to be daminant 
near peak entry heating where increases of up to $20 \%$ were incorporated. No data exist on low-Reynolds-number effects on heating amplification due to shock impingement. Applying a correction such as that for attached boundary layers would be overly conservative and therefore has not been done.

From the detailed data generated (aearly 250 eurves, see Data Fackare), a matrix of aerothermal environments was extracted. Actually, it was schematized in two matrixes, one of 'dominant' heating rates, etc. and one of maximum heating rates. For the stagnation region, figures 3 and 4 give heat flux and pressure gradient respectively; the parameters of the mid points in these matrixes are given in tables 1 and 2 . For the GAC 473 the maximum environment is experienced only on some $2.5 \%$ of the leading edge area. Tables 3 and 4 give the dominant and maximum aerothermal environment for the typical windward region where the windward spanwise joint is located.

The ascent ti ajectories evahated were nominal and abort to orbit. Noninal ascent precedes a normal seven day crbital mission, whereas abort to orbit is succeeded by one revolution and entry. The difference in the two ascent environments is minimal.

The entry environment deserves closer scrutiny. As seen in figure 3 , it depends closely on trajectory and conflguration. Some data points should be discounted on the basis of unreslistic leading edge geametry in configurations that have not been scrutinized from all points of view. The remainder can be grouped into two categories besed on whether or not the leading edge is sometimes, during entry, impinged upon by the bow shock of the vehicle. The categories are designated dominant (no impingement) and maximum (impingement) and exist $f r$ ascent as well. The categories se outlined in figures 3 and 4 and presented in tables 1 and 2 . 


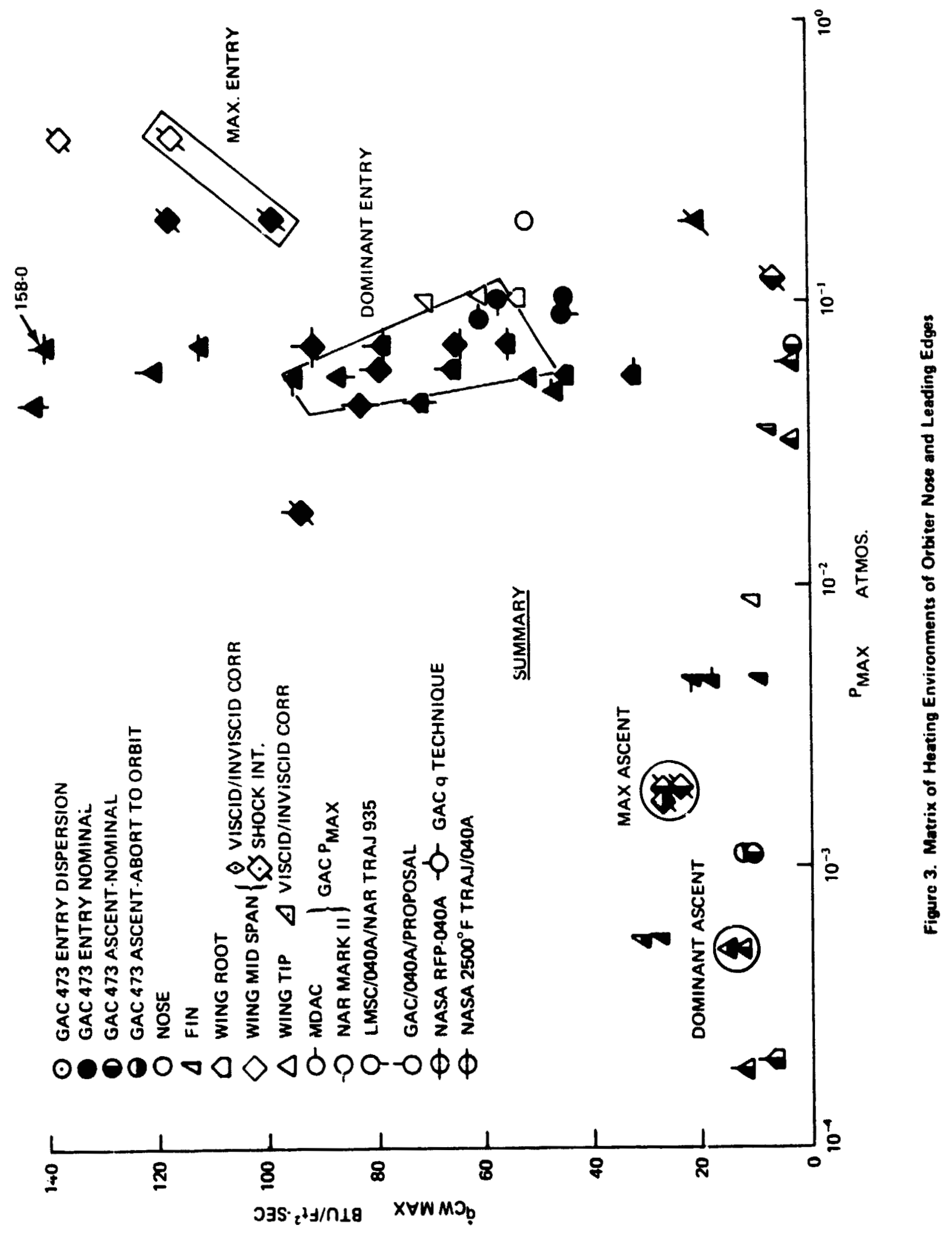




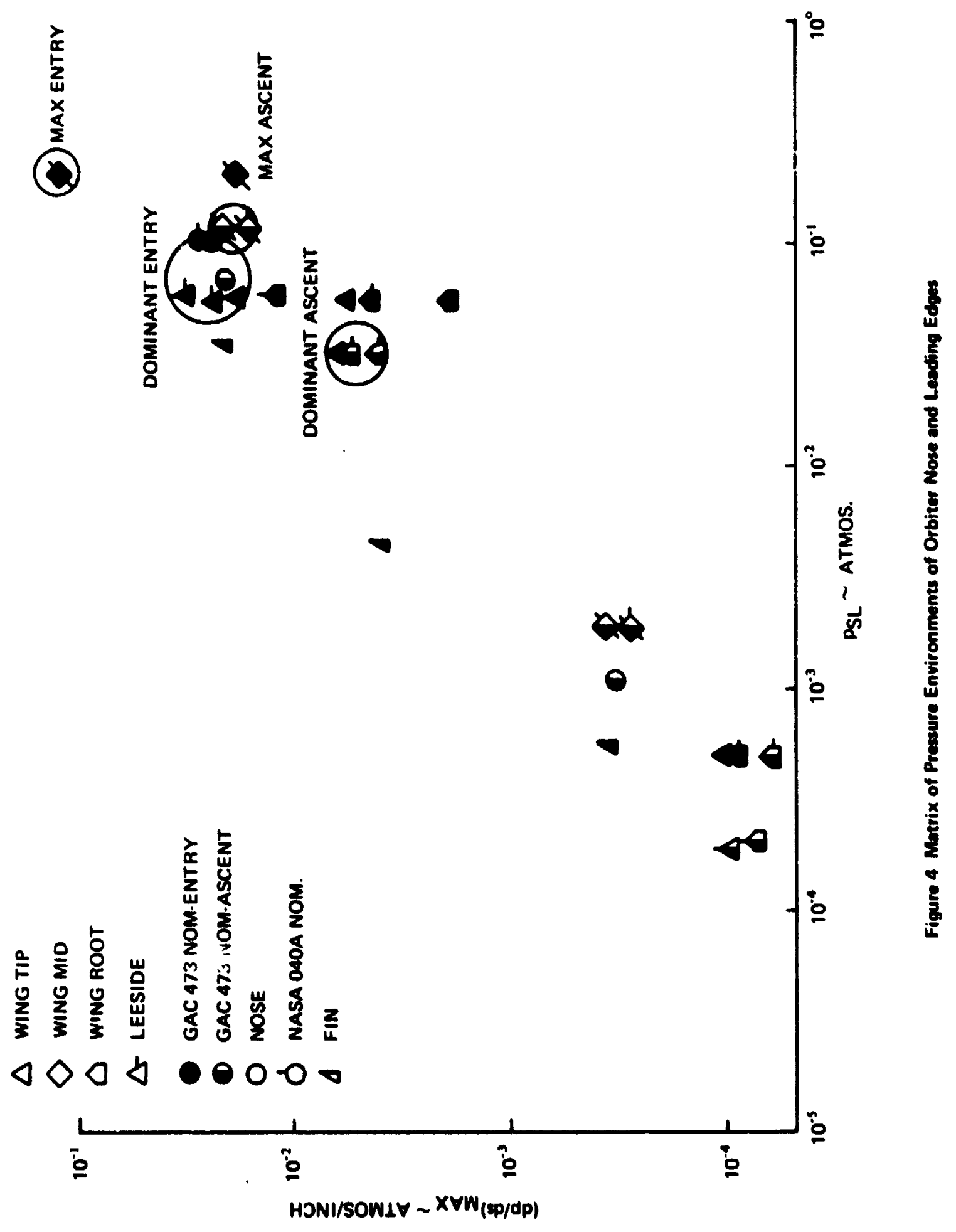


Table 1 Typical Ascent Environments for L.E. Stagnation Region

\begin{tabular}{|c|c|c|c|}
\hline & & Dominant & Maximum \\
\hline$\dot{q}_{c w}$ & $B t u / f t^{2} \cdot \sec$ & 14 & 25 \\
\hline$P_{\text {Max }}$ at $\dot{q}_{c w}$ & atmos & $5 \times 10^{-4}$ & $1.8 \times 10^{-3}$ \\
\hline $\mathrm{H}$ at $\dot{\mathrm{q}}$ & $\mathrm{Btu} /=\mathrm{m}$ & 10.200 & 10,203 \\
\hline$P_{\text {to }}$ at $P_{\text {Max }}$ & atmos & 48.5 & 48.5 \\
\hline $\mathrm{T}_{\text {to }}$ at $\dot{\mathrm{q}}_{\mathrm{cw}}$ & ${ }^{o} R$ & 8700 & 8700 \\
\hline$M_{\infty}$ at $P_{\max }$ & - & 28 & 28 \\
\hline Altitude at $\dot{a}_{\mathrm{cw}}$ & $\mathrm{ft}$ & 300,000 & 300,000 \\
\hline$\rho_{s}$ at $\dot{q}_{\mathrm{cw}}$ & $m / \mathrm{ft}^{3}$ & $1.3 \times 10^{-6}$ & $4.9 \times 10^{-5}$ \\
\hline $\operatorname{Re}{ }_{\infty}$ at $\dot{q}_{c w}$ & $1 / \mathrm{ft}$ & - & - \\
\hline $\begin{array}{l}\text { dP } \\
\text { ds Max }\end{array}$ & atmos/inch & $5 \times 10^{-3}$ & $2 \times 10^{-2}$ \\
\hline$\tau_{\text {Max }}$ & $\pm f / f t^{2}$ & 1.5 & 1.5 \\
\hline $\mathrm{Q}$ & $B t u / f t^{2}$ & 6,700 & 12,000 \\
\hline Time at $\dot{q}_{\mathrm{cw}}$ & sec & 250 & 250 \\
\hline
\end{tabular}

Symbols

P Pressure

$P_{\text {t }} \quad$ Total pressure

$\mathrm{T}$ Total Temperature

$\rho_{\mathrm{s}} \quad$ Density at stagnation point

$\operatorname{Re}_{\infty}=\frac{U_{\infty} P_{\infty}}{\mu_{\infty}}$

$\tau \quad$ Shear stress

$\left(\frac{d P}{d s}\right) \quad$ Max pressure gradient on the L.E.

\section{Subscripts}

$\infty \quad$ Free stream

Max Along trajectory or on L.E. 
Table 2 Typied Entry Environments for L.E. Stapnation Repion

\begin{tabular}{|c|c|c|c|}
\hline & & Dominant & Maximum \\
\hline$\dot{q}_{\dot{c} w}$ & Btu/ft $t^{2} \cdot \sec$ & 70 & 110 \\
\hline$P_{\text {Max }}$ (at $\dot{\mathrm{q}}_{\mathrm{cw}}$ ) & atmos & $7 \times 10^{-2}$ & .3 \\
\hline$H$ at $\dot{q}_{c w}$ & Btu/\#m & 11,400 & 11,400 \\
\hline$P_{100}$ at $P_{\text {Max }}$ & atmos & 320 & 320 \\
\hline $\mathrm{T}_{\mathrm{t} \infty}$ at $\dot{\mathrm{q}}_{\mathrm{cW}}$ & ${ }^{\circ} R$ & 10,75 & $10,75 n$ \\
\hline$M_{\infty}$ at $P_{\text {Max }}$ & - & 14 & 14 \\
\hline Altitude at $\dot{\mathrm{q}}_{\mathrm{cw}}$ & $\mathrm{ft}$ & 220,000 & 220.000 \\
\hline$f_{s}$ at $\dot{q}_{c w}$ & $m / t^{3}$ & $.8 \times 10^{-4}$ & $3 \times 10^{-4}$ \\
\hline Re at $\dot{q}_{c w}$ & $1 / f t$ & $1.9 \times 10^{4}$ & $1.9 \times 10^{4}$ \\
\hline$\frac{d P}{d s}$ & atmos/inch & $2.8 \times 10^{-2}$ & $1.3 \times 10^{-1}$ \\
\hline$\tau_{\text {Max }}$ & $\# / t^{2}$ & 2.4 & 2.4 \\
\hline $\mathbf{Q}$ & Btu/tt ${ }^{2}$ & 64,200 & 124,800 \\
\hline Time at $\dot{q}_{c w}$ & $\sec$ & 800 & 800 \\
\hline
\end{tabular}

Symbols: Ses Table 1. 
Table 3 Typical Accent Environments for Windward Joint Region

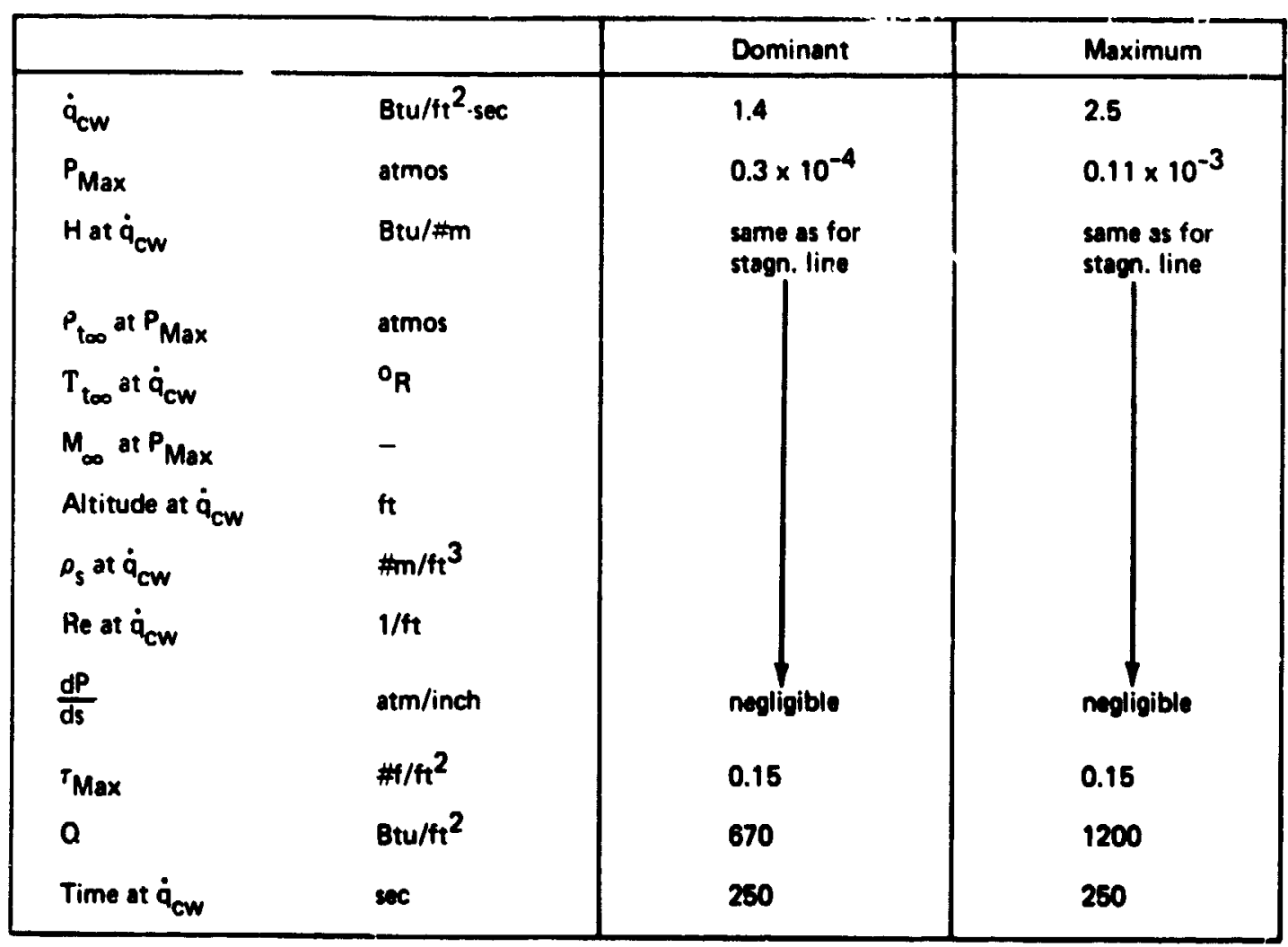

Symbols: See Table 1 
Table 4 Typical Entry Environments for Windward Joint Region

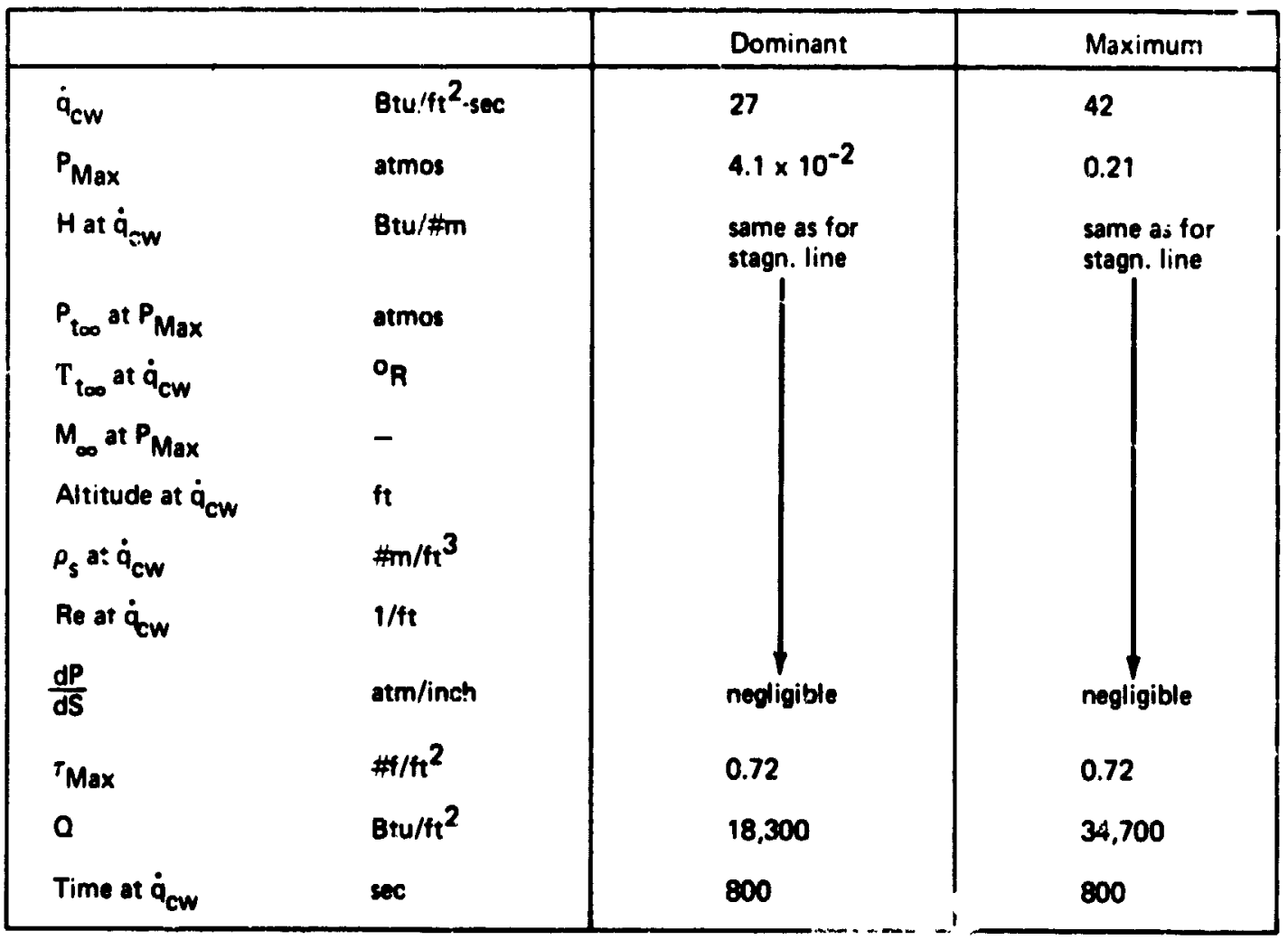

Symbols: See Table 1 
In estimating the surface area affected by ma:imum heating, the infoimation generated or the Grumman 473 represent easily a worst case. since the bow shock is estimated to be stationary on a fixed span position. Figure 5 indicates a minimum no-shock henting of $50.8 \mathrm{Btu} / \mathrm{ft}^{2}-\mathrm{sec}$ to occur at the wing

tip. Figure 6 presents the midspan shock-impingement hest clux. Comparison of these fifures and application for the distribution given in figure $i$ irdicstes that heat fluxes greater than 50.0 will be experienced over $1 y$ $2-I / 2 ;$ chord on the leading edge. Spanwise one can take for safety that there is amplification over $10 \%$ of the exposed span, which is reasonable since the shock traverses only about $5 \%$ exposed span. This leads to the conclusion that only about $2-1 / 2 \%$ of the total wing leading edge surface* receives greater than the dominant (50.8) heat flux. The figuies also indicate that this condition persists for only $2 / 3$ of the total entry time. If shock impingement is eliminated, the midspan enviranent of the 473 orbiter becomes the same as for the wing tip, figure 6 .

The same sort of considerations are applied to the windward region where the spanwise joint is located ( $8 \%$ chord).

\subsection{Structural}

\subsubsection{Static Structural Envirorment}

The structural environment was obtained fram a separate study of three critical flight conditions made for the Grumman 473 and NASA O4OA shuttle orbiters. These critical flight conditions are listed in tables $5 \mathrm{a}$ and $5 \mathrm{~b}$ ider.tified as $\operatorname{Max} \alpha \alpha(+), \operatorname{Max} \alpha(-)$ and 2-1/2g pullout. Data generated for these conditions are as follows:

+ Wing L.E. defined as $10 \%$ of the chord. 


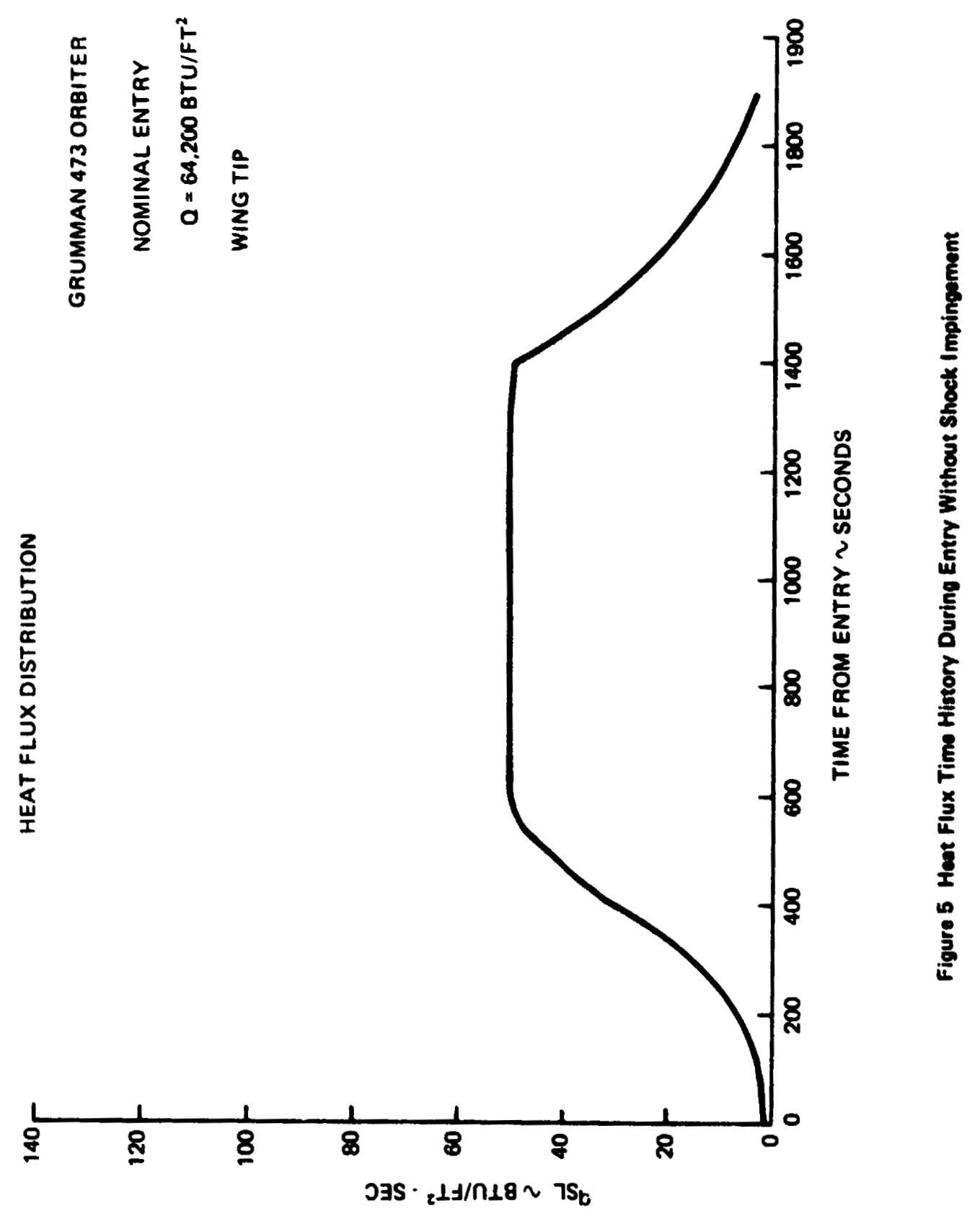




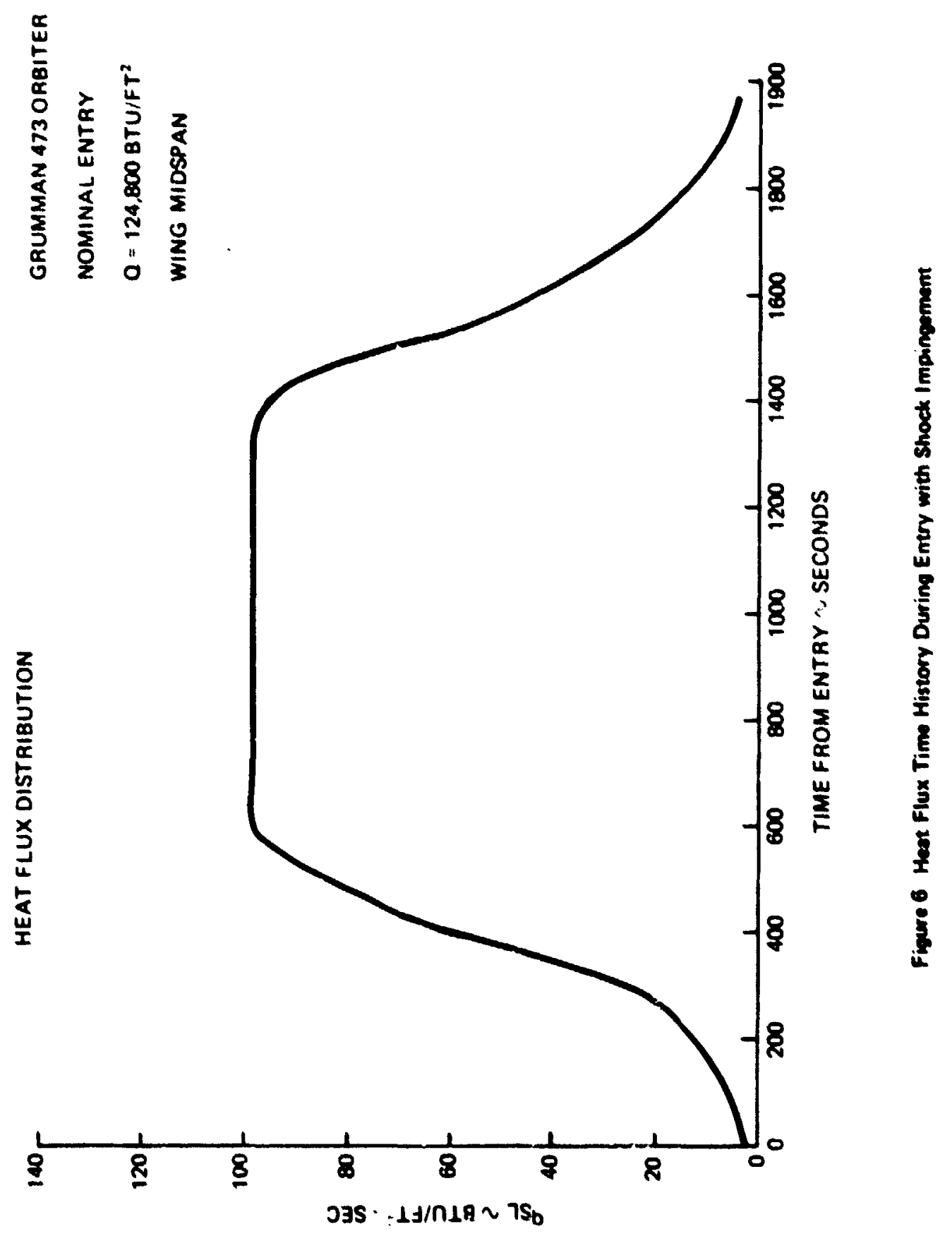


HEAT FLUX DISTRIBUTION

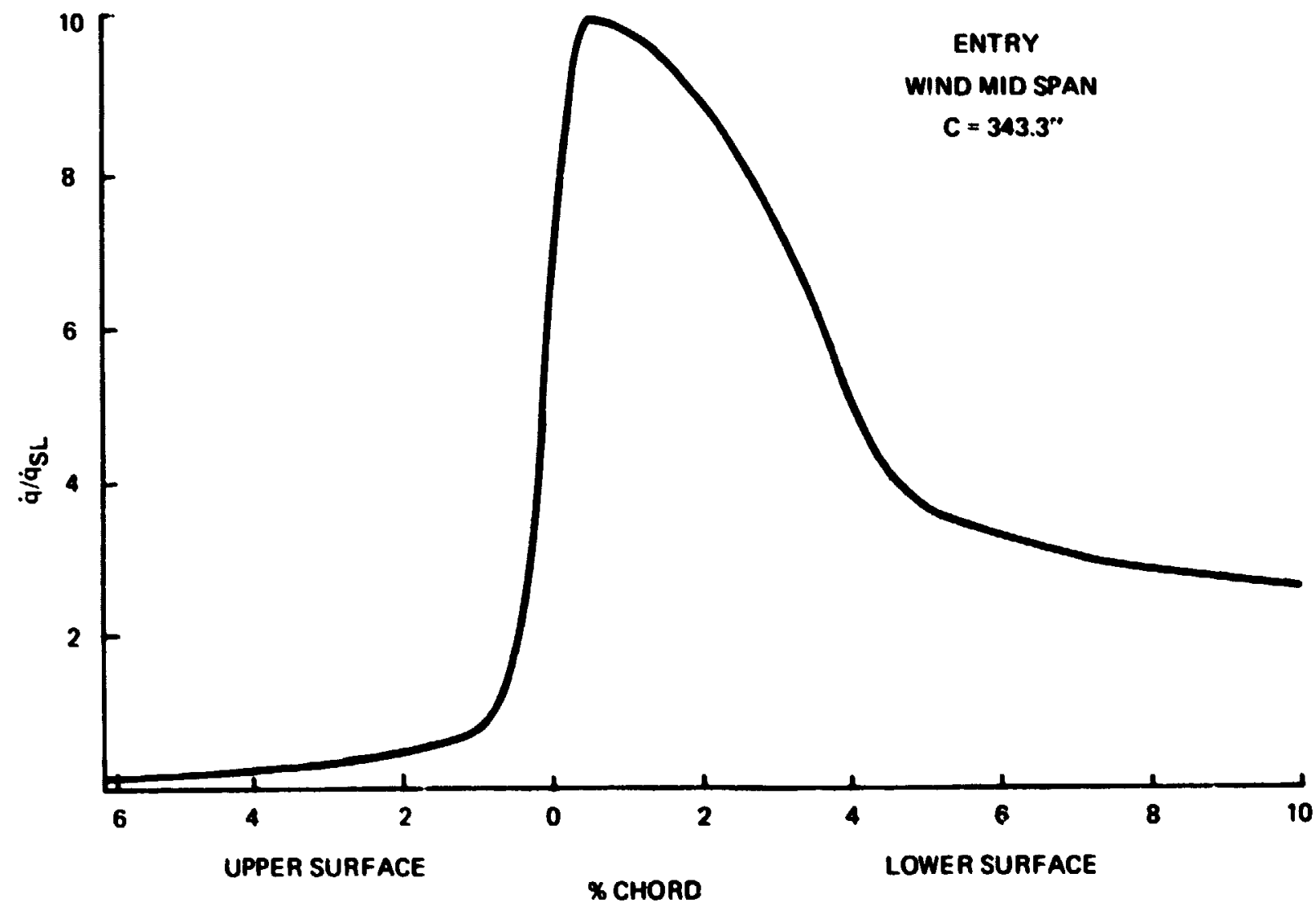

Figure 7 Hent Flux L.E. Distribution During Entry Withour Shock Impinjoment 

1. External pressure distribution along the chordwlse contour (up to the front beam of the leading edge) were obtained at root, midspan, and tip (as shown typically in figures 8 and 9 for the $40 A=473$ orbiters respectively). Complete data for all flight conditions are given in the Data Package. Figures 10 and 11 derine the root, midspan and top locations. Total shear and moment with respect to the front beam for these locations are also available (references in the Data Package).

2. Internal pressure distribution as shom in figures 8 and 9.

3. Spanwise deflections of the front bear are given in figures 12 and 13 and spanvise curvatures in figures 14 and 15.

4. The spanwise strains in the caps of the front beam and therefore also in the aluminum 1.e. substructure if and where the substructure follows the beam deslections is show in figures 26 and 17 .

These data were condensed into ane matrix showing the relation of strain versus curvature in the L.E. upper and lower skin just forward of the front beam (if the skin follows the front beam) for all three flight conditions, figure 18 .

Figure 18 data are used to establish the spanwise stress/strain environment for the design of the substructure.

\subsubsection{Dynamic Structural Environment}

The wing leading edge vibration enviroments were investigated for five conditions--lift off, $\max q$ on ascent, entry, max $q$ on post entry, and touchdown-- 


\section{OAOA ORBITER \\ $\operatorname{MAX} q \alpha(+) \& q \alpha(-)$}

NOTE:

- CONTOURS ARE CROSS SEC

NORMAL TO THE L.E.

- PRESSURES ARE PLOTTED

ALONG NORMALS TO THE OML

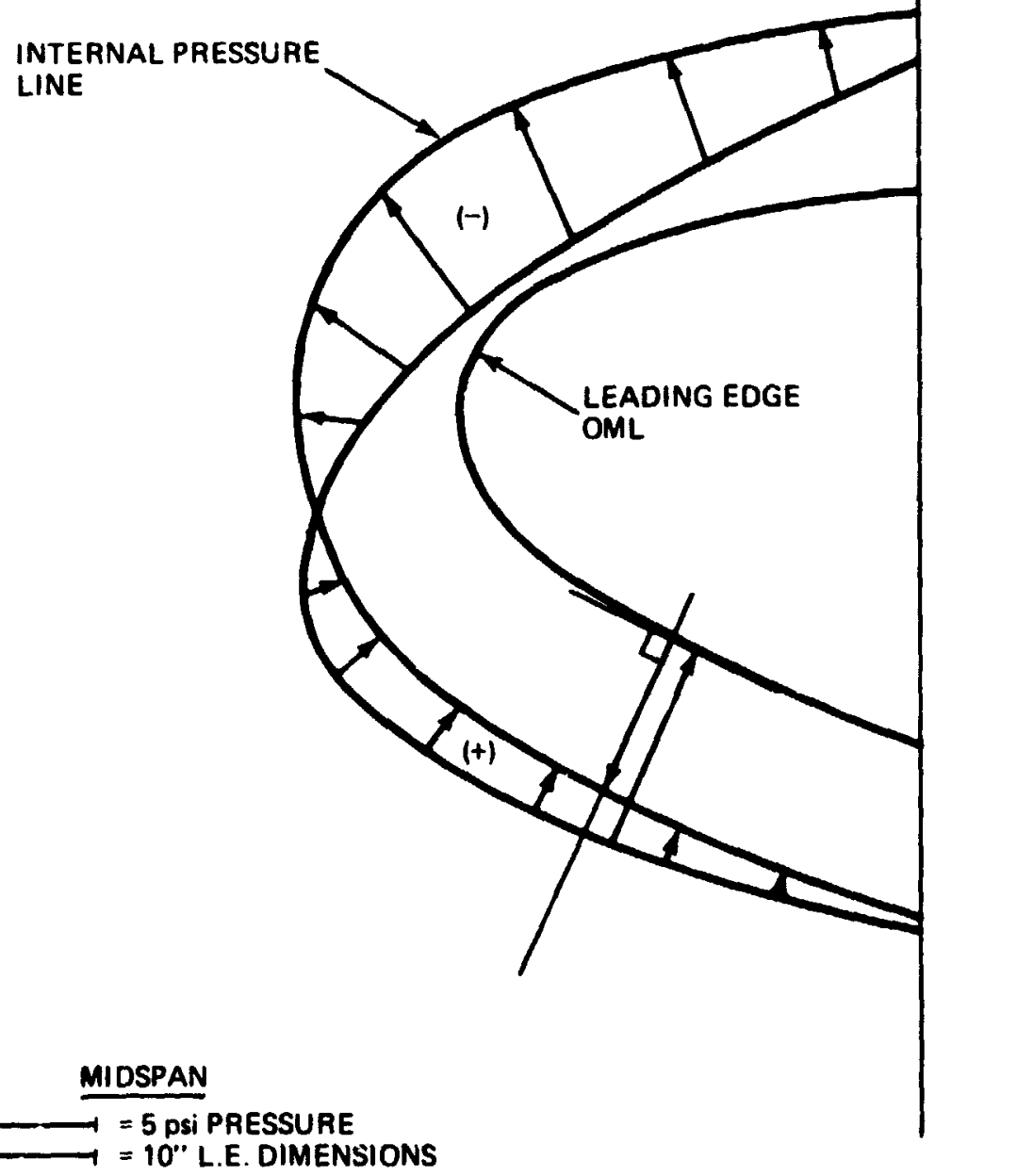

Figure 8 Aerodynamic Loads at One Critical Condition - 040A Orbiter 


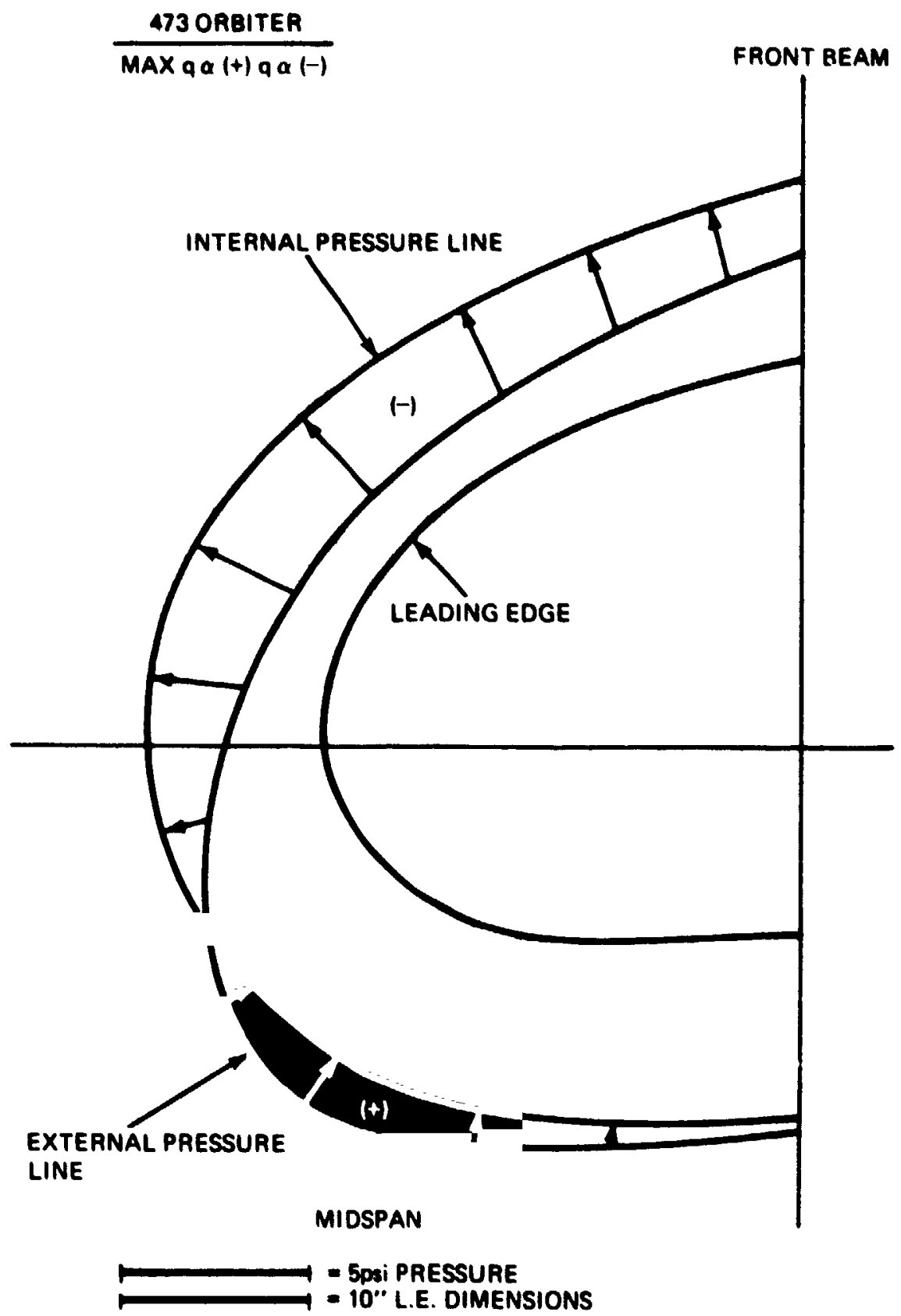

Figure 9 Aerodynamic Laads at Ome Critical Condition - 473 Orbiter 


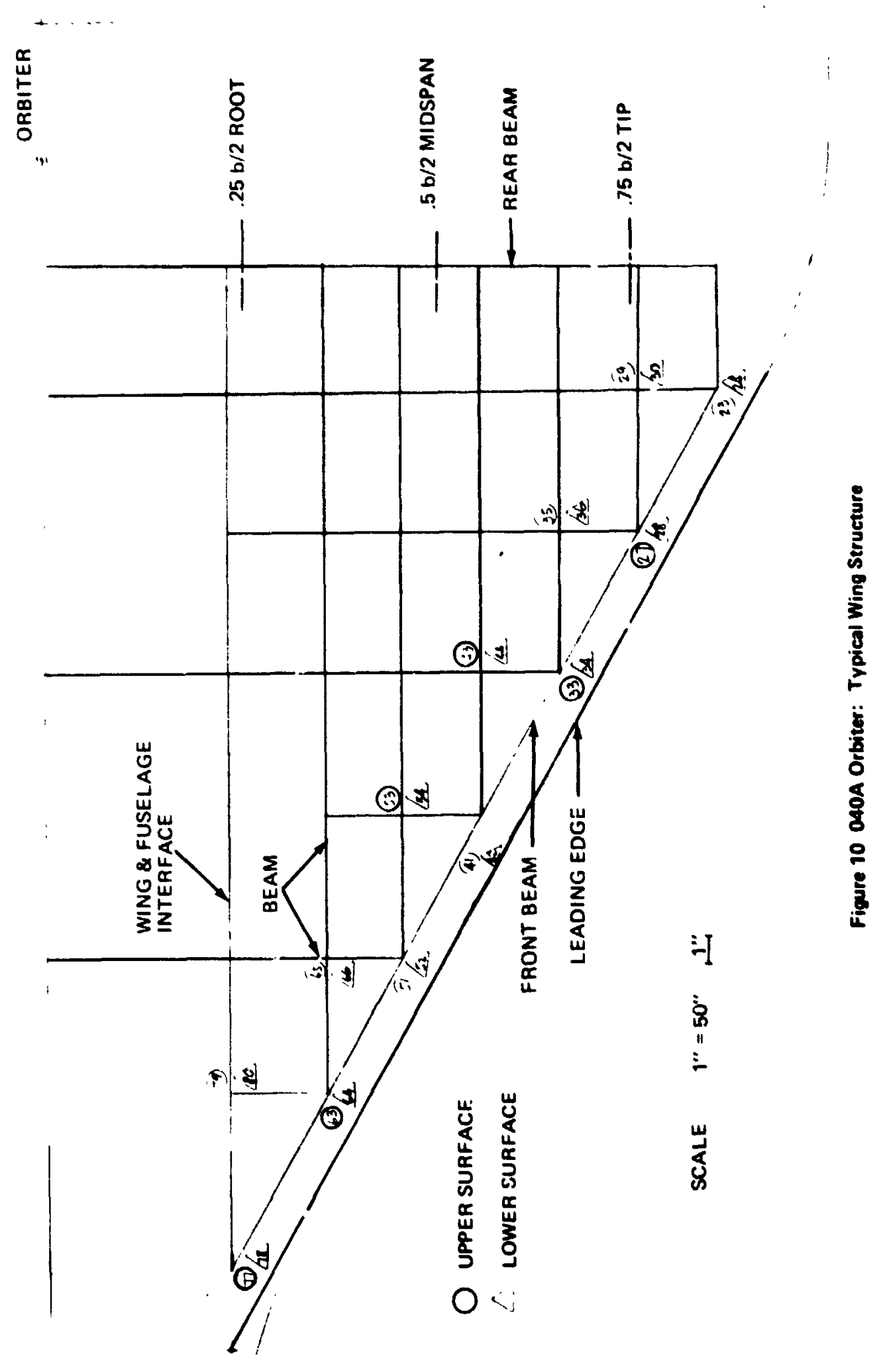




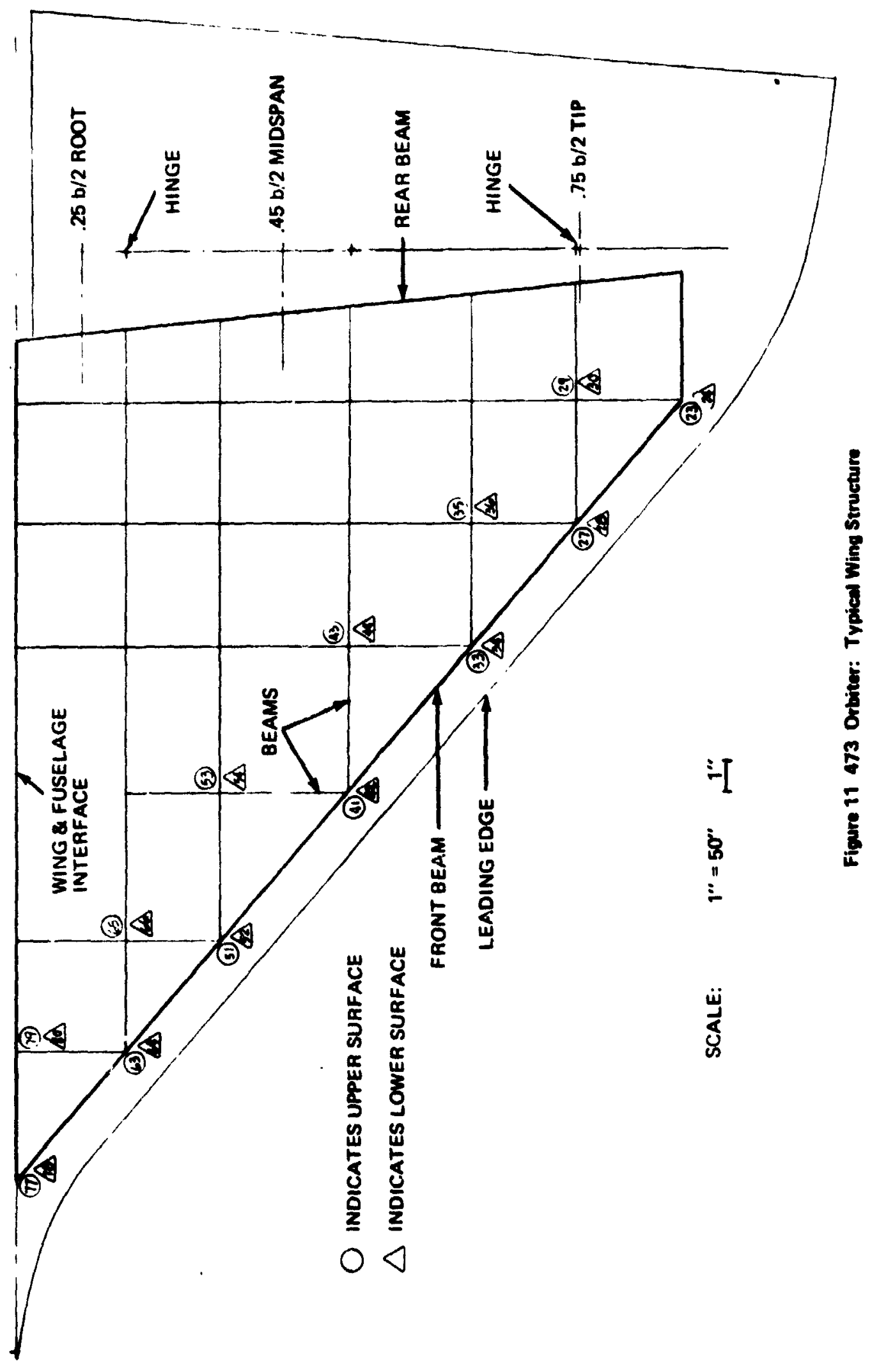




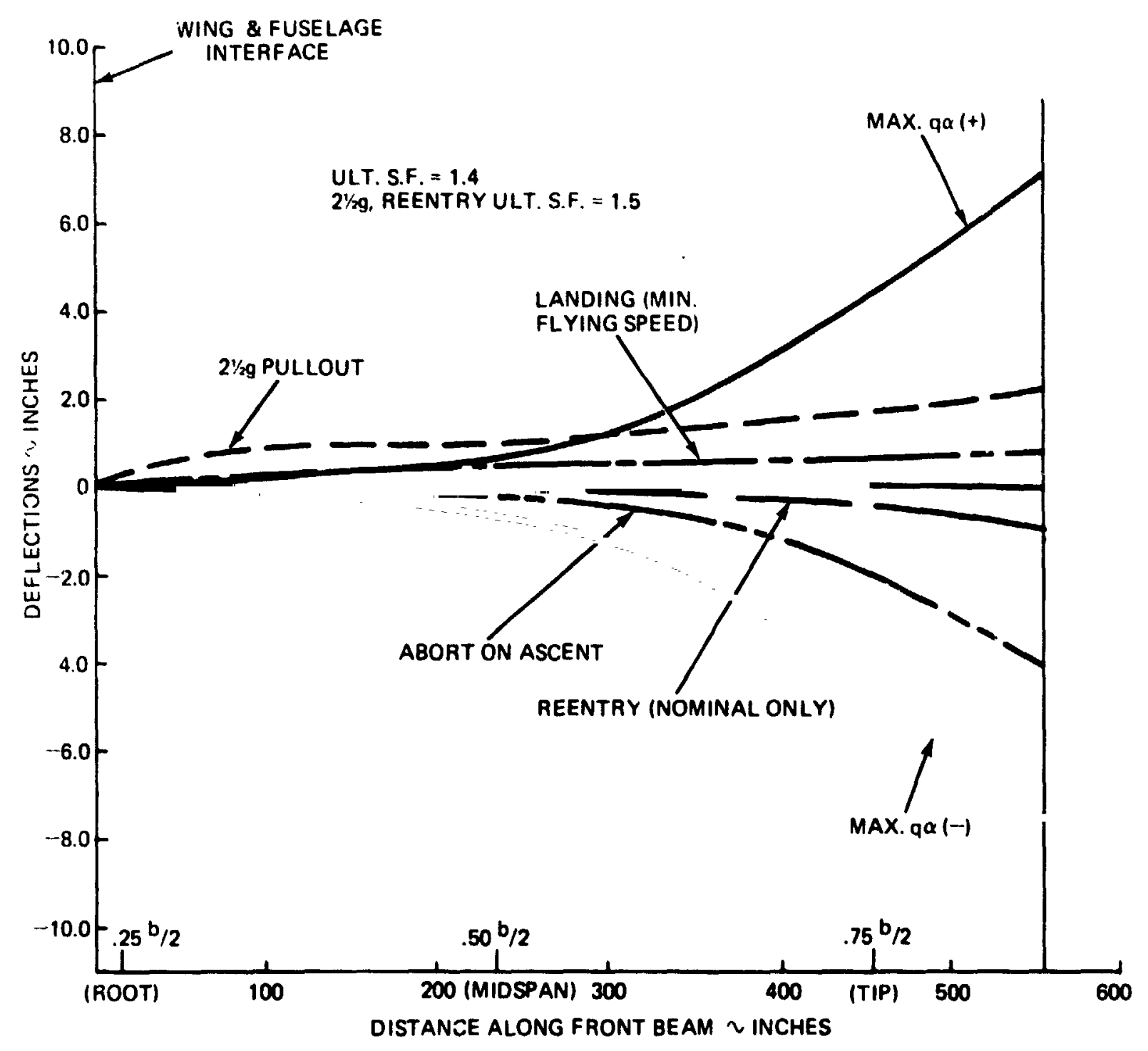

Figure 12. Wing Fromt Baem Deflections For $040 \mathrm{~A}$ Orbiter Configuration 


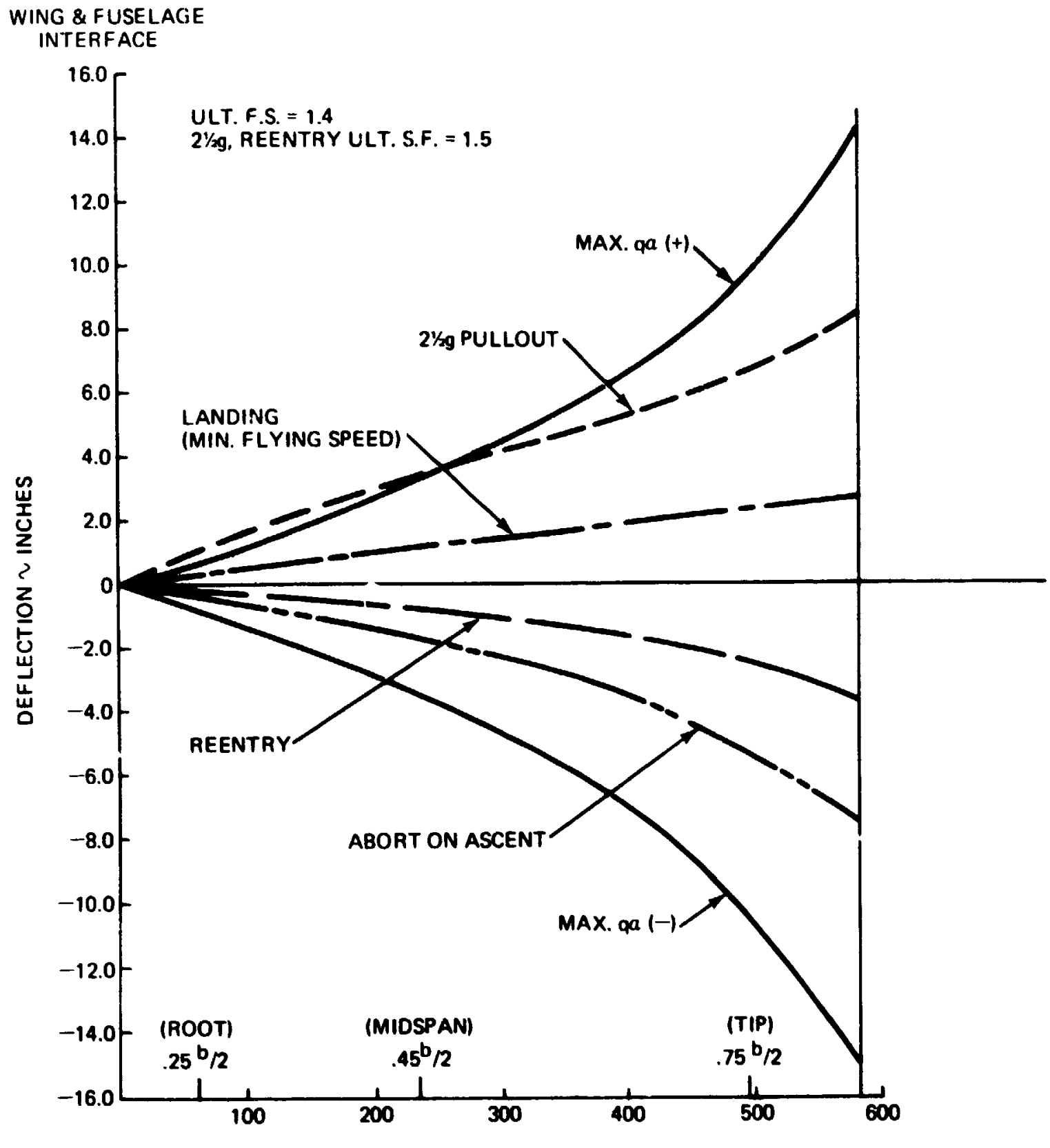

DISTANCE ALONG FRONT REAM INCHES

Figure 13. Wing Front Besn Deflections For 473 Orbiter Configuration 


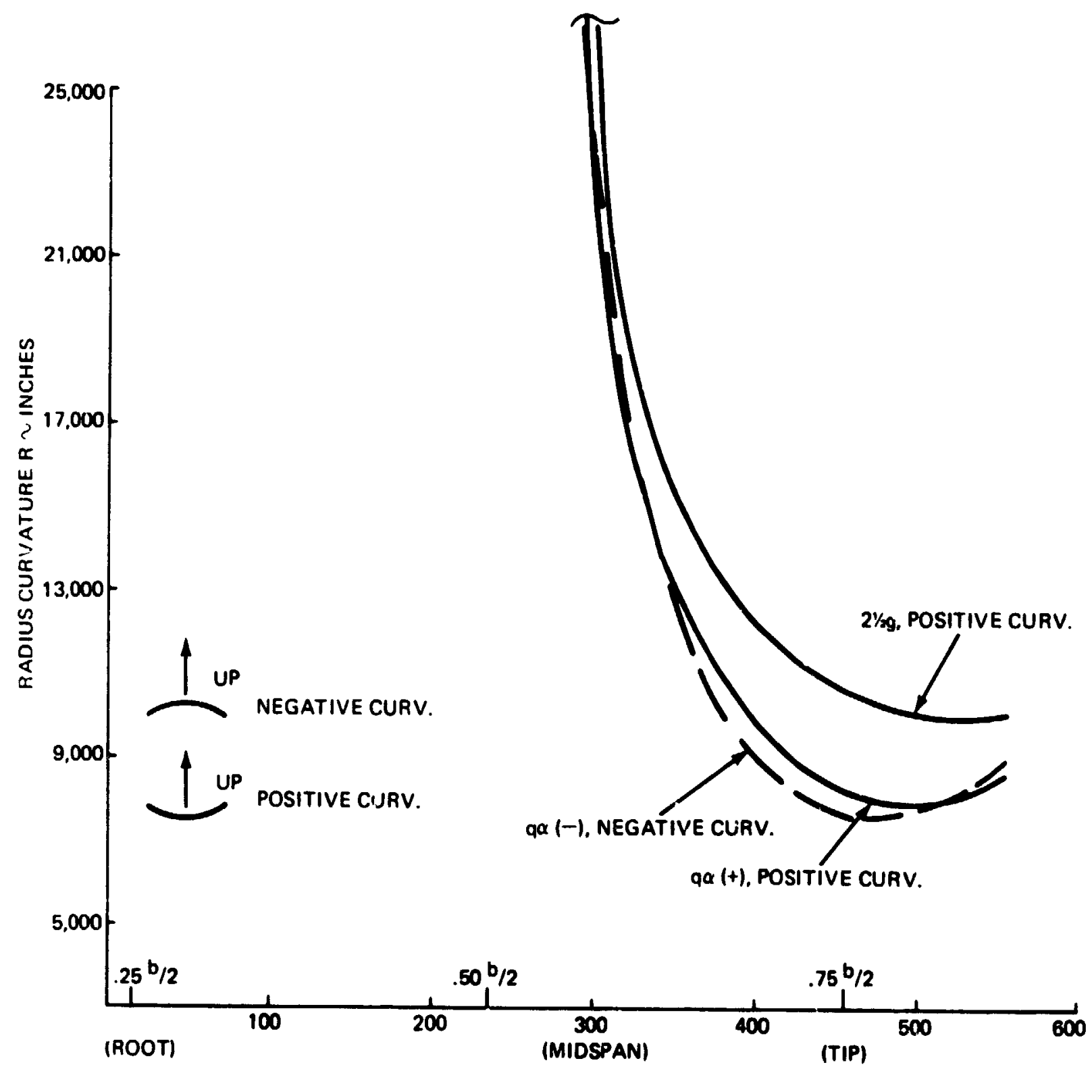

DISTANCE ALONG FRONT BEAM INCHES

Figure 14. O40A Urbitep - Spanwise Curveture of From Beom (ot Midwob) 


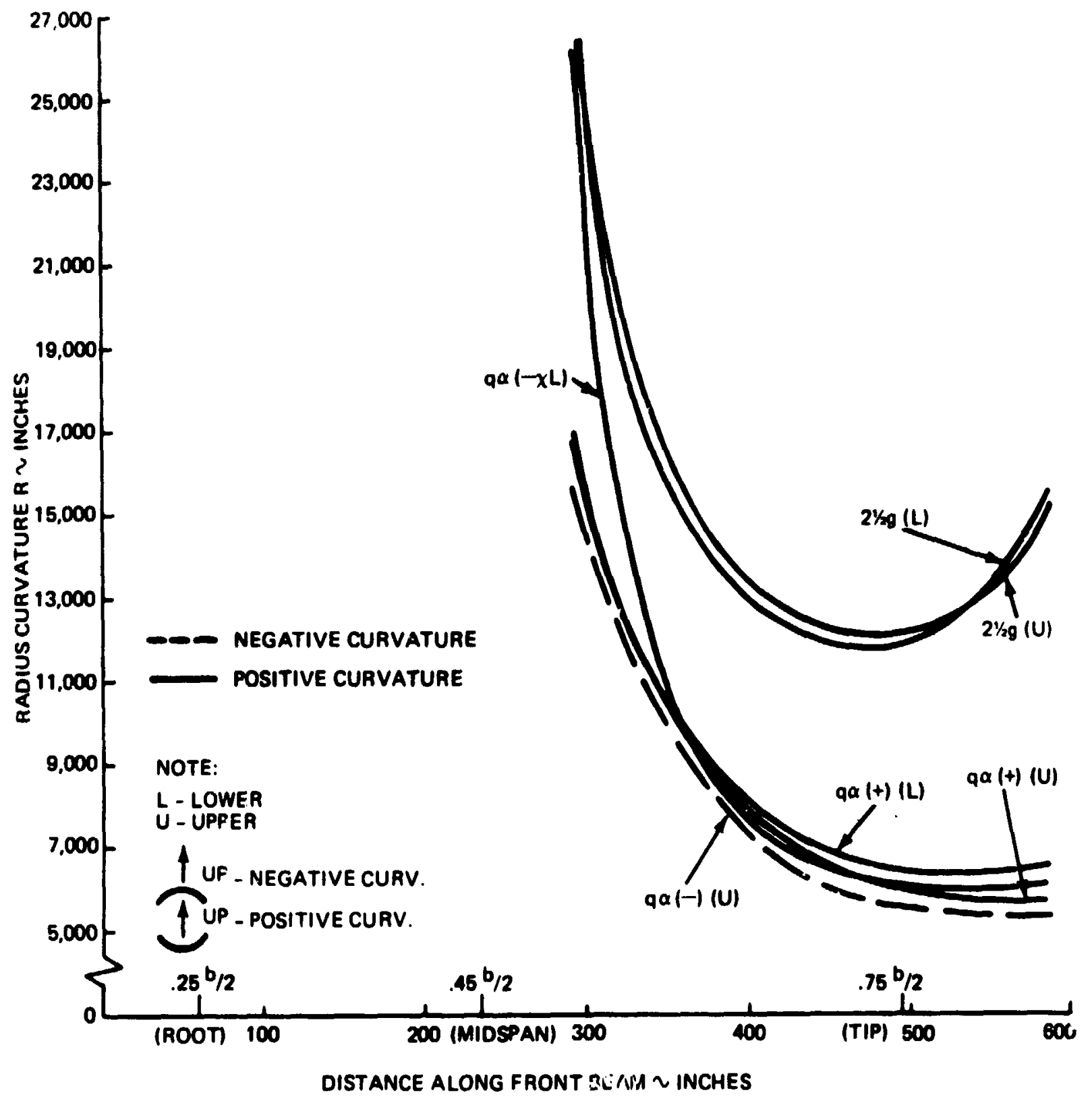

Figure 15473 Orbiter - Spanwies Curvoture of Front Beam Cape 


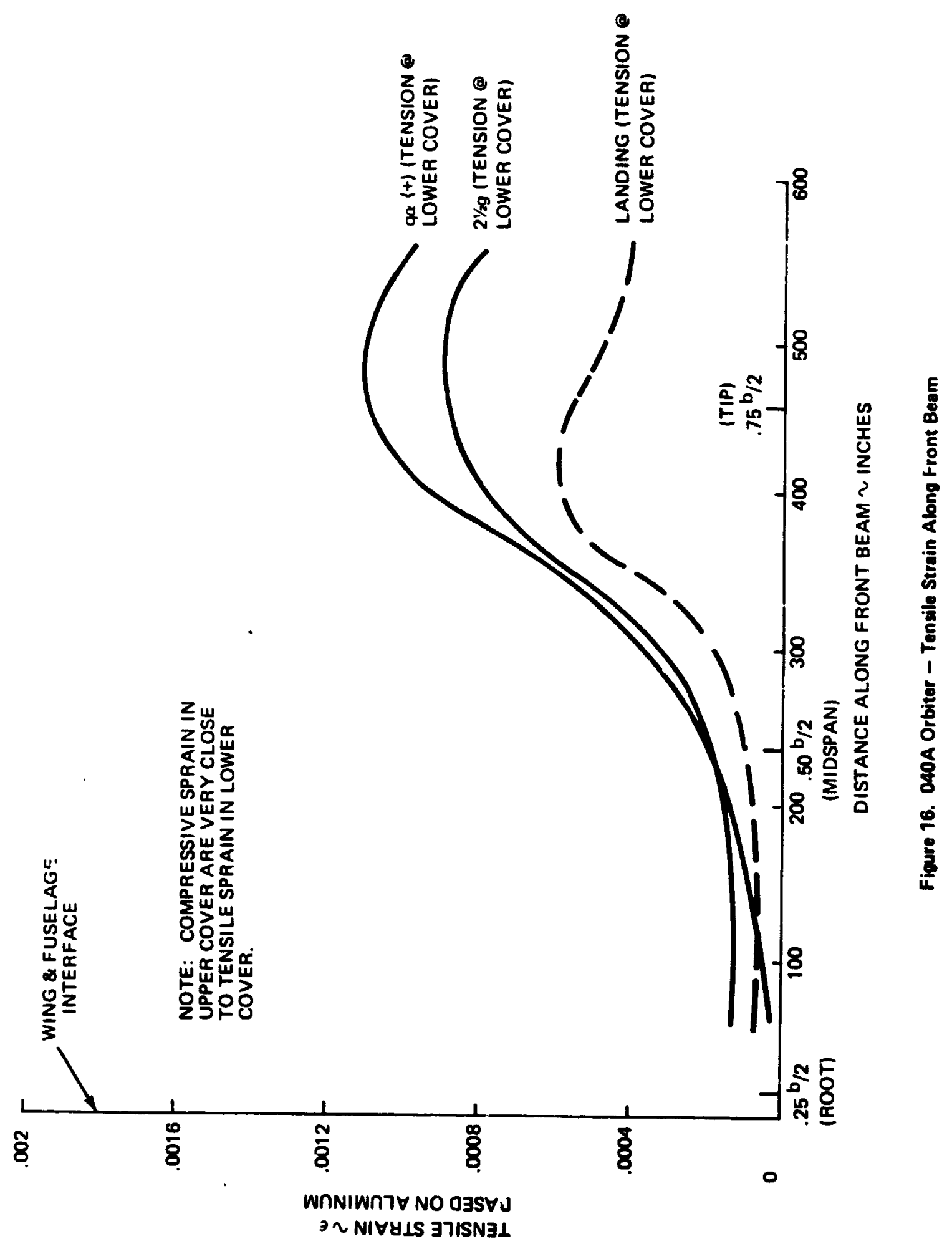




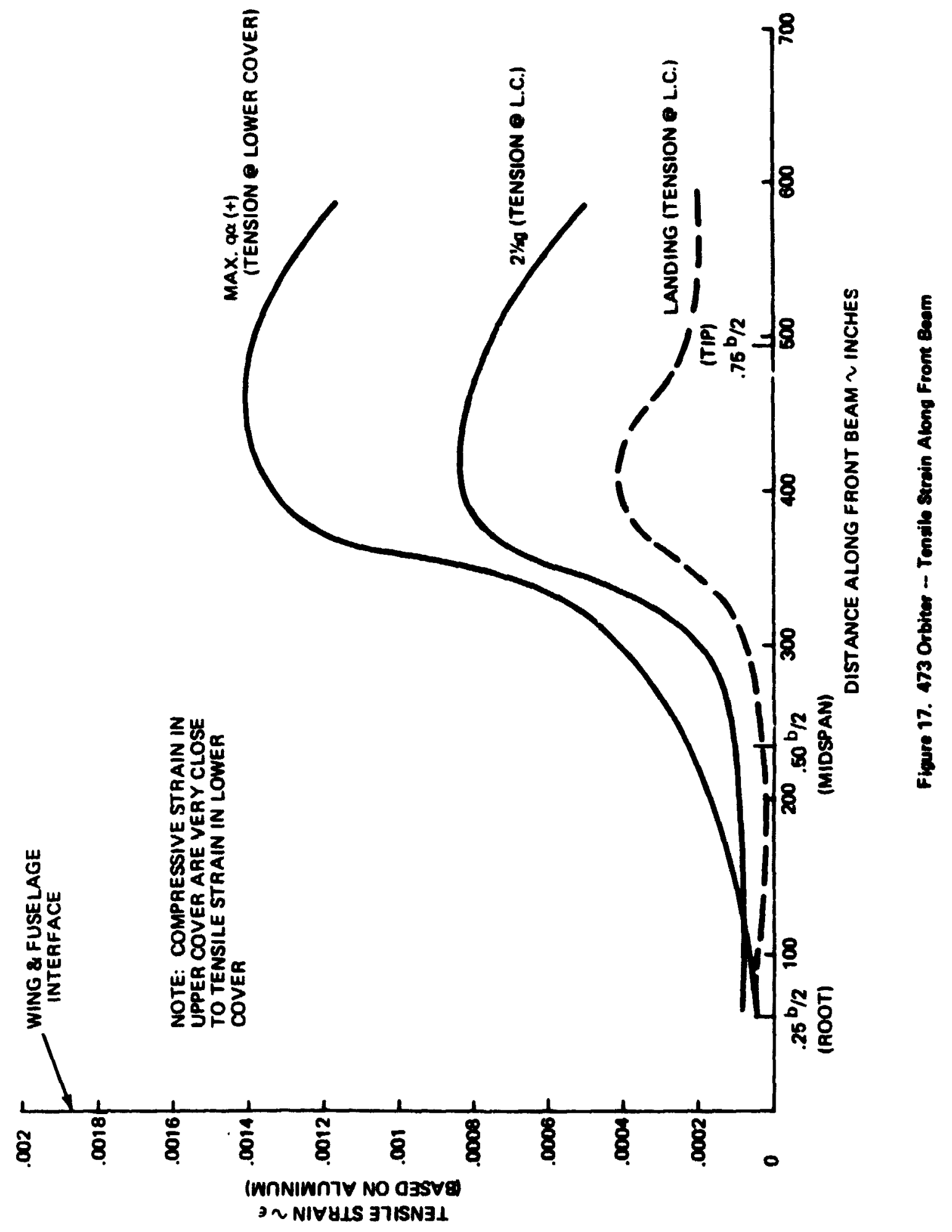




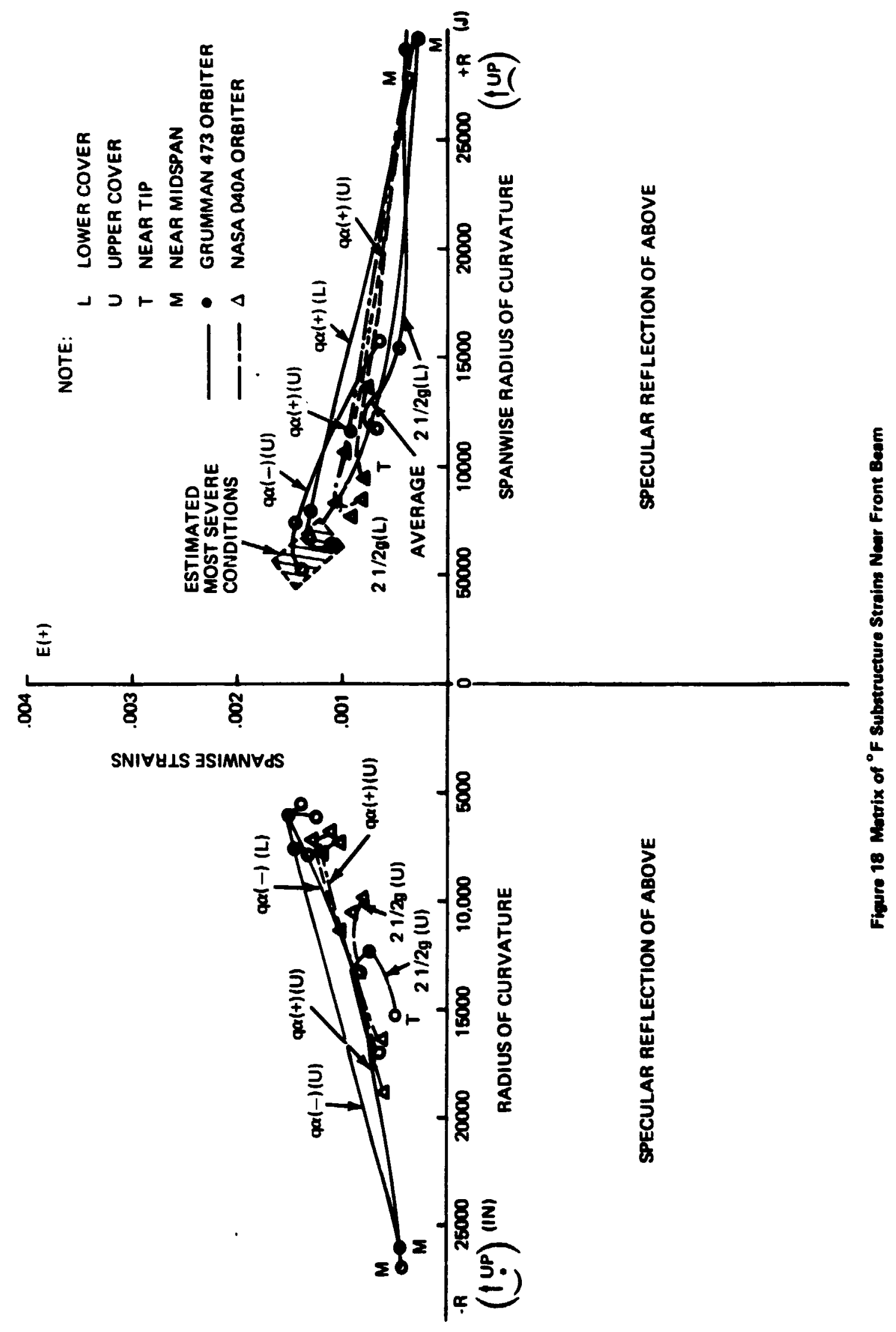


for the Gruman 473 and NASA O4OA stuttle orbiters. The vibration source anit duration are show in table 6 .

Fram the sound pressure levels for each condition firure 19 was prepared which shows the most severe sound fressure levels and duritions which an ablative L.E. would be exposed to in the virgin and the charred state.

In addition, touchdown generates the most severe acceleration condition on the charred ablator, $11 \mathrm{~g}$ at $15 \mathrm{~Hz}$ for two seconds. This may occur twice, once after regular flight and once after ferry to a depot.

\subsection{Natural}

The natural environments for the L.E. Include rain, hail, cold saak, humidity and blowing sand and dust. Not only the values of the environmental factors, but also the conditions on the trajectory must be determined.

The critical natural environments for rain, hail, humidity and blowing sand and dust are given in table 7 .

The trajectory conditions for the most severe rain encounter are given in table 8 .

The orbiter undergoes a cold scak period of fram one orbit to seven days. During that time the external surfaces, including the ablative leading edges are maintained at temperatures of between -150 and $200^{\circ} \mathrm{F}$ and experience prersures of less than 10-6 atmospheres.

A more complex problem is to determine the thermal envirorment during the initial phase of entry which occurs in the upper etmosphere $(>400,000)$. Calculations indicate the flow may be considered to be free molecular and therefore there is $l: t+1$ e heat flux or pressure dependence on geometry. This 


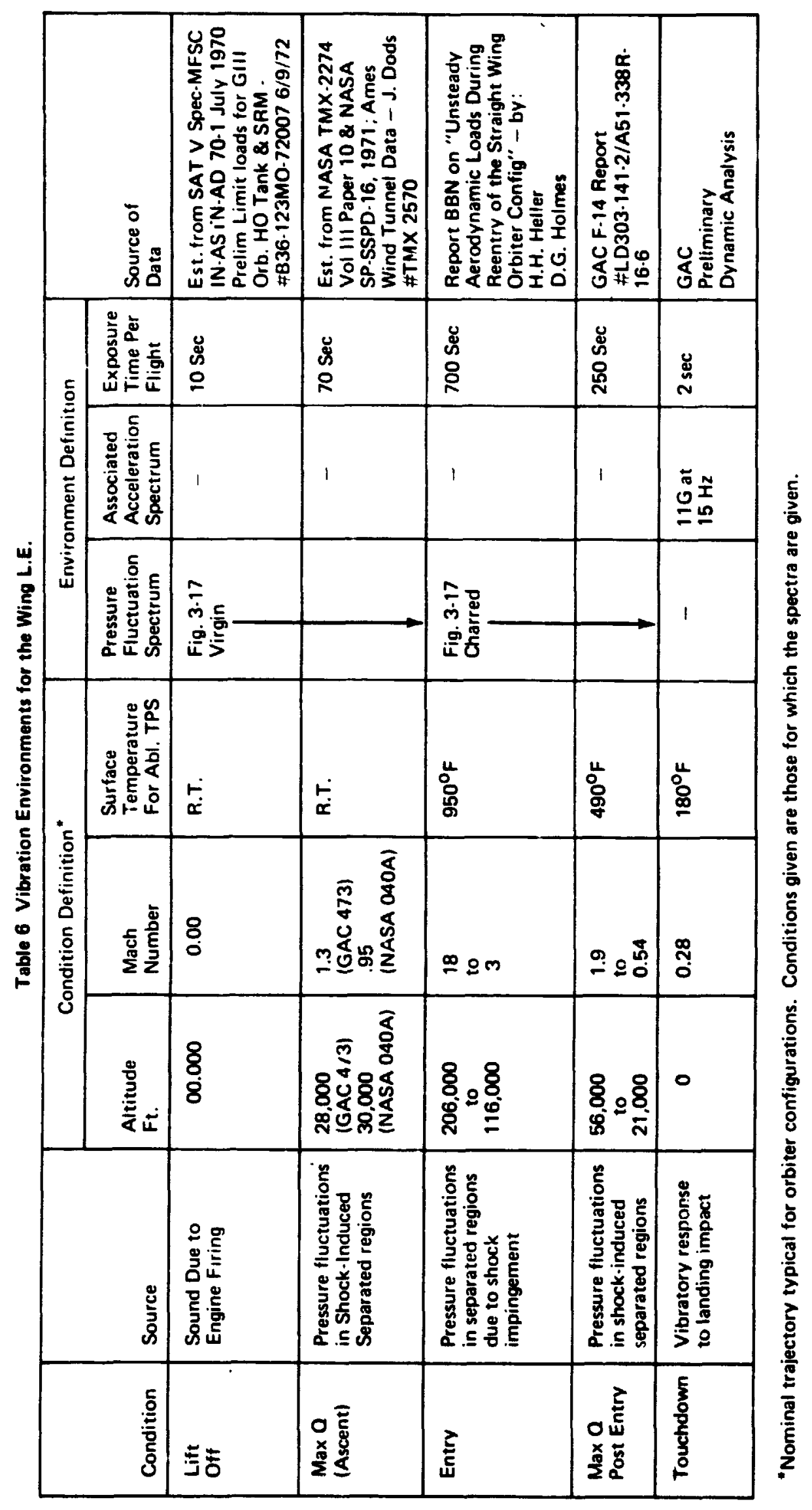




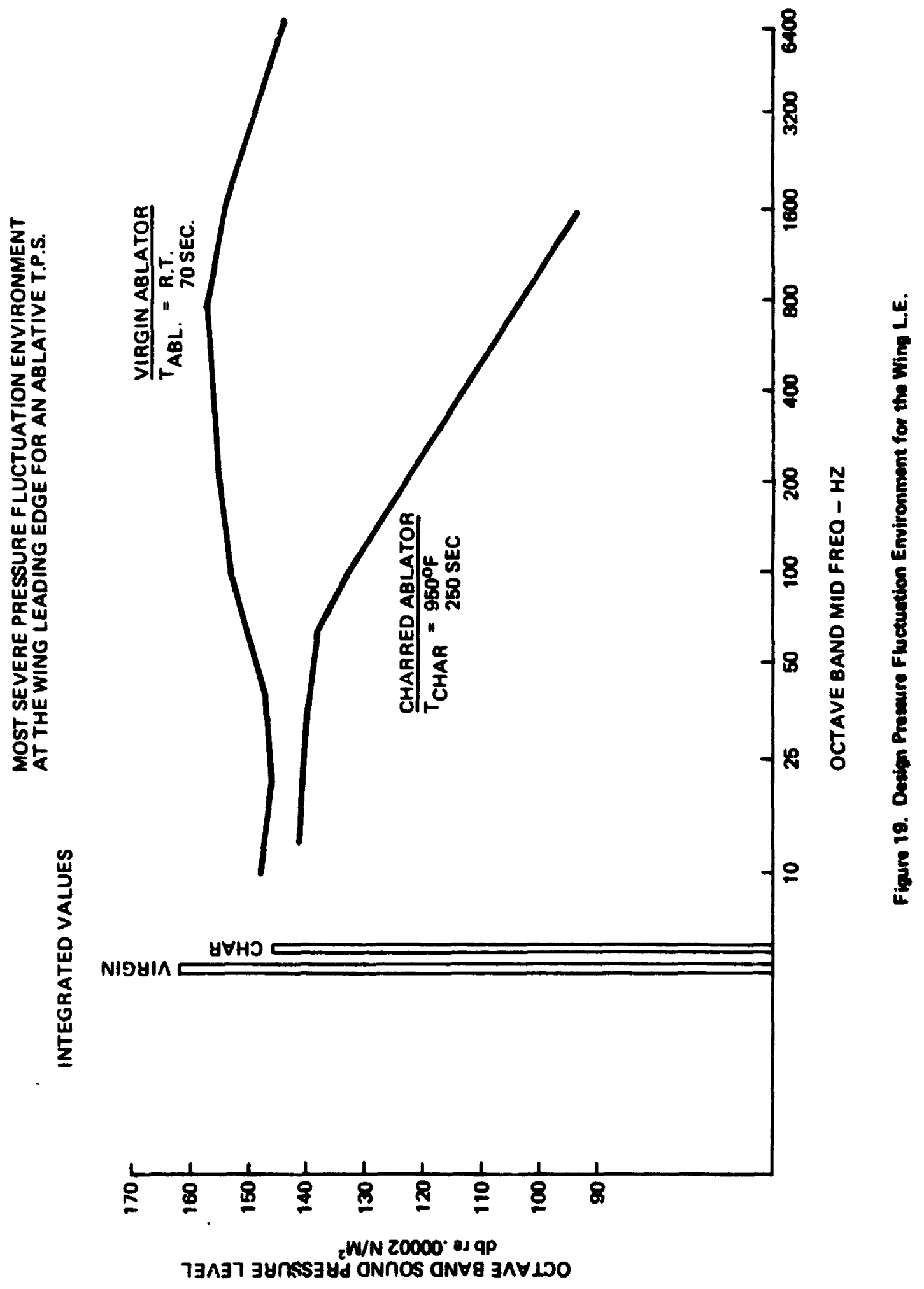


Table 7 Critical Natural Environments for 040A and 473 Orbiter Leading E.dge

\begin{tabular}{|c|c|c|}
\hline Condition & Source & Environmental Definition \\
\hline \multirow[t]{2}{*}{$\begin{array}{l}\text { Launch Pad, Ascent, } \\
\text { Flyback }\end{array}$} & $\begin{array}{l}\text { Rain and Hail Accumulated } \\
\text { damage or erosion }\end{array}$ & $\begin{array}{l}\text { - Raınfall distribution: } \\
\text { NASA TMX } 64589 \\
\text { Tables } 4.1,4.3,4.4 \text { and } 4.5\end{array}$ \\
\hline & & $\begin{array}{l}\text { Hail: NASA SP 8057, para } 6.4 \\
\text { single exposure }\end{array}$ \\
\hline In orbit & Cold Soak & $\begin{array}{l}2 \times 10^{-7} \mathrm{~mm} \mathrm{Hg} \text { at }-200^{\circ} \mathrm{F} \text { for } 7 \\
\text { days }\end{array}$ \\
\hline Ground Operations & Humidity & $\begin{array}{l}\text { Humidity cycle specified in NASA } \\
\text { TiMX 64589, para } 3.2 .1\end{array}$ \\
\hline $\begin{array}{l}\text { Launch Pad, Ground } \\
\text { operations }\end{array}$ & Blowing sand and dust & $\begin{array}{l}\text { As specified in NASA TMX } 64589 \text {, } \\
\text { para } 6.2\end{array}$ \\
\hline
\end{tabular}

Table 8 Conditions Typical for Most Severe Rain Environment for GAC 473 and 040A Orbiters

\begin{tabular}{|ll|ll|}
\hline Mach no. & -0.38 & Altitude & $-1000 \mathrm{ft}$ \\
Velocity & $-420 \mathrm{fps}$. & Flt. Path Angle & $-15^{\circ}$ \\
Dynamic Pressure & $-206 \mathrm{psf}$. & Rain fall rate & $-1.52 \mathrm{lb} / \mathrm{min} . \mathrm{ft}^{2}$ \\
Reynolds no/ft & $-2.64 \times 10^{6} / \mathrm{ft}$. & Rain Exposure Time & $-250 \mathrm{sec}$. \\
Angle of Attack & $-5.5^{\circ}$ & Average Drop Dia. & $-3.8 \mathrm{~min}$. \\
\hline
\end{tabular}


permits the calculated environment of one vehicle (namely the GAC 473 ) to be applied to all. The small difference in wing sweep between vehicles causes a variance of $15 \%$ and $7 \%$ in heat flux and pressure respectively, between the orbiter configurations. The free molecular heat flux and pressure is independent of leading edge radius.

Since this free Lolecular heat $\mathrm{r}^{\mathrm{l}} \mathrm{lux}$ is low $\left(\dot{\mathrm{q}}<1 \mathrm{Btu} / \mathrm{ft}^{2}-\mathrm{sec}\right)$ and the initial starting temperature is assumed to be $-175^{\circ} \mathrm{F}(610,000 \mathrm{ft})$, the wall during the initial phase of entry may not be assumed to be in radiation equilibrium. Rather, the ablator must first absorb most of the heat to raise the temperature to a point where radiation dominates. The task of evaluating the ablator temperature rise involves having a knowledge of its properties. However, for the typical class of ablators to be considered later, general statements can be made. The wing leading edge pressure history is given in figure 20 . Surface temperature records of two typical ablators are given in figure 21 and reflect a realistic balance of heat in the initial entry phase blending into radiation equilibium. Figure 22 was derived from figure 21 and is an indication of the temperature-time gradient experienced by typical leading edge ablators.

\subsection{Aerodynamic}

The flight range in which the ablative leading edge might most affect orbiter aerodynamic performance occurs during the post entry, subsonic portion of the trajectory. It is here that a vehicle designed for hypersonic flight has little margin for change in the critical aerodynamic parameters.

The significant jerodynamic environment parameters (Reynolds number, dynamic pressure, etc) during post entry, subsonic flight are presented in figure 23 ior a typical orbiter. 


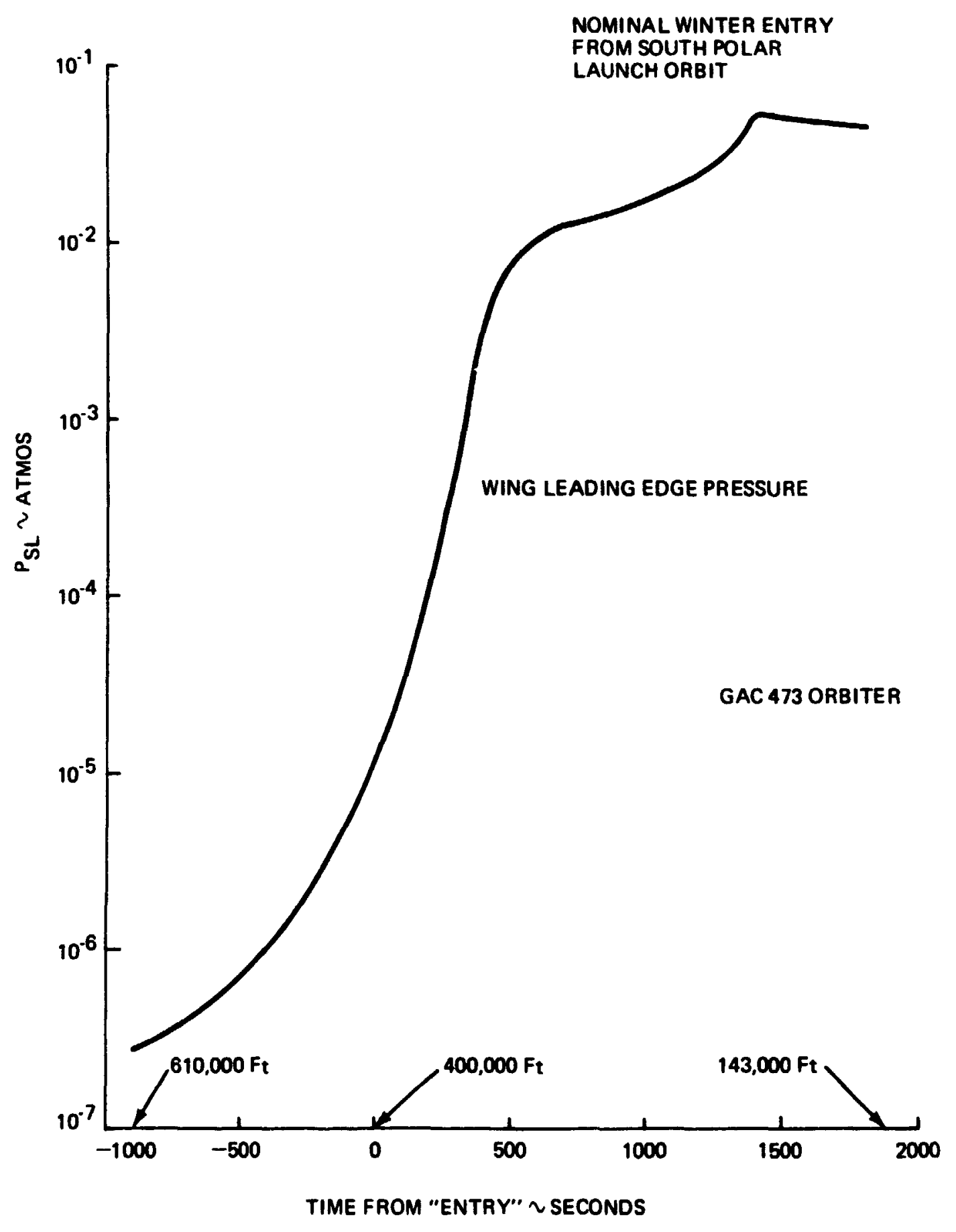

Figure 20. L.E. Prosaure Environment at the Beginning of Entry 
NOMINAL WINTER ENTRY

FROM SOUTH POLAR

LAUNCH ORBIT

WING TIP LEADING EDGE TEMPERATURE

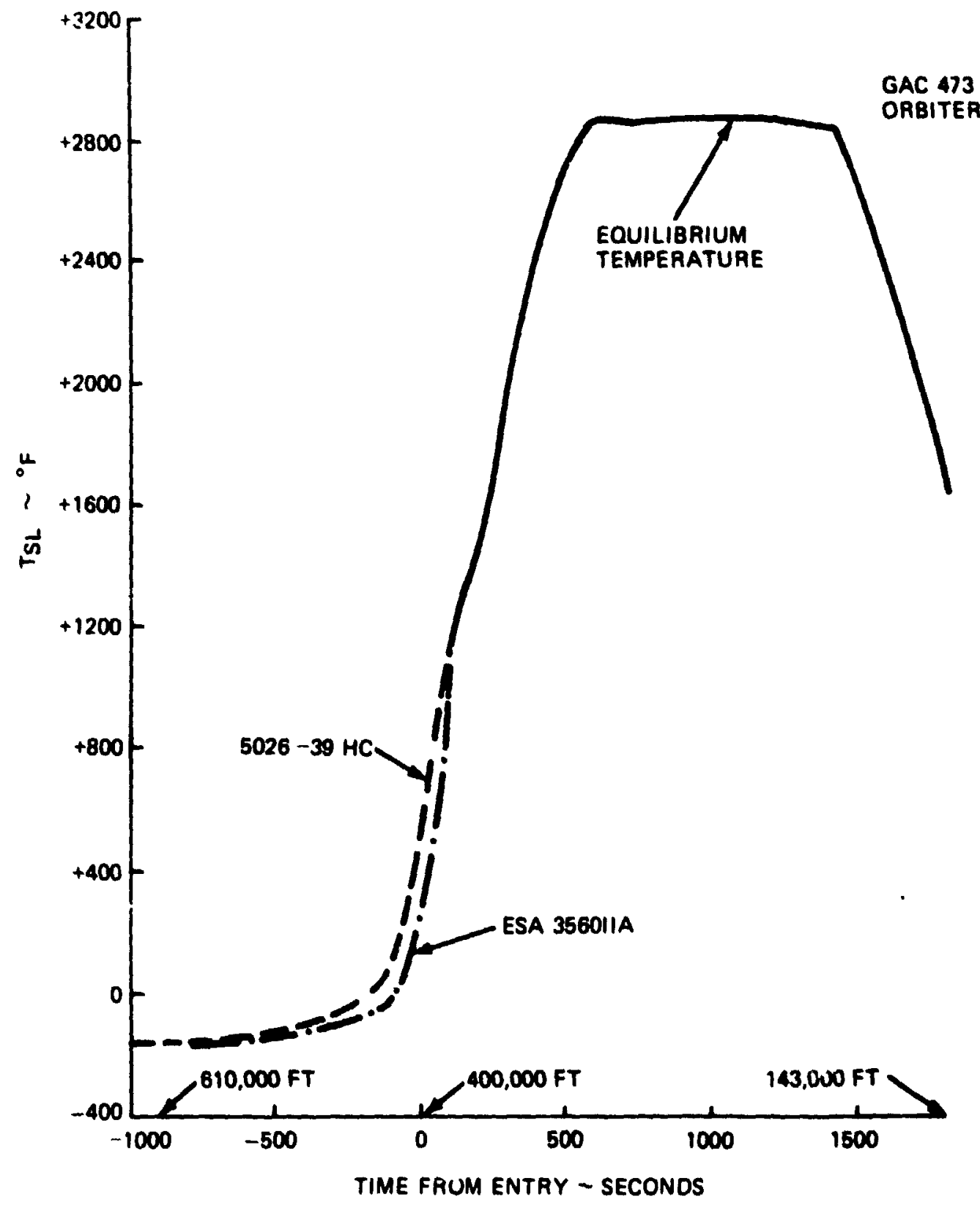

Figure 21 L.E. Surfees Temperature Environment at the Besinning of Entry 


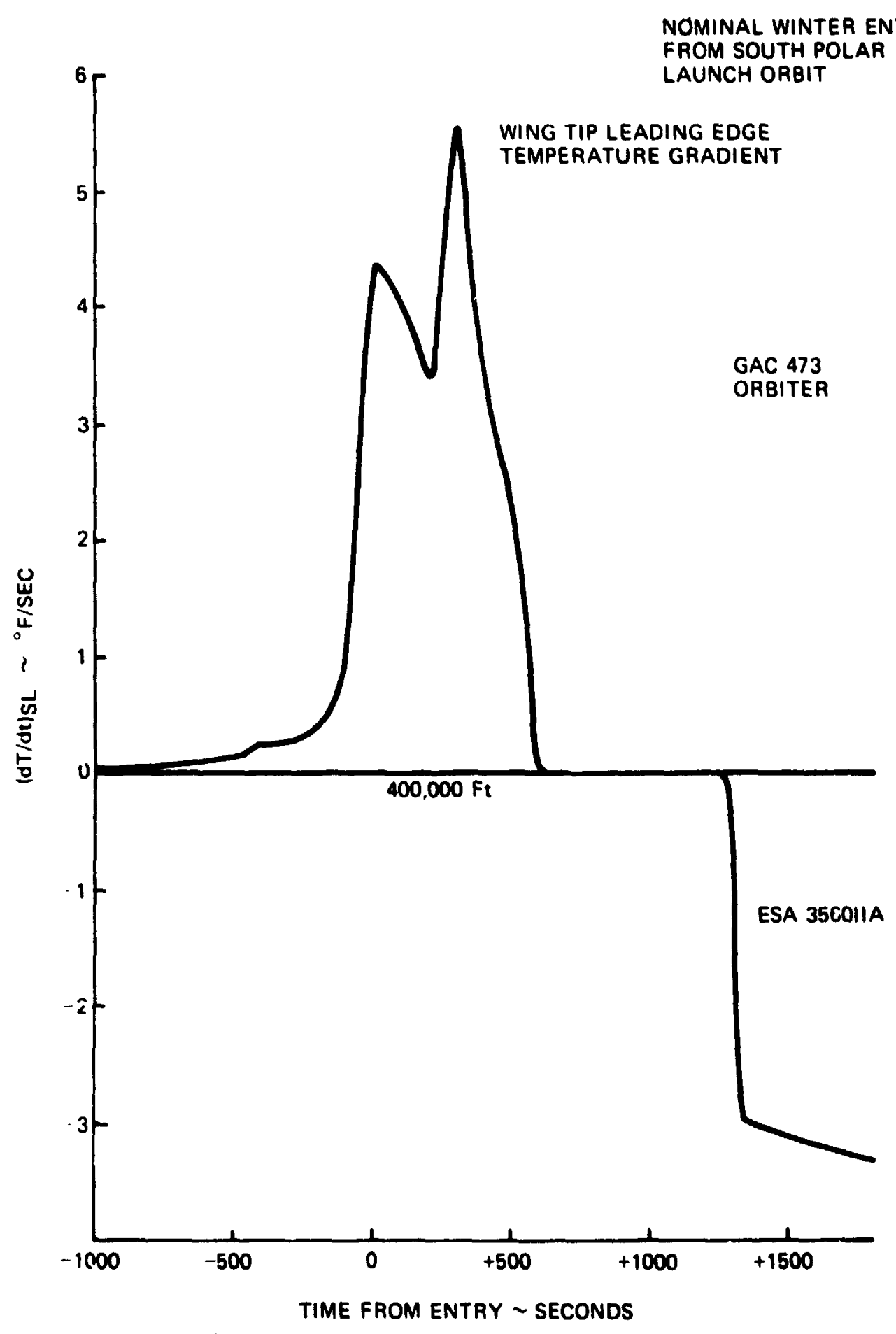

Figure 22 L.E. Surface Temparature Cradient Environment ot the Bepinning of Entry 


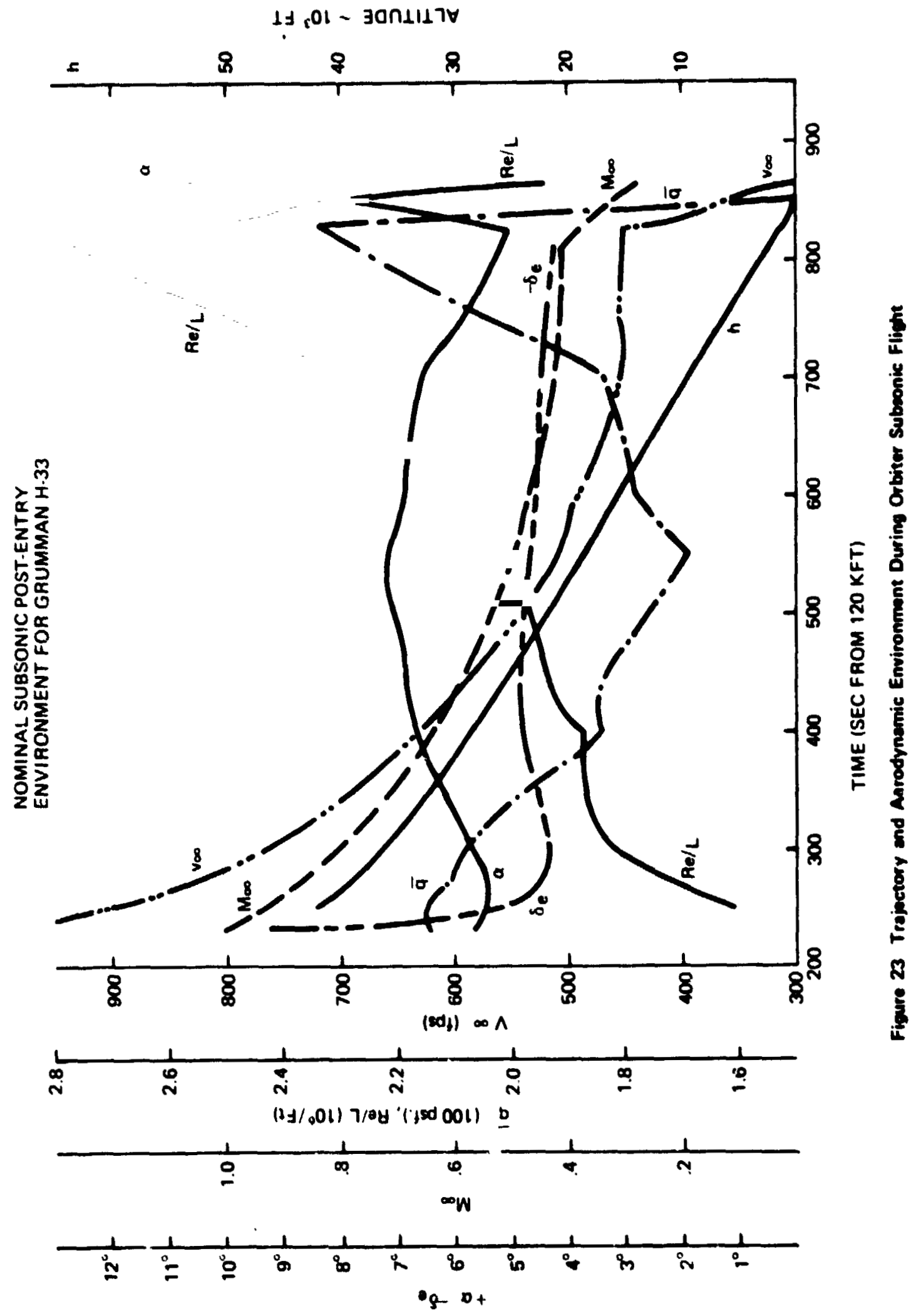




\subsection{Selection of Design Environnent}

The desien trviromert seacted for this study represents typical data of end-of-Phase-B/ve Enning-of-Phase-C orbiters. it co' is of:

a) Aerothermal environment: dominant enviroment; for the stagnation region, tables 1 and 2 ; for the distribution on the $1 . e .$, the iruman LT3 orbiter, fielure 7 ; for the history along the trajectory, the srumuan $47^{2}$ orbiter; for typical values for the windward joint regior; tables 3 and is.

b) itructural environment--static: the Grumman 473 orbiter, takie 5 , figures $3,11,13,15,16$, and 18 .

c) Structural environment--dyramic, figure 19.

d) ilatural environment--tables 7 and 8 .

e) Aerodyramic environment at low speed--figure 23. 


\section{AERODYNAMIC CHARACTERISTICS DEGRADATION DUE TO ROUGHANSS AND RECESSION}

\section{(PRELIMINARY STUDY)}

The ablative 1.e. roughness and recession siould prodnce 'acceptable' dicradation of the low speed aerodynamic characteristics of the orbiter. More precisely one needs to know the maximum 'acceptable' value for roughness and recession and what is the cost penalty of any given : Jughness/recession below the maximum and within the ranges that the candidate ablators may produce.

Since little effort has been devoted to this area, roughness and recession are contimally identisied as an area of uncertainty. We attempt to provide - within the limit of a brief and preliminary study - a quantitative assessement of the degradation involved, at least in some typical orbiter designs at a specific time during the evaluation of the design.

The point of view we take is of providing the degradation assessment (' $\mathrm{gO} / \mathrm{no}-\mathrm{gO}$ ' and cost penalties) under the orbiter requirements as they are now foralated (e.g., landing speed $150 \mathrm{kt}$; minimum float time, $10 \mathrm{sec}$; max retrieved payload, 45,000 lbs) and also within the safety margins that one would like tc set (e.g., in the case of the Gruman orbiters, $4 \mathrm{sec}$ of safety on minimum float time). However it must be burne in mind that, even if none of the wblators we:e to pass all the 'go/no-go' criteria, one has still the option of reexamining the broader policy question of relaxed requirements. For example, the landing speed could be increased; retrieved payload can be reduced, in fact advantage could be taken of the fact that ouch a large mumber of flights for orb.t are empty in the current traffic models; a harder look can be taken at the safery factors with possible lower requirements; even such expensive propositions as wing resizing in a frozen environment can be considered. Therefore, we are examining not absolute ' $\mathrm{BO} / \mathrm{nO}-\mathrm{gO}$ ' limits but rather limits that do not upset current requirements. 
Since this is only a brief preliminary study, a plan for a detailed study is presented in Section 11 .

\subsection{Review of State-of-the-Art}

\subsubsection{Aerodynamic Characteristics Affected}

With a typical delta-wirg orbiter at subsonic speed, the aerodynamic situations to be considered for roughness/recession are usefully schematized (Ref. I⿰氵) as follows:

- Subsonic cruise/cruise to depot, etc - low-to-moderate $\alpha$; main aerodymamic characteristics involved: $c_{D}, c_{L}, L / D$. Typical situation: $\alpha \sim 10^{\circ}$; typical aerodynamic characteristic: (L/D) $\max$.

- Landing/approach to landing/handiing qualities affected - high $\alpha$; main aerodynamic characteristics involved: $c_{L}$, lateral stability, side force, pitchinz noments. Typical situation: $\alpha \sim 20^{\circ}$; typical aesudynamic characteristics: $c_{L_{\max }}, c_{n \beta}, c_{1 \beta^{*}}$

The critical aerodynamic phenomenon is, of course, l.e. separation on the wing and loss of l.e. suction. Roughness/recession may affect the angle-of-attack (suitably , fined) at wich 1.e. separation appears and especially the rate at which l.e. separation spreads inboard as $\alpha$ is increased.

\subsubsection{Importance of Effects}

Mich initial concern was generated by studies/flights of the PRIME and X24 vehicles (Ref's. 13, 14, 15 and 16). These results, especially the performance of the X24 fins were misinterpreted by many. These vericles are lifting bodies. Flow patterns similar to those presented for example by Pyle and Montoya for the X24 (Ref. 13) do not occur on a delta wing orbiter. Noreover, at least some of the effects on drag are due to acreage roughness - we are here concerned only with l.e. roughnes:- Therefore, the lifting bodies results are not applicable here. This is nui t: say that useful information cannot be extracted 
from references 13,14 , and 15 (q.v. in following, sections).

Initial work at Grumman is the basis for initial conclusions that roughness

may cause some 5 to $10 \%$ decrease in $(L / D)$ max and that recession has no seriolis consequences (Ref. 12). NASA/Langley data are the basis for NASA's initial assessment of I.e. roufhness (ien. 1T) as an important but low eriticality area.

No strong recomendations - from the aerodynauic point of view - have been offered as far as the ablator selection for the 1.e. (Ref. 12).

It seems that only the Grumman ent-of-Phase-B configurations incorporated an aerodynamic "safety feature" - forward camber (Grumman H3j and 473 designs)

- against the detrimental effects of l.e. roughness/recession.

4.1.3 Roughness

4.1.3.1 Roughness Levels

Experimental data on roughness on the candidate ablators or for that matter on other charring abiators are extremely scarce, even without precharring. No data are available with precharring. As fte as measurements on flight article, such measurements were made on PRIVIE (Ref. 13), but were directed to acreage roughness. Only an area-weight average is presented in reference 14 . No measurewents appear to have been made specifically around the l.e. of the fins. lio measurements on the $X_{1} 5$ A2 1.e. have been uncovered. On the Apollo, near the rims of the -hield, crack depths between $0.35^{\prime \prime}$ and $0.6 "$ (maximum) have been measured (Ref. 18).

As far as measurements on flat samples tested in ground facilities, there appear to be some old data on some Martin materials (Ref. 19). (ursory maeaurements at Avco on 5026/39:I and !.c flat samples, have given the following results (Ref. 20): 


$$
\begin{aligned}
& \text { 50a6-39M - } 500 k \text {-inches plus cracks } \\
& 506-30 \text { lic }\left\{\begin{array}{l}
- \text { roughness at filler, } 500 \ldots \text {-inches } \\
- \text { honeycomb protmisions above filler, } 0.020^{\prime \prime}
\end{array}\right.
\end{aligned}
$$

As far as roughness measurements on l.e. samples tested in ground facilities, no data appear ti exist.

A tentative picture of the roughness levels at least on a charring ablator

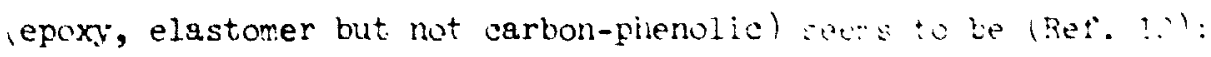

- There are three types of roughness: 1) char roughness (between huncycomb cells); (2) honeycomb-caused roughness: and (3) cracks.

- Iypical values of char rolighness seem to be $500 \mu$-inches (her. 19; $\therefore$ : a graphite value between $100 \mu$-inches and $300 \mu$-inches reported in Fet. 21 .

- Working value for honeycomb protrusions $\sim 0.020$ " for an epoxy (Se:. 20). Elastomers at intermediate heating rates swell and therefore give rise to different levels.

- Cn a molded ablator, apparently (Ref. 20) there is no honeycomb-caused roughness; however, one would expect more crack roughness because of lower char stability. No data on this tradeoff are available. One would expect that for a given ablator, roughness be correlated with:

- Heating rate (and also total heat load)

- Mechanical stress (dp/ds, $\tau$, pressure fluctuation, and thermal stresses) during and after the heat loading time.

Therefore, the previously quoted roughness measurements should be carefully associated with an environment. Unfortunately, nothing is precisely known in this area. 
Information on roughness patterns can be obtained from inspection of Apollo and PRIME, as in Ref. 13. However, this is not essential at this pcint of develupment of the subject. Perhaps a question of some importance is to identify a density or a spacial frequency of cracks on molded and honeycomb ablators. A density for honeycomb-caused roughness follows from cell dimensions. Together, one gets an overall measure of the roughness density. In $k \in t s, 3$ and $4, a$ $40 \%$ grit density was used.

Figure 24 gives an idea of how the roughness levels previously identified compare with the roughness levels that are significant for some of the fluid mechanical phenomena on the l.e. of the orbiter. Note, though, that figure 24 is derived from rough-wall flat plate calculations applied locaily around the 1.e. This appears to be reasonable at low angles of attack, up to say $\alpha_{\text {cruise }}$. One key phenomenon is missing, i.e. formation of l.e. separation bubbles/vortex sheets, since it cannot be easily quantifiea. One conclusion follows from figure 24: Char roughness cannot possibly have any effect on aerodynamic characteristics.

A question that falls outside our scope is how to estimate flight roughness from arc jet tests.

\subsubsection{Testing in Aerodynamic Facilities}

Inexpensive testing for aerodynanic efrects is done neither if flight nor in tunnels with actually ablated surfaces. Therefor " the simulation in tunnel of TPS roughness there are the following three guestions looked at during the PRIME studies (Refs. 13,14 and 15):

a. Can we use 'reproduced and roughness' in place of actual roughness?

b. Can we uie carborundum grit in place of 'reproduced roughness' on large-scale models?

c. Can we use small models instead of large ones (with carborundum grit)? 


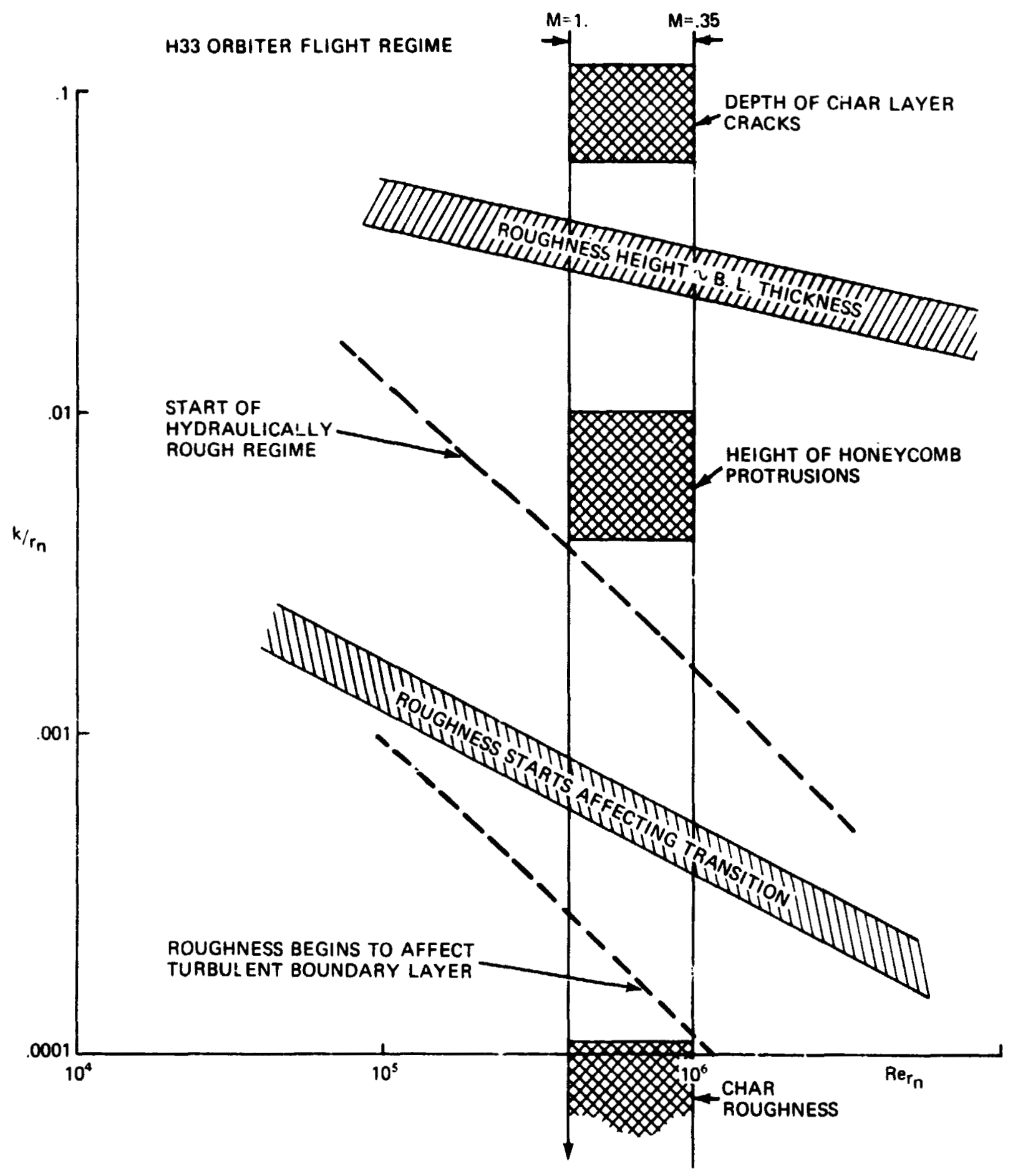

Figure 24. Roughness Levels 
Answers to questions b) and c) are available including a tentative explanation of the lateral directional stability question of kef. $1 .$.

Roughness levels, peak-to-valley, are usually takan to se equal to the grit size, which seems adequate in this context.

In testing, one should try to maintain a constant grit density if one wants to be able to compare different grit sizes. A $40 \%$ density - appropriately measured - was held in references 3 and 4 . A quick method for applying grit while carefully controlling its density has been developed at iruman (Ref. 3).

Unfortunately, roughness simulation for aerodynamic facilities is made very difficult by the mismatch in Reynolds number flight/tunnel (see fig. 25, for flight and two tunnels: the NASA/Iangley LTPT and the Grumman ISWT). A method for extrapolation tunnel-to-flight is needed. This is a crucial toplc. The problem has two aspects: (1) How to reduce an estimated (flight) roughness level, to a $k_{\text {tunnel }}$; and (ii) How to extrapolate to flight the aerodynamic characteristics measured in the tunnel at the tunnel roughness level.

The first question has not been looked at.

For the second question, one procedure is used at Grumman for irag at moderate $\alpha$-. find a drag plateau in $R_{k}$ and interpret that as transition shiftimb that would occur in flight because of high Re rather than because of rougkness. This interpretation is in agreement with actual transition observation in reference 22. Figure 26 shows a typical variation of drag with roighness size, showing the regions with and without boundary layer transition shifting to be separated by a small constant $C_{\eta}$ plateau region. These data are typical of results in re's. 22 and 25; howiver, in Decker's tests (ref. 23) the plateau shrinks to a point, and sometimes there is more than one plateau. These discrepancies have not yet been explained. We do not kr: w wat fluid mechanical 


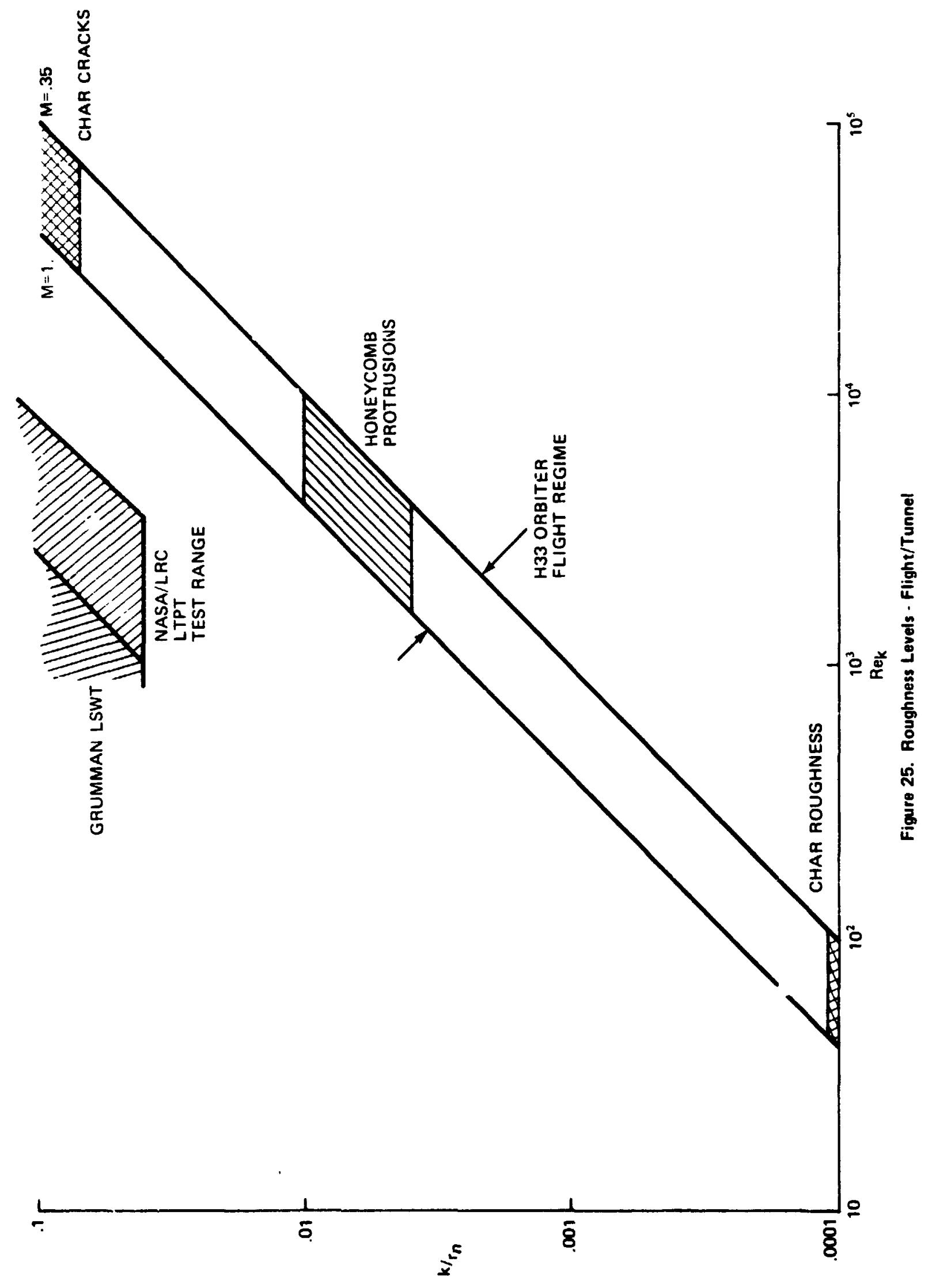




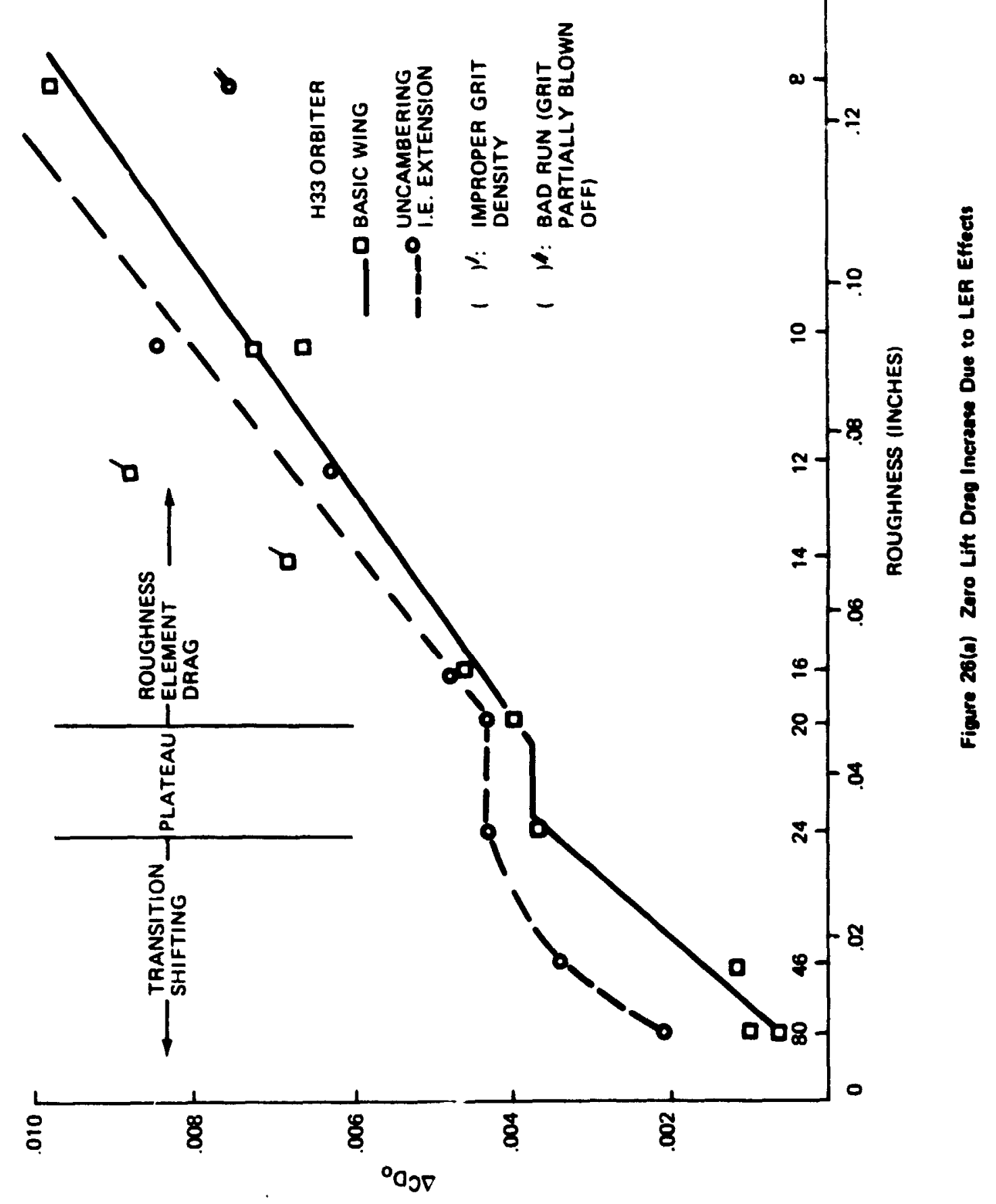




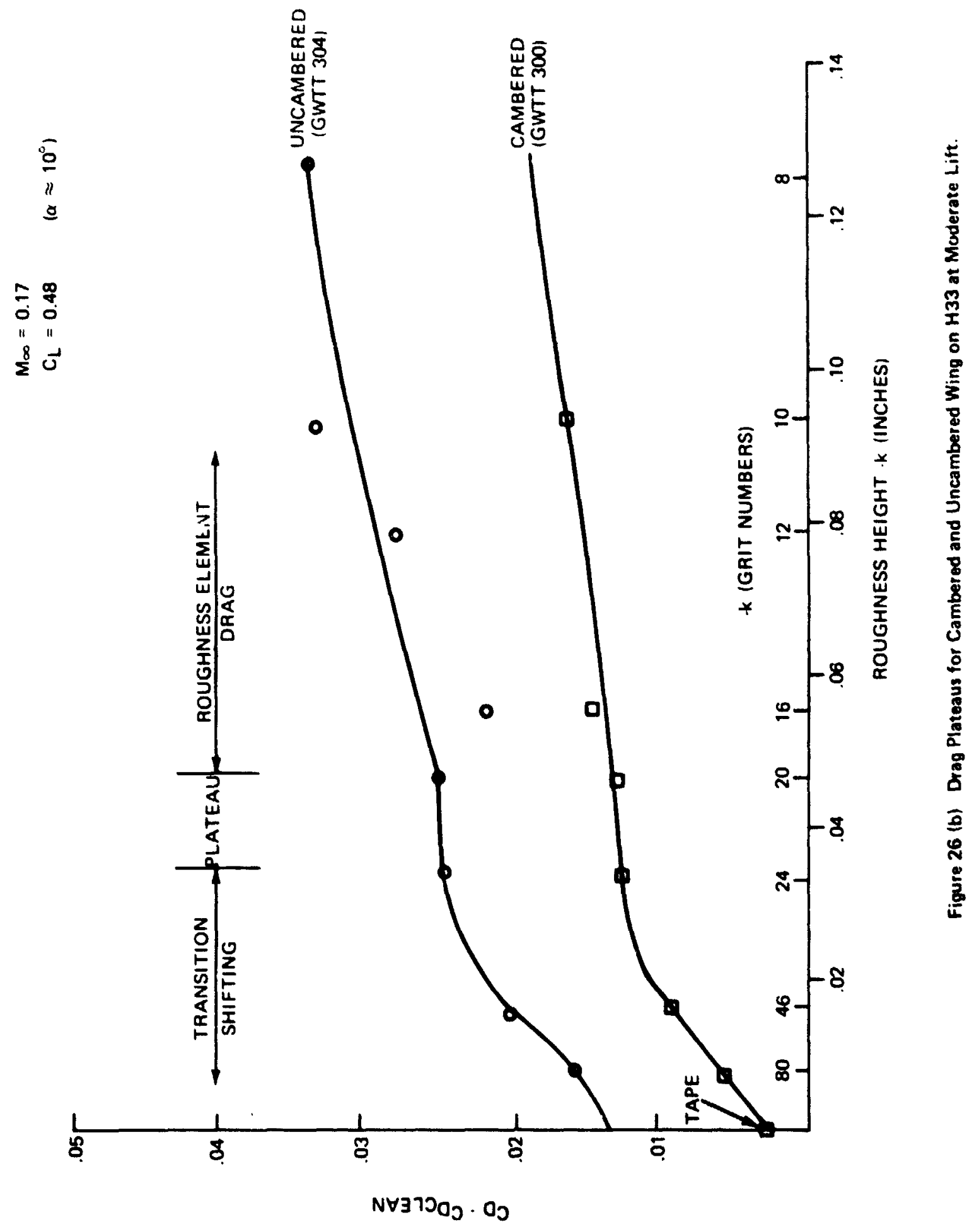


phenomena cause the plateaus in NASA/IRC data and therefore cannot judge whether these phenomena would disappear in flight. One suspects that the one-plateau behavior - transition shifting - is characteristic of low Reynolds number. Therefore, the plateau procedure should be useful also for roughness studies at transonic speeds.

Interpretation of other quantities $c_{\text {Imax }}, c_{n \beta}$ and $c_{1 \beta}$ with transition shifting is not obvious. $c_{n \beta}$ and $c_{1 \beta}$ versus $R_{k}$ have characteristic behaviors and flatten out on high-Reynolds values (see Fig. 27). This holds promise for subsonic and transonic speeds extrapolations. Another scaling method is the use of $R e_{k}$ as the parameter to maintain constant, flight vs tunnel, while neglecting $k / r_{n}$. This method seems to hold promise.

\subsubsection{Theory}

We are not hoping for a predictive theory, but for a guide to identify the various roughness regime and interpret the experimental data. The key issue in the only known effort (at Grumman) is the feasibility of a theory for predicting roughness-induced drag increase and 1.e. separation conditions. This would give a handle on flight, as well as tunnel, Reynolds number effects. Of course, we are looking only for relative effects with/without roughness. There exists the capability of predicting low-speed pressure distributions on wing, tail etc; 2-D boundary layer methods for rough surfaces are also available (Ref. 24). Identification of 1.e. separation with 2-D boundary layer theory also seems possible (Ref. 25). Extension to sweep may be necessary, as yet there is no final answer on whether the entire theory is feasible. of course this would te applicable to moderate $\alpha$. For high $\alpha$ with 1..e. separation, the domirant fluid mechanical mechanisims are insufficiently nepped out to start speaking of theories. There are at least some tunnel deta with surface flow visualization (Ref. 26). 


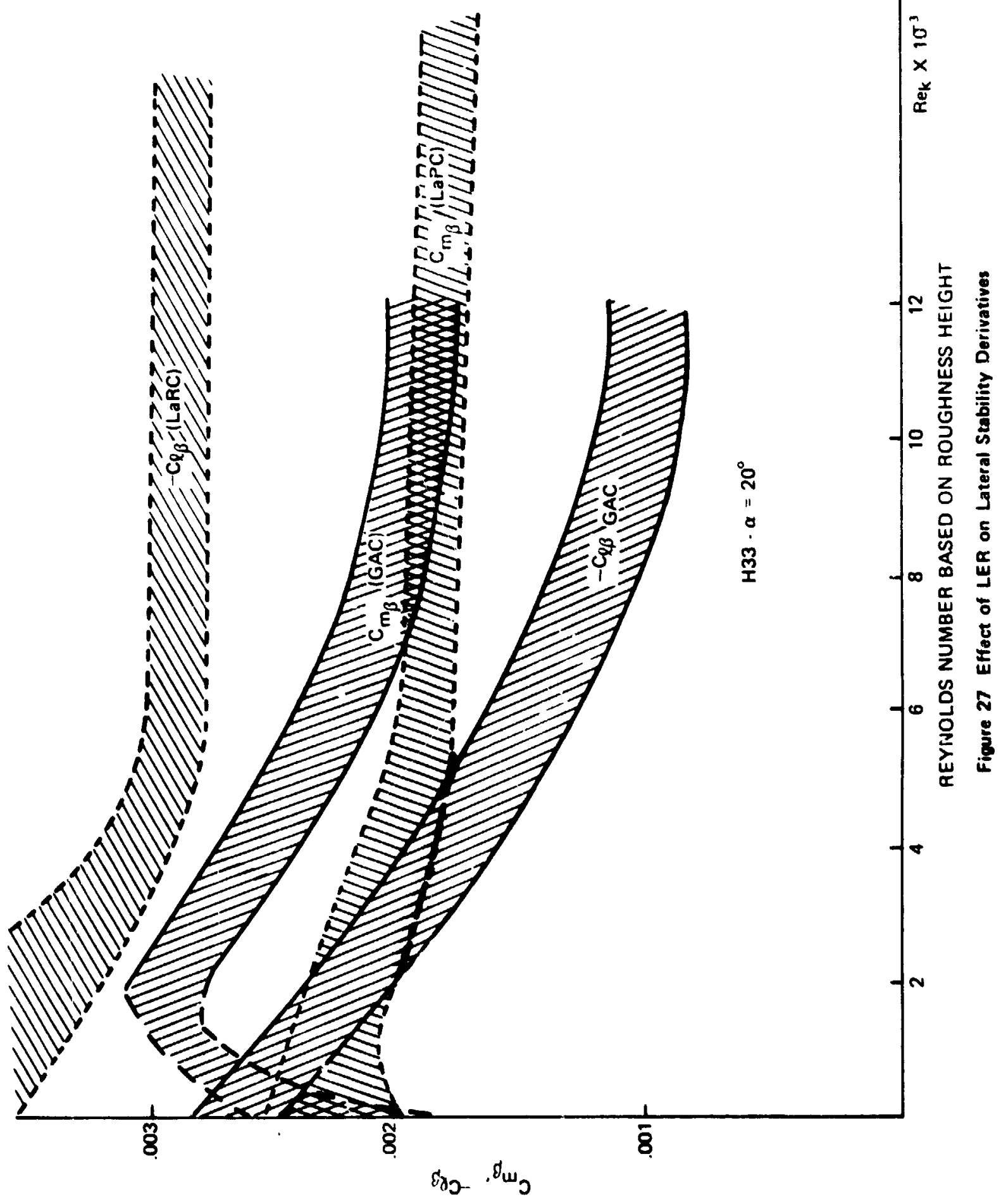

61 


\subsubsection{Aerodymamic Date with Roughness Effects}

A literature search revealed that the only useful data available on (entire) 1.e. roughness at low speed are for:

a. Grumman $\mathrm{H} 33$ orbiter - Lirumman low-speed wind-tunnel tests on 1/25 model scale (Refs. 3 and 4 ).

b. Same orbiter - NASA/LRC LTPT tests on a $1 / 67.5$ model scale (Ref. :3).

c. Same orbiter but with uncambered wing (Ref, 4).

d. A 22\% thick airfoil secition - some old NASA tests (Rer. 2T).

There are also two l.e. roughsess studies in the transonic regime:

e. C5A aircraft models - tests in 3 facilities at $M=0.7-0.79$, moderate to low $\alpha$ (Ref. 28).

f. Cropped uncambered delta-wing half-model (Ref. 22) - extensive roughness program, $M=0.8-1.15, \alpha=0$.

\subsubsection{Results}

The experimental results are currently examined parametrically vs roughness levels - some eight grit levels were tested in reference 4 and some six in reference 23 . The Gruman data are also tentatively interpreted correcting for Reynolds number effects as indicated above in Section 4.1.3.2. General observations from an examination of the data (Refs. 3, 4, ac.d 23) are:

a. As reported previously (Ref. 12) L/D degradation at moderate $\alpha$ is small, typically a $10 \%$ reduction at the largest grit No. 8 , or a $\triangle L / D$ of 0.5 .

b. $10 \%$ reduction in $L / D$ in Gruman's data or $\Delta L / D \max$ of about 0.6 compare with NAL./LRC $14 \%$ reduction from plateau le"el.

c. Wing 1.e. produces essentially the ertire effect - tril and nose cap contributions were negligible. Found botis in Grumman's (low Re) and 
NASA/IF: (high Fe) data. Faint effects of tail seen in NASA/LFC data.

d. Eriects on lateral stability derivatives at moderate $\alpha$ were on the level of data scatter. Bime results from NASA/IRC data.

e. A high $\alpha$, Cinuman data show sizable chances in lateral stability

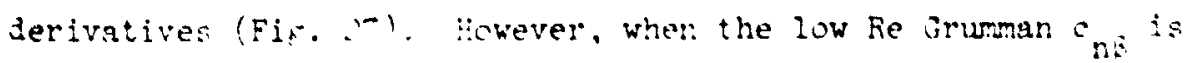
compared to the high he MASA/IR: value, one is drawn to the conclusion that Grumman $c_{n B}$ picks up Feynolds mumber effects (transition shifting: and tiat the good agreement NASA/Grumman data indicate no roughness effects on $e_{n B}$. Why doesr't $c_{1 B}$ follow the same trend with agreement NASA/imuman on the same level above $\operatorname{Re}_{k}>10 \times 10^{4}$ :

f. $10 \%$ reduction in $c_{\text {Imax }}$ at largest (No. 3) grit, no chante of a for cImax (úrumman data).

g. Forward camber effects from (iruman data $-\Delta c_{D}$ on the $H 33$ model with a leading edge extension designed to remove the camber was twice that of the basic cambered conficuration - due mainly to transition shiftine differences. $\Delta(L / D) /(L / D)$ plateau was roughly twice as large for the uncambered as for the cambered wing for $\alpha=7^{\circ}$, but of course as $\alpha$ increased the difference between the two wings vanished.

\subsubsection{Assessment/Recommendation for Ablator Selestion}

The assessment of roughness effects reported in preceding sections 3.1 .2 and 4.3 .3 .5 , is derived by examining aerodynamic characteristics parametrically

* Cae has to keep in mind that the Langley tests have been performed with a $-5^{\circ}$ elevon deflection, wherees the Gruman tests had no control deflections except for one point (Rer. 4), which indicated trat LER affected the drag but not lifit increment due to the contol ierlection. (LER = leading edge rughnessi. 
versus roughness. What has not yet been done is to determ. a roughness level and obtain its associated value of aerodymamic characteristics degrajation. No recomendation has yet emerged for the roughness input to (i) ablator selection, (1i) Hc vs molded question.

The questions tinat need to be looked at at the present time in this area are:

(i) ' $: u / n o-60^{\prime}$ criterinn for what to label 'excessive roughness' from an gerodynamic viewpoint. Some such criterion is aniong the primary criteria for the ablators screening.

(i1) A way to convert in dollar value the aerodynamic penalties, e.g., $\Delta L / \Gamma$ and stability loss. This is a dir.sult problem.

(iii) Leading edje roughness data are necded of the type obtained ir the 1.e. ters of this study.

\subsubsection{Fixes}

The most obvious fixes for the 1.e. roughness problem are:

(1) Ablator selection: assure shar stability; select Hc or molded depending upon whether Hc improves or degracies smoothness - at typlcal o' :ier teating loads for elastomer or epoxies.

(i1) Aerodymanic device (forward camber) as in the Gunrin 133 orbiter. Penalties of this device have not been specifically investigated.

\subsubsection{Ieading Edge Stape Change}

\subsubsection{Recession/Swelling Levels}

Work on defining these levels has been carried out at Orummail. Preliminary (lccally one dimensions? without precharying effects) recession estimates in H33 and O4jA orbiter wings with the Avcoet 5025/39 M have shown very small (5ig. 28) l.e. shape changes crer most of the wing span. This implies that

- See previous footnote. 


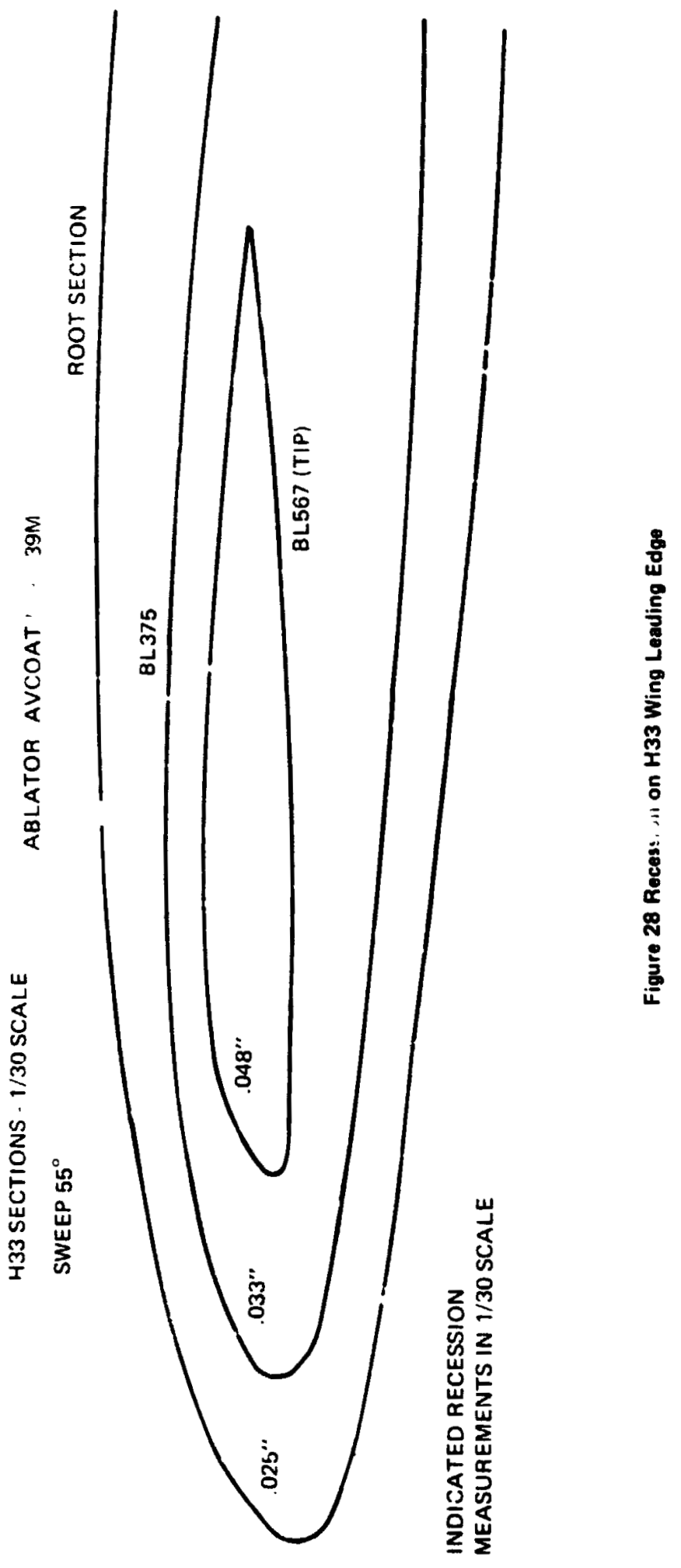


the I.e. shape changes significantly only near the wing and that overall aerudynamic characteristins remain essentially unchanged. For the other materials of this stuly, the same conclusion holds, as for most elastomers. At these heating rates, the material swelling partially balances the recession. Remarkable local swelling resulting in a pronounced shape discontinuity has been measured (Ref. 1) near the joint of two different ablators, such as an elastomer and an epoxy. However in this study we consider only a single ablator 1.e. (see Section 5).

4.1.4.2 Data

For an orbiter the only exploratory data on recessed 1.e. without roughness are those of reference 29 (Grumman $\mathrm{H3} 3$ orbiter).

Daia for airfoils/wings give qualitative clues as to the aerodynamic effects of 1.e. shape change, except that there is no precise comparison with/ without shape change near the 1.e. with the rest of the geometry unchenged. The data of reference 29 indicate negligible change of aerodynamic characteristics with and without recessicn. The recession simulated was several times larger than that estimated $\mathrm{fcr}$ the case in question.

The currently estimated recession, figure 28 , is too small to make more experimen+al effort worthwhile on $\varepsilon$ configuration whose l.e. radii are reasonably large. The esij..te does not account for the preconditioning effect of ascent heating.

4.1.4.3 Assessment/Recommendations for Material Selection

Initial assessment of I.e. recession is that this is not an area of serjous aerodynamic penalties (Kef. 29). Possibly this assessment nurt be tanpered for configurations whose tip 1.e. (chordwise) radii are of the order of a 
couple of inches, but it is doubtful that such configurations will be seriously proposed.

No recommendations have yet been advanced for ablator selection from this point of view.

Current needs in this area are (as for roughness): (i) Go/No-Go criterion; and (ii) dollar value of degradation.

4.1.4.4 Fixes

A simple fiz nas been proposed to prevent l.e. recession to unacceptable shapes which is much simple. thar tryirz to design a stabie 2.e. shape. This scheme, (shown in :igure 29), consints of predicting the recession on a given desires final l.e. shape and adding this amount of ablator to this l.e. This guarartees an acceptable 1.e. shape for post-entry fight. Refinement of this initial shape synthesis by iteration is straightforward. Weight penalties, if any (e.g. thicker ablator near the stagnation point) have not been studied. This scheme depends, of course upon the ability to predict recession for 1.e. shapes (q.v. in following section). If the wing 1.e. radius is very small only at the outboard secticns, this fix could se restricted to that region.

\subsubsection{Recession Predictability on the I.E.}

One dimensional recession predistions for single heating pulses and neglecting mechanical removal are common practice. One question is whether ther are adequate for aerodynamic assessment purposes. Experimental data on recession/swelling rates on flat samples are available for the materials under consideration in this progiom (see Figs. 30 and 31).* Some experimertal data or recession/swelling of 1.e. models are available for the Arcoat 5026,39 HC and the DC $325 \mathrm{HC}$ (Ref. 2). None of these data include ascent keating.

See : : 'note next page. 


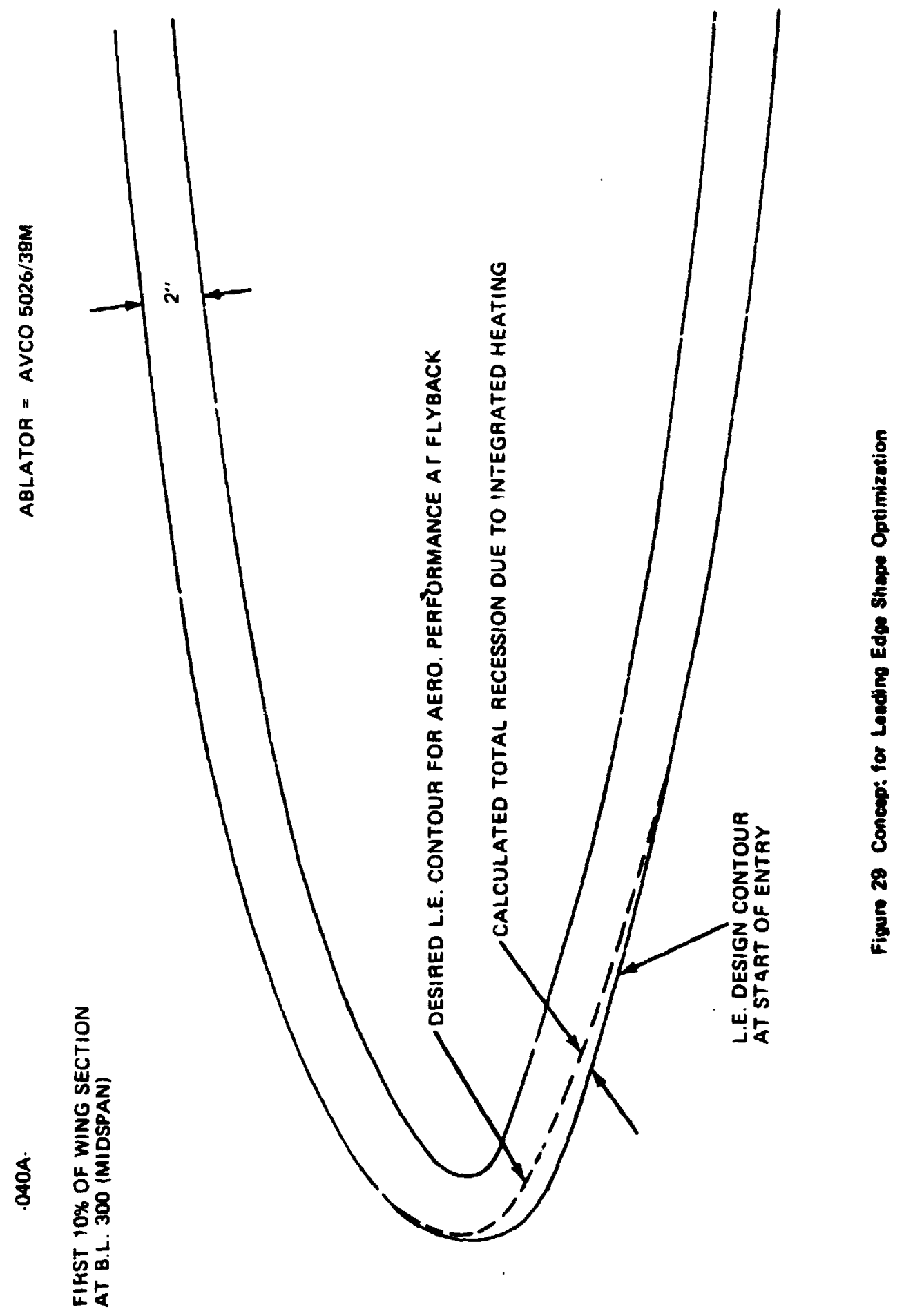




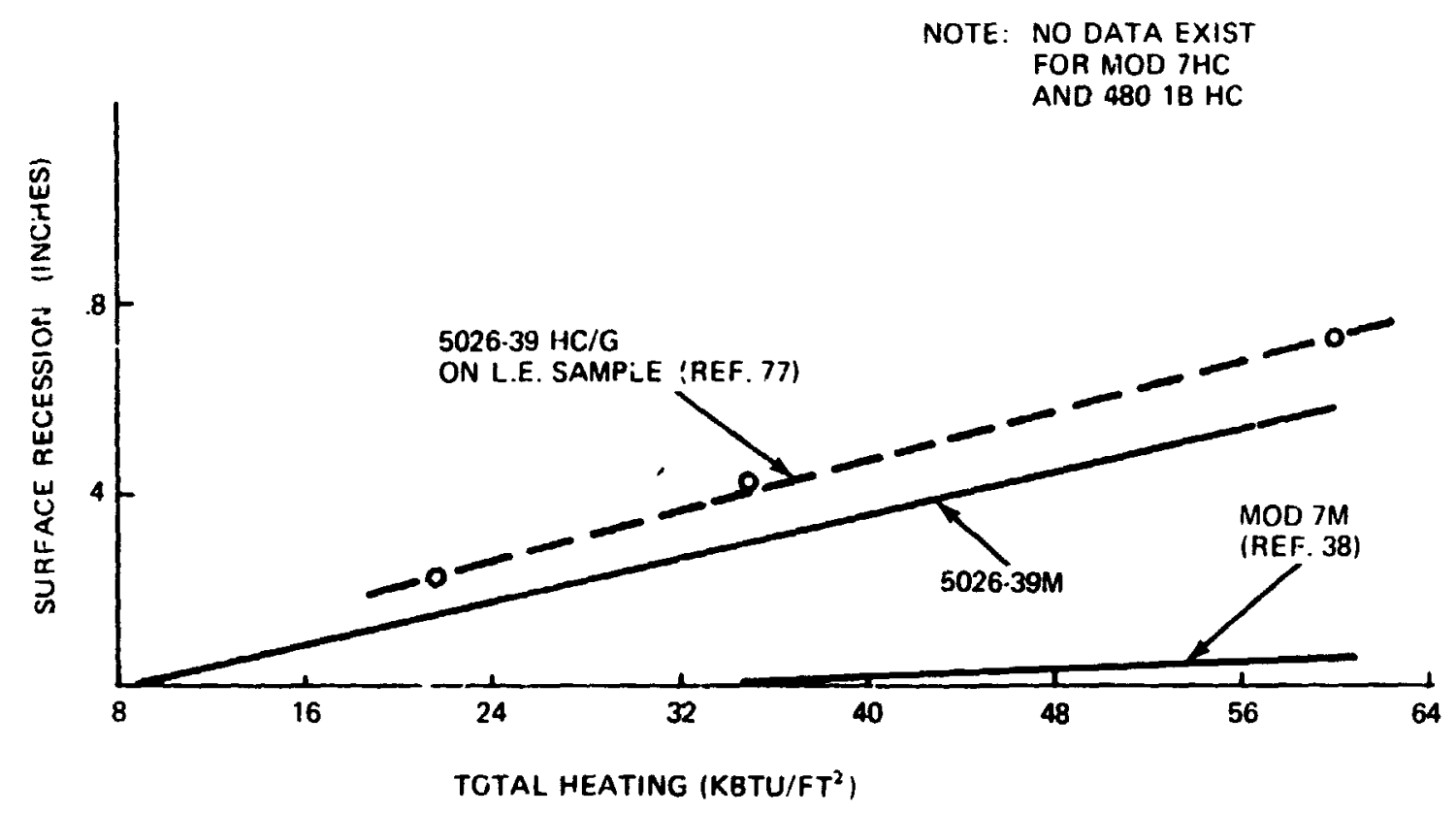

Figure 30 Total Recession of some Cendidate Ablators 


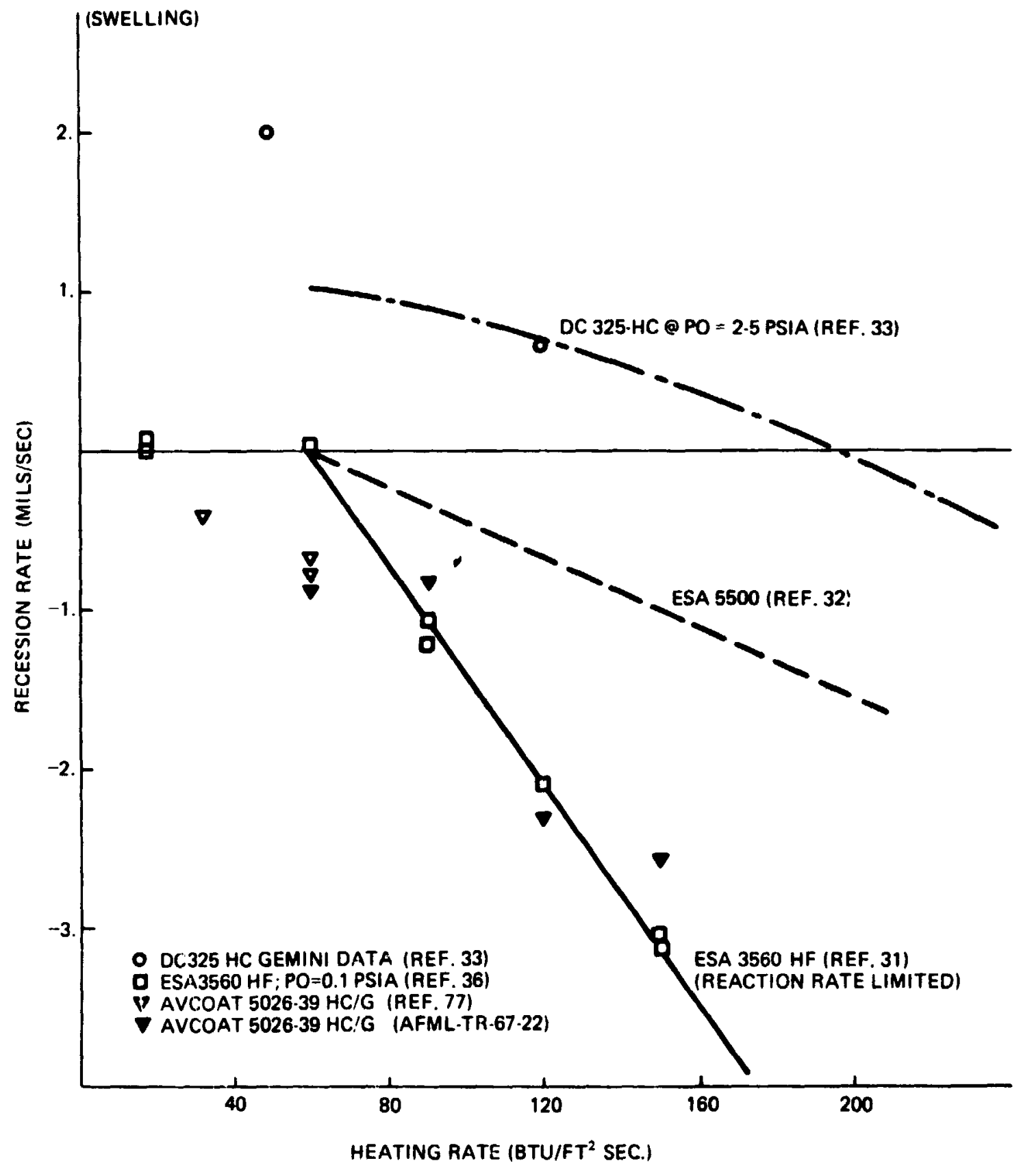

Figure 31 Recession Rates of some Candidate Ablators 
i point that has been looked at whether or not locally one dimensional iecession calculations are adequate for the leading edge in absence of ascent heating. The answer seems to be yus, since splash experimental data on recession agree with l.e. data (Fig. 32) at least at the moderate heating rates anticipated for the orbiter wing.

\subsection{Methods for Deternining Cost Penalties for Aerodynamic Degradation Due to Effects of L.E. Roughness/Recession at Subsonic Speeds}

Three Steps in the Problem

Determination of dollar costs of $1 . e$. roughness/recession-induced aprodynamic degradation can be broken down into three tasks:

1. Taking tunnel data of the relevant aerodynamic characteristics obtained with various roughnesses; relating tunnel/flight aerodynamic and roughness values; obtaining leading edge roughness (LER) increments $\Delta C_{L}, \Delta C_{D}$, etc for flight.

2. Relating the flight aerodynamic performance degradation to dollar costs. (Still parametrically vs roughness/recession)

3. Determination of ablator roughness/recession.

* Data are from refereiz 351 and 30 tc 37 . Data on ESA 3560 H has been included since it is very similar in recession rate to ESA $3560 \mathrm{HF}$ (see Fig. 32). f. few flight data points for the recession of DC 325 on the Gemini vehic.e (Ref. 33) are also incorporated in figure 31. There are also a iew iligkt date on the recession of ESA 3560 HF anc ESA 5500 on FritE (Ref. EC), but these are classified and not incluced in tris memo. 


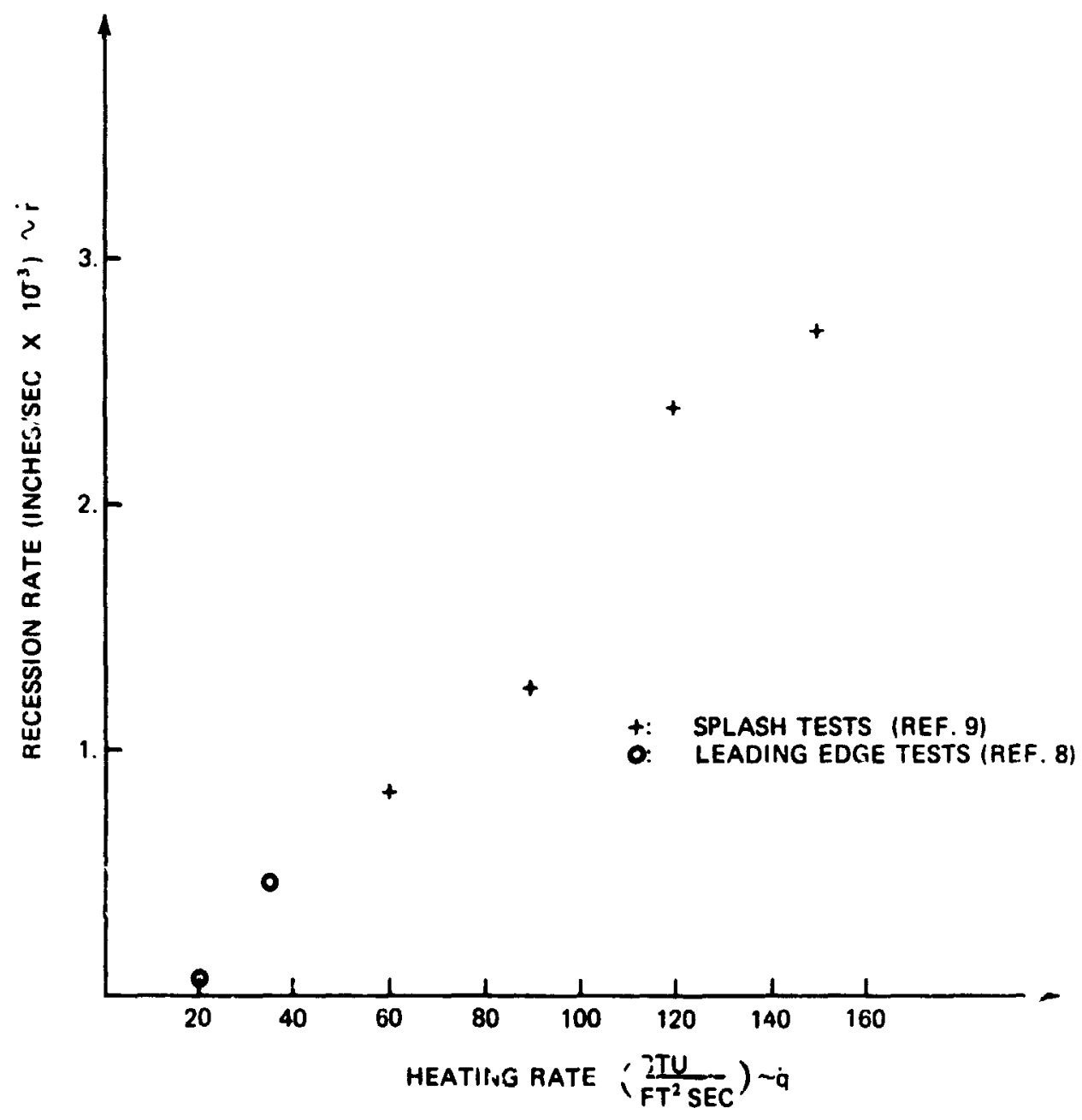

Figure 32 Recession Rate Data for Avcost 5026-39 HC/G 


\section{Aerodynamic Quantities Affected}

The moderate $\alpha$ subsonic regime encompasses the nominal conditions during:

- Subsonic post-entry cruise

- Landing -- approsch/flare/deceleration to touchdown

- Ferry to depot

In this regime, stability is not noticeably degraded by LER effects (Refs. 3 and 4). The most significant LER sensitive nerodynamic characteristic here is $L / D \max$, which governs two quantities of fundamental interest: ( 1 ) range of the post-entry flight phase; and (2) 'float time' -. the time taken to decelerate from the end of flare to touchdown velocity. A minimum subsonic range - therefore a minimum $L / D \max$ is set by tolerances on the inertial navigation equipment during entry. Existings surplus capability and additional buffer potential from aerodymamic clean-up mentioned below indicate that this will not be critical. IER range degradation for ferry-todepot is not a problem, since 1.e. replacement awry from depot is quite feasible. Indeed, air-transportable, alumimum leading edges will be available, at no extra cost, since they are needed in the subsonic flight tests. 'Float time' is of paramount importance to the case of landing the orbiter -a 10-second minimum has been established. At high $\alpha$, the critical condition is landing. The signiflcant Ifi. -affected parameters at this condition are:

$\mathrm{C}_{\mathrm{I}_{\text {trimmed }}}$-- governing the landing speed

$C_{1 \beta}, C_{n \beta}$-- governing the lateral-directional stability of the vehicle Typically we can evaluate these characteristics at $\alpha=19$ deg which is representative of orbiter tailscrape angle. 
Method for Relating 'Float Time' to L/D Degradation

The procedure is indicated schematically in figure 33. From reference 39 , we can relate 'float time' to $(I / D)_{\max }$. Since there is a minimar of 10 seconds 'float time', there is a minimum for $(L / D)_{\max }$. Having selected a desirable safety margin for $t_{\text {float, }}$ there follows a minimum desirable $(L / D)_{\max }$. Then from steps 1 and 3 above, one gets $\approx \Delta(L / D)_{\text {ma: }}$ representing LER degradation of the orbiter configuration fram a smooth, i.e., nonablative, l.e. condition. Now this degradation reduces the configuration $(L / D)_{\max }$ below the minimum desirable.

To restore minimum $t_{\text {float }}$ one looks first for aerodynamic clean-ups of negligible cost; beyond such 'cheap fixes' that involve localized redesign, one gets to the point of vehicle resizing, i.e., the photographic scaling of major components without changing the baseline design as assumed in the typical $\$ 24 \mathrm{~K}$ value of a pound added to, or saved from, the orbiter. Therefore, to arrive at the dollar value of the degradation one needs to:

- Enumerate the 'cheap fixes' that can be brought to bear. Of course, one assumes that the benefits accruing from the nonablative-related fixes have not already been absorbed by some other degradation mechanism not considered here;

- Estimate the costs of introducing these fixes;

- Define the potential clean-up of the configuration, i.e., to estimate the total L/D improvement that all the cheap fixes can provide; and finally,

- Determine the LER L/D degradation that has to be taken care by 'expensive' fixes.

Naturally, in the process one has to work with a reference configuration 'availabie (L/D) max with smooth I.e.) and maike a few policy decisions (desirable $\left.t_{\text {float }}\right)$. 


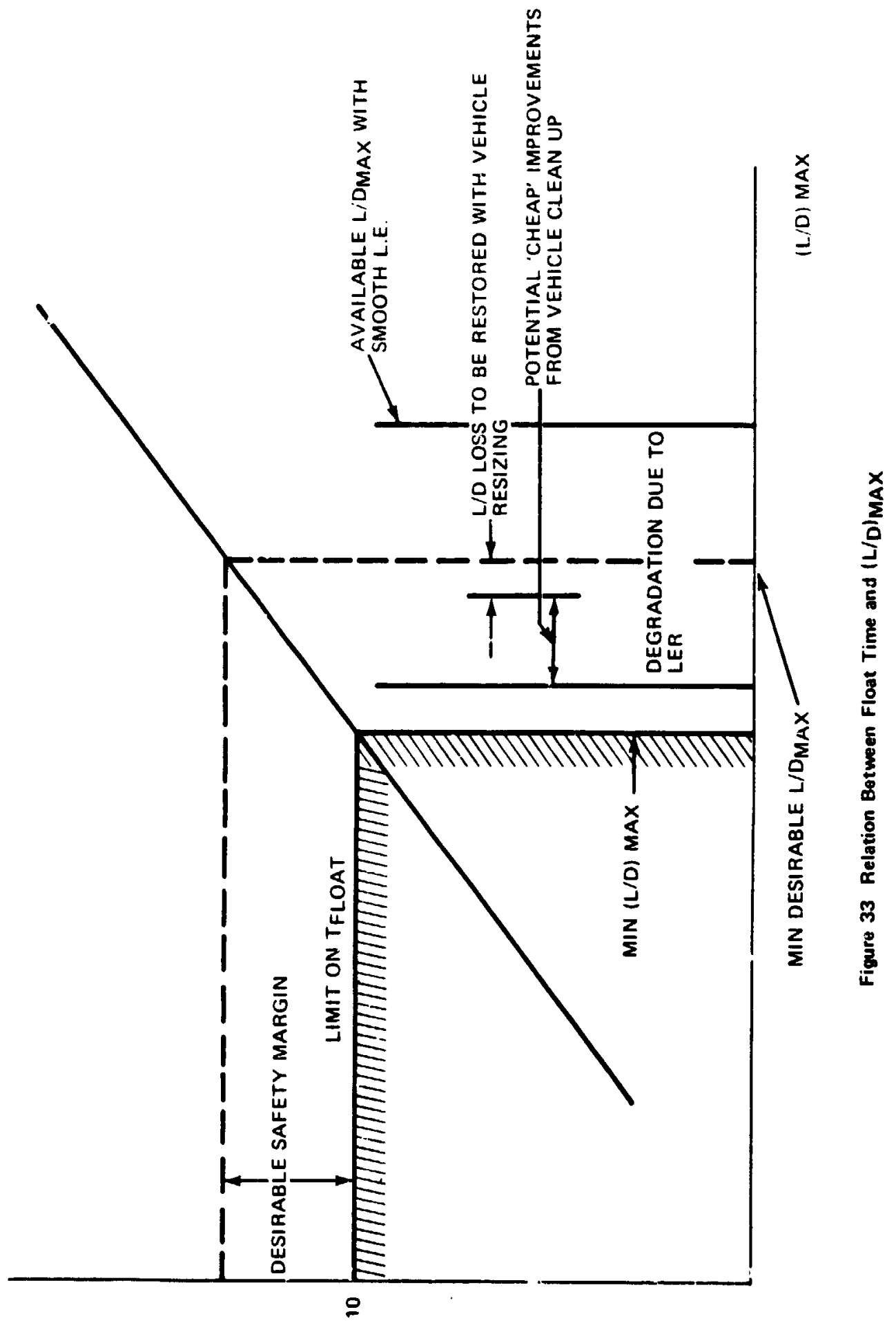

(כ)S) $\exists$ ' 


\section{Levels of Design Rigiaity and Fixes}

We consider three levels of design 'rigidity':

a. Frozen-only l.e. design-free.

b. Partially mbbez-aerodynanic component clean-up (if ai permissible but only through local shape charges, e.g., cleaning the lines of the Oris pods.

c. Totally rubber-freedom to redesign and resize major components of the orbiter, with the correspondins impact on the entire system.

The first level represents the ground rule of this study, but the other two will also be considered briefly.

For each level we have the following potential aerodynamic design changes to improve the aerodynamic characteristics:

a. Frozen vehicle: (1) introduce 1.e. camber - in the Grumman 473 orbiter, further increase 1.e. camber, provided no prohibitive changes in trim irag occur in other speed regimes; (2) reduction of retrieved payload, an extreme measure that implies added flights.

b. Partially rubber, in adc.tion to the preceding options: aerodynamis clean-up for $(L / D)_{\max }$ improvements, depending upon the configuration and also its stage of developement. "or example, in the case of the 473 orbiter in mid-1972, the following clean-ups were attractive: OMS pods lines, ACPS pods lines, boat-tailing.

c. Rubber, in addition to the preceding options: for $(L / D)_{\max }$ improvements, wing resizing; for $c_{n \beta}$ tail resizing.

If instead of the full traffic model, we consider only the test flights, we should account for the absence of retrieved payloed, 1.e. some 45,000 Ib of lower landing weight. 
For a frozen vehicle and the full NASA traffic model, if payload reduction is required, the cost penalties are extremely high. The same occurs if resizing of wing and tail is necessary.

This is brought cut hy simple estimates of such costs as follows. Payload Reduction ine to LER (L/D) Reduction and Related Costs Assume that an ablative 1.e. is used for the entire program; the payload is not quantized; and that all (445) flights planned involved entry with a full 45,000-1b payload (very conserrative). For equilibrium glide at a minimum $(L / D)_{\max }$ (determined by a ninimum allowable $t_{\text {float }}$ ), the payload reduction for an $L / D$ depradation $D(L / D)$ beyond the maximum permissible value is $\Delta W=D \Delta(I / D)$.

Using a cost/flight value of $\$ 10.5 \mathrm{M}$, (which is equal to $\$ 230 / 1 \mathrm{~b}$ of retrieved peyload); a drag of 32,800 Ib; total program payload of 45,000 $445=2 \times 10^{7} 1 \mathrm{~h}$, tine total increase in prosram cost of aditional flights required to return this fini program payload from orbit for a frozen or partially rubber vehicle is :

$$
\text { Cost }=\$ 3.4 \times 10^{9} \times \Delta(L / D) \quad \text { (based on } 1971 \text { dollars) }
$$

For any measurable value of the $L / D$ loss, this cost is clearly extremely high.

Wing Resizing Tue to LER L/D Redustion and Related Costs

Assume: an enlarged wing of same plan-form and characteristics with LER; no change in wing-body interference and equllibrium gilde; using the following values of the basic crummen 473 orbiter: 


$$
\begin{aligned}
& \Omega=\frac{\text { wing weight }}{\text { total weight }} \times \text { iteration factor }=0.156 \\
& A=\text { reference area }=3760 \mathrm{ft}^{2} \\
& \frac{C_{W}}{C_{D}}=\frac{\text { wing drag }}{\text { total drag }} \quad T / D_{\max }=0.47 \\
& \frac{C_{D_{C}}}{C_{D_{1}}}=1.14 \\
& \frac{C_{I_{W}}}{C_{L}}=\frac{\operatorname{ling} 11 f t}{\operatorname{total~1ift}}=0.8
\end{aligned}
$$

and the first order formula for wing area increase required to restore $L / \Gamma$ :

$$
\frac{\Delta A}{A}=\frac{\Delta C_{D_{L E R}} / C_{D}}{\Omega-\frac{C_{W}}{C_{D}}-\frac{2}{\frac{C_{D_{0}}}{C_{D_{1}}}+1}\left[\Omega-\frac{C_{W}}{C_{L}}\right]}
$$

we get $\quad \frac{\Delta A}{A}=3.36 \frac{\Delta C_{D_{L E R}}}{C_{D}}$

where $\frac{\Delta C_{L E R}}{C_{D}}=$ fractional increase in dras due to LER effects.

Now, using the dollar relue or i prund weight increase besed on a trafflc model of 445 flights : ? 1971 doljais, (Ref. 8) with a wing density of $5.31 \mathrm{lb} / \mathrm{ft}^{2}$ of reference area, we lave a cost. figure:

$$
\cos t=\$ 1.6 \times 20^{9} \quad \frac{\Delta C_{D_{L R}}}{C_{D}}
$$

This employs a value of $\$ 2 \mathrm{~h}, 000 / 1 \mathrm{~b}$ wergini increase for parailel burn vehicle, whicn is silghtly high for the wing. This is, however, apjirjpriate to a rubber system. 
Again extreme 1 y high costs result from wing resizing.

Wing Resizing Due to LER $C_{\text {Imax }}$ Reduction and Related Costs

Taking those results in reference $4-14$ where the largest roughness - corresponding in geometric scale to $k_{\text {flight }}=1.57^{\prime \prime}$ - was used, as indicative of corditions in flight. Neglect the question of extrapolation to flight Reynolds number and take the tunnel data at face value. Reference 4-14 indicates an LER induced $\Delta C_{L}=-.065$ untrimmed and $\Delta C_{m}=-.0035$ at $\delta_{e}=0$ deg and $\alpha=19$ deg. inproximately one half of this lift loss is due to increased axial force due to IER. Net effect when trimmed at $\alpha=19 \mathrm{deg}$. is

$$
\Delta \mathrm{C}_{\mathrm{L}_{\text {trimmed }}}=-.08 \text {, }
$$

which is $11 \%$ of $c_{L}$ required to meet the $150 \mathrm{kt}$ shuttle landing speed requirement. If the orbiter wing was simply scaled up $11 \%$ to compensate for this degradation, the cost increase for such a totally rubber vehicle can be determined by :

$$
\begin{aligned}
& \frac{\Delta A}{A}=\frac{\Delta C_{I_{L F R}} / C_{L}}{\Omega-C_{L_{\text {wing }}} / C_{L}}=-1.55 \frac{\Delta C_{L_{L E R}}}{C_{L}} \quad \begin{array}{c}
\text { (Wing area change } \\
\text { required) }
\end{array} \\
& \cos t=\$ 1.25 \times 10^{9}\left(-\Delta C_{L}\right) \\
& \left.=\$ 10^{8} \text { (for } \Delta C_{L}=-.08\right) \quad \begin{array}{c}
\text { (Resultant cost } \\
\text { increase) }
\end{array}
\end{aligned}
$$

This assumes a 1-g landing at $150 \mathrm{kt}$ with a 25,000 lb payload. Tail Resizing Due to IER-Induced Loss of $c_{n \beta}$ and Related Costs For the H33, assuming a tail density of $51 \mathrm{~b} / \mathrm{ft}^{2}$, and having determined experimentally that total contribution of the tail to $c_{n \theta}=40$ counts, in the same fashion as above, we have a cost penality for tail arag increase required to restore $c_{n \beta}$ to be: 


$$
\text { Cost }=\$ 2.65 \times 10^{6} / \text { count of } c_{n B}
$$

Very large amounts are predicted for recovering even a few counts of $c_{n B}$.

Interpretation of High Costs f', r Payload Reduction and Resizing

The costs just estimated connot be taken literaily, since the costs are extremely large (in an e.osolute sense) for degradation values well within the current and in fact even future uncertainties in the $i / D, c_{\text {Imax }}$, etc. What these costs bring out is that payload reduction and resizing are not viable solutions as fixes for LER or recession degradation. The degradation must be absorbed within the aercdynanic characteristics buffer or must be corrected pursuing further the aerodynamic optimization of the vehicle without weight increase.

If the induced degradation exceeds the buffer, the cost of wing resizing or flight schedule incr sase becomes prohibitive, thus providing a raticnal "go/no-go" limit on $\max (\Delta \mathrm{L} / \mathrm{D}) \Delta c_{\text {Imax }}$, etc for use in ablator selection -providec of course that at least one ablator passes this test. The problem is rectuced to establishing maximum levels on $\Delta \mathrm{L} / \mathrm{E}$, ${ }^{A} \mathrm{c}_{I \max }$, etc within the 'cheap fixes,' such as l.e. camber, taking advantage of line improvements, etc. The cost of such fixes is negligible in the scale of costs considered here. The picture emerging is one of essentially cost-free fixes of limited effect and of standard fixes that are to be considered too expensive. Schematizing, this means that there is a 'Bo/no-go' limit for each degraded quantity and below this limit tine degradation is cost free. If more than one ablator passes the 'go/no-go' criterion, the one generating the least $L / D$ reduction is obvicusly the 'more acceptable' from the aerodynamic viewpoint. Since, however, the cost penalty is negligible in this range, we cannot rationally assign a non-zero dollar value rating for the $\Delta I / D, \Delta c_{I \max }$ induced by recession and roughness. 
Naturally one must also keep in mind that the costs estimated are dependent upon policy, for example upon the traffic model for the retrieved payload. In the traffic model most of the flights from orbit are empty and taking advantage of such available weight is excluded here.

\subsection{Aerodynamic Degradation vs Roughness}

In this section we give a crude estimate of the degradation of $c_{1 B} c_{n B}(L / D)_{\max }$ and tailscrape $c_{L}$ for one typical end-of-Phase-B configuration, the Grumman 473 orbiter. This configuration had considerable potential of minor aerodymamic clean-ups.

Since the only roughness data available are for the Grumman $H 33$ orbiter, we will use those data as typical.

The end result is to be an estimate of the roughness values that cause the maximum acceptable degradation of $c_{1 B} c_{n B}(L / D)_{\max }$ and tailscrape $c_{L}$. Such values will be considered typical of the end-of-Phase-B orbiters.

Erfect on $c_{18}$

Figure 34 shows the effect of roughness on $c_{1 B}(\alpha)$. Note that any 'wandering' in the $c_{1 B}$ variation with $\alpha$ is restricted to $\alpha>\alpha_{\text {drag break }}=\alpha_{\text {suction break }}$. Inspection of figures 35 and 36 indicates that detail design differences (Fig. 35) and basic longitudinal control effects (Fig. 36) exert a more profound effect on $c_{13}$ at high $\alpha$ than the worst roughness investiggted. Preliminary flying qualities investigation (Ref. 40) indicate that shuttle orbiter designs nilaracteristically exhibit too much lateral stability at high $\alpha \mathrm{ra}^{+}$uer than too little. Any firm conclusion on this point, however, is configuration dependent and subject to verification by man-in-the-loop simulation.

The best general assessment at this time is that roughness effects on $c_{1 B}$ need 

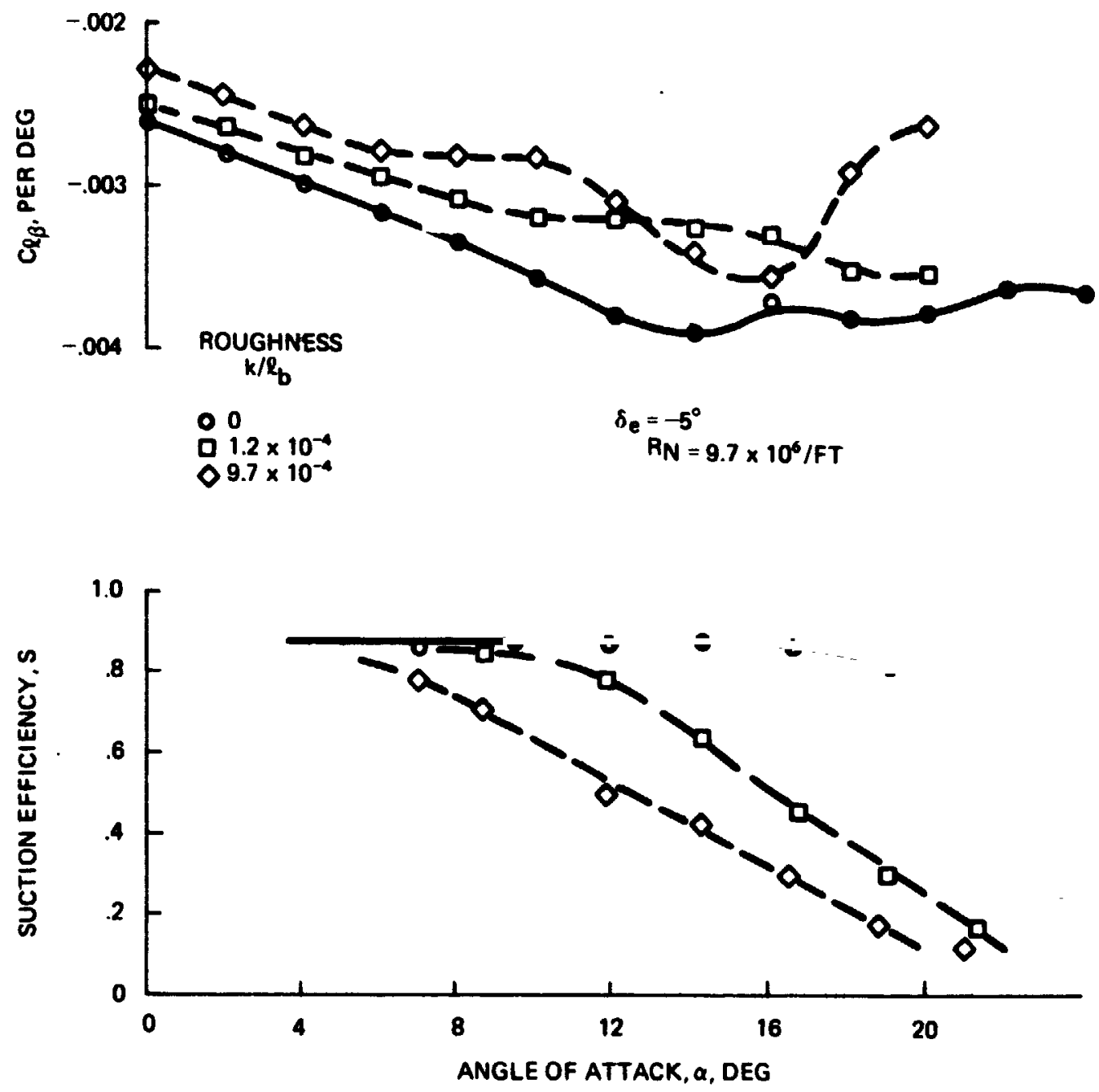

Figure 34. Effects of Roughnes on H-33: Correletion Between $C_{\ell_{\beta}}$ as 


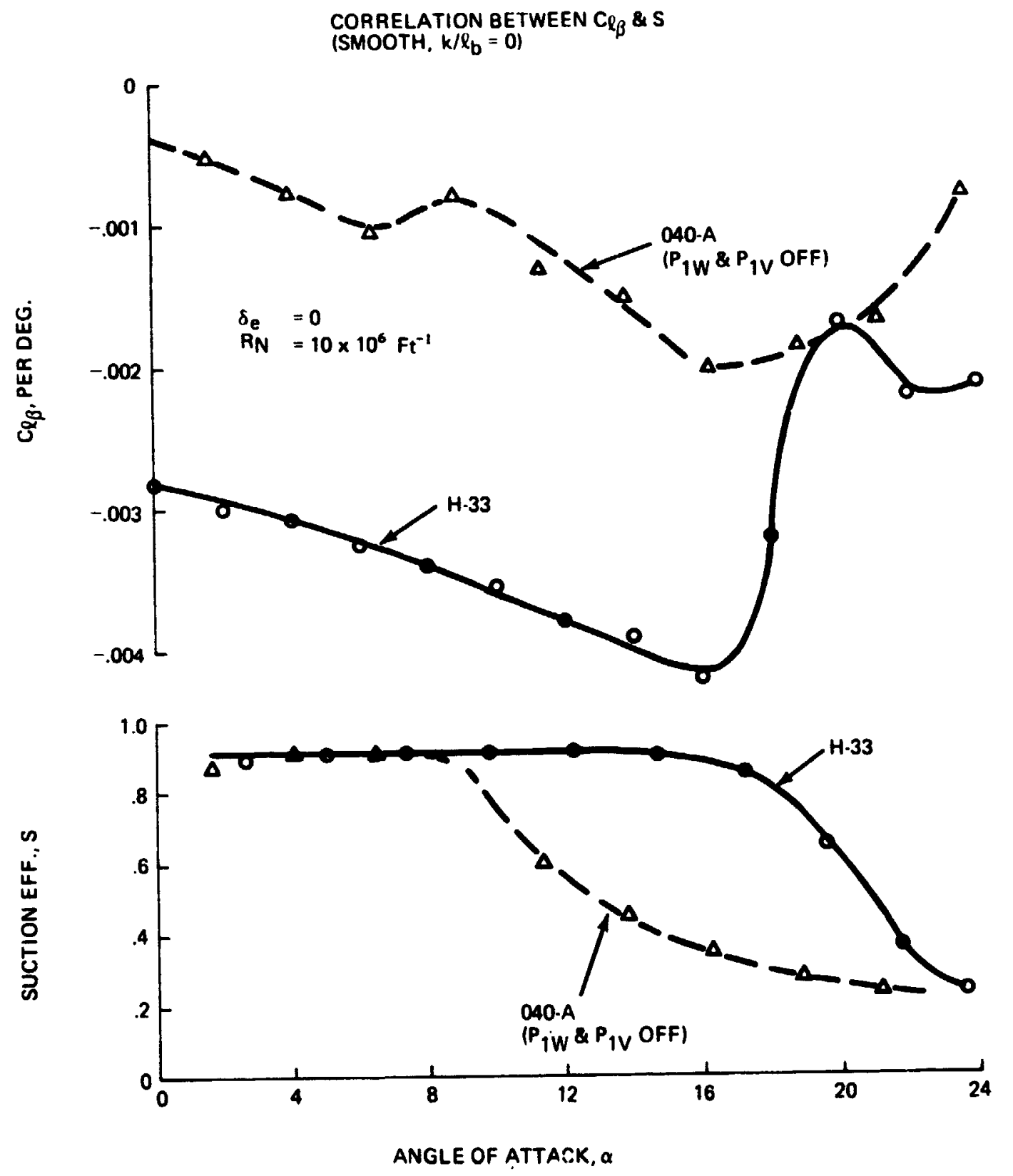

Figure 35 H.33 \& 040-A Loteral Cherrecteristics 

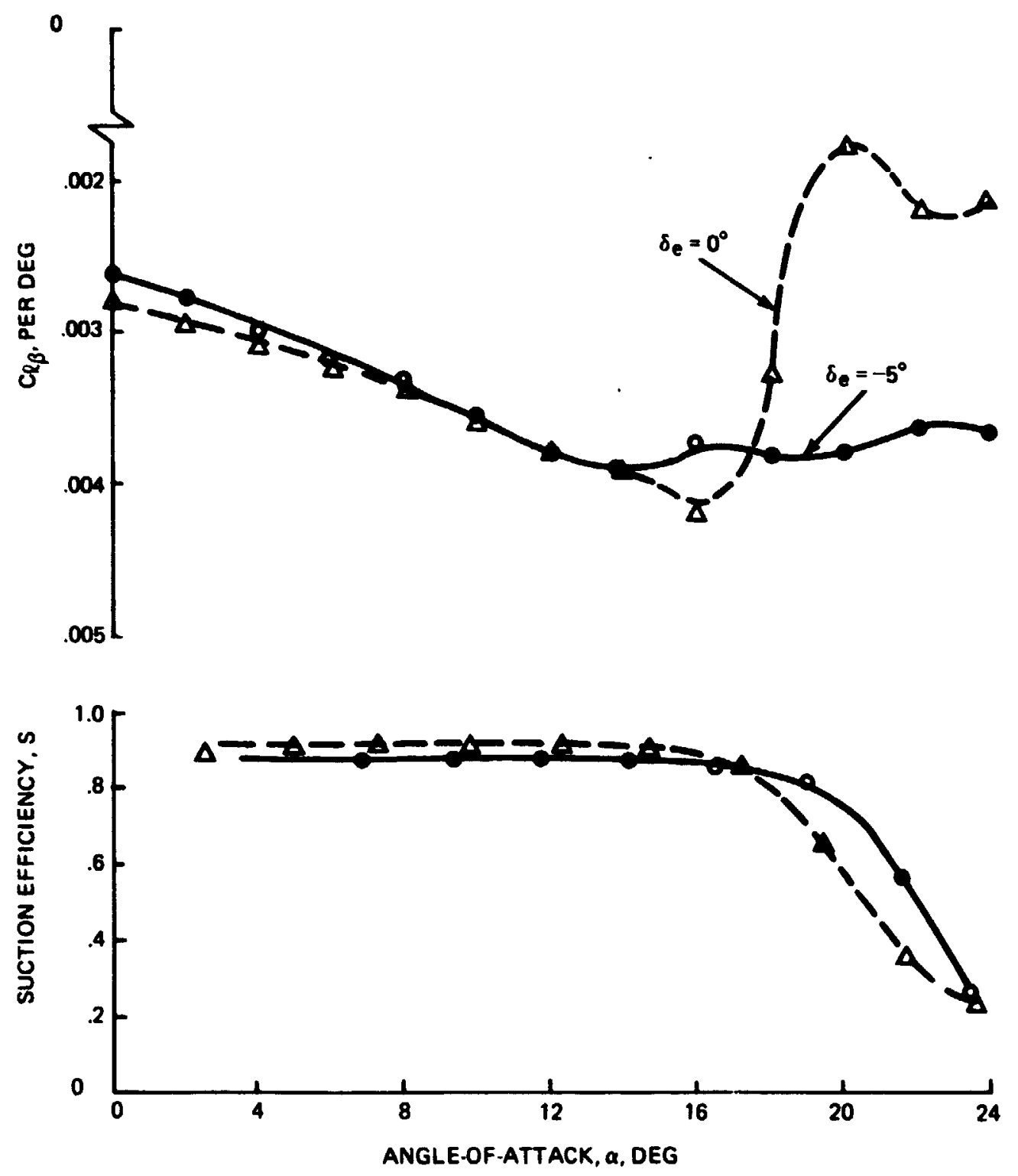

Figure 36 Effect of Elevator Deffection on H-33 Lotoral Stublity 
not impect the design. Also, a preliminary gross statement is that roughness does not degrade significantly $c_{18}$ up to roughness (peak-to-valley) values of one inch (the largest roughness used for figure 34 corresponds to $1.5 \mathrm{in}$. if scaled by $\mathrm{k} / \mathrm{r}_{\mathrm{n}}$, to 1.3 in. if scaled by $\mathrm{k} / \delta$ ). Effect on $c_{n e}$

Figure 37 indicates that the tunnel data exhibit a four-count loss in $c_{n b}$ at low $\alpha$ with $k / l_{0}=9.67 \times 10^{-4}$ roughiness. The effective tail arm data in figure 37 incicate that the degradation at low $\alpha$ is due to a loss in vertical tril effectiveness. At $\alpha=10 \mathrm{deg}$ and above, roughness effects on the wing apparently custribute to the degradation. Approximately $10 \%$ more vertical tail area would be required to overcome the low $\alpha \mathrm{a}_{\mathrm{n}}$ degradation due to $\mathrm{x} / \mathrm{l}$ $=9.67 \times 10^{-4}$ roughness.

At nigh $\alpha$ ( $\alpha=19 \mathrm{deg}$ as reference), $c_{n \beta}$ is essentially unchanged in the tunnel data.

Considering the uncertainties in the extrapolation to flight Reynolds numbers, it is quite proobble that the high $\alpha$ degradation in $c_{n \beta}$ is at most a couple of counts for the H33. Although this would not be serious for the H33, which exhibits a basic $c_{n B}$ level of $\sim 20$ ccunts, the effects on the $040 \mathrm{~A}, c_{n \beta}$ clean $\sim 2$ to 5 counts, would be substantial.

The preliminary conclusion is that, roughly peaking the effects of roughness up to the one-inch range, are not ceusing important degradation of $c_{n B^{*}}$ Effect on $c_{L}$ at Tailscrape Angles

The H33 tunnel data (Ref. 37) showing the $c_{L}$ degradation are presented in figure 38. Accounting for Reynolds number uncertainties, one obtains a maximim $k$ for cost-free degradation of $0.8 \mathrm{in.} \mathrm{(see} \mathrm{Fig.} \mathrm{39),} \mathrm{with} \mathrm{increasing}$ risks between $0.65 \mathrm{in}$. and $0.8 \mathrm{in}$. 

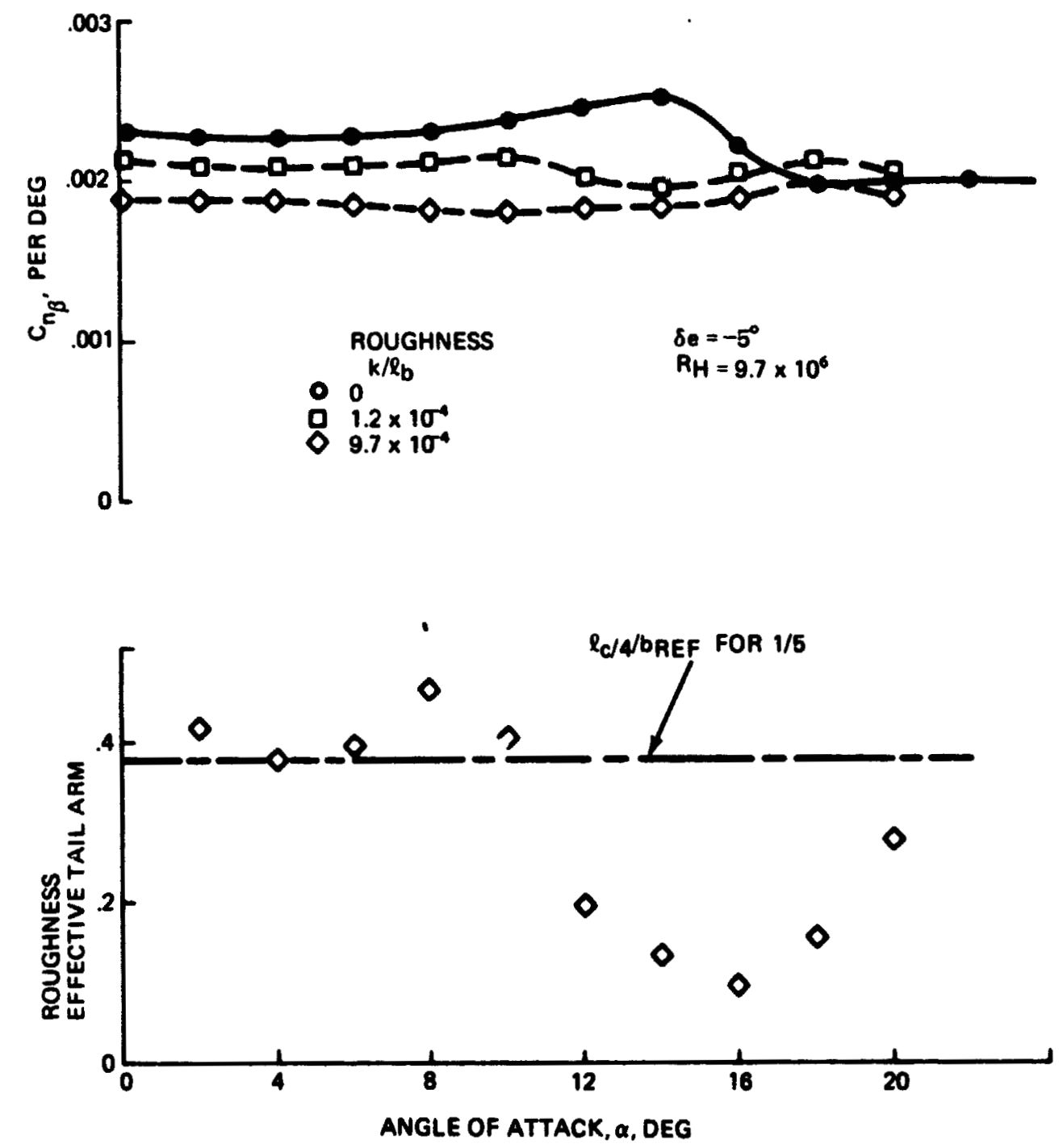

Figure 37 Effect of Roughness on H-33 Directional Stability 


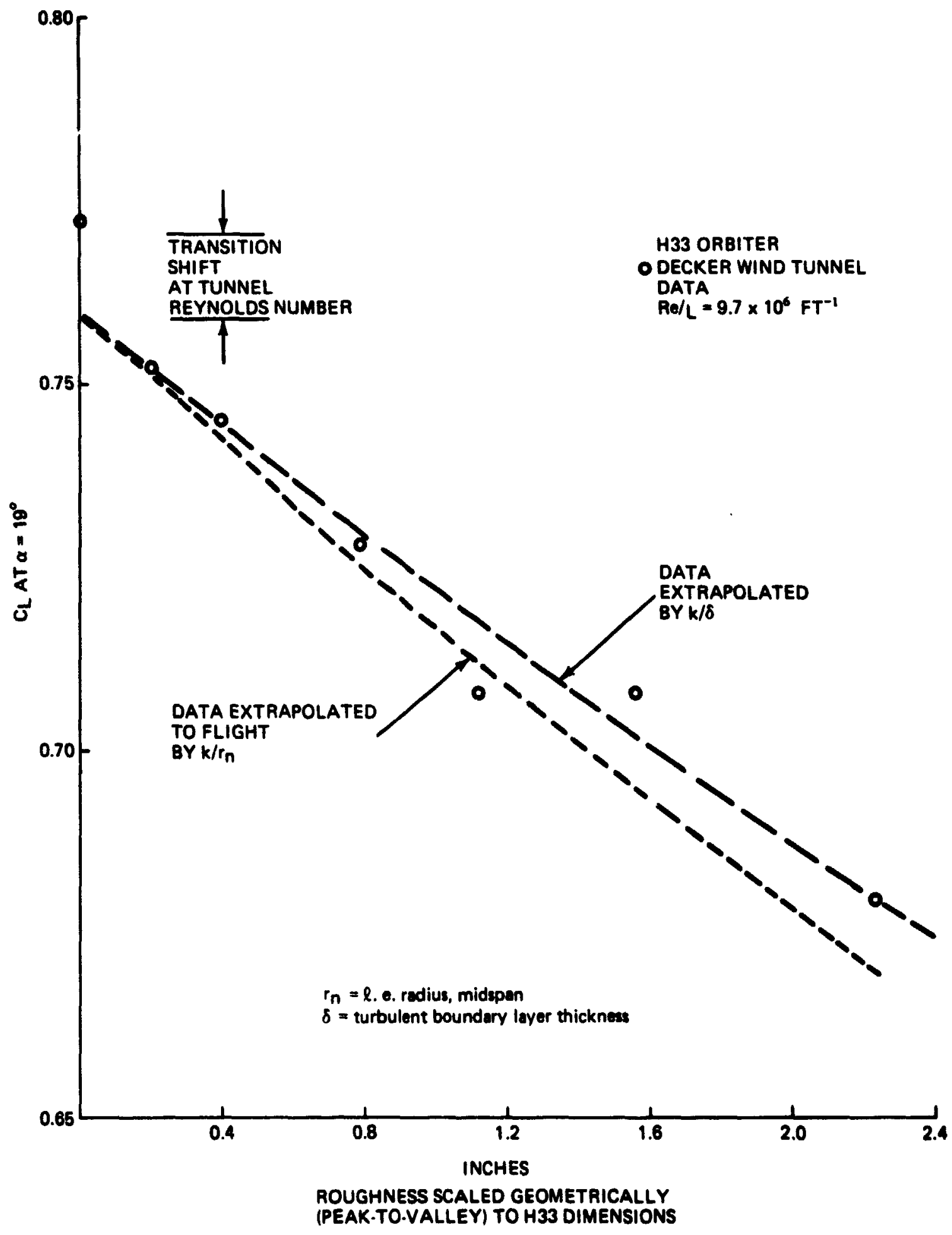

Figure 38 High a Lift Dogradation Due To L.E. Roughness. 


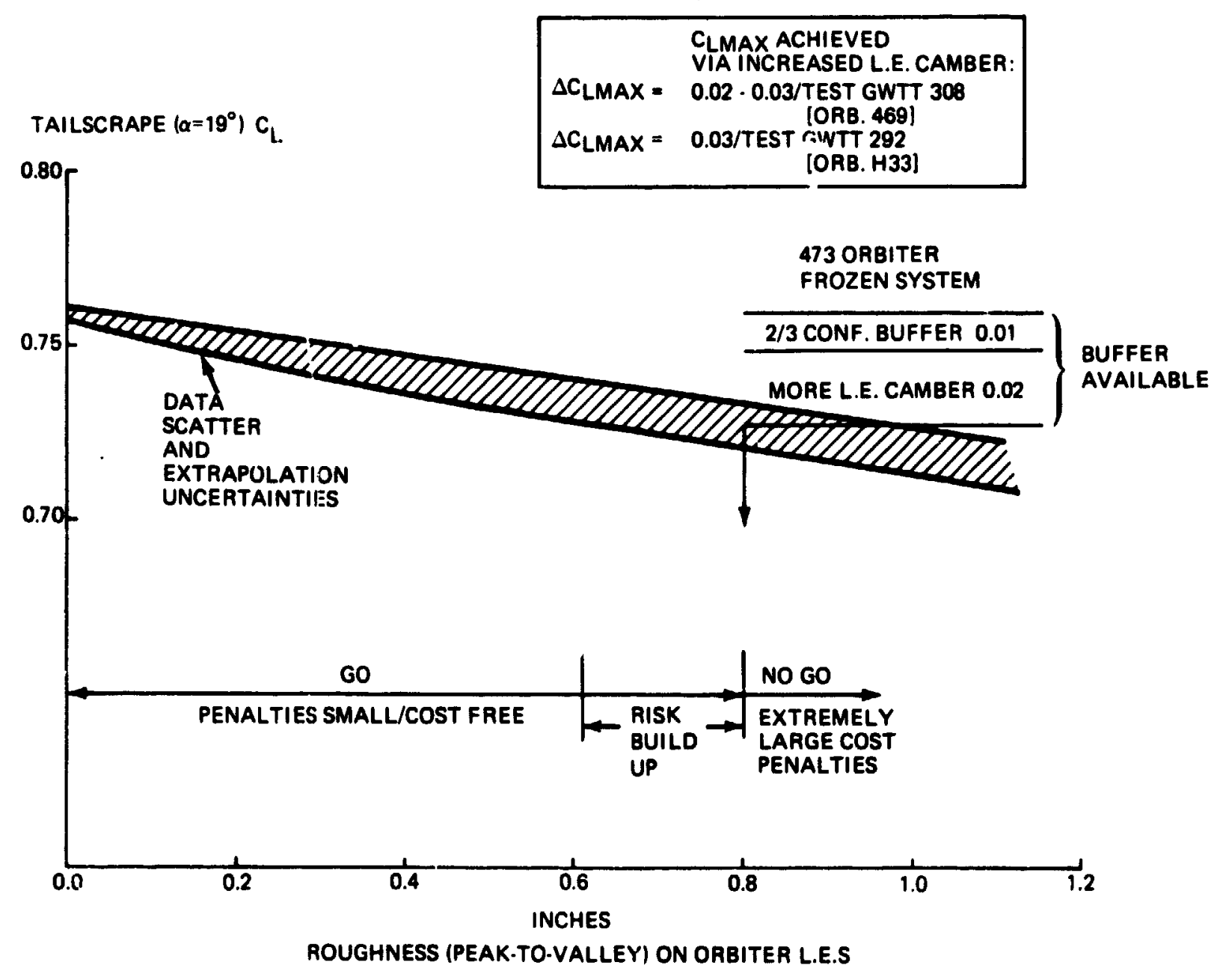

Figure 30 Maximum Acceptablo Roughness Dus to Landing Spoed Rcquirements 
If the orbiter wing were rubber, it would be possible to forestall roughnese degradations on $c_{\mathrm{L}}$ to beyond $\alpha=19 \mathrm{deg}$ by further optimizing the wing twist, camber, nose form and tip shape. The fousibility of this is indicated by:

(1) the fact that serious LBR-generated $c_{I}$ degradation is confine: $i * \cdots+16$ deg as shown in figure 34 ; and (2) the existence of a 6 deg shi.t in idrac break' attributable to camber in the H33 design (see Fig. 35). Such a fix to give an added $3 \mathrm{deg}$ in a (before LER induced lift deterioration becomes significant) would be essentially cost-free. At this time, it does not seem feasible to determine how munh of an additional buffer can be built up with such fixes without further teating.

$(L / D)_{\max }$ Degradation

The procedure given in Section 4.2 is quantized for the Gruman 473 orbiter (Refs. 41 to 43). The result is given in figure 40. For the frozen vehicle the basic buffer in $(I / D)_{\max }$ is 1.25 , so that even substantial portions of this 'up to say $2 / 3$ of 1 , 1.e. of 0.8 ) could be allowed to be lost in the roughness degradation.

In general, 1.e. camber on smooth 1.e.'s can give relatively small Improvements in $(L / D)_{\max }$. In the case of a vehicle like the 473 orbiter, in which there is already l.e. camber, further 1ncrease of camber should probably give an extra $\Delta L / D$ of negligeable magnitude. One therefore obtains as quantitative indication that the 473 should be able to accept a maximum of L/D loss of, say, 0.8 . The 473 orbiter in mid-1972 was at least pertially rubber in the sense indicated above. It had also considerable clean-up potential that is conservatively estimated as follows: 


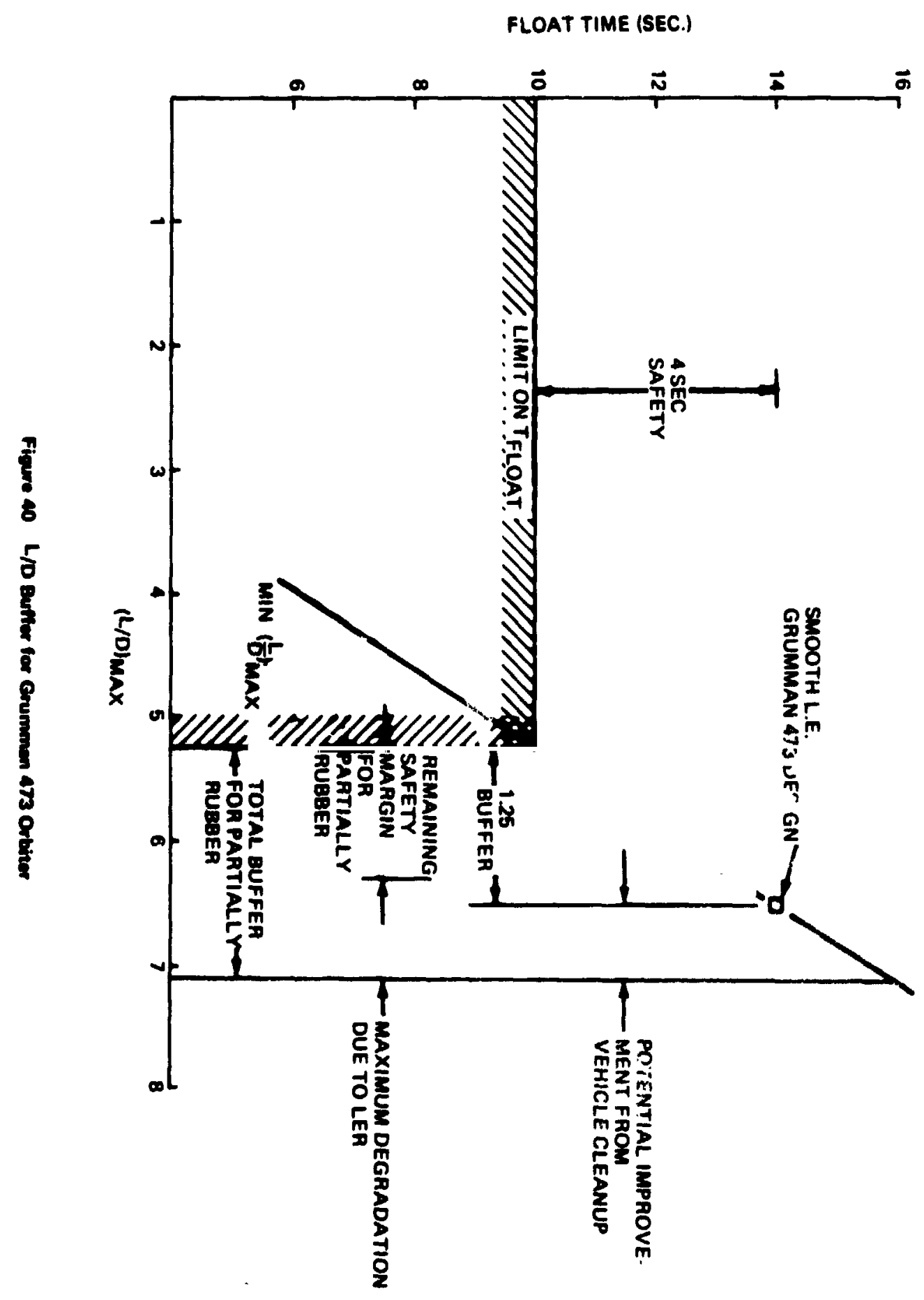




\begin{tabular}{lccc} 
Corjonent & Ourrent L/D Penalty (1972) & Conservative Improvement \\
\cline { 2 - 2 } Ors pods & 0.7 & 0.25 \\
ACPS pods & 0.5 & 0.15 \\
Shroud (boat-tailing) & 0.35 & 0.2
\end{tabular}

$\operatorname{Total} \Delta(\mathrm{L} / \mathrm{D})=0.6$

Costs: Negligible design and far ication cost increments at this stage. In summary then, for the Grumman 473 orbiter, the "go/no-go" limit is typically as tobulated:

\begin{tabular}{lc} 
Vehicle & $(\mathrm{L} / \mathrm{D})_{\max }$ Degradation Limit \\
\cline { 2 - 2 } Trozen & 0.8 \\
Partially Rubber & 1.4 \\
Rubber & 1.4
\end{tabular}

Therefore we find that there exists an appreciable tolerance to $L / D$ degradation before the 'float time' at landing is reduced beyond an acceptable minimum. This buffer can be increased by minor aerodynamics clean-up at negligible costs. On the other hand, tunnel data (extrapolated to flight as in figure 41) show that the $L / D$ degradation due to roughness is quite visible.

In terms of roughness that can be tolerated within the limit $\Delta(L / D)_{\max }$ of 0.8 , figure 42 shows that $k$ can be as high as 0.4 in. to 0.5 in. even taking a conservative attitude to the use of the available buffer.

\section{Conclusions}

of the four quantities involved, $c_{1 \beta}, c_{n \beta}, c_{L}$ and $(L / D)_{\max }$, we conclude that (on a typical flight scale, 6 in. of l.e. radius at midspan):

- $c_{1 B}, c_{n \beta}$ unchanged up to peak-to-valley roughness of 1.0 in.

- $c_{I}$ loss at tallscrape angles acceptable up $\sim$ rougtness of 0.65 to $0.8 \mathrm{in.}$

- $(L / D)_{\max } 1088$ ace ptable up to 0.4 to $0.5 \mathrm{in}$. 


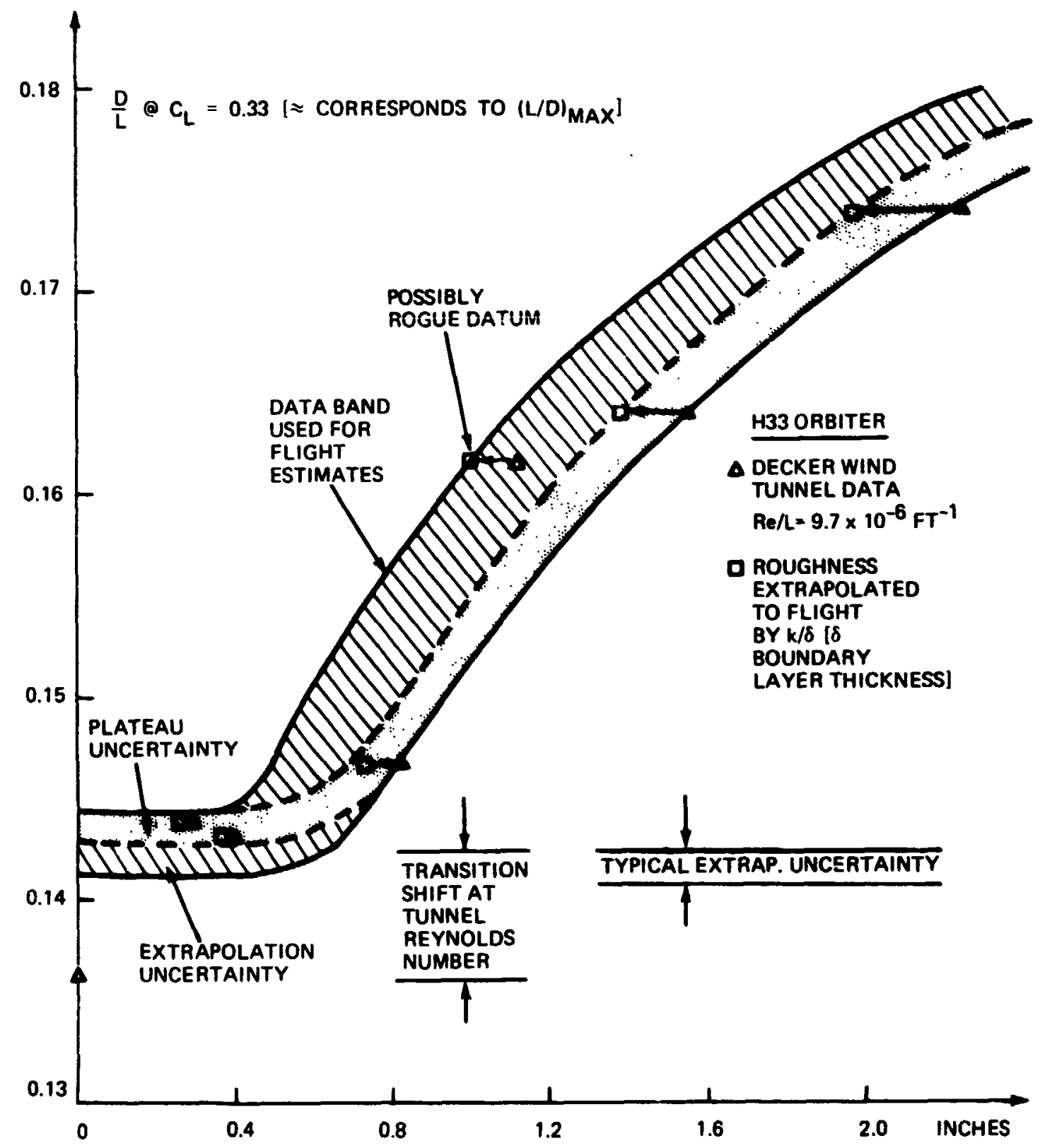

PEAK-TO.VALLEY ROUGHNESS SCALED GEOMETRICALLY TO H33 DIMENSIONS

Figure 41. Extrapoleted Tunnel Date Showing (L/D) Max Degredation Due to L.E. Roughness 


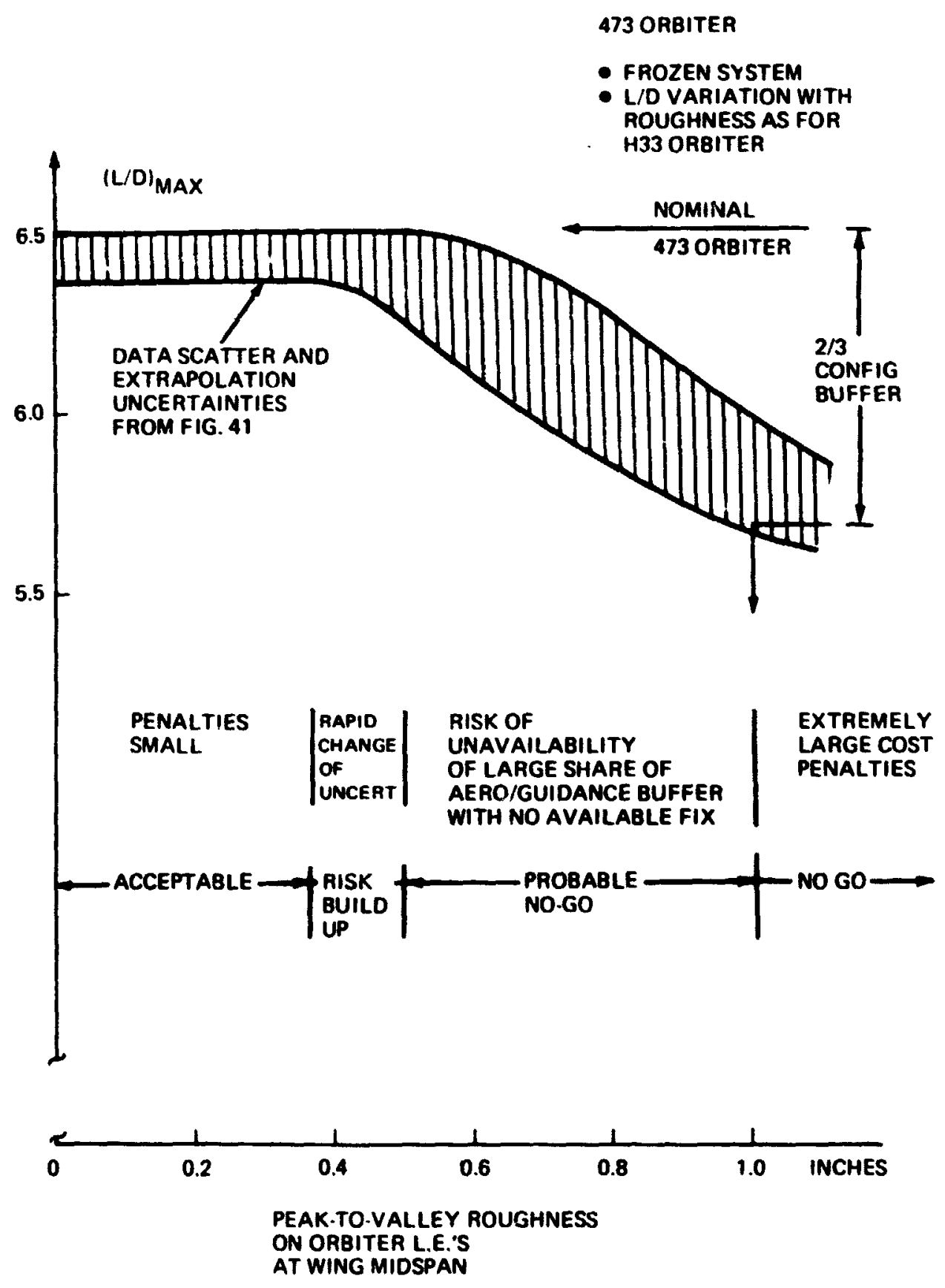

Figure 42. Maximum Acceptable Roughness Due to Floet Time Requiremo is for a Typical Orbiter 
These are the values for a typlcal single-delta orbiter like the 473, a frozen system and large traffic of operational flights.

\subsection{Minimizing Shape Change}

We assume that one is willing to apply the concept presented in Section 4.1 to eliminate the major effects of shape change. Of course, one must be willing to do the work necessary to predict recession from ground experiments and theory; we believe that this is possible, but by no means do we imply that it can be done using information obtained from ablators flat models not subjected to the sequence of ascent heating, cold soak and entry heating at typical environmental conditions. In other words, the data for the prediction may have to be obtained.

Therefore, one has to contend only with the residual uncertainties in the predicted recession.

\subsection{Aerodymamic Degradation vs Recession Uncertainties}

We will now examine for a typical orbiter like the Grumman 473 the degradation of $c_{1 \beta}, c_{n \beta}, c_{I \max },(L / D)_{\max }$ due to recession uncertainties.

It turns out that wind tunnel tests (Ref. 44) have established that 1.e. recession effects at noderate $\alpha$ can be neglected relative to roughness-produced effects. A l.e. shape change was simulated on a 1/25-scale $H 33$ model, which corresponded to a recession more than three times that of the largest recession estimated* for any of the candidate ablators (see Section 5), and procuced a $\Delta(\mathrm{L} / \mathrm{D})_{\max }$ of only -0.08 . The major effect was a change in $\alpha$ stall resulting from a change in l.e. camber. Conclusion: $\Delta(L / D)$ from recession on delta wing orbiters for $\alpha$ below $\alpha$ stall w1ll not exceed -.03 to $-.04-$ an order of magnitude less than LER effects. Note that this refers to the entire recession,

* Using, however, data from flat samples without ascent heating. 
not just the residual prediction uncertainty.

The preliminary conclusion is that the degradation due to recession uncertainties is not a problem.

\subsection{Conclusions}

The preliminary assessment of the aerodynamic degraciation is as follows:

- Tinere are four aerodymamic characteristics we are concerned with $c_{1 \beta}$, $c_{n \beta}, c_{\text {Imax }}$, and $(L / D)_{\max }$

- Roughness does not seem to affect $c_{1 \beta}$ and $c_{n \beta}$

- $c_{L} \max$ and $(L / D)_{\max }$ degradation due to roughness give the limits of go/no-go roughness as shown in figure 43. Below the 'go' limit the cost penalty is negligible

- Recession should be eliminated with the concept proposed; recession uncertainties have negligible effects

This preliminary assessment is based on a typical Phase-B single-delta orbiter such as the Grumman 473 with 1.e. camber, a frozen vehicle and an operational traffic. For just the test flights at no payload, there is cons" "erable buffer in the degradation acceptable, up to, perhaps, roughnesses of 1.0 in. (peakto-valley) on the typical orbiter l.e. 
AVERAGE

PEAK-TO-VALLEY ROUGHNESS

INCHES
PHASE B ORBITER $(\mathrm{H} 33+619)$ CONFIGURATION WITH L.E. CAMBER NASA TRAFFIC MODEL

"FBOZEN" SYSTEM
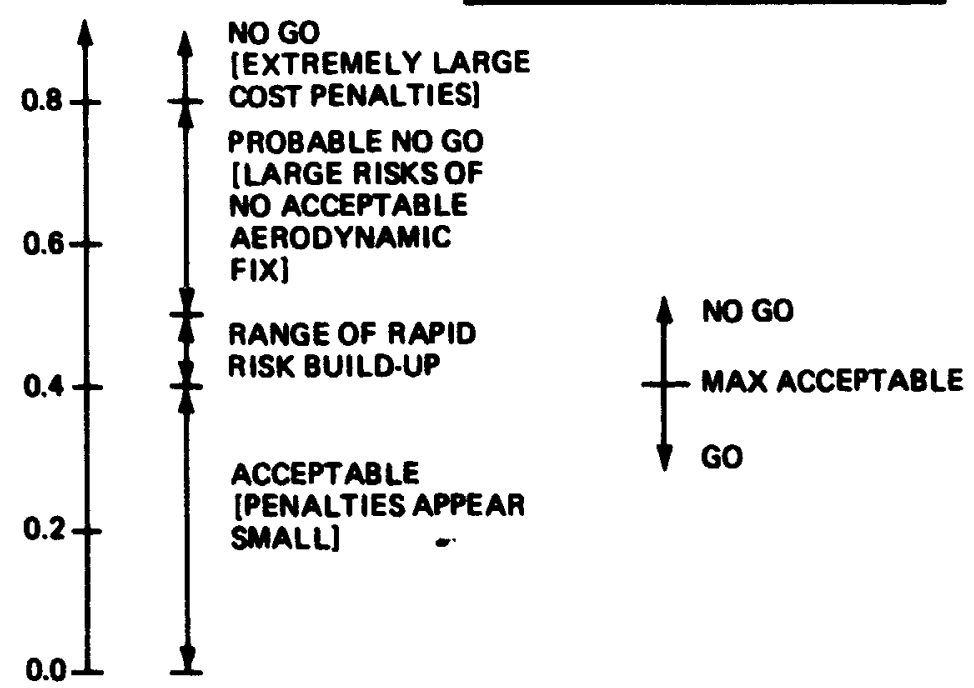

Fipure 43. Estimatud Maximum Aceaptable L.E. Rouphnes for On Orbiter 


\section{AMTATOR SEIECTION}

\subsection{Gxound Rules and Criteria for Selection of Candidate Ablators}

\subsubsection{Ground Rules}

Important ground rules were set out by NASA for the candidate ablators that could be considered in this study. These are:

a) To select developed materials (either off-the-shelf or requirine minor modifications for this application), especially flight tested.

b) To restrict the virgin density to the range 15 to $60 \mathrm{lbs} / \mathrm{ft}^{2}$.

c) To consider a large number of candidates, in fact a minimum of six; this is consistent with the ground rules (Section 2) of a technology study and an absolute optimu l.e. for a large traffic model rather than a back-up system for a few initial flights.

d) To disregard improved formulations offered by the ablator mamufacturers after the flrst test--a rale dictated by the need to conclude at same point the selection of the ablator.

Ground rules a) and b) are eminently reasonable when one considers the two key performance qualities desired in the ablators, 1.e. thermal performance (t.e. Insulation capability and char stability at low welght) and developed status (for low cost, low risks and short lead times). In fact, from these two points of view, charring ablators can essentially be grouped into three density ranges e.s show in table 9 . It becomes obvious that the ground rules codify the expectation that materials below $15 \mathrm{lbs} / \mathrm{ft}^{3}$ will not work and that above $60 \mathrm{lbs} / \mathrm{ft}^{3}$ the weight penalty is unacceptably high. 
Table 9 Leading Edes Ablators Grouped by Density

\begin{tabular}{|c|c|}
\hline Desainy Raves & 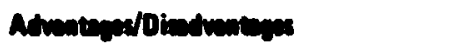 \\
\hline $15-301 b / t^{3}$ & $\begin{array}{l}\text { Low Woight } \\
\text { Cher Stebility Problems } \\
\text { Low Lewil of Flight Experience }\end{array}$ \\
\hline $30-60 t h / t^{3}$ & $\begin{array}{l}\text { Suble Cher } \\
\text { Flipht Prowen Condidutes } \\
\text { Inepection and Repair Procedures Defined }\end{array}$ \\
\hline $60-1001 b / t^{3}$ & $\begin{array}{l}\text { Whight Pondty } \\
\text { Strong Chan } \\
\text { Flight prowen on Ballistic Miwile }\end{array}$ \\
\hline
\end{tabular}


It turned out that, because. of the scope of the study, it bece e necessary to eliminate hybrids, i.e. multiple ablator 1.e. designs. This would have required to study the compatibility problem between materials, since problems may arise from. hybrids (Ret. 45). This would also have required to solve before hand the question of the joint between ablators. Of course, hybrid designs for the orbiter 1.e. have been sketched (but not developed), see for example Refs. 46 and 47 .

Another question in the nature of policy that had to be clarified is the difference betiveen the followine two material concepts, a developed 'material formulation' and leveloned 'material system'. 'Material formulation' is the basic material, 'mrterial system' is that material fabricated in a $\mathrm{H} / \mathrm{S}$ system, e.g. in a molded form, in a Hc form, etc. The question is: When for a certain material there is a developed formulation and a developed raterial system in the molded form, is the Hc form autamatically a developed material system? The answer that we gave to this question is affirmative when the molded material system 'works' in the desired envirorment. Then the thermal behavior of the Hc system is expected to follow closely that of the molded system. The thermal properties should be very close and real variations should exist only for the structural properties. In this case we decided to consider the Hc system is marginally developed system.

It is almost obvious that when we speak of candidate materials or ablators we mean materials systems as defined above.

\section{1 .2 Criteria}

The number of candidate ablative materials applicable to the shuttle leading edge is quite large. This is true even when it is noted that the requirement and the materials be in the density range $15<0<601 \mathrm{~b} / \mathrm{ft}^{3}$ excludes the higher 
density carbon phenolic and silica phenolic $\left(\rho=90 \mathrm{lb} / \mathrm{ft}^{3}\right)$ which have been well characterized and flight tested on numerous Atr Force missile programs. Several lower density materials, some of which have undergone limited development testing are available and appear attractive for leading edge use. In fact it is clear from table 9 that trade-offs exist since insulation efficlency tends to decrease with increasing density, while char stability increases and the weight penality increases.

The choice of candidate materials for this study was based on the desire to investigate both epoxy and elastomeric systems in the density range of 15-60 $\mathrm{lb} / \mathrm{ft}^{3}$. An additional objective was to select materials which can be considered in the well developed category. In addition to the Dolan (Reference 48) and Price (Reference 49) sources, various other material studies (References 50 through 54) have been reviewed to insure a large degree of overall selection objectivity.

The following criteria guided the selection of the candidate materials:

1) Char Stability - The thermal nature of this material group is characterized by in-depth decomposition (charring). Extensive mass loss is possible, such as that associated with the NASA $60^{\prime 2}$ material (Ref. 48).

Char stability, related to both extent of decomposition and char matrix constituents, is an important parameter since both surface recession and roughness must be "predictable" and char instability (spalling, erosion, etc) shouid be minimized to prevent degradation in subsonic aerodynamic performance. It should be noted that the char 
layer will be subjected to vibration loads during low altitude maneuvers.

a) Thermal Efficiency - Materials will differ both in ablation and insulation performance. The objective is, of course, to select materials which have a high thermal efficiency (1.e., low weight) while also satisfying other system requirements.

3) Honeycomb or Molded - Factors such as cost, surface roughness, density, and char stability may be significantly influenced by whether a molded or honeycomb reinforcement version of a material is used.

4) Development (Characterization) Status - To meaningfully interpret the experimental data which are to be obtained from the screening tests only materials for which characterization (property) data are readily available should be chosen. A positive relatioiship exists between the amount of such property data and degree of development (process, fabrication techniques, etc.) and, hence, well-developed and characterized materials are desired. 
5) Prior Flight Bxperience - As much :"s, possible, the primary leading edge ablatives should be chosen from materials whlch have a listing of proven entry applications. Modifications based on shuttle appl1cation or basic process improvements should be considered for maximum program benefit.

6) Ease of Fabrication - Application of the naterial on a leading edge configuration gives rise to questions of fabrication both in respect to ease as well as to more fundamental concerns such as feasibility and cost. A significant factor here is the possibility of problems arising iue to the use of a honeycomb material in a small radius leading edge.

7) Cost - This criterion (involving matters of material, processing, fabrication, development and refurbishment) is of primary concern and will strongly influence fliral selection.

\subsection{Selection of Candidate Materials}

\subsubsection{Candidate Naterials Selected}

Based on the criteria just described the materials shown in table 10 are considered to best represent the group of candidates from which the ablative lsading edge material may be chosen. This group represents also the best choice in terms of cost/time effectiveness for this program. The materials recommended for study cover a range of densities $\left(22\right.$ o $\left._{0}-55 \mathrm{lbs} / \mathrm{ft}^{3}\right)$ and include only systems which are elther fllght tested or are ir an advanced state of development.

The following information describes the rationale used in choosing each material: ESA 3560 IIA $\left(c=56 \mathrm{Ibs} / \mathrm{ft}^{3}\right)$ This Martin elastaner was specifically developed to assure controlled contours and essentially 


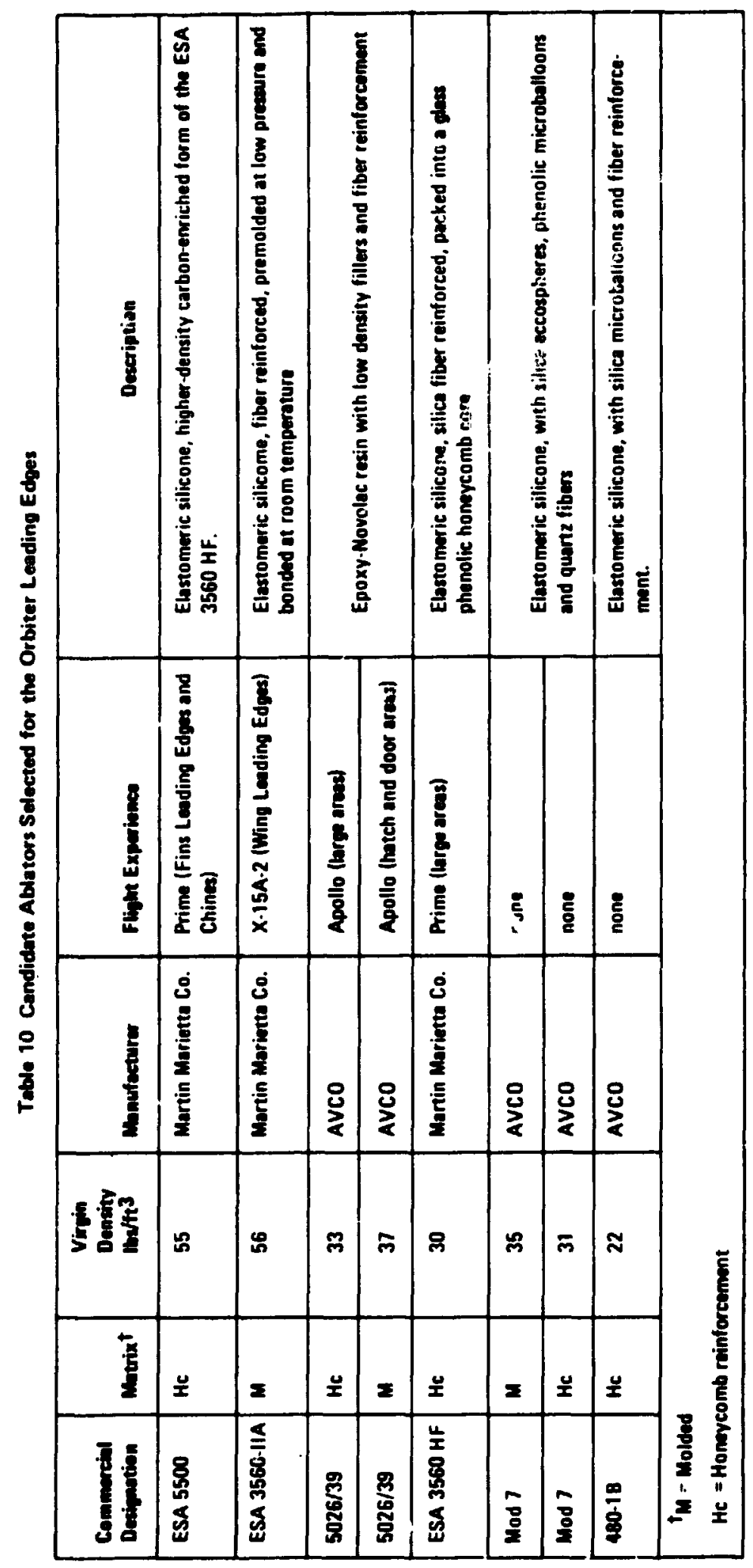


zero recession to the 1.e. of the $015-A 2$. It is premolded (to assur, contour crontrol) and is bonded at rocm temperature and low pressure (to simplify tooling). This material was chosen by MDAC for the Phase-B, 1.e. design, because of 'easy fabrication and application for wide range of design thickness' and 'because of good rain erosion resistance' (Ref. 46, page B 3-25).

ESA $5500\left(\rho=55 \mathrm{lbs} / \mathrm{ft}^{3}\right)$ This aliernate, higt--ansity Martin elastomer has demonstrated performance in the sigt speed environment associated with entry vehicles ( $f$ in leadi. . ges on PRIME vehicle). This material, which is used in a ho ....be, utilizes a filler which is principally carbon to minimize surface recession. Avcoat 5026/39 $\left(\rho=33 \mathrm{lbs} / \mathrm{ft}^{3}\right)$ The besic Apollo heat shield material, this epoxy is one of the three materials selected to explore a medium value of density. The honeycomb version of this material was one of the three materials found superior in Ref. 9. This matcrial was chosen iy Gruman during the Space Shuttie Phase B studies (Ref. 55). The molded version of Avcoai 5026/39 is also flight tested -- It was used on the Apollo vehicle in hatch and door areas. The use of this molded configuration would be attractive, of course, due to the possibility of significant reduction in production costs.

MOD $7\left(\rho=35 \mathrm{lbs} / \mathrm{ft}^{3}\right)$ This material is considered representative of the elastomers at this density level. Avco recomends it for study in both molied and honeycomb configurations, as the resulting data should help assess the capability of elastomers in the medium density class to efficiently perform in the flight leading edge envirorment. 
The material has been exposed to a significant amour: 0 : testine, during development of Avco. It was developed originally for plenetary-entry, thermal-protection applications and has been extensively evaluated at Avco and at various NASA facilities. In addition to baing well charazterized, the Mod 7 material has been subjected to a varlety of processing and fabrication sturies.

The material has been successfully exposed to $-260^{\circ} \mathrm{F}$ on an aluminum substructure. As with the 5026-39, the need for honeycomb reinforcement in the Mod 7 will have to be established. Mod T's advanced stage of development eliminates thi: need for any extensive activities relating to formulation, processing and Pabrication.

In view of the large amount of development studies (Ref. 59), Mod $7 \mathrm{M}$ is a developed material system.

Mod 7 HC is a (mar(inaliy) developed system in the sense of Section 5.1.1, on the expectation that the thermal performance of Mod $7 \mathrm{M}$ under entry heating is good, but there is the usual question of whethe: after the heating pulse the material possesses a char-virgin interface 
strong enough to give the confidence 8 designer must have. A good reason to select Mod $7 \mathrm{HC}$ to include in the study at least one true comparison, molded versus honeycomb, for elastomers. One alternative would have been to select the molded counterpart of the $3560 \mathrm{HF}$. This material, however, appears to be a research material*.

ESA $3560 \mathrm{HF}\left(\rho=30 \mathrm{Ib} / \mathrm{ft}^{3}\right)$ This Martin material was utilized in the large areas of the PRIME vehicle. Because of the flight experience and background investigavions (Reference 57) associated with this material, it appears to be a promising candidate. This is the material that has been considered in Lockheed's alternate Phase B studies (Ref. 58 ).

480-1B $\left(P=22 \mathrm{lbs} / \mathrm{ft}^{3}\right)$ This Avco elastomer, which utilizes silica microballoons rather than the less stable phenolic balloons of the 480-2 material series, is considered to be a representative of the low density candidate materials. As in the case of Mod 7, prior experience will a.llow more definitive data interpretation of the material group during this study. Use of alternate, non-Avco material candidates at this density level will make reliable data interpretation more difficult. While it might be possible to utilize this material in molded form Aveo reccumenis that evaluation of this material be in a honeycamb configuration due to its low density.

The $480-1$ series represents a class of Avco-developed, Iow density

*There is however a molded version or modification of the 3560 HF that was flown on PRIME in the fin fillet areas as a joint riller. 
materials in the range of 15 to $22 \mathrm{lb} / \mathrm{ft}^{3}$. These materials are lower density materials of Mod 7 and the same fabrication moiding and bonding procedures are used. The particular version of 480-1 that is recoumended for space shuttle L.E. evaluation is designated as 480-1B. This is a $22 \mathrm{lb} / \mathrm{ft}^{3}$ material developed primarily for use as tactical missile thermal protection. This material has been tested under relatively high-shear conditions $\left(\sim 9 \mathrm{lb} / \mathrm{ft}^{2}\right)$ and exhibited a hard char with no cracks. However, a fiberglass honeycamb is recommended because of the material's low density and the uncertain strengths of the char-virgin material interface. As with the Kod 7, Aveo has conducted extensive processing and fabrication studies with 480-1 materials.

As a whole, the group of ablators of table 10 covers quite well the key issues/criteria for the selection of a l.e. ablator. How the driving criteris/issues are covered is summarized in table 11.

Besides the ablators included, a point should be made about one outstanding ablator excluded, the $\underline{D C} 325 \mathrm{Hc}$ ( $\left.p=55-57 \mathrm{lbs} / \mathrm{ft}^{3}\right)$ or $\mathrm{S}-3$ material. The Gemini heat shield material, developed by Dow Corning for the NASA program and McDonnell-Douglas, is also a high density elastamer in a flexible honeycomb matrix. This material was one of the three that exhibited best thermal performance in a first test program aimed at verifying the feasibility of using state-of-tha-art ablators for the orbiter leading edges (Ref. 45). Unfortunately, this material had to be excluded becaus it could not be procured. 
Table 11 Driving Criteria for Selection of the Cendidate Ablators

\begin{tabular}{|c|c|}
\hline Drinien Crivenit fer Sencetion & Intwiens Sechetud \\
\hline Prios flight experience & $\begin{array}{l}\text { AVCOAT 5026/30 HcaM, ESA 5500, ESA } \\
\text { 3550 IIA, ESA } 3560 \text { HF }\end{array}$ \\
\hline $\begin{array}{l}\text { Recescion/contour comtrol/cher } \\
\text { stimility }\end{array}$ & $\begin{array}{l}\text { ESA 3560 IIA, ESA 5500. AVCOAT 5026/30 } \\
\text { HC }\end{array}$ \\
\hline $\begin{array}{l}\text { Honneycomb is. molded queation } \\
\text { lespecially at } 30 \mathrm{lba} / \mathrm{ft}^{3} \text { ) }\end{array}$ & $\begin{array}{l}\text { AVCOAT 5026/3E, HC } \rightarrow M \\
\text { Mod } 7 \quad \text { Hc } \rightarrow M \\
\text { Abo ESA } 5500 \text { and ESA } 3560 \text { IIA. }\end{array}$ \\
\hline $\begin{array}{l}\text { Good coverese of madium den. } \\
\text { sity (30 toath } 3 \text { materials) }\end{array}$ & $\begin{array}{l}\text { AVCOAT 5026/39 HedM, ESA } 3560 \text { HF, } \\
\text { Mod } 7 \text { Hedil }\end{array}$ \\
\hline 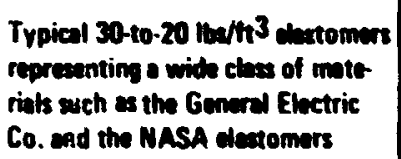 & $\operatorname{Mod} 7 \mathrm{HcaM}, 480 \mathrm{lb} \mathrm{Hc}$ \\
\hline Ease of tabricutionnow costs & AVCOAT 5026/39 M, ESA $3560 \mathrm{HA}$ \\
\hline 20 lba/ft ${ }^{3}$ density range & $49018 \mathrm{Hc}$ \\
\hline Elastomers ve epoxies & ESA 3560 HF, Mod $7 \longrightarrow$ AVCOAT 5026/39 \\
\hline
\end{tabular}




\subsubsection{Key Material Properties}

Table 12 summarizes the more significant properties $c$ " the candidate mateliels. These properties have been determined not only be direct measurement but in same instances from interpretation of flight test data. A systematic effort at collecting property information for all candidate materials gave the detailed information found in the Data Package.

\subsection{Screening Test Program}

\subsubsection{Rationale}

The objectives of the screening test program were 1) to evaluate the candidate ablators under realistic leading edge envirorment conditions 2) to determine the critical factors which might affect the performance of an ablator on the leading edge and 3) to provide data which permit the selection of one ablator for the initial design. In order to define a meaningful test program consistenc with these objectives the entire leading edge environment was reviewed. The leading edge must withstand moderately high ascent heating followed by cold sosk in orbit and subsequent entry into the atmosphere. Combined with these thermal enviroments is the flexure experienced by the wing during ascent (peak $q_{x}$ ) and during maneuvering prior to landing.

Figure 44 shows schematically the sequence of environments encountered. Reviewing these envirorments it is clear that one of the primary requirements of the selected material is a stror is char which will provide a stable cortour for subsonic performence and also minimizes the chances of particles from the char impinging on the adjacent TPS. In order to properly assess this char realistically it is necessary that the material be tested 1) using a leading edge contour (where aerodynamic shear and pressure gradients exist) and 2) in a sequential envirorment where the gross effects of the total flight can be evaluated. Of particular interest is the effect of ascent heating on material 


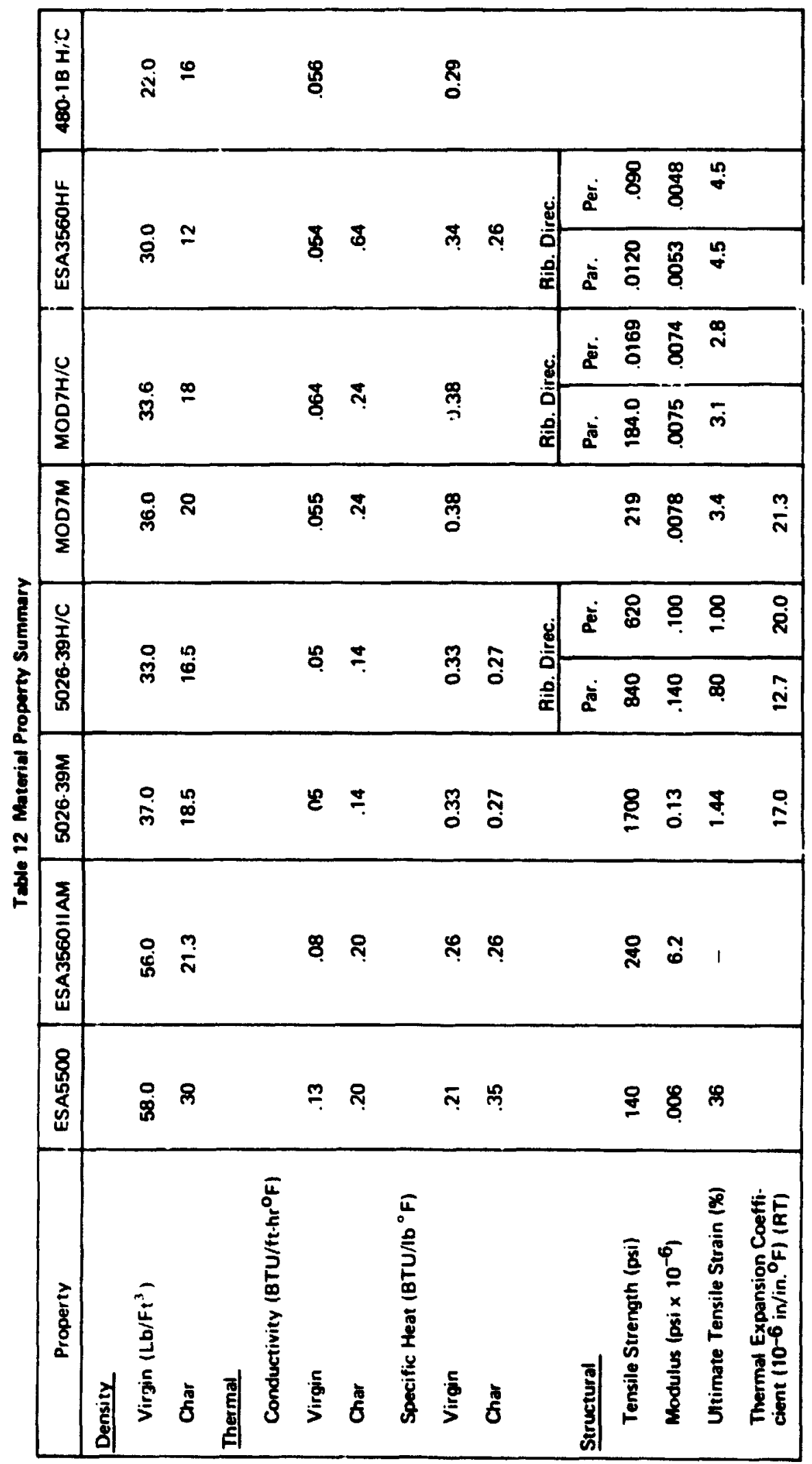




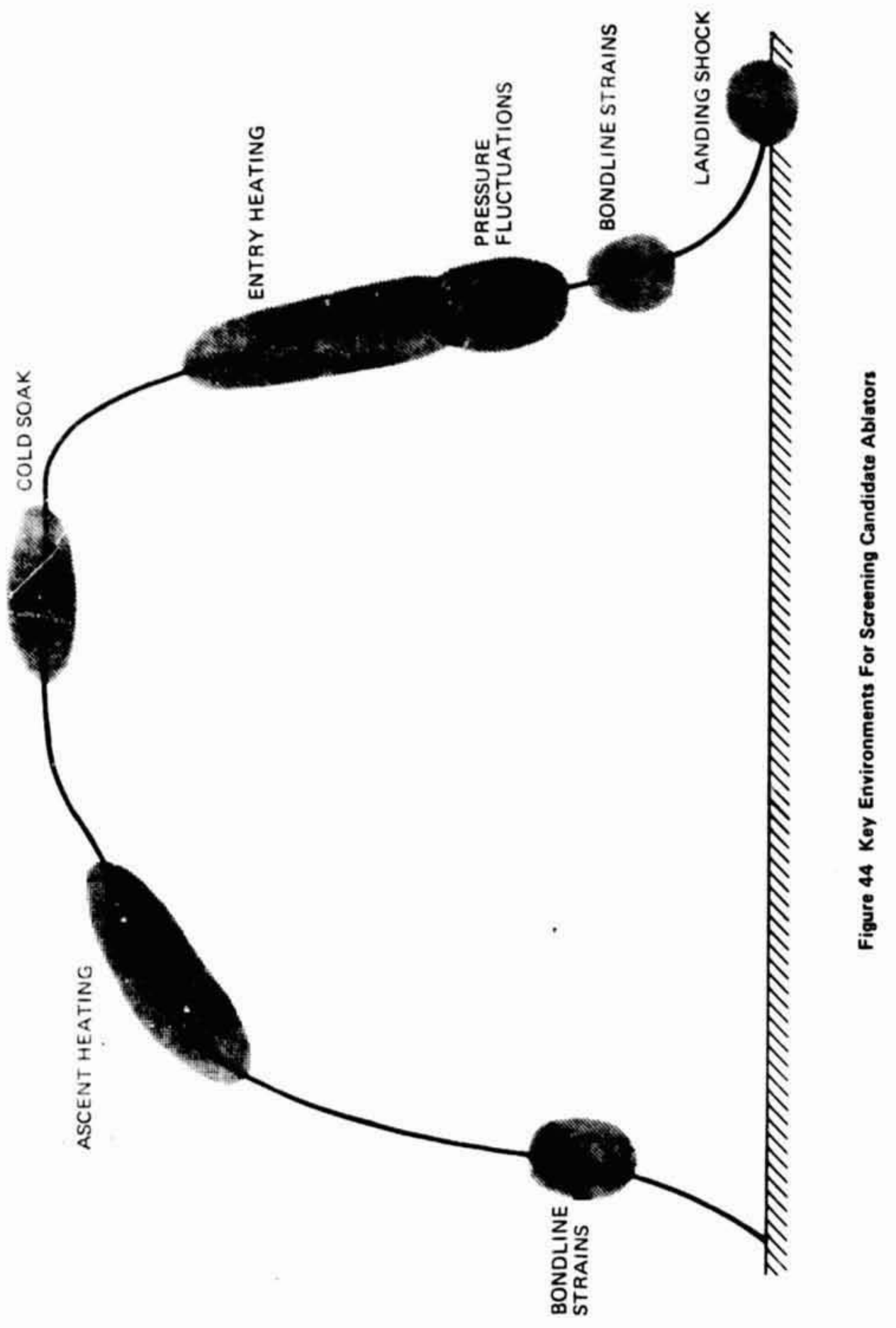


performance during reentry. In addition to the sequential environmentel tests described above it was also desirable to determine the thermal efficiency and structural characteristics of the various materials so that they could be ranked according to weight and reliability considerations. The thermal efficiency could be best determined by instrumenting the leading edge models while the structural characteristics (flexure strength) of the materials were determined using beams of both the virgin and char material. The virgin tests allowed comparison with existing material property data while the charred beams would simulate the state of the ablator on the leading edge during maneuvering prior to landing.

\subsubsection{Overvien of Tests}

The description of the ablator screening test program is shown in figure 45 and table 13. As can be seen two basic configurations were used 1) a leading edge specimen which was subjected to the sequence of enviroments shown and 2) a Mexure beam which was used to determine the characteristics of the virgin and charred material. Samples were also procured for rain erosion tests which however were not carried out.

One model, the Mod $7 \mathrm{M}$, was used by NASA Lafic for other purposes. A replacement model was fabrisated by Avco, however it was instrumented differently and was not cold-soaked. The results obtained with it are occasionally used here.

The key envirorments selected (table 13) are those that represent the most severe conditions for the four performance qualities just mentioned.

The policy we followed for the aerothermal environment tests was to fabricate a single specimen per material, in a relatively sophisticated model for an elaborate test sequence. The model was a l.e. configuration (figure 46), complete of substructure, tested sequentially under simulated ascent heating, 
1. AEROTHERMAL TEST

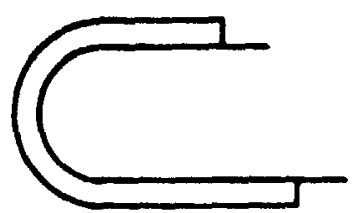

2. FLEXURE TESTS

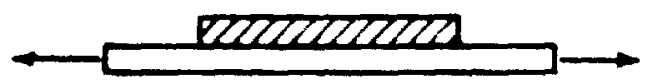

ASCENT HEATING COLD SOAK IN ORBIT

SEQUENTIAL REENTRY IIEATING VIBRATION LANDING SHOCK

VIRGIN MATERIAL CHARRED SURFACE

Figure 45 Sereening Tests 


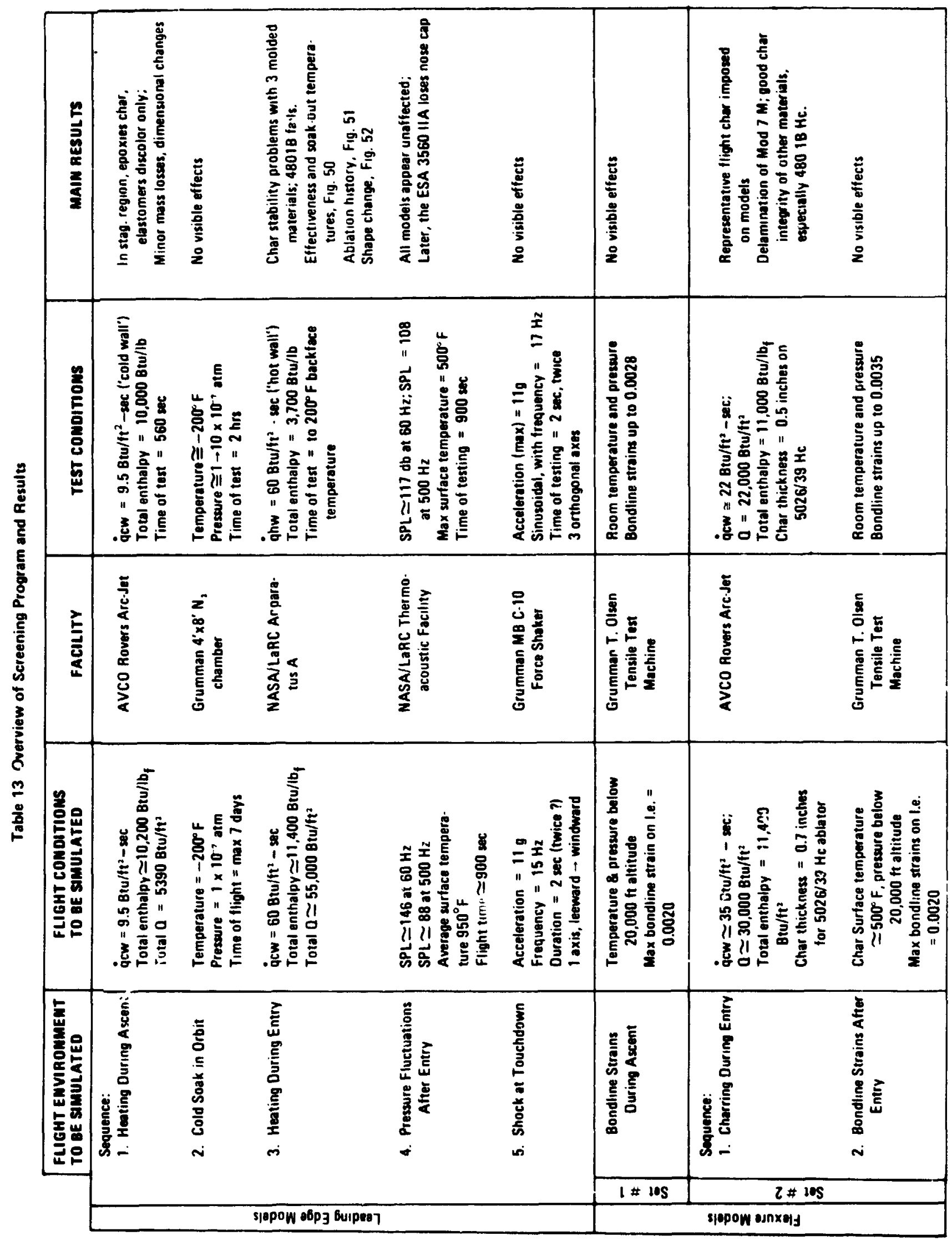




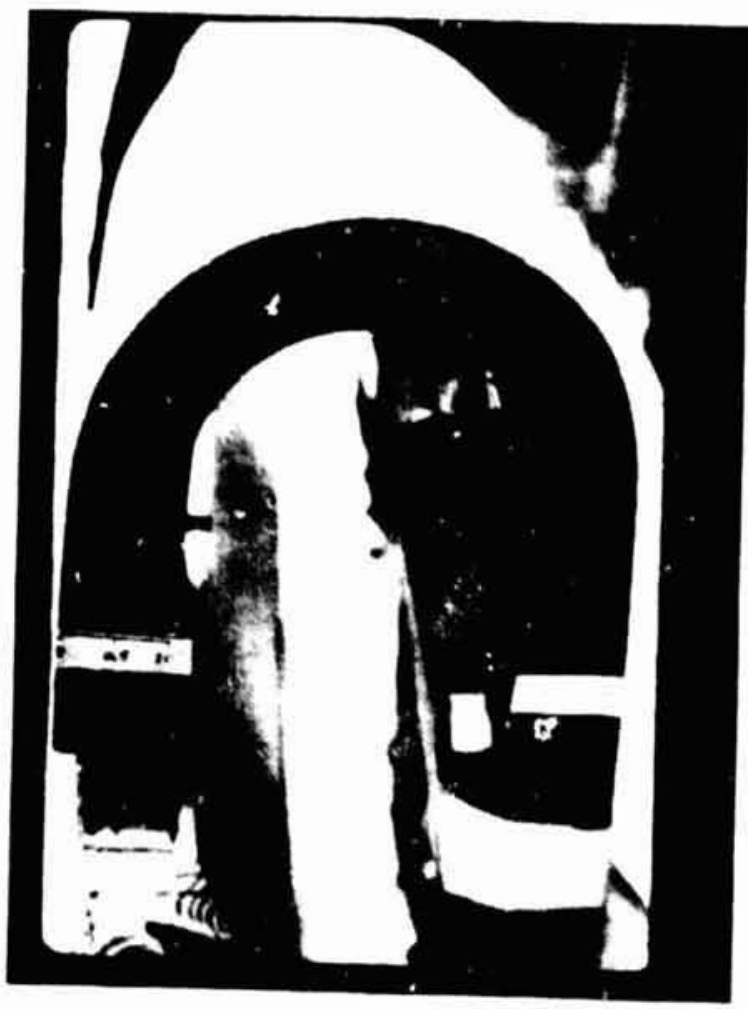

Figure 46 Typical Leading Edoe Specimen

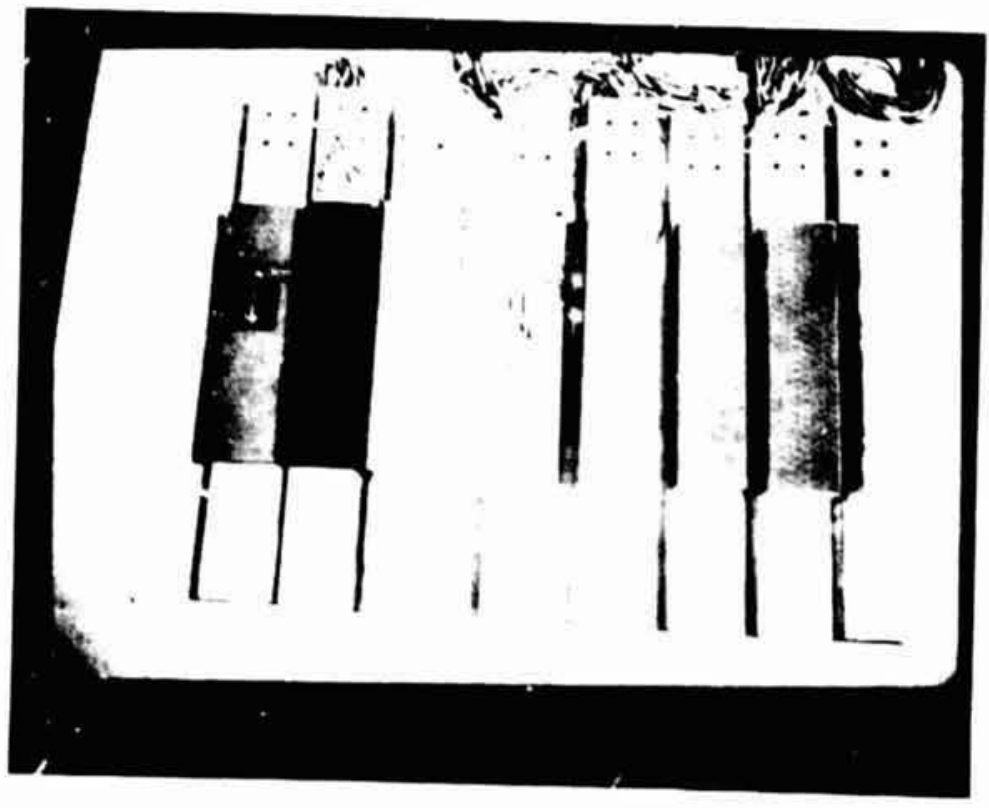

Figure 47 One Set of Flexure Models of the C.nndidate Ablators 
cold soak, entry heating, pressure fluctuation and shock environments The facilities used are indicated in table 23 . The instrumentation on eash l.e. model was seven backface thermocouples, appropriately isclated to eliminate lateral conduction effectis in the substrusture. The cppnsite policy was used for the flexure tests; the models (figure $4^{-1}$ ) were very simple strips, one flexed in its initial form and one first charred and then flexed. The facilities in which these flexure models were tested are indicated in table 13 . The instrumentation was also very sirple, two strain gauges anc two thermocouples per model.

In all models, l.e. and strips, the thicknesses of the various ablators (uniform over the models) were scaled according to density so as to afford a comparison of the results at the same unit weight. Of course, there were in all tests other appropriate measurements such as surface temperature, roughness, recession and mass loss measuremerts, and extensive photographic coverage including $16 \mathrm{~mm}$ movies * of the arc-jet tests and the shock tests. Each ablator manufacturer borded its cwn materials on the appropriate substructure. The following provides a brief cutline of the two series of tests.

\section{- a) Leading Edge}

The aerothermal tests utilized the leading edge specimer, shown in figure 48. This configuration provided the proper environment for the evaluation of the materials and at the same time maintained compatibility with the NASA/LRC Apparatus "A" facility. The nose radius was dictated by flow biockage considerations while the material thackness was imited by the ability to curve the flexeore honeycomb. $\because 1+i t$ the excepticn of the 480-1B He the weight per unlt arma of aklatcr $(3, a)$ we held sorstant so that the

Films can be seer. $a^{t}$ the Ferma? Errtection Eranch, iASA Largley Research Center, Hemfton, virginia. 


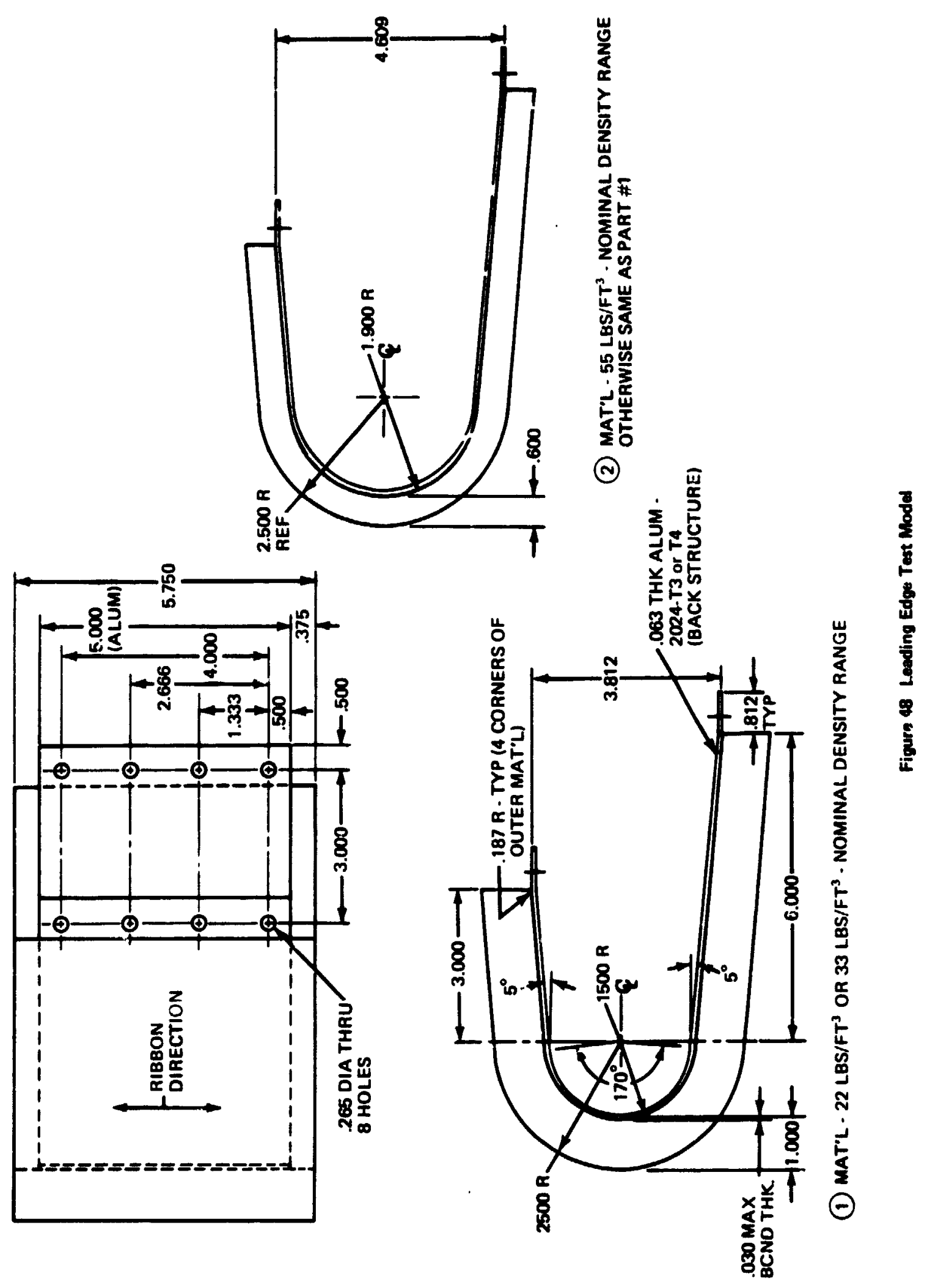




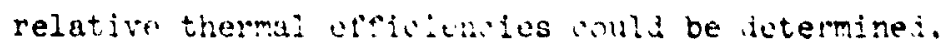

The leading edge specime: ins expcsed to the various environsents shown in figure 45. The differen: conditions isquired that the

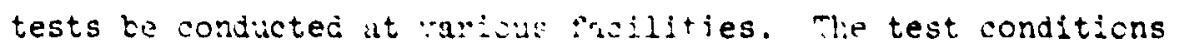
indicated in table 13 are :e; "esentative of the fligt environment and comparisons between test ard flight as show there and in Sections 5.3 .3 to 5.3 .12 .

b) Flexure tests

In order to determine the virgin and char flexural properties a series of beam tests were conducted. The sests utilized the specimer shown in sigure 49 ard were instrumented with thermocouples and strain gages $t c$ aid in determining thermal efficiency and strain limits (note that for all materials the weight per unit area was kept constant). Two sets of tests were run as show in table 13. The reentry heating tests were conducted in the Avco ROVERS facility whice ail structural tests were conducted at Grumnan. In general, the simulation of the r:ighi conditions was good, with the exception of the enthaipy simulation in the entry heating test. Thls was unfortunate and may well have penalized the epcxy materials ir comparison to the elastomers.

A conslderable amount of data worth studying was accumulated. A few significant sarples are: the effectiveness" and soak-out temperatures in the ontry test (rigure 30), a summary of the abiation history (figure 51), the shape of two models after the entry test (f1gure 52), ard the roughness values measured after the shock test (figure 5: :

A brief statemert ir. the results of the tests are collected in table 13 . It

- Defined es $\dot{\mathrm{q}}_{\mathrm{KW}} \hat{i} \mathrm{~T} /(\because / \mathrm{A})$, where $\dot{\mathrm{q}}_{\mathrm{HW}}$ is the stagnation-point hot-wall heating rate, $\Delta t$ the time for the stagnation point baskiace temperature to rise to $200^{\circ} \mathrm{F}$ and $W / \mathrm{A}$ the atlator welght per unlt area. 


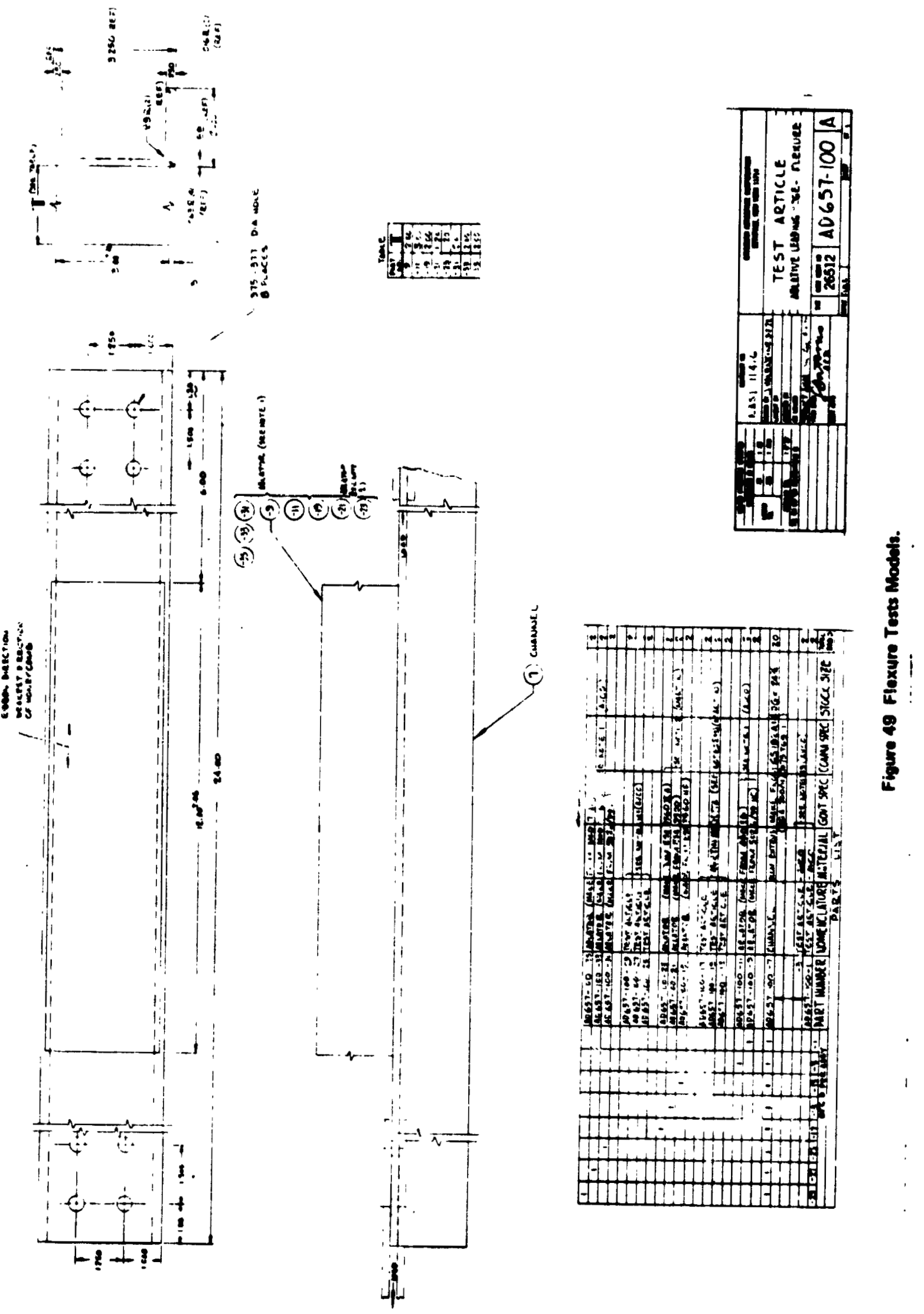




\section{COMPARISON OF INSULATION EFFICIENCIES}

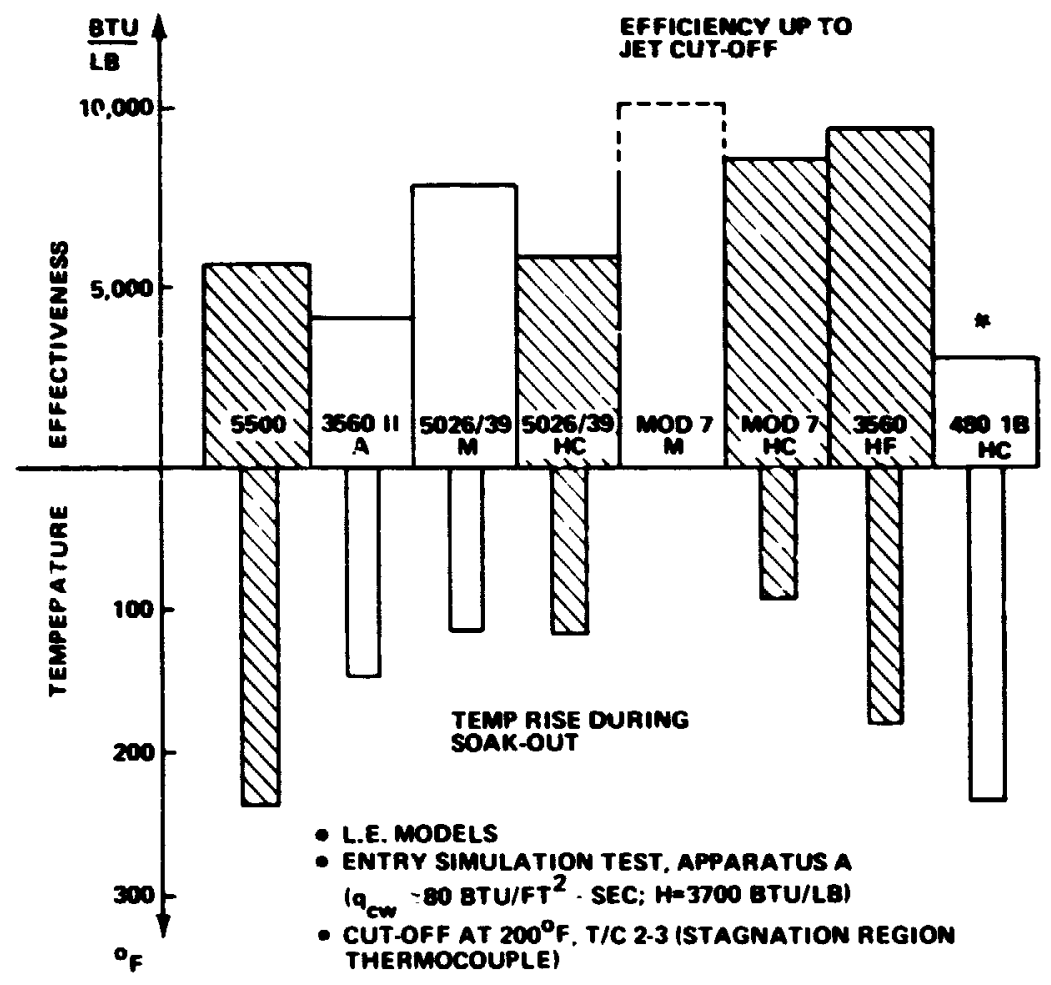

"NOT SCALED BY WEIGHT

Figure 50 Comparison of Insulation Efficiency of Candidate Ablators 
L.E. MODELS: ABLATION HISTORY AT STAGNATION POINT

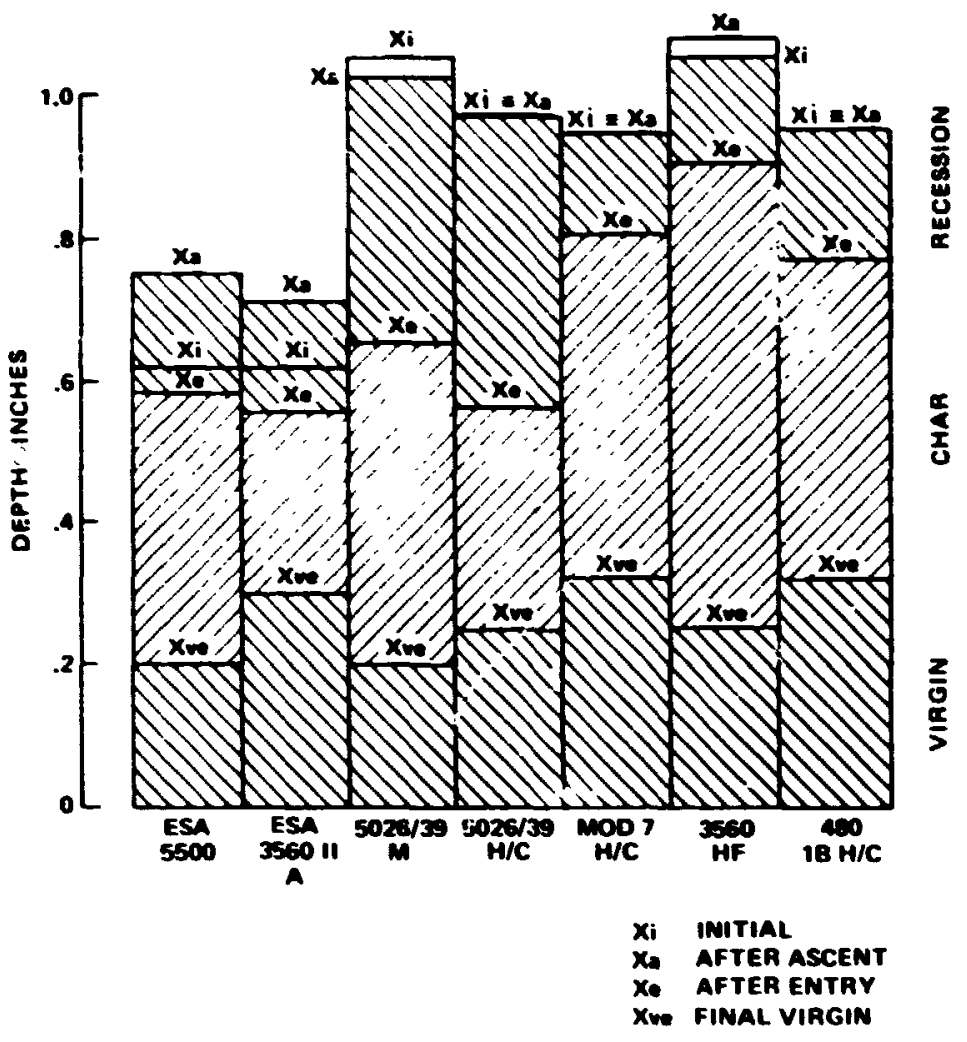

Figure 51 Comparison of Ablation Historias of Condidate Materials 
TYPICAL SHAPE CHANGE \& ROUGHNESS OF L.E. MODELS

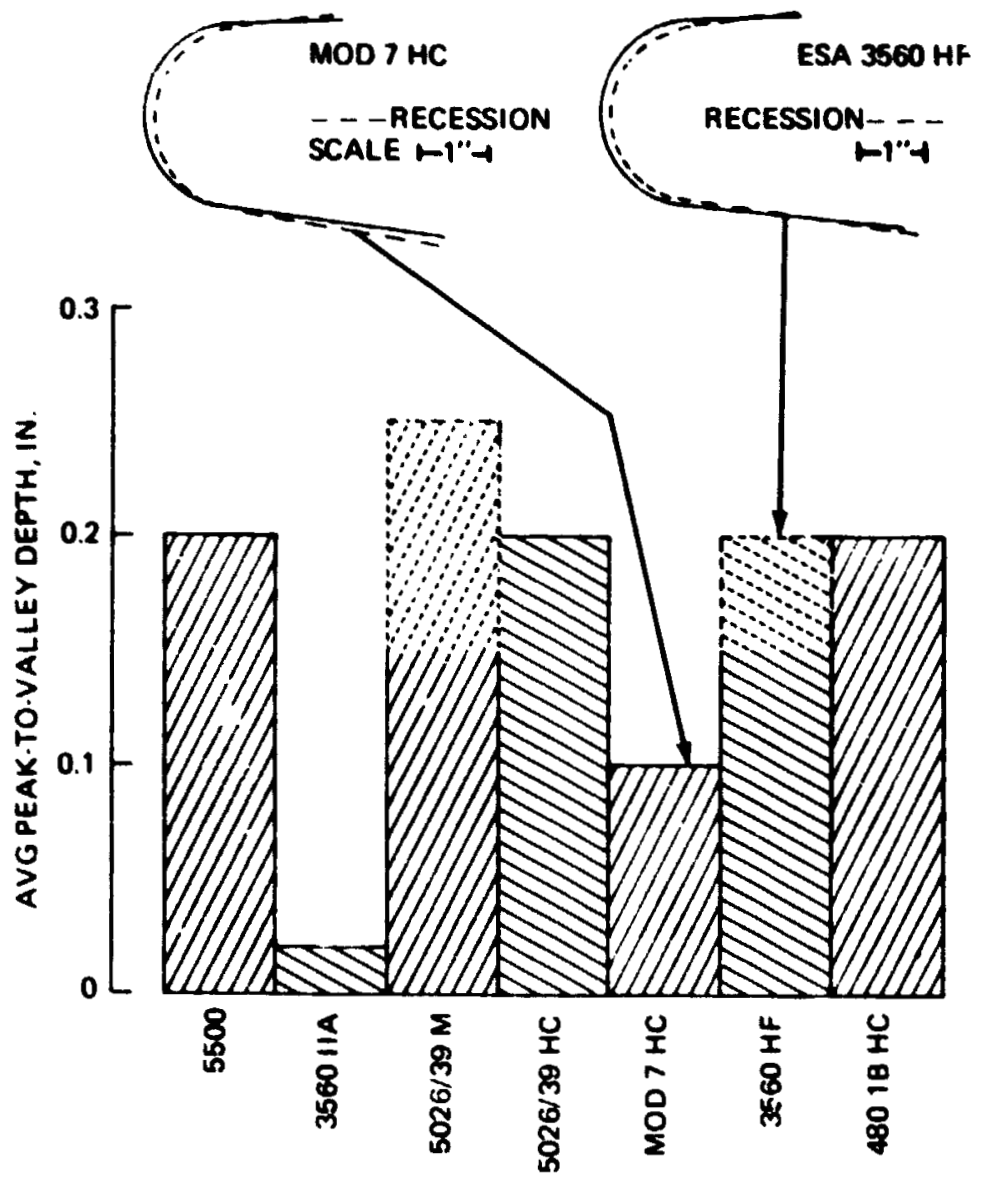

GROSS CHARACTERIZATION OF ROUGHNESS IN THE STAGNATION REGION ON L.E. MODELS AFTER ACCELERATION TEST

Figure 52 Typical Shape Change \& Roughness of L.E. Models 
is obvious that many tests went uneventful, without visible effects. One important lesson learned from the uneventful tests is that the testing sequence can be simplified to the first three steps of ascent heating, cold soak, and entry, eliminating both vibration and shock tests and flexure tests. Even though at the end of the vibration test one model, the ESA 3560 IIA, Iost the entire cap down to the char-virgin interface, clear signs of a continuous crack at the char-virgin interface were visible before the test. Horeover, the flexure tests on the charred models failed to affect the delamination cracks that had occurred during charring of the Mod $7 \mathrm{M}$ material.

More details on each of the tests are given below in Sections 5.3.3 to 5.3.12. The flll documentation on test rationale, model desigl and test data report is given in the Package.

\subsubsection{Ascent Heating of L.E. Models}

The first test to be run in the leading edge models was the ascent heating simulation in the Aveo ROVERS facility. NASA prescribed for simulation the flight environment corresponding to the Grumman 473 orbiter and a NAR trajectory, (see table 14a).

For this series of tests the ROVERS Arc made use of the square nozzle configuration "sing a two-dimensional nozzle of dimensions 4.5 by 4.5 inches. The enviroment shown in table 14b. was measured using a water-cooled copper calorimeter model of the same size and shape as the test models. Figure 53 shows the location of the various calorimeter plugs. The plugs designated $2-3,-5,-6$, -7 , and -8 are all located in the center line plane of the model. Plugs designated -1 and -4 were located two inches on either side of plug 2-3. All models were subjected to this enviroment for a total of 560 seconds. The extrapolated stagnation point heat flux rate was $9.5 \mathrm{Btu} / \mathrm{ft}^{2}-\mathrm{sec}$. 
Table 14s Aseent Environments

Flight vs ROVERS Arcjot on L.E. Models

\begin{tabular}{|c|c|c|c|}
\hline \multicolumn{4}{|c|}{ Flight vs ROVERS Arcjot on L.E. Models } \\
\hline & Dominant & $\begin{array}{l}\text { GAC } 473 \\
\text { Vehicle } 8 \\
\text { NAR Traj }\end{array}$ & $\begin{array}{l}\text { ROVERS } \\
\text { Facility }\end{array}$ \\
\hline 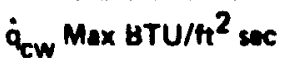 & 14 & 9.5 & 9.5 \\
\hline$P_{\text {Max }}$ ot $Q_{\text {ow }}$ atm & $5 \times 10^{-4}$ & (*) & $7.2 \times 10^{-4}$ \\
\hline$H \odot \dot{q}_{\mathrm{cw}}$ BTU/lb & 10,200 & & 11,200 \\
\hline$r \operatorname{Max} 1 b_{F} / f t^{2}$ & 1.5 & & $(\cdots)$ \\
\hline q BTU $/ \mathrm{H}^{2}$ & 6700 & 5300 & 5300 \\
\hline Time at $q_{\mathrm{cw}} \sec$ & 250 & 250 & - \\
\hline Test Time sec & - & - & 560 \\
\hline (dP/dS) at $\dot{\mathrm{a}}_{\mathrm{Cw}}$ atm/in. & $0.44 \times 10^{-4}$ & & $0.7 \times 10^{-4}$ \\
\hline
\end{tabular}

(") Not Calculated

(“) Not Estimated 
Table 14b ROVERS Arc Test Environment

\begin{tabular}{|c|c|c|c|}
\hline $\begin{array}{l}\text { Station } \\
\text { No. } \\
\end{array}$ & Calorimeter No. & $\begin{array}{l}\text { Location From } \\
\text { Stughation Point } \\
\text { Inches }\end{array}$ & $\begin{array}{l}\text { Cold Wall } \\
\text { Hoat Flux } \\
\text { BTU/tt } 2 \text {-sec }\end{array}$ \\
\hline S5 & 1 & -08722 & 6.13 \\
\hline S5 & 23 & -0.8722 & 8.39 \\
\hline S5 & 4 & -0.8722 & 7.03 \\
\hline S4 & 5 & +1.091 & 7.53 \\
\hline S6 & 6 & -2.835 & 1.53 \\
\hline S7 & 7 & +5.207 & 0.54 \\
\hline \multirow[t]{7}{*}{ S9 } & 8 & +6.707 & 0.29 \\
\hline & Gas Enthalpy & - 11200 BTU/16 & \\
\hline & Plenum Pressure & -23.0 Torr & \\
\hline & Pressure - Station 5 & -0.30 Torr & \\
\hline & Pressure - Stagnation Point & . 0.55 Toir & \\
\hline & Calorimeter Angle of Attack & - O degrees & \\
\hline & Model Angle of Attack & -5 degrees & \\
\hline
\end{tabular}



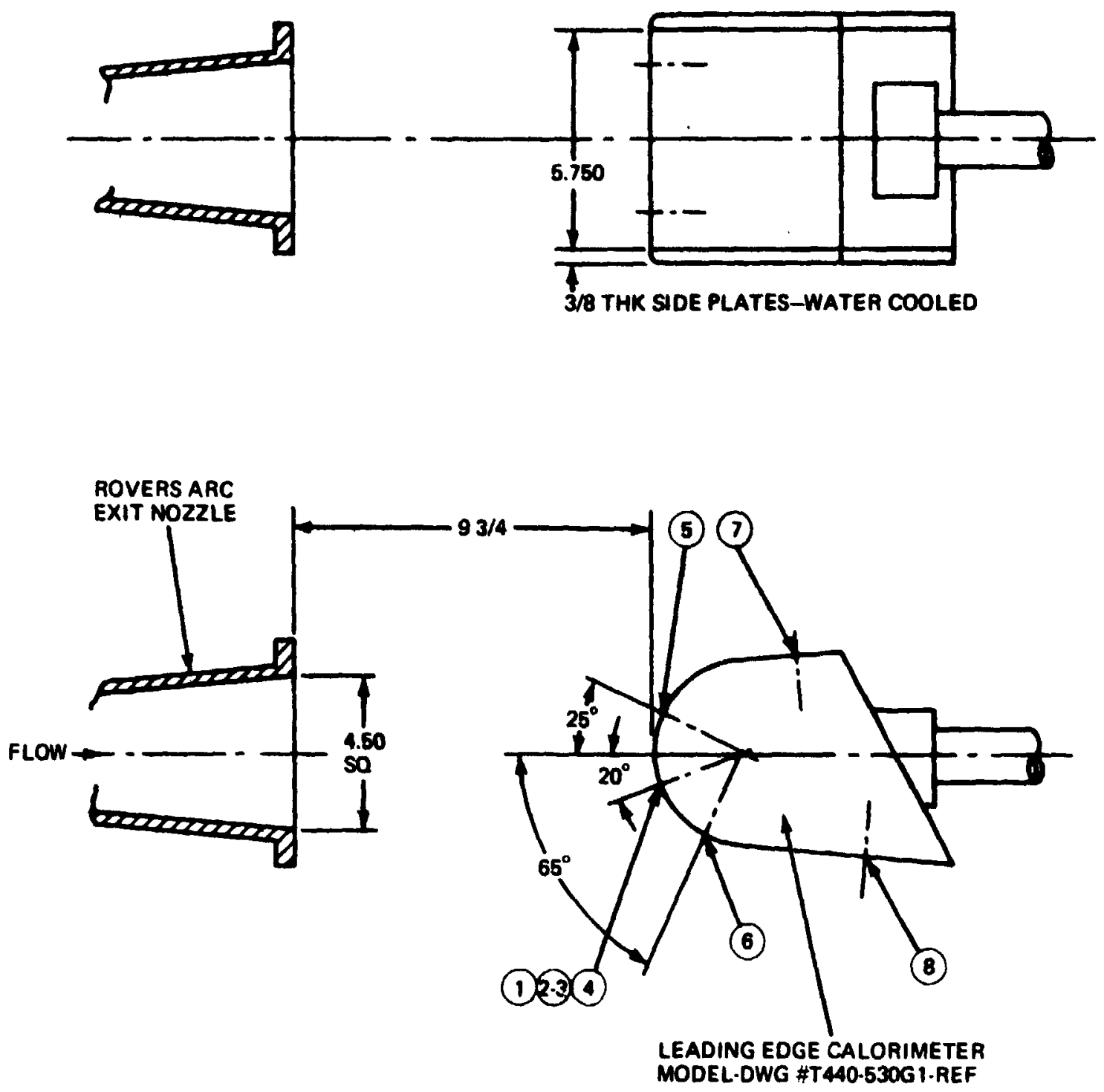

Figure 53 Ladim Edu Colorimater Configuration - Rovers ARC Facility 
For each material tested the following data were noted:

a) Physical ablation characteristics.

b) Surface temperature response (stagnation point of model).

c) Whar layer inte:rity.

d) Shape change (ten stations in each of five planes).

e) Backface temperature response (itations 1,2-3, 4, and 5).

To obtain the above data, various instmunents and flxtures were used. Table is presents a summary of the duta.* Table lóg presents appropriate comments on the post-test appearance of each of the materials. Pictures of the materials after the test are given in figure 54.

In general, each sample discolored in the stagnation region where the heating was greatest. During each test, no otviuis adverse ablative characteristic was noted by test observers. In all cases, sample decamposition products were generated which deposited on the cooler downstream surfaces. Surface temperature measurements were continually recorded and showed no discontinuities or abnormal behavior. Four rear surface temperatures (chramel alumel thermocouple peened into the 0.060 inch thick aluminum rear structure) were recorded (stations 1, 2-3, 4, and 5). Table 15 reports only the 2-3 station temperature rise for the 560 second time period. The other remaining thermocouples in the model showed a similar tempersture rise.

\footnotetext{
- It is noted, that because of a machining error in the sample holder plate all test nodels were tested at an angle of attack of 5 degrees rather than zero degrees as the calorimeter model.
} 


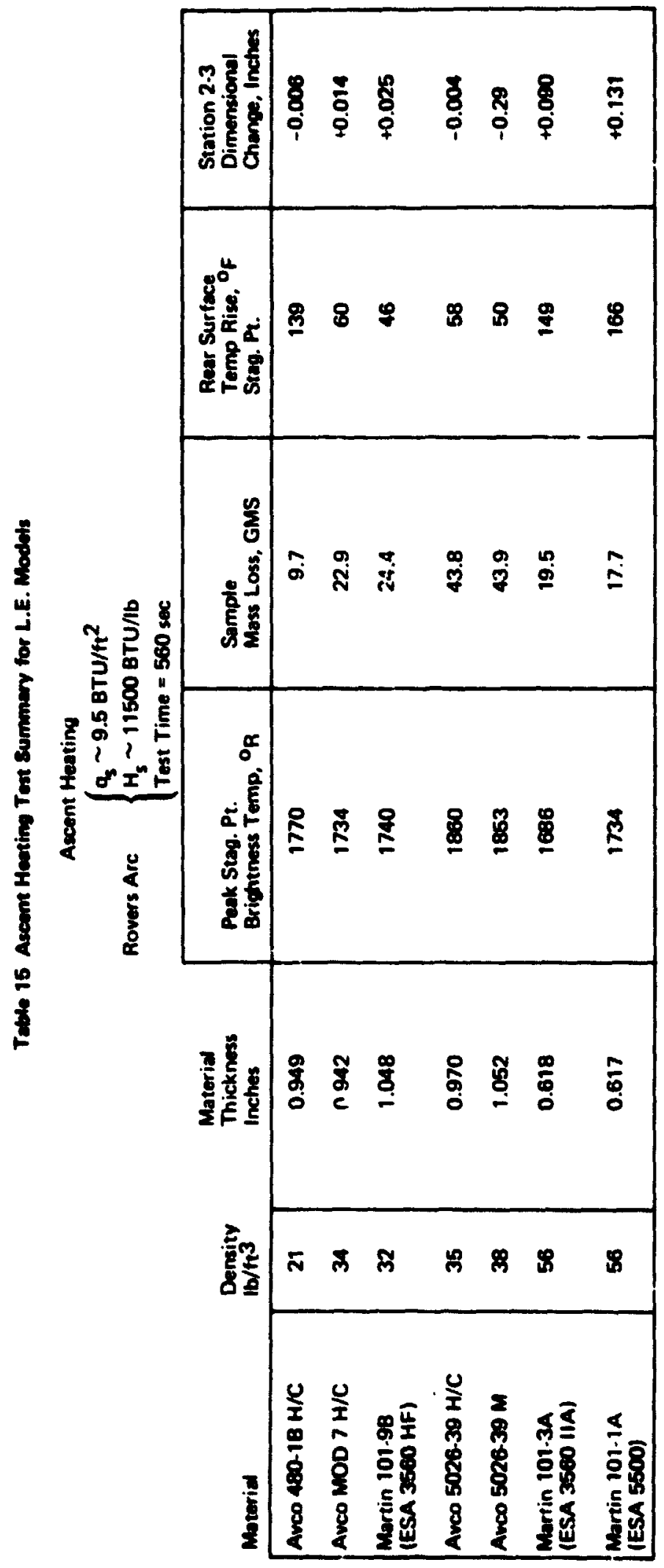


Table 16n Comments on Gemeral Appesance of the L.E. Models After Ascent Heating

Model No.

Comments

Avco $480.18 \mathrm{H} / \mathrm{C}$

Avco MOD 7 H/C

Martin $|101.98|$

ESA $3560 \mathrm{HF}$

Avco 5026.39 H/C

Avco 5026.39 Molded

Mortin [101-3A]

ESA 356011 A

Martin $[101.1 \mathrm{~A}]$

ESA 5500

Darkened stagnation legion becoming lighter in color as one moves down stream. Chat appears wolid with a few small areas wheie H/C semil ated slightly from cell materid.

Whitish costing on stiqnation region not too stable as il can be thown oft

$\mathrm{Gidy}$ - whilish deposit on stagnation region. Some sepaiation of $\mathrm{H}^{\prime} \mathrm{C}$ ficm ciell material. Chat appears stable. Some flaking occurred at ter the test and during handling.

Dirk charied heating pattern in stagnation region of model. Cell material ill stagnation region receded below the H/C material $(0.015 \%)$. Suifars had d roughened rexture. H/C mater al separ ated from cell material in stagnation region

Dark charred heating pattern in stagnation region. Nuinerous ciacks present in stagnation region running parallel with flow. Crack dimensions were about $1 / 16 \times 1 / 8^{\prime \prime}$ wide by 2 inches long. Crack phenomenon decreased as one progressed downstream of model.

Crusty surface laver with bubbles generated at the $\mathbf{4 5}$ degree stations on tonth the leeward and windward sides of the model. It appeared that delaminated sections were present as evidenced by surface discontinuities at fuur locatinns. Char zone appear solid to touch.

Cell growth evidenced over entire stugnation region - decreased downsti eam of stagnation regicn. Char laver cracked in a few cells. 

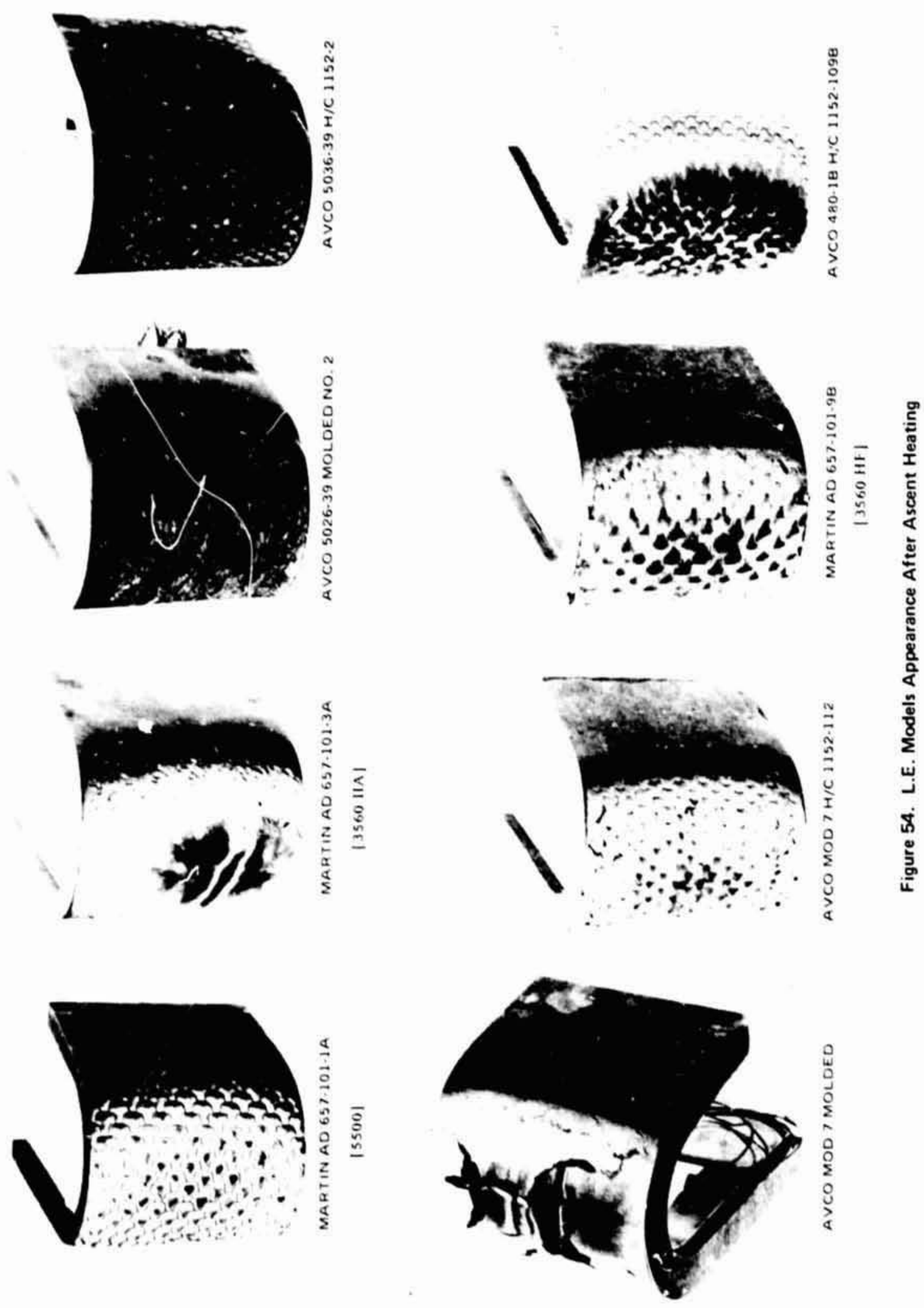


\subsubsection{Cold Soak of the I. F. Models}

The test on the leading pdge models called fu: a cold sook environment of two hours at a pressuze of $10^{-7}$ atmospheres and a temperature of $-200^{\circ} \mathrm{F}$. During the test it was found that the liquid nitrogen used to ccol down the double walled $4^{\prime} \times 8^{\prime}$ thermal-vacuum tank wall was leaking 1nto the tank. After the target temperature was reached the liquid nitrogen input was stopked and the pressure dropped to its design value. Figure 55a shows the pressure! temperature values of the test during which the target conditions were met although not faite for the full two hours intended. Figure 55b shows the models in the chamber. Note that the modeis' ends are not tied, as the purpose of the tests was to investigate only the 1 cal compatibility of ablator and substructure.

Observations during the after tests of the models showed there were no apparent changes in either the ablator surface or to the ablator/substructure bond. Weights remained essentially unchanged. Appendix 3 gives the pertinent dati on the test.

Although the cold soak duration during testing was not a full two hours it was decided not to run another cold soak test because 1) tha conditions obtained were close to the target ones, and 2) prior tests on another set of L.E. models (Data Package) were cold soaked for seven days with no apparent change.

\subsubsection{Entry Heating of the L.E. Models}

The most important test to be conducted during the sequential series is the entry heaine tests since it can determine l) the effects of ascent heating on reantry performance 2) the thermal efficiency of the material and 3) the performance characteristics (including char stability) of the various materials under the most severe thermal environment. It is important to note that 


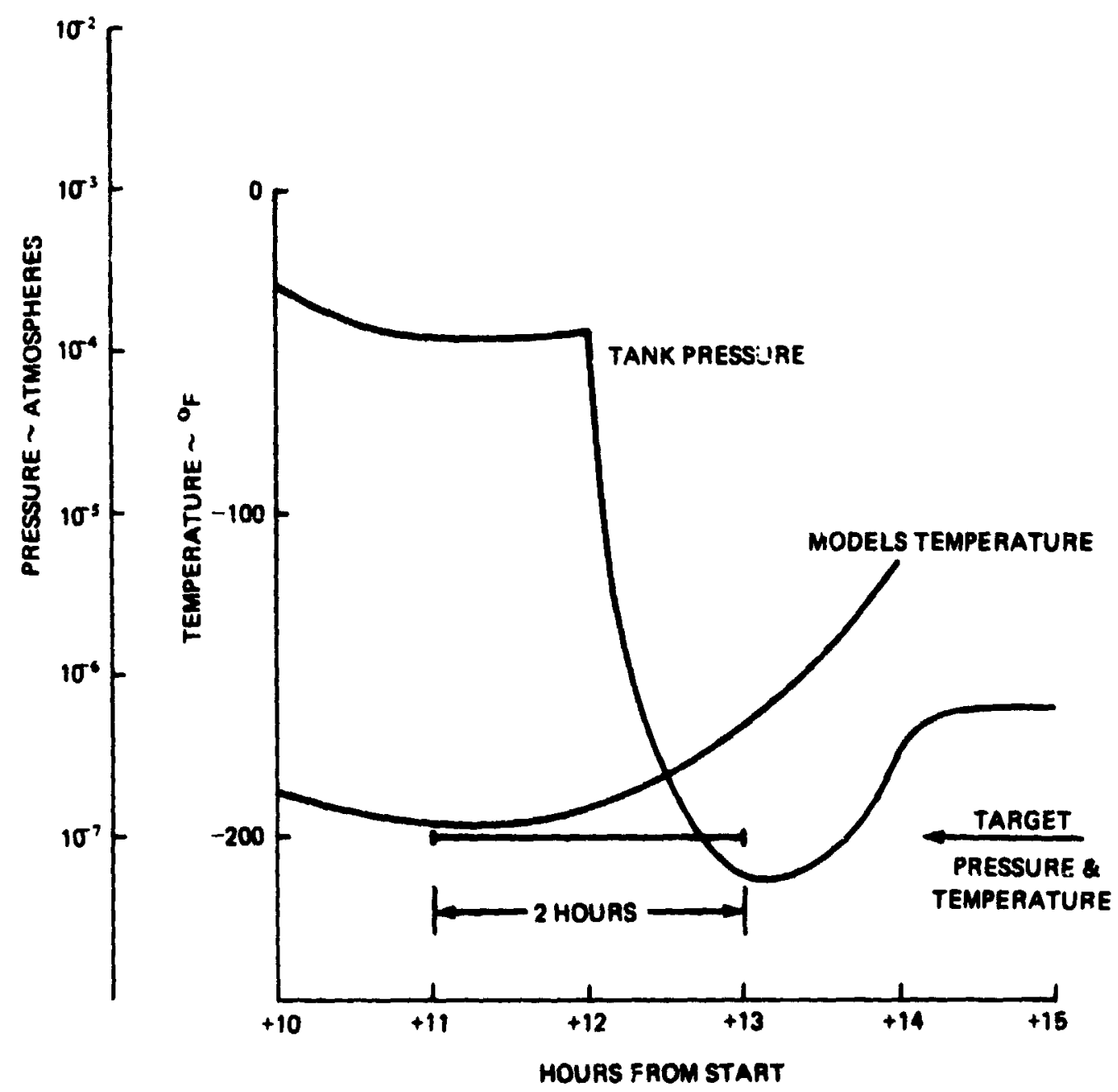

Figure ste Enwironmont Mainteined During ColW soak Takt 


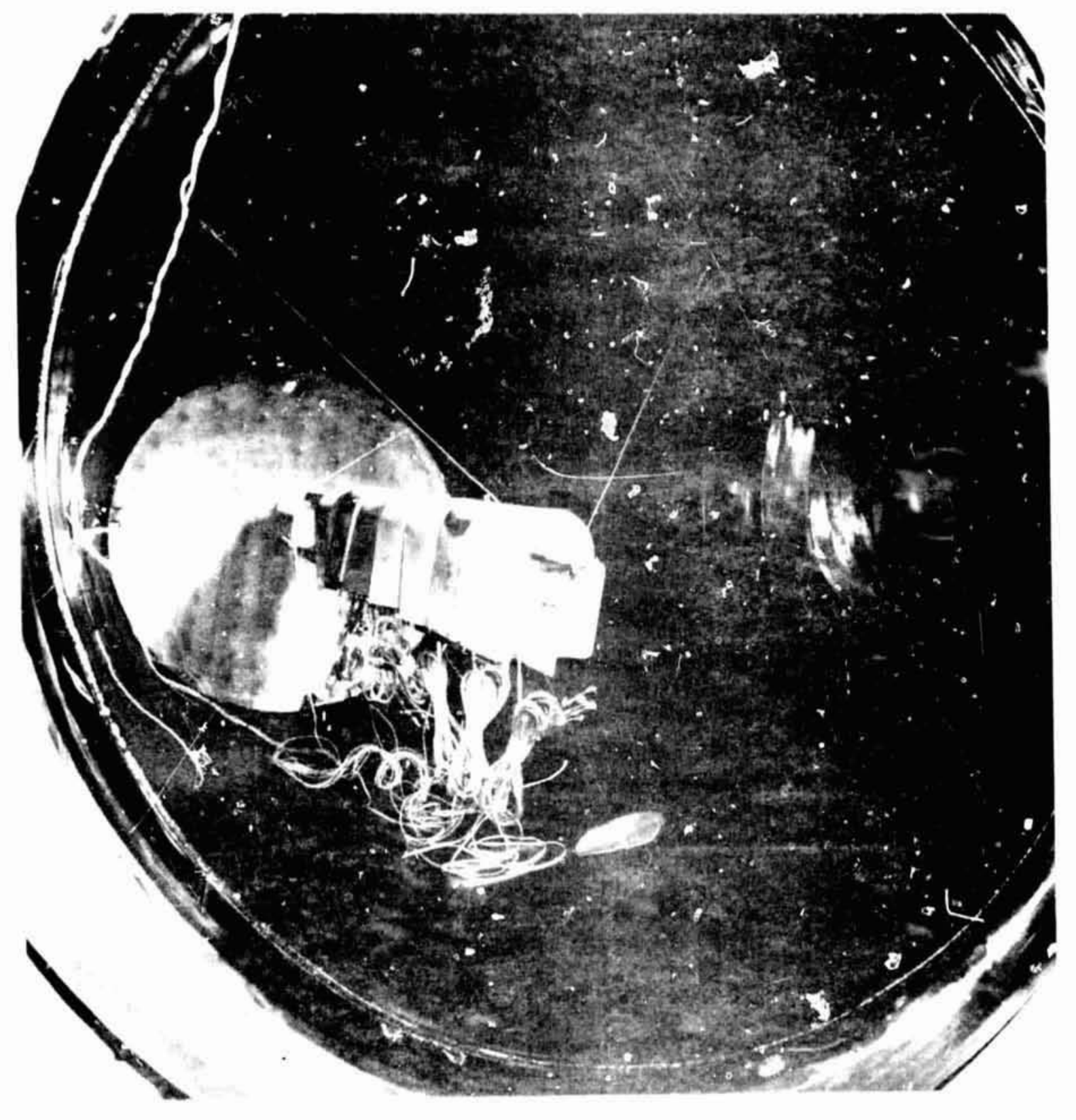

Figure 55b The 1.E. Models in the Cotd Soak Chamber 
previously no signficant data has been presented relative to ablator material performance in an entry environment on samples previously subjected to ascent and cold soak environments.

The reentry tests were conducted on the pre-conditioned leading edge specimen in the IASA/LRC Apparatus "A" Facility. The conditions selected for the test are shown in table $16 \mathrm{~b}$ together with the comparative flight conditions. As can be seen the simulation is quite good except for the lower enthalpy and integrated heating experienced. Prior to testing the candidate materials, calibration runs were made using the leading edge calorimeter.

Table 17 summarizes the results of the reentry heating tests. The recession values represent an average near the stagnation point. Representstive recession profiles are shown in figure 56, a to d for the ESA $3560 \mathrm{HF}$ and Mod $7 \mathrm{Hc}$; temperature histories at a typical location are shown in figure 57 . Detailed weight, recession and thermocouple data are shown in the Data Package. Photographs or the specimen before and after test are provided in figure 58 .

\subsubsection{Vibration of L.E. Models}

The vibration tests were conducted in the Thermo-acoustic Fatigue facility at NASA LRC. Figure 59 shows the acoustic levels attained in the facility at locations upstream, in front of and downstream the models respectively. Included in these plots are the target or flight acoustic levels which were exceeded in the test. During the test the surfaces c the seven ablative leading edge models were brought to $500^{\circ} \mathrm{F}$ via radiant lamps to complete the simulation of the flight conditions occurring in the latter part of entry. Figure 60 
Table 18b Entry Flight us Simulation Emironment

\begin{tabular}{|c|c|c|c|}
\hline & \multicolumn{2}{|c|}{$\begin{array}{c}\text { Flight } \\
\text { (Dominant) }\end{array}$} & Test \\
\hline & GAC Veh. & $\begin{array}{l}\text { NAR CID } \\
\text { Orbiter }\end{array}$ & \\
\hline$\dot{\mathrm{q}} \sim \mathrm{BTU} / \mathrm{ft}^{2} \mathrm{sec}$ & 70 & 60 & $\begin{array}{l}80 \text { (Coldwall) } \\
60 \text { (Hotwall) }\end{array}$ \\
\hline$P_{\text {Max }} \sim$ ATM & $7 \times 10^{-2}$ & i & $7 \times 10^{-2}$ \\
\hline $\mathrm{H} \sim \mathrm{BTU} / \mathrm{lb}$ & 10.750 & & 3700 \\
\hline$a \sim B T U / h^{2}$ & 64.210 & & $5400 \rightarrow 23.000$ \\
\hline Time $\dot{\theta} \dot{q} \sim \sec$ & 800 & & $68 \rightarrow 309$ \\
\hline$A P / \infty \sim A T M /$ in & $2.8 \times 10^{-2}$ & & $2.8 \times 10^{-2}$ \\
\hline
\end{tabular}

Unavailable 


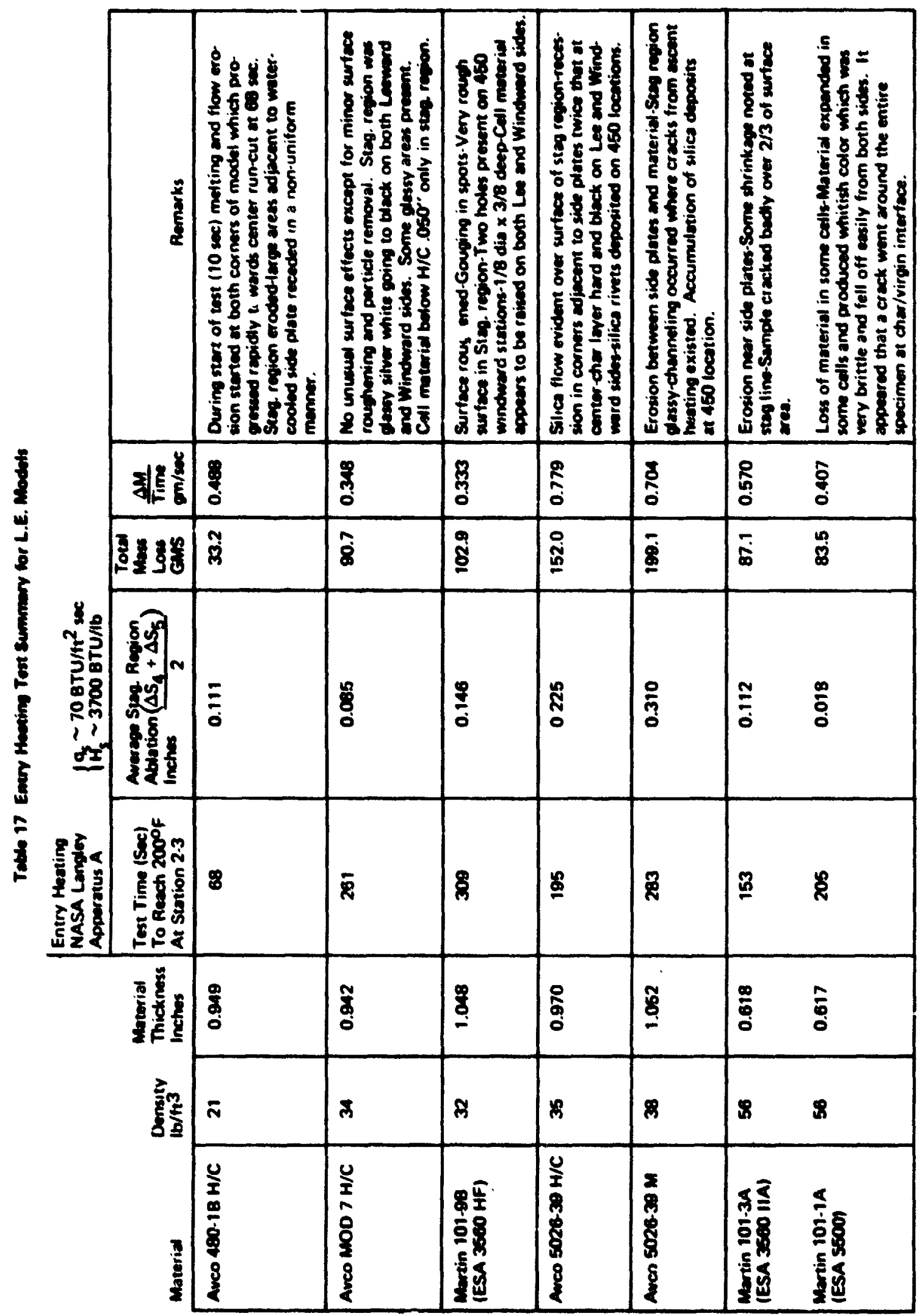




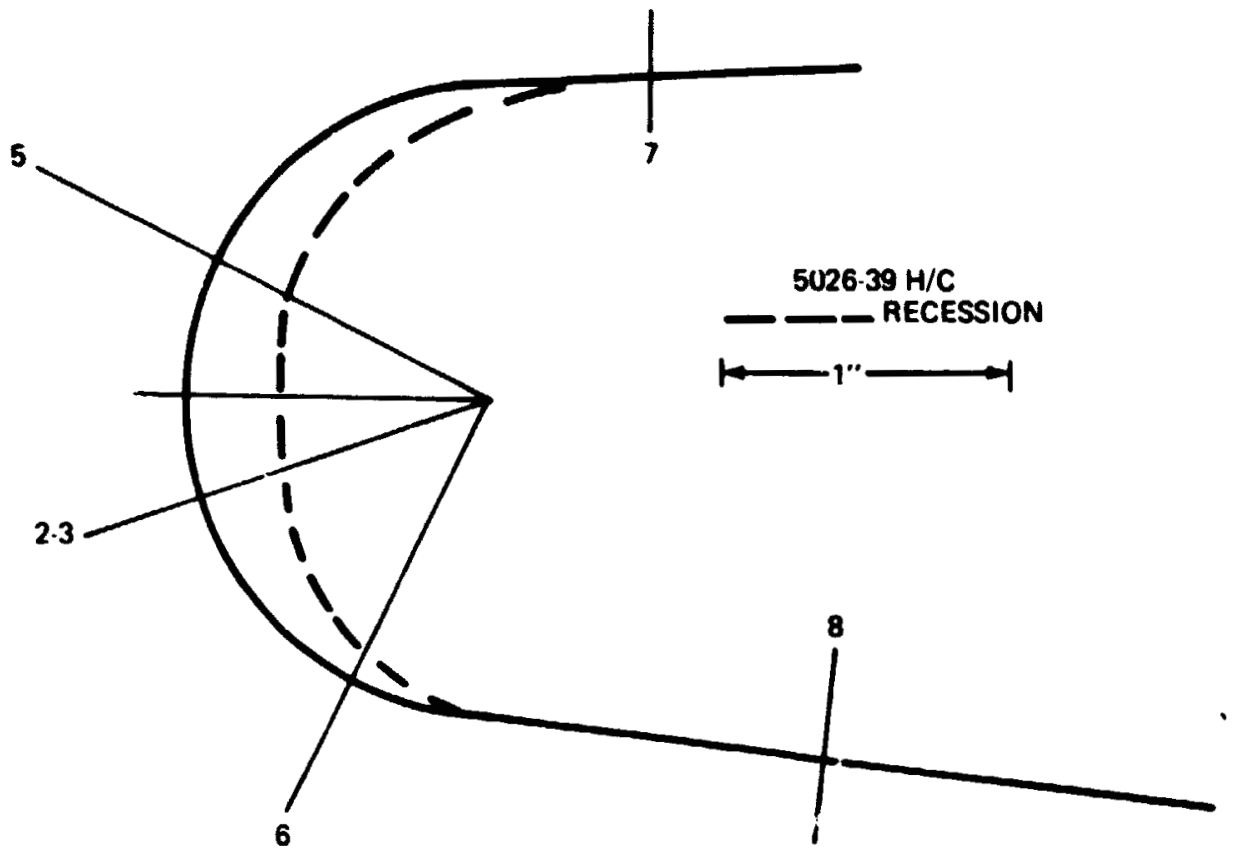

(a)

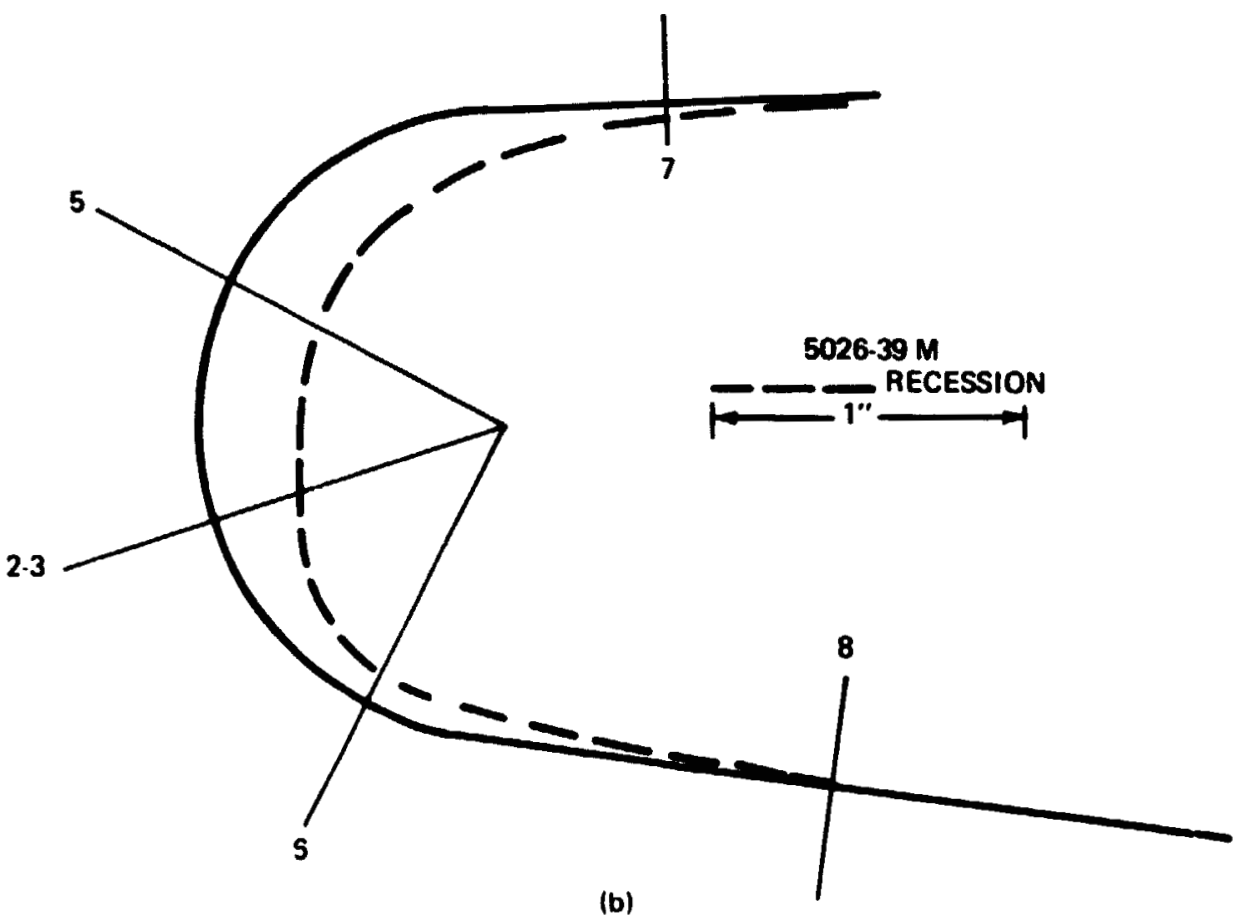

Fiqure 56 Shape Change of Leeding Edge Models After Entry Heating 


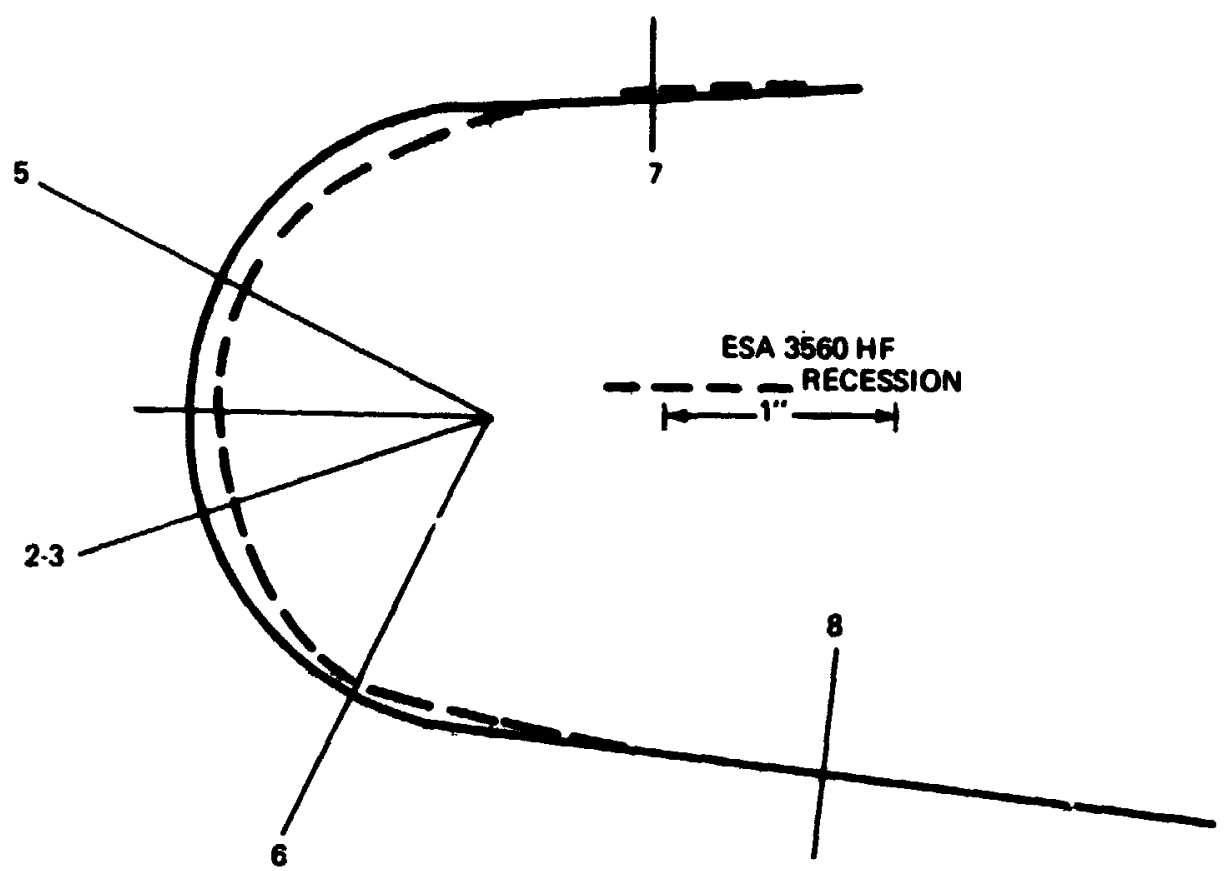

(c)

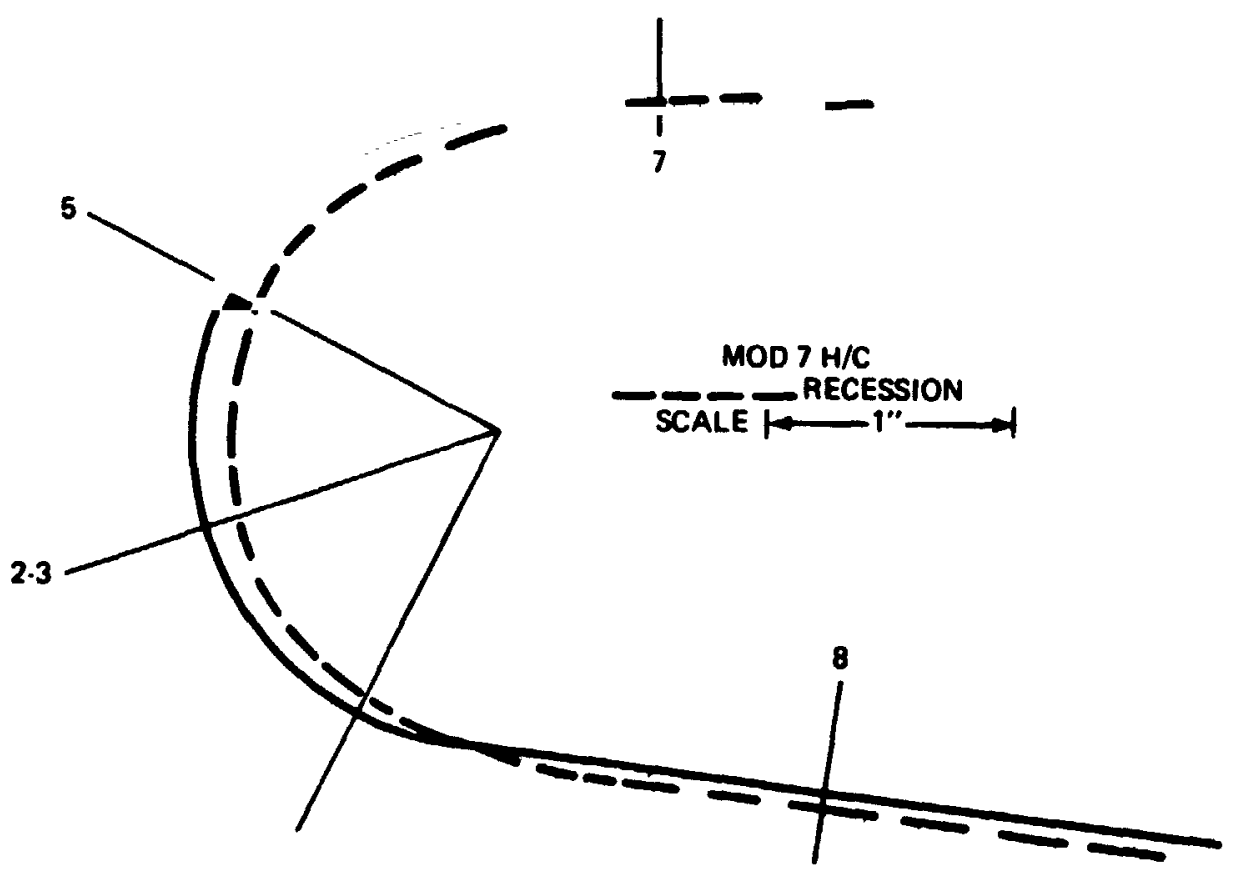

(d) 


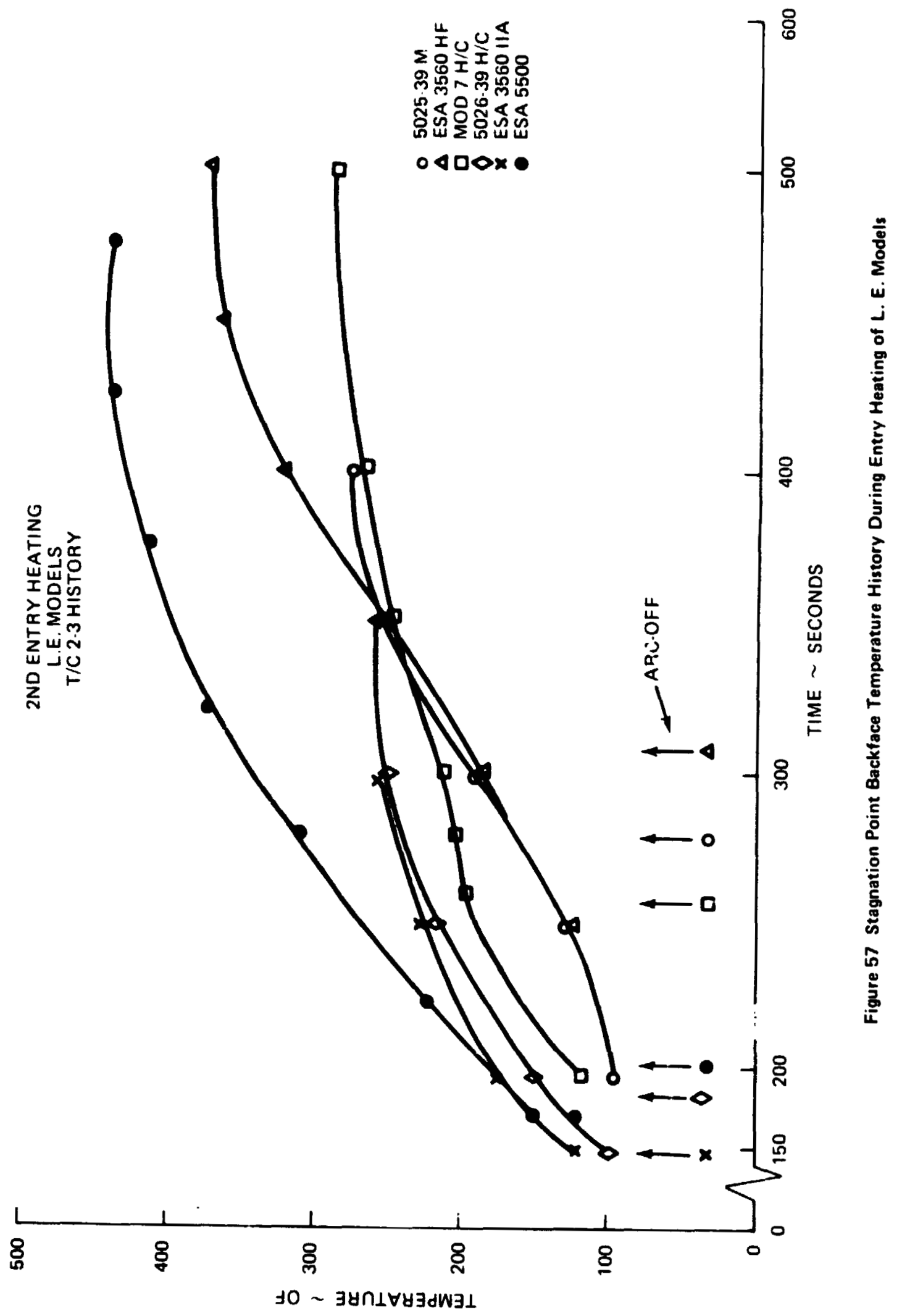



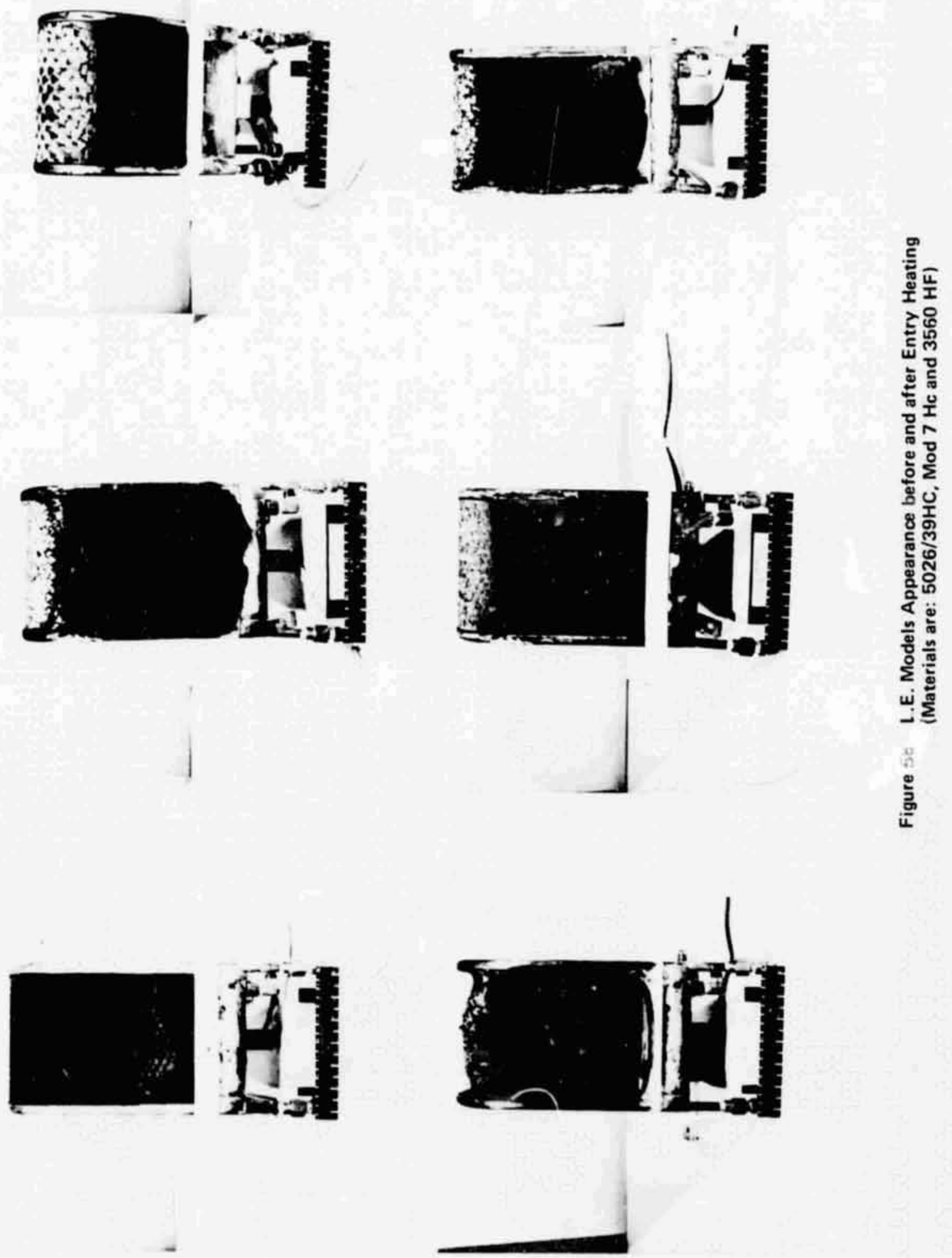


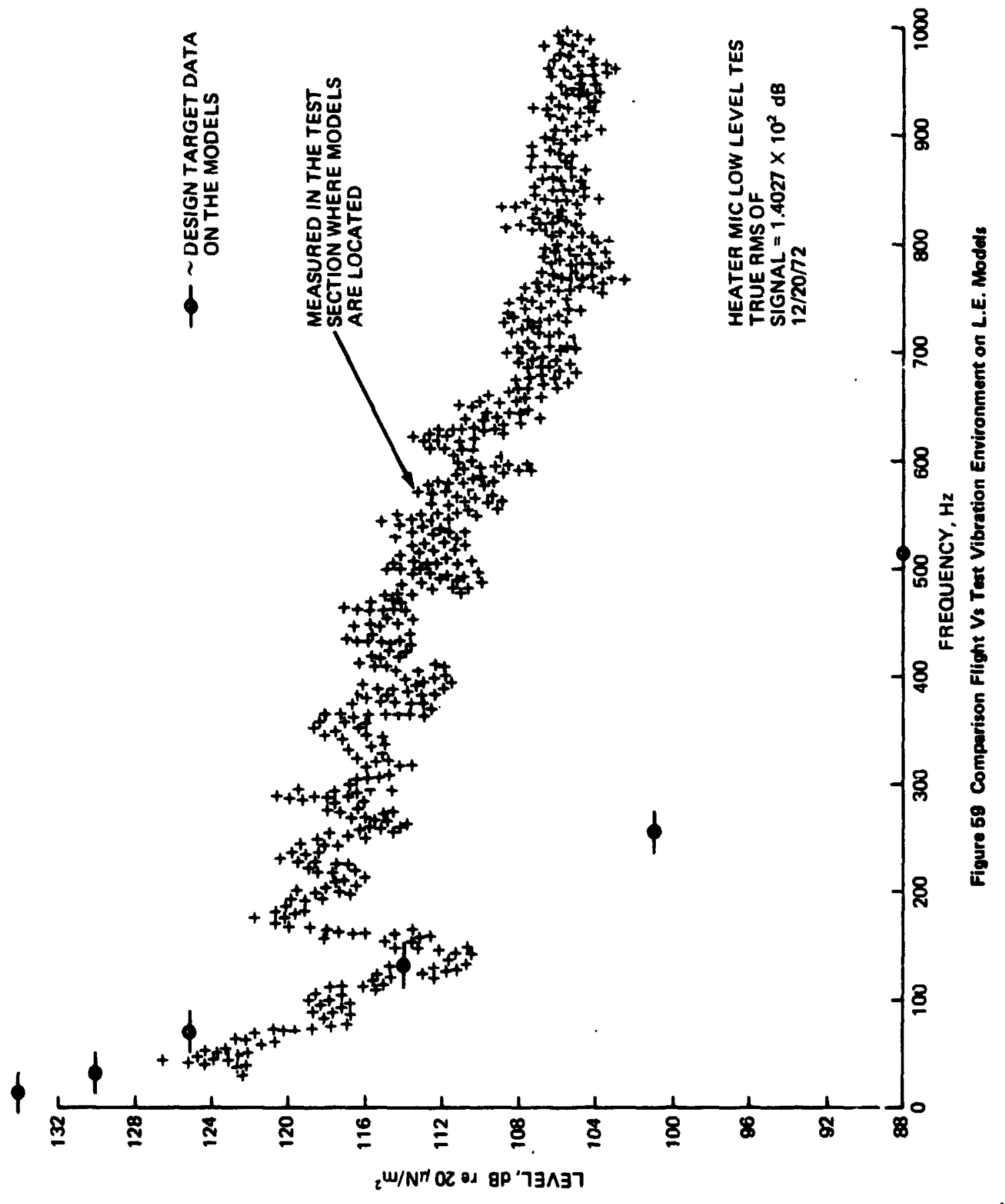


and 61 give an ides of tim installation of the wodels in the racility.

An examination of the models immediately after testing showed that none appeared affected by the themal-acoustic test. Later upon removal trom the fncllity, one model, the ESA 3500 IIA material showed that separation had develored at the char-virgin interface: the entire stagnation region cap came loose. The loosened cap was about .25 inches thick and covered approximately $\pm 30^{\circ}$ of the stagnation area.

\subsubsection{Acceleration Tests of L.E. Vodels}

After the thermal-acoustic tests the seven L.E. models were slibjected to acceleration shock tests at Gruman simulating the landing conditions for the orbiter wing.

The test set up is shown schematically in figure 62. Each specimen was subjected to 2 seconds of $17 \mathrm{~Hz}$ sinusoidal oscillation $\pm 1 \mathrm{l} g$ 's in amplitude twice in each of three axis. The order of the tests in each axis was numbered in the following:

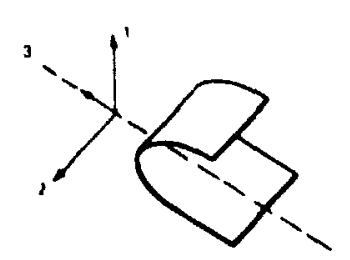

The installation of the models is shown in figures 63 and 64 .

Cther than a few small particles of charred ablator flying off during the tests, the L.E. models were unaffected in appearance or in weight.

\subsubsection{Cutting of L.E. Models}

After the L.E. models were tested under simuiated orbiter shuttle flight conditions (ascent - cold sonk - entry - thermal vibration-shock), the models were cut along the centerline normal to the L.E. to determine the depth of char and virgin material remalnine. The models were cut through both ablator 


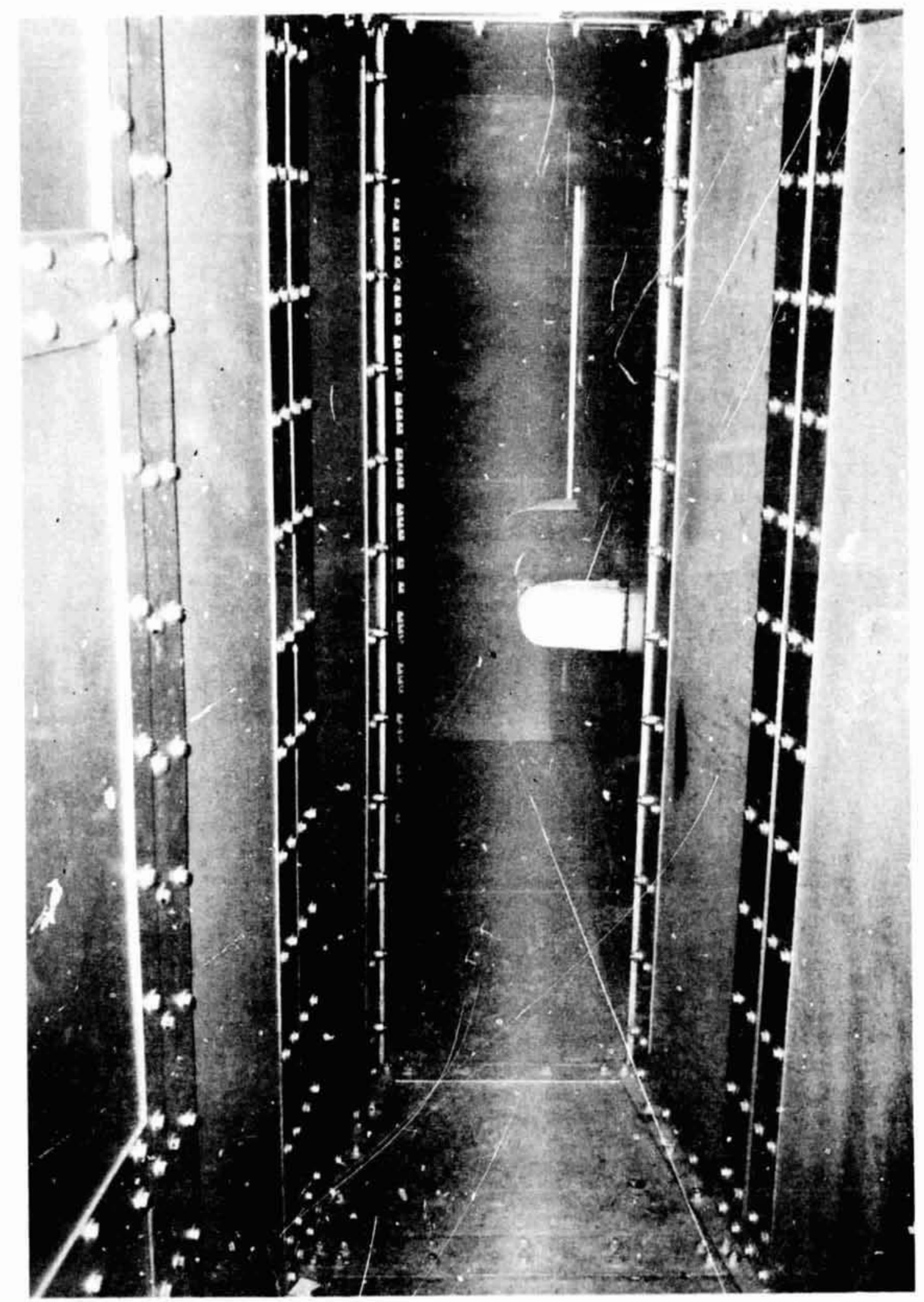

Figure 60 Vibration Test on the L.E. Models - the Models installed in the Thermo - acoustic Fatigue Facility 


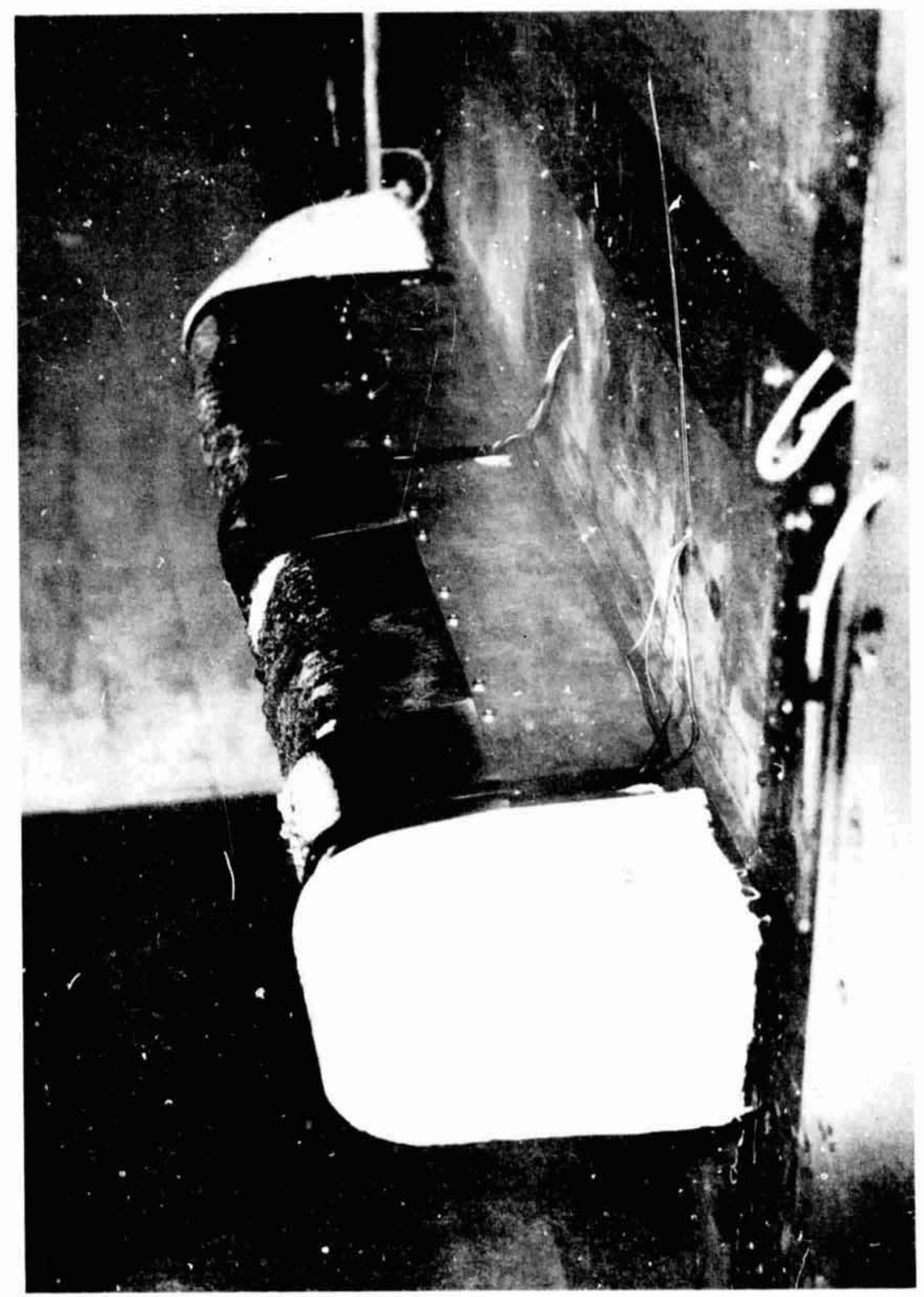

Fiqure 61 Vibration Test on the L.E. Models - Detail of the Models Installation 


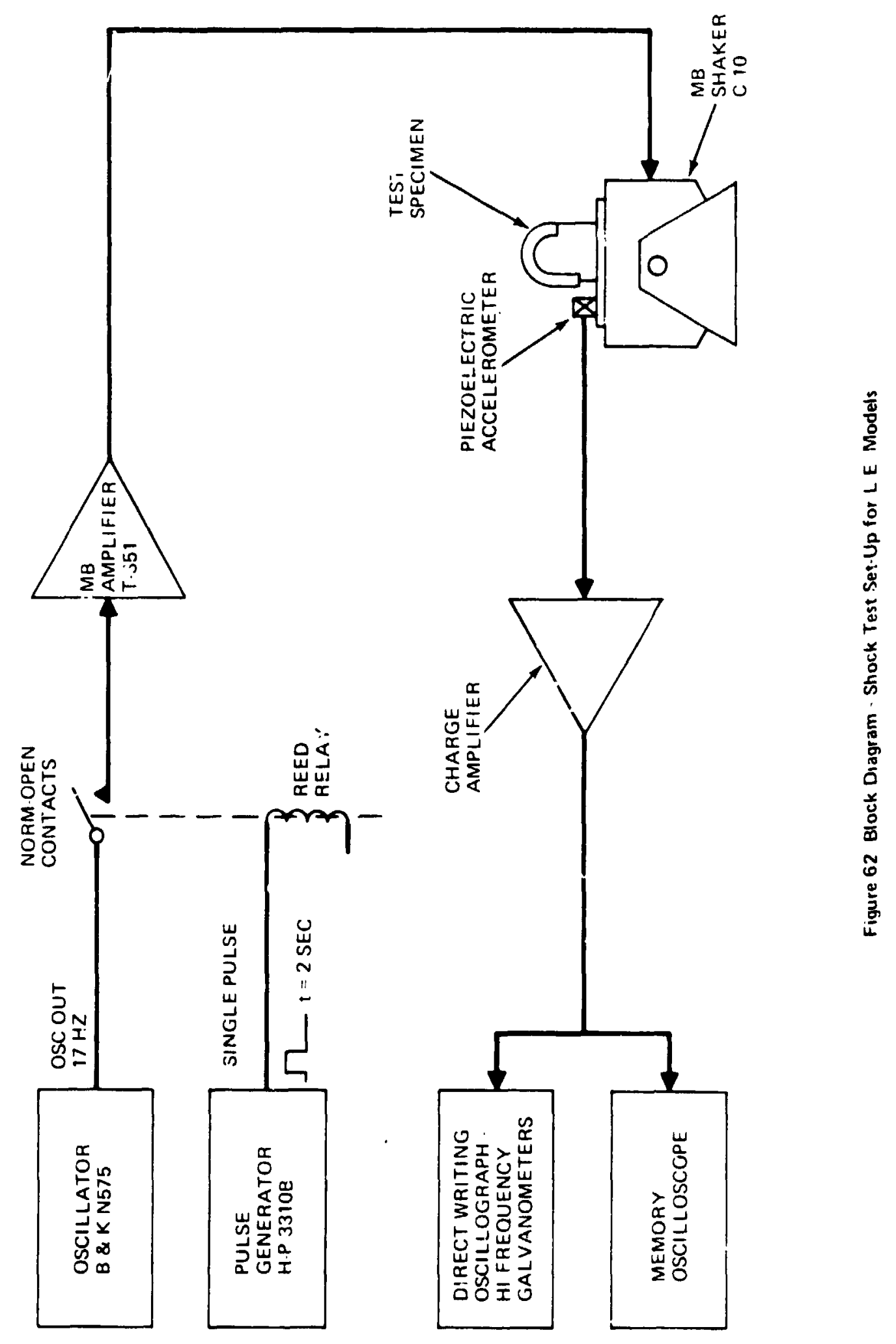




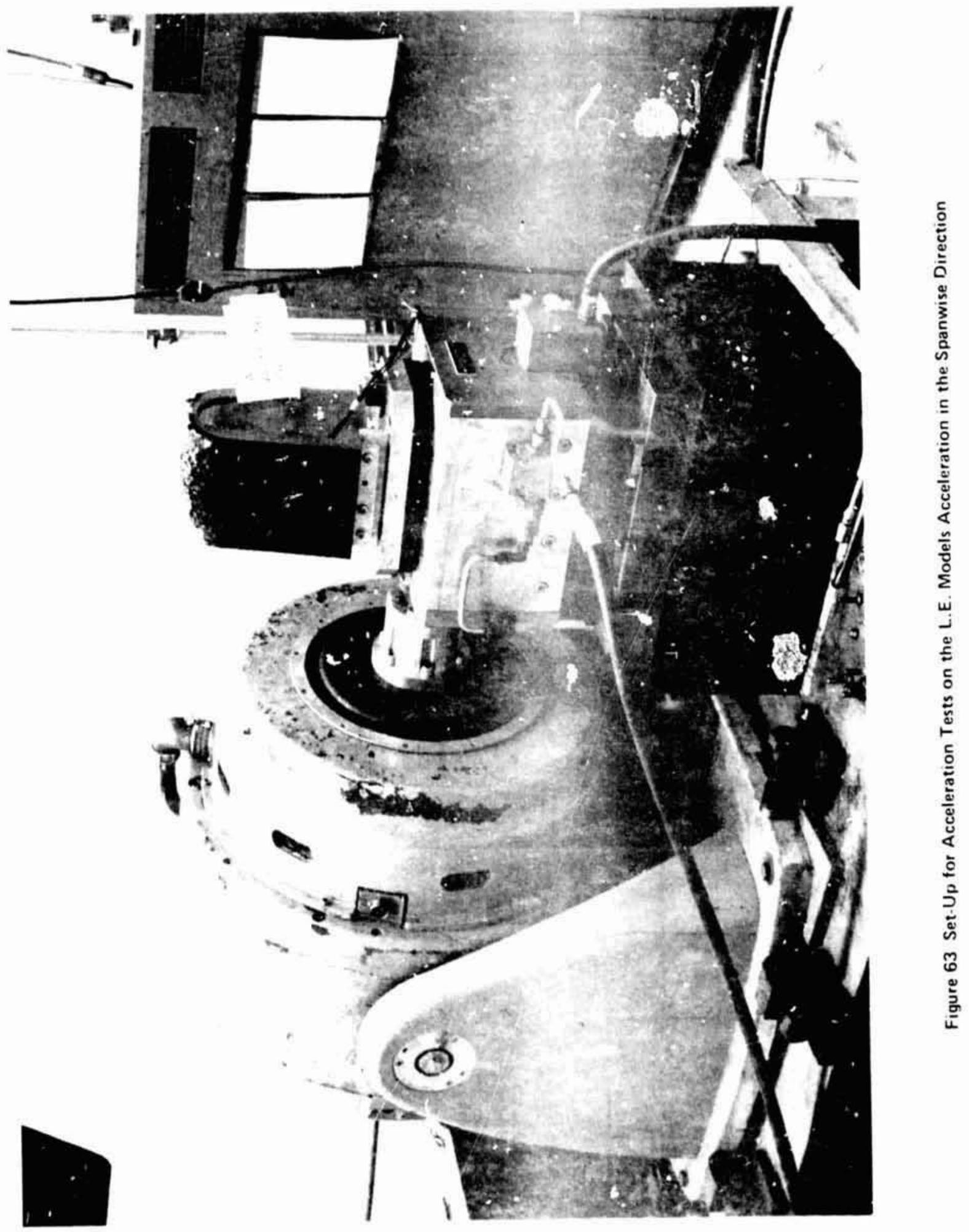




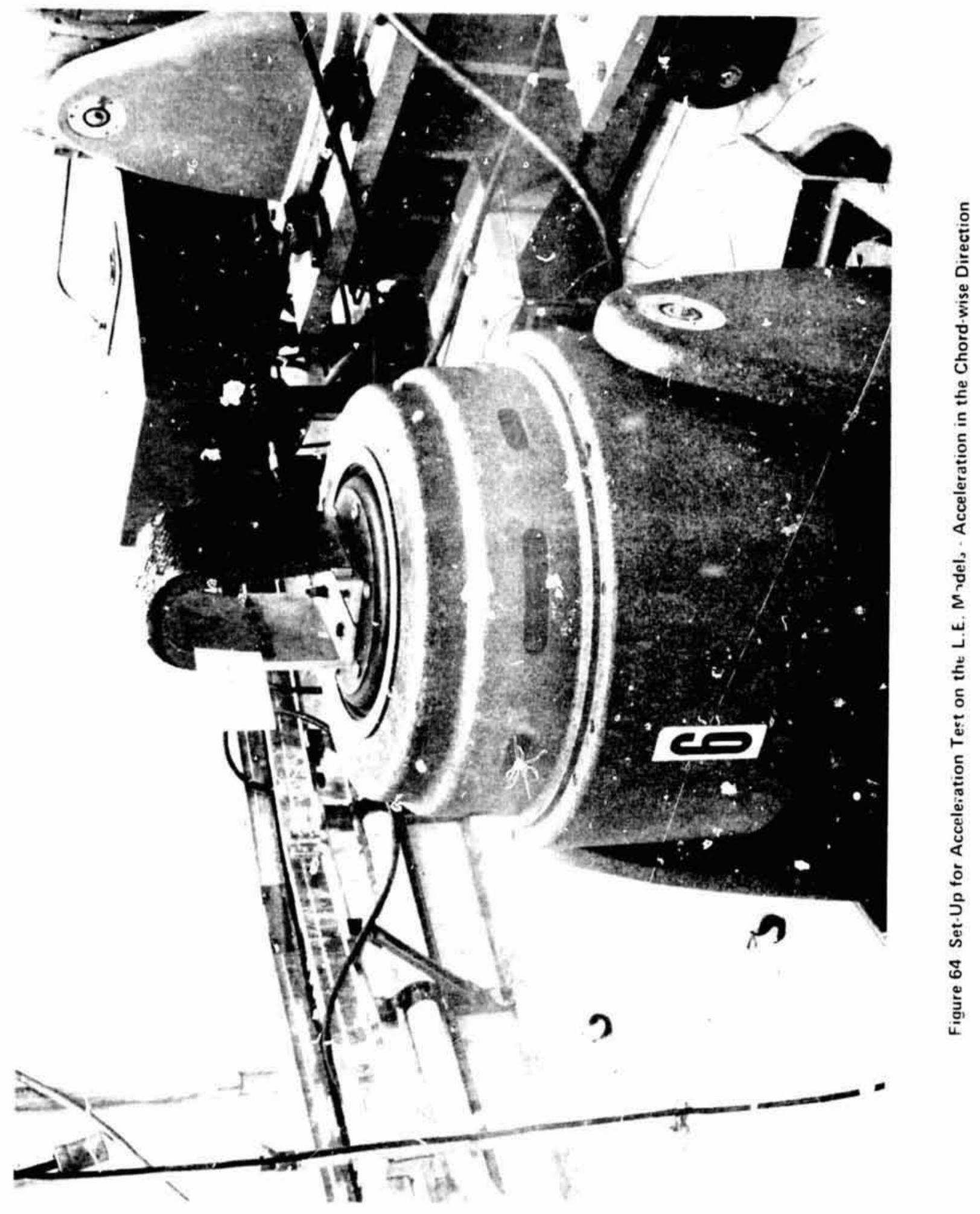


and aluminum substructure with a diemond edged abrasive saw. Some models were repeatedly cut to examire the spanwlse appearance of the char, of the He cclls, etc.

Figure 51 gives a bar-graph history of the changes in depth of each materiel after ascent and en'iry and the final 'cut' of char and virgin material remaining.

Table 18 gives some observations on the fabrication, char layer, the charvirgin interface and the bond along the centerline cut of each L.E. model.

\subsubsection{Flexure of Virgin Strips}

The purpose or these tests was to examine the ablators behavior under the tersile streins induced by the defornations of tre substructures. The substructure strains in flight had to be estimated at this stage as the substructure design was not yet available.

Figure 65 gives a comparison between the flight bondline tensile strairs and those induced in the models. The model was somewhat umasual in that a strip of abl +or was bonded on a channel bean which was pulled off the neutral plane so as to induce bending maments and strains. Figure 66 gives an idea of the installation of the models in the Olsen Universal Testing Machine. A bare channel was also tested for reference.

The tests showed no visible effects on any of the ablators up to bondline strains (a) ong the strip direction) of 0.003 . The models were not taken to failure.

\subsubsection{Charring of Strips}

In order to evaluate the strength of the char typical of thet expected at low altitudes before landing $\because$ was first necessary w. subject a set of rlexural $b$ ams to a reentry heat $i \cdot z=7$ vironment. It was determined that satisfactory 
Table 18 Observetions of Cut L.E. Sections

\begin{tabular}{|c|c|c|c|c|}
\hline Material & Bond & Fabrication & Char & Interface \\
\hline $\begin{array}{l}\text { Avco } \\
48018 \mathrm{H} / \mathrm{C}\end{array}$ & Good & $\begin{array}{l}\text { Voids Many. } \\
\text { Mostly at } \\
\text { Pondline }\end{array}$ & $\begin{array}{l}\text { - Stable Randem Cracks } \\
\text { - Some H/C Cell Walls Gone }\end{array}$ & $\begin{array}{l}\text { - Wavy (Non Homogeneous) Contour } \\
\text { - Stable } \sim \text { Whitish }\end{array}$ \\
\hline $\begin{array}{l}\text { Avco } \\
\text { MOD } 7 \mathrm{H} / \mathrm{C}\end{array}$ & Good & $\begin{array}{l}\text { Voids } \sim \text { At } \\
\text { Boindline At } \\
\text { C/L and } \% \text { cuts }\end{array}$ & $\begin{array}{l}\text {-Stable } \\
\text { - A few Cracks }\end{array}$ & $\begin{array}{l}\text { - Smooth (Homogeneous) Contour } \\
\text { - Stable, Whitish }\end{array}$ \\
\hline $\begin{array}{l}\text { MMC } \\
3560 \mathrm{HF}\end{array}$ & Good & No Voids & $\begin{array}{l}\text { - Brittle } \\
\text { - Many Cracks, Blowout Area } \\
\text { Has Covity } 1 / 2 \text { in Deep }\end{array}$ & $\begin{array}{l}\text { - Smooth Contour } \\
\text { - Weak. Light Grey }\end{array}$ \\
\hline $\begin{array}{l}\text { Avco } \\
5026-39 \mathrm{H} / \mathrm{C}\end{array}$ & Good & No Voids & $\begin{array}{l}\text { - Brittle at Stag. Pr. } \\
\text { - Small Random Cracks }\end{array}$ & $\begin{array}{l}\text { - Stable. No Zone Apparent } \\
\text { - Color Not Distinct From Char } \\
\text { - Slightly Uneven Contour Q S.P. }\end{array}$ \\
\hline $\begin{array}{l}\text { Avco } \\
5026-39 M\end{array}$ & Good & No Voids & $\begin{array}{l}\text { - Brittle - Many Cracks } \\
\text { - Some Propagate Into Virgin } \\
\text { Layer }\end{array}$ & $\begin{array}{l}\text { - Stable, Darker Than Char } \\
\text { - Uneven Contour P S.P. } \\
\text { - No Separation }\end{array}$ \\
\hline $\begin{array}{l}\text { MMC } \\
3560 ~ I 1 A\end{array}$ & Good & No Voids & $\begin{array}{l}\text { - Nose Cap Separated } \\
\text { - Remaining Char Brittle }\end{array}$ & $\begin{array}{l}\text { - Exposed S.P. is Like Grey Felt } \\
\text { - Sides: Grey. Separation Line } \\
\text { Evident }\end{array}$ \\
\hline $\begin{array}{l}\text { MMC } \\
\text { ESA } 5500\end{array}$ & Good & $\begin{array}{l}\text { Several } \\
\text { Pinhole Voids }\end{array}$ & $\begin{array}{l}\text { - Brittie A Fow Cracks } \\
\text { - Separation From H/C Cells }\end{array}$ & $\begin{array}{l}\text { - Uniform Contour } \\
\text { - No Color Distinction } \\
\text { - Separation Evident }\end{array}$ \\
\hline
\end{tabular}




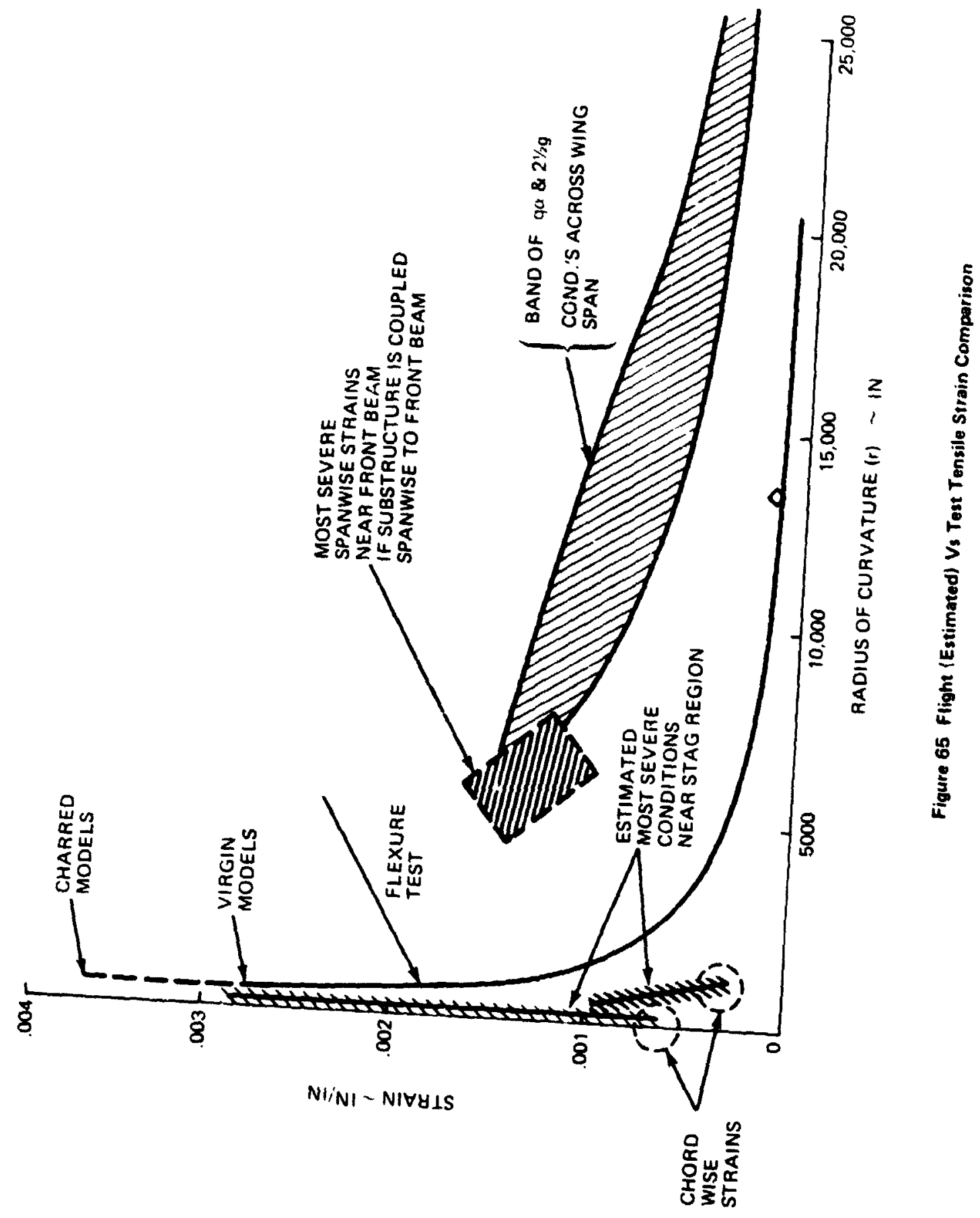




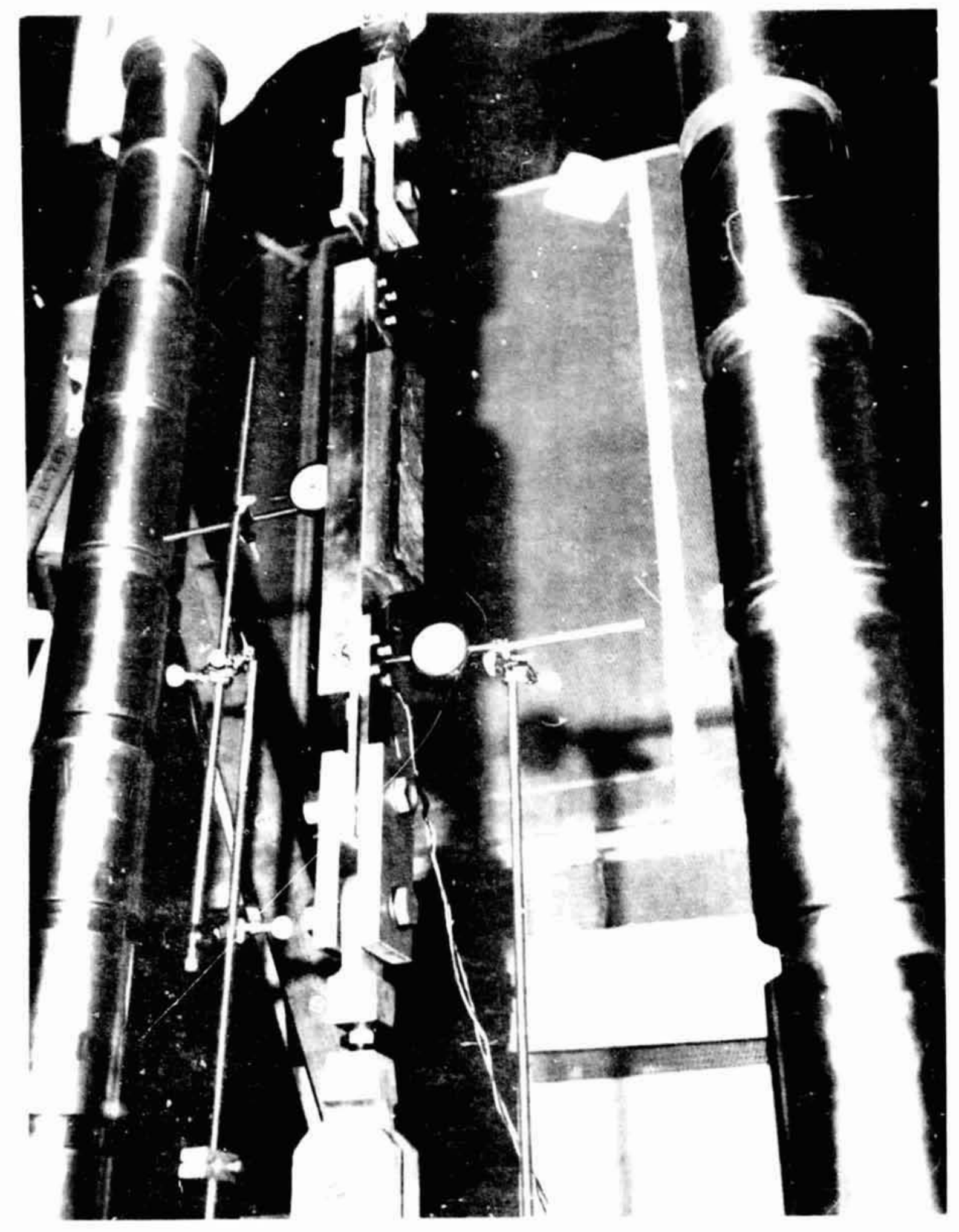

Figure 66 Strip Model mounted on the Olsen Machune 
conditions which resulted in the formation of a realistic shar could be obtained in the Avco ROVERS Arc facility, as shown in table 19.

The specimen was located at the exit of a nozzle as shown in figure of. Thermocouples were placed in the aluminum channel at locations of $1.0\left(\mathrm{~m}_{1}\right)$ and $6.0\left(\mathrm{~T}_{2}\right)$ inches from the leading edfe. In addition weight and thickness change measurenents were made.

Table 20 summarizes the results of tie test including weight loss, Aimensional change data and general post test ippearance description.

\subsubsection{Flexure of Charred Strips}

The purpose and procedure for these tests were as for the virgin strips.

There were no visible effects on all the ablators up to 0.0035 bondline strains. Close observation, during the test, of the surface or side cracks produced during charring indicated that the strain bad no visible change on the crack dimensions or appearance up to $\epsilon=0.0035$.

\subsubsection{Cutting of Charred Strips}

The observations collected after cutting the charred strips are sumamized in table 21 .

\subsection{Evaluation Criteria}

The first step in the evaluation of the candidate ablators consists of establishIng the evaluation criteria which are of the usual two type, 'go/no-go' criteria (those which the material must meet to be applicable to the orbiter 1.e.) and 'rating criteria' (those that will rank the ablators that are acceptable for this application). The evaluation criteria used here are presented in table 22, where the criteria are listed roughly in order of importance. 
Table 19 Comparison. Flight is Test, of Thermal Environment for Charring the Flexure Models

\begin{tabular}{|c|c|c|}
\hline & Flight & $\begin{array}{l}\text { ROVERS } \\
\text { Arc } \\
\text { Facility } \\
\end{array}$ \\
\hline$\dot{\mathrm{q}}_{\mathrm{cw}}$ BTU, $\mathrm{ft}^{2} \cdot \mathrm{sec}$ & $17 \cdot 56$ & $22^{* \prime}$ \\
\hline$Q_{c w} B T U / f t^{2}$ & $16,000 \rightarrow 52,000$ & $22,000 *$ \\
\hline H BTU/Ib f & 11.400 & 11,000 \\
\hline $\begin{array}{l}\frac{d P}{d s} \text { in the direction } \\
\text { of the flow }\end{array}$ & Negligible & $\begin{array}{l}\text { Small } \\
\text { (not measured) }\end{array}$ \\
\hline$\frac{R e}{L} t^{-1}$ & $\begin{array}{l}1.9 \times 10^{4} \\
\text { (at } 220 \mathrm{Kft})\end{array}$ & $1.6 \times 10^{4}$ \\
\hline Type of Flow & Laminar & $\begin{array}{l}\text { (probably) } \\
\text { transitional }\end{array}$ \\
\hline
\end{tabular}

"Winctsard flat region of L.E. during entry/no charring during ascent/dominant environment

- Average over model 


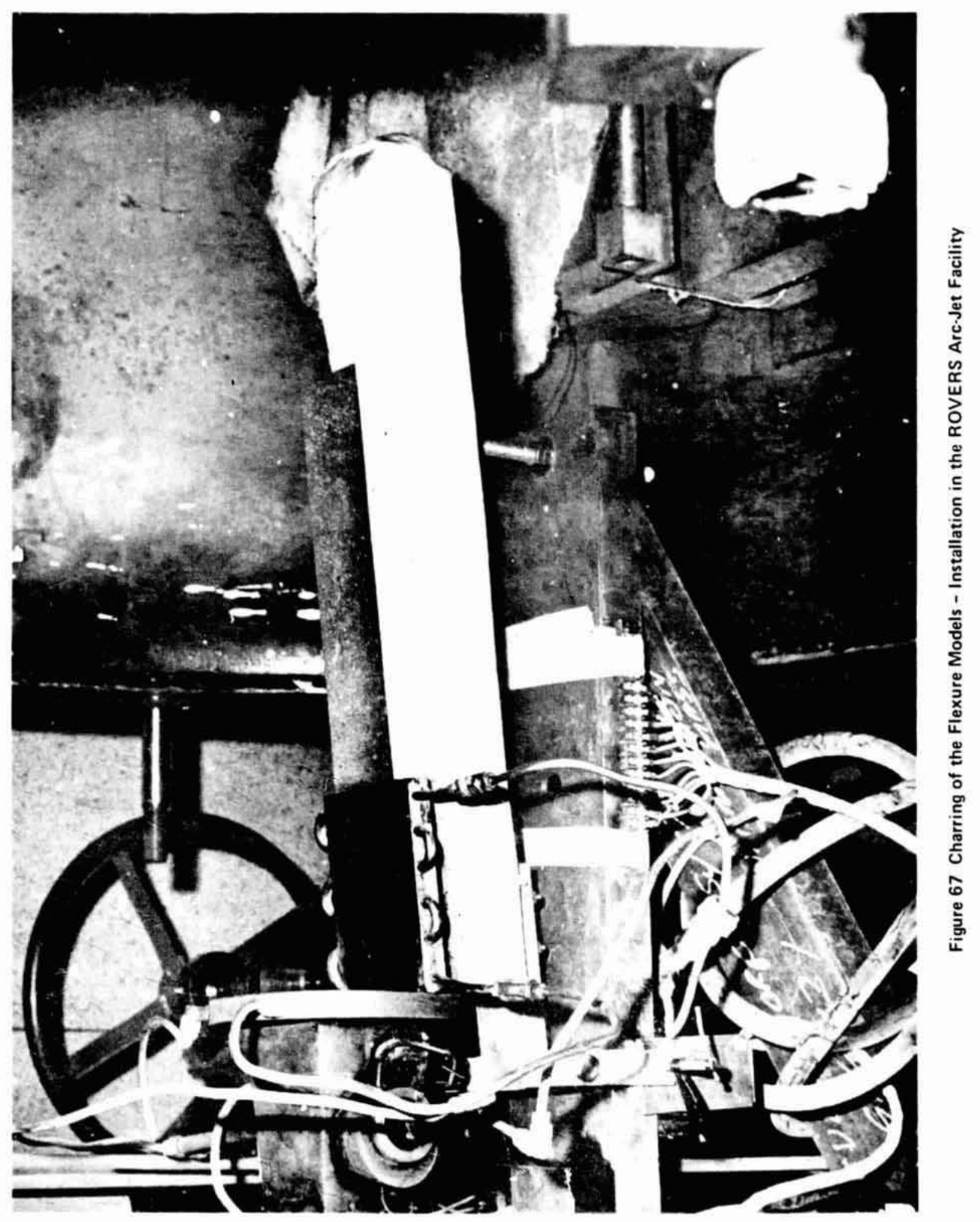




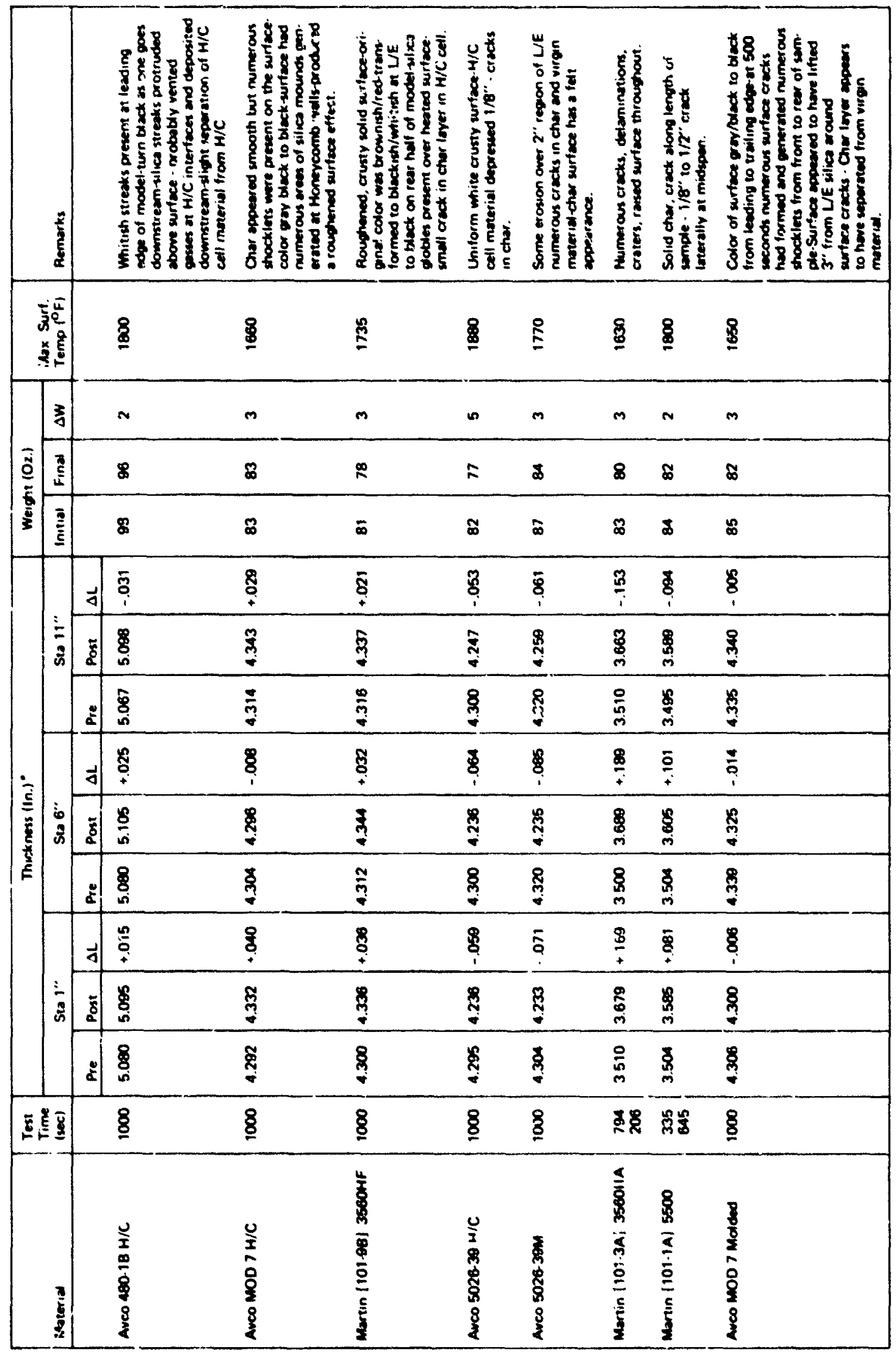


Table 21 Observations of Cut Charred Flexure Models

\begin{tabular}{|c|c|c|c|c|c|}
\hline \multirow[b]{2}{*}{ Material } & \multirow{2}{*}{$\begin{array}{l}\text { Char Depth } \\
\text { Calculated } \\
X_{c} \sim \ln .\end{array}$} & \multicolumn{3}{|c|}{ Measured Char Depth After Tests \& Cutting } & \multirow[b]{2}{*}{ Remarks } \\
\hline & & $\begin{array}{l}@ 1 \text { In. From } \\
\text { Front End }\end{array}$ & Mid Point & $\begin{array}{l}\text { @ I In, From } \\
\text { Back End }\end{array}$ & \\
\hline $\begin{array}{l}\text { Avco } \\
480.1 \mathrm{~B} \mathrm{H} / \mathrm{C}\end{array}$ & 1.051 & $.6-.8$ & $.6 \rightarrow .9$ & $.5 \rightarrow .7$ & \multirow[t]{8}{*}{$\begin{array}{l}\text { Large number of } \\
\text { voids within } \mathrm{HC} \\
\text { cells }\end{array}$} \\
\hline $\begin{array}{l}\text { Avco } \\
\text { MOD } 7 \mathrm{H} / \mathrm{C}\end{array}$ & 0.502 & .63 & .65 & .63 & \\
\hline $\begin{array}{l}\text { MMC } \\
3560 \mathrm{H} / \mathrm{F}\end{array}$ & 0.545 & .52 & .57 & .60 & \\
\hline $\begin{array}{l}\text { Avec } \\
5026.39 \mathrm{H} / \mathrm{C}\end{array}$ & .79 & .52 & .50 & .46 & \\
\hline $\begin{array}{l}\text { Avco } \\
5026-39 M\end{array}$ & .502 & \multicolumn{3}{|c|}{$\begin{array}{l}\text { ARTICLE DESTROYED } \\
\text { IN FLEXURE TEST }\end{array}$} & \\
\hline $\begin{array}{l}\text { MMC } \\
3560 ~ ॥ A\end{array}$ & .537 & .5 & .4 & .42 & \\
\hline $\begin{array}{l}\text { MMC } \\
\text { ESA } 5500\end{array}$ & .442 & .55 & .52 & .52 & \\
\hline $\begin{array}{l}\text { Avco } \\
\text { MOD 7M }\end{array}$ & .44 & .49 & .52 & .48 & \\
\hline
\end{tabular}

"From weight loss and dimensional change.

Note: Front end refers to edge nearest nozzlo exit. 
Teble 22 Criteria for the Evaluation of the Candidate Ablators

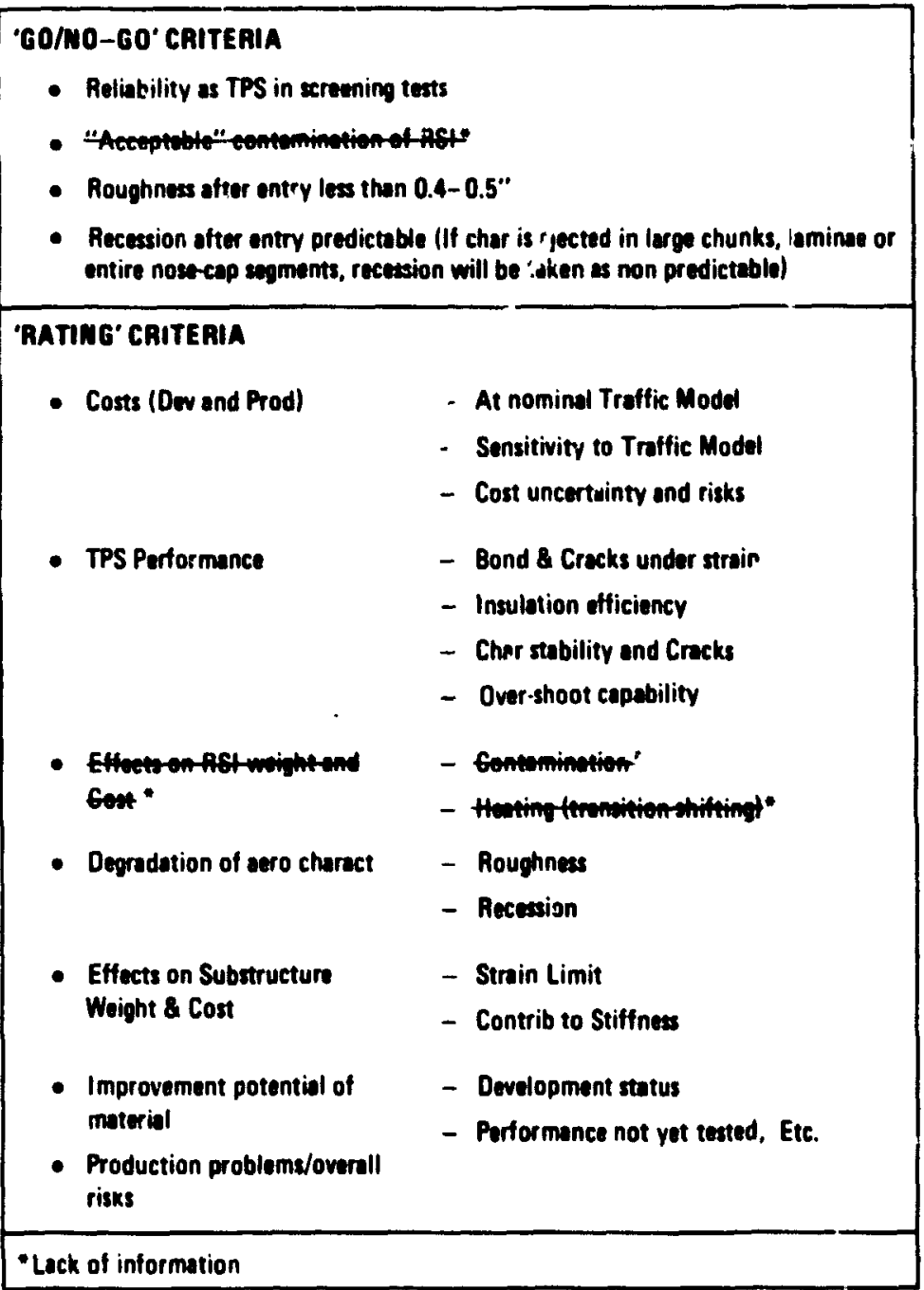


'Reliability as TPS' means the confidence that the material inspires of being able to perform the TPS function; therefore it comprises such items as char integrity, char regularity in the cracks (if any) produced under flexure in the virgin state, etc. Naturaly the fac: that the judrement on the reliability is to be done from the results of the test performed, means that such factors as poor simulation or exclusion of a test (e.g., rain erosion) can influence the result.

Ideally, all the rating criteria should be reduced to either costs or imponderables. Weight, for example, should be reduced to cost via the usual notion of value of weight saving. Criteria such as degradation of aerodynamic characteristics caused by $1 . e$. roughness should also be reduced to cost penalties, the proc-dure being often complicated and configuration-dependent, as inciicated in Section 4. It turns out that such a systematic reduction to cost of each 'rating' criterion is not necessary to select the ablator.

Cost information on ablators is, of course, a subject of large uncertainties. Often the belief is expressed that it is just impossible to make realistic comparisons between costs offered for planning purposes by cilferent manufacturers. To at least reduce the obviois excuses for discrepancies, 3 considerable effort was made at uniformity by (a) defining the bookkeeping system, i.e. in defining the items to be bookkept under a given heading, and (b) fixing the grcind rules for pricing, i.e., l.e. area, number of flights, etc.

To compare the ablators, only ablator - connected items are priced under ablator costs. The items bookkept under 'development' and 'production' enst of the tablator are defined in abie 3 . The grount rules are sveliec out in table 24 . Unforumately, zmong the evaluation criteria there are two that are jat listed for completeness but had to be neglected. Contamination effects on the FSI 
Table 23(a)

\section{COST ITPUS BOOKKGSPT INDER}

\section{DEVELOREENT COSTS AND PRODUCTION COSTS}

'Development costs' and 'production costs' Involve only eblator-linked costs, specifically the 1tems Indicated in Table 23(b) ('development costs') and in Teble 23(c) ('production costs' or $\$ / \mathrm{ft}^{2}$ ).

In particular, the substructure costs (Isbrication, refurbishmert, ets) are not be be included. But if a particula: ablator, on account of its charecteristics or the bond required, were to require extre wanhours for refurbishment, then such extra costs should be bookkept agsinst tha ablator. 
Takle $: 3(b)$

\section{ABLATOR DEVELORTENT COST ITESS}

1.0 Material Characterizstion (1: cay)

1.1 Property Measurements (Thermal, Structural)

1.2 Thermal Performance Evaluation (are tests)

1.3 Thermal Performance Evaluation in representative sequenticl tejtinj

1.4 Capabjlity of Generating Design Charts

1.5 Structural Performance (cold soak, flexure tests)

2.0 Fabrication Studies (1f any)

2.1 Investigation of Low Cost Fabrication Approsches

2.2 Prelininary Production Flan

2.3 Process and Fabrication Specifications

2.4 Set-up Pllot Plant Opersziors

2.5 Eveliate sharscteristics of gijct plart asie:ials (properit:s)

2.6 Investigate aná Define Reny: : Prosedures

3.0 Quality Assurance

3.1 Define sblator acceptance criteria

3.2 Define acceptirice critariz for sbictoriond attscincnt, seals and Jolnis.

3.3 Define acceytance criteils iur sesalis 
Table $23(c)$

AELATOR PRODUCTION COSTS ITEMS

1.0 Design and Fabrication of Final Tooling

2.0 Fabrication of Ablator

Table 23 (d) for Molded

Table $23(e)$ for Honeycomb

3.0 Seals, Joints, Bolt Plugs etc.

3.1 Raw Materials

3.2 Tooling

3.3 Fabrication

3.4 Inspection

4.0 Packaging and Shipping*

5.0 On-Site issembly Inspection

6.0 Field Repairs (as required)

*Account only for costs of shipping from production plant to KSC. For packaging assume that the crates used for delivering the substructures to the production plant will accommodate also the substructure-and-a, iator panel. Therefore, such crates are not to be charged under the ablator production cost. 
Table $23(d)$

OPERATIONS IN HONEYCONB ABLATRR FERPICATION

\author{
1.0 Procure and Inspect Raw Material (includinq honeycomb) \\ 2.0 Clean and prime structure* \\ 3.0 Bond $\mathrm{H} / \mathrm{C}$ to structure \\ 4.0 Cure and Inspect $\mathrm{H} / \mathrm{C}$ bond \\ 5.0 Prime $H / C$ walls \\ 6.0 Mix ablator and inspect \\ 7.C Fill H/C with ablator \\ 8.0 Cure and inspect for voids, fiber clumps etc. \\ 9.0 Post Cure \\ 10.0 Rough a -irish machine \\ 11.0 Inspect dimensionally \\ 12.0 Pore Seal and moisture barrier application \\ 13.0 Final Inspection
}

\footnotetext{
* Clean Substructure' means any cleaning operation starting from a substructure that (1) has been refurbished by scraping of the ablator but leaving perhaps as much as some $5 \mathrm{mils}$ of silicone-based adhesive and that (2) has been structurally inspected.
} 
Table $23(e)$

OPERATIONS IN MOLDED ABLATOR FABRICATION

1.0 Procure and Inspect Raw Material

2.0 Mix ablator and inspect

3.0 Charge Mold

4.0 Cure and Post Cure

5.0 Remove from mold, trim and inspect for voids, fiber clumps, etc.

6.0 Clean and prime structure*

7.0 Bond ablator to structure and cure iunless mechanically attached)

8.0 Inspect bond

9.0 Rough and finish machine

10.0 Inspect dimensionally

Il.0 Pore Seal and Moisture barrier application

12.0 Final Coating (if any)

13.0 Final Inspection

*'Clean substructure' means any cleaning operation starting from a substructure that (1) has been refurbished by scraping $c f \tilde{f}$ the ablator but leaving perhaps as much as some $5 \mathrm{mils}$ of silicone-based adhesive and that (2) has been structurally inspected. 
Table $24(a)$

\section{Groundrules for L.E. Ablators Costs}

1. Three traffic models, see Table $24(b)$

2. 1971 uninflated dollars

3. The orbiter is 'frozen' (not 'rubber')

4. Trically use tha wing L.E. Wain areas (not tail, aor special areas, e.g. fillets)

5. Ab.ative L.E. is not a back-up systex for(and interchangeatle with) carbon-carbon system, it is just a L.E. TPS to be attached at tre wing front beas.

6. If needed, use a typicai reference design such as the GAC 473 orbiter,

7. Use an area per vebicle of $600 \mathrm{ft}^{2}$.

8. Aluminum (not titaniun) substructures

9. Use, for each ablator, tionesnesses typically reyuired for the phese C/D shuttle mission. 


\section{TABIE $24(b)$ - TRAFFIC MODELS}

\section{Traffic Model \#l}

(This is the first year of the IASA Traffic Model, or the DDTEE effort, increments I and II of the Phase C/D Shuttle program*)

6 flight tests

2 development orbiter vehicles (orbiter flight verhicles No. 1 and 2)

Schedule: CY 1978

\section{Traffic Model \#2}

(Source: Mod 2 to sow of contract MAS 1-11416, 'Ablative L.E. Research')

5 flight tests and 120 operational flights

2 operationel orbiters

Schedule: not available

Flight rate: 24 operational flights per year for 5 years.

\section{Traffic Models \#3}

(This is the entire IASA Traffic model to 447 flights or to CY 1988, or increments I to IV of Phase $C / D$ shuttle program*)

6 flight tests and 441 operational flights

5 operational orbiters of which 2 are the upgraded/retrofitted development vehicles

Schedule and flight rate: see Table 2 líc)

* Source: RFP No. 9-BC-421-67-2-40P, ipace Shuttle Program, NASA MSC, p. $1-7$ and $1-8$ 

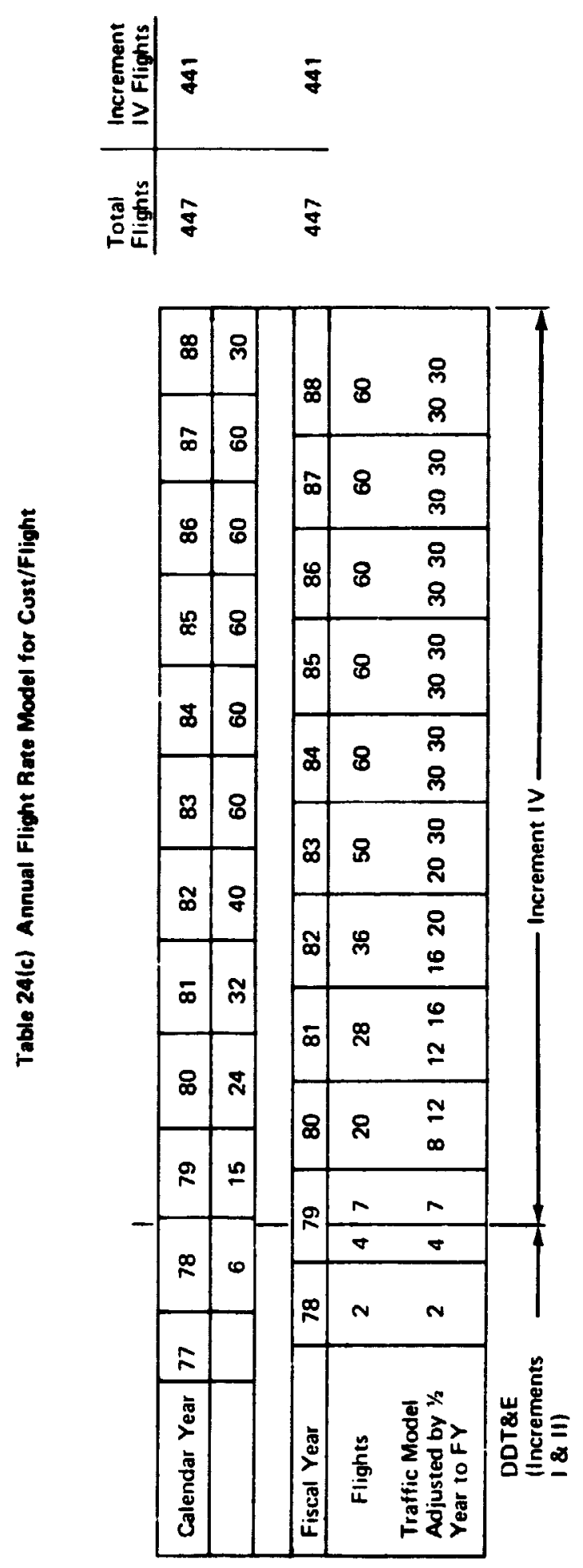
weight and cost had to be neglected because of total lack of data, while a detailed separate study would have been necessary to estimate the transition shift induced by l.e. roughness and the joints, especially the ablator-RSI joint. In this study we could not embark on those two separate questions, as indicated in Section 2.

\subsection{Evaluation of the Cendidate Ablators}

When the eight candidate ablators are examined in the light of the 'go/no-go' criteria, four materials are eliminated as unacceptable. This is shown graphically in figure 68 , where a judgement is marked for each test. Inadequate char stability and lack of regularity in the char appearance were the main problems. Specifically, the objectionable features in each case can be described with hopefully expressive words, as follows:*

ESA 3560 II A: delamination; irregular erosion; weak char-virgin interface; recession not predictable;

5026/39M: cracks, same deep into the virgin meterial, incon. sistent char surface;

Mod $7 \mathrm{M}: \quad$ in $\quad$ ufficient strength in the char-virgin interfece; recession non predictarie;

480 IB Hc: demolished materi: ' texture; excessive char melting.

Note that all three molded materials are eliminated, the elastcmers, not surprisingly, because of weak char-virgin interface. The behavior of all four 'no-go' materials is consistent with previous informa:'ion, in particular the

* The models and the extensive photographic coverage of the tests can be examined at the Thermal Protection Branch, Material Division of the NASA Langley Research Center. 


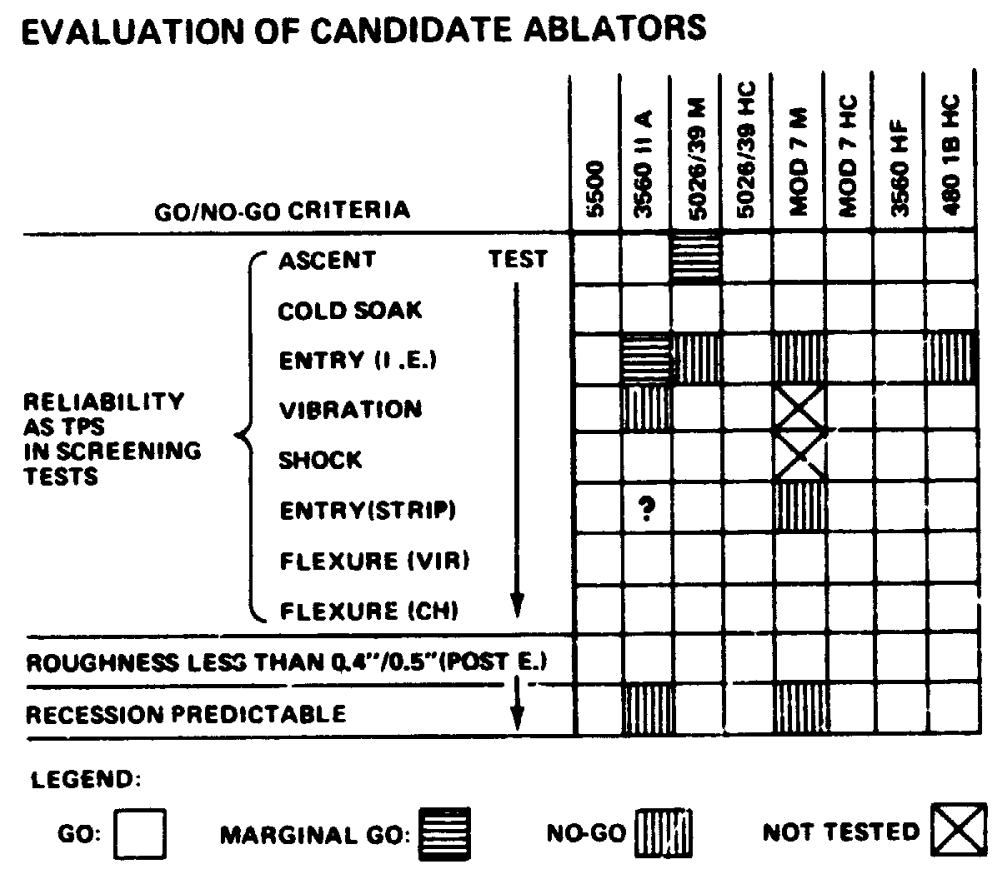

Fig. 68 Evaluation of the Cendidate Ablators - Go/No-Go Criteria 
ESA 3560 II A with the flight experience on the X 15 A-2 airplane.

The remaining four ' $g 0$ ' materials were examined against each of the rating criterla (table 22), except of course those neglected for lack of information.

As far as ablator costs are concerned, relatively good information was obtained from the manufacturers. ${ }^{*}$ It amounted to the following: 1) at the nominal traffic model, the ESA 5500, the Mod $7 \mathrm{Hc}$ and the ESA $3560 \mathrm{HF}$ have the lowest cost. a few million dollars for the development cost and between 150 and $250 \% / \mathrm{ft}^{2}$ for the production cost ( 1971 dollars); the ESA 5500 and the ESA $3560 \mathrm{HF}$ have scmewhat lower production costs than the $\operatorname{Mod} 7 \mathrm{Hc}^{+} \quad$ 2) the sensitivity to the traffic model is minimal; 3) the cost uncertainties are described as some $15 \%$ for the $5026 / 39 \mathrm{Hc}$ and some 20 to $25 \%$ for the $3560 \mathrm{HF}$ and the Mod I Hc, with the risks being clearly highest for Mod $7 \mathrm{Hc}$. The only conclusion that we could extract - when the necessary realism is exercised - is that the ESA $3560 \mathrm{HF}$, the ESA 5500 and Mod $7 \mathrm{Hc}$ are attractive and that they are about equal in cost.

Concerning bond performance under the substructure strains, the flexure tests and the cold soak tests on the l.e. models showed that all the candidate materials are equally good. The tests corered adequately the flight-condition (the virgin strips were subjected to bonding strains of about 2.5 times the maximum strains;

* This information is not for general dissemination and therefore only vague statements are reported here. Obtained were the glubal value of development cost and $\$ / \mathrm{A \tau}^{2}$ for three traffic models (5 Avco materia].r) and \#2 and 3 traffic r.ndels (MMC materials), as indicated in the costing ground rules (Sectio 4).

+ This judgement, as t'ie evaluation of the candidate ablators, is the responsibility of the first authur only. 
the cold soa!. was done with the models unloaded and unt ied at tr. nds; the charred stri.js were subjected to bondine strains about twice t: e maxima flight strains, however at room temperature).

In the area of 'nsulation eff:ciency, the rosult of the l.e. test i:ign:e 50: pernits only one completely objective conclusion, j.e., that within the incertainties of the measurements in the single test performed, Mod $7 \mathrm{Hc}$ and the ESA $3550 \mathrm{HF}$ are best and equal. However, if one wants to search for tronds within the uncertainties, it appears likely that Mod 7 Hc is a more efficient insulator $\mathrm{a}^{+}$least in range 60 to $100 \mathrm{Btu} / \mathrm{ft}^{2}-\mathrm{sec}$. (the Mod $7 \mathrm{Hc}$ had lower soalout temperature by some $80^{\circ} \mathrm{F}$, lower surface temperature by some $500^{\circ} \mathrm{F}^{*}$ anci a thic'ser $v^{2}$ rgin layer left - figure 51 ; moreover in the first set of $1 . e$. Lesus, the Mod $7 \mathrm{HC}$ showed generally lower temperature than the $3560 \mathrm{HF}$ ).

As far as char stability anō cracks are concerned, we concluded--on an absolutely objective basis--from the tests on the l.e. models and the strip model that the Mod $7 \mathrm{HC}$ and ESA $3560 \mathrm{HF}$ are best and equal, while the ESA 55C.0 exhibited excessive tendency to swell and the 5026/39 Hc displayed undistinguished performance and may well be unfairly penalized vis-a-vis the elastomers by the poor enthalpy simulation in this single screening test. Again, if one searches for trends within the uncertainties ( 2 tests, 20,000 $-27,000 \mathrm{Btu} / \mathrm{ft}^{2}$, etc), the conclusion is that Mod $7 \mathrm{HC}$ appears to be sumewhat better than the $10 \mathrm{KF}$ wh:ch exhibited (a) less regularity in the char appearance, (b) higrer char depth, and (c) a more fragile char, when compared to the Mod $7 \mathrm{Hc}$.**

The values actually were $2300^{\circ} \mathrm{F}$ for the Mod 7 He and $2890^{\circ} \mathrm{F}$ for the 3560 HF. This last value is a little surprising since it is even higher than that of the $5026 / 30$.

* The $3560 \mathrm{HF}$ models ef the second set exhibited two irreglilar spots, essentially in the fcrm of a 'hole'. A check of the X-ray picture of the model (done by Martin) showed absolutely nothing. The explanation of these 'holes' remains elusive. 
As far as behavior under a heating overshoot (an increase of, say, 30-40\%), no hard information was obtained in this study. However, some information can be extracted from the tests that were conducted on one set of 1.e. models that had a different design for the side plates (with considerable effects of the sides of the model) and that were tested at heating rates representative of the extreme environment. Other difficulties with these data (see Data Package) are the ascent heating applied via radiant lamps aud the very low enthalpy in the entry tests. In spite of these uncertainties, the data obtained in the entri test suggest that in a heating overshoot, (a) the Mod $7 \mathrm{Hc}$ char appearance is somewhat better than that of ESA $3560 \mathrm{HF}$ and (b) at high if the $3560 \mathrm{HF}$ appear to develop 'tunnels', i.e. void channels into the material. Naturally this indication should be taken with caution, since the tests were conducted at $q_{\mathrm{w}}$ of about $107 \mathrm{Btu} / \mathrm{ft}^{2}-\mathrm{sec}$ and this is considerably more than an overshoot. Moreover, the $3560 \mathrm{HF}$ is not recommended for applications beyond some $\dot{q}_{\mathrm{cw}} \sim \dot{q}_{\mathrm{hw}} \approx 90 \mathrm{Btu} / \mathrm{ft}^{2}-\mathrm{sec}$ (Refs. 47 and 59 ) and therefore the indications from a high $\dot{q}_{w}$ test may be even less representative of an overshoot. As far as degradation of aerodynamic characteristics, the roughness degradation for all four ' $\mathrm{gO}$ ' candidate materials is small and probably cost-free, as indicated by the roughness measured (figure 52) and the cost of the degraded aerodynamic characteristic (figure 53). The roughness of the $3560 \mathrm{HF}$ and the Mod $7 \mathrm{Hc}$ is about equal with'n the uncertainties. The degradation due to recession should also be small (at most a L/D loss of some 0.15 ) when the concept for minimizing shape change is used. Again, Mod $7 \mathrm{HC}$ and the ESA $3560 \mathrm{HF}$ are best and equal (see figure 56).

There is no strain limit imposed on the substructure hy any of the 'go' materials, since the maximum kondline strains in the 1.e. substructure are aoout 0.002 and, In the flexure tests at room temperature with a typical char thickness, bondine 
strains up to 0.0035 do not affect any of the candiate ablutors. Therefore all the 'go' materials are equally good from this point of view.

As far as the ablators contribution to the stiffness of the substructure, this is merely an added cualitative merit of the nblator but not one that would result in savings in cost or weicht of the substructure, since it is not conceivable of a realistic structural desien that counts on the ablator stmactural contribution. In this senie, this criterion is a minor one. All the 'go' mater.als are equally good, and in fact a quantitative .easure of this contribiltion (see figure 69) shows that Mod 7 Hc and the $3560 \mathrm{HF}$ give exactly the same contributions.

By the criterion 'production problem/overnll lisks'* the best of the four 'go' is $5026 / 39 \mathrm{Hc}$ since it is the one that has beer. fabricated in the largest quantity**, whose fabrication techniques have keen developed in depth in a well funded program, and simultaneously is well characterized and well known. However, for what follows, we are interested in a comparison between Mod 7 kic and the ESA $3560 \mathrm{HF}$. The Mod $7 \mathrm{Hc}$ is a developed material formulation, but not a developed 'material system', as elaborated in Section 5.2. On the other hand,

* We heve in mind, under this criterion, unexpected difficulties, surprises, uncertainties or probability of errors in planning end estimating and similar uncertainties that ail amount to risks. We a not accounting here for differences in the development between ablators and their prejictable differences in effort requimed, since these are accounted under develipmert osis of each ablator.

* To jate, the total production of 5020/39 $\mathrm{KgG}$ kas been around $25,000 \mathrm{ft}^{\hat{c}}$ ( 30 Apolio Command Modules at about $400 \mathrm{ft}^{2} / \mathrm{ship}$, plus odds and $2 n \mathrm{ss}$ ). The next highest production among the candidate ablators is for the 356. iF anc is about 2,L00 ft 2 (4 PRIME vericles at $300 \mathrm{ft}^{2}$ /article plus some $1200 \mathrm{st}{ }^{2}$ of jevelopment activities: the tcte? is actually $\equiv, 200 \mathrm{ft}^{2}$ if we adi materials if the same family such as those for the PAET 8 vehicles, the XI5AE ard Vir: :rg. 


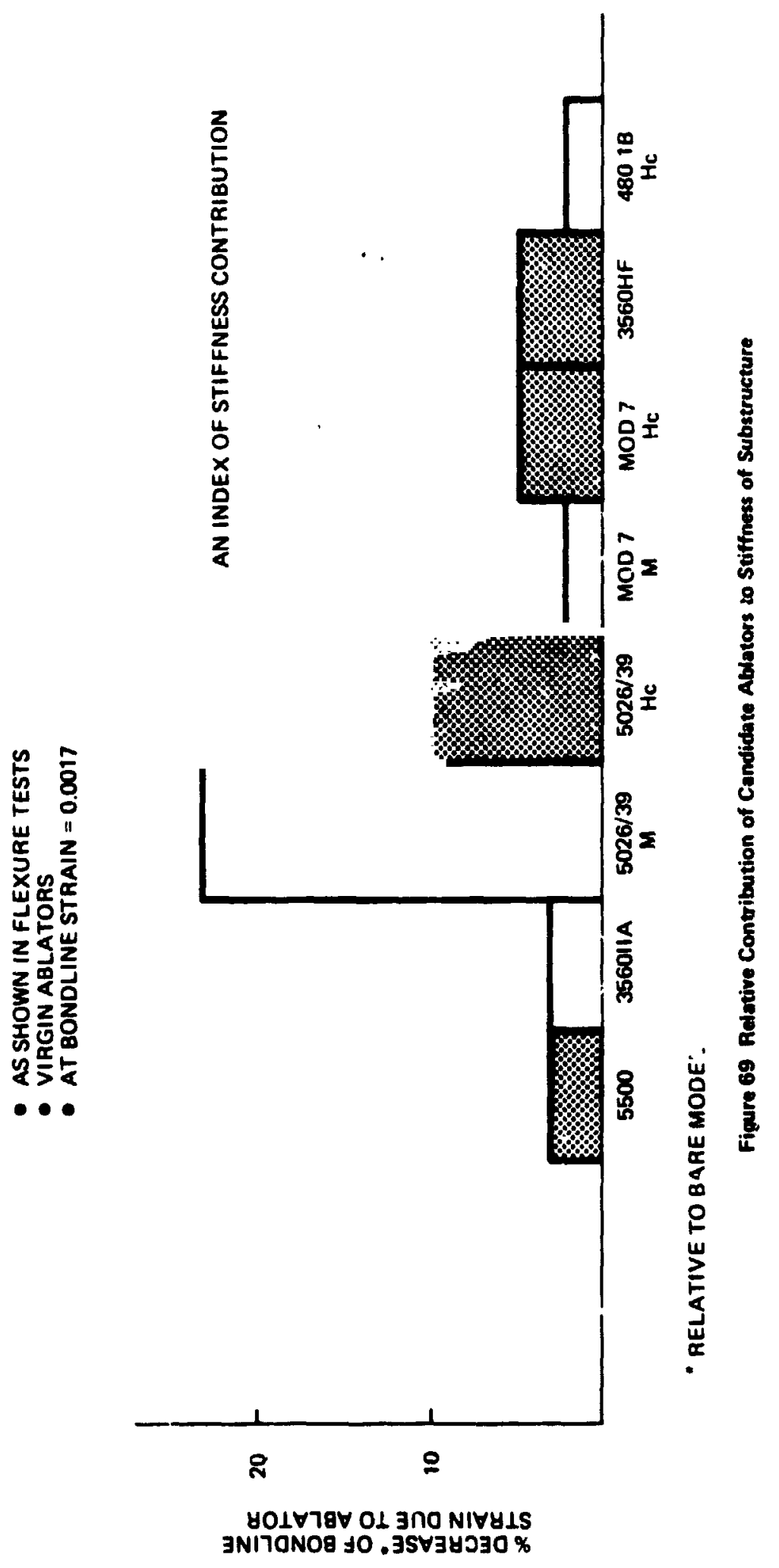


the ESA $3560 \mathrm{HF}$ is a 'developed system' produced for and flown successfully 0. . PRIME. Therefore, the ESA $3560 \mathrm{HF}$ has a clear adge as far as nossible production problems and overall risks, while Mod 7 HC is only marginal.

It is not necessiry to stress how cloudy and complex the criterion 'improvement potential' is. Among other thirgs, it depends upon whether there is time and support for the improvements envisioned; it is at least debatable whether there wlll be such support for an ablative l.e. for the shuttle orbiter, even though there was some for such research vehtcles as the XI5 A2 or PRIME. Moreover, in ablator development, even if there is a clear and obvious approach to furmulation modifications, there is so guarantce beforehand that the expected improvement will in fact be realized. In parallel to this study, both the Martin Corporation and the Avco Compary proiuced various modifications of the $3560 \mathrm{FF}$, Mod 7 M, ESA 5500, and 3560 II A. The iritial results of many of these materials appear very disappointing, but only ascent heating and cold soak tests have been carried out so far (tief. 56). Therefore the issue of improvement potential of the four ' $\mathrm{BO}$ ' materials is one of complete un :ertainty.

Sumarizing now, the rating criteria point fairly systematically at the two elastumers, Mod $7 \mathrm{Hc}$ and ESA $3560 \mathrm{HF}$ as definitely the best of the four ' $\mathrm{gO}$ ' materials at least within the data generated and the criteria considered. The performance of these two materials appeared very close, as shown in table 25 . Again, we distinguish between an objective conclusion from the few test results with their many uncertail.ties and a likely trend that is noticeable within the data uncertainties.

\subsection{Ablator Selection}

It is clear from table 25 that not much difference is left on which to base a selection of one material over the other. Or, in a different light, the two 
Table 25 Evaluation of the Two Best Cendidate Ablators, Rating Criteria

\begin{tabular}{|c|c|c|}
\hline & $\begin{array}{l}\text { Objectively } \\
\text { Whith Dot } \\
\text { Gothered: }\end{array}$ & $\begin{array}{l}\text { Pescible Trends } \\
\text { In Dote Gathy is } \\
\text { Forrer: }\end{array}$ \\
\hline & $3880 \mathrm{HF}$ Mod $7 \mathrm{HC}$ & \\
\hline Cost per unit ares & Equal & $3560 \mathrm{HF}$ \\
\hline TPS Performance: & \multirow[b]{2}{*}{ Equal } & \\
\hline - Under Strain & & Equal \\
\hline - Insulation Efficiency & Equal & $\operatorname{Mod} 7 \mathrm{Hc}$ \\
\hline - Char Stab \& r,recks & F.qual & $\operatorname{Mod} 7 \mathrm{Hc}$ \\
\hline - Ovar-Shoot & No Info & $\operatorname{Mod} 7 \mathrm{Hc}$ \\
\hline Aero Characteristics & Eq̣ual & Equal \\
\hline Effects on Subst:ucture & Equal & Equal \\
\hline Improvement Potentia & $?$ & $?$ \\
\hline Production Problems/Overall Aisks & Merginal & $3560 \mathrm{HF}$ \\
\hline - Complex/Debarable lssue & & \\
\hline
\end{tabular}


materials are close enough in properties and characteristics to perform in a very simflar manner in the screening tests of this program, and therefore, hopefully in flight. The lack of objective performance differences mukes them both equally attractive from the point of view of a techrology study such as this (ground rule b), (Section 2).

Therefor:, sotin materials, ESA $3560 \mathrm{HF}$ and Mod $7 \mathrm{Hc}$, were selected for the invelopment of two versions of the l.e. design. Actually, the versions are as similar as the performance of the materials. Questions not yet studied (e.g. contamination), or further tests may in the future suggest the selection of one material over the other. 


\section{WIMG L,E, DESIGN}

For the purpose of this program the orbiter Leading Edge ( $L / E)$ was assumed to consist of all wing structure including TPS forward of the wing front beam. The learing edge system design included thermal and aerodynamic design of the selected heatshield as well as structural design of the L/E substructure and associated attachments to the wing front beam. In view of the fact that at the program inception there were several orbiter concepts in contention it was decided to maintain design flexibility such that the ablator L/E system arrived at would be as configuration independent as possible.

Consistent with this approach and due to program limitations a typical midspan L/E segment was selected for design evaluation. Interfaces were established for the TPS at the ablator/RSI juncture in the spanwise direction and between adjacent ablator segments in the chordwise direction. The design of the joints and seals along both boundaries was also included in the design task. As alluded to above the strictural interface was taken to be the wing front beam with the design effort encompassing all wing structure forward of this point including attachment schemes to the front beam. Figure 70 illustrating a tipical orbiter wing segment at midspan defines the areas which were covered under this program. This figure also presents the general configuration and nominal fimensions selected to represent a typical midspan $I / E$ segment.

The following sections present the resulis obtained in the various tasks which led to the definition of the final design presented in Section 6-5.

\subsection{LNE REFURBTSEMENT AND DESTGN CONCEPT}

\subsubsection{Refurbishment Concepts}

The first tack performed prior to conducting the detailed iesign trade-off studies was the selestion of the L.E. refurbishment concept. (We call L.E. 


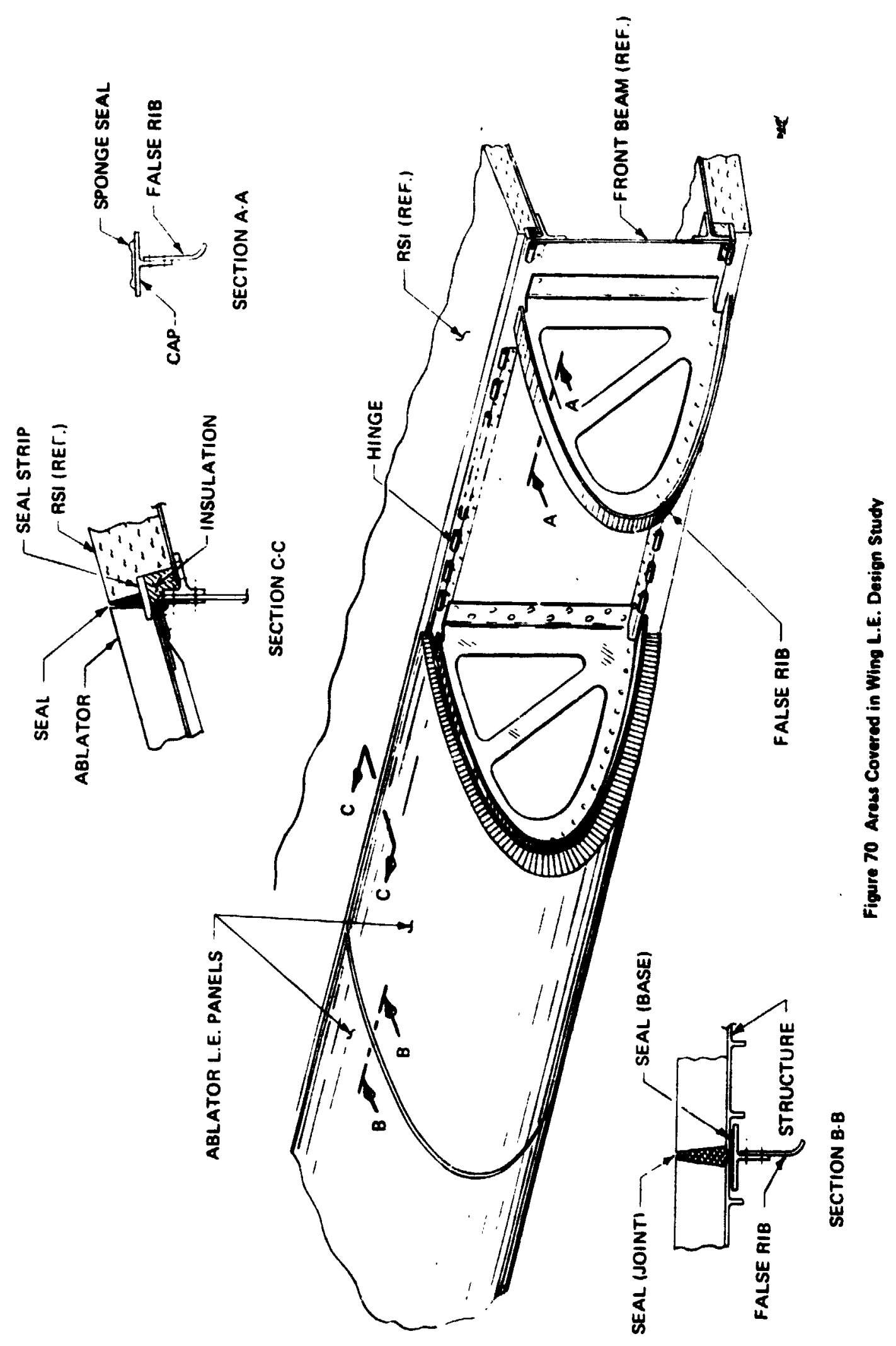


refurbishment the procedure by which, after each flight, the orbiter l.e.s are repristluated to a flying condition).

Essentially, this task was a systems trade-off study where all potential concepts were identified and subsequently evaluated relative to all pertinent factors; ultimately leading to the selection of the single most promising concept. Although simple in concept this task proved to be one of the more difficult due to the large number of potential candidates and the number of engineering disciplines involved in the evaluation.

A variety of design concepts were considered ranging from systems which are refurbished on the vehicle to totally disposable systems. In general, the concepts reviewed can be grouped into three broad classes relating to the number of different operations done on the vehicle as opposed to work carried out at the ablator manufacturer's plant or at a refurbishment depot. From another point of view the three basic classes differ in the amount of leading edge structure that is permanently attached to the vehicle and is not removed after each flight.

Figure 71 presents a series of thirteen sketches illustrating, with the description in table 26 , the various leading edge concepts evaluated in this program. In this figure the class division becomes evident. For example, those included under Type A have a nonremovable substructure and only the heatshie]d is removed after each flight. Under Type $B$, only part of the $L / E$ substructure is removed and etther reused off site or discarded, whereas in Type $C$ the entire leading edge system forward of the front beam is removed and again one has the option of $e^{\text {ther }}$ reused off site or disposal.

There are substantial differences anong the variants on such factors as cost, weight, vehicle tum-around time, reliability, etc. Table 26 lists some of 


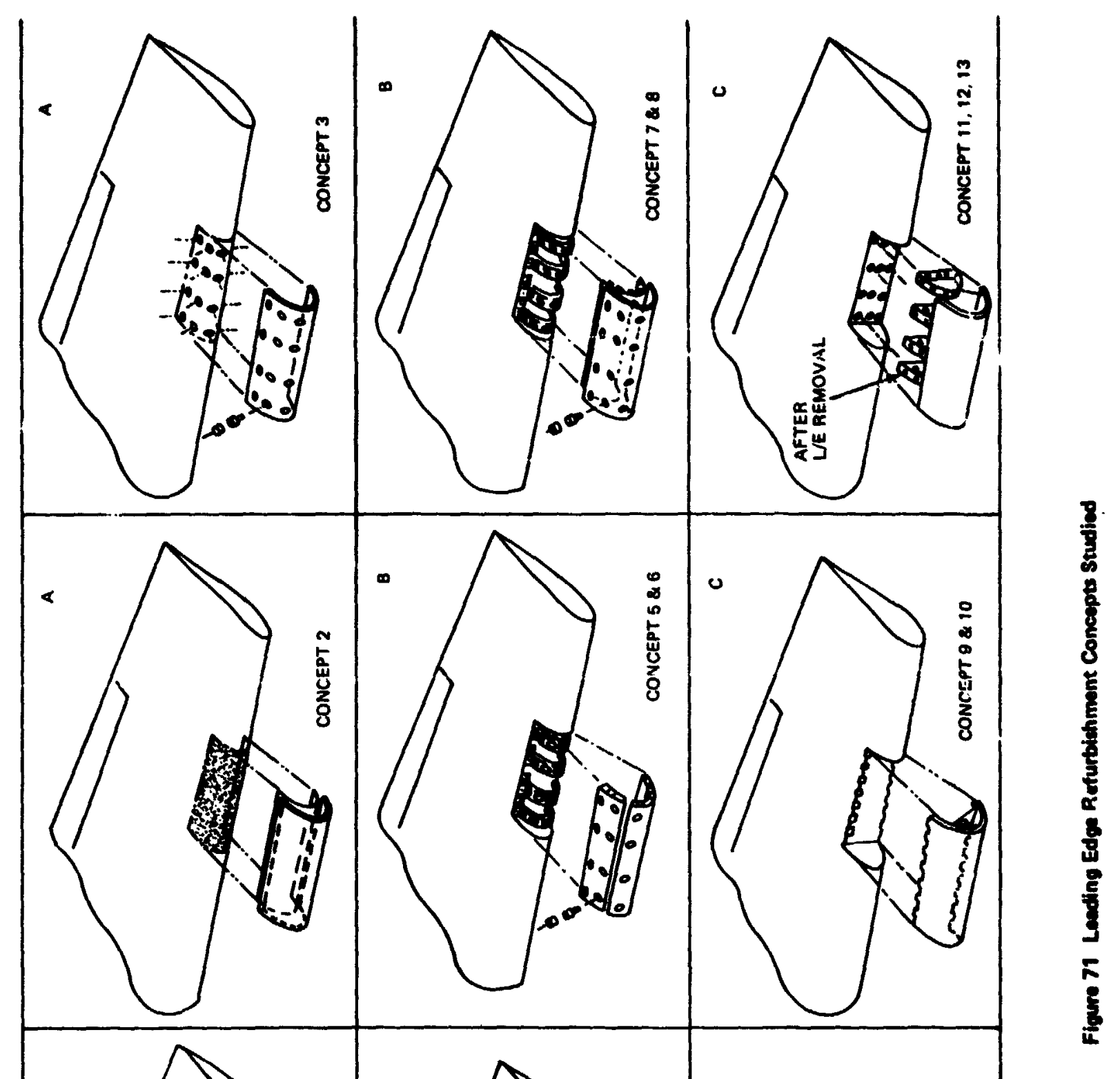


FOLDOUT -
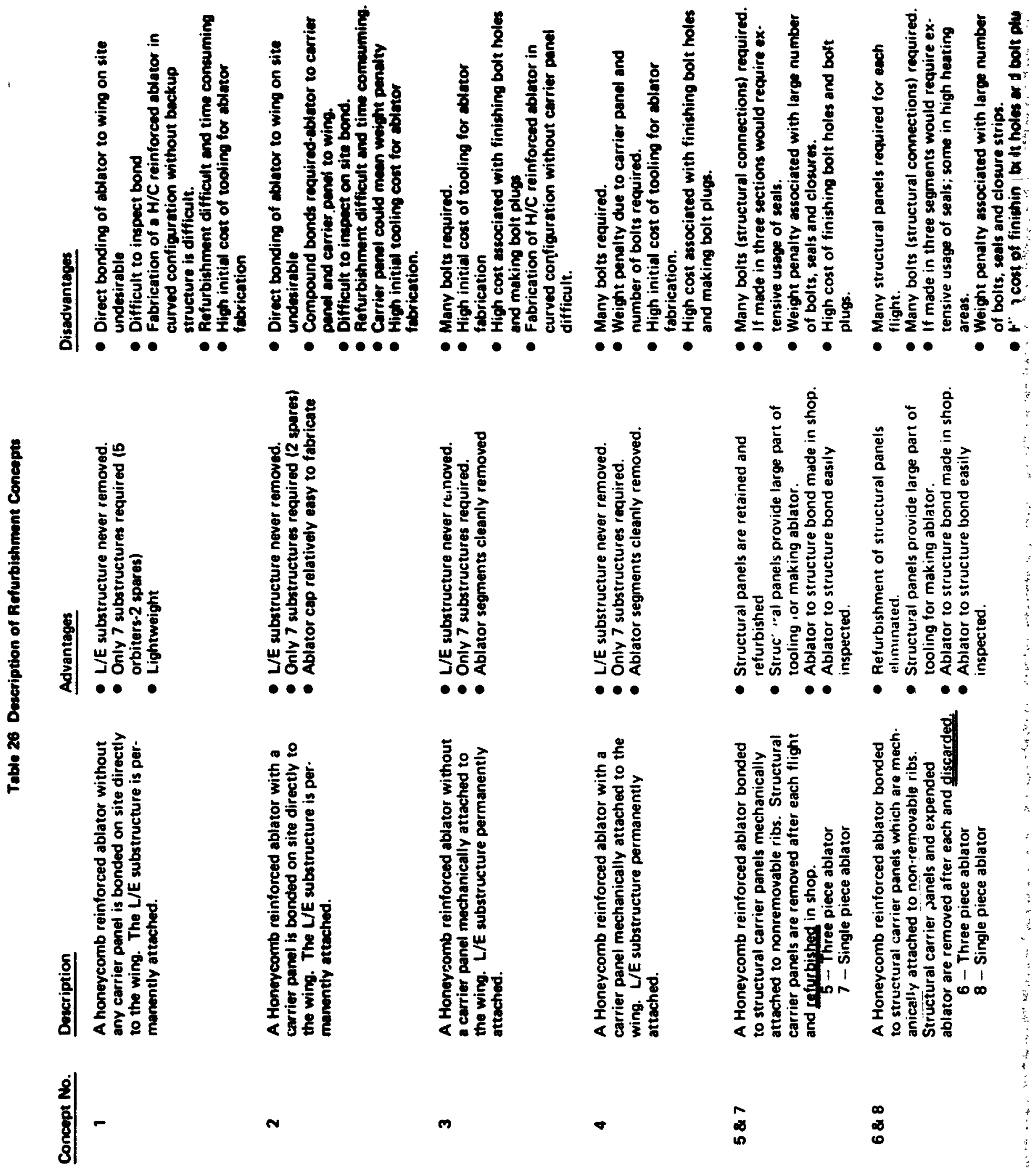


\section{FULDOUT FRAME}

\section{7}
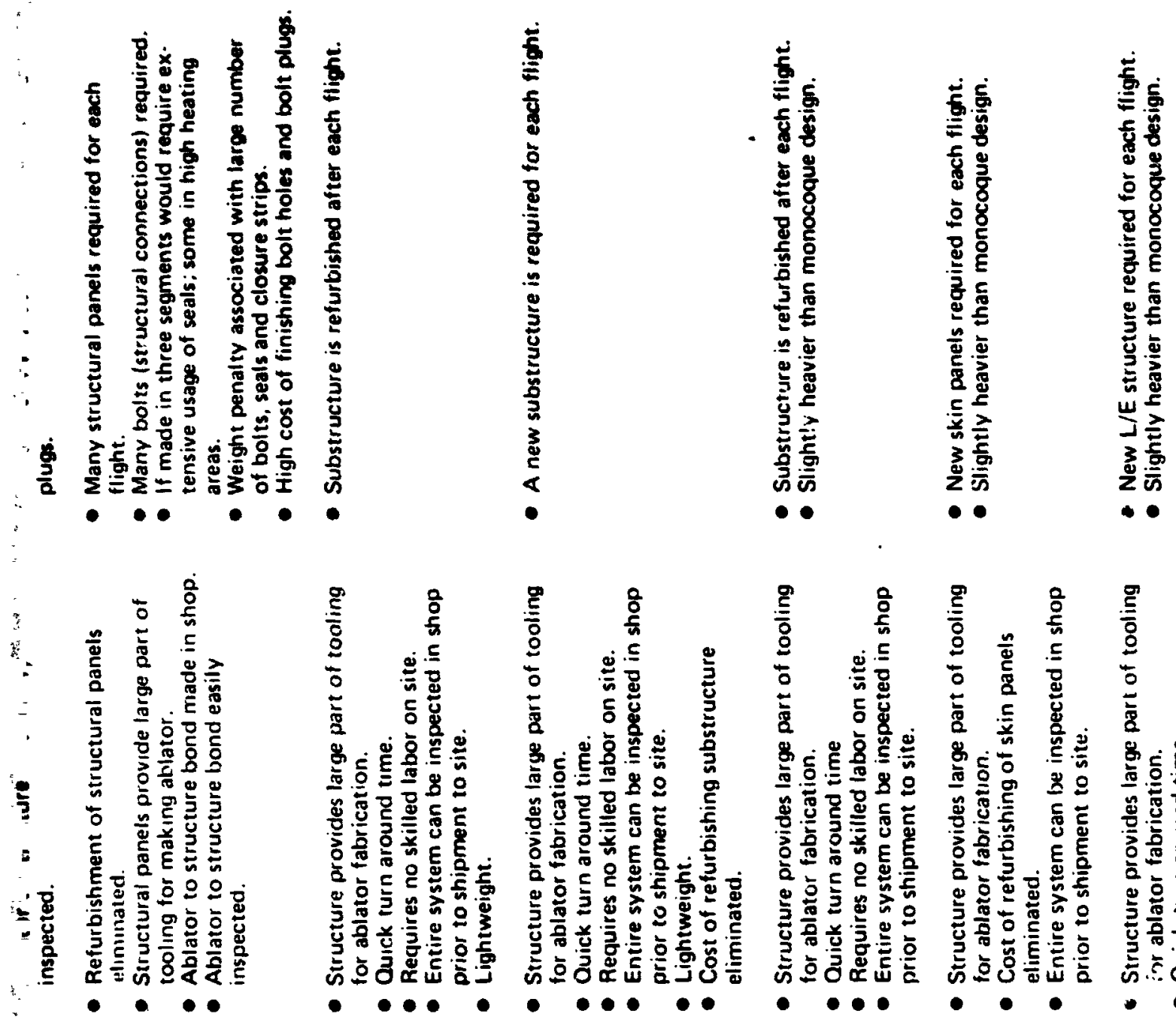

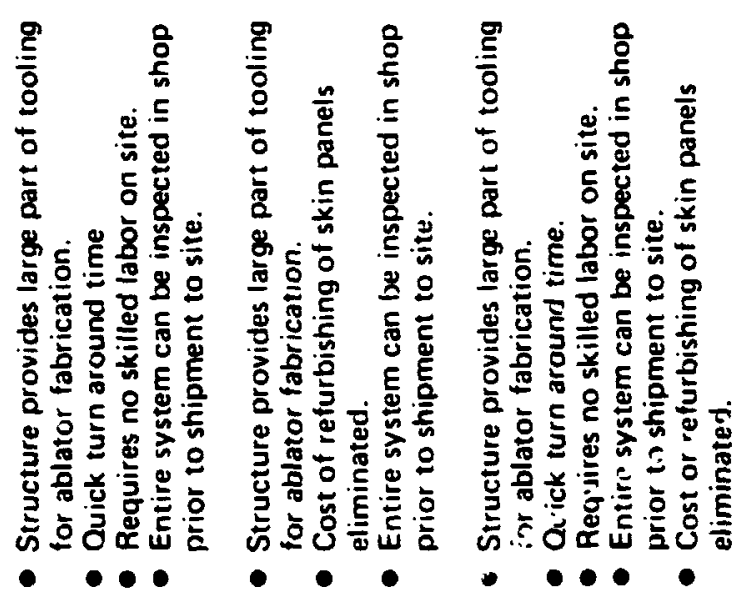
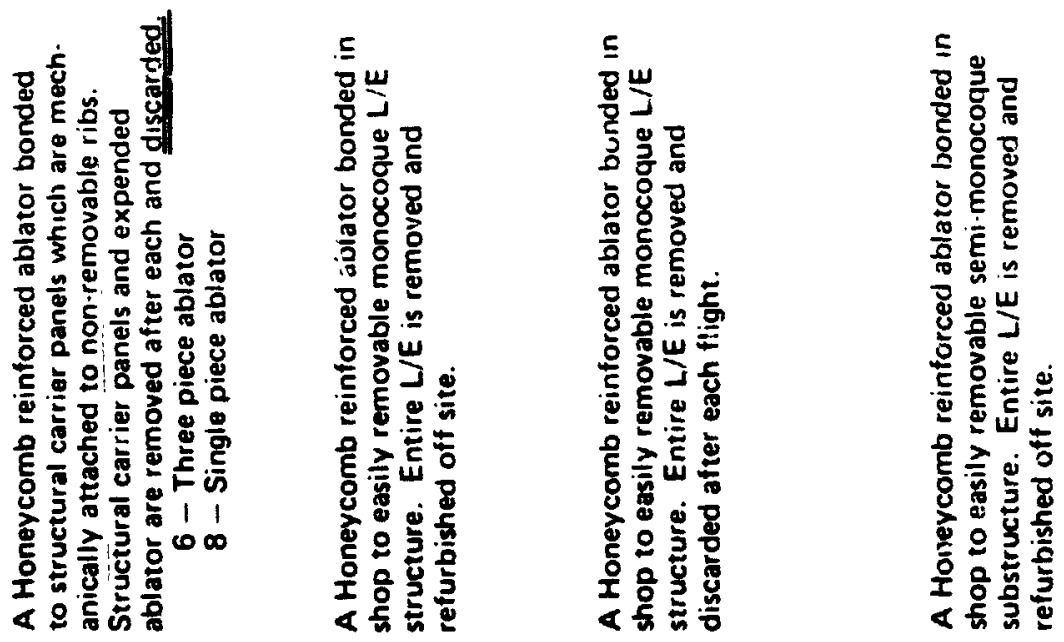

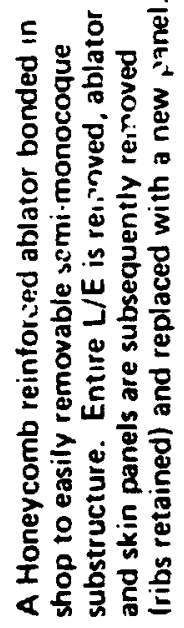

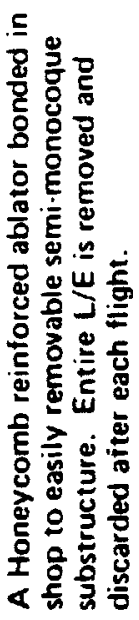

$\infty$
$\infty$
0

우

$=\quad \simeq$

$\underline{m}$ 
the advantages and disadvantages of each concept and the results of the design trade-offs are sumarized in the following section.

\subsubsection{Weight, Cost and Concepts Eveluation}

Having identified and reviewed each desion the concepts were rated relative to their cost, weight, risk factors (e.g. reliability, fabricability, maintainability) and requirements (turn-around time required). As can be seen this evaluation considered the primary driving factors of cost and weight as well as other items requiring judgement (1.e., reliability, maintainability, etc), all of which must be considered in making final decision. In preparing the rating schemes the following ground rules were observed, which were set out in Section 2:

a. The traffic model would consist of 447 flights.

b. The L/E would employ a single ablator covering $600 \mathrm{ft}^{2}$. The following assumptions were also used:

a. The results for the ablator material Avco Mod 7 reinforced with fiberglass honeycomb were also applied to the ESA $3560 \mathrm{HF}$.

b. For handleability the $L / E$ would be made up of discrete segments approximately 36" long. Later desipn studies supported this decis'on.

c. When the substructures are not discarded after each flight, only nineteen substructures will be fabricated.

Table 27 presents a summary of results chtained from this evaluation and figure 72 displays a comparison of weight and cost.

Costs in terms of 1971 uninflated dollars were generated on a dollars per square foot basis using the area and traffic model presented above. To arrive at a true total program cost/ft ${ }^{2}$ it was necessary to include the cost of refurbishment along with the basic costs associated with the fabrication of the ablator and substructure and the costs have been segregated accordingly. Precisely 


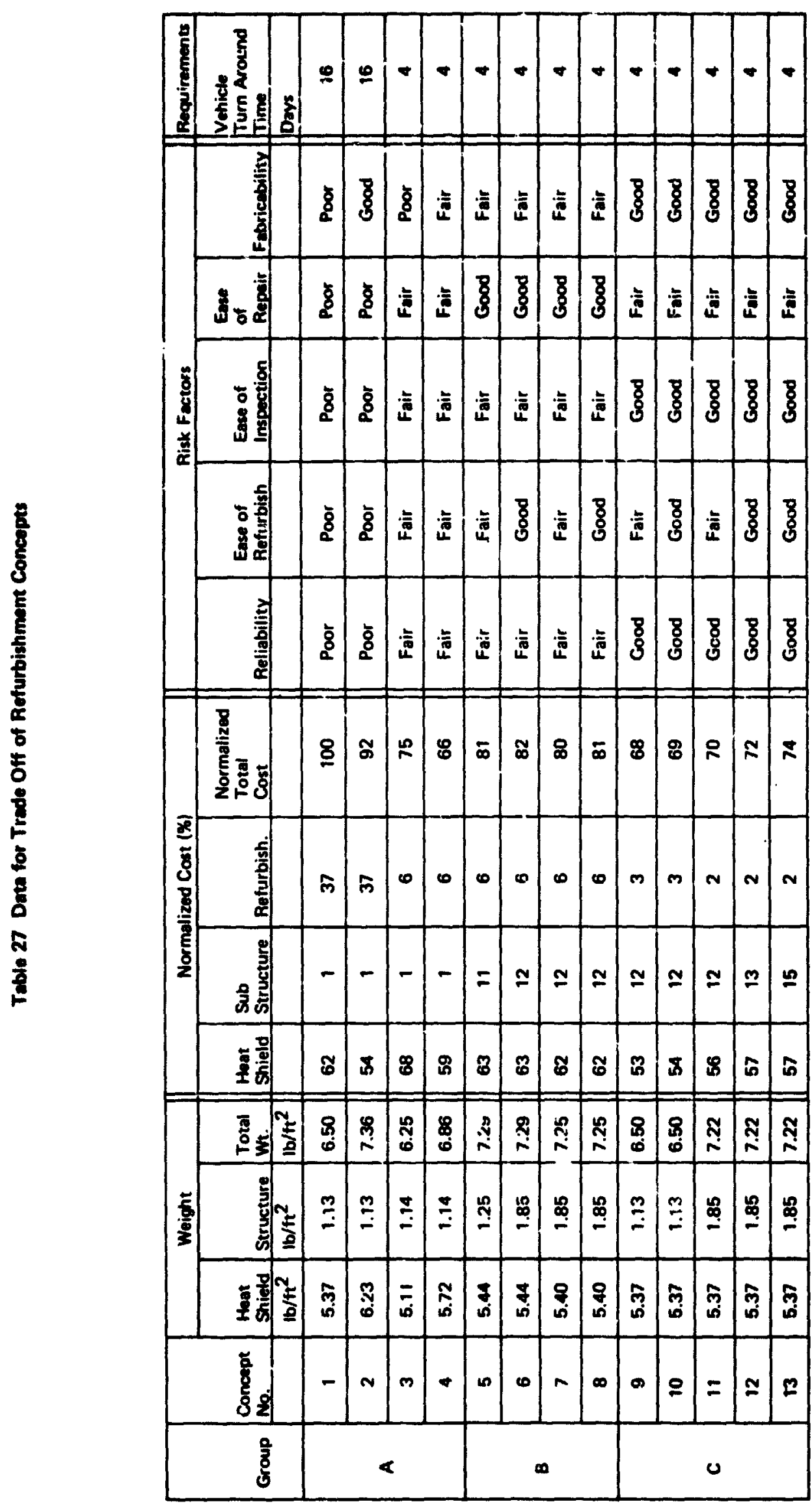



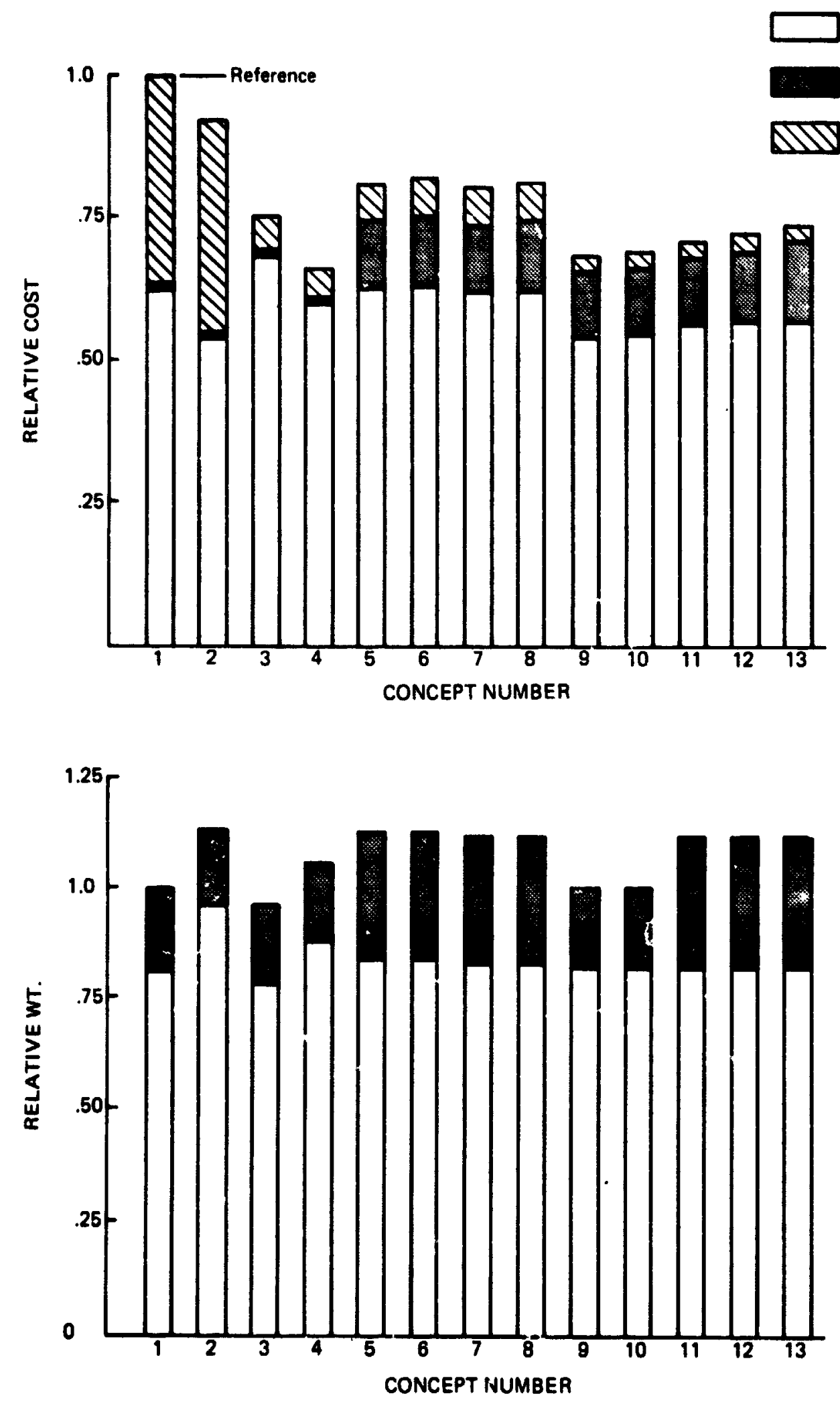

Figure 72 Weight and Cost Comperison of Refurbishment Concapts 
what items have been bookkept for the various cost elements is indicated in table 28. It should be polnted out that in the cost bookkeeping as defined here, "refurbishment" and the associated refurlishment costs are taken to include only those operations directly traceable to the removal and raplacement of the leading edge TPS system on the vehicle. Consequently, the costs incurred (if any) for removing the charred ablator from the substructure after a leading edge assembly has been removed from the vehicle have been accounted for under the cost of the substructure. For the refurbishment sust of table 27, teble 29 presents a detailed man-hour breakdown for each of the operations covered under refurbishment costis. In addition to providing the basis for the refurbishment costs this information was also used to estimate the total turnaround time required to replace the leading edge TPS which is also listed in table 27 .

Weight estimates were prepared for both the Mod 7 Hc heatshield and the aluminum substructure. The bookkeeping used in preparing the weight estimates is indjcated in table 30 . In general, and as expected, the heatshield weight is nearly constant whereas variations are noted in the estimated substructure weights. Although all the structures presented are relatively light-welght when considered in terms of the primary structure, there exists a reas nable percentage difference between some concepts which sould have an impact on the overall vehicle weight. of course, the total $\mathrm{I} / \mathrm{E}$ system weight does not seflect such large variations since the heatshield contributes greater than $75 \%$ of the I/E total weight.

The remaining items included in table 27 are less tangible but nonetbeless important in the overall selection process. These items can be looked upon as risk factors and rely heavily upon experience, understanding and judgement. Some of the 1tems considered are reflected in the cost data presented earlier 
Table 28 Items Bookkept Under Cost

(a) Heat Shield \& Substructure

Heat Shield Cost: includes all the items indicated as ablator production cost in connection with the ablator costs (see Section 5.4); includes also carrier panel (if any) and relative bonding operation.

Substructure Cost: includes all items in the production of the substructures including spares (not DDT \& E or start up). Specifically:

1. Tool design.

2. Tool fabrication

3. Material.

4. Production.

5. Manufacturing management.

6. Packaging and shipping of new substructures (Grumman - Avco).

7. Quality control (inspection, acceptance, certification).

8. Manufacturing documentation.

9. (If substructures are reused) refurbishment cost.

10. (If substructures are reused) packaging and shipping of substructures ,from KSC to Avco).

11. (If substructures are reused) depot cost for the reuse of the substructure.

\section{(b) Refurbishment Costs}

Refurbichment Corty; the cost of all operations needed to remove and replece any pert that needs to be removed and replaced plus the cost of maintaining storage areas, equipment, etc., needed for the operations. These costs are only recurrent costs, not DDT \& E or stert up. Items included:

1. a) Takd-off from vehicle the l.e. seament (or anything that need be taken off for replacement).

b) Ship it to storace area.

2. Inspection of 1.e. area after removal (for example: in concept 1, inspect substructure after removal of charred ablator, in concept $7-13$, inspect front beam).

3. Ship new 1.e. (ablator, ablator panel, l.e. segments, etc.) from storage.

4. Install new l.e.

5. Install joint seals.

6. Final inspection of installation by vehicle manufecturer.

7. Cost of storege for new 1.e. parts (ablator penels, ablator, l.e. cogments, otc., depending upon the concept).

Noplected were:

8. Cost of depot spece for the refurbishment of the vehicle when sblator removal is to be done on site.

8. Storage for discarded 1.e. parts. 


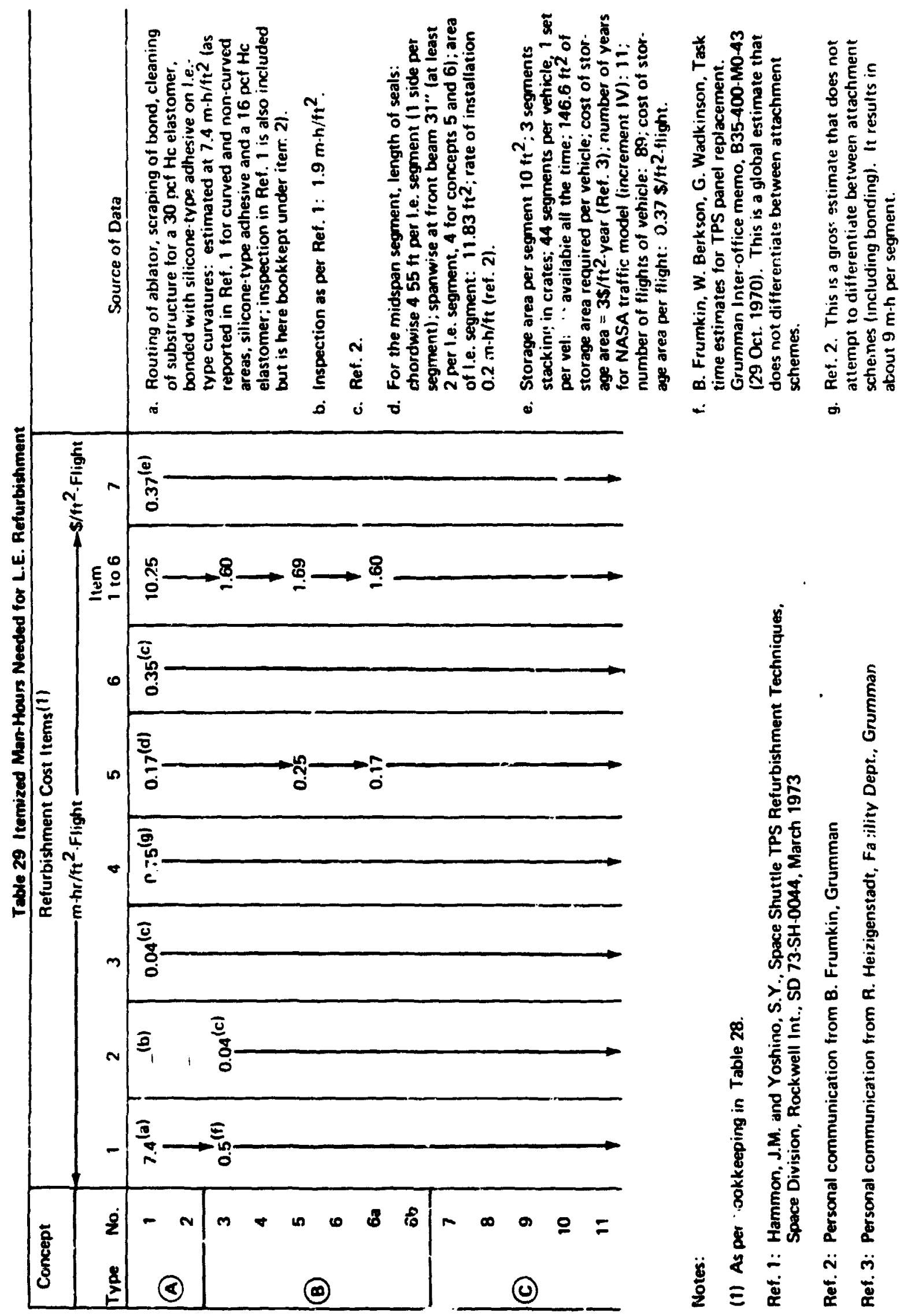


Table 30.

Bookkeeping of Weight Items

Beat Shield Weight: includes the veight of all the items book kept under the cost. Specifically:

1. Ablator.

2. Bond between ablator/carrier panel and substructure.

3. Coating (if any).

4. Seals, including internal insulation strips (if any).

5. Bolts and plugs,

6. Cerrier panel and bond between carrler panel and ablator (if any).

Substructure Weight; includes the following:

1. Substructure proper to the wing front beam.

2. False ribs.

3. Attachments welght (hinge pin, quick release mechanism). 
in the table, only insofar as one can predict their impact on weight and cost; however, it is necessary to examine these factors in the light of the uncertainties in prediction. Moreover, all factors that may contribute to deviations from nominal operations must be considered in the light of the risks taken. This gives further insight into the understanding of the individual concepts. Since there is no exact or absolute rating system available for these items it was decided to rank them on a good/fair/poor basis. Given time it is pcssible that a more exotic rating system could have been arrived at, buit, the end result would be about the same. In examining table 27, it shourd not be inferred that the specific rating assigned to each concept is absolute from the overall design standpoint but, rather, based upon our combined judgement this is how it ranked relative to the other concepts presented. For example, giving a poor rating to concept one for reliability simply means that its reliabilit; relati:e to the other concepts presented is judged to be lower.

The risk factors selected cover the more important aspects of the design with admittedly some overlap. In making the evaluation the following factors were considered for tre various topic headings; reliability, ease of refurbishment, ease of inspection, ease of repair and fabricability.

Reliability is the confidence level one can assign to the final piece of hardware in accomplishing its intended mission. Items considered were design complexity, amount and type of inspection required, caliber of inspection procedures available, and the type of labor end work area in wich the fabrication was conducted.

Ease of refurbishment is taken to mean how difficult and time consuming would be the job of refurbishment. Although this would be reflect ad in the costs 
to some degree the effect of cost was not factored into this rating. Rather, items related to preparing the vehicle for flight were considered, such as removing and replacing the leading edge and refurbishing the substmucture. Concepts ratin $n^{-}$high in this category obviously would be those where the leading edge is easily removed and jiscarded.

Ease of inspection involved the amount of inspection required, the caliber of the inspection techniques available, the importance - $f$ the inspection, and the amount of confidence one could assign to the inspection having been perform: $x$. Here, concepts where to accessibillty for inspection was possible during the bul's of the assembly cycle rated highest.

Under ease of repair it was assumed that a complete segment on the vehicle would have to be removed and replaced. The amount of effort required and difficulty encountered in performing this task was rated here.

Fabricability considered the relative amount of difficulty expected in developing and implementing a fabrication scheme for the assembly of the leading edge. This included tooling development and the various molding, trimming and finishing operations required to produce a complete piece of hardware.

\subsubsection{Refurbishment Concept Selection}

In its entirety table 27 presents a goo overview for all the potential refurbishment concents considered. Taken individually the elements in the table show that (a) from both the weight and cost aspects (figure 72) the ablative heatshield is the driving force; it constitutes about $75 \%$ of the system weight ana accounts for $\lesssim 2 \%$, on the average, of the total system costs, (b) with the excepticns of Group A, for equivalent designs whether the substructure is refurbished or discarded does not influence the overall subst,ructure cost dramatically, (c) vehicle turn around time -s prohibitive for 
direct bonding to the vehicle (Group $A$, coecept I 2) and the least time is required for concepts where the eatire leuding edge system is rewoved and replaced and, (d) concepts where the bulk of the fabrication activity is confined to work performed in a refurbishment depot or at the ablator manufacturers plant rate the best from an overall risk point of view:

Taken collectively these elements show that Concepts 1 \& 2 are strongly objectionable from the required turn-around time since the target time for the vehicle is between 150 and 250 hours (see Section 2). Additionaliy, the cost and reliability factors for these two cancepts are also unacceptable when compared to the other alternative appecaches. The combined aupects of system weight and cost can be used to eliminate all the Group B concepts as well as Concepts 11 through 13 in the Group C classification. It should be pointed out here that this elimination process is directed at obtaining a ninimm weight, cost system within the fremorror of acceptable risk fuctors and turnaround time. Consequeatiy, the fact that a particular concept is eliminated does not necessarily mean that it is undesirable or unworkable but rather based upon the data presented it was concluded that a more attractive system is available. Accordingly, having made these cuts, four candidates remain, concepts 3 and 4 of Group $A$ and Concepts 9 and 10 in Group $C$. Although Concept 3 is the 11ghtest it is also the most expensive. Cost alone is insufficient to elininate this concept since lor veight can result in considerable cost savings when assessed on an in-orbit-payload basis. Looking rurther, however, it is observed that the overall risk factors associated with this concept are high. In fact, the desirability of fabricating an ablative heatshield in this configuration without a back-up structure is in question, notwithstanding the use of embedded mechanical fasteners without a back-up structure. These concerns are reflected in the high cost for the heatshield as well as the fair rellabllity and poor 
fabricability rating assigned to this concept. This combination of factors was considered sufficient fustification to eliminate Concept 3.

Jf the thrie remaining concepts, namely Concents 4,9 , and 10 , there was only : need to se'ect concept 4 or Concent a since Concept 10 differed from $?$ only relative to whether the substructure was reused or discarded after each flight. It was folt that in the event that concent. a nroved to be the most desirable the decision on whether to reuse or discard the substructure could be deferred to a later time. On the other hand Concept 4 being in Group $B$ represented a totally different approach to vehicle refurbishment as compared to Concepts 9 and 10 taken collecti rely.

Weightwise Concept 9 is slightly lighter than Concept 4 and it also has a nore favorable risk factor rating taken across the board. Additionally, the rehicle turn-around time is somewhat less for this concept. The only negative factor pertaining to Concept 9 relative to Concept 4 1:; that its total cost is slightly higher. In the final analysis it was concluded that the lower system weight wo. a more then compensate for the modest difierence in total system cost. This combined with the other desirable features lead to the selection of Concept 9 as the best refurbishment concept. The decision as to whether a rotally disposable system (Concept 10) or a reusable substructures approach (ancept a) we lld be the most attractive is left open at this point in time. It would reen, however, that based on these initial estimates for the substructure cests, reusing the substructures in a totally removable leading edge ...lds a very slight cost advantage.

\section{6.? Attachmerts}

In view of the fact that a tot.al ly removable monocoque leading edge system was siected as the candidate desien, all leading edge to front beam attachment 
schemes investignted were directod at this tape of concept. Besides examining the primary attacknent of the leading edge to the ving frout beens, the connection (if and) between adjacent leading odge segments was also evaluated. The details of this evaluntion and selection process are presented in the following sections along with the governing design criteria.

\subsubsection{Desion Ground Rules}

As with all trade-off studies a set of design ground rules were prepared prior to evolving the attachment schenes. It was intended that these rules define specific operational requirements of the leading edge of the shuttle orbiter, more than the obvious good practice of designing for hardware integrity and maintainability. Accordingly, the following ground rules were specified.

1. Wore thin two extre enomis need to be removed in order to remove

\section{given segment.}

This rule is a compromise between the two extremes of sequential and random removal (see schematic, figure 73) should a segment require reinspection and/or removal before flight. The argunente egainst sequential removal are: a) the time and expense of removal of all the segnents; b) the dasire to limit (for reliability) to twice the handling of a segwent even if during inspection there were a aeed to rewove more than odce a given segent. On the other hand, completely random removal is somentat too stringent a requirement that is not really justified per se and may eliminate outright potentially interesting attachment concepts.

The implewentation of the semisequential approach set forth above would require key segments (externaliy renovable) at every sixth $L / 8$ element in order to meet the no more than two segments be removed to resove a given segment. This is 1llustrated in figure 74 , where left to right removel sequence vould 


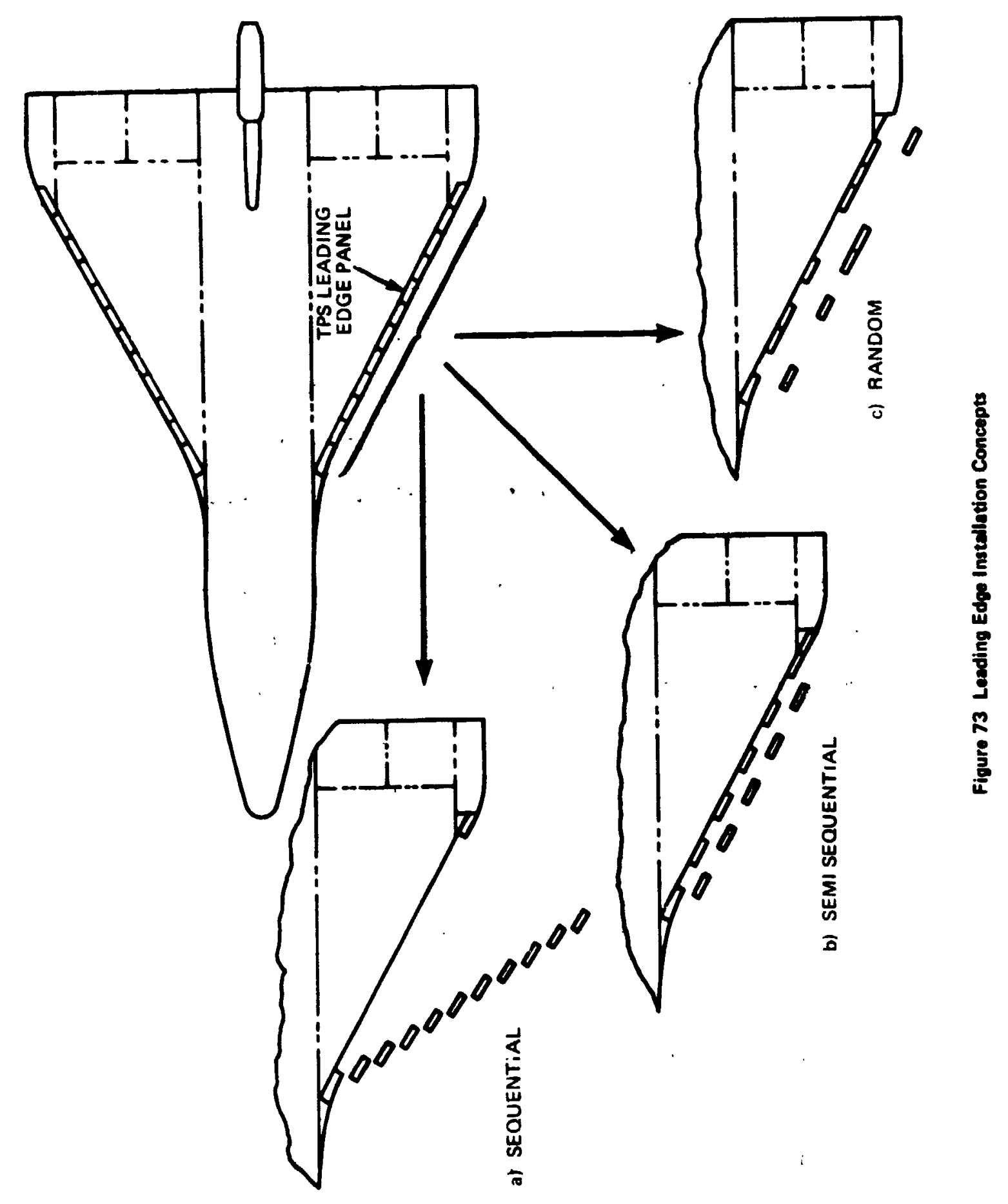




$$
\nabla
$$


be employed to remove the third inboard segment, whereas a rifht to Ieft approach would be utilized to remove the fourth inboard segment. A repeating spanwise pattern of this type would be needed as a minimum to meet this ground rule. It should also be possible to install segments in each wing simultaneously so that with a reasonable operation (e.g., 2 shifts and 2 crews of 8 each) the 1.e. refurbishment time is well within orbiter turn-around limits ( 150 to 250 hrs.).

2. No access to the front beam shali be relied upon from inside the wing, as had been envisioned at one time during Phase $B$ of the Shuttle Program. This rule is justified $3 y$ the desire:

a. To maintain flexibility of the ablative 1.e. design sith respect to the orbiter configuration in that the attachment should be applicable to a double-delta orbiter where access to the (thin) forward wing may not be possible or to orbiter configurations with 1 .e.'s of small radil ( $3-4$ inches).

b. Assure that the ablative 1.e. design can be easily adapted to one that is interchangeable with the carbon/carbon system or to one that admits RSI ahead of the front beam, though the ground rules (see section 2) do not require to consider these possibilities. The most natural adaptation to such a case would be to substitute a nose spar for the front beam in our design. However, accessibility to the nose spar from inside the wing may well be impossible.

c. To provide independence of the 1.e. refurbishment fram the refurbishment of rest of the vehicle, which is strongly suggested by the tight turnaround time required for the orbiter(150 to $250 \mathrm{hrs}$.$) . Incependince$ 
assures parallel rather than series operations.

d. To eliminate, at least for the 1.e. refurbistment, the samewhat exotic operation for having a person crawl into the wing through the gear opening.

3. No removal of a RSI tile or a plug through the RSI shall be required for the segment attachment. The reasons for this rule are:

a. Independence of the 1.e. refurbishment as stated in Nhmer 2c. above.

b. Good design practice for reliability. The RSI tiles ideally need not be removed except after a mundred flights or so while the ablator is changed after each flight; therefore, if a plug is needed it should be through the ablator and not the RSI.

\subsubsection{Leading-Edge-to-Wing-Front-Beam Attachment Schemes}

In general there are three basic approaches which can be employed to make the primary attachment between the leading edge and the front beam. These include direct bolting, continuous attachments, and quick release mechanisms as illustrated in figures 75 through 78 .

The most fundamental approach is by direct bolting as depicted by figure 75 . There are a number of variations which could be made on this basic concept, however, consistent with ground rules Nos. 2 and 3 all access to the bolts must be made through the ablator L/E. Obviously, all segments would not have to employ bolts passing through the $\mathrm{H} / \mathrm{S}$ and covered by bolt plugs as shown in figure 75. Rather, external bolting could be used for selected L/E segments (every sixtl segment - ground rule No. 1) with internal bolting (see figure 76) employed for intermediate segments. Of course such an approech carries with it the requirement that access to these interral bolts 


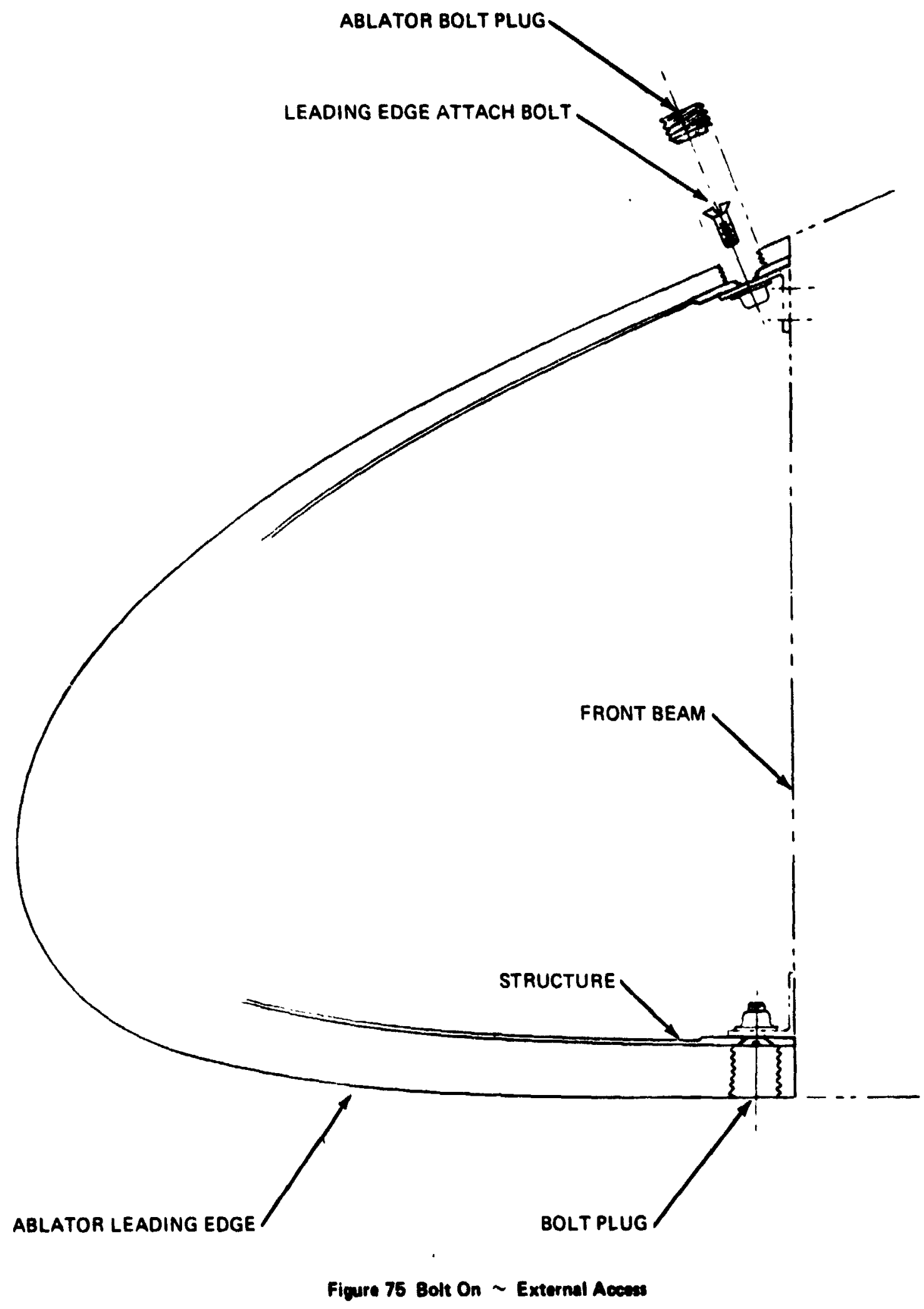




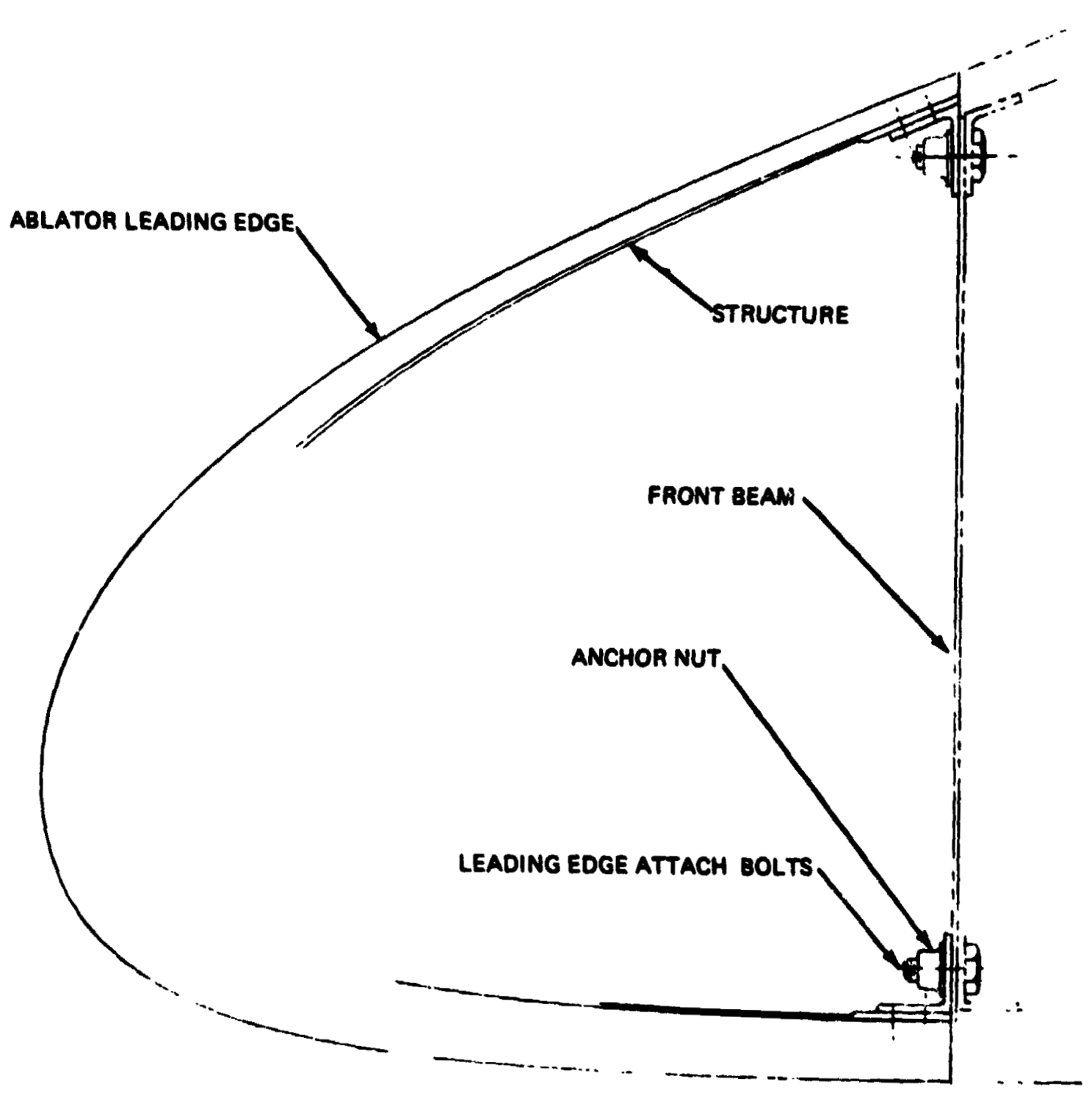

Figure 76 Bok on Internel Acoem 

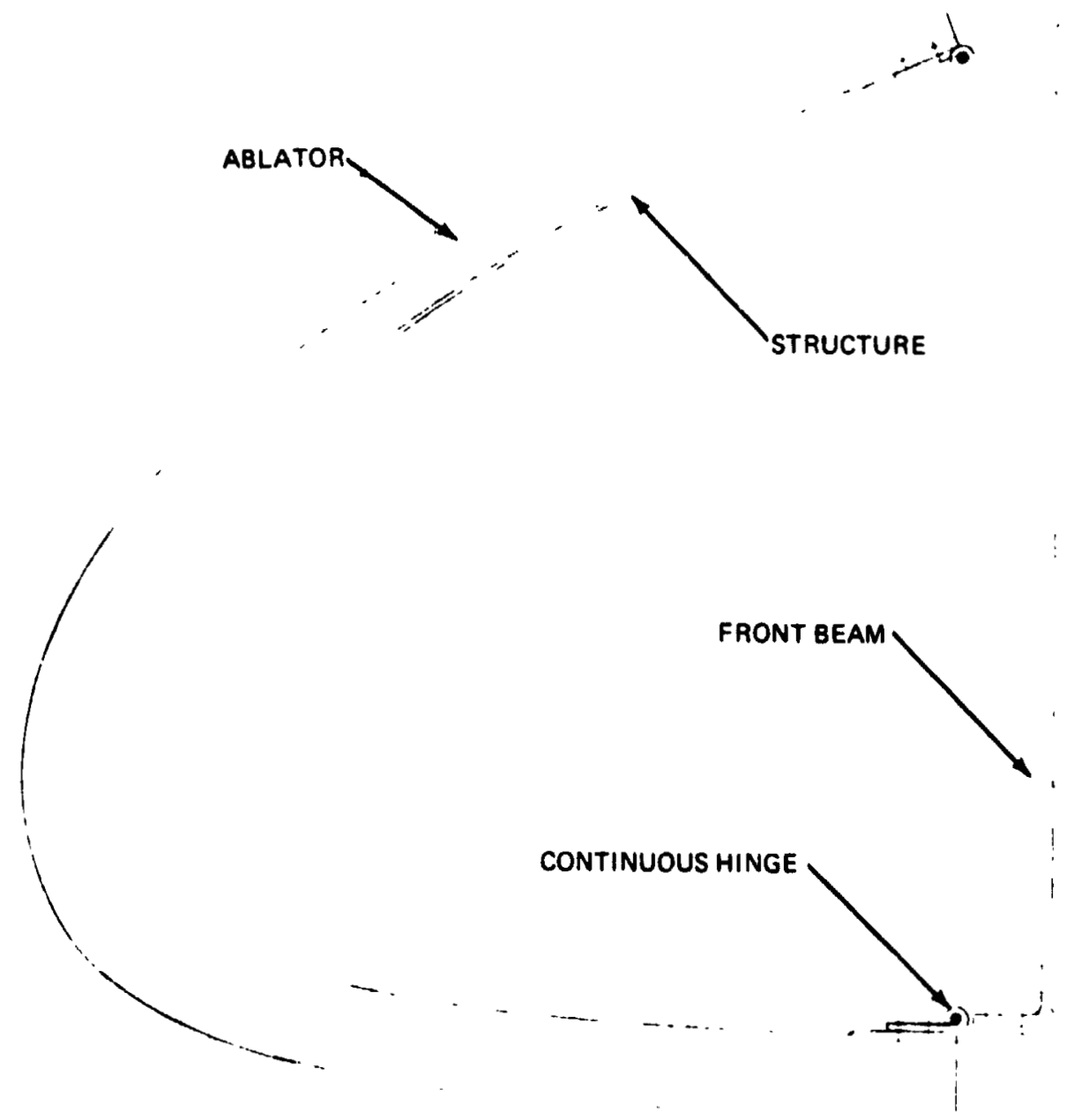

Fiqure 77 Hirne Pin 


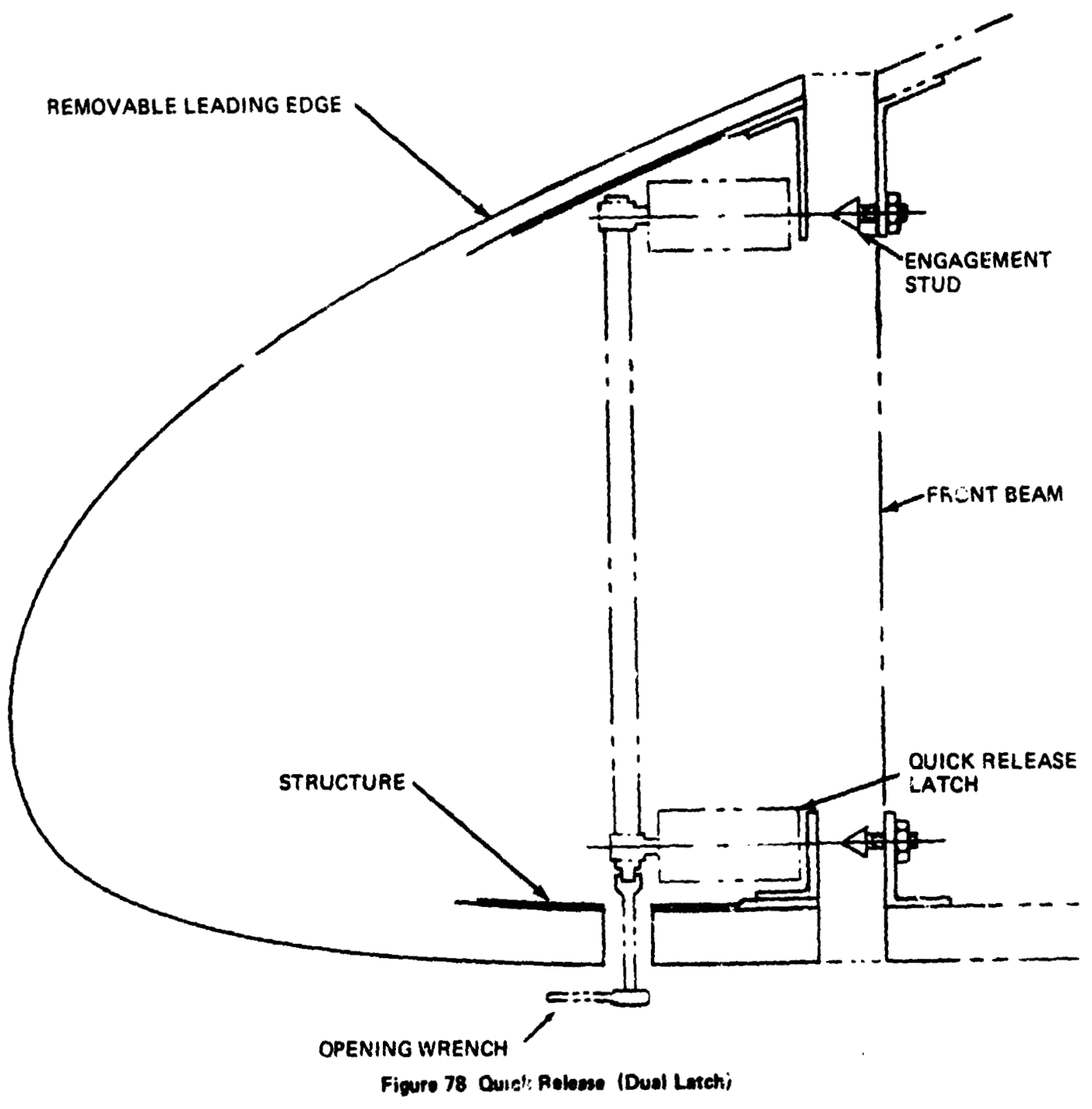




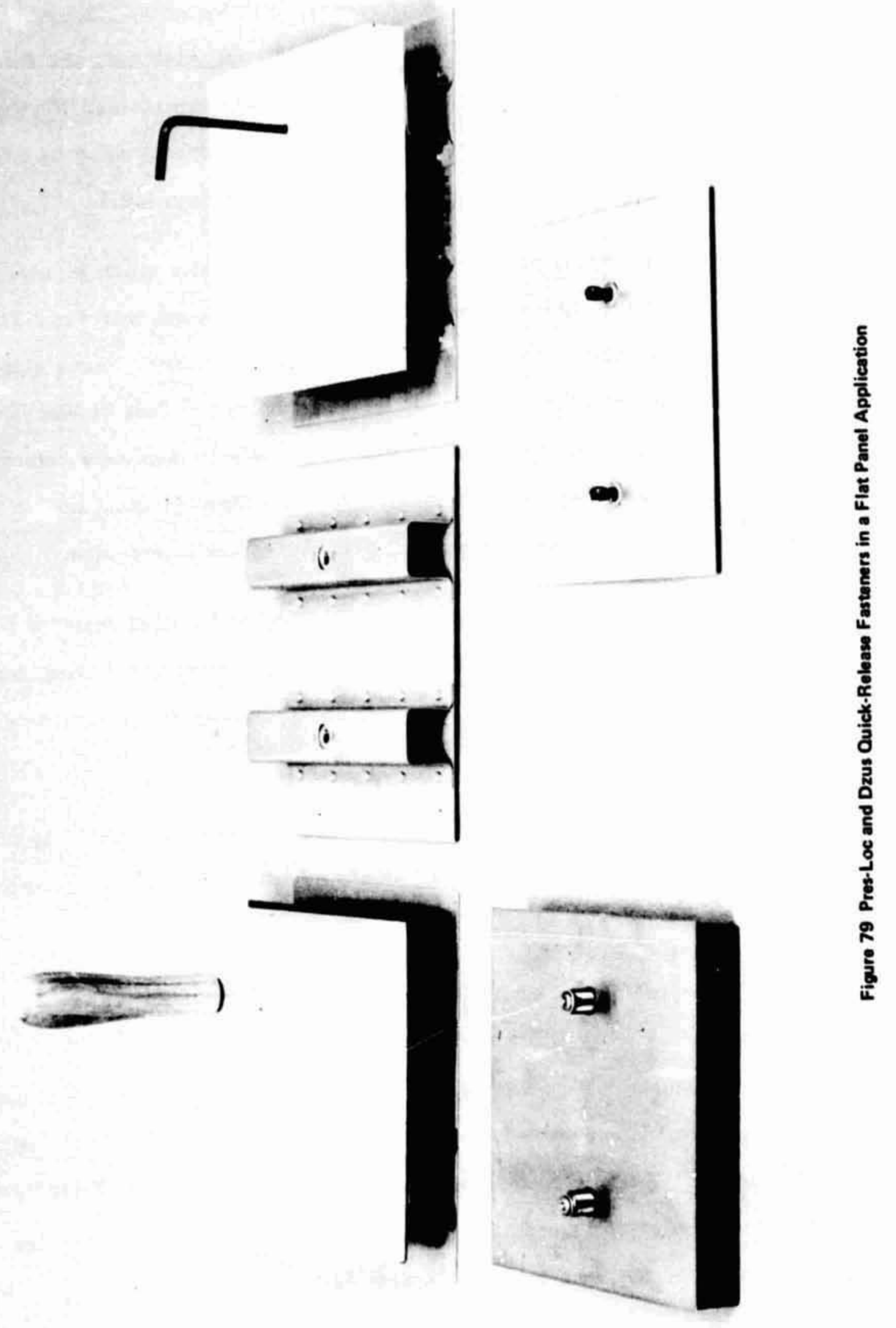
a more in depth investigation would be needed. For instance, calculations Indicated that the structural loads at the front beam attachment are modest such that all attachment schemes presented are viable candidates. Furthermore, with some minor alterations, each of the approaches proposed could be designed to satisfy all the basic ground rules set forth in Section 6.2.1.

Also, with the exception of the Hartwell Plus Latch System which employs a mechanism to activate the attachment, it could be concluded that the difference in weight between the various other schemes would be minimal. Costs also proved to be inconclusive since on the one hand bolts are less expensive than the quick release machanisms, whereas with quick release fasteners refurbishment time for the vehicle would ive less. Here the piano hinge seemed to be more favorable both in terms of initial cost and refurbishment time.

Higher reliability of bolts and the piano hinge could be cited relative to the quick release mechanism, bu his wulidi ily be conjecture since there has been little experience acquired with quick release fasteners in this type of applicator.

The key question should te one of ease, simplicity, consistent rapidity of the operation of installation and removal of the typical segment. The schemes appear essentially comparable from this point of view.

This was borne out by the evaluation of the schemes using the two Avco leading edge mock-ups (Ref. 2). Figure 80 shows Mock-up No. I which containea bolt plugs to fasten the $\mathrm{H} / \mathrm{S}$ panels, and a combination of bolts and piano a hinge to attach the nose cap. Figure 81 shows Mock-up io. 2 consisting of two leading edge segments. The left hand segment is attachea using the Plus latch system shown disassembled in figures $81 \mathrm{~b}$ and $c$. The rose cap of the right hard segment employed the dual latch hinge shown disassembled in figures $81 \mathrm{~d}$ and $e$. 

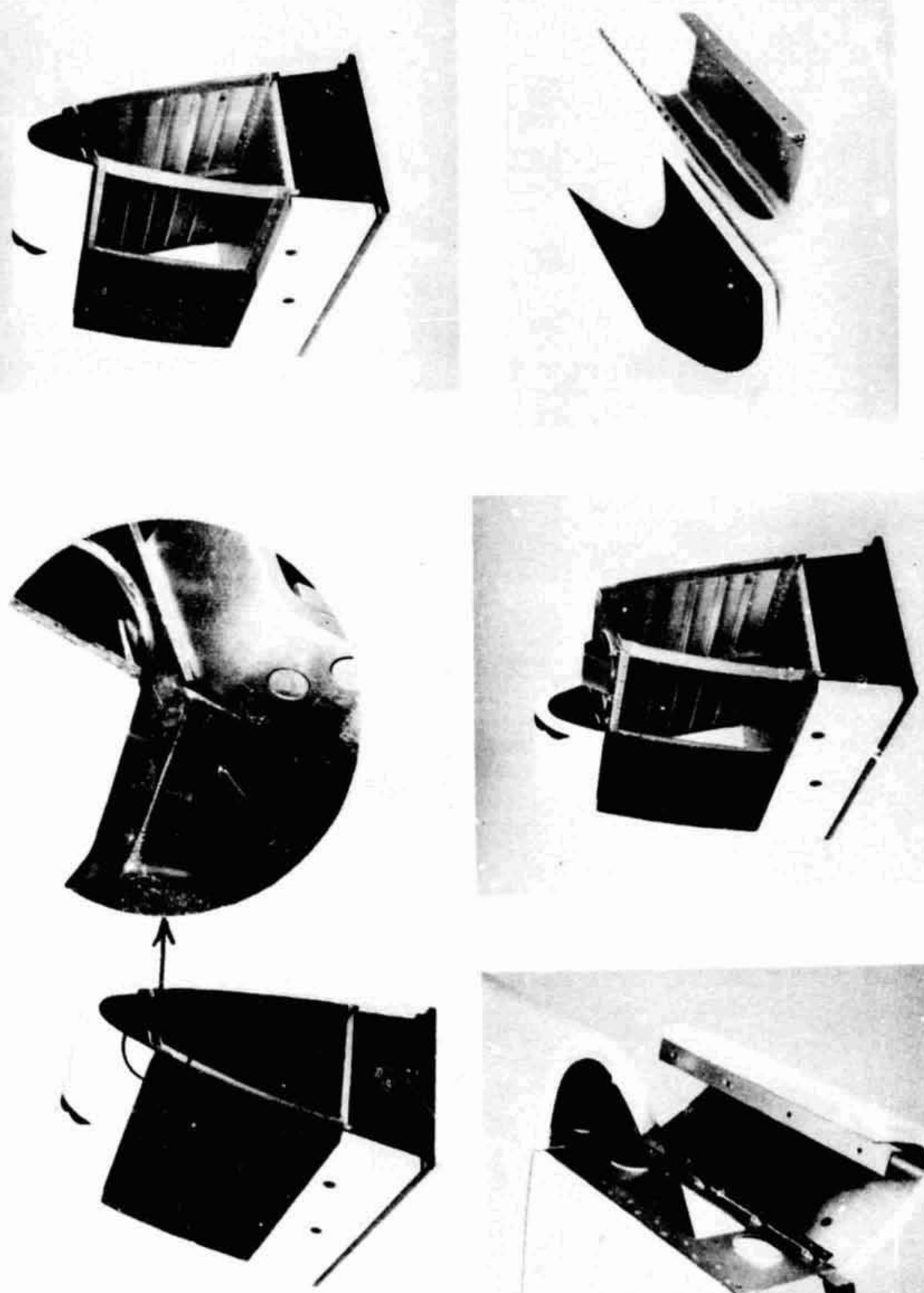

 

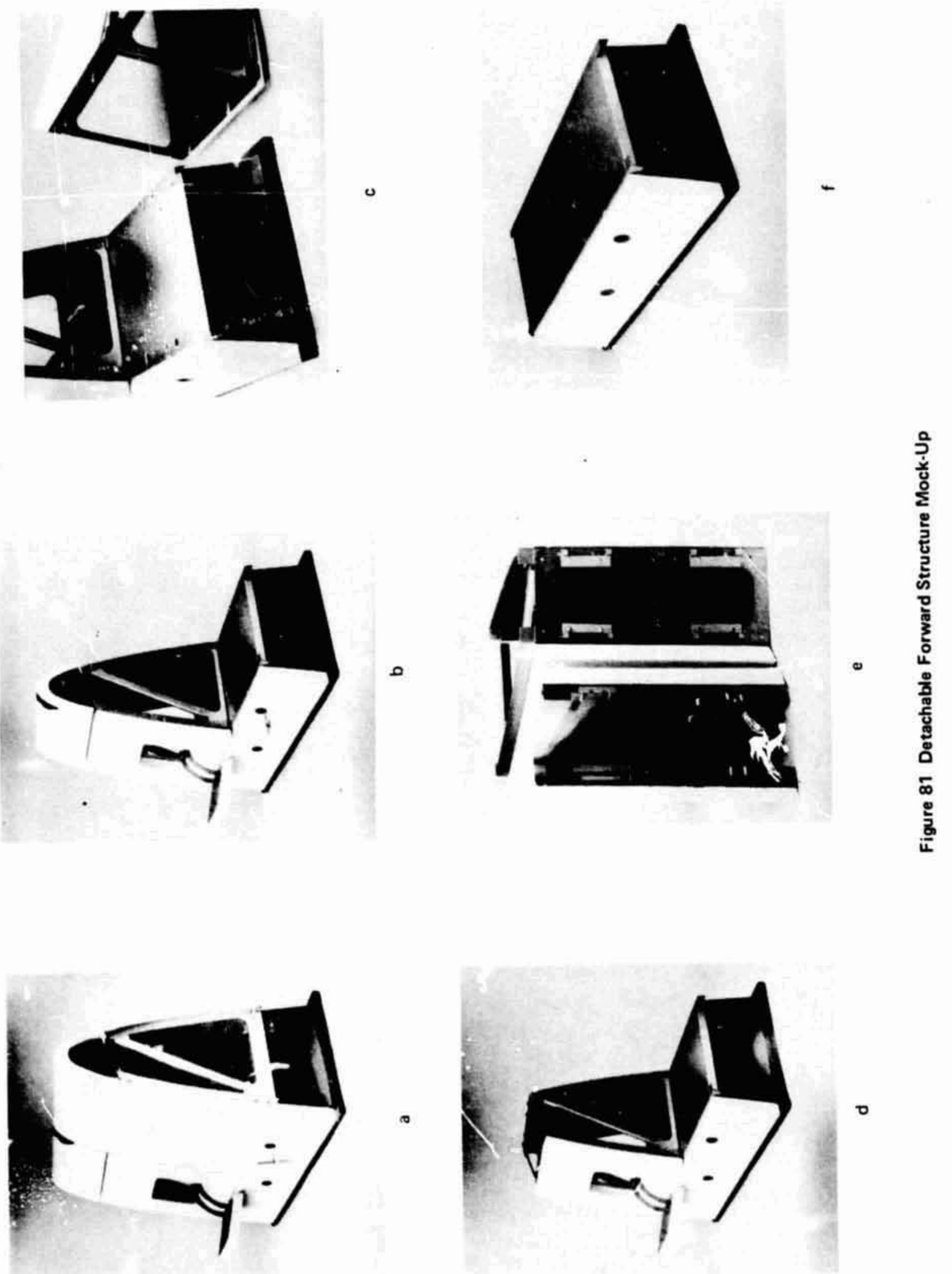
Natura1ly, mock-up tests are carried out in somewhat ideal conditions, definitely better than the operational environment and therefore caution is required in interpreting the resuits.

The one item that tended to discriminate between the schemes was the structural concept selected for the design of the substructure, i.e. uncoupling the leading edge from the front beam in the spanwise direction (see Section 6.4.2).

For the bolted or quick release method of attachment a means had to be implemented to allow for free spanwise expansion. One approach envisioned was to fix the segments at their midspan and use slotted holes for the remaining connections. This would allow for free expansion in both spanwise directions with the center tie providing a fixed reference point. Such an approach was eliminated because of the concern registered by the Gruman design personnel relative to unsatisfactory performance of slotted holes in this type of application. Gruman's recommended procedure for connections which have preferred directions of movement is to use flexible members which allow movements through deformation. As a result the proposed scheme would still have a central flxed tie but the ends would have connections with built in spanwise flexibility. Alternatives to this would be to have connections at either end of the segment only, with one end fixed and the other floating. In either case the number of bolts or fasteners per segment would be minimal ( 4 to 5 ), making both the connection detail more complex as well as affecting the structural design of the leading edge. With these discrete connectlons the leading edge structure would have to be reinforced at the upper and lower edges along the attachment interface in order to distribute the surface loads Into the connections. Additionally, since both positive and negative pressures were considered, these edge members would have to form an integral part of the leading edge assembly. With the rib stiffened designs selected (see section 6.4), 
this added member tended to complicate the fabrication frocedure.

In comparison the piano hinge concept provides a contimuous means of attachment which can zccommodate free :panwise relat.ive motion betwen the front beam and the leading edge. Moreover, the continuous adge support is structminly more desirable for reacting the relatively uniformly distribated swanwise pressure loads experienced by the leading edge segments resilting in a clear structural design.

The combined attributes of low initial cost, short vehicle turn-around time and overall design simplicity make the plano hinge an attractive concept. This attachment scheme readily lends itself to a semi-sequential installation and removal approach. The strongest objection to the plano hinge concept is a general feeling that the pin might be difficult to remove after being subjected to the severe flight environment. It was noted that most prior applications of this approach for attaching flaps, cowlings and ailerons allowed the part to be rotated while extracting the pin a freedom that does not exist in this application. Counter arguments in favor of the piano hinge were: the pin would be used only once, its length of about $30 "-36$ " is not excessive; the method of installation and removal includes a small drill attachment which could rotate the pin while heing inserted or extracted;and fingliy since the pin is protected the flight environment wculd be probably less severe than equivilent camponents on conventional aircraft.

\subsubsection{Selected Lew-to-Front-Bean Attachnent.}

The piano hinge concept was selected because of the simplicity of the structurel design and the absence of strong objections with regard to the difficulty of inserting the pin over and over in in the hinges fixed with the wing. The hinge will be of stainless steel. 

joint and act as a former to Frovide a means of alignment for the L/E segments during assembly. There is no positive attachent between the $L / E$ and these ribs but they will tend to retain the continuity of the $L / E$ reross the joint when subiected to iir lozds.

\subsection{Ablator Design}

The main contributor to the weight of the leading edge is the ablator material. Therefore, it is critical to review the design considerations and define the safety factor rationale so that a rellable (but not overly conservative) design is produced. This section describes the approach used in defining the reference design together with the final results. All results shown here are based on. the Avco Mod $7 \mathrm{HC}$ and ESA $3650 \mathrm{HF}$ materials.

\subsubsection{Design Thermal Loads}

Table 31 summarizes the heatir. data for various locations on the Grumman 473 orbiter leading edge that were utilized in sizing the ablator heat shield. Maximum values are presented for ascent (nominal and abort-to-orbit) and reentry (nominal and dispersion). For ascent the nominal condition provides the highest integrated heating with only slightly lower rates than the abortto-orbit case. For reentry the integrated heating for both the nominal and dispersion case is quite close with the dispersed hoatirg rates, about 20\% higher. The heating values shown in tabje 31 and used in defining the heat, shield requireme.ts do not include the effects of shock impingement (see Section 2).

Of additional interest is the relationship between the ascent and reentry heating. Table 32 summarizes the heatirg at the missan region for various locations around the leading edge. As - an be seen the maximum total heating occurs where the reentry heating is a maximum. It is also important to note 
Teble 31 Summary of Leeding Edge Heating Stagnation Line of GAC 473 Orbiter Wing

\begin{tabular}{|l|c|c|c|c|c|c|}
\hline Trajectory & \multicolumn{3}{|c|}{$\dot{q}_{\text {Max }}\left(\mathrm{Btu} / \mathrm{ft}^{2}\right.$-sec) } & \multicolumn{3}{c|}{ Q $_{\text {Total }}$ (Btu/ft ${ }^{2}$ ) } \\
\hline Ascent & Tip & Mid-Span & Rout & Tip & Mid-Span & Root \\
\hline Nominal & 12.4 & 12.4 & 12.4 & 6,100 & 6,100 & 6,100 \\
\hline Abort to Orbit & 14.2 & 14.2 & 14.2 & 4,440 & 4,440 & 4,440 \\
\hline Reentry & & & & & & \\
\hline Nominal & 51 & 51 & 45 & 64,200 & 64,200 & 57,100 \\
\hline Dispersion & 60 & 60 & 52 & 64,300 & 64,300 & 55,200 \\
\hline
\end{tabular}


Teble 32 Summary of Herting Distribution at Mid-span Location (CAC 473 Orther)

\begin{tabular}{|c|c|c|c|}
\hline $\begin{array}{l}\text { Location } \\
\text { (\% Chord) }\end{array}$ & $\begin{array}{c}\text { Nominal } \\
\text { Ascent }\left(\text { Btu } / \mathrm{ft}^{2}\right)\end{array}$ & $\begin{array}{l}\text { Nominal } \\
\text { Roentry (Btulft }{ }^{2} \text { ) }\end{array}$ & Total $\left(B t u / f t^{2}\right)$ \\
\hline-10.0 & 548 & 643 & 1181 \\
\hline-5.0 & 1035 & 1288 & 2323 \\
\hline-3.0 & 1645 & 1927 & 3572 \\
\hline-2.0 & 2135 & 3215 & 5360 \\
\hline-1.5 & 2745 & 4503 & 7248 \\
\hline-1.0 & 3660 & 5142 & 8602 \\
\hline-0.5 & 5185 & 11572 & 16757 \\
\hline o & 6100 & 41795 & 47895 \\
\hline+0.5 & 5915 & 64300 & 70215 \\
\hline+1.0 & 3355 & 63010 & 68365 \\
\hline+1.5 & 1707 & 61084 & 62791 \\
\hline+2.0 & $\theta 16$ & 57869 & 58784 \\
\hline+3.0 & 548 & 48224 & 48772 \\
\hline+5.0 & 548 & 23788 & 24308 \\
\hline+10.0 & 648 & 17363 & 17911 \\
\hline
\end{tabular}


that the ratio of ascent to total heating varies fram $45 \%$ at the leeward joint to $3.4 \%$ at the stagnation point to only $1-3 \%$ along the windward side. It is obvious, therefore, that ascent heating must be accointed for in defining the heat shield thicknesses particularly in the leeward regions where the offect may be quite pronounced.

\subsubsection{Thickness Predictions Charts}

To establish same initial estimates of heat shield thickness, $r$ lculations were performed using the Avro charring ablation code (Computer Program 2500). The transient environment as defined in Section 3.5 and the material properties as shown in Section 3 of Volume 2 were used in the calculations. The results of these calculations are shown in figure 82 which indicates the thickness requirements of the Avcc Mod 7 and ESA 3560 HF as a function of maximum struc'ure temperature (allowing for soak out) for two integrated heating conditions. Figure 83 indicates the local weight $\left(1 \mathrm{~b} / \mathrm{ft}^{2}\right)$ for the two materials as a function of integrated cold wall heating for a liniting structure temperature of $350^{\circ} \mathrm{F}$. The two conclusions to be gained from these data are (1) Avco Mod 7 HC and ESA $3560 \mathrm{HF}$ have apparently the same thermal efficiency, and (2) the ablation thickness on the leading edge will vary from about $1-3$ inches over the contour of the surface.

In order to establish ablator thicknesses on the leading edge it is necessary to determine the effect of iscent heating. The effect varies over the leading edge due to the relationship between ascent and $r_{-1}=1 r_{\Sigma}$ heating shown earlier (see table 32). Figure 5t indicates the result of this study for the Nod $7 \mathrm{HC}$ material. Two conditions are shown, one for the case of reentry with virgin material and the second for reentry with an ascent char. The curves Indicate that approximately 0.16 inches must be added to the virein material thicknesses in areas where the ascent heating is $\approx 6,000 \mathrm{Btu} / \mathrm{ft}^{2}$ while in lower 

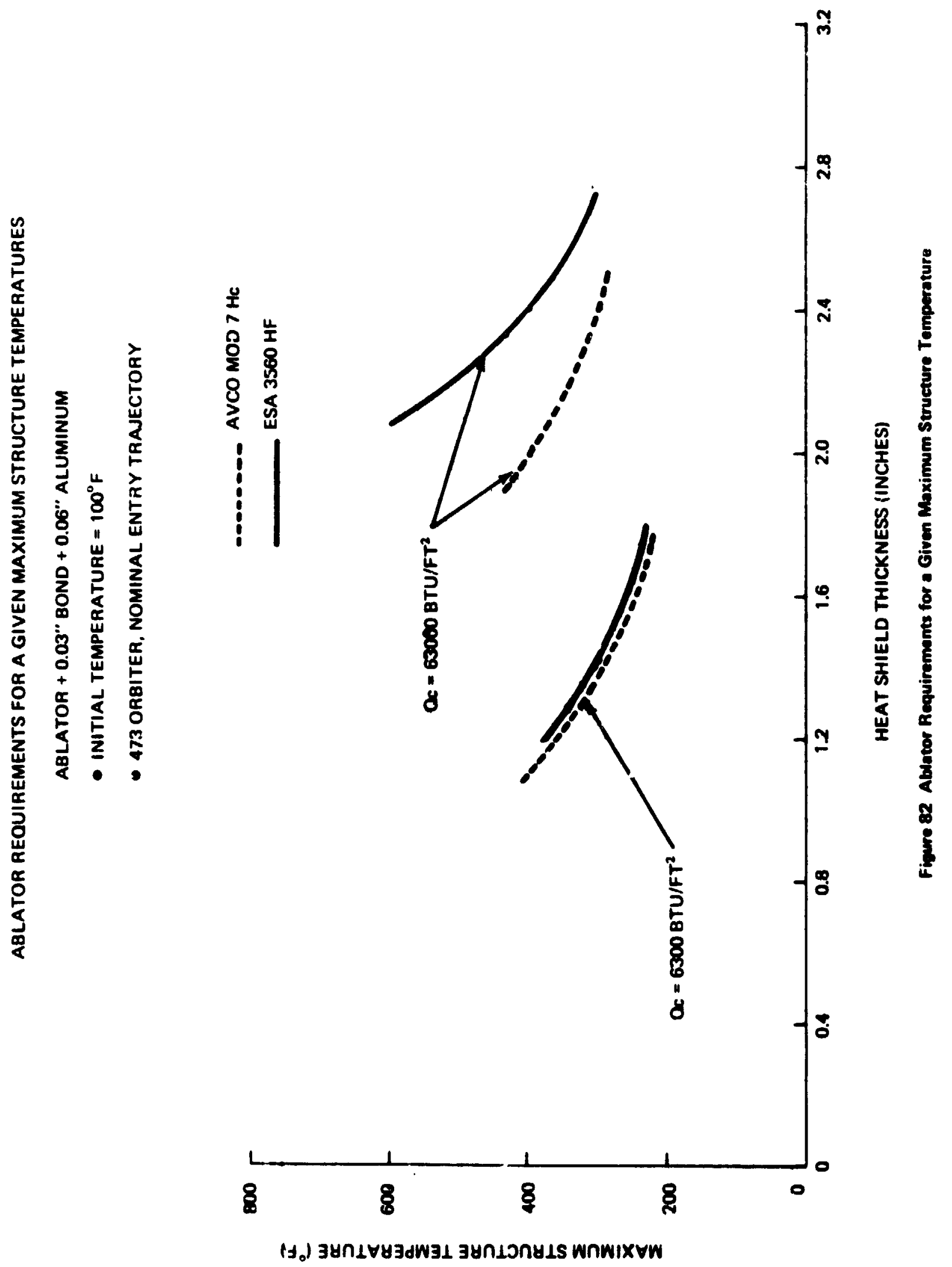


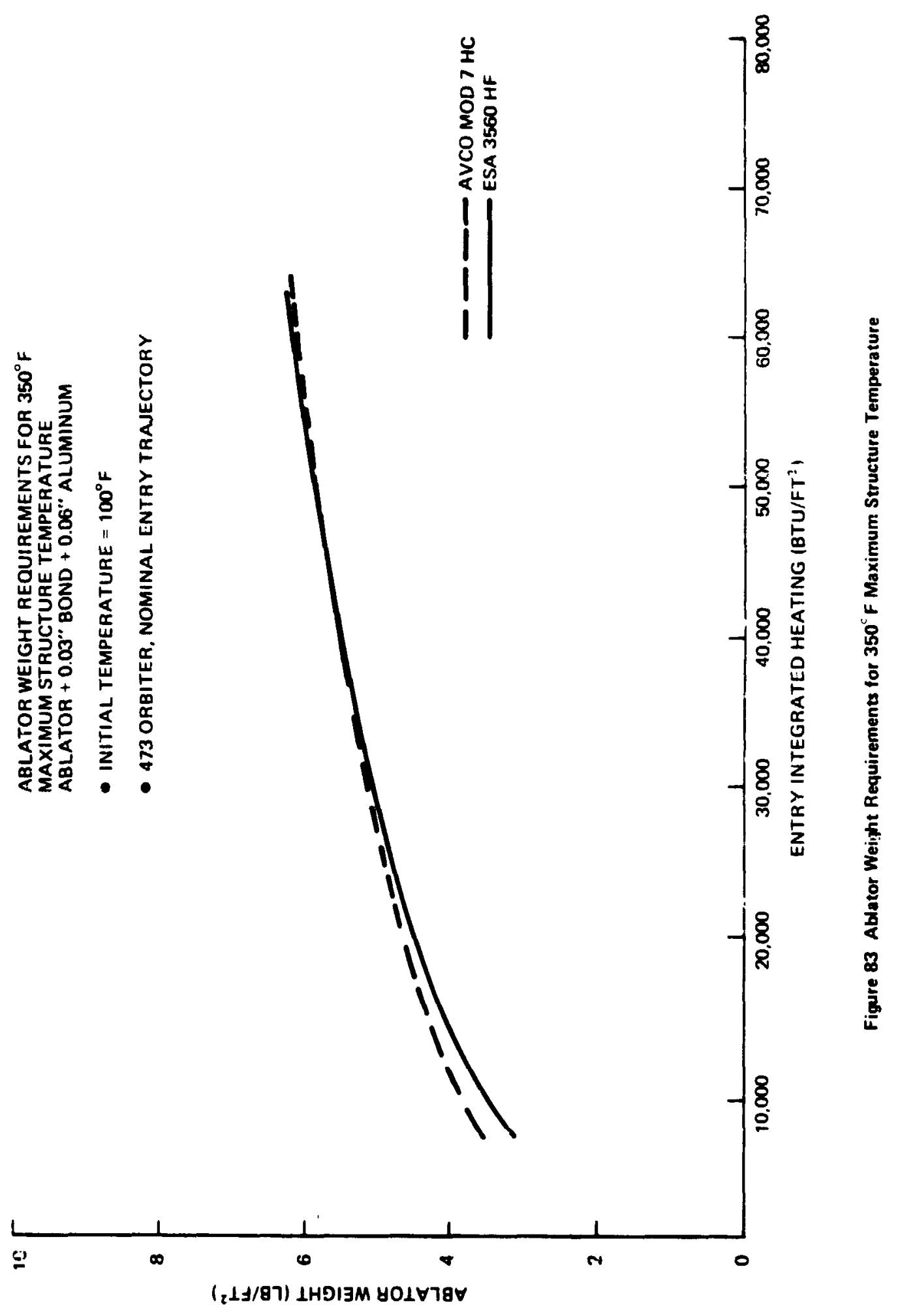




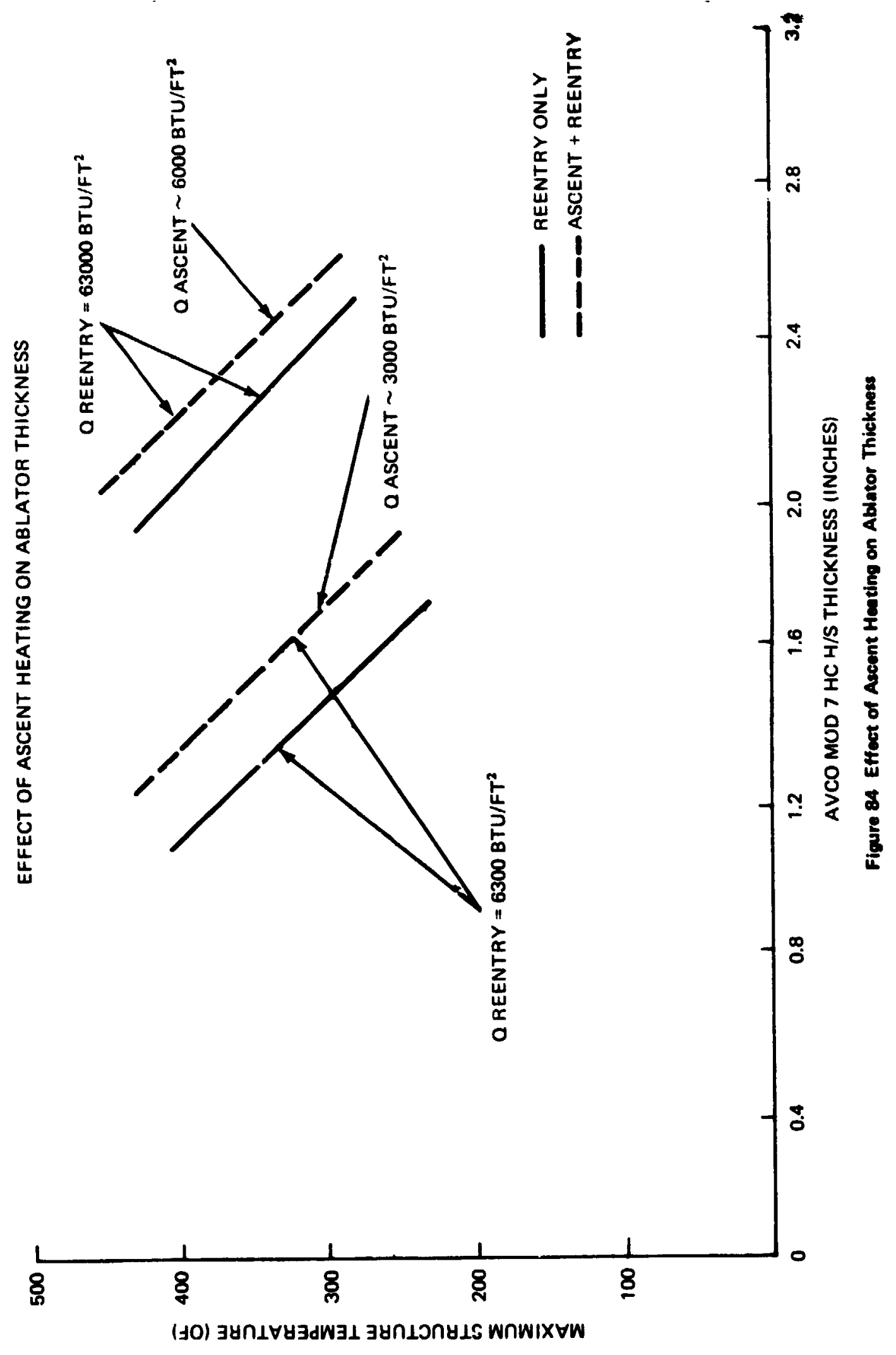


heating areas $\left(\approx 3,000 \mathrm{Btu} / \mathrm{ft}^{2}\right)$ additional 0.26 inches are required. This apparent inversion is due to the fact that in the locations where ascent heating is low the heat shield is relatively thin, hence the percentage of material which is charred during ascent is Ereater than in regions of higher ascent heating where the reentry environment controls the thickness.

Figure 85 shows the Mod 7 Hc char thicknesses developed during ascent as a function of heating level. While these data were examined for Mod $7 \mathrm{Hc}$ only, the magnitude of the increase in thickness for the ESA 3560 HF should be similar.

Figure 86 indicates the heat shield requirements for various total heating levels (ascent and reentry) for both Mod 7 and ESA $3560 \mathrm{HF}$ using a bond 1 ine temperature of 3500F. This curve was employed in defining the heat shield thickness variation around the veilfcle. Figure 87 shows the char depth levels that can be expected with the various heat flux levels. Note that for the reentry environment currently anticipated for the leading edge negligible recession is predicted for either Mod $7 \mathrm{HC}$ or ESA $3560 \mathrm{HF}$. The total char thicliness if seen to constitute about $60 \%-70 \%$ of the thickness for a bond line temperature of $350^{\circ} \mathrm{F}$, with 0.6 to 0.8 inches of virgin material left after entry.

\subsubsection{Safety Factor Rationale}

In order to establish a realistic design for the ablator leading edge it was necessary to define safety margins which will provide adequate confidence of success while at the same time not being unduly conservative. There are several approaches used in defining the safety factor including using multipliers on the aerodynamic heating (e.g., Ref. 59), using conservative preperties (e.g., Ref. 60), and 21 so ading a specifled material thickness (e.g., Ref. 59). 


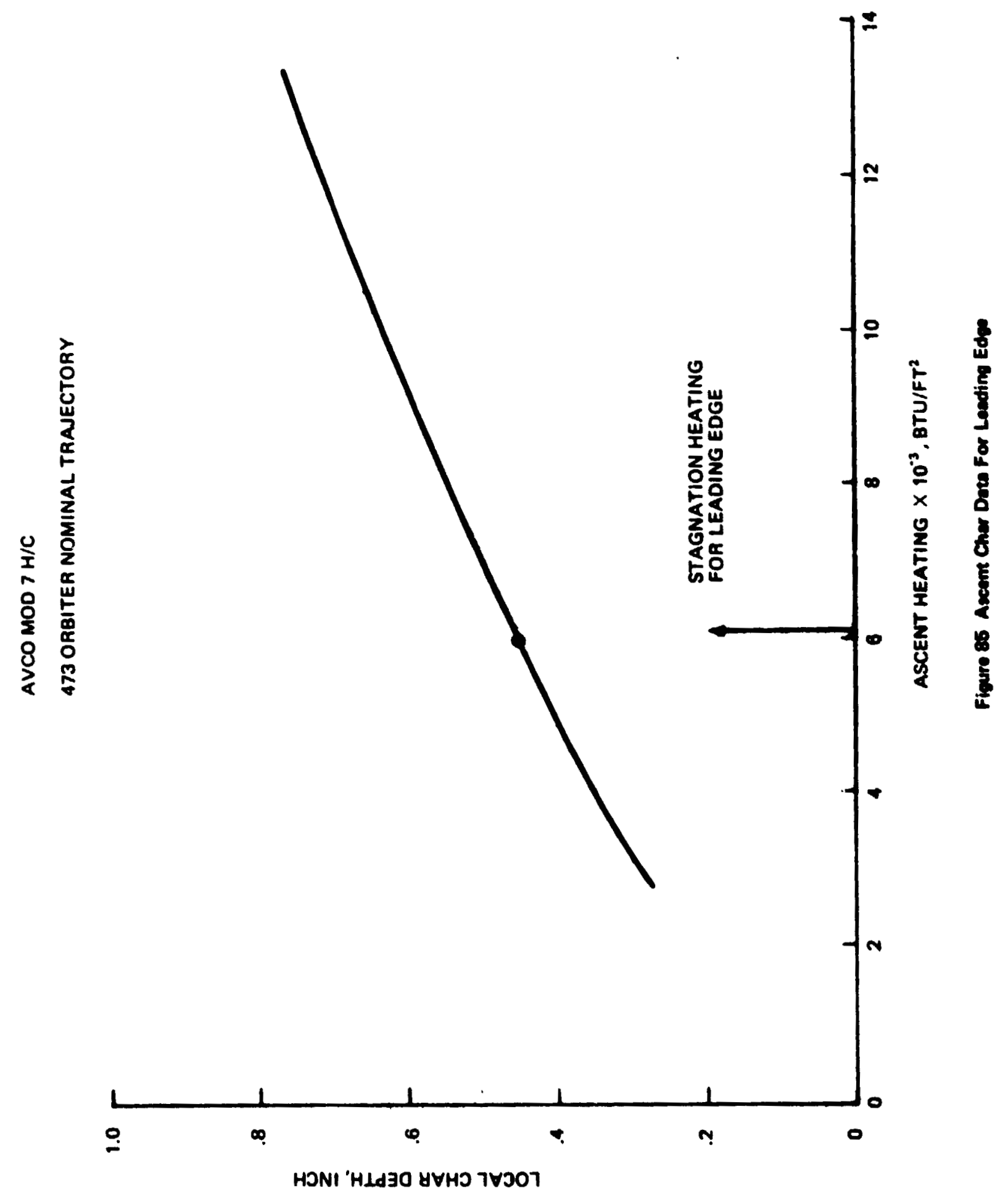

218 


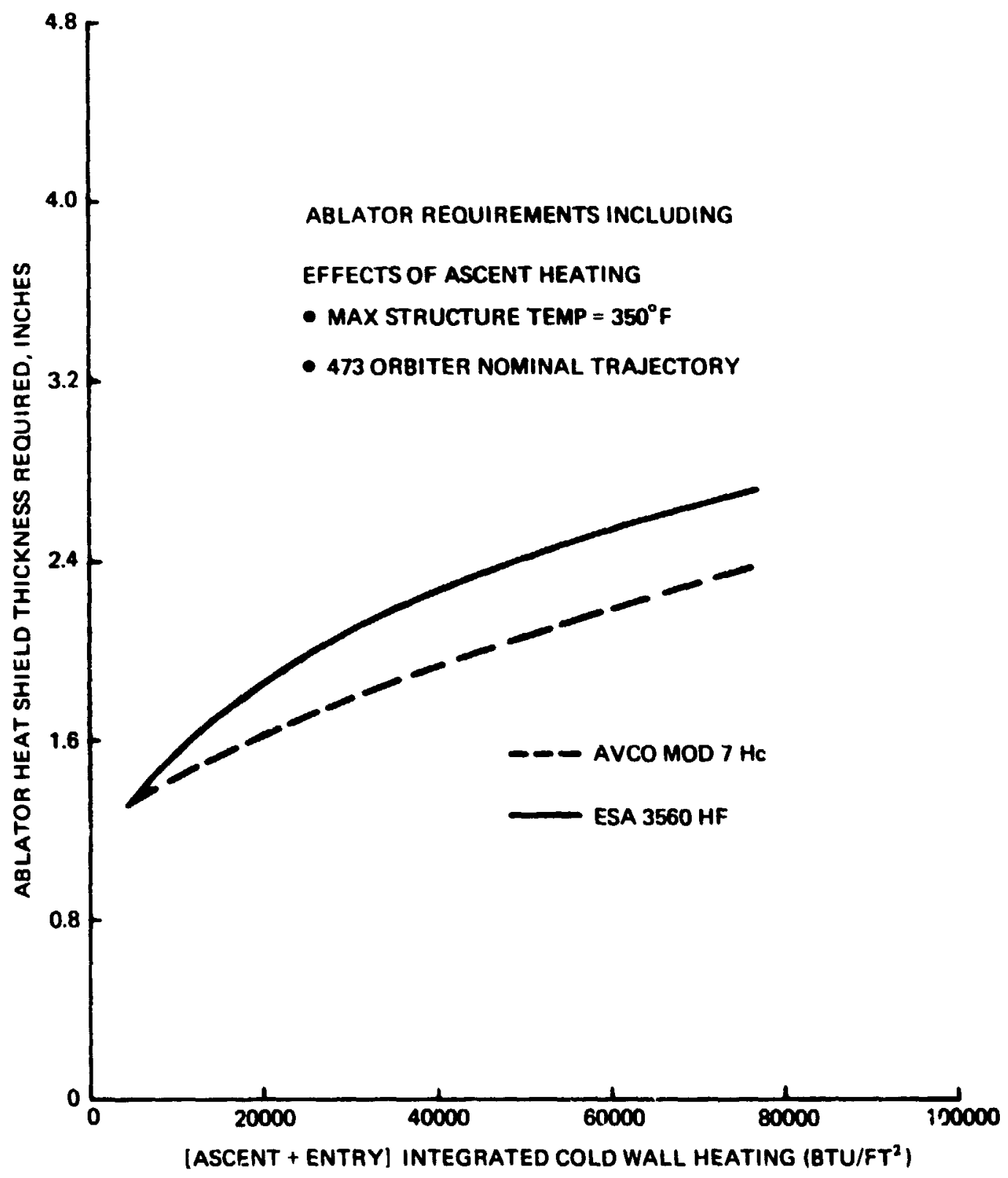

Fig. 88 Ablotor Thickness Requirements 


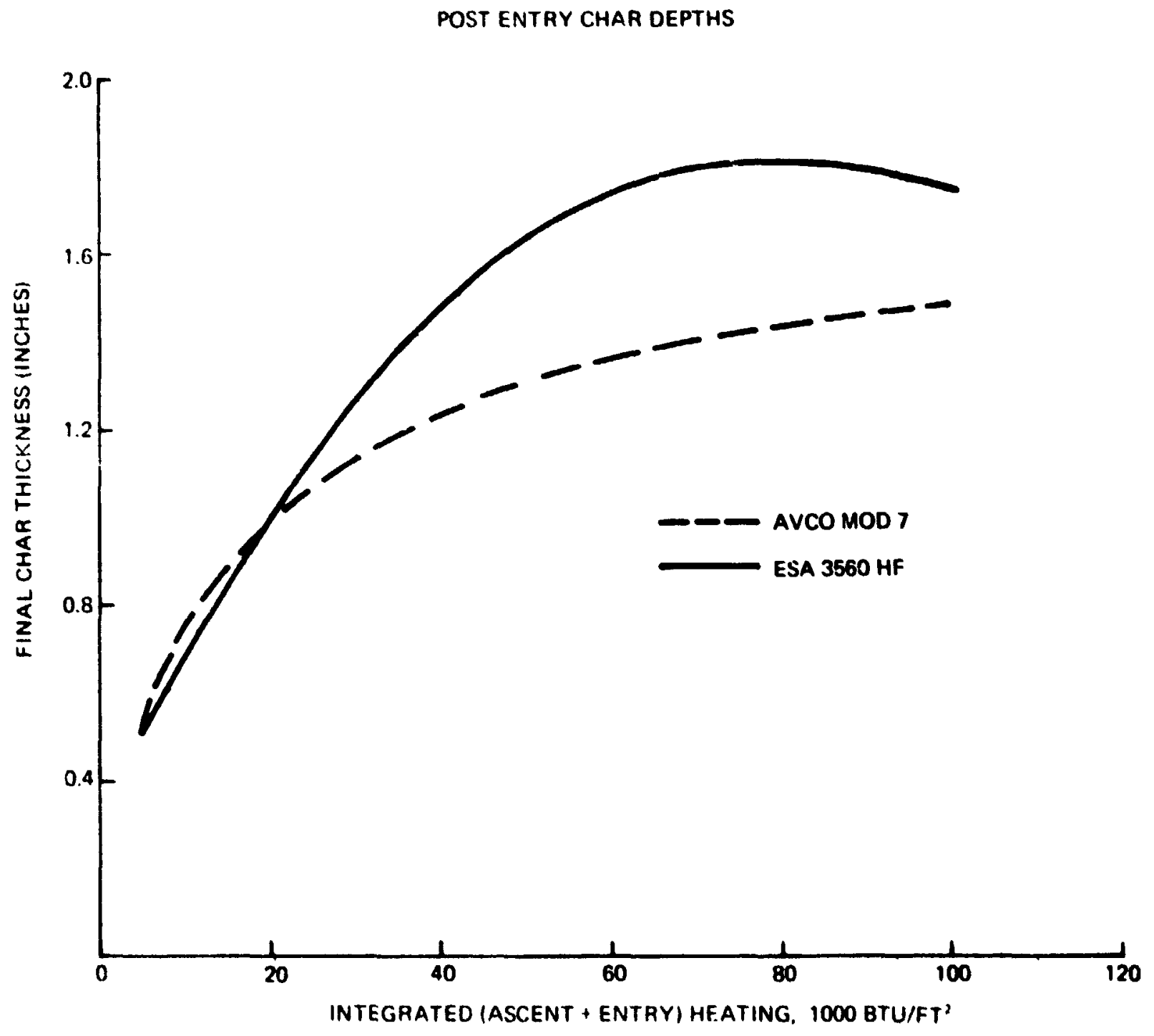

Fig. 87 Pons Entry Cher Depths 
For the design developed in this program the following procedure was used:

1) A multiplier of 1.10 was used on the heating to account for a $10 \%$ uncertainty currently considered reasonable for the 1.e. of the orbiter (e.g., Ref. 61).

2) An additional thickness was added to the nominal thickness so that a $25^{\circ} \mathrm{F}$ margin is produced in the maximum structure temperature (i.e. design is based on $325^{\circ} \mathrm{F}$ ). This additional thickness is 0.10 inches.

This approach was used since it accounts for the only uncertainty that can be reasonably defined (i.e. $10 \%$ on heating) while at the same time providing a $25^{\circ} \mathrm{F}$ margin for uncertainty in properties, analytical techniques, accuracy, etc. A $50^{\circ} \mathrm{F}$ marg in would have caused significant weight increases, chiefly on the leeward side, and was thought to penalize considerably the design. It should be noted that there is an additional area of conservatism that is inhererit in the design.

The design was based on a "soak out" condition, and the structure temperature does not reach $350^{\circ} \mathrm{F}$ until after 2500 seconds (nominal touchdown) when the final mechanical load is experienced due to shock. Note that as shown in figure 88 at touchdown the temperatures are 284 and $334^{\circ} \mathrm{F}$ for the Mod $7 \mathrm{Hc}$ and ESA 3560 HF respectively. These data would indicate that the safety factor, at least for the crew, for the Mod 7 may be somewhat higher than the ESA 3560 HF.

Still another area of safety, at least for the leading edge, follows from the different temperature histories in the ablator and the RSI. It seems that with the profected (and rather conservative) RSI thickness at the ablator/RSI 
ABLATOR + 0.03* BOND + 0.06" ALUMINUM

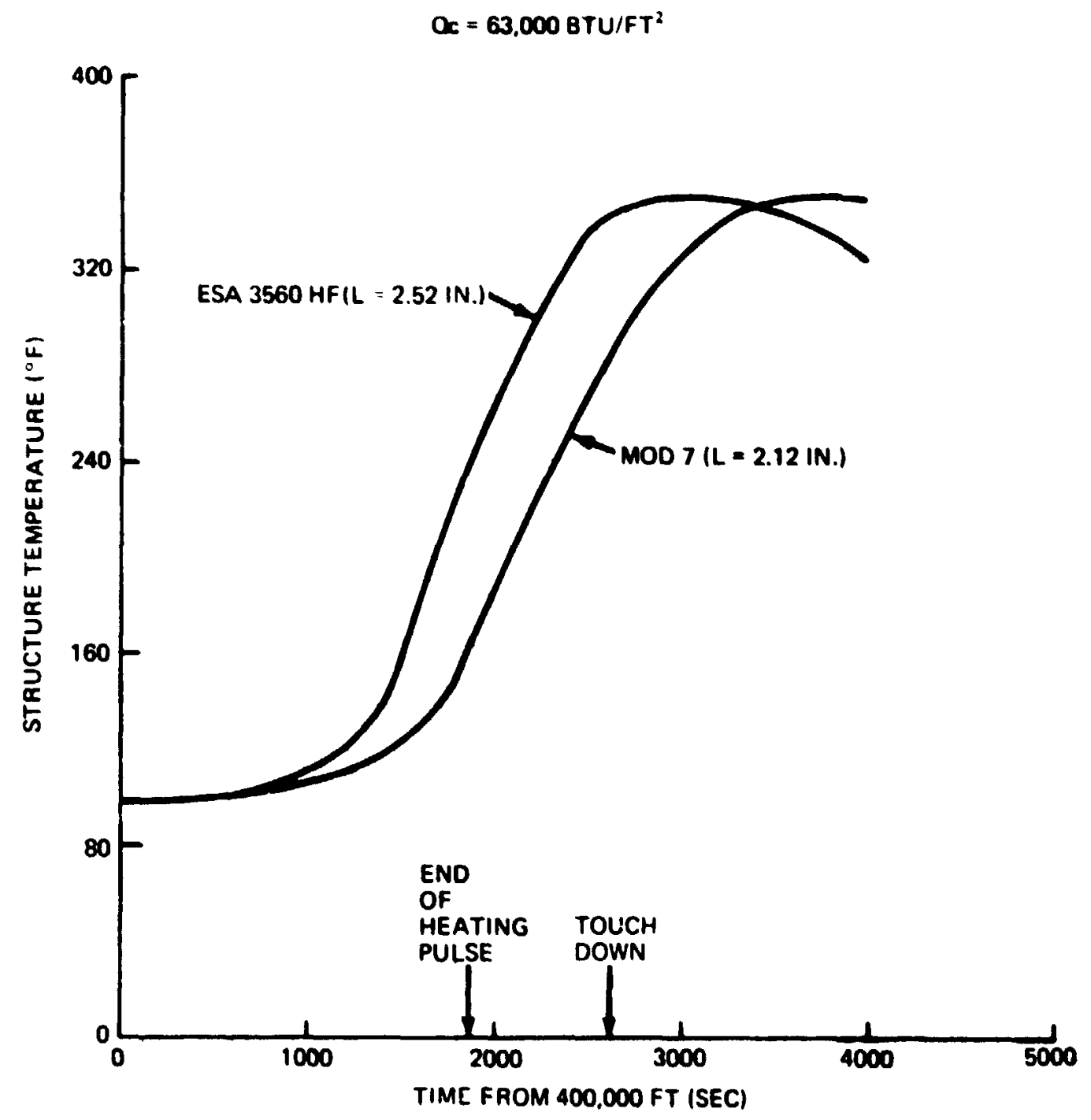

Fig. 8 Structure Tomporturs Historios. 
interface (scoe 2 to 3 inches), the wing structure will be considerably cooler than the l.e. substructure, thereby setting up lateral conduction to the benefit of the 1.e. Therefore especially near the ablator/RSI joint the 1.e. substructure will have this added safety.

We feel that the safety factor rationale described above is a reasonable one.

\subsubsection{Single Ablator}

One of the general rules used during the performance of the effort was that i single ablator (i.e. one material) would be used in the lcading edge areas. While this rule appeared to be reasonable in view of the objectives and scope of the program it nevertheless precluded irvestigation of alternate :pproaches (i.e. two ablatnr systems) which could prove to be attractive. In this section we set out brief qualitative coments on the two-ablator system. The most obvious alternate two material system would be comprised of the selected honeycamb ablator in the high heating region (1.e. Mod $7 \mathrm{Hc}$ or $3650 \mathrm{HF}$ ) with the introduction of lower density $(\rho=15 \mathrm{lb} / \mathrm{ft} 3)$ unreinforced ablator in the reduced heating regions away from the stagnation point. Such an arrangement is shown in figure 89 . Whether or not this concept would be advantageous fram an overall systems standpoint depends on several factors and the pros and cons of such an approach are listed in table 33. As can be seen, the use of a dual ablator system provides lower weight and material cost but introciuces; additional camplexities into the design. The extent of cost savings (if ary) resultant from such a design mast include the effects of the additional refurbishment and mamafacturing efforts required.

The potential advantages of a dual system will be reduced as the area forward of the front beam covered by ablator is reduced. For example, the present TIS concept used in the shuttle wing is camposed of a relatively small area of 


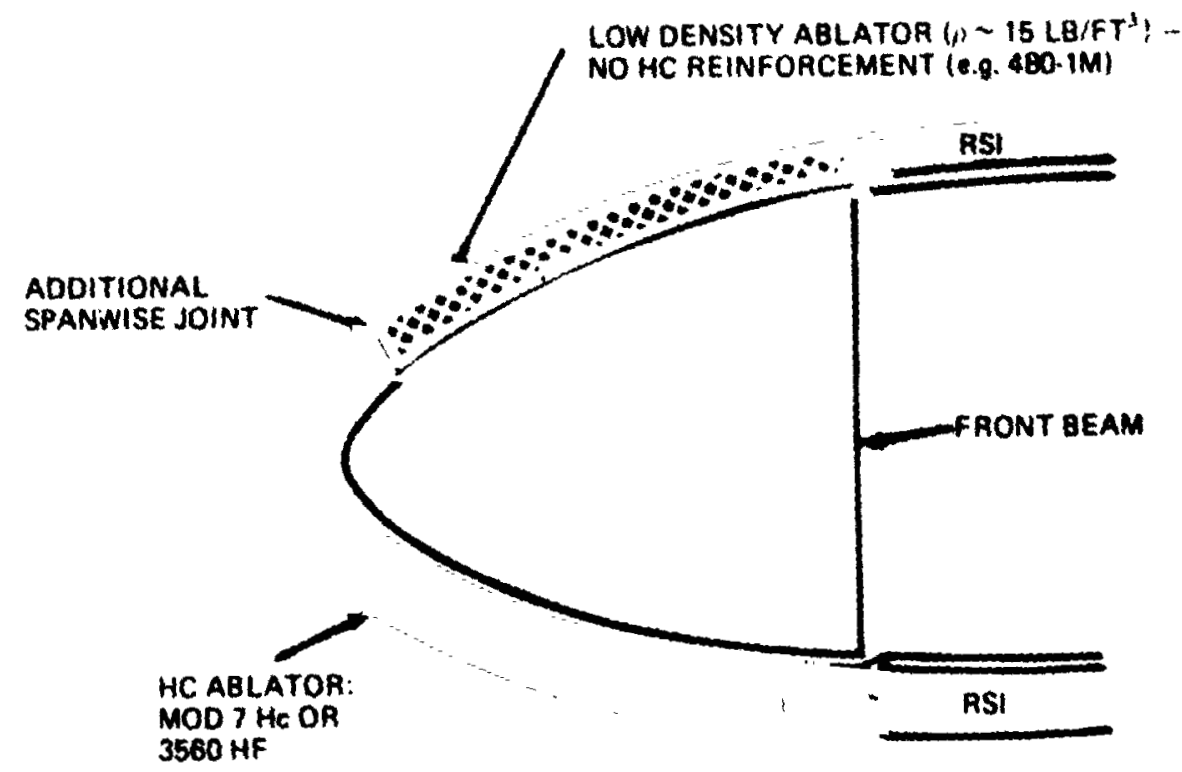

Fig 80 Doubs Abtutor Leating Edo Conoept 
Table 33 Tredeoffs in Double Ablator System

\begin{tabular}{|l|l|}
\hline Advantages & Disadvantages \\
\hline $\begin{array}{c}\text { A. Lower Weight } \\
\text { Use of low density material will be more } \\
\text { effient. }\end{array}$ & $\begin{array}{l}\text { A. More Complex Bonding Operations } \\
\text { - Bonding requirements may be different. }\end{array}$ \\
$\begin{array}{l}\text { B. Lower Material Cost } \\
\text { efficiency }\end{array}$ & $\begin{array}{l}\text { B. More Manufacturing Operation Required (Cutting } \\
\text { tooling. etc.) }\end{array}$ \\
& $\begin{array}{l}\text { C. Additional Span Wise Joint Required } \\
\text { Doncomb. More Complex Structural Detai? at Interface of } \\
\text { two Ablator Materials (Dissimilar thickness } \\
\text { requirements): more comple thermal design for } \\
\text { minimum weight. }\end{array}$ \\
\hline
\end{tabular}


oxidation inhibited carbon/carbon and the remainder of the leadin edfe (i.e. the region forward of the front begm) is protected by RSI. For this design it would appear to be more nractical (and in fact lower 'n cost' to utilize a single honeycomb material rather than at temnt to optimizo the concent by incorporatine a second material for a reintively small area.

\subsubsection{Shmpe Cotimization}

Une of the major concerus in the selsction of an ablator for use on the leadirfe edge is the potential depradation in subsonic performance due to surface recession. The most attractive approach would be to utilize a material which recedes a negligible amount and therefore produces a very small shape change. An alternate concept would be to size the virgin material in such a way so that the shape that exists after reentry is that desired from a subsonic aerodynamic performance standpoint. This latter approach however requires that the recession performance of the vehicle be predictabie and this is where a difficulty arises.

The matter would be simpler if experimental data obtamed in splash tests, in flat samples and without ascent heatin could be used for the l.e. with precharring. Unfortunately this does not appear possible, since in general the elastomers 1.e. models tested here showed non-neglifible recession, while it has been known for some time that elastomeric mater'a!s in f?at conf puration without presharring, recede very little or in fact even expand at relatively low heat flux levels in the order of $50 \mathrm{Btu} / \mathrm{ft}^{2}-\mathrm{sec}$ (e.g., Refs. 62 thru 65). Table 34 provides a sumary of tyrical test atata (Ref. 69-65) obtaines in splash models without precharrine at the Avco RCVEFC Arc Facility on Mod $7 \mathrm{M}$. The conclusion reached from these data is that only a small cmount of recession will occur on the leading edges and perhans even some expansion wil be noted. It is important to recurnize that the data show in table 3 it are in 
Table 34 Typical ROVERS Arc Test Date on Mod 7 M Splosh Test-No Precharring

\begin{tabular}{|l|c|c|c|c|}
\hline Test No. & $\begin{array}{c}\text { Cold Wall Heat Flux } \\
\text { (Btu/ft 2-sec) }\end{array}$ & $\begin{array}{c}\text { Enthalpy } \\
\text { (Btu/lb) }\end{array}$ & $\begin{array}{c}\text { Test Time } \\
\text { (Seconds) }\end{array}$ & $\begin{array}{c}\text { Surface Recession or (Gain) } \\
\text { (nches }\end{array}$ \\
\hline$(479 \cdot 122) \cdot 1$ & $5 !$ & 10,200 & 610 & $(0.014)$ \\
$(479-122) \cdot 2$ & 113 & 10,400 & 505 & 0.015 \\
$(479-122)-3$ & 150 & 9,950 & 475 & 0.015 \\
$686-7$ & 98 & 8,400 & 162 & $(0.05)$ \\
$686-8$ & 100 & 8,400 & 161 & $(0.06)$ \\
$687-17$ & 31 & 8,500 & 234 & $(0.06)$ \\
687.18 & 30 & 8,500 & 372 & $(0.01)$ \\
$559-4$ & 82 & 11,300 & 800 & $(0.048)$ \\
\hline
\end{tabular}


agreement with other data generated at Avco on other elastomeric materials. Note also that the data cover the heat flux and integrated heatinf rarec typical of the leadirg edge (i.e. $q_{c}=70$ Btu/ft ${ }^{2}-\sec , Q_{a},(i),(m)$ Ptul $/ \mathrm{ft}^{2}$ ). of course, the situation would be even simplicr if theoretical dat? from typical quasionedimensional charring codes that nerlect mechanicai removal could be used for the present case of 1.e. with rrecharring. Cf course, in such codes surface recession is predicted after modeling cata sinilan to those shown in table 34 are used in iesinitg the thermal models. In the case of Mod $7 \mathrm{M}$ and the $3560 \mathrm{HF}$ it was found that up to integrated heating levels of $60,000 \mathrm{Btu} / \mathrm{ft}^{2}$ negligible recession is anticipated in flat samples, no precharring and no mechanical error. However, when data from the tests on the leading edge models with precharring are reviewed, it is clear that the prediction is inadequate. Table 35 sumarizes the surface recession of the leading edge mudel center line for both the Mod 7 and ESA $3560 \mathrm{HF}$ materials. While same expansior is noted in the lower heating regions its is suite or vious that significant recession occurs in the stagnation region.

There.sore, the difficulty announced above is that we have only one set of data on which to base the prediction.

Moreover, even with this set of data, there is the froblem of the extrapolation to flight conditions since the total entry heating on the model was only some $16,000 \mathrm{Btu} / \mathrm{ft}^{2}$ (hot wall) versus a flight value of some $55,000 \mathrm{Btu} / \mathrm{ft}^{2}$ (cold wall). If the stagnation-point test data are extrapolated to the total heating expected on the vehicle $\left(Q_{c}-60,0003 t u / \mathrm{ft}^{2}\right)$ it would be expected tiant ...": and 0.45 inches of Mod $7 \mathrm{HC}$ and ESA $35 \mathrm{FO}^{\mathrm{HF}}$ respectively would recede isins reentry . However, $1:$ view of the previous arc test data where insignifis tri recession was observed in ilat samples without precharring: we feel that the 
Table 35 Recession in Ablutor Leading Edge Models During Reentry iest at LRC (L/E Modals Precharred)

\begin{tabular}{|c|c|c|c|}
\hline & Position & Avco Mod $7 \mathrm{H} / \mathrm{C}^{*}$ & $\begin{array}{c}\text { Recession or (Gain)/nches } \\
\text { ESA3560HF"* }\end{array}$ \\
\hline \multirow{10}{*}{$\begin{array}{l}\text { Stagnation } \\
\text { Region }\end{array}$} & S1 & $(.02 .3)$ & $(.016)$ \\
\hline & $\mathbf{S 2}$ & (.033) & $(.007)$ \\
\hline & S3 & $(.005)$ & .035) \\
\hline & (S4 & .060 & 0.13 \\
\hline & S5 & .101 & .161 \\
\hline & Is6 & .009 & $(.004)$ \\
\hline & s7 & $(.016)$ & $(.017)$ \\
\hline & S8 & $(.009)$ & $(.018)$ \\
\hline & $\mathbf{s 9}$ & $(.004)$ & $(.005)$ \\
\hline & $S 10$ & $(.014)$ & $(.004)$ \\
\hline
\end{tabular}

Test time $=261$ seconds

" Test tirne $=309$ soconds 
recession which occurs on the leading edge models during the leading edge tests is in fact mechanical removal of the char layer which was deveioped during ascent exposure. Therefore we expect that the shape change recorded bn the leading edge models would in fact remain at these levels (i.e. negligible further recession) if the $Q_{c}$ were simulated and should not be extrapolated. This of course should be checked by appropriate tests. It whould be pointed out that the thooretical prediction of recession on the leading edge accounting for mechanical removal of th. ascent char is difficult if not impossible based on the limited amount of leading edge data and one set $o_{i}$ data including precharring. Considerably more testing of the recession characteristics of these two materials in pressure gradient environments when precharred is required to validate the explanation of the recession measured on the 1.e. models and to develop, if desired, the appropriate modeling of the mechanical removal.

In view of this discussion, it is concluded that the most recession that will occur is about 0.10 inches (fran table 35) and wili drop off rapidy from the stagnation point and in fact same expansion will exist on the windward and leeward siles. Therefore, no adjustments were made to account for this minor recession in the design because of its expected minimal effect on system performance.

\subsubsection{Ablator Requirements}

Using the data from figure 86 , the design safety factors and rationale from Section 6.2.3 and the assumption that the substructure is of aluminum with $35 n^{\circ} \mathrm{F}$ maximum temperature, ablator thickness distributions were defined as a function cf chord position around the leading edge at the tip, midspen, and root locations. These data are presented in table 36 for both the Arco 


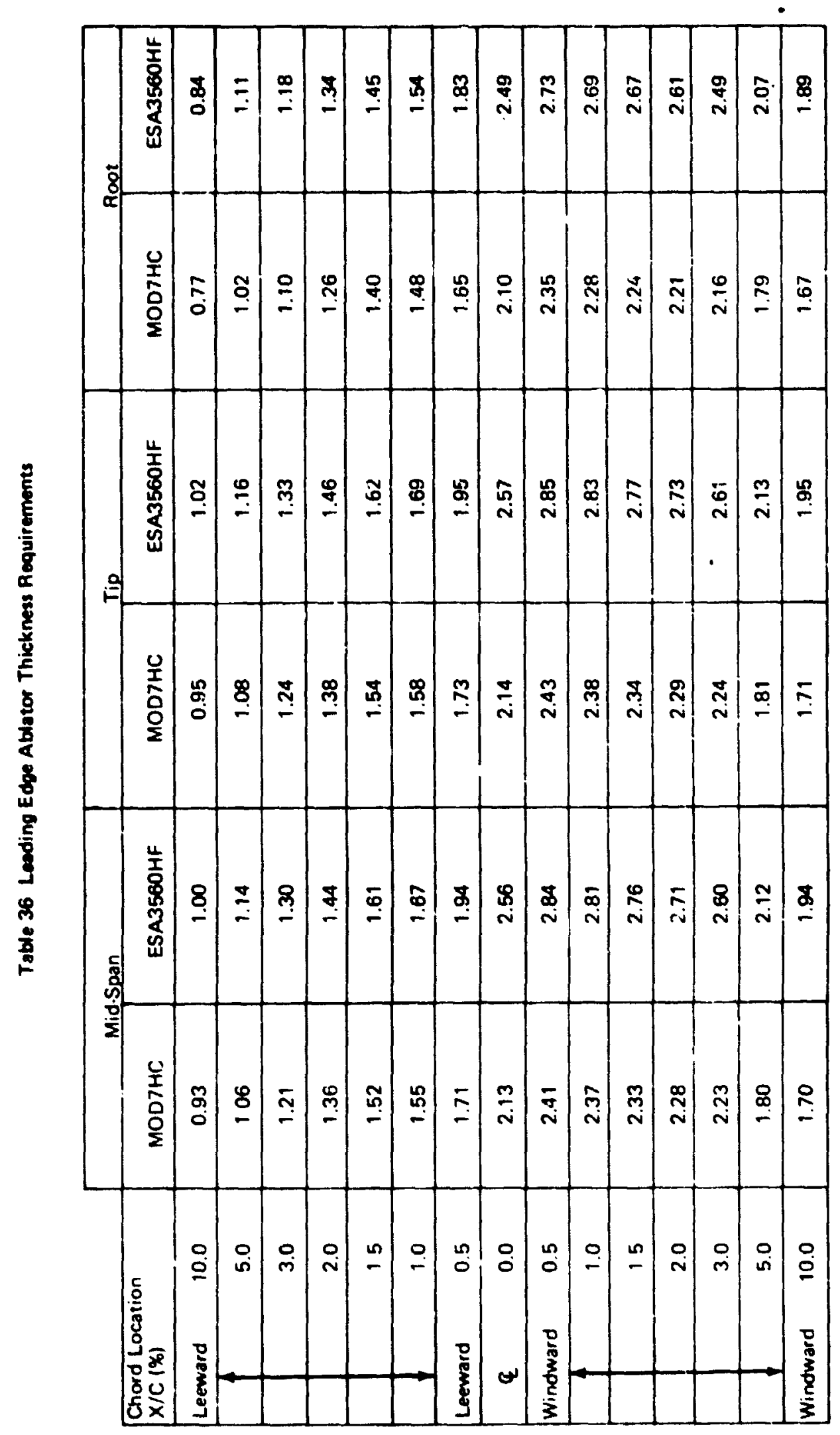


Mod $7 \mathrm{Ho}$ and ESA 3500HF merteris. The correspondin weillts will be given in section (1)

The assumption of aluminum substructures (and $350^{\circ} \mathrm{F}$ maximum temperature) will be verified in "iaction ...'.

\subsection{SUBSTRUCTURE DESIGN}

\subsubsection{Desion Criteria}

Tris section summizes the oriterin whicit we a the stmeth al dasion of the orbiter leading edge. Stunctural design limits were established for critical desi,n parameters sich as streneth, stiffness,

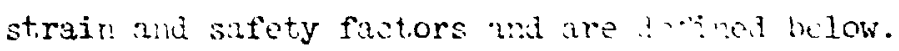

Stress - The structure shall be capable of withstunding the combined limit loads without causing yielding, heatshield cracking or excessive deformation. Furthermore, at ultimate loads the structure will not rupture, collapoe or otherwise produce a catastrophic system failure.

Combined Loals - The external mechanical, thermally induced and pressure loads shall be combined in a mitional manner and in no case shall the ratio of the allowable load to the combined limit loads be less than 1.40 . Factor of Safety - The factor of safety for all mechanical loads shall be 1.5 and the factor of mfety for lil therm. I Ioaks shall be 1.2.

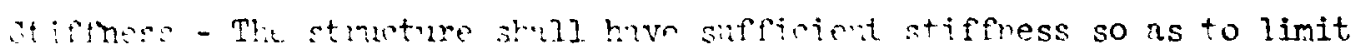

the maximum deflection at ny point normal to the surface, to \pm .20 inches when measured from the static position at ultimate load conditions, Heatshield strain - Thrine tlu ground handling, ascent, staging and in-orit phuse, the strains in the hertshield and its attachments shall not exceed their filiure limits at combined ultimate loads. Also, during entry, horizontal, flight and landing hastshield strains shall be maintained below 
failure limfts in the Hroin material and at the char interface for he ultinate load conditions.

Heatsheld stifmess and strenkth - Naturally, such contrimition from the charred ablatior is not factored in the design. However, no position has been taken on the question of whether or not to take idvintage of the stiffness contrilution of the ablator furine the inftial phase of ascent. This question is left open for a study in which the level of detail is considerably higher than here. If course, it becames a question of desien polley as to whether or not the heatshield should be relied upon to provide stmactural support as well as thermal protection.

Maxdmum Structural Temperature - $350^{\circ} \mathrm{F}$ for aluminum and $600^{\circ} \mathrm{F}$ for titanium. Note that we rule out the possibility of designing for these maximum temperatures at landing orly, allowing for higher temperstures after landing (provlded that the 1.e. sibstructure are not $r$ ased after each flight, the 1.e. substructures are thermally isolated from the wing structure and a set of metal 1.e. is provided for a ferry flight to the refurbishment depot). The maximum temperatures are reached approximately at landing so that this concept. is not usetul.

Recommended Desien criteria - MASA recommended desian criteria (ket, 0.2) and proposed modiflcation thereof (Ref. 61) have also been followed. These are the only two 'specification-ilke' documents that are presently avallable and that are appropriate to a technolozy study such as this. We consider inappropriate to follow the specifications of the current shuttle program hardware procurements.

\section{4.: Structurnd Concepts}

Conventional aircraft leadine edge designs normally consist of :imple curved metallic or flberglass skins stiffened when required by either a corbination of light spanwise stringers and discrete ful depth ribs or by closely spaced 
shallow ribs. Since in most cases the leading edge in an aircraft is nonstructural and simply provides an aerodynamic shape the selection of the $L / E$ construction is influenced more is matter of choice than by design requiru...ts. On the other hand, the lendint edee for the onbiter has specific structural and systams requiruments which can strongly influence the fimal desien.

As in all aerospace structures weight is of paramount importance. In addition deflection constraints, thermal loads and limitins ablator strains exert a strong influence on the design. Fotential loninf conditions (see Section 3.3) or ..sisted of aerodymamic pressure loads both positive and negative, acoustic and inflight vibrition loads, thermally induced laads and spanwise wing bending loads actine independently or in various combinations.

Fran a review of these loads, it was concluded that a design concept in which the 1.e. is uncoupled from the wing front beam in the spanwise direction would be lesirable. That is, a design in which there would be no spamwise shear transferred between the front beam and the leading edge at their attachment points. In doing this, the high spanwise tensile and compressive strains induced in the wine skins due to overall wing bending would be virtually eliminated from the 1.e. Instead, only localized skin curvatures would result in t:.. 2.e. at the attachment points where the curvature compatibility between the two elements is enforced by the attachment. This has the positive effect of eliminatine the need for incorporatine relativaly heavy soanwise stringers in the leading edge for stability, had the spanwise coupling existed. Correspondingly, a lighter weight desigl concept should resuit.

A second desirable feature of this approuch is that it removed the possibility of develnpine spanwise thermal stresses between the front beam and the l.e. due to the different thermal historles of front-beam a:d 1.e. Also, the strength 
and stiffuess and hence the complexity of the 1.e. attachment scheme can be reduced thereby making the attachment lighter.

In view of this design decision, the predominant loading condition became the aerodynamic pressure loads directly exerted on the l.e. To take these loads, three structural concepts were examined. The first consists of discretely spaced deep ribs supporting a lightweight skin (tigure 90). The second concept involves using a thin skin supported and stiffened by closely spaced shallow ribs. A third concept which was included for comparison was a sandwich design; although, fabricability, operational requirements, specifications and costs could most certainly have eliminated this last concept, it being potentially the lightest weight concept provides a lowest limit o i the structural weights against which to gauge the other concepts.

As it developer preliminary calculations indicated that to achieve a reasonable rib spacing in the deep rib concept (i.e. 12" - 15") the pressure loais were sufficient to require that spanwise stiffeners be incorporated between ribs. This requirement became necessary in order to limit the heatshield strains. Further evaluation of this concept indicated that the weight of the skins and the spanwise stiffeners alone would be comparable to the weight of the entire shallow rib design. Skin and stiffeners weights in the order of 1.5 $\mathrm{lb} / \mathrm{ft}^{2}$ were indicated which was equivalent to the weight of one of the heavier shallow rib designs and was significantly heavier than the sandwich concep:

Consequently, it was deciaed at an early. stage to eliminate the deep rib concept from further evaluation and concentrate on trade-offs between ribs stiffened designs while carrying the sandwich designs along for comparison. The following sections present in detail the results ohtained from these studies. 


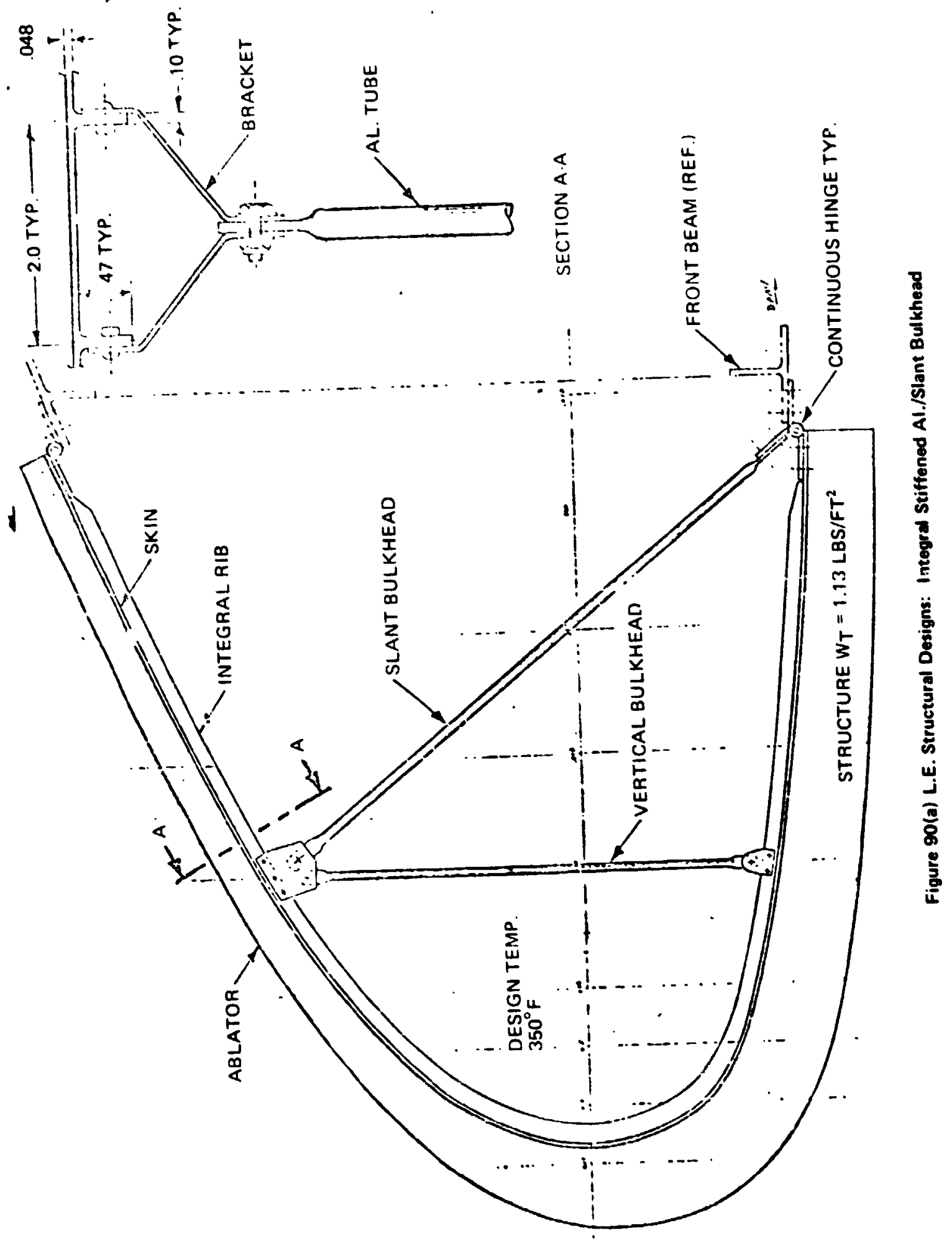




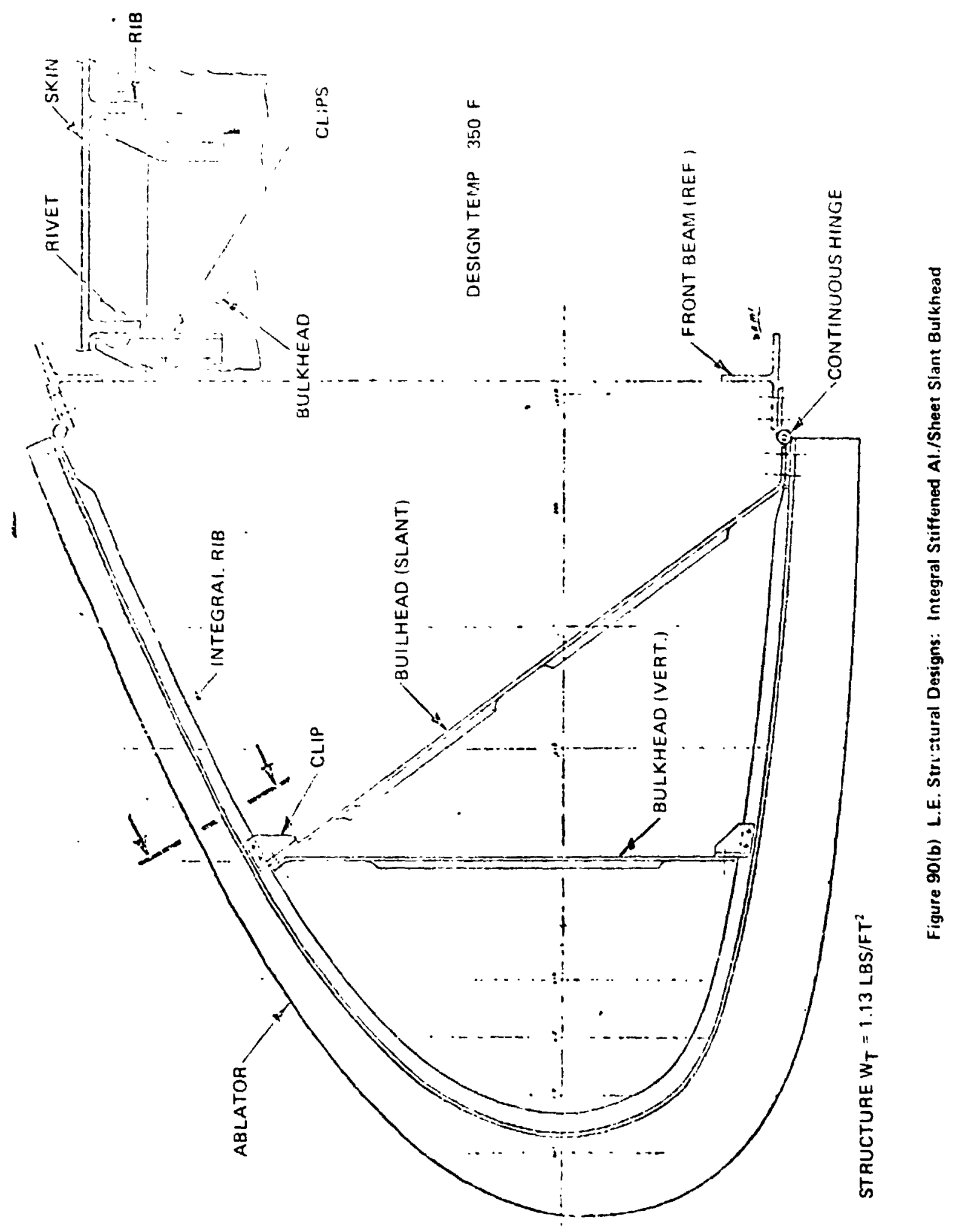




\section{4 .3 scone of structural dualysis}

Limits had to be established on the scope of the structural analysis that can be fitted into a 'first-cut' study such as this, We dectied to carry out the structural anklysis and desten for the static lands and post pone the study of the thermal stresses, dynamlo loads and int ine (If the substructures are reused) to the next step after this study. This is a reasonnhle scope for this initial development and is consistent with the structural work done on most the Phase $B$ - beginnine of Thase C orbiter confthurations. Moreover, for the structural concent develored theimal lands appenr less important, as seen In section 6.4.2.

\section{4 .4 statio londs and irlterla for Trade-off dnilyses and substructure}

Destan in This study

For trade-orf analyses the following design constraints vere employed in all calculations":

1) Only the $2-1 / 2$ and the maximum $Q^{\alpha}$ land conditions were considered and taken as ultimate loads (1.e. $1.5 \times 1$ imit lands)

2) The stifmess and strength provided by the virgin heatshield during ascent wold not be included in the analysis, and

3) To nceount for strain limitations imposed by the heatshledd the maximum endeulated strain at ane hats of an Inch frow the stmeture surme shull not exced. 5 .

*These represent reasonable simplifications. The Initial motintion was nlso to accommolate the need to start this efrort while the nolator had not yet selected. Of course, these simplifications are necessury for Inftial trade-off studies. 
Constraint 1 is consistent with normal preliminary design practice where only those loads considered the most severe are initially used. Although it must be admitted that the heatshield will contribute to the strength and stiffness of the substructure eliminating it, the preliminary design evaluation is not totally inconsistent. The question only arises during the initial phases of flight, where the mechanical loads are similar in magnitude to the post entry 2-1/2 "g" condition considered. As a result, the designs generated without the heatshield stlffness contribution will be conservative as long as stress or strain limitations imposed by the heatshield are factored into the calculations. Constraint 3 satisfies this requirement and was determined on the basis that in no case shall the uncharred material be allowed to fail. The .5\% allowed strain represents the lowest of the maximum allowable strains for al] candidate ablators of this study.

Fo: the sizing of the final design, it was further checked that when the ablator strength and stiffness is included, the stresses induced in the ablator are acceptable. The design ultimate loads for the $\max q^{\alpha}$ and $2-1 / 2$ "g" post entry conditions used are presented in figures 91 and 92 . As san be seen in these figures, both loading conditions are comprised of both positive 'collapse' pressures and intoinal 'burst' pressures. When -ombined, these pressures produce a chordwise varying pressure field reaching maximum pressures of up to 4.5 psi which cause both local deformation and overali chordwise bending of the 1.e. For the purpose of these analyses, no spanwise variation of the design loads was considered. Any spantise variation would be minur in view of the fact that tyfical segments of the 1.e. would be in the order of only $40^{\prime \prime}$ long or less.

Initial sizing was accamplished using simplified models and closed form solutions followed by more detalled evaluation using finite element models of chordwise segments. 


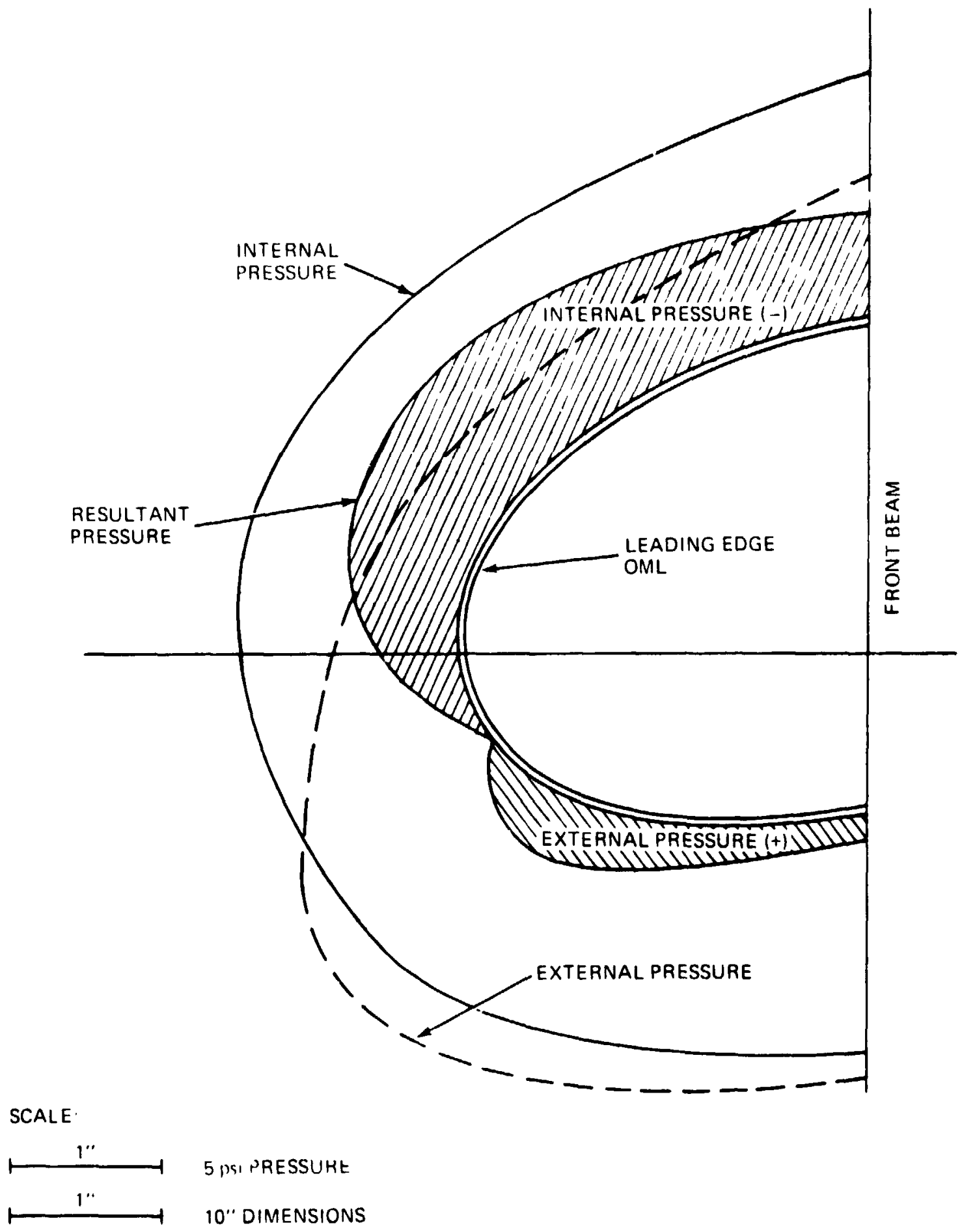

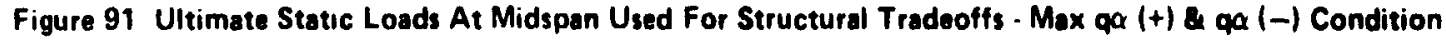




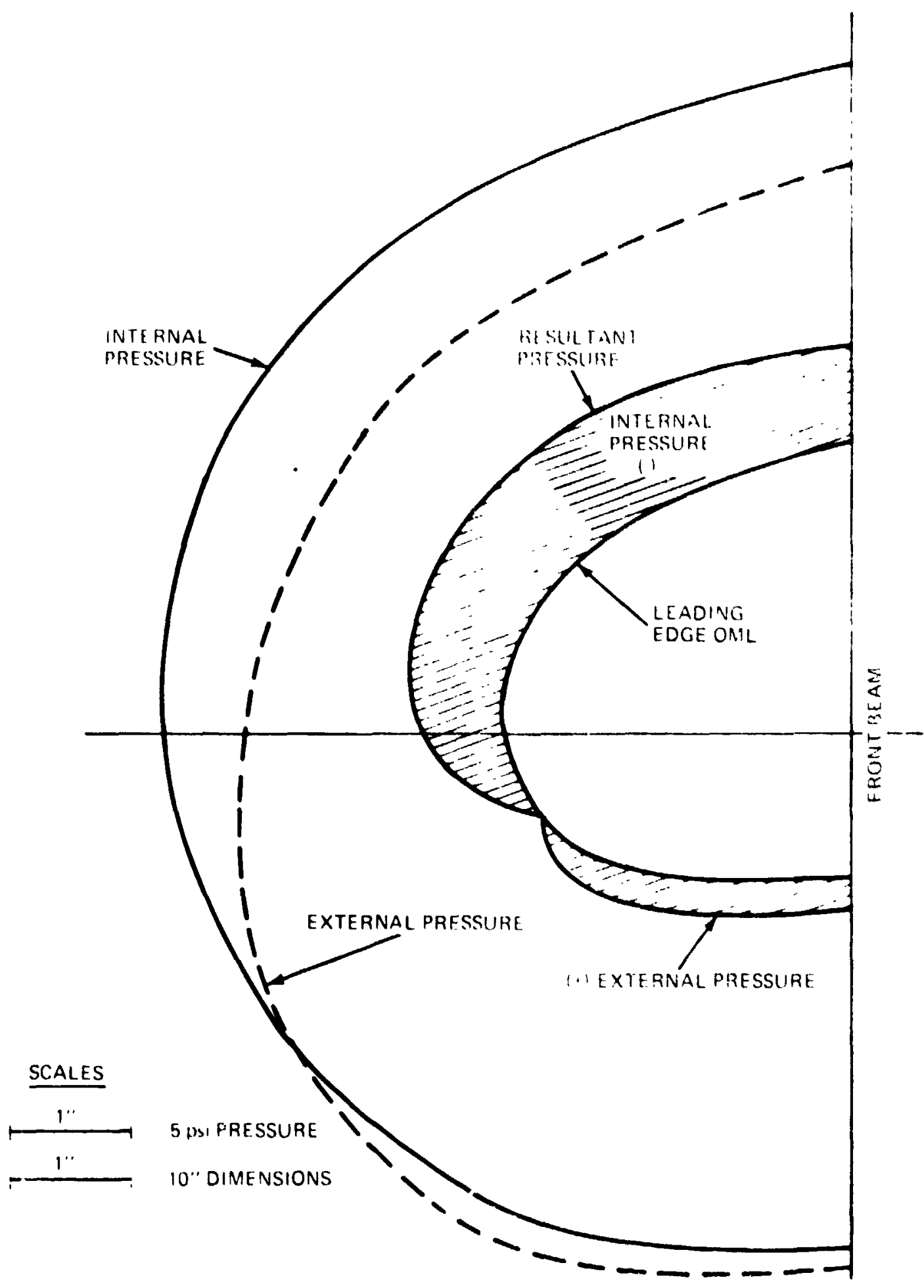

Figure 92 Uliımate Static Loads At Midspan Used For Siructural Tradeoffs $21 / 2$ g Condition 


\subsubsection{Develogment of Candidate Rib-Stiffened Designs}

Trade-orf studies were performed for two rib-stiffened designs considering both aluminum and titanium os potential substructure materials. " the aluminum designs a maximum backface temperature of $350^{\circ} \mathrm{F}$ was assumed whereas maximum temperatures of $350^{\circ} \mathrm{F}$ and $600{ }^{\circ} \mathrm{F}$ were investigated for the titanium designs. The distinguishing features of the two design concepts are illustrated in figures 90 and 93.

Figure 90 11lustrates the Integrally Stiffened Slant Bulkhead Design concept where shallow closely spaced integral ribs are used to react the local pressure loads and the slant bulkhead serves to limit the cverall l.e deflections. The zee stiffened design is depicted in figure 93 where the skin is supported by deeper relatively closely spaced ribs which combine to reect all loads. Essentially, the trade-off betireen these respective concepts reduses to whether it is more efflcient weightwise to increase the ov. rall depth of the Individual ribs to limit the deflections and stress as opposed to reducing the rib welghts and incorporating some or all of this welght in a bulkhead.

As noted earlier a sandwich design was also considered and this concept is 11lustrated in figure 94. For the sandwich design only aluminum face sheets with a maximum temperature of $350^{\circ} \mathrm{F}$ were evaluated.

In these inftial trade-off studies the analyses were conducted for the purpose of determining the relative merits of one design conflguration versus another and each therefore was constrained by the same requirements and assuptions as indicated in Section 6.4 .4 .

With these ground rules flrmily established optimization studies were conducted within each design conaldering such items as rib pitch, skin thickness, rib depth and bulkhead stifmess and location for the rib stiffened concepts. 


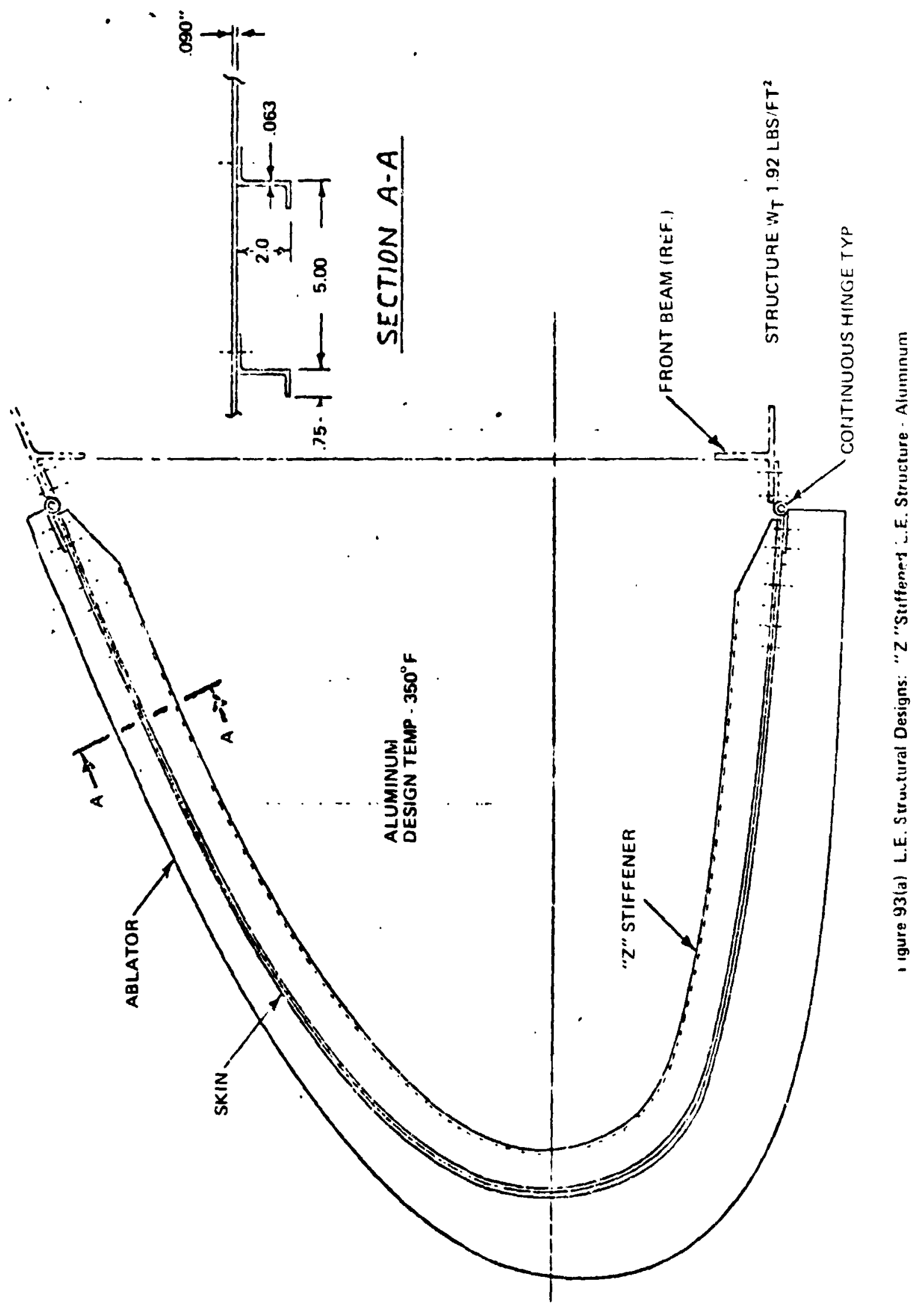




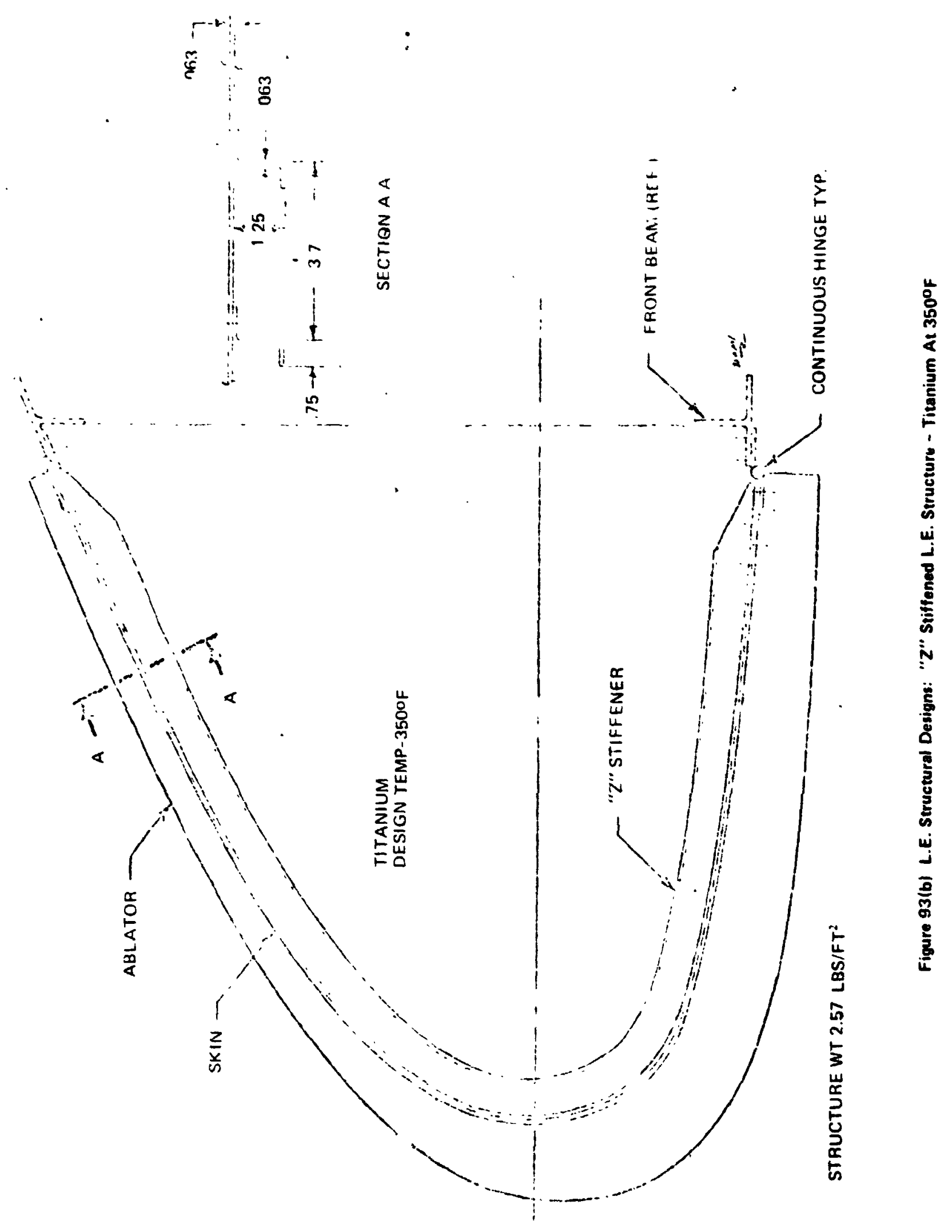




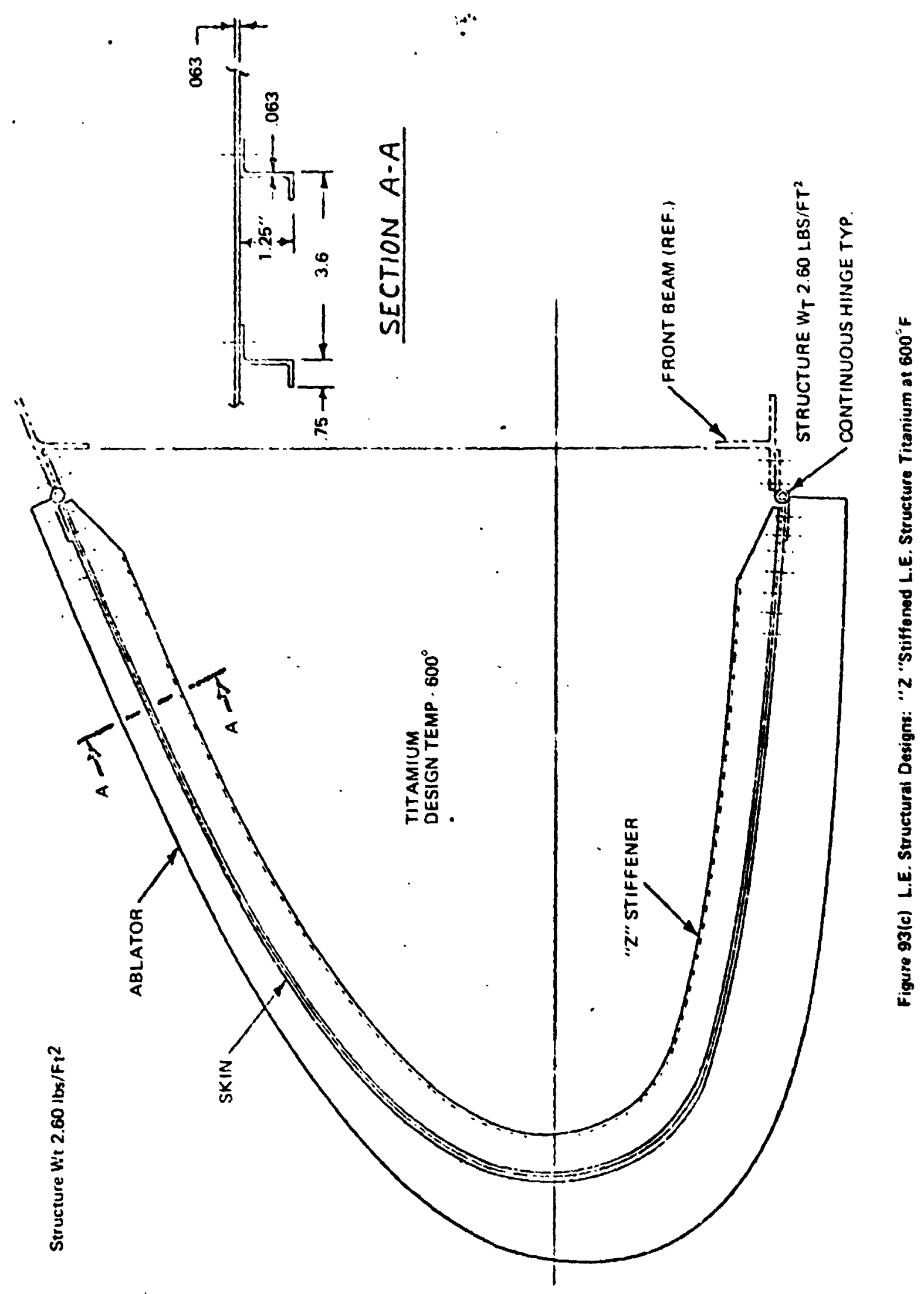




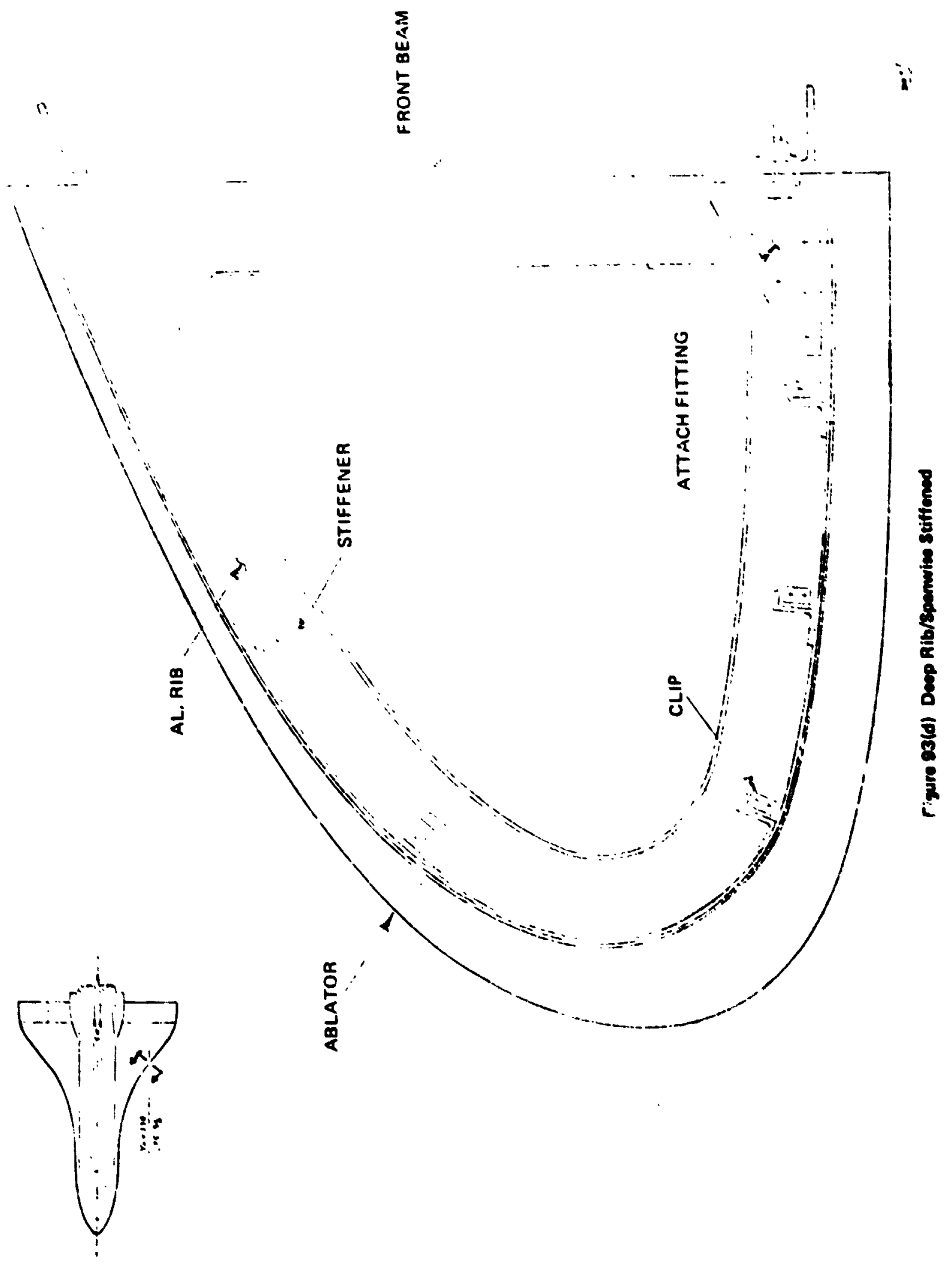




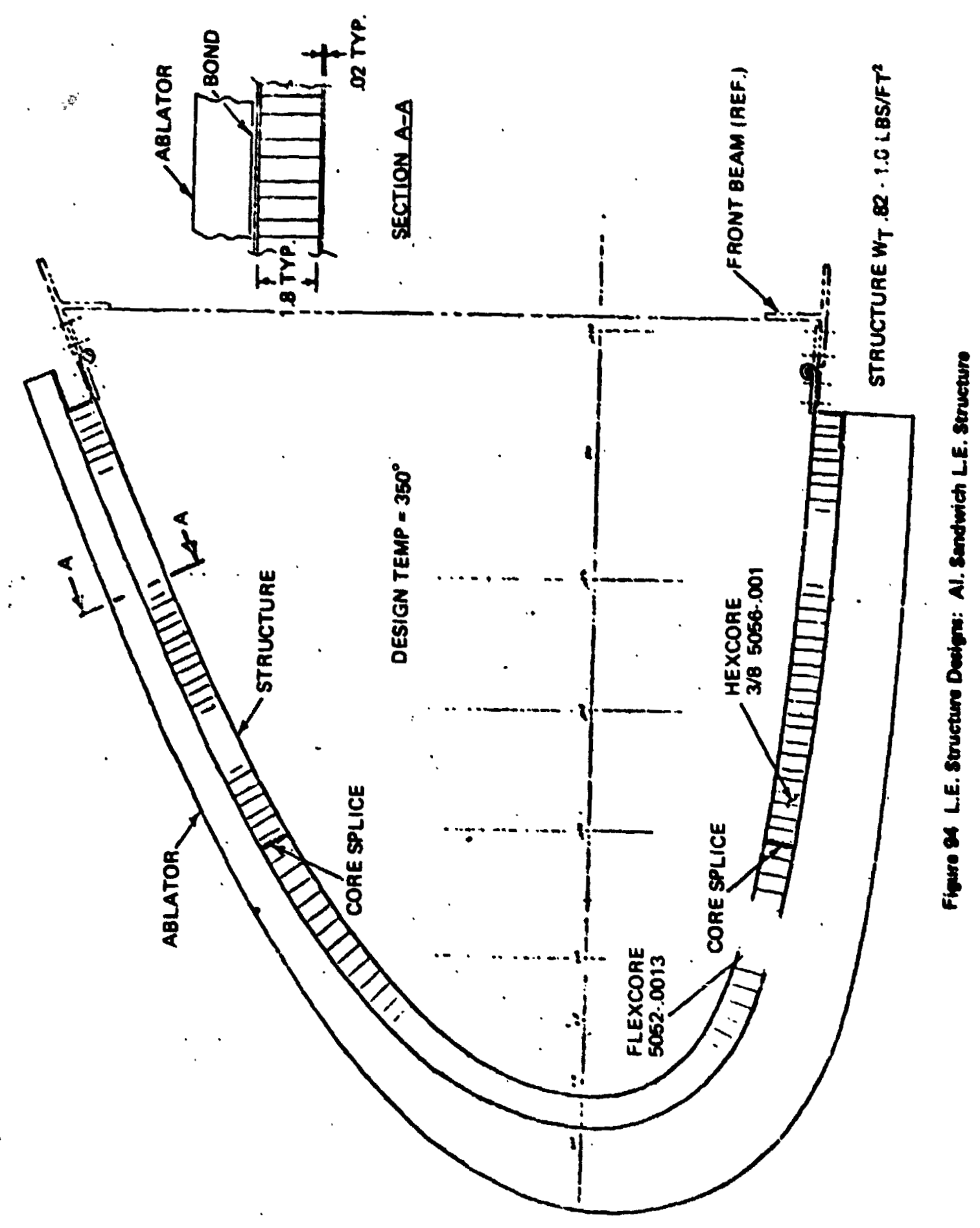


For the sandwich concepts core depth and fince fhert thickness weie investignted.

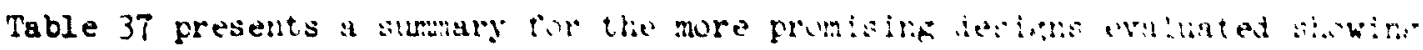

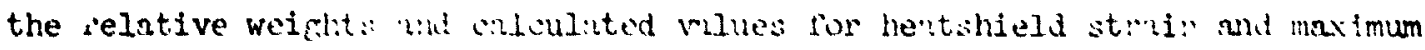
deflection of each. Highlights of these desinns are discussed below with detailed calculations incluied in ippendix 4.

\section{Integral Stiffened $\mathcal{U}$ /Slant Bulkheal nesign}

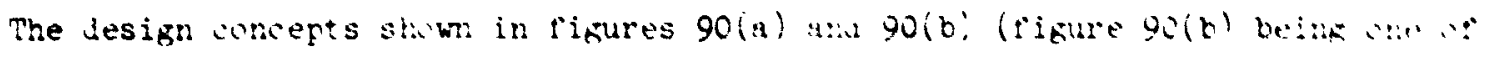
two versions of the sume concept) were found from among the configurations evaluated to have the best characteristies of lightweight and leflection stifmess with sood prospects for low cost. The controlling aspect of this design conficuration was the strain allowable of the hestshield (.59i) with a resultant ma:imum deflection of 0.14 inches. An increase in the allowible strain for the heatshield would result in a weight savins of about $10 \%$ for a heatshleld strain allowable of $2-1 / 2 \pi$ and the deflection of 0.20 inches would then become the governing factor.

Various modifications of the integral stiffened concept could be incorpornted to ease possible manufacturing problems but nay increase manufacturing costs prohibitively.

One approsch would be to decrease the depth of the outstanding les in the area of maximum curvature to facilitate bending or stretch forming. This wouli also require an increase in the depth of the outstanding lef in the flatter portion of the structure and add a mohinine step thst would not exist. with the reference design.

\section{Sandwich Structure Design}

The sandwich structure iesign concept shown in figure gis is as asual the 
Table 37 Summary of Preliminary Design Concepts

\begin{tabular}{|c|c|c|c|c|}
\hline \multirow[b]{2}{*}{ Design } & \multirow{2}{*}{$\begin{array}{c}\left.\text { (lb/F, }{ }^{2}\right) \\
\text { Substructure } \\
\text { Weight }\end{array}$} & \multicolumn{2}{|c|}{ H/S Strum } & \multirow{2}{*}{$\begin{array}{l}\text { Maximum } \\
\text { Deflection }\end{array}$} \\
\hline & & Spanwise & Chordwise & \\
\hline $\begin{array}{l}\text { " } Z \text { " Stiffened } \\
\text { Aluminur" }\end{array}$ & 1.92 & $.5 \%$ & $1 \%$ & 13 \\
\hline $\begin{array}{l}\text { " } Z \text { " Stiffened } \\
\text { Ti } 3500 \mathrm{~F}\end{array}$ & 2.57 & $47 \%$ & $.14^{\circ} \circ$ & 19 \\
\hline $\begin{array}{l}\text { "Z" Stiffened TI } \\
6000 \mathrm{~F}\end{array}$ & 2.60 & $.50 \%$ & $.14 \%$ & .19 \\
\hline Aluminum Sandwich & .82 & - & $.23 \%$ & .20 \\
\hline $\begin{array}{l}\text { Integral Rib/Slant } \\
\text { Bulkhead-Al }\end{array}$ & 1.13 & $.50 \%$ & $499^{\circ}$ & .14 \\
\hline
\end{tabular}


lightest design from arong the concepts evalusted. The controllins aspect of this design was the deflection requirement of 0.20 inches with 3 resulting mechanical heatshield strnfn of $0.23:$. Witl: the exception of possible thermal strain incompatibilities betwen the structure ur.d heatshield due to 2 possible large thermal mismatch between the tiro faces of the panel, the sandwich design would probably be the best approach if costs a.e determined as beine acceptable.

\section{Zee Stiffener Desimss}

Three zee stiffened designs were evaluated: (figures $93(a),(b)$ and $(c)$ ine aluminum and one titanium for service tempuratures of $350^{\circ} \mathrm{F}$ and one tatarian for a service terperature of $600^{\circ} \mathrm{F}$.

All three configurations were constrined to the use of standard sheet thicknesses and standard extruded zee stiffeners.

The results of the analysis indicated that, within the constraints used, a minimu wolght aluaimu design was not dictated by either demection (.13 in.) or allowble heatshield strain (.10\%) in the chordwise direction. The optimum welght for the titanium designs however were dictated by the allowable deflection of $0.20 \mathrm{in}$. The titanium design conflgurations therefore cannot gain any weight savings dus to an increase in allowable heatshield strain and the aluminum design weight savings will amount to about $3 \%$ of the reference design welght for an allowable deflection of 0.20 inches instead of 0.13 inches.

The use of sparwise intercostals wh consicied for the nurpose of reducinf the weight of each desien however, this appronch was not mursued for the following reasons.

For the reference aluminum design the shell weight (skin) sccounts for $68 \%$ of 
the total weight. The stiffness contribution of the shell in terms of chordwise bending is about $75 \%$ of the total bending stiffness. The use of intercostals will sllow a reduction in the trickness of the shell however, this will also reduce the chordwise bending stiffness of the total structure which will reguire increasing the stiffness of the zee stiffeners and therefore the weight of the stiffeners.

The purpose of the intercostals would be to reduce the spanwise deformations of the shell between $z$ stiffeners which would in turn permit a reduction in the thickness of the shell. In order for the intercostals to be effective they would have to be deep in arder to have adequate stiffmess and would have to be spaced probably as close as 4 to 5 inches apart. In any case, the weight associated with the use of intercostals is totally ineffective with regard to the chordwise deformation of the leading edge structure and therefore not considered as being an efficient use of material.

Although a detalled analysis of the use oi intercostals was not conducted, it is rather doubtrul as to whether weight savings could be realized and whether the weight savings would justify the costs of fiabrication of such a multi part stricture.

Another complication Involvings the use of intercostals would be the negative effect the denth of the intercostals would have on the induced strain in the heatshield due to wing flexure. The analysis contained in Appendix 4 1llustrates the importance and exfect of structure depth and should be referred to.

For the reference titanium designs the shell welght is approximately $58 \%$ of the total welght and accounts for about $42 \%$ of the total bending stiffiess. The arme corments apply relative to feasibility of an intercostal design however, the efflciency may be greater when considering titanium as opposed to aluminum. 


\subsubsection{Ditanium ve Aluminum}

Both titanium designs, rib stiffened and $:$ ot.iffener, are simifient? hegvier han the alumimu desims, thereby elimimti"f" for: further consiciowition, the titanium concent desigmed for a beliface tumpersure of ony $33^{\circ} \mathrm{F}$. However the total system weicht, (i.c. hertshicla md stbstructure) must be considered

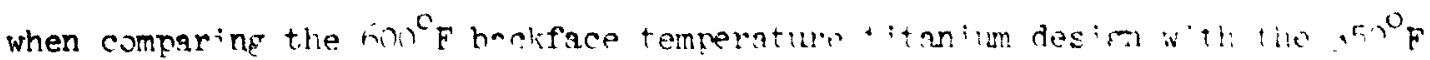

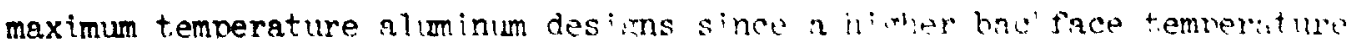
would result in a thinner and hence 1; ghter hentshield. Comparing the total 0.50 psf weight of this :..'. concept operating at a maximum

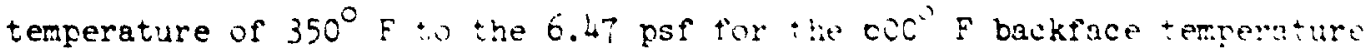
titanium design, it is evilent that the titarium design is still signicicantly heavier, when the aditional insuiation requirements and the atteniant complexities of the titanium design are considered.

Examining costs for materials and fabrication of the substructure the titanium design is conservatively estimated to cost approximately 1.5 times that oi the Z-stiffened aluminum design. Because of the higher weight and high cost assigned to the high temperature titanium design it was eliminated from further consideration.

\subsubsection{Tradeof of Duminum Designs and Design Selection}

As exfected, on the basis of weight (table 37 ) tite ligitest struitura: wncent is the aluminum sandwich jesign, but, as alluded to earlier this concert was not included as a serious a.e. candidate but rather wa" sarried a:nns in the preliminary design cycle to provide an estimate of the structurnl eficiency for the other concerts. Excluding the aluminum sandwich, the second lightest substructure evaluated is the intetral rib stiffened design with the slanted bulkhead followed by the $z$ - stiffened aluminun design.

When comparing the two aiuminum designs one should not expect that because of 
the different weights of substructure, i.e. a slightly different heat capacity for each substructure, the heatshield thickness is significantly affected. In this instance, the heat capacity of the ablator is greater than the aluminum, therefore, an increase in the heat capacity of the substructure would not lead to a large enough reduction in heatshield thickness to compensate for the higher structural weight. Furthermore, the hesvier aluminum design consists of a thin skin supported by relatively deep, discrete ribs which are less effective in distributing the heat input so as to reduce the heatshield thickness measurably. Consequently, for minimum system weight the superior alumimum design is the integral rib design.

As far as costs for material and fabrication, in ilmited quantities (7 shipsets) the $\mathrm{Z}$-stiffened aluminum design would be the lesst expensive to fabricate, however, in volume production it was estimated that the fabrication costs of both designs would be comparable. As shown earlier in tuble 27, for limited quantities of seven ships sets (i.e. refurbishing for all subsequent flights) the cost of the substructure is inconsequential when amortized over the 447 filghts. In terms of overall progrem costs, the only time the cost of the substructure exerts a strong influence is in those cases where a totally disposable l.e. system is contemplated. As a result it was concluded that on 8. cost träleoif both aluminum designs are equivalent. In adation, both designs could elther be refurblshed or discarded for the same relative cost. Therefore, the final selection criterion reverted back to a weight tradeoff resulting in the selection of the lightweight integrally stiffened aluminum design.

\subsection{JOINTS}

The design of both the chordwlse joints between adjacent lealing edge segments 
and the spanwise joint at the ablator leading odge/RsI Interface form an Integral part of the overall leading edge system. In arriving at an acceptable joint desion and its associntal sen, if needed, all facets of the iystem must be consldered, Involving such diverse items as seals materials selectio", structural requirements, thermal prolection, zerothermodynamic effect: and installation and inspection.

For example, if a special seal is reauired in the joint then a seal material must be selected wich is compatible with the adjacent materials (ablator and RSI) such that it does not adversely influence the TPS in the regions near the joints. Furthermore, the joint must be designed to perform thermally in n manner equivalent to the local heatshield to prevent local hot spots. Aerodynamically the joint must not affect the flow characteristics in the leading edge area to cause premature transition to turbulence or downstream contamination of the KST. Strusturally the joint must maintain its own integrity while accommodating differential expansion and the mechanical loads Introduced by the abutting leading edge segments. And finally, manufacturing of the joint and seal must be considered along with their inpact on the overall Installation and final inspection procedures. Consequently, the joint design process requires that a concept be selected which satisfies 311 asrects of the leading edge system. To illustrate this, table 38 lists some of the more important considerations for the joint desion relative to the various phases of the mission.

Figure 95 depicts a typical win; legdirg edge cra: isting of a nimber : Individual ablotor segments. In this illustration the chordwise joint is perpendicular to the wing front beam, while the RSI joint mus parallel to the front beam. Due to the wing sweep argle ranging from 800 inboard to $50^{\circ}$ fram atilspan to the tip the flow direction will in general be oblique to both 
Table 38 Fectors Influencing the Deaign of a Leading Edes Joint/Saal

1. Prelaunch

2. On Pad

\section{Ascint}

4. Tank Separation/Docking In-orbit

5. Roentry

6. Postentry/landing a) Should not complicate installation of L.E. Panels

b) Ease of installation - min. interference with other subsystems

c) Time compatible with turn around time allotted L.E.

d) Ease of inspection

a) Resist environment - seal aginst rain

b) Easily repaired/replaced, if damaged

a) Resist rain, hail

b) Withatend ecoustic and vibration environment

c) Resist effects of char - must not protrude or conteminate

a) Resist shock and vibration

b) Cold Souk - expand to maintain contact with ablutor segments

a) Protect sub-structure thermally

b) Compress as ablator exments expand keap land low

c) Not protrude above sblator/RSI surface

d) Recession (if any) must be combatible with ablator/RSI

-) Must not coniaminate adjecent TPS surfaces

f) General surfece condition must be aerodynamically acceptable

a) Must not affect sub-sonic serodynamic charecteristics

b) Resist rain, hail

c) Resist landing shock loads 


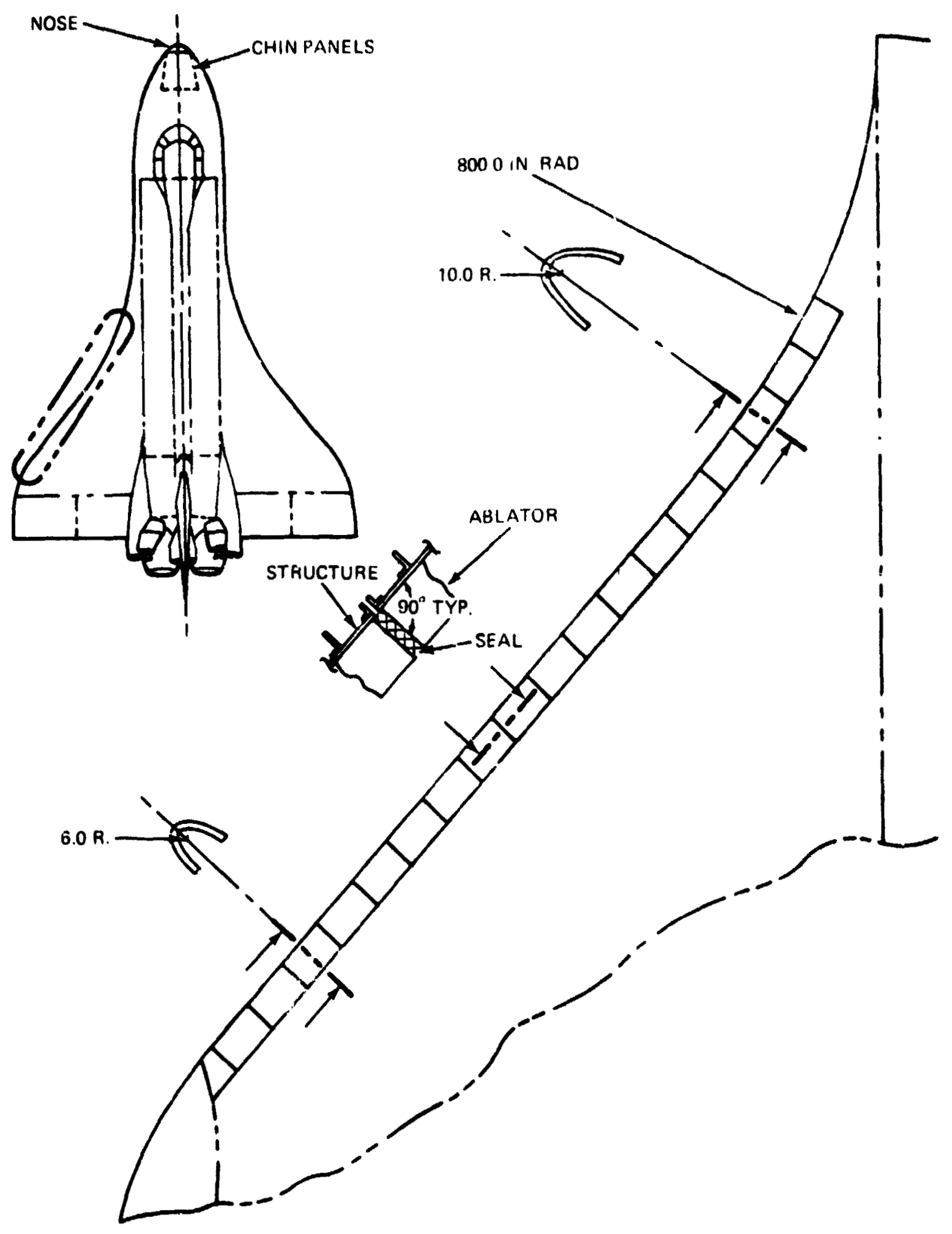

Figure 95 Typical Wing Lending Edge 
joints. This teods to minimize the joint dealen problem for filled joints as ccupared to jolnts which run parallel to the now, as long as the surfaces are flush or have a slight, dornstream facing step. Such a step can be easily provided by setting design tolerances which always insure that the joints be at worst flush and in most cases present a slighi rearward step.

For the purposes of this program, in the seleccion of the joint designs, both ablator to ablator (A/A) and ablator to RSI(A/RSI), apecial emphasis was given to the good design rule of keeping the design as stmple ani 'nexpensive as possible without lacrificing performance. Two bastc approsches were examined, namely: controlling the sfice between adjacent segments (gap with) such that no csel would be required, or using a soe? material in the joint and thereby relarding the restraints on gap whath control. The concepts examined and the rationale for selecting the final $\mathrm{A} / \mathrm{A}$ and the A/RSI joint designs are presenter in the following sections.

\subsubsection{Ablator/Ablator Joints}

\subsubsection{Gep Sizes}

Ideally, it would be desirabli: to have a continuous leading edge with no chordidse jolnts, however, such a situation io physically imprectical. Consequent2y, a compromise must be made which attempts to minimize the rumber uf folnts while satisfyling a mmber of physical and thermal/mechanical constraints.

Factors which affect the chordwise joint design are the leneth of the individia]. 1.t. segments, the thermal enviroment, wing flexure and the choice of a seal. The length of the l.e. segments is controlled to some extent by practi:s".

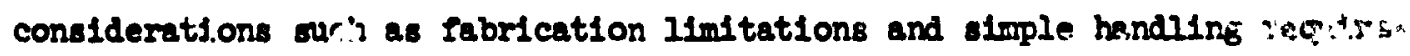
ments where size and bulk weight are important. As indicated carlier in the 
refurbishment studies, the physical size and weicht of each segment was limited such that they could be easily handled by no more than two murly men. In addition to these practical considerations. the section leneth will fictate the amount of differential expansion that will occur during thermal exposure and wing flexure. This differential expansion between the front beam and the leading edge controls the gap si-n between adizcent segments where under cold soak condition the gap size vill enlerge and corversely during heati, $;$ the gap size will decrease.

Figure 96 illustretes the geverai tehavior of the chordwise gap tethor. adjacent ablator segments as a furction of $2 . e$. lengt $t$. when exposed to the extremes of cold soak and entry heating. This figure was prepared for various initiai assembly gap size nine the l.e. as uncoupled from the wing front beam in the spanwise direction, as in the selectea attachment scheme. It was assumed that the aluminum substructure controlled the over3ll expansion and contraction o: the l.e. and that during cold soak and entry heating the i.e. substructure would attain its maximum ecuilibrium temperatures of $-25 c^{\prime} F$ ard $+350^{\circ}$ F respectively while the wing front beam ramained at a nominal temperature of $70^{\circ} \mathrm{F}$. This latter assumption is extreme?, conservative since although ne might expect the leading edge to respond to temperature veriations more rapidly tian the wing front beam a lag of the manitule assumed is extremely liniikely. Hnwever, this assumption was justified on the besis that if a gap ceal could be designed to satisfy these condstions, it would certainly perfor:. in the less severe real enircrent. Figur gt indicates that for ary gtven Infial gap size there is a critical leading edge length at which the se $_{t}$ rents come inio contact during ertry heating. This condition was considered to be undesirable since it could lsaa to interactivn between the segments and could pussibly promote pre:. cure failure of the charred portion of the ablator. 


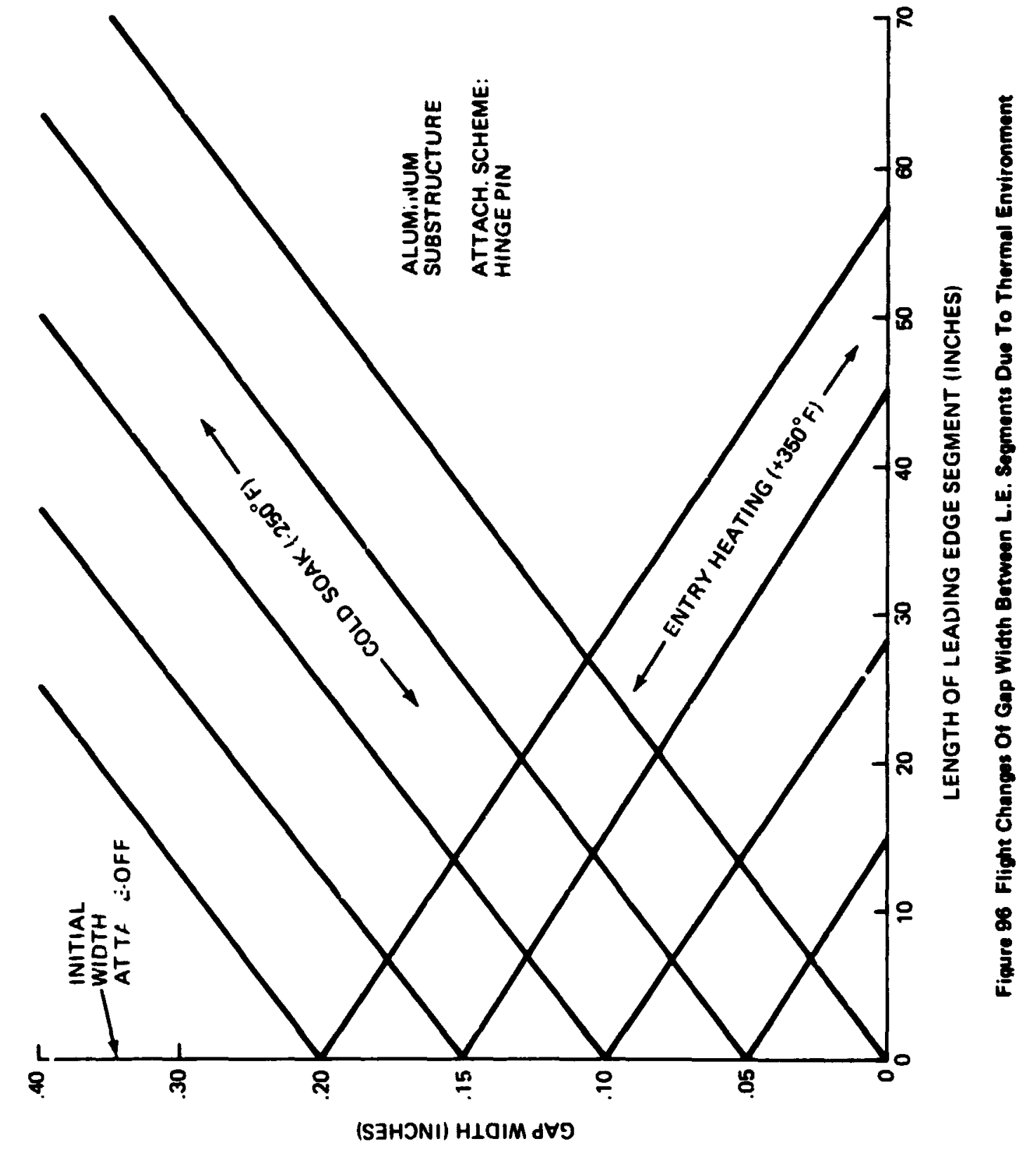


Actually, no condition approaching a zero gap width could occur for the juint designs envisioned (see below) because all concepts employed a form of flexible seal in the gap which would impose a finite gap width on the design urder all flight conditions. For the cold solk condition the figure indicates thrt the gap width constantly increases as a function of leadirg edge leneth.

The changes in gap width sue to wing flexure must also be considered. These changes arise by vi: $: e$ of the fact wat the l.e. is essentially un uflet from the front beam in the panwise direction. As a result any spanwise curvatures in the front beam are not transmitted into the leading end, but rather, the l.e. bridges these curvatures by a series of linear sements. Consequently, any bending of the wing will cause the gap to open on the upper surface and cicse on the lower surface or conversely depending upon the direction of bendine. Figure 97 illustrates how the gap wiath will vary as a function of wing span. This figure was prepared using predicted curvatures produced during the most severe wing bending condition (i.e. $\max . q^{\alpha}$ figure 91 ) and accounts for the depth veriation of the leading edge as a function of span. For conservatism it was assumed that the seal material would be sufficiently stiff to prevent any gap closure during wing flexure, thereiy forcing the leading edge to pi vot about its outer extremity rather than the front beam neutral axis which causes the maximum opening of the joirt (see figure 97 insert). As can be seen in the figure the maximum change in gap width occurs out at the wing tip where the curvatures are the most severe with little or no changes indicated inboard of the midspan position. Also, for wing bending as was the .. se for differential thermal expansion the longer leading edge segments result in lareer changes in gap width. Forturately, the cold soak and maximum wing fle:ure desicn conditions do not, occur simultaneously. In fact, an examination of sigures 96 ani 97 shows that the cold soak condition controls the maximum gap openire for all 

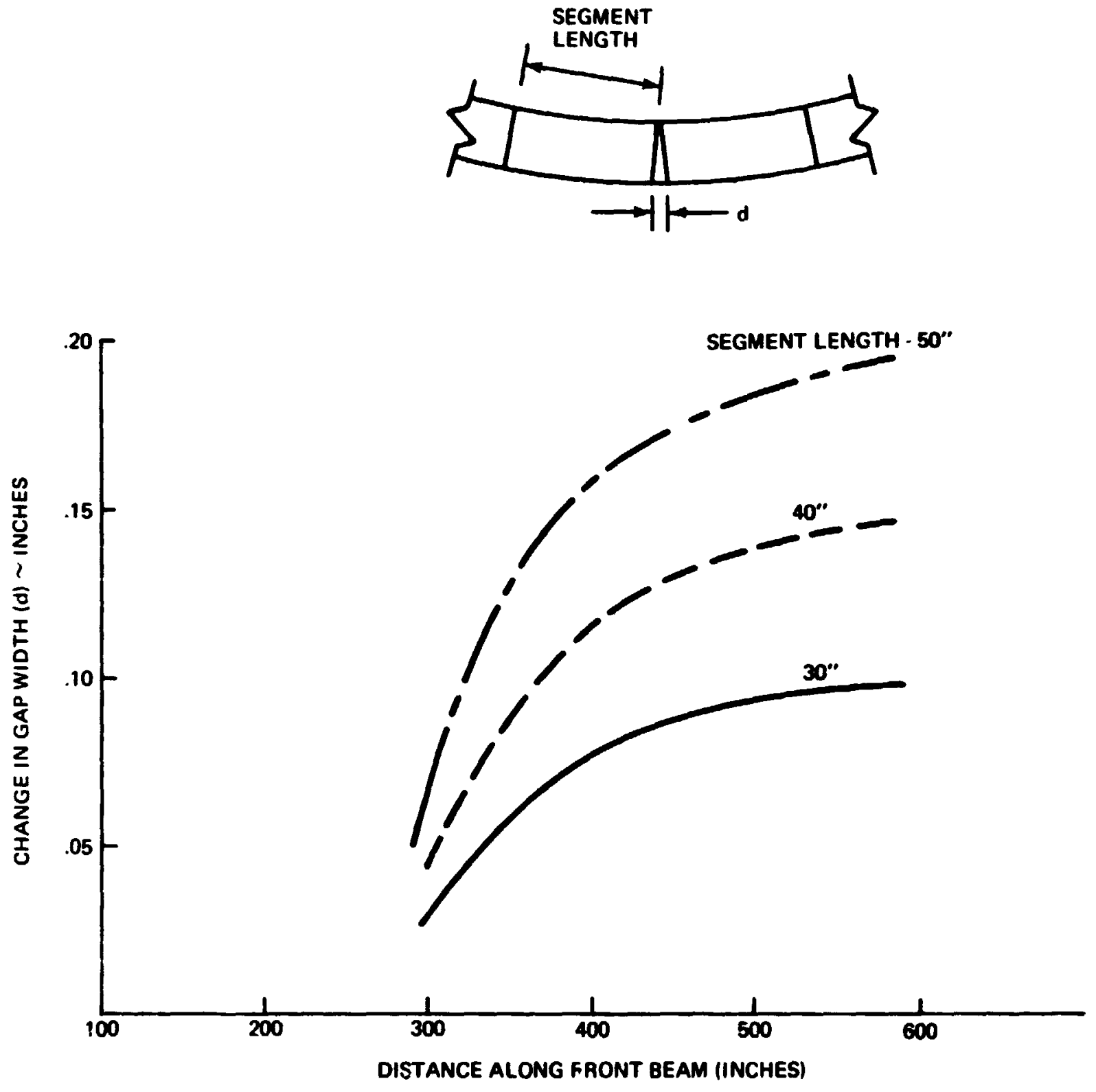

Figure 97 Flighe Changes In Gap Width Botwoen L.E. Sogments Due To Wing Fhexure 
lengths considered even in the region of the wing tip. Consequently only thermal excursion need be considered to size the gap.

Cambining these two conditions with the themal heating requirenents it was possible to place some desien constraints on the leading edge gap size. To begin with, thermally it would be desirable to minimize the size and extent of the joint. From the thermomectanical viewpind, during the entry heating the joint must maintain a width sufficient to prevent the seal from extruding or from compressine to the point where it causes excessive compressive strain. b-tween adjacent ablator segments. Also during cold soak and wing flexure, the seal must be flexible enough to expand to fill the gap such that it does not becone dislodged or displaced prior to reentry.

With these as design constraints the problem resolved itself into selecting 2 leading edge length and associated assembly gap width which would be compatible with the compressible seals envisioned. Since it was established that the seal must always fill the gap, this required that the seal be installed with an initial compression such that it could expand during cold soak. Although seemingly minor, this initial compression of the seal could lead to some rather high canpressive forces being applied curing assembly due to the large surface area of the sial. In fact for some relatively cumpressible seals considered, the assembly forces required to compress the seals to the desired levels approached $200 \mathrm{Ib}$ (see Section 6.5.1.3). Consequently, this became an important considuration in tile overall selection of the seal. 
Leading edge lengths less thar. $20 "$ were eliminated simply on the besis of practicality. In examining 1.e. lengths greater than 40", one is forced to employ either a high initial precompression of the seal or to enlarge the initial gap width to $.20^{\prime \prime}$ and larger. For example, for a $50^{\prime \prime}$ segment, the gap width opens by .20" during cold soak. To fill this gap under ideal conditions, assuming complete expansion of the seal, would require an initial gap width of .20" for a seal compressed by $50 \%$ during installation. This does not allow for the embrittlement of the seal at $-250^{\circ} \mathrm{F}$ nor has any allowance been made for any residual compression in the seal during cold soak to retain its position. Therefore the gap widths expected for 1.e. lengths greater than 40" would have to exceed . 20 " or the seal precompresion would have to be greater than 50\%. Neither $c$ : these alternatives were acceptable. Consequent.ly, the leading edge lengih was confined to the range of greater than $20^{\prime \prime}$ and less than 40" per segment.

Initial gap widths of $.30^{\prime \prime}$ or greater had already been eliminated and, with the segment-length bands set, it would appear from figure 96 that initial gap widths of much less then . $15^{\prime \prime}$ would be undesirable since they would lead to relatively high seal compressive stresses under the assumed entry heating conditions. In fact, at a .10" initial gap width, tı. seal would be fully compressed during entry heating for segment lengths greiter than approximately $28^{\prime \prime}$. Consequently, the initial gap width range selected for evaluation was set at between . $15^{\prime \prime}$ and $.20 "$ which is compatible with the 20 to $40 "$ segment length. This woul' result in a situation where there would never be a possibility of the leading edges coming into intimate contact and the initial compression of the seal during assembly would be in the order of 50 to $60 \%$. 


\subsubsection{Joint Concepts}

a. Controlled Gap Width Desigr. (No Seal)

The first approach investigated for the chordwise ablator/ablator

(A/A) joint design was the concept in which the gap width is controlied ath no seal is employed. Typical concepts for this type of design are showr: in figure 98 where the intent is to prevent the entry to the substructure of hot gases by creating a narrow indirect path. For the leading edge A/A chordwise joints this approach was deemed impracticai for the following reasons:

Even though the l.e. joint is not parallel to the flow, in the nose region the flow will impinge directly into the joint and in all likelihood this would dictate a very small $(.01-.04 \mathrm{inch})$ gap (Ref. 66, 67). Dimensions of this magnitude are not practical when you consider vehicle structural tolerance build-up and ablator segment shrinkage/growth. Larger gap would probably be required, in conjunction with this, to inhibit flow directly into the gap with modifled designs such as 3 half lap or other joint design similar to tiose depicted in figure 98 , but the gaps would still be impractically small. Buth of these are expensive to fabricate within reasonable tolerances. Also, calculations indicate that in the stagnation area depth of char would be 


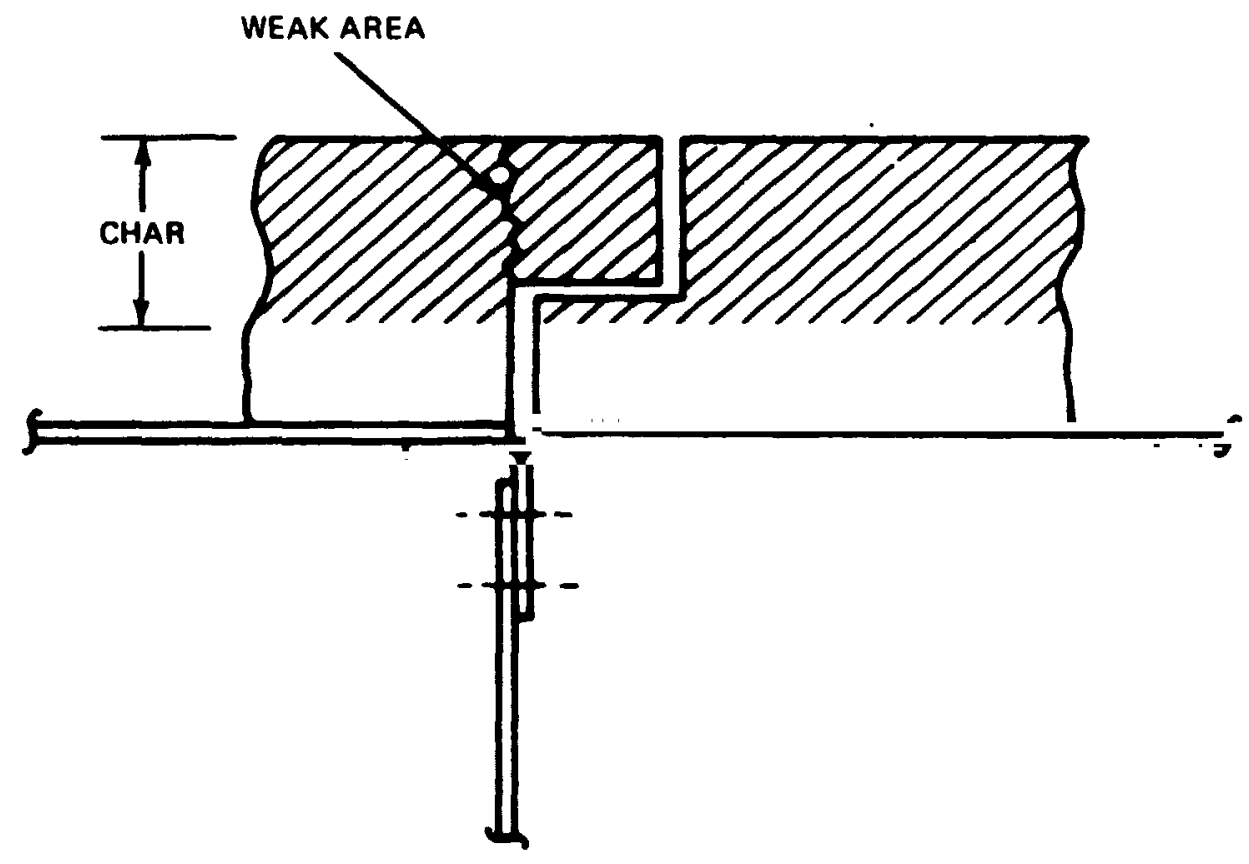

HALF I.AP JOINT

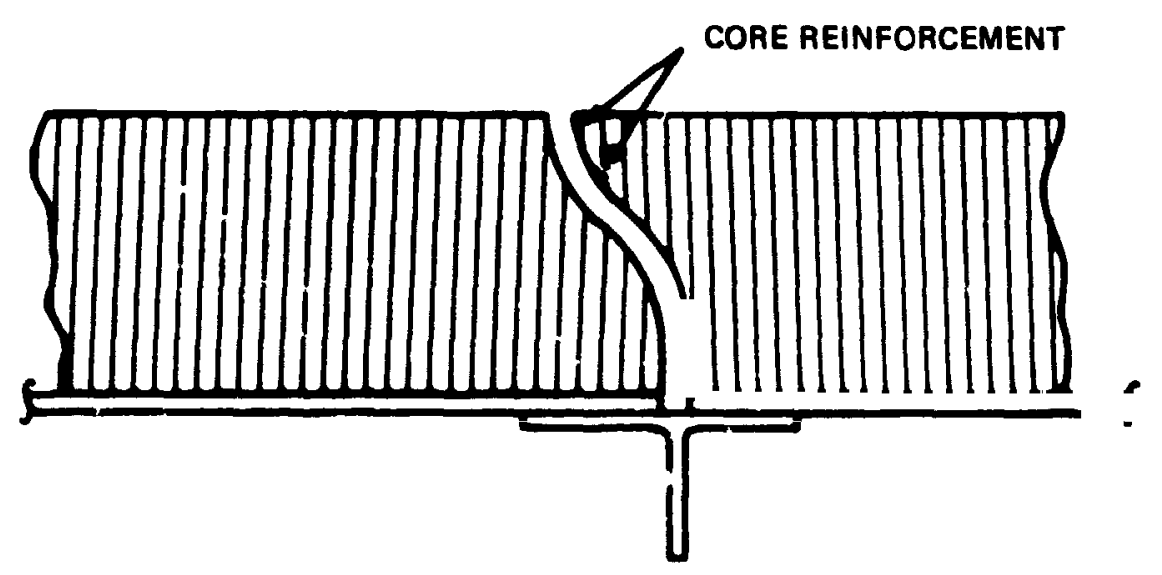

BEVEL JOINT

Figure 98 Controlled Gap Width A/A Joints 
deeper than the overlap plane makine the outer overhanging ablator strip weak and subject to loss during flight. The honeycumb relnforcement does not improve this situation to any great evtent.

Therefore, the approach involving the insertion of a filler material in a gap having dimensions of a more practical magnitude (.1-.2 inch) is the one selectei for the A/A joint.

\section{b. Seal Materials and Concepts}

Seal Materials: Several materials were considered for use as a high temperature seal between the legling edge segments. Leading the Iist were the RTV materials which have undergone extensive flight evaluation as $\mathrm{A} / \mathrm{A}$ seals on the Apollo vehicles (Ref. 68-69). Their performance has been good and they are easy to work with, are castable and not overly expensive. On this basis, this material is considered a prime candidate.

Silica and zirconia are high temperature materials that, when utilized in a felt or woven mat form, can easily be compressed to absorb closing of the gap. An attractive characteristic of this class of materials is that they do not expand to any great extent upon heating and/or compression, therefore ther are not likely to protrude into the air stream. Also, these materials are not likely to contaminate the adjacent TPS in any way. Preliminary testing has verifled these two latter characteristics and for these reasons and due to the availability, silica felt is considered an attractive candidate.

Metals, such as Hastelloy $\gamma_{2}$, Haynes 25 and Haynes 188 , fabricated in the form of a wave spiling, offer an attractive approach from the stancipoint of protrusion, contamination, and force applied to the edges of the ablator. Formine this seal to the 1.e. contour would require extensive tocling, and thermal performance for parallel or near parallel flow has not been determined. Such a 
spring with the metal perforated and encased in RTV or silica felt offers another possibility.

Seal Concepts: Combined with the materials selection there are specific performance requirements pertaining to the seal design which also wust, be considered in determining the overall joint/seal concept. Ideally the seal stould be capable of absorbing mamfacturing tolerances for initial ase mbly purposes, expand as the ablator segments shrink during cold soak, and compress as the ablator segments and structure heat up during entry. Throughout this environment, the load (pressure) that the seal exerts against the edges of the ablator must be small enough such that the ablator, even in the charred state, does not fail.

There are two approaches to accomplishing this:

1) Fill the cavity with a soft compressible materiel, such as silicone foam in a partially compressed state, suck that will expand in the cold soak or

2) Insert a mechanical seal in the cavity such that the material deforms in the bending mode or by bellows action, thus allowing movement at a low or controlled force.

Figure 99 shows a typical joint configuration between two adjacent $1 . e$. segments employing a campressible filler material. The carity between segments has tapered sides which act as a mechanical ti ap to retain the seal material. In this partic"lar illustration the cavitv is filled after the leading edges have been installed with a pressure-operated caulling gun. The caulking material is envisioned as a modified RTV having a reduced density and a viscosity such that it w1Il not run cut of the cavlty. In the cured state, 1t would be a soft, easily compressible material similar to existing RTV sealers and 


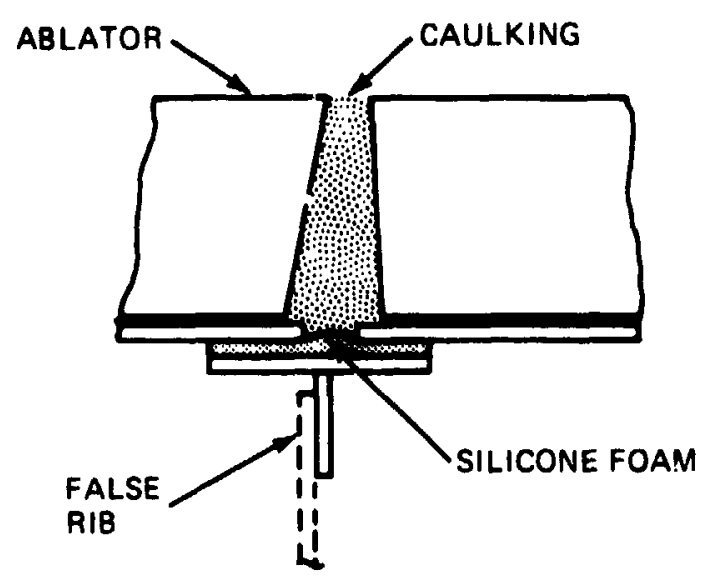

(a)

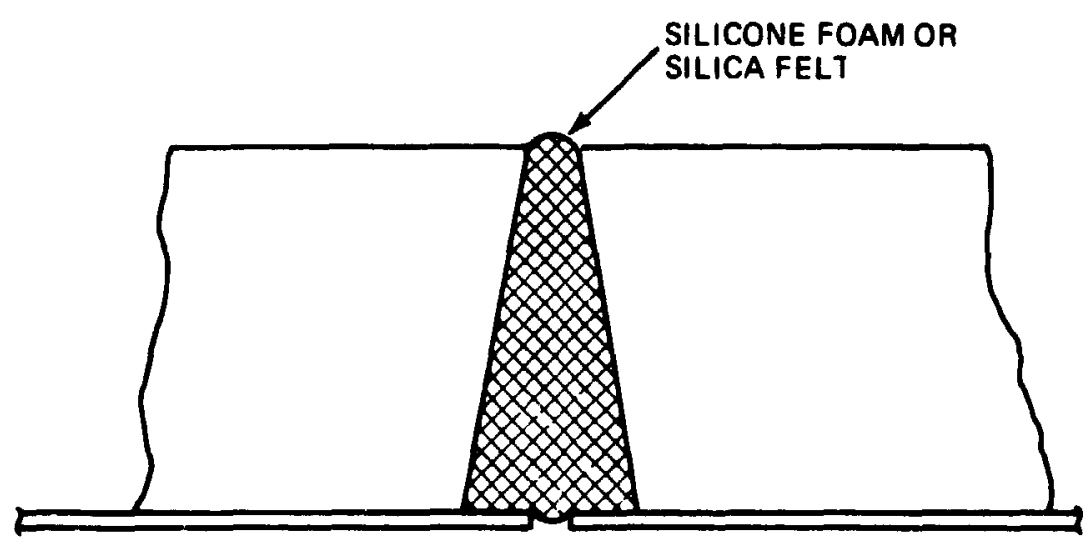

(b)

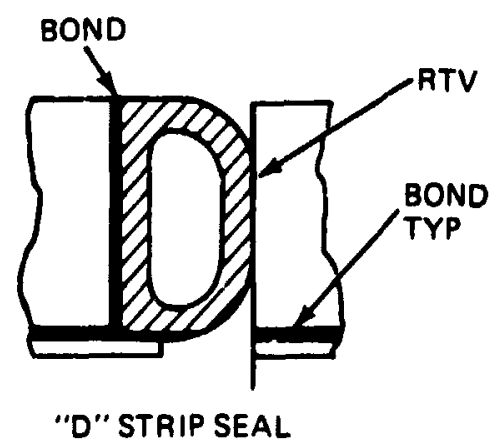

(c)

Figure 99 Compressible Seal Concepts for A/A Joints 
adhest ves.

Alternative compressible seal designs shown in figure 99 (b) and (c) would involve insertion of preformed seals (gaskets) using a sil'cone foam or silica felt material. Unlike the caulked seals these preformed seals would be put in place and inftially compressed during installation of abutting segments. One disadvantage of these approaches is that the ccmpressive force requitred during installation increases rapidly as the percent volumetric compression increases, thus, this may cause some difficul.ty during installation. However, from a thermal performance standpoint, this design appears to perform very well. It also would provide one of the better moisture seals.

Two general types of mechanical seals were also considered; one being the wave seal using either RTV slifcone or super alloy metals and the second being a labyrinth type of seal employine a silicone material. Typical wave seal configurations a.e shown in figure 100, and consist of a premolded corrugkted seal strip which is mechanically trapped in ple e during leading edge installation and absorbs expansion/coitraction by bending. The wave seal as shown in figure 100 (a) has been previously fabricated in straight ard leading edge conflgurations and installation has been demonstrated on full scale mouk-ups (see 11gs. 80 and 81, Ref. 2).

A varlety of labyrinth type seals are show in figure 101. These seals allow for the greatest amount of differential motion while at the same time providing the least resistance to relative inotion. Sealing is accomplished by the interlocking components which tend to prevent any hot gas penetration to the substructure. Also, several of the concepts shown, can be put in place after installation of the leading edge panels. The primary disadvantage of these seals is cost, both in terms or inftial tooling and subsequent fabrication. 


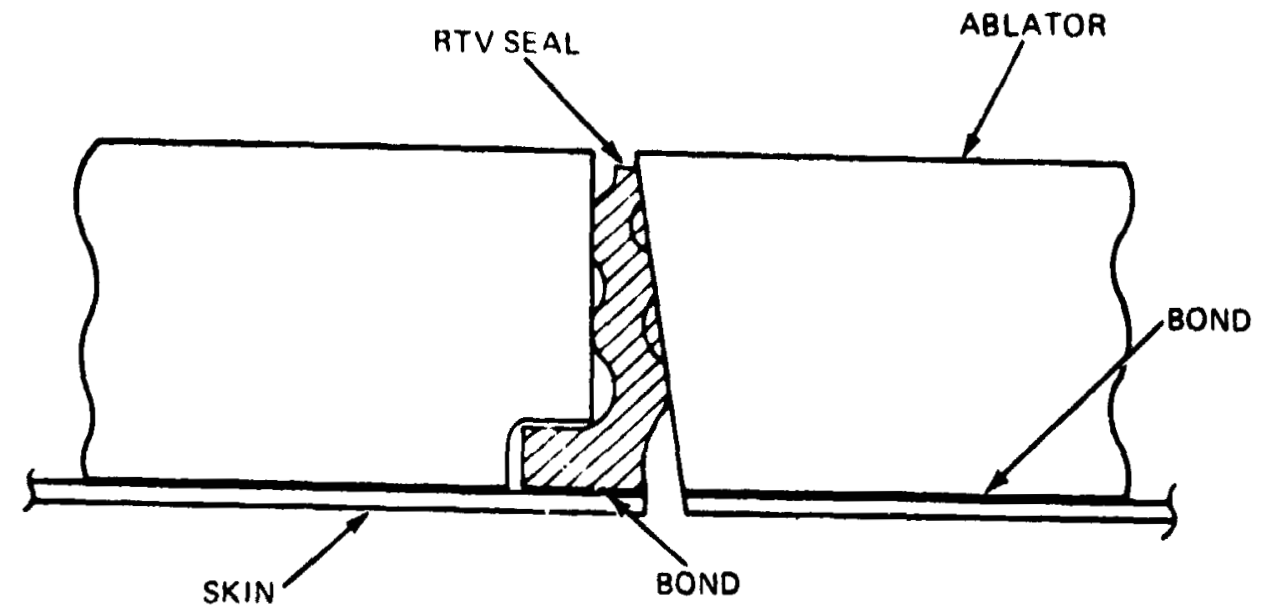

(a)

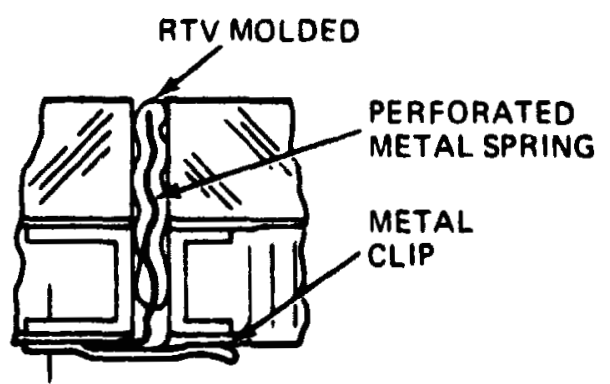

WAVE SEAL MECH ATTACH.
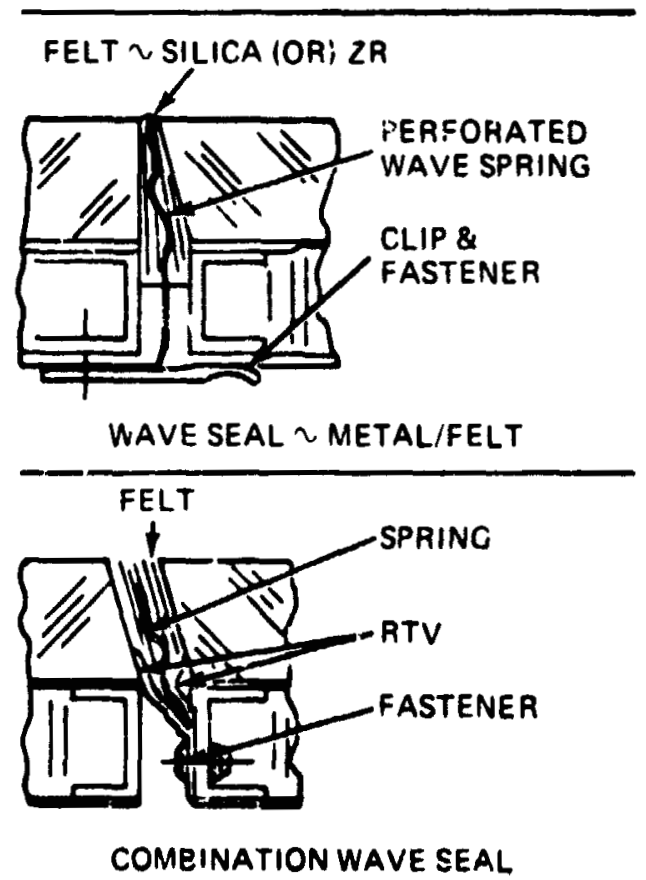

Fiqure 100 Wave Seals For A/A joint 


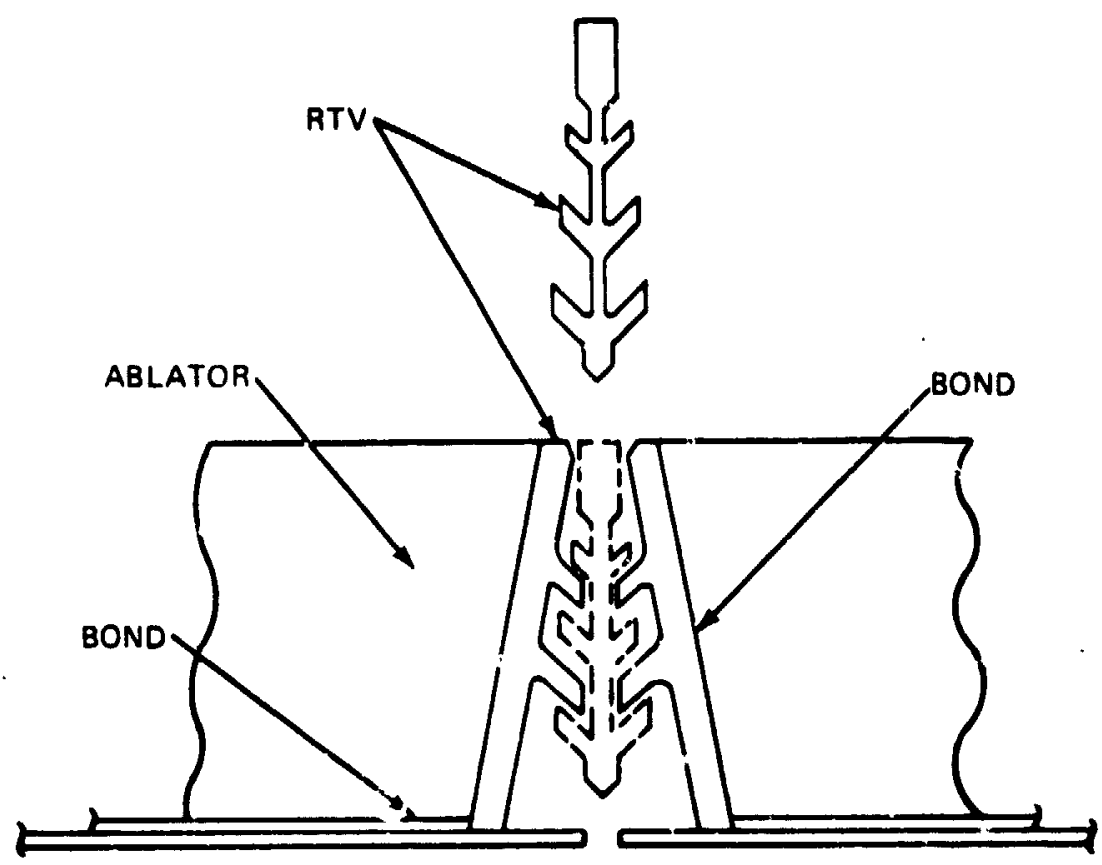

(a)

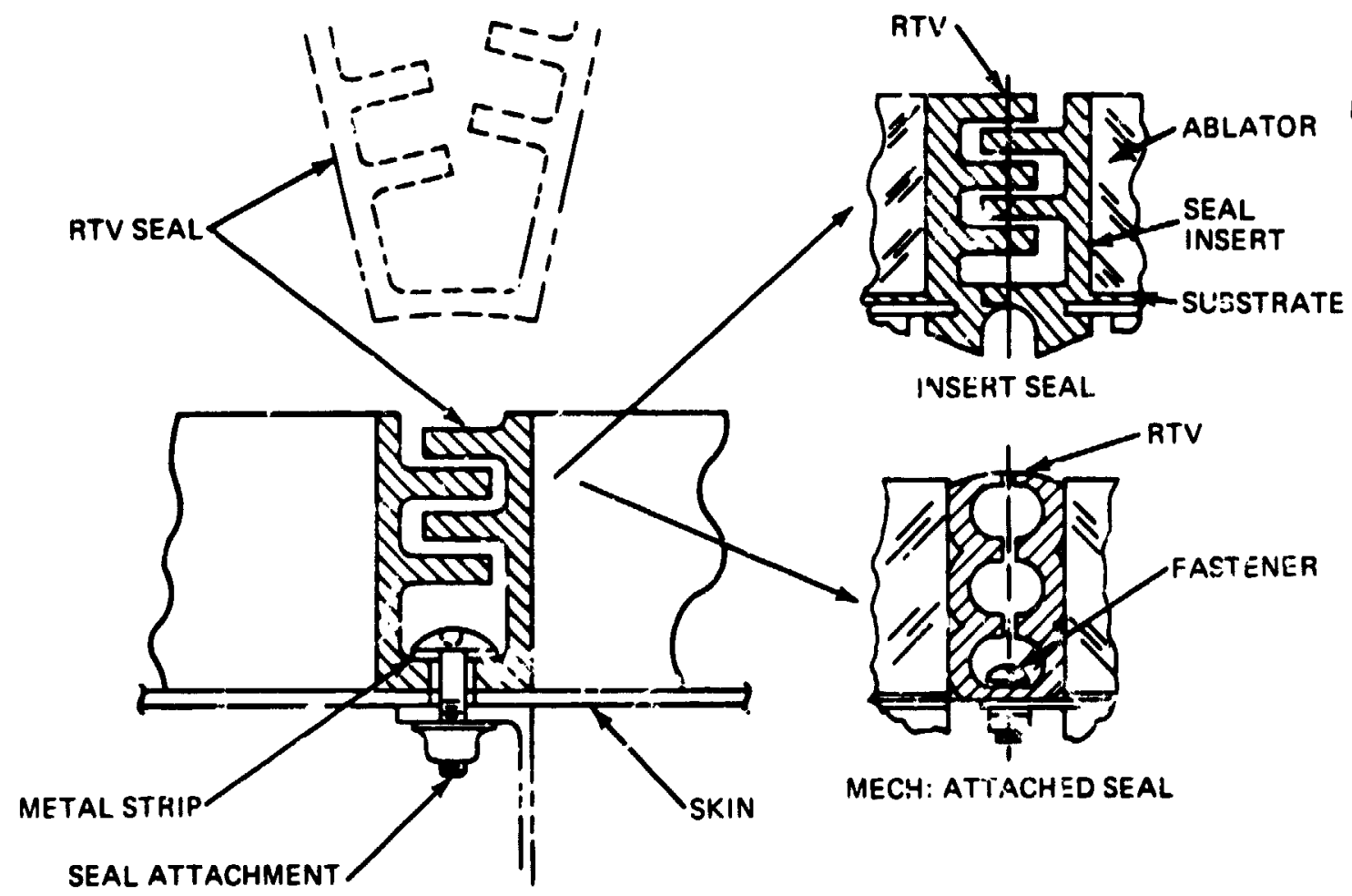

(b)

Fiqure 101 Labyrinth Seals for A/A Jnin ," 


\section{c. Cop Confiquration}

Just about the simplest means of obtaining a positive hoiding pressire or. the seal without resorting to secorlary fastering or other schemes for mechanical entrapment, consists of leveling the edges of the ablator to entrap the seal.

\section{$6 .: .: 3$ Seal Evaluation and Trade-off Studies}

of the seal concepts presented in the previous section the compression seal and the vave seals represented the simplest and least expensive concepts. Therefore it was decided to pursue the evaluation of these two concepts in more detail. The labyrinth seals though somewhat more sophicticated did not afford any sigrificant advantages over the other two methods, consequently the projected higher cost of fabricating these seals was sufficient justification for eliminating them from further consideration.

Evaluation studies conducted consisted of mechanical testing of candidate seal materials, screening via available thermal tests, on splash specimens, and final validation via arc testing of leading edge models with seals in a LaRc arc test facility.

\section{a. Seal Coupressibility Evaluation}

A series of tests (Ref. 66) were run to determine the relative compressibility of the following seal designs (See figure 102):
a) Wave Seal - RTV 560
b) Silicone Foem
c) Silica Felt
d) Hastelloy " $\mathrm{X}$ " Wave Spring

The teat consisted of a six inch length of simulated foint as show in floure 103 and measurements were made of deflection versus applied load (See 118, 104). 


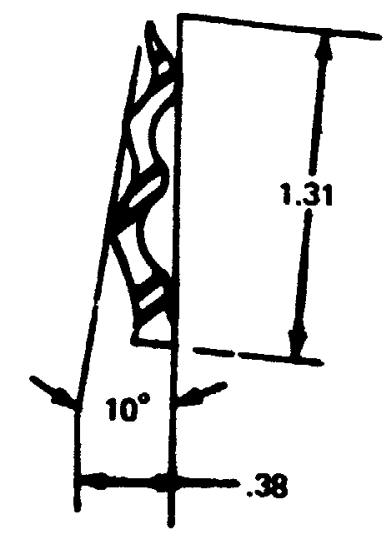

RTV 500

WAVE SEAL

(a)

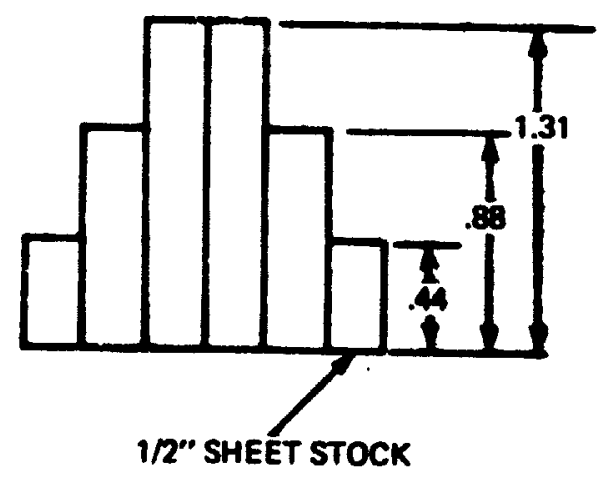

SILICA FELT STRIPS

(c)

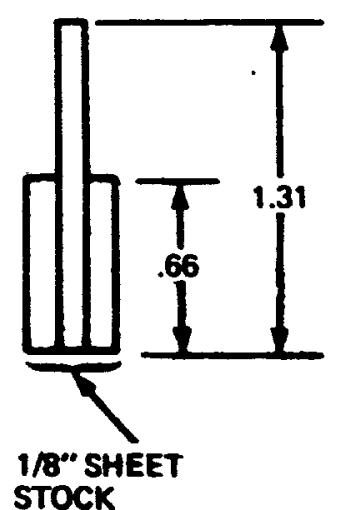

SILICONE FOAM

(b)

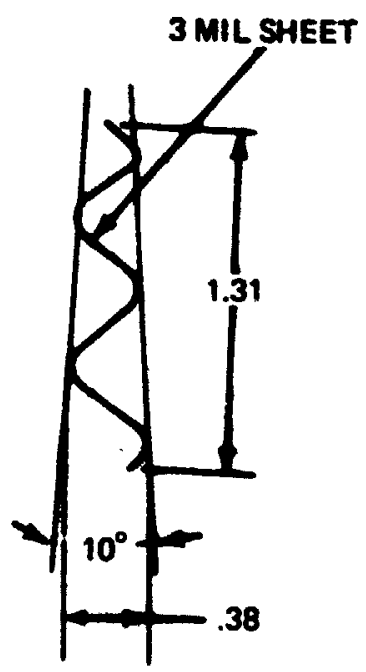

HASTELLOY $X$ WAVE SEAL

(d)

Figure 102 sen Comprementility Tes Spacimens 


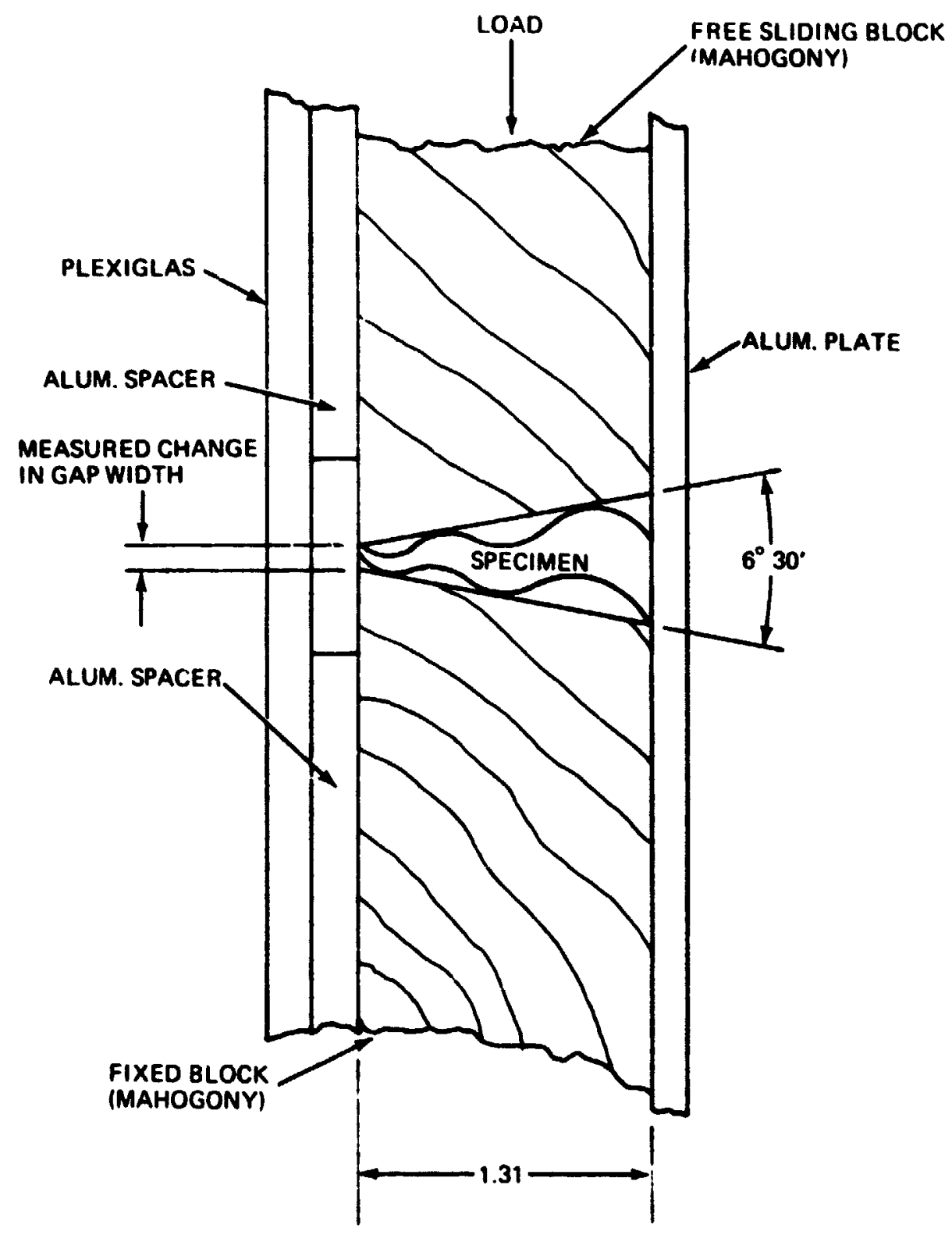

Figure 103 Tent Fixture For Soal Compreadbility 


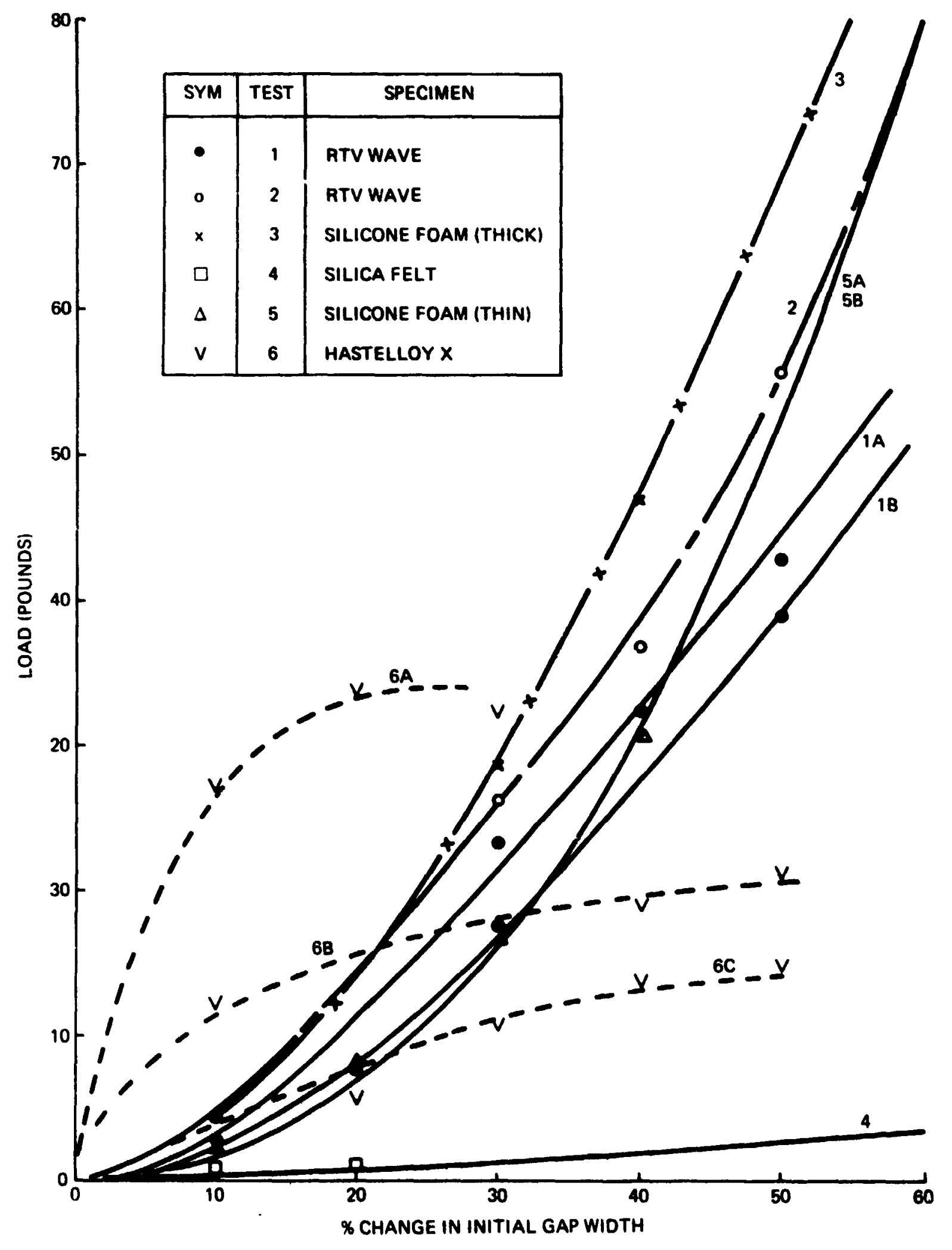

Figure 104 Results Of Sed Compression Text 
Tests were performed using an INSTRON Model TTC-M Universal Testing Machine.

Test No. I was conducted on a wave seal molded from RTV 560, as shown in figure 102, and was set. up to stop loai application at a gap dimension of 0.060

(the approximate seal thickness). The test was repeated a second time with the curves labeled $1 \mathrm{~A}$ and $1 \mathrm{~B}$ in figure 104 showing the behavior for the first and second cycles respectively. Test No. 2 was conducted on the same specimer. varying the load from 0 to 100 pounds, allowing the gap to close less than the .060 above.

Test No. 3 was conducted on a specimen consisting of three strips of $1 / 8$ " silicone foam. See figure 102 (b).

Test No. 4 used the test specimen shown in figure 102 (c) (6 pieces standard Astro mat (tradename), style No. 550).

Test No. 5 used a modified version of the configuration used in Test No. 3. The two outer pieces of silicone foam were made of $1 / 16^{\prime \prime}$ sheet rather than the 1/8" previously used. The test was repeated once.

Test No. 6 used a wave seal similar to that used in tests 1 and 2 but was fabricated from 3 mil thick Hastelloy (see figure 102 (d). This test was set up to stop loading when the seal was compressed $50 \%$ of its initial dimension. In the first test (Curve $6 \mathrm{~A}$ ) the tip of the wave seal contacted the test fixture (plexiglas plate) before $50 \%$ compression was reached, so the test was halted and the fixture was modified. It is interesting to note that at the conclusion of the first run (6A) the seal had taken a set of .047. Four hours later, at the start of run $6 \mathrm{~B}$, it had almost completely recovered. At the conclusion of $\operatorname{man} 6 \mathrm{~B}$, the seal again had a set of .047 . The load required to achieve $50 \%$ deflection dropped in each run. 
In all tests the initial gap used was that resulting from the weight of the test fixture ( $1.3 \mathrm{Ib}$ ) resting on the seal.

It can be raadily seen from figure 104 that the silicone foam is likely to build up large loads against the ablator and/or RSI edge as the seal material is compressed in excess of say 40 to 50 percent of its original (free state) gap dimension. This can be controlled through proper selection and precompression of the original assembled dimension. Of particular interest is the very low initial and negligible load buildup, even up to $80-90 \%$ compression, for the silica felt seal (see figure 104 and 105 ).

\section{b. Preliminary Screening via Thermal Test Data}

It was fortunate that some Avco test data (Ref. 70,71 ) were available for an initial thermal evaluation of the candidate seal materials.

Five specimens of Avco 5026-39 Hc ablator with various seals installed had been tested, in the ROVERS Arc facility, for entry heating withe'st precharring or cold soak. Four of these were seal candidates mentioned in the previous section and one was a reference ablator. The specimens had been fabricated at Avco Litilizing standard Avco 5026-39 Hc ablator material. These specimers were 3 inch diameter, flat-faced cylinders measuring 1.25 inches thick and were bonded to a 0.25 inch thick fiberglass backing plate. A ten degree total angle, tapered slot measuring 0.100 inch width on the front surfaze was cut for the full diameter and for the full thickness of four of the specimens. Each of these specimens was then provided with a different type of seal. The four types of seals tested were:
a. Caulked
b. Silicone Foam
c. RTV Wave Seal, and
d. Silica Felt 


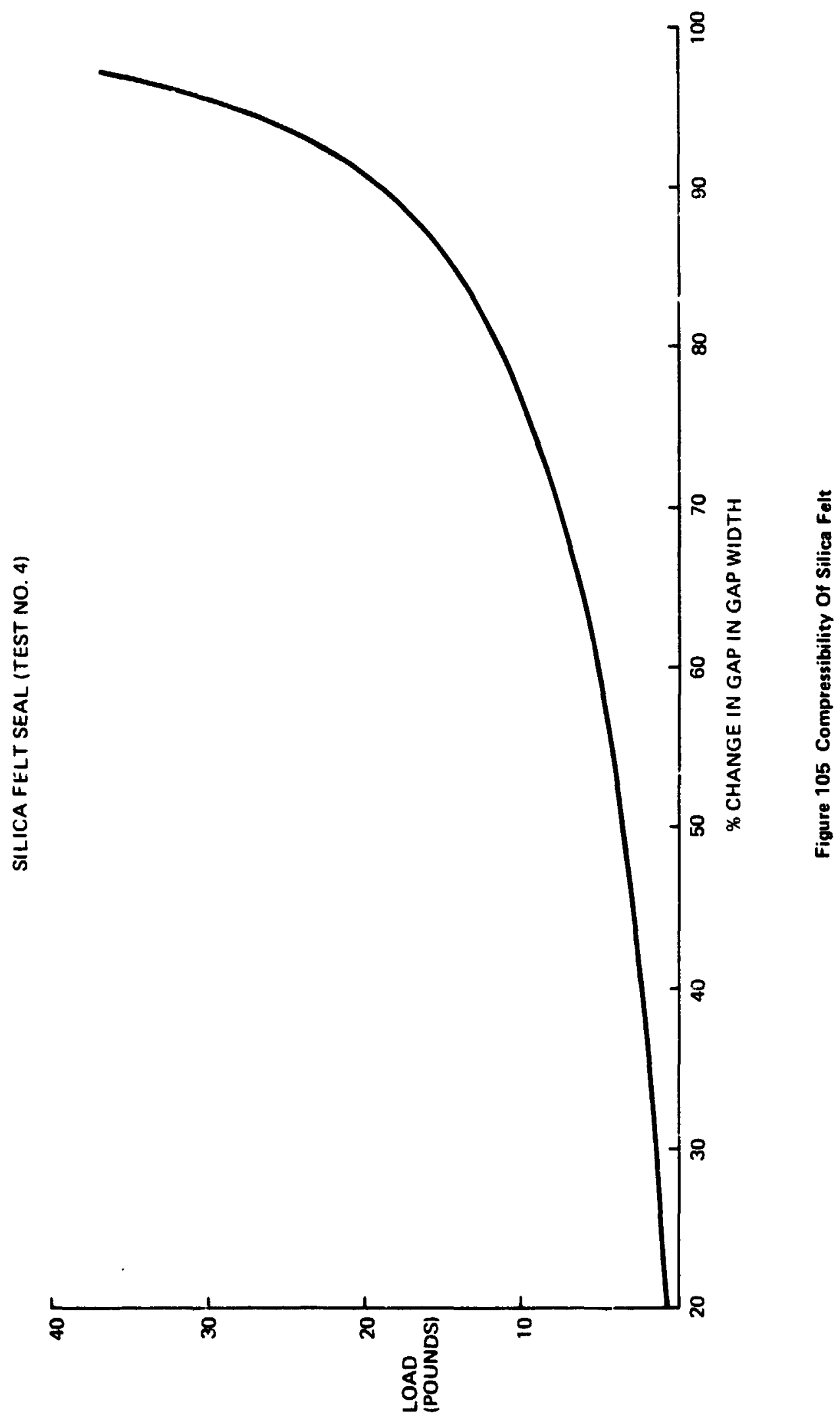

278 
Note that this combination represents a gross manner, the two basic approaches considered here. For example, the wave seal has built in volds as do a number of designs and therefore, thermal performance will be similar. Figure 106 defines the test specimen configuration and instmment for each of the test specimens.

All specimens had been instrumented with two chromel-alumel thermocouples located at the interface of the ablator meterial and the fiberglass backing plate and positioned so that one was directly behind the seal on the specimen centerline and the other was offset one inch from the centerline and located in the ablator meterial. A recording pyraneter was utilized to monitor the surface brightness temperature throughout the test period. Notion pictures of the exposed surface at various time intervals are also available (Raf. 72 ).

The test specimens were weighed, measured and photographed (figure 107(a) \& (b)) prior to installation. They were then installed in the square model holder with insulating strips wedged between the specimen and the holder and the spaces left, were $1: 1 a_{i}$ with fiberfrax insulation to reauce conduction between the sample and the model holder. The model holder was then attached to the remotely operated, overhead injector and adjusted to position the front surface of the test specimen in the center of the arc jet and at a distance of 10 inches downstream from the $\underline{r}^{7}$ ne of the exit nozzle ( $3 \times 3$ inch section).

The test conditions were nominally a heat flux of approximately $60 \mathrm{Btu} / \mathrm{ft}^{2}-\mathrm{sec}$. at an enthalpy of approrimately $12-13000 \mathrm{Btu} / \mathrm{Lb}$. Each specimen was injected into the plasma stream and exposed to the heating environment for a pre-set time of 600 seconds. This was followed by a cold-soak period of at least 500 seconds. After testing, the specimens were removed from the model holder, welghed (to determine mass change), measured (to determine thiciness change), 

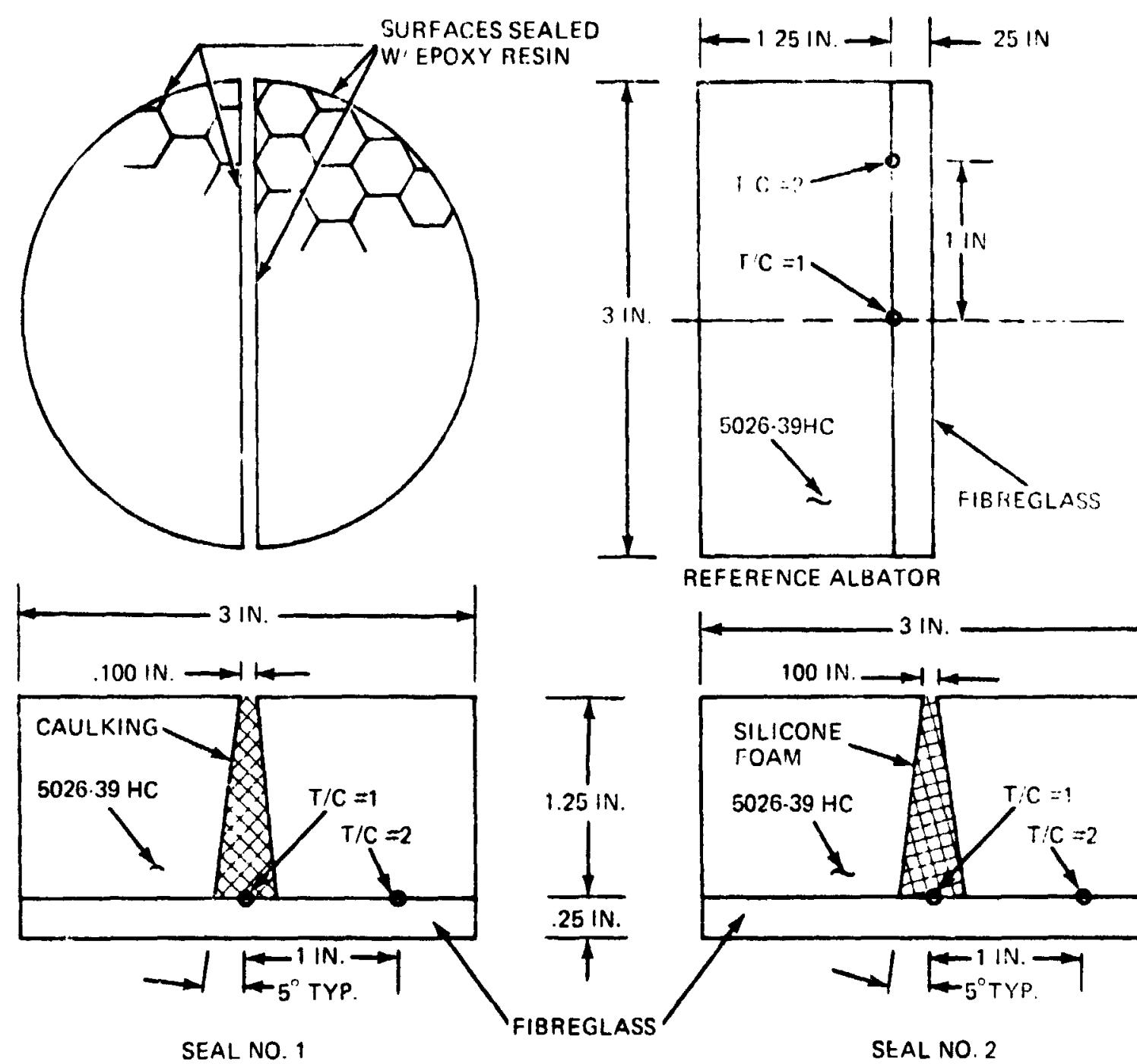

REFERENCE ALBATOR
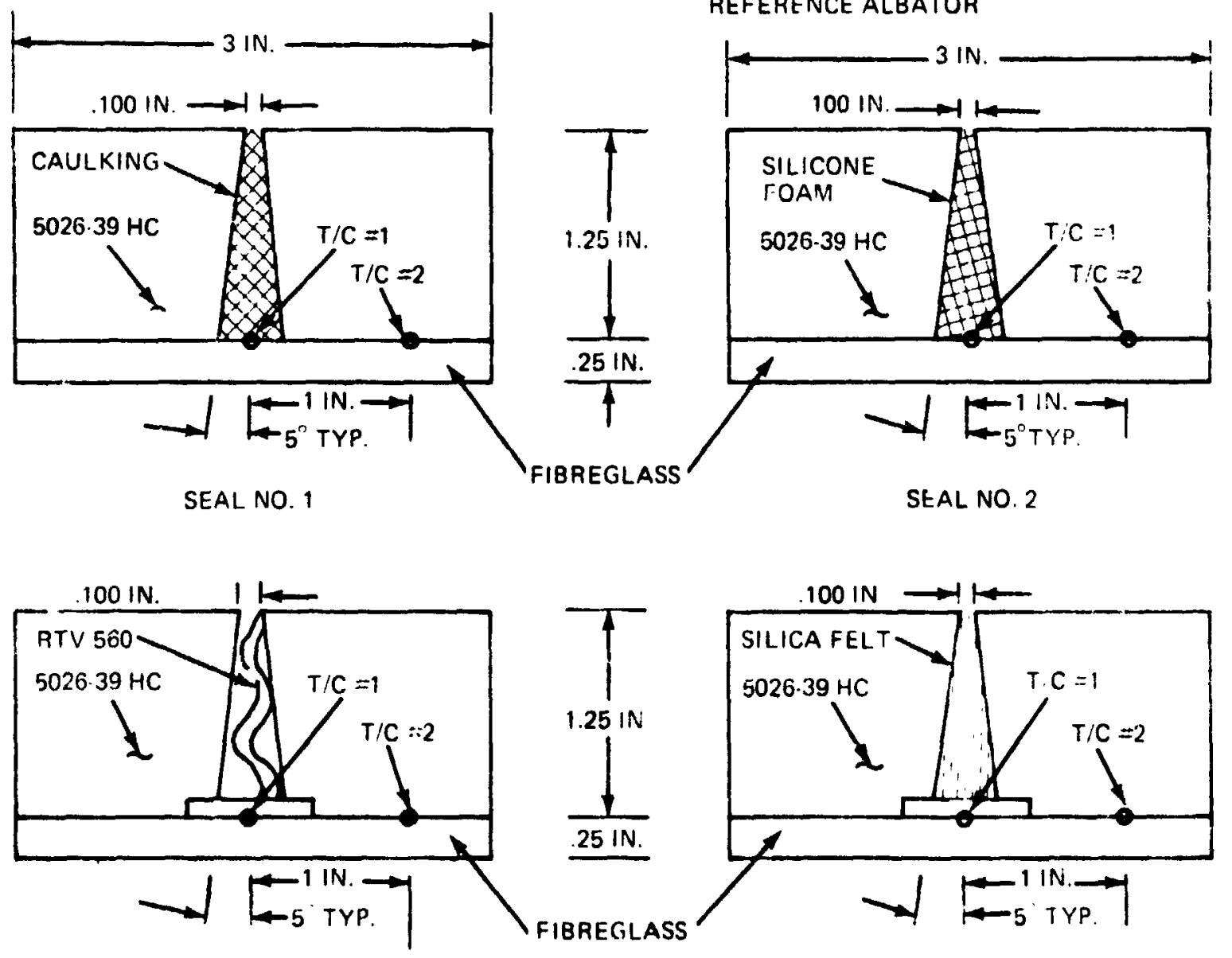

SEAL NO 3

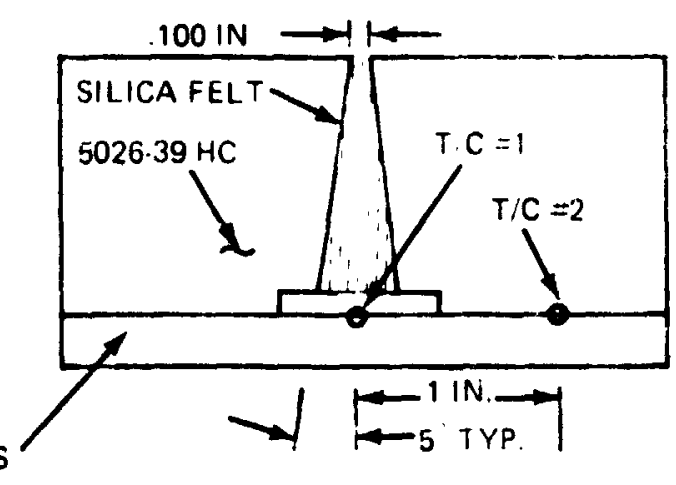

SEAL NO. 4

Figure 106 Details of Seal Construction and Instrumentation of Pravious AVCO Seal Tests 

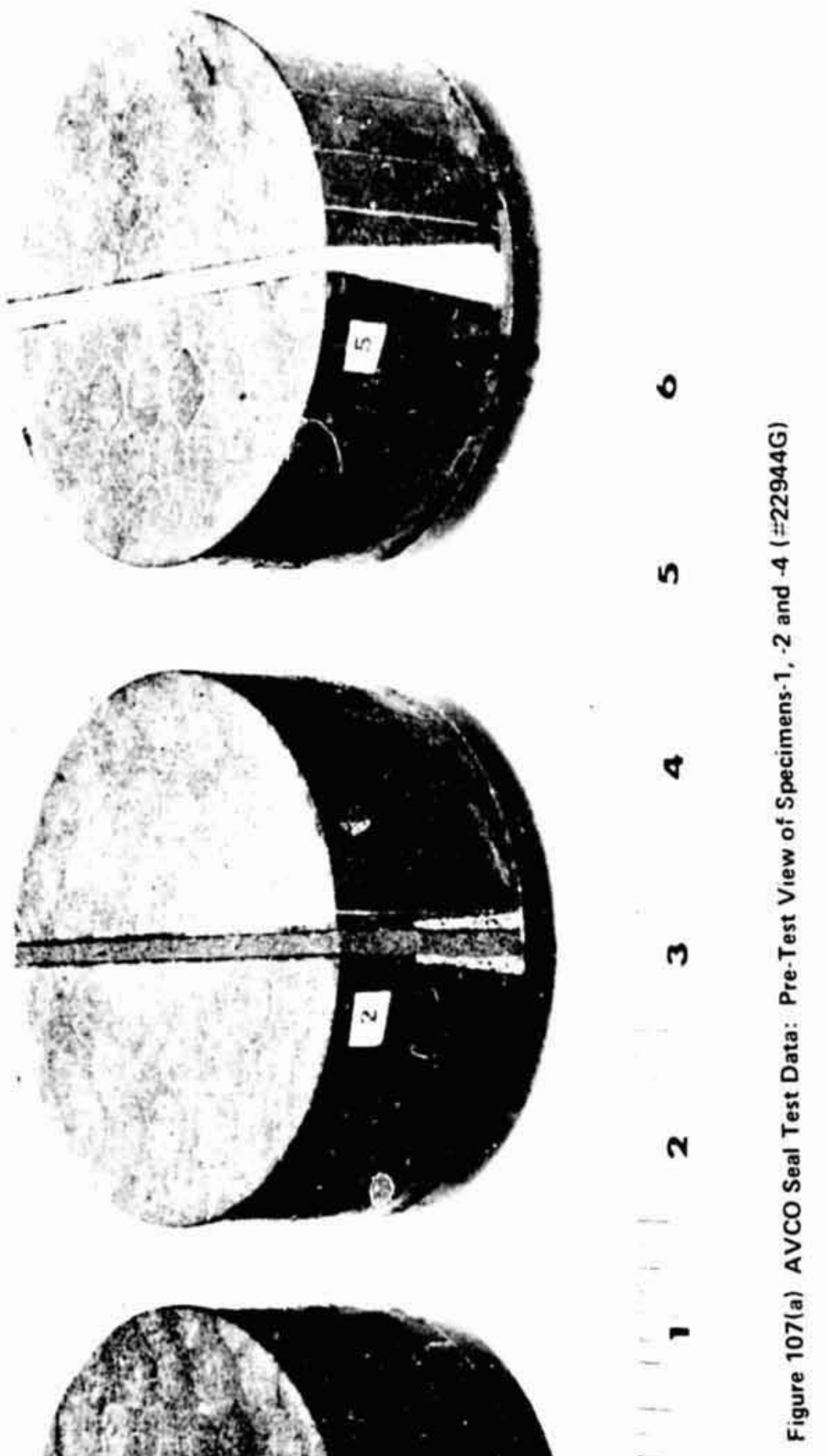


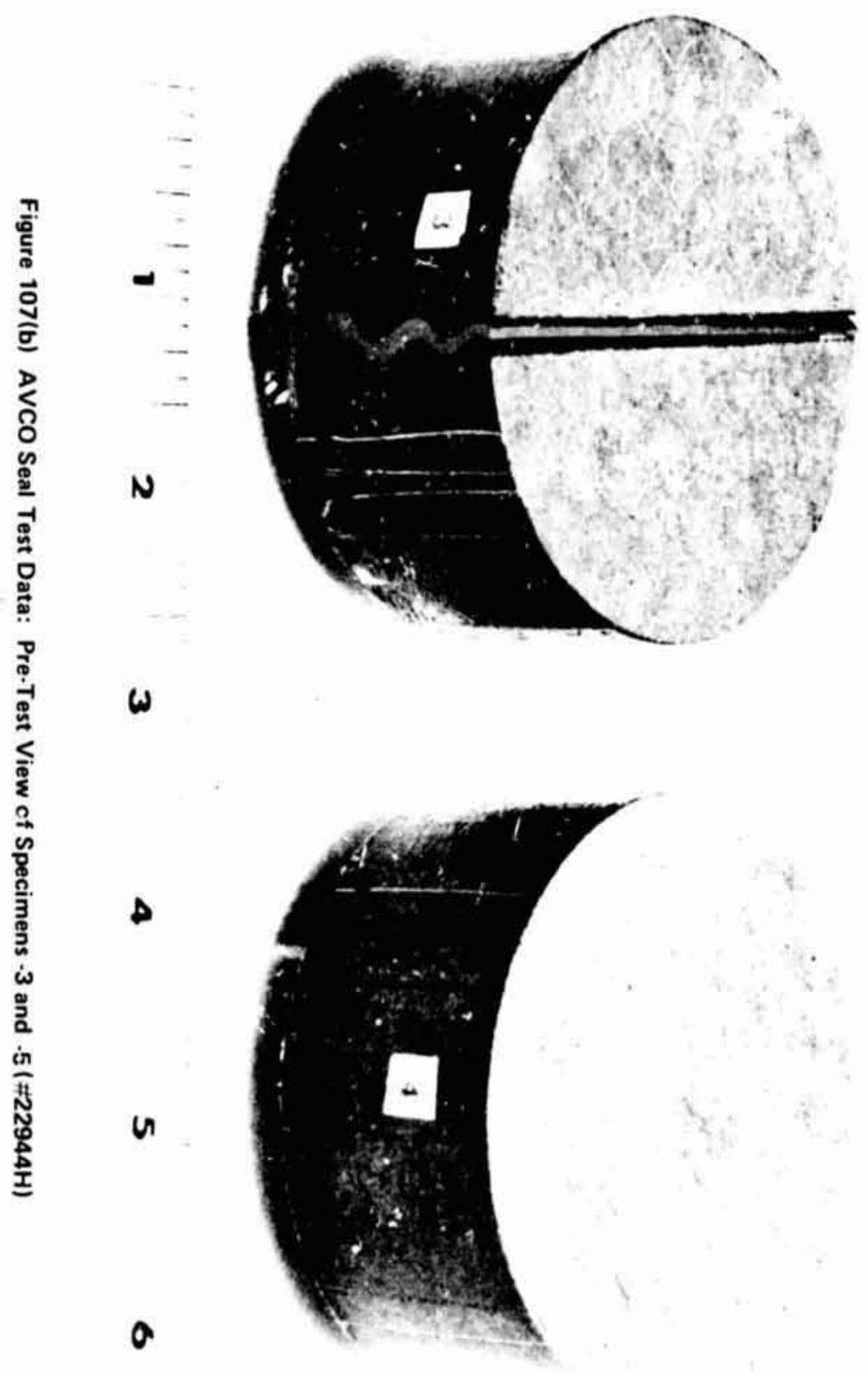


zoments pertainine to the surface appearance of the ablator and of the seal noted and post test photographs taken of the surface (see figures $108(a),(b) \&(c)$. Beckface temperature data from thermocouple No. 1 (located on the specimen centerline directly behind the seal) is presented is temperature rise is i function of time in figure 109.

No severe degradation of test specimen surfaces was noted during the test series. No unusual effects were noted in viewing the motion jictures. Some contamination of the charred ablator surface in the seal area was ncted on all specimens except the silica felt which remained very clean. The RTV wave seal protruced above the surface from early in the test run and upon cool-dowr. was extendec approximately .10" above the ablator surface. Both the caulked and silicone foam seals showed some cracking in the charred surface and evidence of slight pulling away (shrinking) from the ablator edges.

It is noted from observing the temperature dat that seal No. 2 (silicone foam) had the lowest rate of temperature rise $(0.1$ desree Fahrenheit/second at test time) and seal No. 4 (silica felt) had the highest slope $\left(0.2^{\circ} \mathrm{Fai}-\mathrm{e}\right.$ it at the corresponding mid-test time). The silicone foam seal design (No. 2) also produced a slightly lower total backface temperature at the end of the test period than the reference ablator material did.

\section{c. Selection of Candidate Seals}

Based upon these preliminary mechanical and thermal evaluations, two seal concepts were selected for further evaluation using leading edge models simalating the actual joint contour in a sequential test inciuding ascent, cold soak and entry. The two selected were the silicone foam and the silica felt seals. Table 39 presents a summary of the most important factors considered in making this selection. 

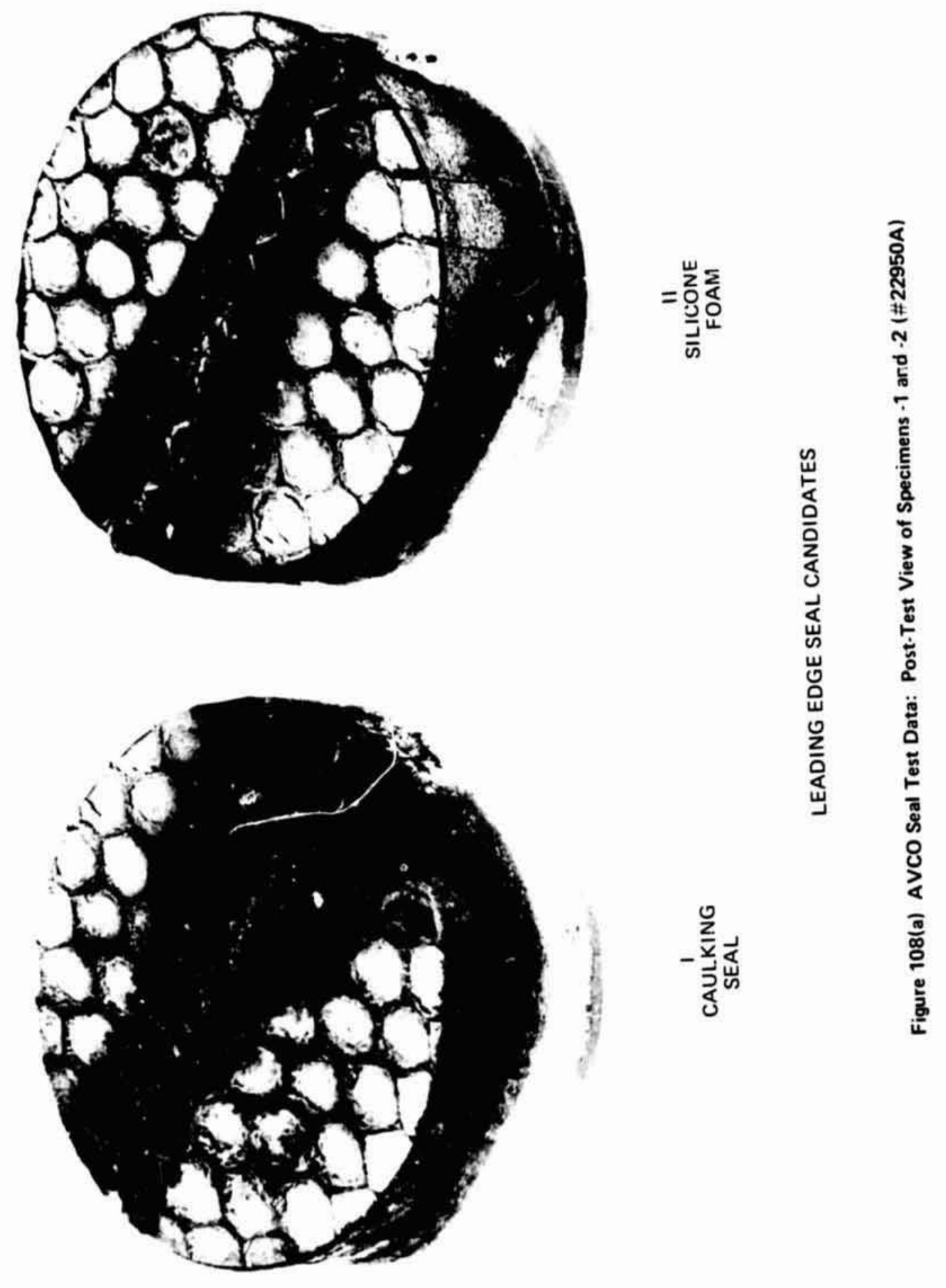

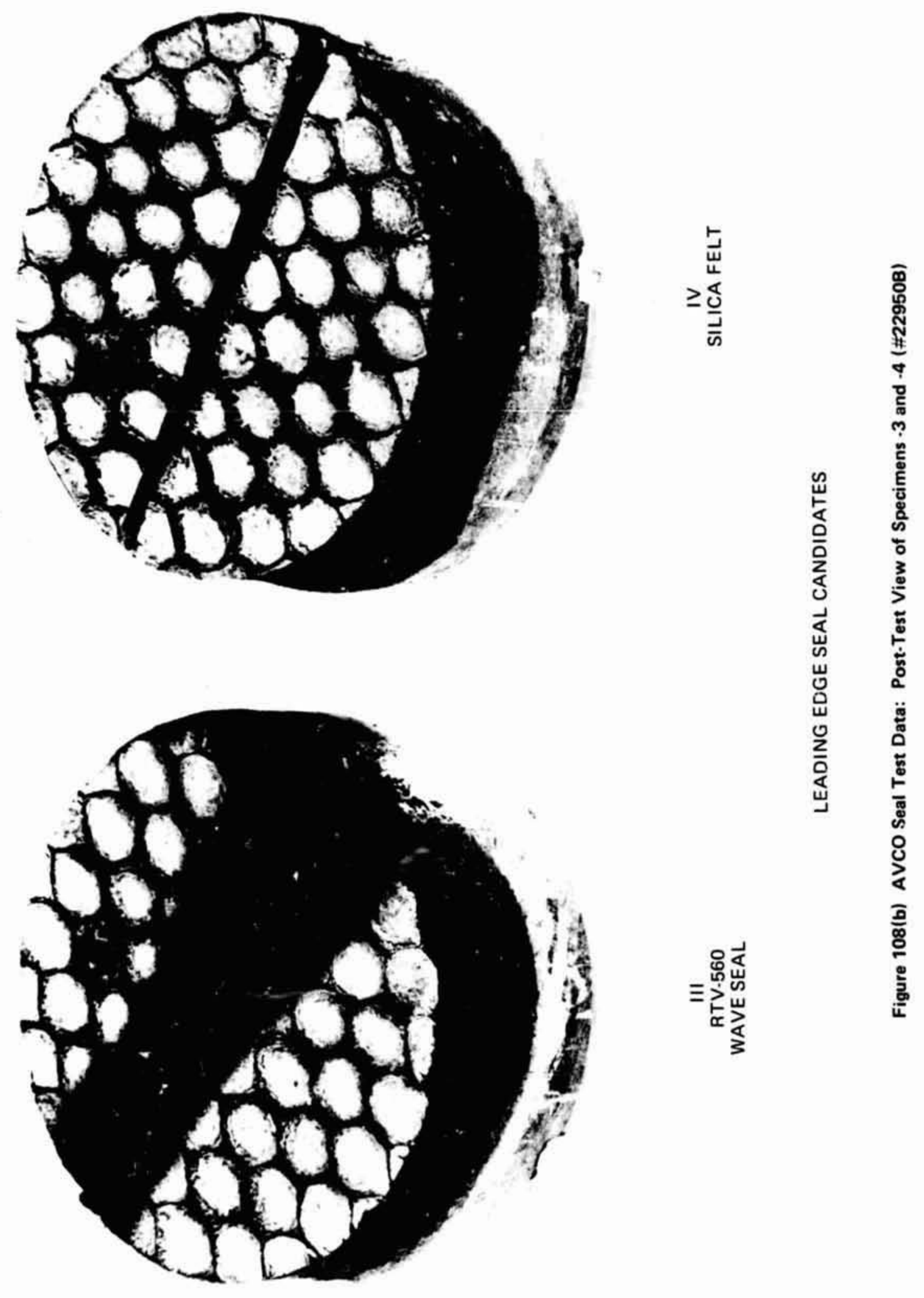


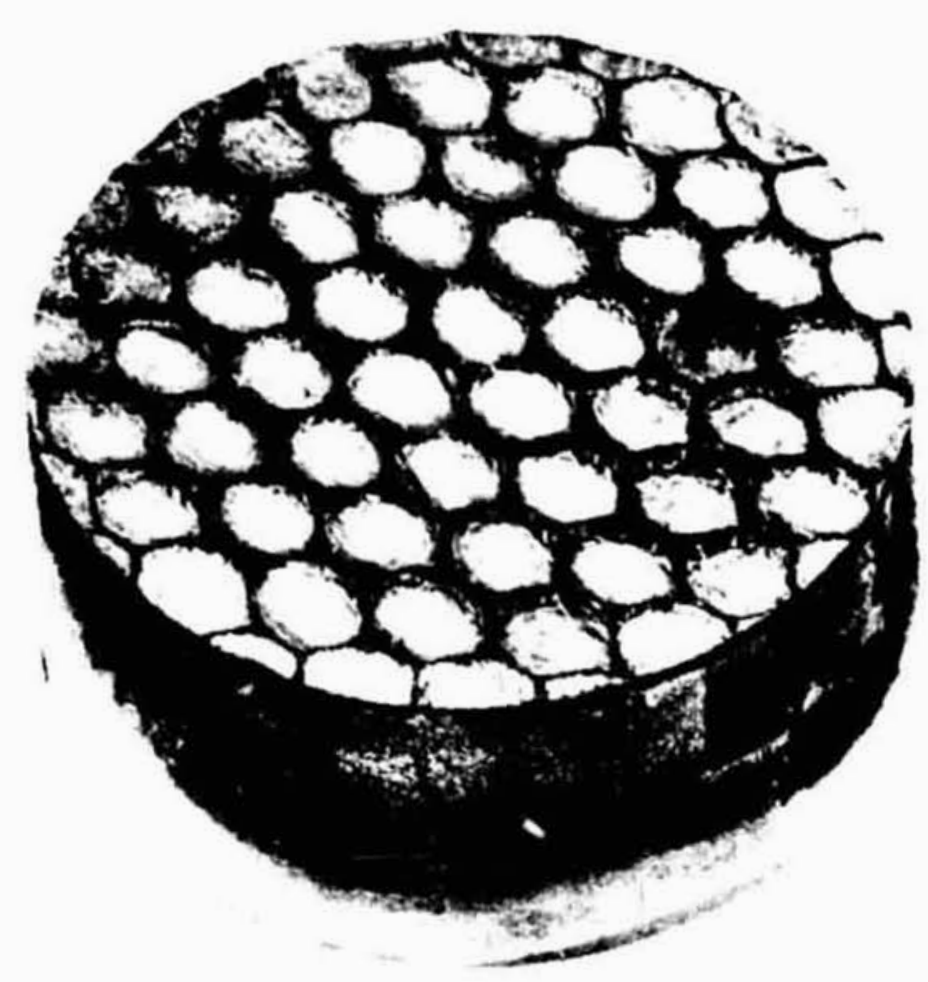

$\mathrm{V}$

REFEFENCE

MATERIAL

LEADING EDGE SEAL CANDIDATES

Figure 108(c) AVCO Seal Test Data: Post-Test View of Rifierence Ablator Specimen ( $=22950 \mathrm{C}$ ) 


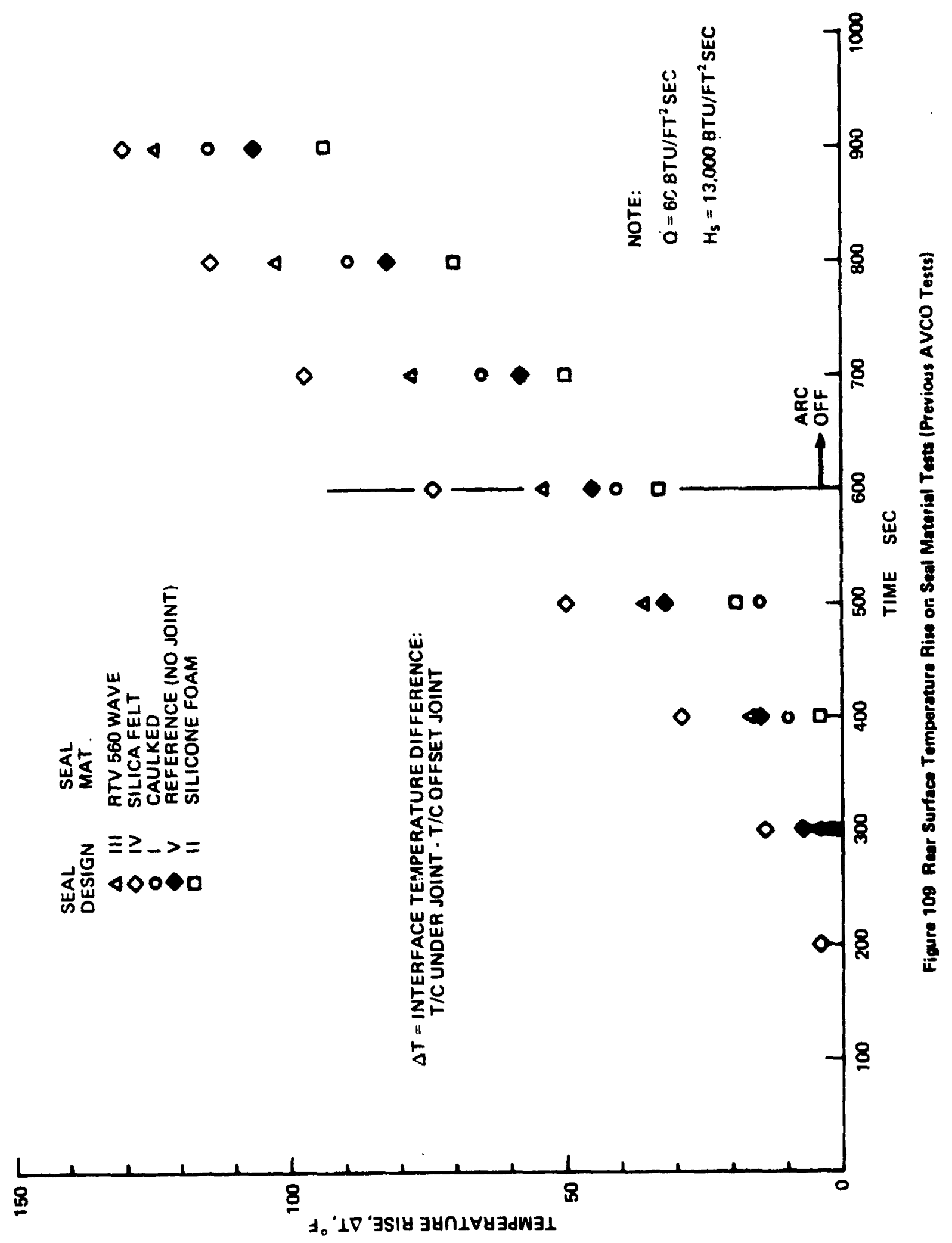


Table 39 Ablator To Ablator Seal Comparisons

\begin{tabular}{|c|c|c|c|c|}
\hline & Caulked & $\begin{array}{c}\text { Silicone } \\
\text { Foanı } \\
\end{array}$ & $\begin{array}{l}\text { RTV } \\
\text { Wave } \\
\end{array}$ & $\begin{array}{l}\text { Silica } \\
\text { Felt }\end{array}$ \\
\hline Thermal Performance & Good (3) & Excellent & Fair & Poor \\
\hline Moisture Seal & Good (3) & Excellent & Fair & Poor \\
\hline Ease of Inst. & Excellent (4) & Poor & Good & Fair \\
\hline Ease of Inspection & Fair (2) & Good & Good & Good \\
\hline Cost & Excellent (4) & Good & Fair & Good \\
\hline Contamination & Poor (1) & Poor & ruor & Excellent \\
\hline Growth (Protrusion) & Good (3) & Good & Poor & Excellent \\
\hline Total Ratıng & 20 & 19 & 14 & 18 \\
\hline
\end{tabular}


Although the compressibility of the sllicone foom was sanewhat lower than desired its recovery after loading was very good. Thermally, it performed better than all other materials tested. The reverse was true for the silica felt seal which was by far the most compressible material, but its thermal performance (insulation efficiency) was less satisfactory. However, other points in its favor were that the silica felt seal did not show any contamination effects or protrude above the surface or become emtrittled after the arc testing.

The caulked in place seal showed gond thermal performance, but, because there had been same problems encountered in curing the seal material at roam temperature (Ref. 73), it was decided this concept required further development and therefore would be inappropriate for our design. The metallic wave seals were eliminated because of their poor recovery rate after loading.

\subsubsection{Seal Evaluation in Leading-Edge Kodels}

As an aid in making the final decision on the two best seal candidates, two ieading edge models containing a typical joint with seals in the Mod $7 \mathrm{HC}$ ablator were fabricated for ascent, cold soak and entry tests. However, the essential step in the sequence, the entry heating to be conducted in a NASA Langley arc jet, could not be carried out within the span of this study because of srhedule conflicts in the Langley facility.

Only the results of the first step of the sequence were conducted within the span of the study. In the first step alone, very little is expected to turn out. In any case, the model design is shown in figure 110 and the complete test rationale, test procedure, and results are presented in the Data Package. Both models were exposed to the ascent heating environment in the Avco ROVERS facility (and then subantted to NASA LaRc). 

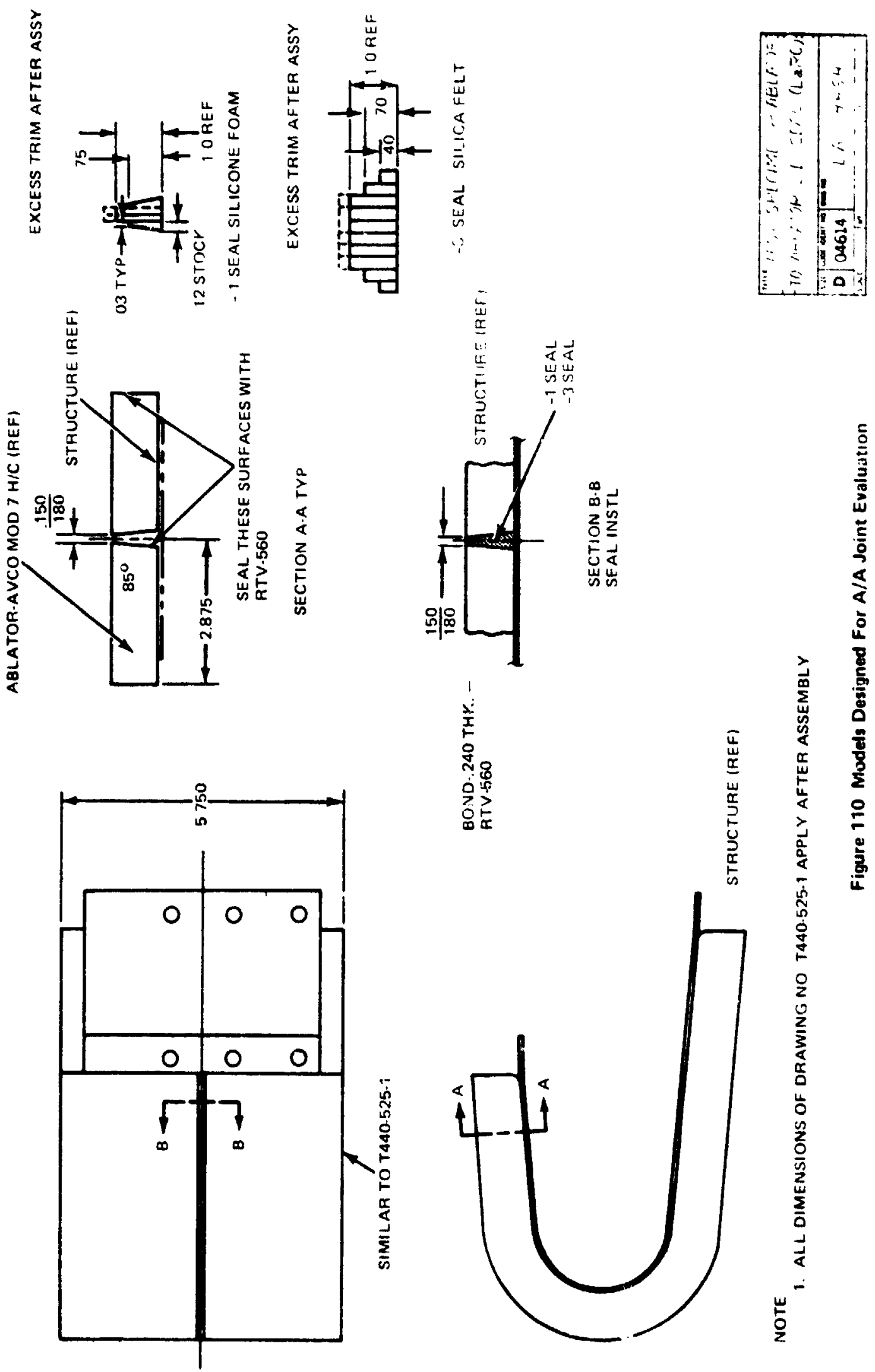
Ascent heating test results for both models for a stagnation point heat flux of $9.7 \mathrm{Btu} / \mathrm{ft}^{2}$-sec showed a maximum rear surface temperature rise directly beneath the seals $00^{\circ}: 2^{\circ} \mathrm{F}$ and $32^{\circ} \mathrm{F}$ for the silicone foam and the silica felt seals respectively after soo seconds. Thermocouples located under the ablator: offset spanwise 2" from the seals showed identical readings indicating no adverse thermal effects under the seals for these test conditions. Post test examintion of the models showed that the silica felt seal was somewhat rigid to the toluch near the surtace and had a tendency to scparate from the Mod $T$ he ablator ablator (see figure 111). The silicone foam seal had a tendency to swell and protrude above the Mod 7 Hc ablator. There was also some surface separation between the two strips forming the seal in the nose region as show in figure 112. With the exception of a thin flaky coating which appeared on the stagnation region, the surface of the ablator looked good after the test.

\subsubsection{Selected Ablator/Ablator Joint Concept}

Because of the unavilability of the leading-edge model data, the selection had to be made based on the basis of past experlence and data accumilated to this point.

Based upon the test data generated, model fabrication experience, and working with both seal materials, there appeared to be little justification for selecting one material over the other. If anything the results tended to favor the silica felt material. Although the thermal performance of the silicone foom was somewhat superior to the silica felt in the splash tests, both materials performed about equally well in the leading -eige configuration during ascent heating. The compressibility of the silica felt was shown to be substantinlly higher than the silicone foam making it more desirable for installation as well as relleving any stresses between adjacent leading edge segments. Also, no contamination was observed on the adjacent ablator after elther test using 


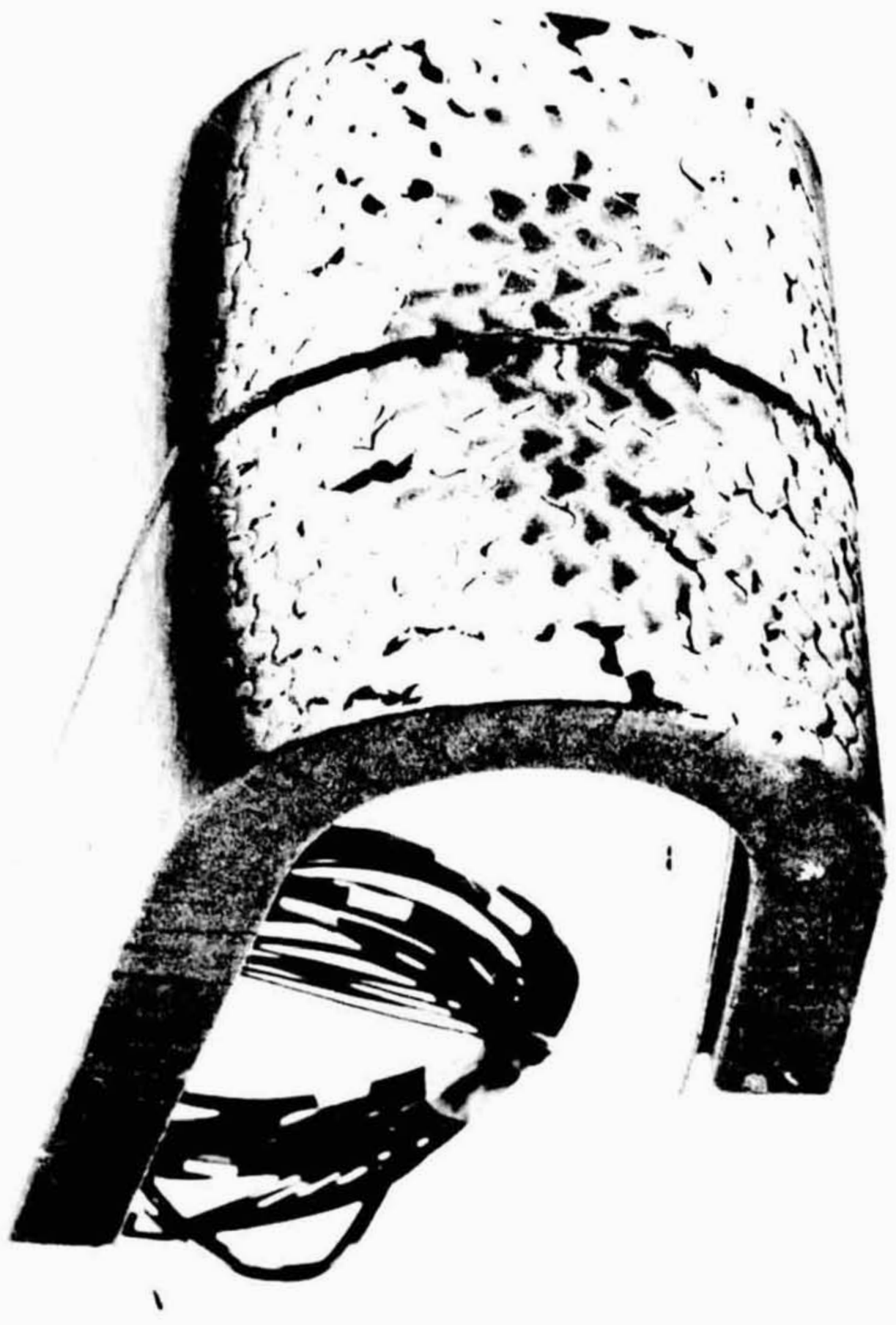

Figure 111 Post Ascent Appearance of A/A Silica Felt Seal Model 


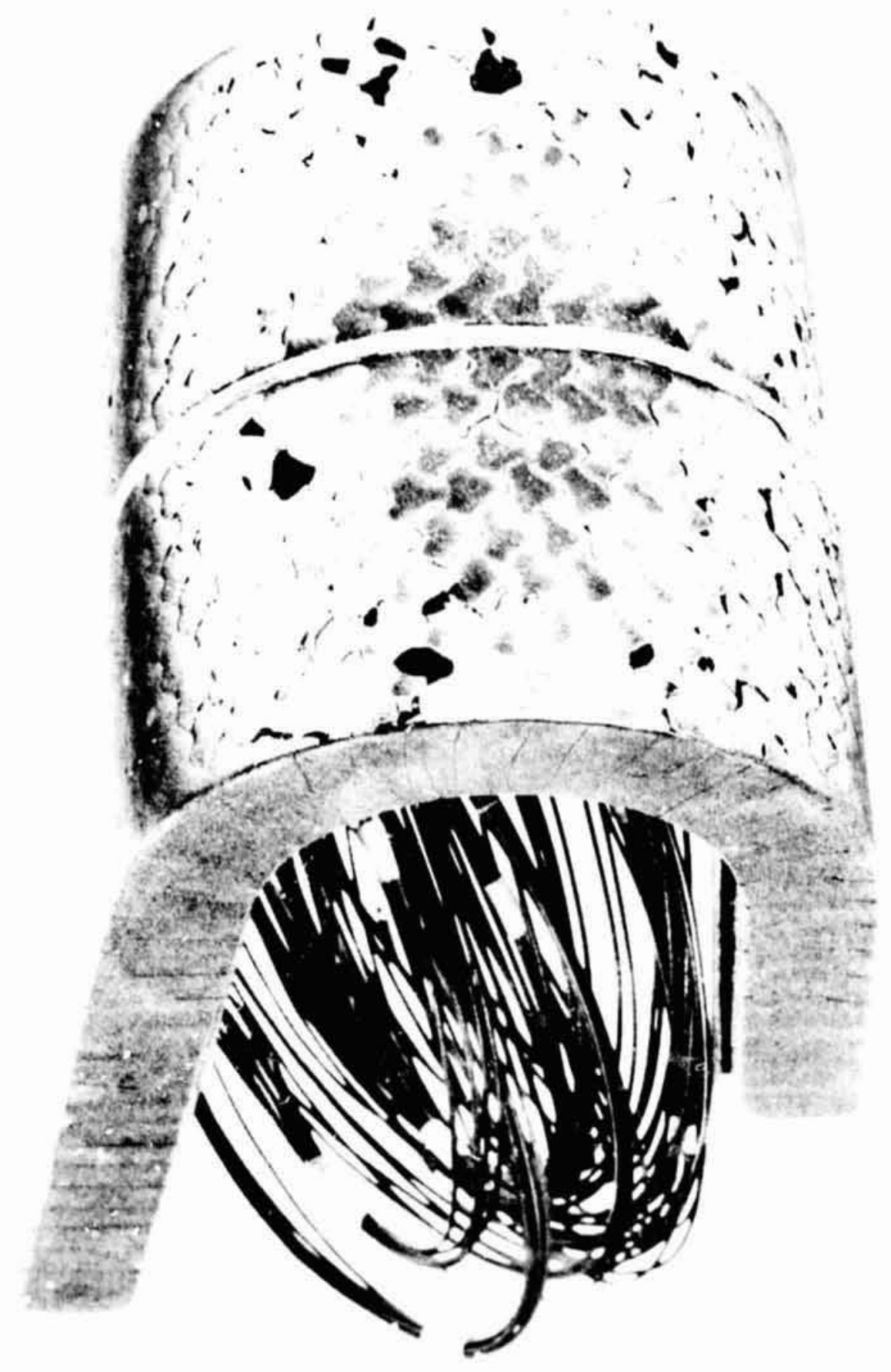

Figure 112 Post Ascent Appearance of A/A Silicone Foam Seal Model 
the silica felt whereas some deposits were observed after the splash tests with the siliccne foam material. Finally, the surface appearance of the silic? felt was good unlike the silicone foam which showed a minor temeny to protruide above the surface.

In spite of all these positive features, there was one crucinl unkrown relative to the silica felt; namely, the performance of this relatively porous material under entry heating and the simultaneous 1.e. Fressure gradients and shear: which could calse flow along and possibly down into the joint. The silicone foam seal on the other hand, having a closed cell structure, did not have an equivalent potential weakness. Moreover, the KTV class of materizls have been flight proven as seals on the Apollo vehicle.

Without this vital piece of information (which would have come from the l.e. tests), and since one seal had to be selected for the final design, it was decided to go with the more well characterized and proven material; namely, the silicone foam seal.

The joint configuration chosen consists of beveling the edges of the ablator to entrap the seal, because it is about the simplest means of obtaining ' positive holding pressure on the seal. Minimum gap widths of the OML of the ablator were set at $0.15^{\prime \prime}$, because it is a compromise between assembl" tolerances, thermal expansion requirements, and minimum gap width for entry heating.

The operational procedure to install the joint durine the 1.e. refurbishment will be taken up in section $6-6$.

6.5.2 Ablator/BSI Joints

6.5.2.1 Joint and Seal Concepts

Some differences exist in the criteria affecting the design of the ablator to 
RSI foint and seal as noupered to the ablator/ablator foint and are as follows:

a. Due to the location, the heating is lorrer

b. Unless excessive spenwise flow develops over the wing, little or no parallel flow will occur

'c. The allowable compres:ive force the seal exerts against the RSI must be lower than for the ablator since it is expected the RSI be more susceptible to demage

d. The thermal expansion/contraction across the joint is less than ablator/ablator designs

e. The upstream ablator must not recode so as to generate a forward step

The above differences lmediately open up the possibility of controlling the gap width and not using any seal material in the cavity. Therefore there are two basle approaches to the A/RSI joint: a) controlled gap width foints; and b) Joints with seals.

In selecting the gap shape and in developiug the joint schemes, ane wust keep In misd what can be feastble--from a fabrication aspect--for the RSI. Considerable freedom seems to be avallable in the gap shape, since the current thinktng on the RSI-RSI tile jolnte Include rather sophisticated concepts, as 1s shown in flgure 113. (From Ref. 74). Note that the schemes in Plgure 113 are all for unsealed gaps and that the tolerance control for the RSI-RSI tiles joints te expected to be auperfor to the RSI-ablator joints. Therefore the disadvantage noted in figure 113 for the hevel joint disappears if the gap is sealed.

Two criteria were considered in developting the schemen prenented below:

1) Even though the ablator is lie reinforced, it is not desirable the ablator to be cut as in the otrlp concept 
of flgure 113, since the charred thickness would be higher

then the 'bridge' height (figure 98)

2) It would be desirable to eliminate the situation in wich the RSI bridge is subjected to loads that increase the danger of fracture of the RSI overhand part. In other words, it would be desirable not to rely in closing the gap as in the lap and strip concepts of figure 113 .

a. Controlled Gap Width Designs

The first of mary basically similar designs is shown in figure 114 . This involves an ablator strip adjacent to the RSI which is mechanically attached to the leading edge structure. One reason for the higher density non-ablating strip is to allow for the ablator change (recession or swelling) and yet guarantee a swall rear-facing step at the joint to protect the RSI from a localized overheating at the corner of the file. The other reason is to be able to adjust the gap between 1.e. and RSI and therefore eliminate the seal. The screws which attach this strip are in over-size holes allowing the ablator strip to be adjusted in the chordwise direction so as to control the width at the gap betwean the strip (leading edge) and the RSI. An additional seal strip is incorporated in the lower portion of the TPS adjacent to the structure.

Since the gap butween the adjustable strip and the ablator edge will vary, depending upon the amount of adjustment, it is planned to gun (caulk) this after installation of the leading edge.

Figure 115 is basically the same as above except the ablator strip can be adjusted externally through the removal of threaded ablator plugs rather than requiring leading edge removel.

PRDCEDING PAGE BLANK NOT FILMED 


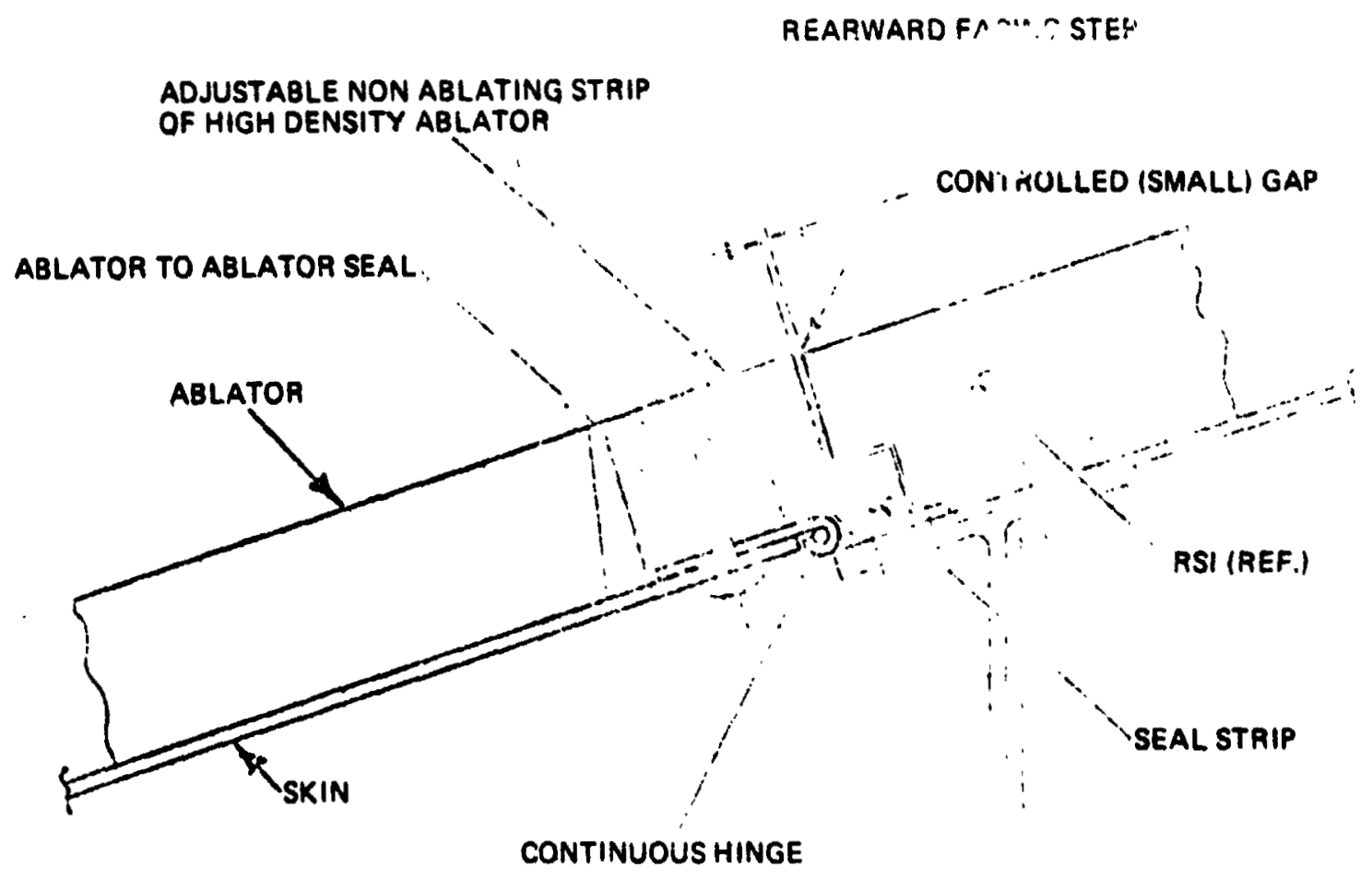

Figure 114 Ablator/ASI Joint: Controlled Gap with a Machanically Attoched Ablator Strip 


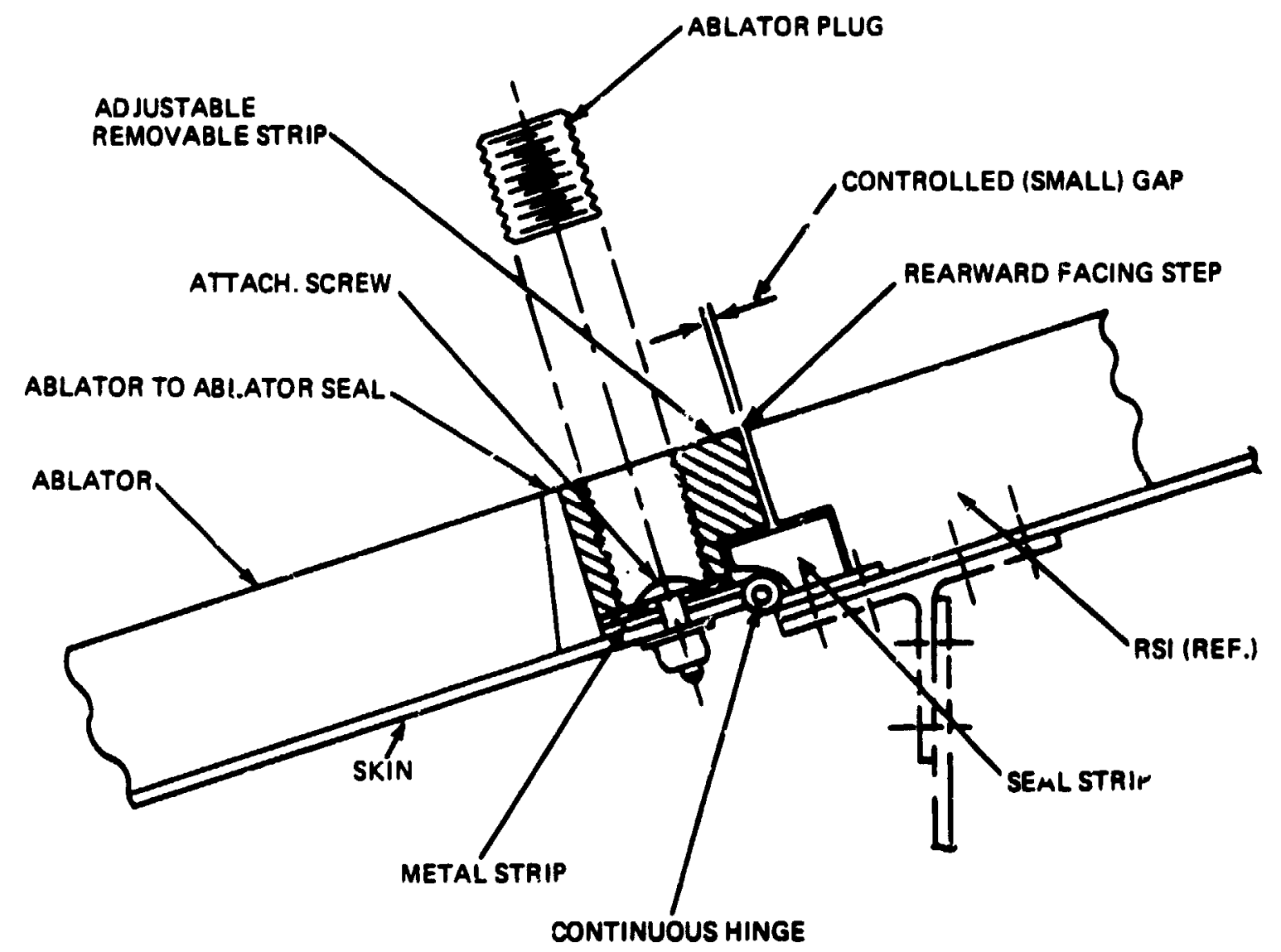

Figure 115 Ablator/RSI Joint: Controlled Gap With An Extennally Bolted Abletor Strip (Mntel Strip) 
Figure 110 incorporates a seal wesign intlidicul to thith of figure 115 above, however, remuml of the adjustable strip cxposes the lending edge attachment boits whinh attach the lcading edre structure to the hinge. The hinge is mairtained for purposes of structurelly uncoupline the leading edge from the wine.

\section{b. Joints with Seals}

The second approach is depicted in figure 117. This approach utilizes

eal strip in depth as well as, filling the gap to the surface; in this case, with silica felt materinl. The lond exerted by the felt on the RSI, due to thermal growth and/or vehicle tolerances appears to be small as a function of compression of the felt (see Section 6.5.1.3). It is believed that this felt riller will not recede or expand into the air stream.

Figure 118 shows the incorporation of a metal wave spring seal which is mechanically attached via a number of screws along the length. Figures 119 and 120 incorporate the use of RTV as the seal material. The "Y" seal of figure 119 is bonded into the ablator edge and is in place when the l.e. panels are installed. The ser.l of figure 120 is a similar approach to that depicted in figure 119 and can be inserted after the leading edge panels are in place.

\subsubsection{Ablator/RSI Joint Trade-off}

With the selection of Mod $7 \mathrm{Hc}$ and the $3560 \mathrm{HF}$ as the ablative materials, no recession is predicted at the ablator to RSI interface; i.e., at the front spar. Since the primary reason for the higher density non-ablating strip in the designs of pigures 114 through 2.6 was to allow a material change to maintain a smooth outer surface (no recession), less complicated designs would appear adequate. Morec. $r$ this approach requires the use of bolts ( an unhappy 


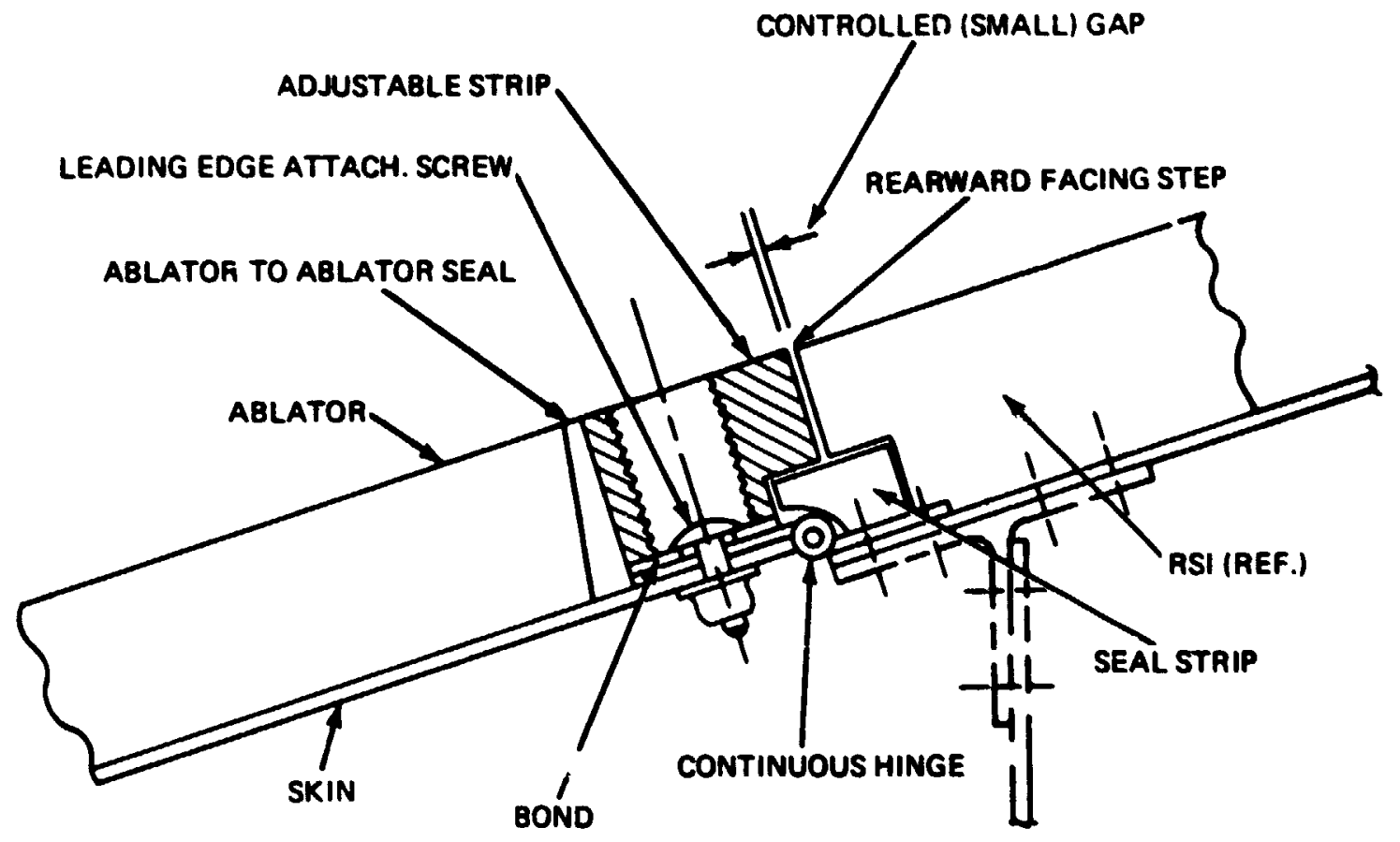

Figure 116 Ablator/RSI Joint: Controllid Gep with an Exturndly Boltad Ablotor Strip (BondV ariant) 


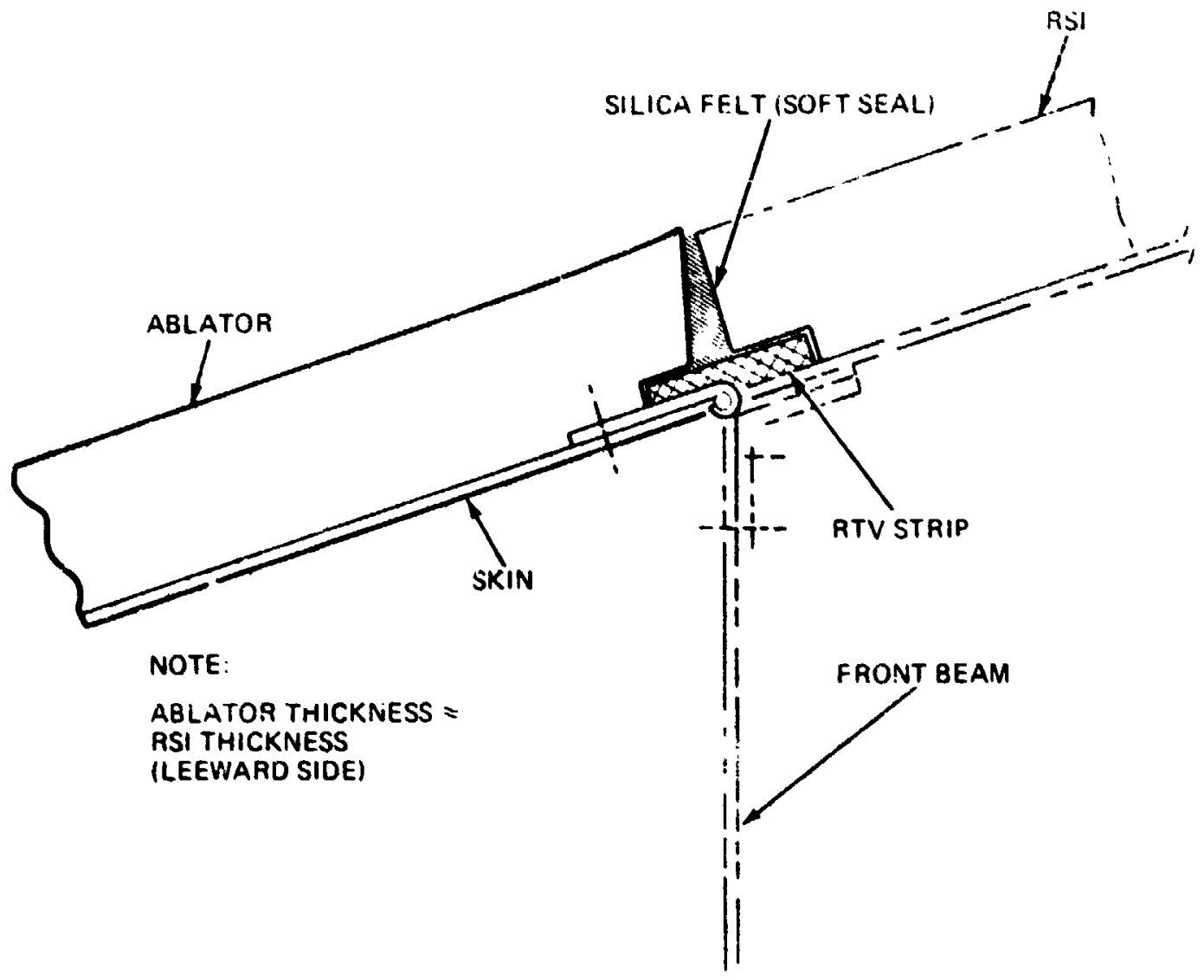

Figure 117 Ablator/RSI Joint: Silica Folt Seal 


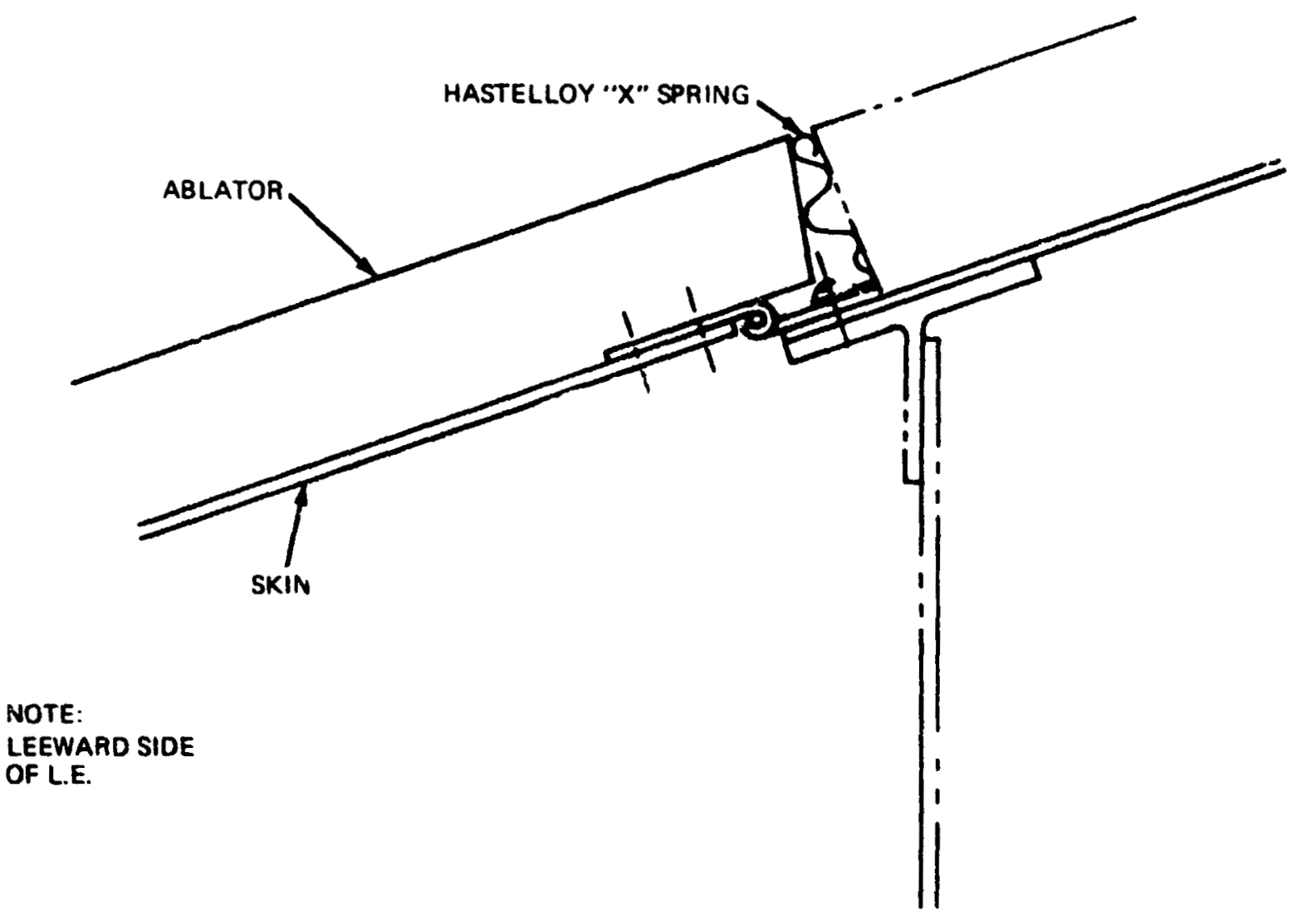

Figum 118 Ablatc:/RSI Joint: Motallic Wove Sod 


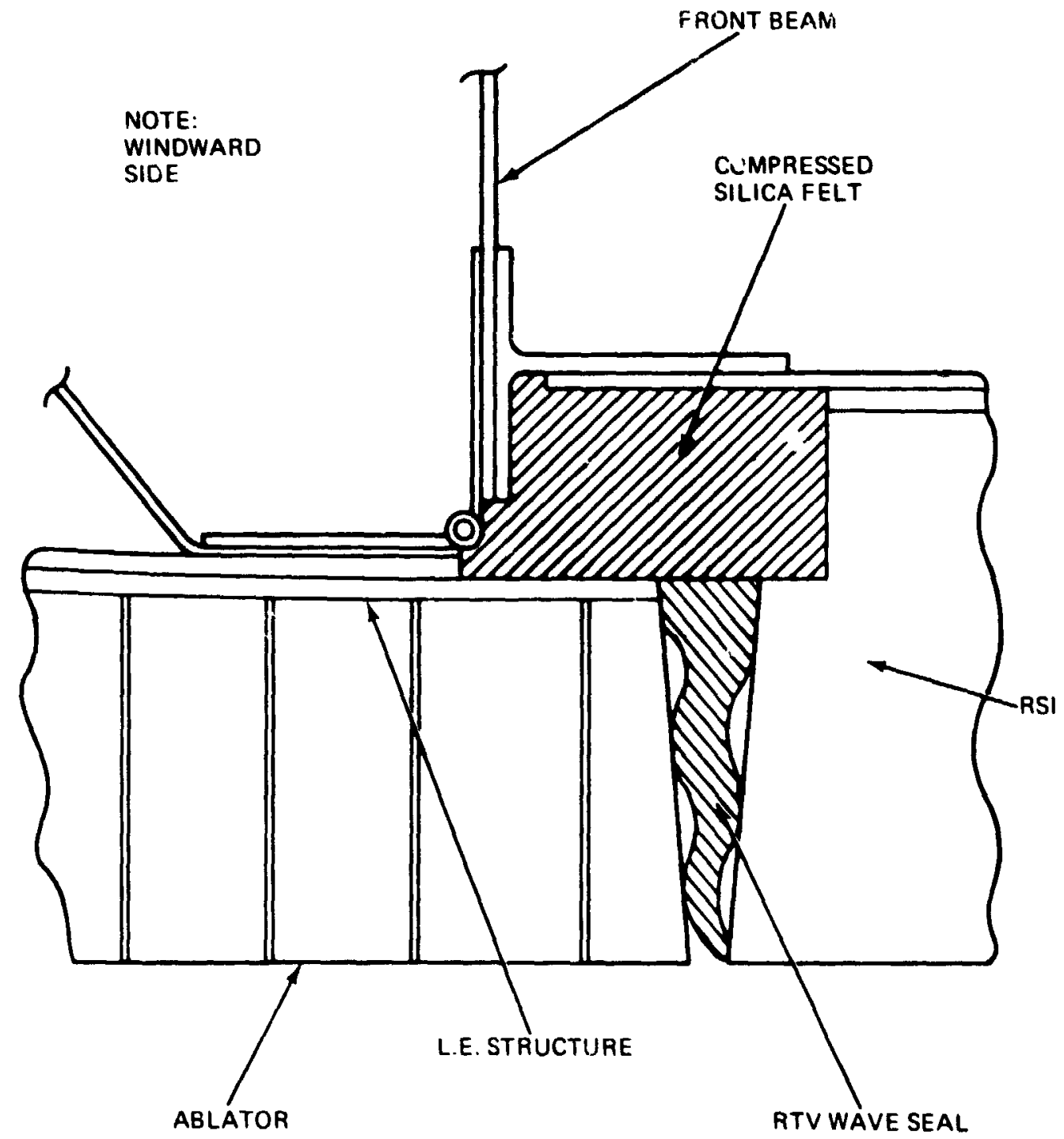

Figure 119 Ablator/RSI Joint $\sim$ Gap Sealed with RTV Wave Seal 


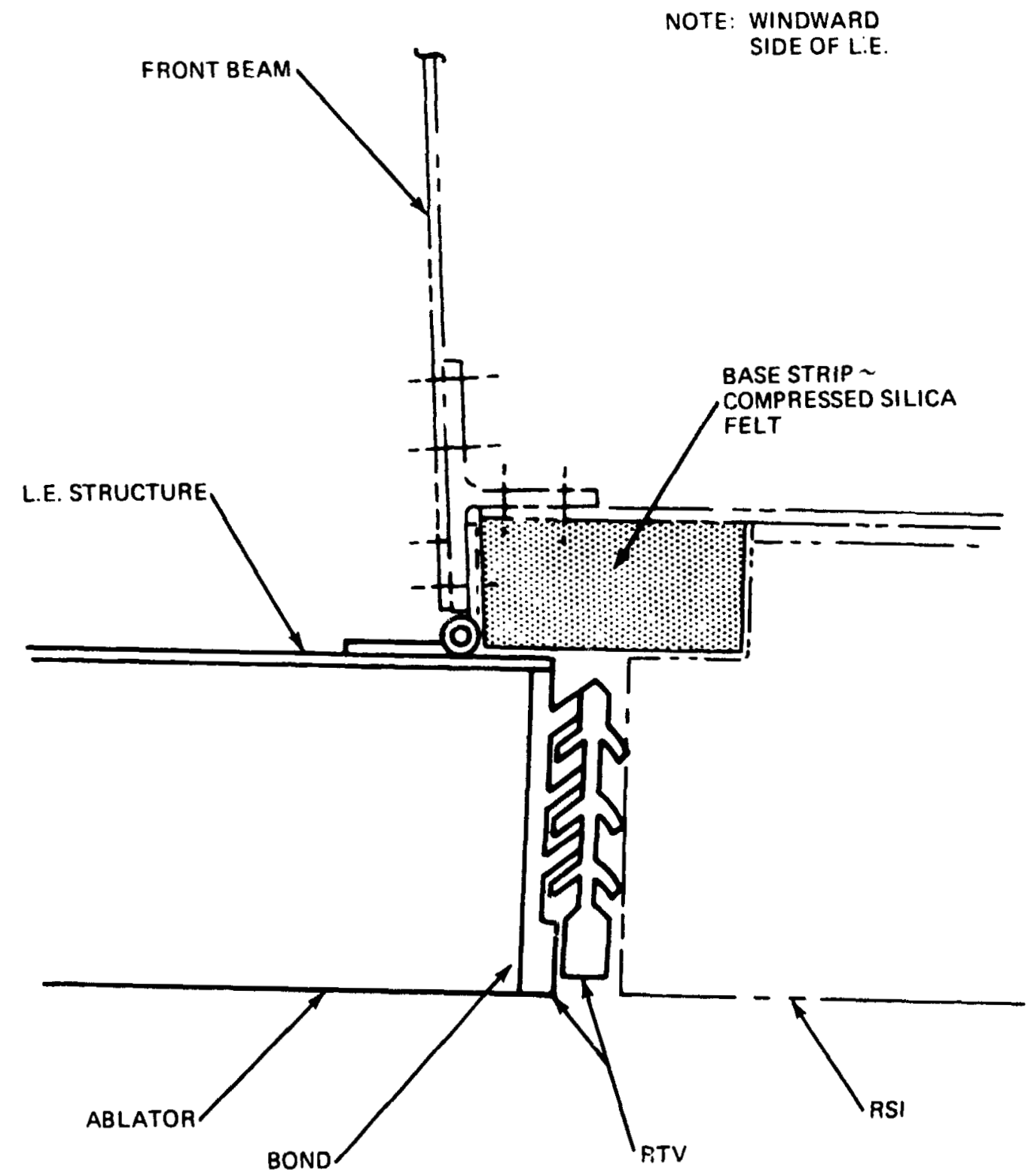

Figure 120 Ablator/RSI Joint: Gap Sealed With Labyrinth Seal 
camplication after the bolts were eliminated for the more important function of attaching the l.e. to the wing). A simpler version consists of ciaryine the leading edge ablator directly up to the RSI interface with a controlied width unsealed gap similar to those envisioned for the gaps between ad,iacent RSI panels. This was eliminated for several reasons. Imong these was the fact that for the RSI the gap width could be controlled mise closely during installition since each RSI tile is bonded in place. Secondiy, the herting at the front beam would be higher than that ex. rienced uver the bulk lower surface. Lastly, this joint was between two dissimilar materials.

of the sealing joint schemes presented (figures 117 to 120 ), the silica felt appears to offer the most advantages, speciflcally, low compressibility, no contemination, ease of installation and no protrusion above the gap as noted In connection with the A/A joints. Moreover, with the lower heating and less likelihood of spanwise flow there was little concern about flow down into the seal as was the case in the chordwise leading-edge seals.

As a back-up to this design the RIV wave seal appeared to be a strong candidate. In addition to its good thermal performance in the splash tests, it offered lower compressibility than the other remaining materials, This was a strong factor in selecting ablator to RSI seals in order to avold damage to the RSI.

As a result, the seal joint approach was selected i.e. a simple narrow gap with a compressible material appears the most direct approval. The two seal materials, silica felt and RTV wave seal were identified as the two attractive candidates.

\subsubsection{T.ro Candidate Designs}

The complete joint design for upper and lower wing surface consists of beveling the edges of both the ablator and the RSI at the juncture to entrap the seal and using the scheme of figure 120 ior the area underncatin the seal. This is ar. 
added bit of conservation over the simpler, but less safe design of figure 119. On the upper surface (leeward side) where it is expected that the thickness of the ablator and RSI will be nearly equivalent the joint line will occur above the front beam directly over the hinge (see figure 121). To provide an added margin of protection to the hinge and seal off the leading edge cavity a narrow strip of RTV 560, will be placed directly beneath both heatshield overlapping the joint.

On the lower surface (windward side) where the RSI is expected to be markedly thicker than the ablator, the hinge connection will still occur at the front beam, but the ablator and leading edge aubstructure will be carried slightly aft of the connection. (see flgure 121). This w1ll protect the lower connection. Belon the silica felt seal, it was decided to fill the void formed by the ceading edge overlap with a low density insulator rather than attempt to cut a special RSI tile for the area.

These two designs were identliled as the two candidates which mertt experimental evaluation with a small scale simulation of the windward joint area. The results of these tests would be used to make the selection of the design.

\subsubsection{Test Evaluation of the Two Ablator/RSI Desigms}

As with the ablator/ablator seal models, scheduling problems in the LaRc arc jet made it impossible to run these tests within the time-fram of this program. The arc test models designed for the evaluation of the sillca felt and the RTV wave ablator/RSI seal are show in figure 122. Rationale and details are given in the Data Package. These models were fabricated and submitted to NASA. The planned test sequence is cold soak and entry heating (there is no charring during ascent). 


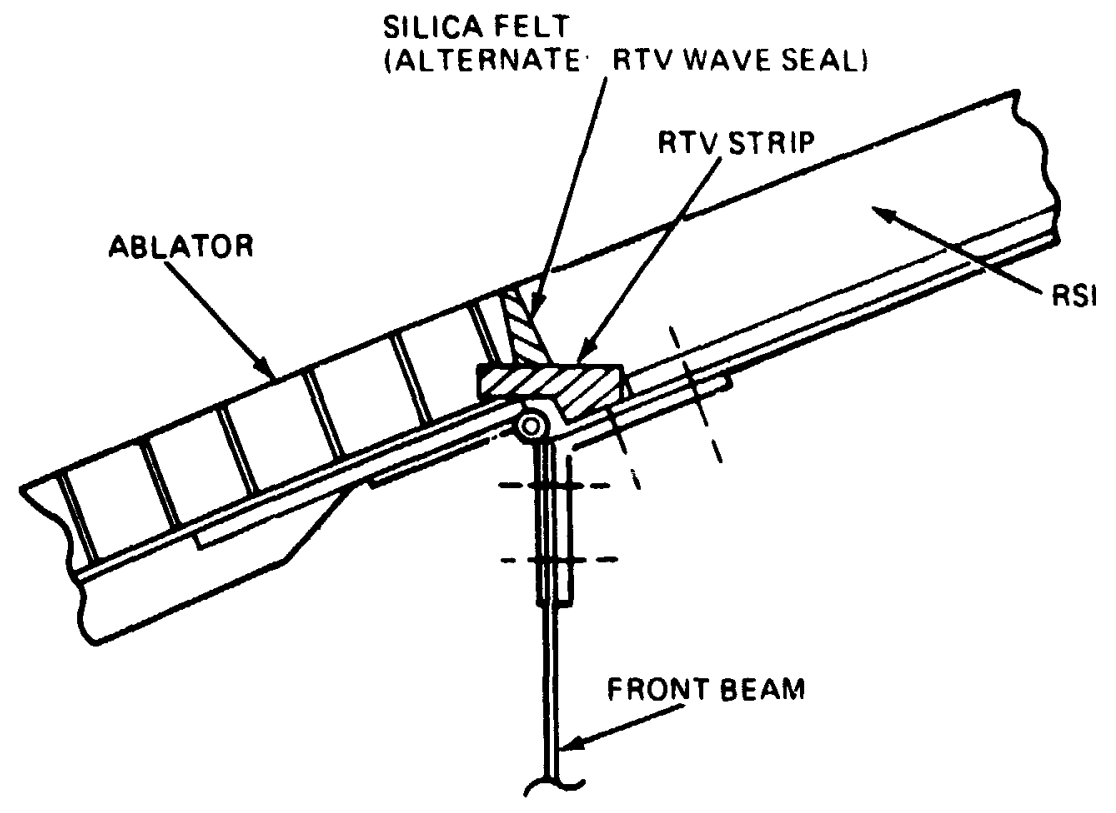

LEEWARD SURFACE

ABLATOR/RSI JOINT

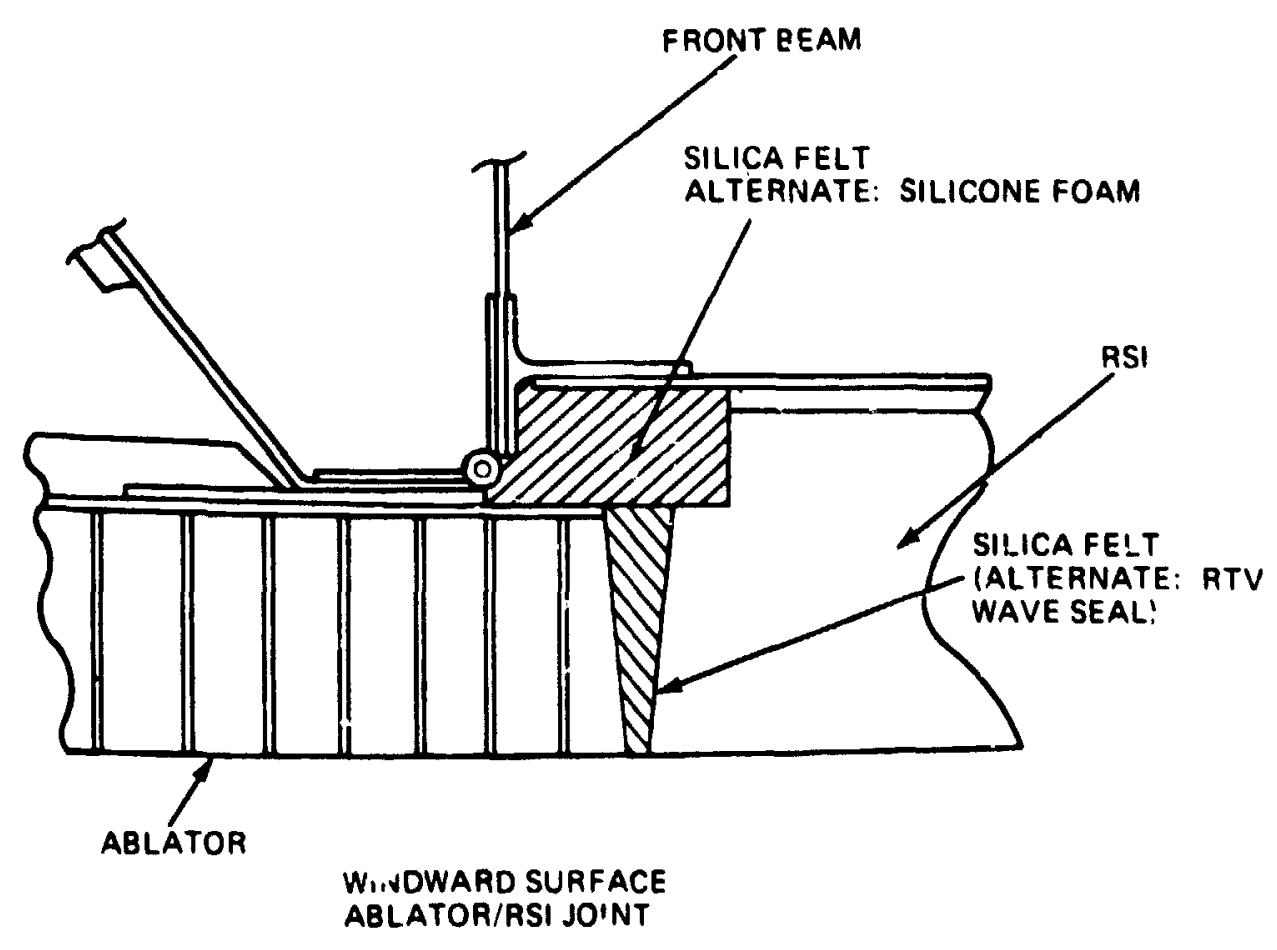

Figure 121 Ablator/RSI Joint Candidate Designs 
2
4
5
0
0
$\infty$
$\infty$
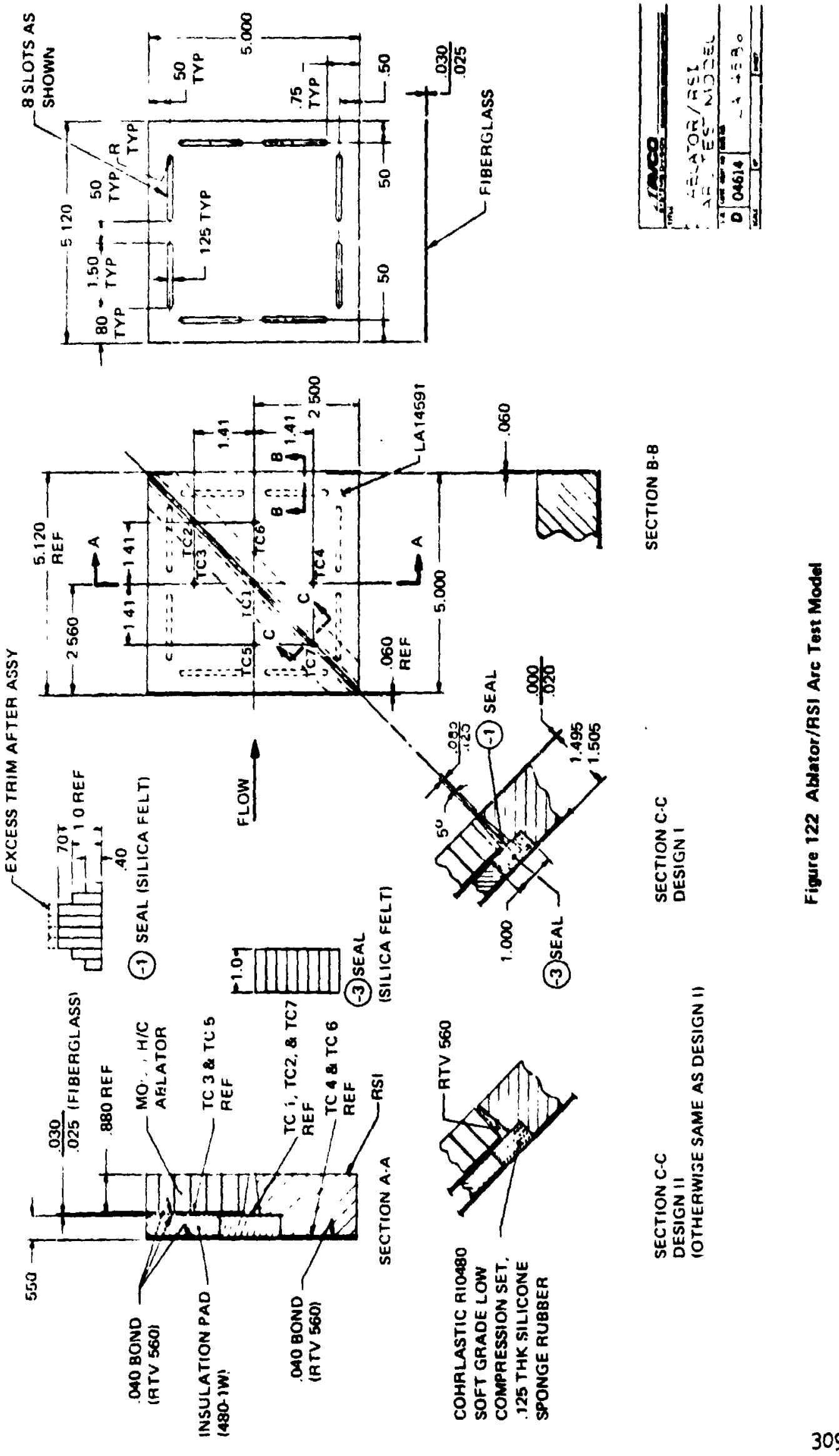


\subsubsection{Selected Design for Ablator/RSI Joint}

The selection of the design out of the two carididites had to be dore without $A / R S I$ test data. In view of the $A^{\prime} A$ test dat? ana the over:il design requirements at the ablator/RSI interface, although not. substantiated by the subscale tests, the silica felt was by far the best candidate for the seal (see figure 121). It met all requirements enumerated earlier, of :ow curpressibility, no contamination, no protrusion into the air stream and it could be eas:ly installed.

The installation procedure will be taken up in Section 6.6 .

\subsection{Final Design}

\subsubsection{Drawing}

A layout of the Leading Edge Final Design for the midspan section of a typical Space Shuttle wing is shown in figure 123 (the drawing attached to this volume). The wing plan form chosen for this presentation is the Rockwell $7 D$ orbiter and is typical of the current base-line design.

\subsubsection{Characteristics of the Final Design}

The main features of the design are summarized in table 40. In particular the design uses a single honeycomb reinforced ablator (Mod 7 He or $3560 \mathrm{HF}$ ) bonded to an integrally rib stiffened aluminum substructure. Each leadins edge segment is approximately 31 " long and is attached to the front beam using an easily removable plano hinge. Vehicle refurbishment is accomplished by coupletely removing the leading edge segments (22 per wing, 44 per vehicle) and replacing them with new segments. The entire segment, once flown, is discarded (1.e. the substructure is not reused).

Leading-edge removal is semisequential in that every sixth segment is a key segment which can be removed externally be removing bolts which fasten the 


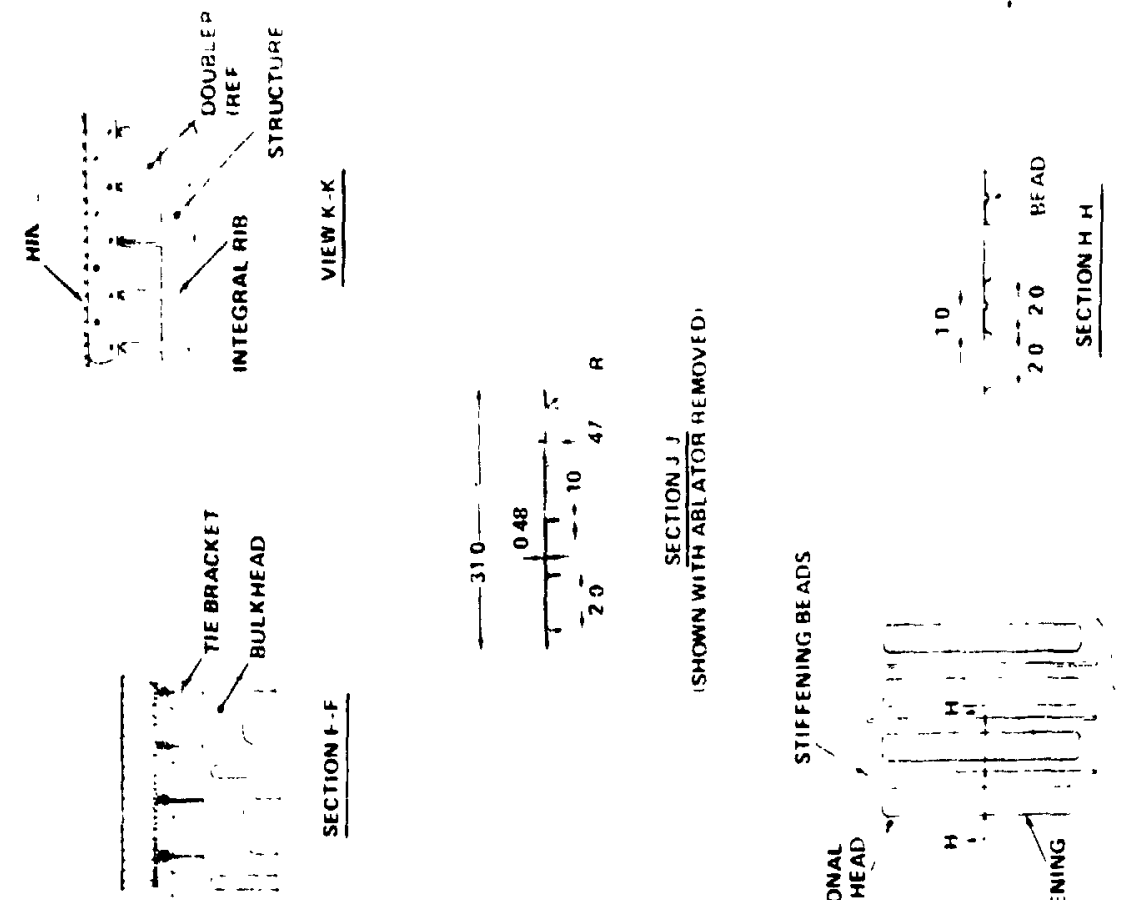

|

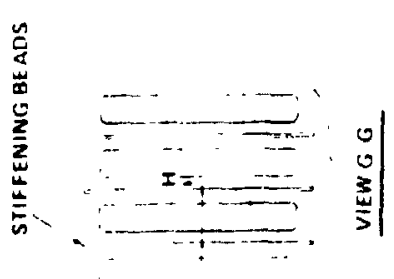

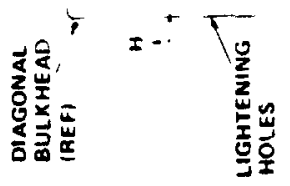
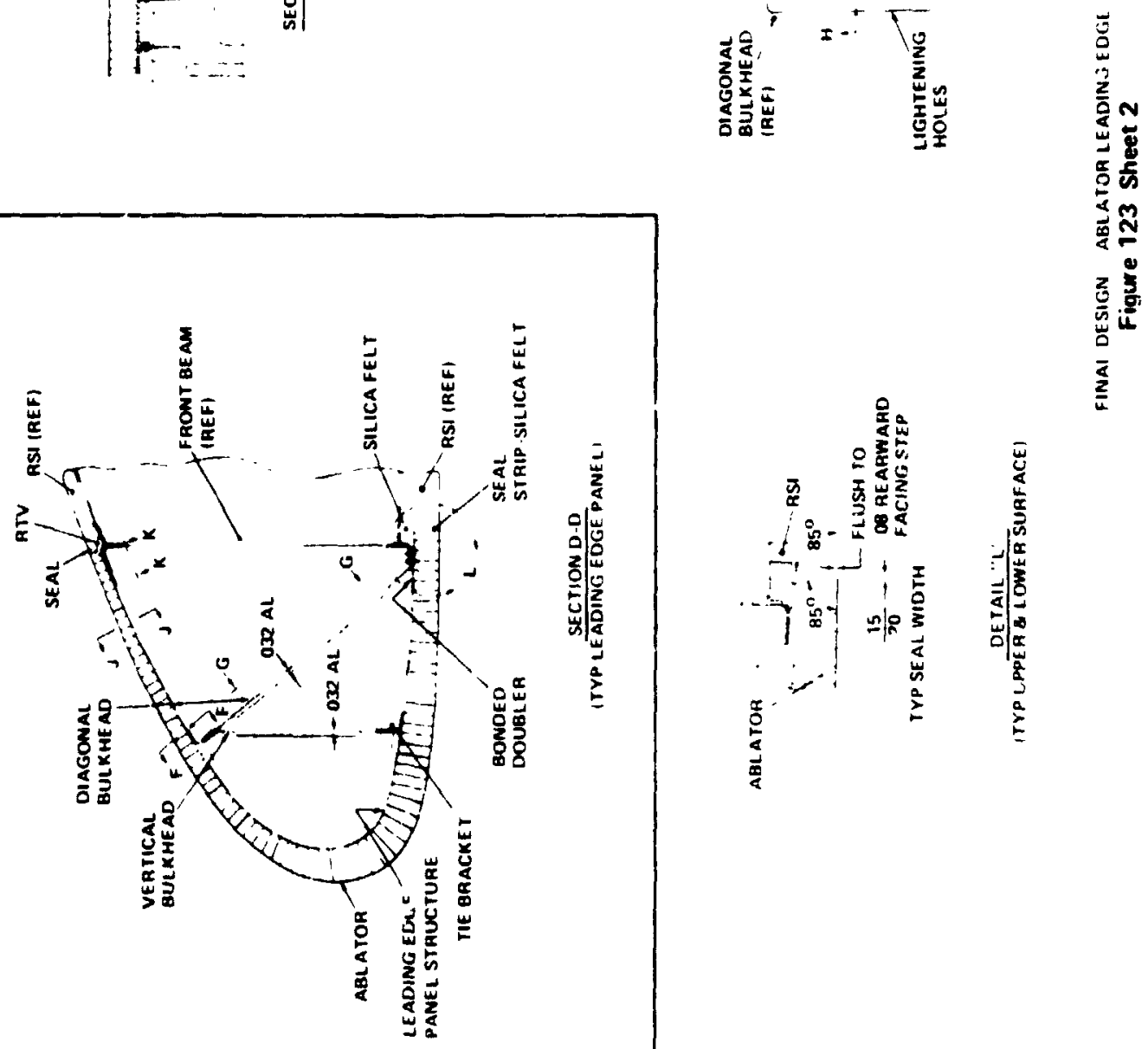


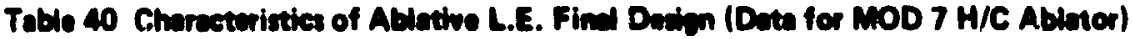

\begin{tabular}{|c|c|}
\hline Item & Charecteristic \\
\hline L.E. Refurbishment & $\begin{array}{l}\text { Detech L.E. Segments from front beam and } \\
\text { replece }\end{array}$ \\
\hline Turn Around Time & 4 Doys \\
\hline $\begin{array}{l}\text { Attechment of L.E. } \\
\text { Segment to Vohicle }\end{array}$ & $\begin{array}{l}\text { Piano Hinge - except bolt/plugs on key } \\
\text { segments }\end{array}$ \\
\hline $\begin{array}{l}\text { Attachment of Ablator } \\
\text { to Substructurs }\end{array}$ & Direct bonding of H.C. core. \\
\hline Subrticture & $\begin{array}{l}\text { Integrally stiffened sluminum/1 afurbishod } \\
\text { in shop }\end{array}$ \\
\hline L.E. Ares & 600 sq. ft. \\
\hline No. Serments & 44 per vehicle, each 31" long \\
\hline Operational Saquence & Soe Tablo 41 \\
\hline
\end{tabular}


structure to the hinge connection. Access to the bolts is gained by removal of bolt plugs in the ablator. Having rewoved the key segments the adjacent segments can be detached simply by extraction of the upper and lower piano hinges. To facilitate removal the hinge pins have been designed such that they may be removed from either side. Consequently, i: the limiting condition it would be necessary to remove only one key segment by exiernal means nd the remaining 21 segments could conceiveably be removed by simply removir, the pins, since even the key segments retain the hinge connection. Table 41 presents a breakdown of the operational sequence required to refurbish the leading erige.

Caps between abutting ablator segments are sealed with a coupressible silicone foam (Cohrlastic RlO470) to prevent hot gas entry. The seal is sufficiently compressible sis.h that it can be installed with a prencompression during installation of adjacent segments. Retention of the seal is acsomplished by this preccupression as well as the slight taper provided along the chordwise edges of the ablator. The seal is trapped by blocking off the joint at the substructure rear surface with a second sponge gasket (see Section BB). This gasket is supported on a 'false' rib ('false' because it has no primary structura function except to close off the back surface of the joints) that acts as a former during leading edge installation.

Spanwise joints at the ablator/RSI Interiace along the front beam attachment also employ a seal material, i.e. silica felt (Astro Quartz, Style 550). The smalj void beneath the seal (due to the difference in thicknesses between the RSI and the ablator at this joint) is filled with a preformed RTV strip on the leeward side and with silica felt on the thicker windward side. The silica felt strip can easily be inserted ard removed after each flight. 
Table 41 Refurbishment Operational Procedure

$\operatorname{Stmin} N$

1

3

4

b

i

7

8

9

10

11

O1A2,It1(1)!

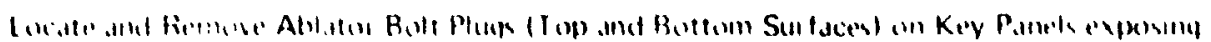
atlathment |xils

PRembre. Athehment Bults

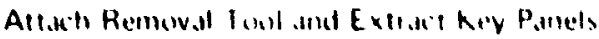

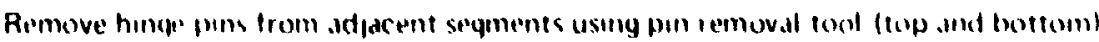

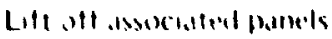

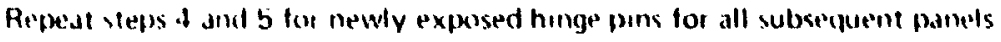

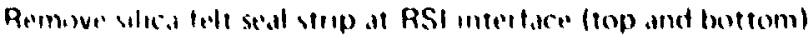

Imspece henge straps attached to trunt beams and exposed RSI edges ftop and turttoml

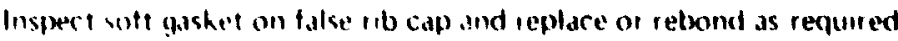

Ilentify iwo centel segments between edch palr of key panels

Inst.sll silica telt seals tor two centet segments, using conl. t cement to hold in place

Install one of the two cenfer segments and insert hinge pins (top and bottom)

Imtall preformed chordwise seal adjacent to second center panel position

Pusition second ienter partel adjacent io previously installed segment

Attach segment installation inol in tion* beam

Alıgn seyment to be installed, ensuring clearance between hinge straps

Us'ng installation jack segment in spanwise direction (compressing chordwise seal) until hinge sequnents at aligned

Jack panel normal to front beam using installation tool, into position and insert hinge pins (top and bottom)

Repedt steps. 11, 13 thru 19 for remaining segments except key panels

Inst.ill silica lelt seals for key panel

Install two preform: d chordwise seds to panels adjacent to key pand

Position key panel and insert ship strips between edges of key panel and previously installed chordwise seals

Jack Rey manel into position perpendicular to fromt beam

Install attachment bolts

Install ablato holt plugs

Remove slip stiıps

Install remaining key segments repeating steps 21 thru 27

Inspect and trim where necessary all protruding seais and surface irregularities to conform to applıcable drawııgs. 
The substructure show in $S t$, in $C-C$ of the drawing consists of an lnterrilly rib stiffened aluminum siell reinfurced with two continuous stiumpal alumimum 3ulkhewas. Its fabrication is planned :us follows.

The aluminum shell is extruded in long sheets, cut to lencth, "nd then stret.cl. formed to the leading edge shape. The two lulthends are stumped to shape lin: subsequently riveted to the rib stiffened shell. For ill but the key sement: the piano hinge is riveted to the :Iuninum substructure using flush rivets. An aluminum doubler (View $K-K$ ) is bonded to the leading elge wiong the hinge connection line prior to riveting the hinge strap in place.

The completed substructure is used as the form for frbricating the heatshield where the honeycamb core is rirst bonded to the substricture and subseupently fllled with the ablative material. Once the core is filled and the nulator is cured, the contour and edzes are trimmej to shape and the surface is seraed to complete the assembly.

The thicknesses for both heatshield materials (Mod $7 \mathrm{Hc}$ and $35(n) \mathrm{HF}$ ) are given in figure 124 for the root, midspan and tip stations. Included in this figure is a normal cross section of the leading edge typical of the midspan location showing the relative thickness vinition arould the perimeter.

\subsubsection{Final Desien Welghts}

Tabses 42 and 43 present a summary of the weight distribution for the milspan segment for the ablator 1.e. final asign slown in "igure 1.j". In

* The systen welght per square root of $7.24 \mathrm{lb} / \mathrm{ft}^{2}$ is slightly freater than that predicted in the earlier trade-off studies which gave a vilue of $6.501 \mathrm{~b} / \mathrm{ft} 2 \mathrm{for}$ reference Concepts 9 and 10. The major incrense in this weight is due to the added weight of the substructure as a result of including the two inllkhends. These bulkheads were required solely to limit the leading edge leflections mi would be required in all the designs examincd in the trale-off studies. Consequentiy, all concepts in Section 6.1.1 should have the substructure weights increased by $a$ constant amount resulti: 6 in no change in the reliat ive ranking of the concepts. 

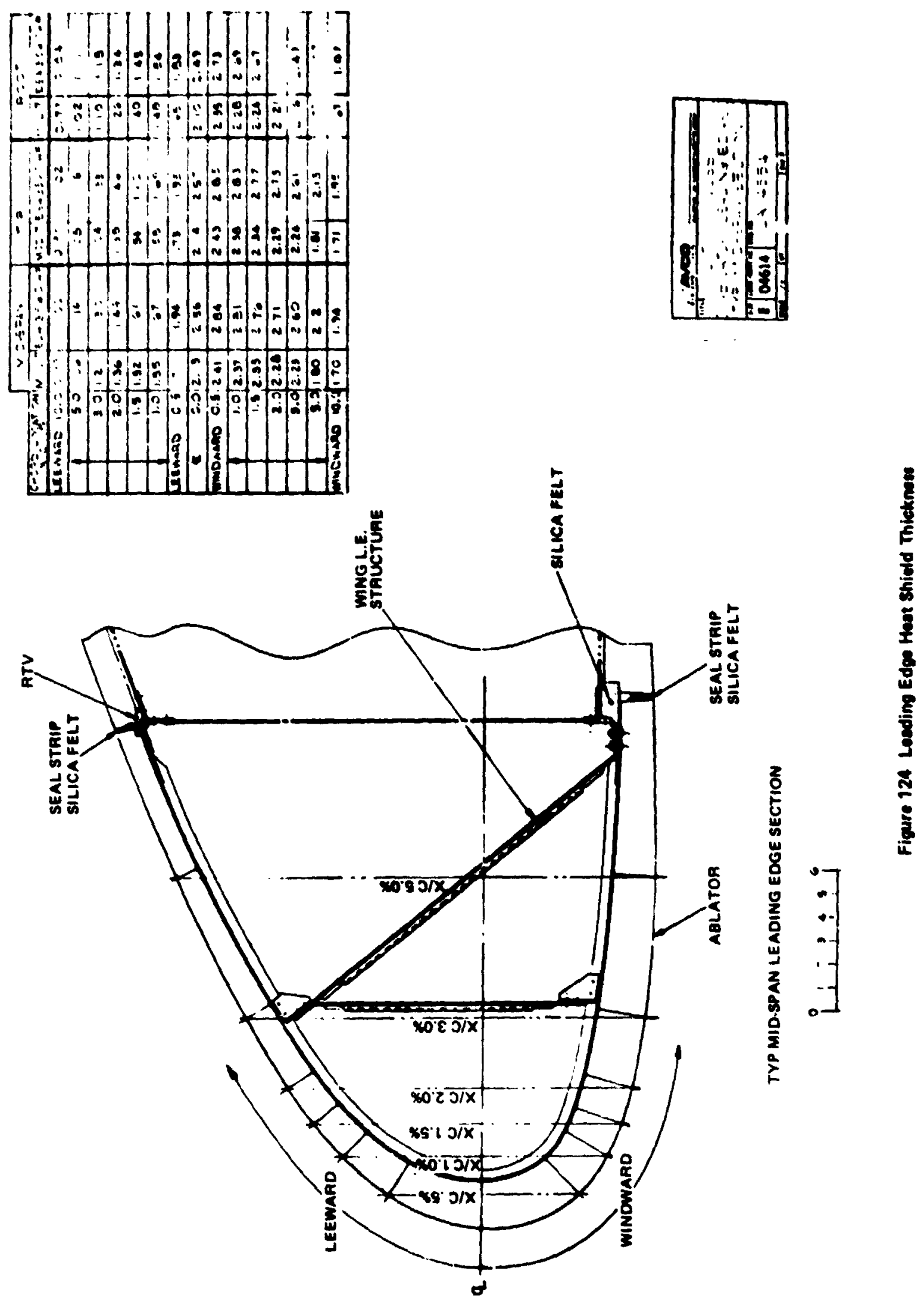
Table 42 Weight Summary

Mid Span L.E. Segment

Length 31.0"

Surtace Area - 11.84 S.F.

\begin{tabular}{|c|c|c|c|c|}
\hline Component & Item & Material & $\begin{array}{l}\text { Weight } \\
\text { (tb) }\end{array}$ & $\begin{array}{l}\text { Totals } \\
\text { (lb) }\end{array}$ \\
\hline \multirow[t]{8}{*}{ Substructure } & Skın with Integral Ribs & Al. & 13.4 & \\
\hline & Doublers & Al. & 1.0 & \\
\hline & Hinge \& Pin & StI. & 0.6 & \\
\hline & Vert. BHO & Al. & 1.2 & \\
\hline & Diag. BHD & Al. & 1.7 & \\
\hline & Tie Bkts. & Al. & 0.4 & \\
\hline & Hdw. \& Dblr. Bond & - & 0.5 & \\
\hline & & Total Substructure: & & 18.8 \\
\hline \multirow[t]{3}{*}{ Heatshield } & Ablator & Mod-7HC(ESA.3560HF) & $63.5(63.6)$ & \\
\hline & Bond \& Coating & HT.424 & $1.9(\sim 1.9)$ & \\
\hline & & Total Heatshield: & & $65.4(65.5)$ \\
\hline Gaskets \& & Abl/Abl Seal & Silicone Foam & 1.7 & \\
\hline \multirow[t]{3}{*}{ Seals } & Abl/RSI Seal & Silica Felt & 0.0 & \\
\hline & & Total Seals: & & 1.7 \\
\hline & & Total Segment Wt (lbs) & & $85.9(86.0)$ \\
\hline
\end{tabular}




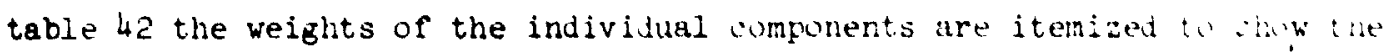
contribution of each item. These weights are subdivided into three major

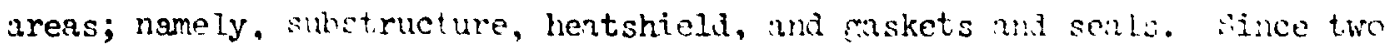
ablators were considered, two weights are given, one for Mod $7 \mathrm{Hc}$ und one for ESA $3560 \mathrm{HF}$, shown in parenthesis. Note that both ablator weithts are essentially the same and that they constitute the bulk of the overall louline edre weight. This is illustrated in tacle is which presents the percent of the total weight and weight per square foot for each component. Here one can see that the hent shield contributes $76 \%$ of the total weight.

Although the total segment weight given applies to a midspan serment only, the weight per square foot calculated for this segment should represent a reasonable average value for estimating the total weight of the camplete leading edge system. This follows fran the fact that at the root the ablator weight per square foot would be somewhat less than at the midspan due to the combined effects of a slightly thinner ablator (see figure 124) and a larger surface area. At the tip the reverse is true where a thicker $\mathrm{H} / \mathrm{s}$ and smaller surface area combine to bring about a slightly higher weicht per square foot. Little change in the substructure unit weifht is anticipated alons the entire span since the applied loads tend to be lower at the deeper roof section and gradually increase toward the tip.

As a result, a reasongble estimate of the leading edge system weight can be obtained using an average unit weight of $7.24 \mathrm{lb} / \mathrm{ft}^{2}$. Taking the base line area of $600 \mathrm{ft}^{2}$, the estimated weight of the ablator leading edge system per vehicle would be $4,344 \mathrm{lb}$. 


\section{COMMENTS ON WING SPECIAL AREAS AND FIN L.E.}

The design of the leuding edge presented in this report is that typical of a wing midspan location under nominal heating conditions. There are cther regions, however, to which the results contained here can be extrapolated, namely; 1) areas of shock impingement heating (if the shock impingement is localized, as in the Gruman 473 orbiter), and 2) fln 1.e.

The main problem that arises due to shock impingement is the ability of the selected ablators (Mod $7 \mathrm{Hc}$ and ESA $3560 \mathrm{HF}$ ) to withstand the higher hortine and pressure gradients without erosion. While negligible recession is predicted for the nominal leading edge condition for either of the ablators the increased heating due to the shock can produce significant recession in the stagnation line region. This effect will introduce undesirable gouging along the span. This problem can be solved by substitution of a higher density silica phenolic meterial $\left(p=100 \mathrm{lb} / \mathrm{ft}^{3}\right)$ for the reference ablators in these localized regions. The use of the silica phenolic appears attractive since negligible recession will occur and in addition the thickness requirements should be close enough to the adjacent ablator so that only minor local modiflcations to the design will be required.

In the fin region typical heating levels of $30,000<Q_{c}<40,000 \mathrm{Btu} / \mathrm{ft}^{2}$ are expected. This envirorment requires Mod $7 \mathrm{Hc}$ or ESA $3560 \mathrm{HF}$ thicknesses on the order of 2.0 inches (see flgure 6-17). The radii (normal to the 1.e.) of the root, midspan, and tip of the fin are 5.65, 3. 96 and 2.0 inches respectively for the Rockwell orbiter $000089 \mathrm{~B}$. In vlew of these data it appears that a desigm similar to the leading edge can be used in the fin root and mid-span but an alternate approach must be used in the fin tip area if the 2.0 inch radius cannot be increased. One possible redesign would be to have the fin 


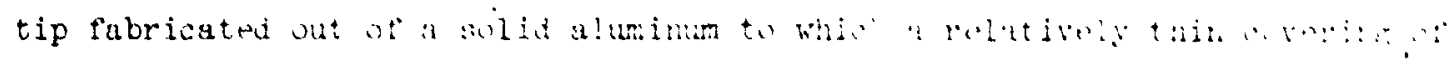

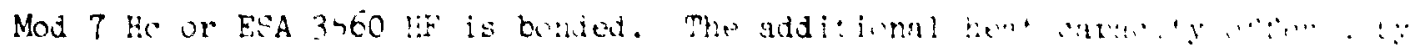

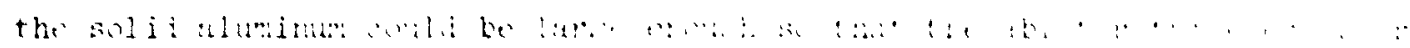

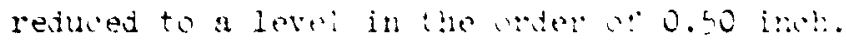

\section{Table 43 Average Weight'Square Foot}

Mid Span LE Segments (Mod /HC)

Surface Area $=1184$ S.F.

\begin{tabular}{lccc}
\hline Component & $\begin{array}{c}\text { Weight } \\
(\mathrm{Ib})\end{array}$ & $\begin{array}{c}\text { Per Cent } \\
\text { Total Weight }\end{array}$ & $W_{\mathrm{t}} / \mathrm{Ft}^{2}$ \\
\hline Substructure & 188 & 22.0 & 1.58 \\
Heat Shield & 65.4 & 76.0 & 552 \\
Seals & 17 & 2.0 & .14 \\
\hline & & Total & 1.21 \\
\hline
\end{tabular}




\section{WING ABLATOR LEADING FDGE COSTS}

The expenditure requirements for the leading edge can be broken up into two major categories, i.e. the non-resurring (or DDT\&E) and recurring (production) costs. Frogram costs can then be determined using these data together with any given traffic model. For the cost analysis presented below, this was done for the following three traffic models for the operitional flights:

1. 15 flights ( 3 per year for 5 years, 2 overational orbiters)

2. 120 flights ( 24 per year for 5 years, 2 uperational orbiters)

3. 445 flights (average production rate during the 1980's is 60 flights/year).

In all cases, there are in addition five test flights. All costs were based on 1973 dollars with no escalation factor. Unless otherwise noted all costs are based on a requirement, of $600 \mathrm{ft}^{2} /$ vehicle.

In general, the program envisioned is cost-conscious, thrifty and directed to essentials.

\subsection{Non-Recurring (DDT\&E) Costs}

The elements contained in these costs ano their estimated value is shown in table 44. This effort will essentially be completed before the major production effort is reached and does not presume committment to the production effort. Five flight tests are included in the DDT\&E phase. The estimated total for this DDT\&E phase is eight million dollars.

\subsection{Recurring Costs}

Figure 125 shows the total costs of the ablator for the various traffic models as a function of unit ablator cost (this included fabrication of the ablator and seals, bolt plugs, insulation, etc). Also indicated on the figure are the 
Table 44 Non-Recurring DDT\&E Costs

\section{Elements}

1. L/E Design (entire L/E, develop test excluded)

2. Material Develooment

3. Design Development Tests

4. Proauction Development (entire L/E, ablator + rest)

5. Qualification, Acceptance and Certification (entire L/E)

6. Tooling and Special Equipment (entire L/E, ablator + rest)

7. Five Flight Tests

\section{Estimated Cost}

$\$ 2,000,000$

800,000

700,000

$1,000,000$

500,000

2.000 .000

$1,000,000$

$\$ 8,000,000$ 


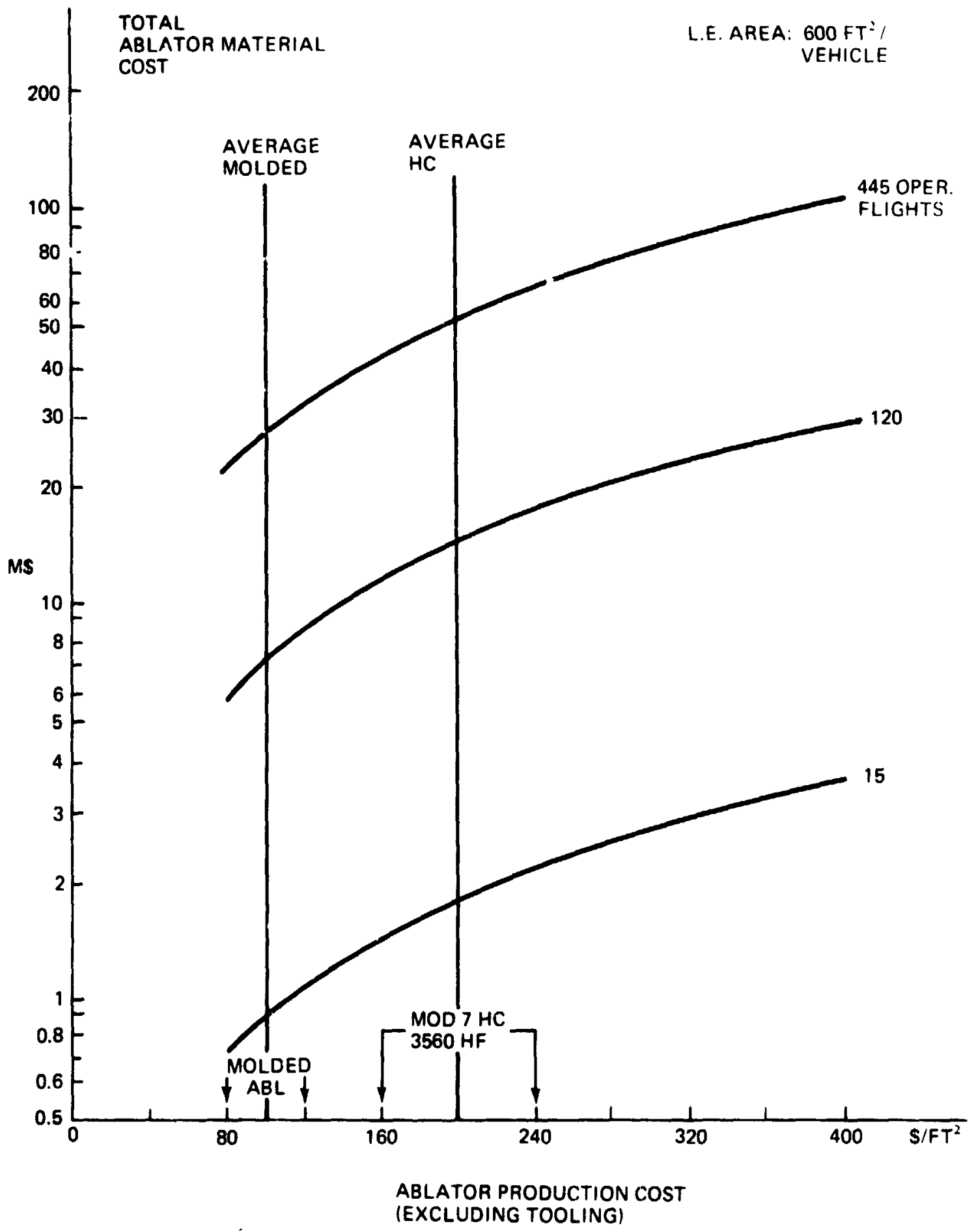

Figure 125 Total Ablator Cost For Wing L.E. 
estimated ranges of cost for the molded and honeycamb reinforced $c \downarrow-2: t$ meric materials. These total ablator costs include all cxpenditures required ror ablation materials, fabrication, machining, bonding, and inspection, and also allowances for seals, bolt plugs, etc.

The aluminum structure cost is estimated to range from $\$ 150 / \mathrm{ft}^{2}$ for the 15 flights traffic model to a 445 -traffic model level of $\$ 40 / \mathrm{ft}^{2}$. Similurly operational (refurbishent) costs are expected to range between $30 / \mathrm{ft}^{2}$ in the 15 flights to $45 / \mathrm{ft}^{2}$ for the 445 traffic model.

\subsection{Prosram Costs}

Figure 126 presents the total program costs for the ablative leading edge. These data include all DDT\&E, abletor, structure, and operational costs associated with the effort. As expected, the cost of a small traffic model is controlled to a great extent by the DDT\&E requirements. For materials in the Mcd $7 \mathrm{HC}$ and ESA $3560 \mathrm{WF}$ category the cost of the program varies between 12 and 90 million dollars for the traffic models considered. If a mulded ablator could be used the cost wonld be reduced to 10 to 52 million.

While this study has as a ground rule that an ablator is used forward of the front beam with an associated area of $600 \mathrm{ft}^{2}$, the Shuttle program leadine edge designs which currently utilize RSI in areas forward of the front beam, require only about $280 \mathrm{ft}^{2} /$ vehicle of ablator. The effect of this latter desiun is shown in figure 127 and the dramatic influence is apparent. The ablator program cost: are now reduced to 9 to 45 million dollars for the vartances in triffle models assuming that efthe= Mod 7 He or ESA $3560 \mathrm{HF}$ is used.

The flrst unit cost is estimated to be $\$ 500,000$ for ablator, substructure (including attachents), and installation for a vehicle with a wirg leadine edge area of $600 \mathrm{ft}^{2}$. 


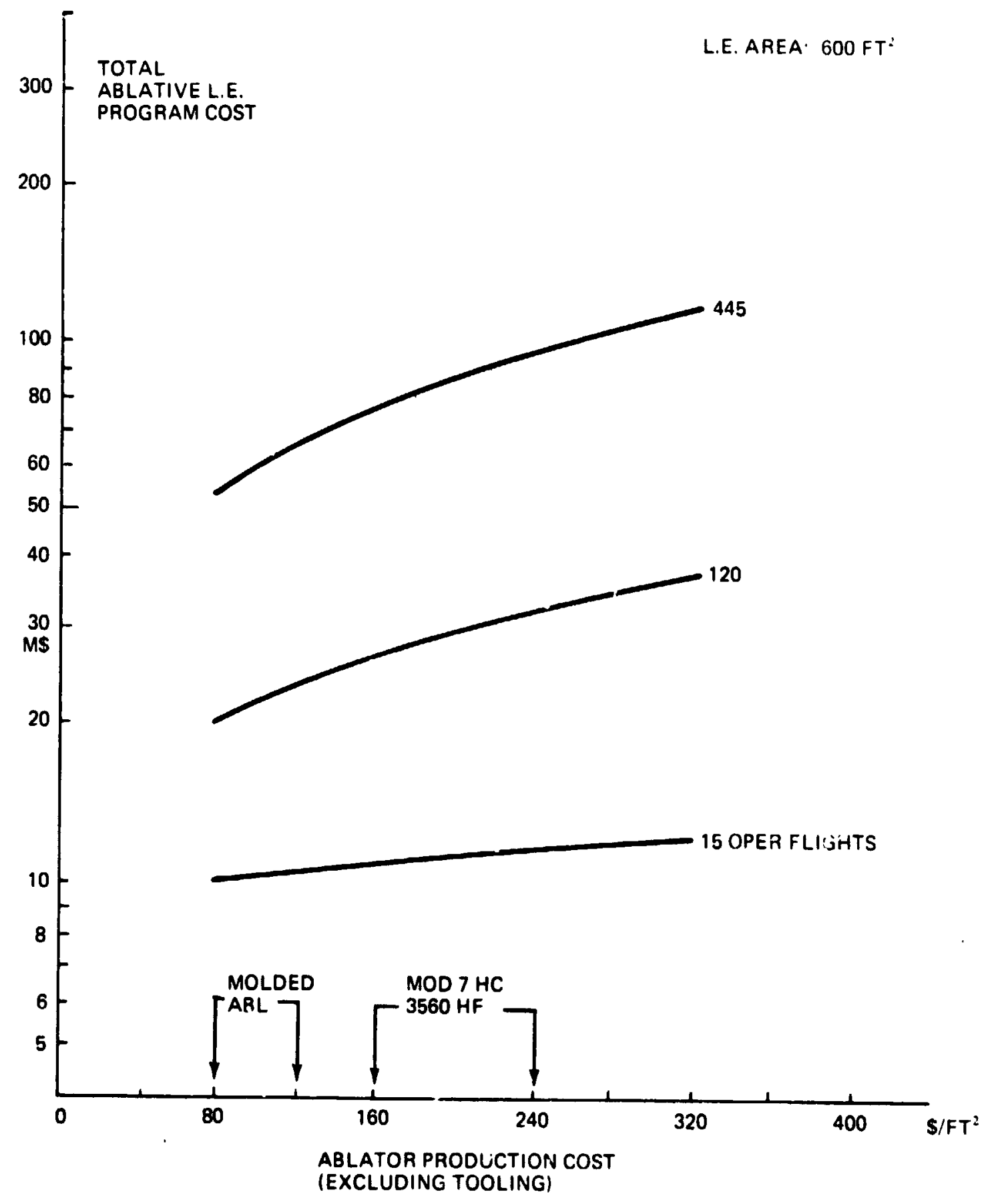

Figure 122 Total Program Cost For Wing L.E. Of $600 \mathrm{Ft}^{2}$ 


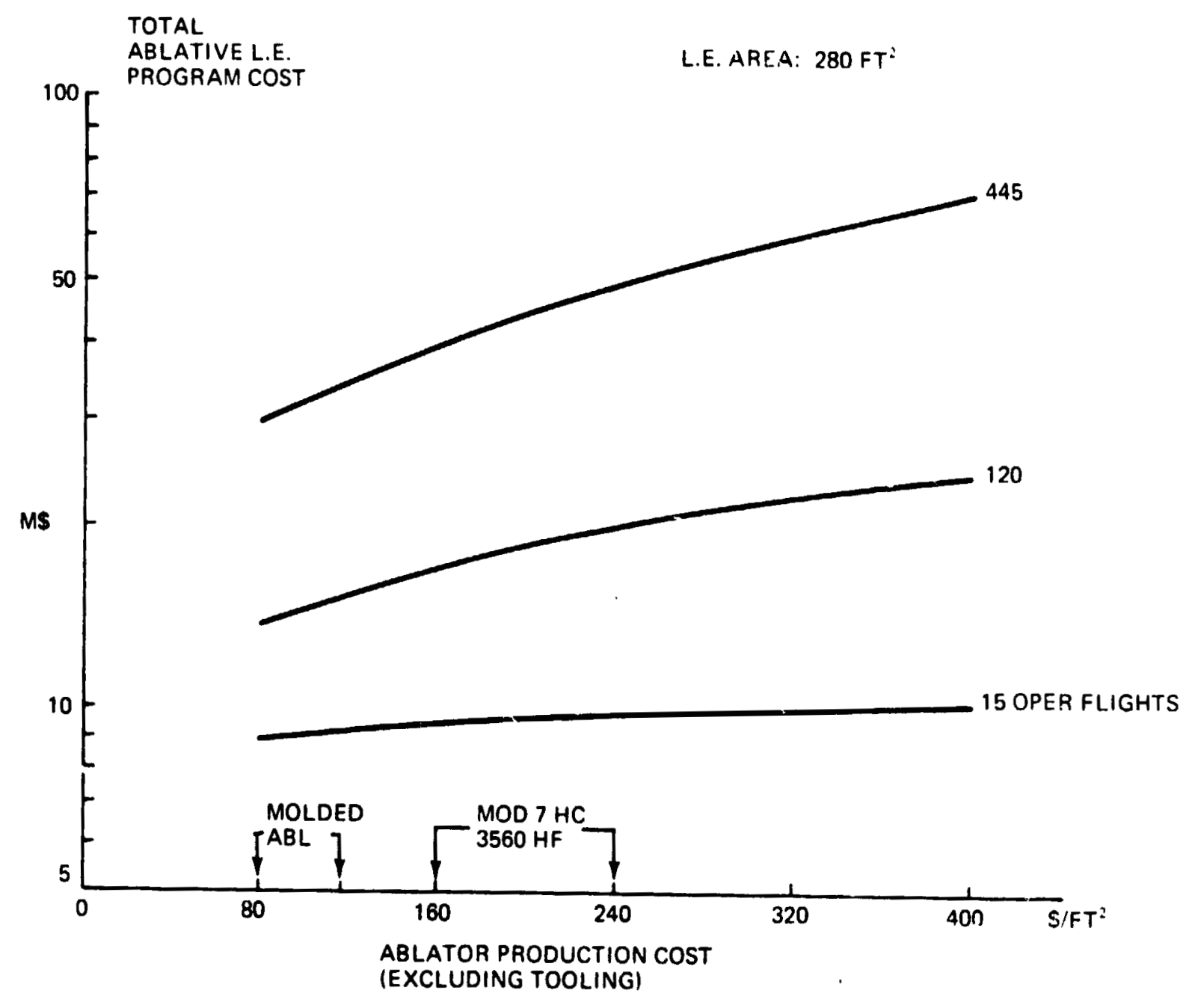

Figure 127 Total Progrnin Cost For Wing L E. of $280 \mathrm{FT}^{2}$ 


\section{YROSPECTIVES FOR COST/WEIGHT IMPROVEMENTS}

The results discussed in Seciion 8 clearly indicate that the ablator cost is the ariving factor in determining the total program funding requirements. Therefore the search to reduce overall costs should concentrate on finding some way to modify the Mod 7 or ESA 3560 so that the unit ablator costs can be reduced from the $\$ 200 / \mathrm{ft}^{2}$ to $\$ 80 / \mathrm{ft}^{2}$ category. The following sections describe some alternatives along these lines that could reduce costs significantly.

\subsection{Molded Ablators}

While none of the three molded materials could be accepted for the design, there is same hope that by varying the fiber, resin, filler ratios of the constituents a satisfactory molded material could be realized. The primary problem with the molded elastomeric moterial is that a weak interface exists between the charred and virgin material. This "weak link" is of concern because of the basic requirement of clear integrity. By proper variation of the constituents it may ke possible to produce a stronger char/virgin interface to relieve this problem.

In addition, one molded material, Mod $7 \mathrm{M}$, performed well during simulated ascent heating, cold soak and entry heating*, but developed char senaration after entry cooldown. This would seem to indicate that thermal performance during entry heating may be acceptable, but of course char separation may be objectively unacceptable from other points of view such as impact damage to the RSI, contamination of the RSI, and low speed aerodynamic characteristics. It is also conceivable that tests that do not simulate the gradual increase/decrease of the heating pulse and surface temperatures as experienced in flight result

* In these steps of the test sequence, both the 5026/39 $\mathrm{M}$ and the ESA 3560 II A developed objectionable char or cracks features. 
in poorer performance of Mod $7 \mathrm{M}$. And it may even turn out that this mat...inl

is acceptable. This would lead to an ablative l.e. that is comparnl in in costs to the C: (see section 9-5). Therefore, further evidution of molide? materials performing like Mod $7 \mathrm{M}$ seems especially in order."

\subsection{Alternate Ablator Reinforcement Techniques}

The major problem with both the Mod $7 \mathrm{Hc}$ and ESA $3560 \mathrm{HF}$ materials is in t!!" honeycamb. Not only is the honeycamb material itself experisive but its $11 \mathrm{e}$ also introduces costly flling and inspection function. Figure 123 show: an alternate reinforcement system (Ref. 75) which should reduce fabricatior costs significantly. This concept consists of a loop pile corstruction 0 backing material to anchor and stabilize the char. Tests conducted at litu un an elastaneric material similar to the Mod $7 M$ (Ref. 75) showed that the har remained anchored to the fiberglass loops even when the char prctressed impletely back to the fiberglass base.

* Since in this upplication there are two 'cooldowns' in a fight, ont. after ascent and one aft, $r$ entry, one may wish to eliminate the first cooldown even though the char interfice is very close to the surface. Une approach is to coat the molded ablator with a low cost coatinf which will absorb most of the ascert heating and therefore provile '? "non-charred" matericl for reentry. While this concept will not solvr the post reentry interface problem, it will provide a predictable stror surfice on the ablator prior to reentry and therefore redune or eliminate the char erosion noted esrly, in the IRC lendins edge tests. Fnc s:...e Idea could be applier to the Hc materials if an ixactly predictable surface at the beginning of entry were required. 


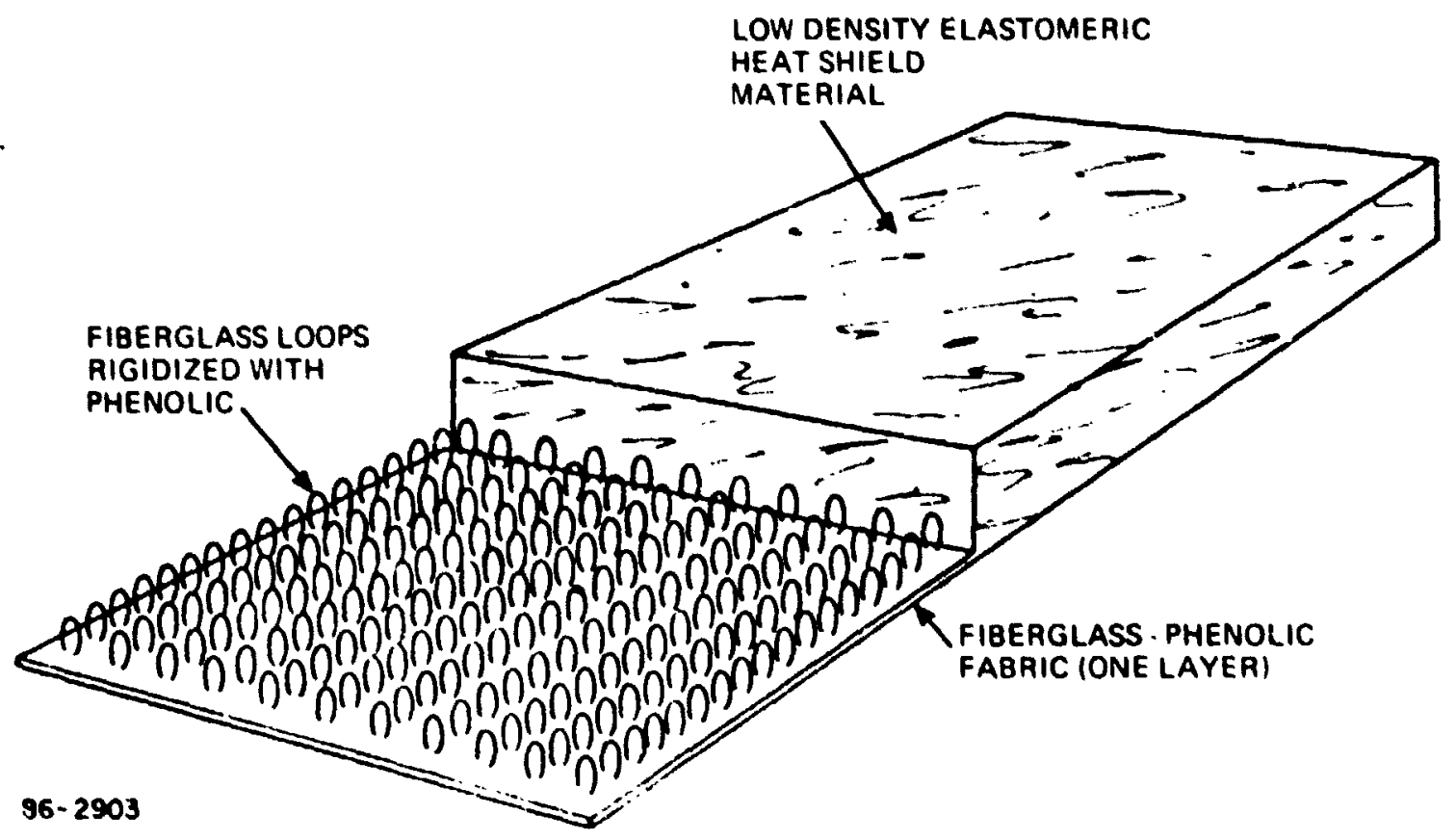

Figure 128 Loop Reinforcement Concept 


\subsection{Multiple Ablator Leading Edge}

The need for honeycamb reinforcement in the stimmation refion of the leatine edge for all current ablator formulatiors has been unply icmonstratel in the test program. Additionally it was shown that two molded (non-reinforced) materials (i.e. Mod 7 molded, 3560 II A) performed unsatisfactorily locally in the nose region, but the bulk of the ablative material both on the leeward and windward surfaces where the heating was lower showed no adiurse effects after the tiests.

Insofar as the current program is concerned, a single ablator leading design was a design decision that follows from the ground rule of selecting off-theshelf ablators. Consequently, the honeycomb reinforcement was employed throughout. If, however, there were same effort directed at developing hybrids of off-the-shelf materials, a more cost effective design could be achievei by the use of multiple ablatc. materials. In the stagnation region a honeycomb reinforced heatshield would be used, and in areas downstream wnere the heating rates decreased a molded $\mathrm{H} / \mathrm{S}$ could be employed. The Hic wouli taper off so that the ablator would form a single element eliminating a spanwise joint in a $r$, on of considerable heating. Moreover, to avoid the problem of trying to match materials and their attendant ablation and thermal properties it would be possible to use th. identical material formulation throughout with honeycomb reinforcement placed only where needed. The Mod 7 would fulfill this need since it performed exceptionally well in the molded form and with Hc reinforcement it met all the mission requirements.

Further refinements of the multiple ablator concept could be achieved by changing material formulations entirely in an attempt to reduce the ablatcr weight through the use of a material in the $20 \mathrm{Ib}_{\mathrm{f}} / \mathrm{ft}^{3}$ class. But as alluded to above this gives rise to problems of matching materizls, difserential ablation, 
different thicknesses at the juncture, etc. Although not unfeasible, nore . study would be required to qualify this approach as opposed to concept where the only change involved is the inclusion of honeycomb. Also, as pointed out in Section 6.3.4 the desirability and cost effectiveness of a dual ablator leading edge system diminishes rapidly as the area forward of the front beam which is devoted to ablators rather than RSI is reduced.

\subsection{Honeyconb Ablator Reuse}

The appearance of two $\mathrm{Hc}$ materials (Mod $7 \mathrm{Hc}$ and $3560 \mathrm{HF}$ ) after the tests of this program suggests that there may be a reuse capability, at least when these ablators are used twice on the windward side of the l.e. only (about half of the 1.e. area in current carbon-carbon designs). It may be prudent - in the context of Shuttle program totally camitted to minimum cost - to reexamine the following three questions of the reuse concept: a) thermal performance, b) trade-offs cost versus extra weight and, c) Inspection after the first filight.

\subsection{Estimates for Cost Savings}

Figure $129(a)$ presents rough estimates for the costs savings for few of the concepts proposed above, using as reference materials such as Mod $7 \mathrm{M}$ and Hc in which there is a marked cost difference between the molded and Hc material. Flgure 129 (b) presents the corresponding savings if the l.e. area is comparable to the current carbon-carbon areas. It is clear that the molded materials costs are comparable to the CC costs for the 445 filights traffic. 
TOTAL PRCGRAM COST

FOR WING ABLATIVE L.E.

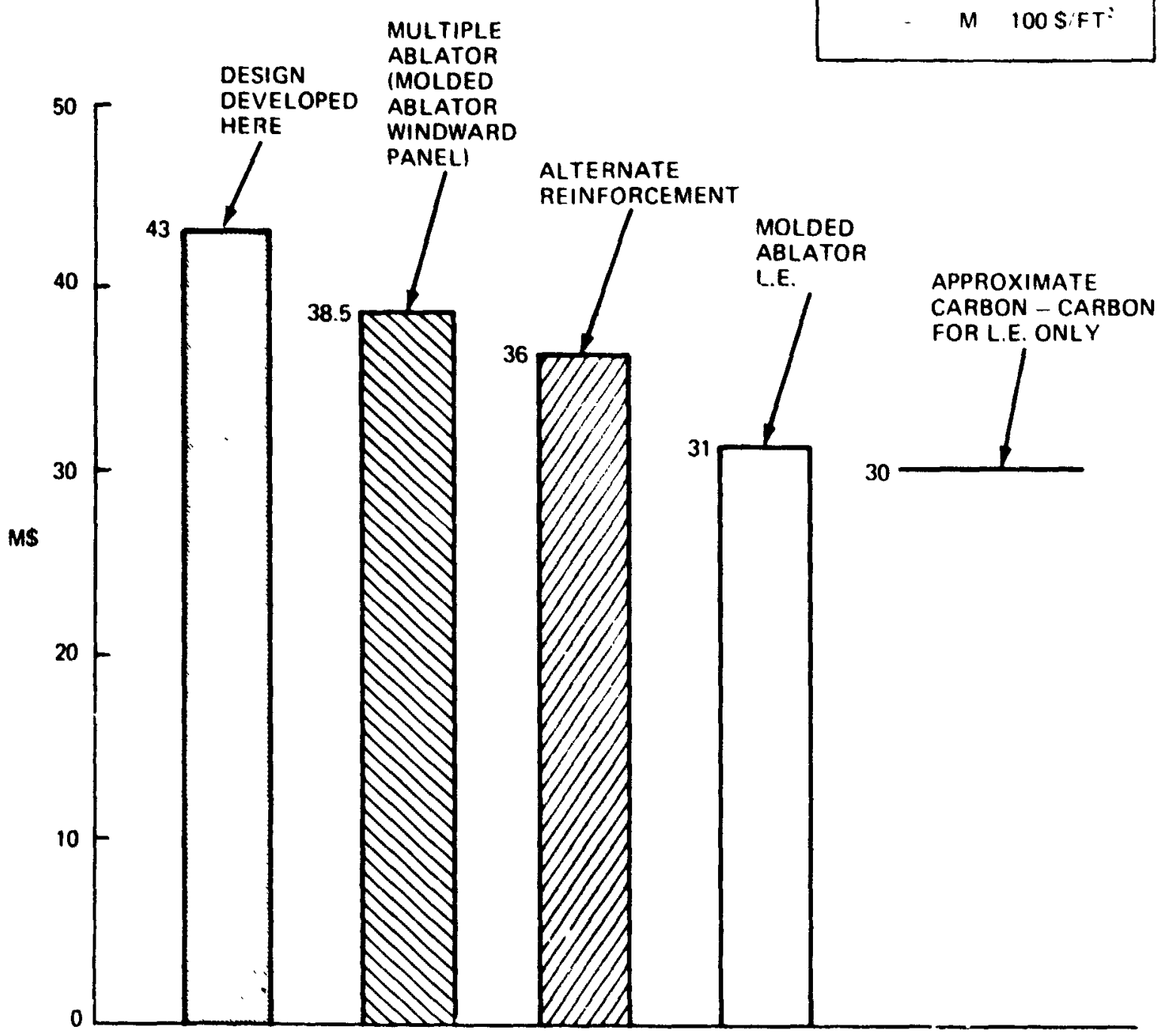

- 445 OPER. FLIGHTS

- $280 \mathrm{FT}^{2}$ L.E. AREA

- ablator pROd COST.

$\mathrm{H}^{\prime} \mathrm{C} 200 \mathrm{~S} / \mathrm{FT}^{\circ}$

$100 \mathrm{~S} / \mathrm{FT}$

(MOLDED

WINDWARD

REINFORCEMENT

ABLATOR

CARBON - CARBON

OR L.E. ONLY

Figure 129 Total Progrem Cost Sovings With Three Concepts Recommended For Development (a) Full Traffic Model 
TOTAL PROGRAM COST

FOR WING ABLATIVE L.E.

300 OPER. FLIGHTS
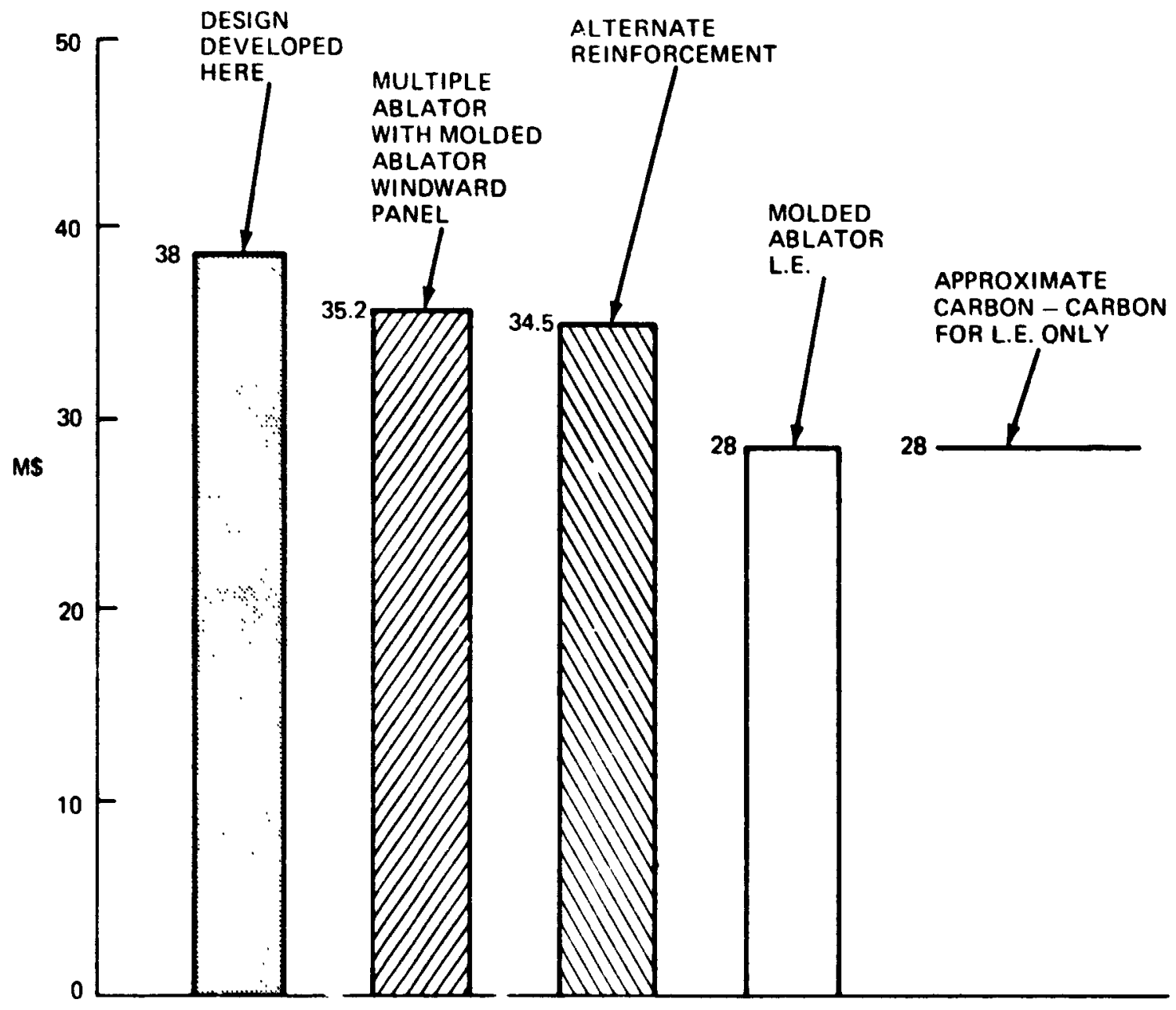

Figure 129 (cont'd) (b) Reduced Traffic Model 
10. CONCLUSIONS

The main conclusions of this study are:

(On the ablator)

a) An ablative z.e. is fensible with four state-of-the-art $u$ blittor: :

the 30 to $60 \mathrm{lbs} / \mathrm{ft}^{3}$ class (out of the eisht cindiate miterials. seds table $5-2 !$

b) of the four materials, two proprictary elastomers, the Arre ind $7 \mathrm{he}$ and the MMC ESA 3500 BF, are best and equal within the dat.? kenernted In this study;

c) In general, honeycomb reinforcoment appenrs needed :ss none of the thrce molded materials tested (ESA $3560 \mathrm{IIA}, 5026 / 30 \mathrm{M}$. Mol $7 \mathrm{M}$ ) is acro:table within the scope of this study:

d) Screening tests for the stagnation recion must include in the test sequence ascent charring but the sequence car. he simplified to three steps, ascent heating, cold sank and entry heating lof coursu there is no sscent charring in the windward or leeward jol.t aro:l, so that there screening tests can be reduced to cold sakk and entry henting). No attempt has been made to separate the two ascent heattik effects, nmely the production of sane char and the nreconditioning of the vireir: material.

(On the degradation of low speed aerodymamic churncteristics - Moluminisy

\section{conclusions)}

e) The roughness of the tiro nblators selected pronice small arrolymaic characteristics degradation: stability is unchangea and the (Lin) max decresse is about 0.1 : and probnbly cost-rree. These conclusions are configuration lependent, but sppear typical of single-ielti: Fhase-3 orbiters with 1.e. camber; 
f) The recession messured for the two ablators selected, interpreted as ir df cated in this repurt, produces very smmll decriblation of low speed nerodynumic characterlstics; a concept for correctine recession effects is availuble but has not been found necessary;

Won the technical characteristics of the ablative 1.e.)

8) Ensed on a study of 13 different l.e. refurbishment concents, a design in which the 1.e. Is removed in a single plece from the wins front berm gives minimum weight and cost:

h) The piano-hinfe pin sttachent concept has been found the most attractive for attachins each d.e. sesment to the wing front beam; no segment-to-segment attschment has been found necessary;

1) Both abluturs, ESA 3500 trF and Mod $7 \mathrm{Hc}$, resulted in the same velght; ascent heating required an increase of 0.2 inches of material in the stagnation region;

1) An aluminum $\left(350^{\circ} \mathrm{F} \max \right)$ integrally rib-stiffened substructure turned

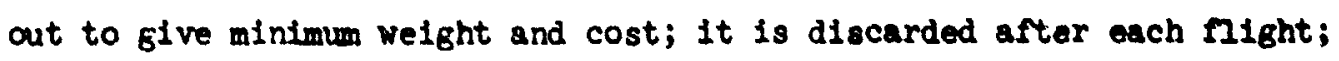

m) For the allator-ablator joints between l.e. segments, a sealed gap, using as seal a compressible silicone foam mas selected us the best desisn; however un alternate concept, i.e. a silica felt seal, was found promising and may turn out superior to the silicone foam seal in future tests: neither design could be tested on a l.e. model;

n) fur the ablator-RSI ioint, again a seal gap concept was found best, with the gap fliled with. (very compressible) slilica felt;

o) The weight of an ablative l.e. for typical delta-wing orbiters turns out to be 7.24 psf (78. heatshield and 224 eubstructure);

p) An Initial design incorporating the features above has been developed; 
q) The ablative 1.e. turned out to be made up of 44 segnents per vehicle, each 31 inches long, 80 lbs heavy. The procedure recommended for removal and installation is semisequential. Ti.e refurbishent of the orbiter wing 1.e. can be carried out in four days;

r) The welght of the ablative 1.e. $\left(600 \mathrm{ft}^{2}\right.$ of 1.e. area) turned out to be 4350 Ibs;

\section{(Bstimated ablative l.e. costs)}

s) The ablative 1.e. costs are estimated around $\$ 8$ for DDT\&E. Total program cost for 445 flights is estimated $\$ 43 M^{\prime}$ (for $600 \mathrm{ft}^{2}$ of 1.e. area) and $\$ 38 \mathrm{M}$ (for $280 \mathrm{ft}^{2}$ area as in the current carbon-carbon wing l.e.);

(Prospectives for cost reduction)

t) Since one molded ablator performed well up to and including the entry heating, but developed char separation after entry cooldown, further evaluation and/or improvements may prove that this ablator or ablators performing in similar manner are acceptable. This would lead to ablative l.e. costs comparable to $\mathrm{CC}\left(280 \mathrm{ft}^{2}\right.$ of l.e. area, 445 flights); and

u) Hybrid Hc-and-molded ablative 1.e.'s also of fer attractive cost savings. 


\section{RECONOTNDATIONS}

\subsection{Development of the Ablative L.E.}

We recommend that a modest effort be continued with the aim of providing a backup for the carbon-carbon l.e., at a price that the Space Shuttle Program can live with.

The areas we recommend for investigation are:

a) Improved molded ablators (See Section -1 )

b) Alternate reinforcement schemes (See Section 9-2)

c) Multiple ablator's with a molded panel (See Section 9-3)

These concepts seem to Imply costs (see figure 129) that the Shuttle Program could live with.

The evaluation of these concepts can take the form of a modest program for fabrication and test evaluation of l.e. models, summarily instrumented, subjected to ascent heating, cold sook and entry heating.

\subsection{Tests with Models Fabricated under the Present Study}

Under this study or in connection with this study, many models have been produced that have not yet been tested. The recommendation is that these models be tested and the results used to continue the ablative 1.e. development. The models in questions are the following:

a) The 8 1.e. models, 4 of Mod $7 \mathrm{Hc}$ and 4 of $3560 \mathrm{HF}$, that have been fabricated for future testing at JSC. These models will provide a good small-scale evaluation of the materials and the $\mathrm{d} / \mathrm{A}$ joint in tests at high enthalpy. The description of these models is given in Appendix 6.

b) The 4 joint models, 2 1.e. for the $\mathrm{A} / \mathrm{A}$ joints and 2 flat models for the A/RSI joint, that were fabricated. but not tested in the IaRc 


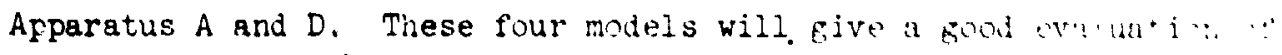
the joint designs, which are the two designs finally $-10 c^{2}$ ed $(\mathrm{N} / \mathrm{A}$ and A/RSI), a backup desion for the A/RSI joint and n hei : er (int as yet untested) design for the $A / A$,joint. These model: and the test procedures are presented in Appendix 5.

c) The three rain erosion samples of MMC ablators of this prorram (i.e. $3560 \mathrm{HF}, 5500,356 \mathrm{C}$ JI A). Initially tests were plinnad on these samples (after charring) in the Bell Whirling-arm facility. By NASA directions, these tests were cancelled. However, the interest for data on rain erosion still remains.

d) The eight strips (one for each candidate ablator of this stidy) nac? for the flexure tests of the virgin ablators were intiat after the tests. If anything, they have been preconditioned with strains renresertative of the max qa condition during ascent. These models can be tested, in a representative sequence, to Eive more dati on the performance of the two selected materials (or, for that matter, of all eight materials) in the windward region of the 1.e. (Recall that the charred strips in this study have not been subjected to ascent heatinf and cold soak). A test condition, and a crude calorimeter ule avilable for these tests in the Avco ROVERS facility (see Inpendix 3).

e) Both Martin and Avco produced modification of their basic materials, especially adapted for the shuttle orbiter 1.e.* Eight l.e. moilels exactly as those used in this program have been sumitted to iAS.l (o::e

* There was also a modified $5026 / 39 \mathrm{Hc}$ 1.e. model that was nroluce 1 fo: the special purpose of elimination of the flow in the LaRe Apparatus A. This model was summarily instrumented and tested under ascent testing (ROVRR facility) and entry heating (Apparatus A). 
modified $480 \mathrm{M}$, three modified $3560 \mathrm{HF}$, two modified 5500 and two modified 3560 II A). Even though these modific. 'ormulations may rot turn out successful, we reccmmend that the models be tested and something learned in the ine of yerformance improvement potential (which may mean weight savings and, if a molded version works, cost savings).

f) A 480-1B M 1.e. model is also avallable. It is the counterpart of the $4801 \mathrm{~B} \mathrm{HC}$ tested under this program. There is stij] same question $3 s$ to why the 48018 Hc performed so bedly in the entry test. Therefore there may still be some ground for testing this molded material given that the model is avallable.

B) The reuse concept for the 1.e. Windward side can be tested with available moduls. The strips mentioned under(d) could be surtected to repeated heat pulses. Moreover the twc A/RSI joint maiels can also be subjected to multiple heat pulses thereby providing even an evaluation of the foint and of the added RS: contamination due to reuse. 


\subsection{Plan for Detailed Study of Aerodynamic Characterlstics Degradation}

On the grounds of the preliminary assessment (Section 4), a detailed study should be directed at apnlying the procedure of Section 4.2 , as carried out in Sections 4.3 and 4.5 , to a typical double-delta orbiter for which considerable data, analyses, and mumerous low-speed tunnel mudels are already available. It may be necessary to update the requirements on float time, landing speed and safety factors, together with the policy as to whether there is potential recovery through clean-ups.

We assume, consistent with Section 12.1, that this detailed study would be modest and would not attack fundamental questions such as understanding of the fluid mechanics of the l.e. separation on the orbiter wing, or Reynolds mumber affects at high $\alpha$.

The study should comprise the tasks outlined below:

\subsubsection{Study Criteria}

The rollowing should be done:

- Update, if necessary, the ground rules (float times, safety factors, etc) and establish limits of acceptable degraderion of $c_{n \beta} c_{18}(L / D)$ $\max , c_{L} \cdot$

- Estimate the expected roughness ranges for the $3560 \mathrm{HF}$ and Mod $7 \mathrm{Hc}$, the predicted recession and also the estincted recession-uncertainties 1.e. profile. The question of the roughness density should he examined more closely, so that the Hc roughness of the two ablators can be reaso-2bly represented vie grit density.

- Select baselane configuration. 


\subsubsection{Test Program}

The objective of this program is to determine separately the effects of camber, 1.e. roughness and shape changes.

The facility preferred is the NASA LaRe ITPT $3 \times 7-1 / 2-f t$ tunnel which has a high Reynolds number capabiluty along with a very precise force-measuring capability which is very useful in accurately determining the oftentimes small force increments. However, the key question is whether for the configuration selected there is a model available for this facility, especially a model that has been run, as was the case for the $1 / 67.5$ scale $H 33$ models, in the Langley 8-ft transonic and 4-ft unitary turnels. Then 111 model support and compatibility problems have already been solved. The wing should be removable without removing the model from the sting. If not available on the model, a new wing with several interchangeable leading edges should be fabricated out of fiberglass.

As far as grit application one should take advantage of the technique used in the G. jmman tests with total model refurbishment (cleaning and regritting) times of about 15 mimutes. This technique simply involved sticking on precut strips of Monokote, and adhesive-backed Mylar used by amateur modelmakers, on the ciesired model ourface regions. The strips are prepared prior to testing by gluing carborundum grit of the desired fineness on the roughened tape surface with a polyurethane spray and allowing 12 hours for drying. The technique should be able to cope wilh the dynamic pressure of the LTPT tunnel; however if it does not, one can fabricate two wings on just two leading edges, which can be pregritted and rapialy interchangad. This appears better than applying the grit to the del itself. It's important that grit dersity be maintained and the grit size varied. 
Tentative test conditions include:

- Grit sizes Nos. $20,24,36,46,60 \& 150$

- $M=0.25 ; \mathrm{Re} / \mathrm{L}=14 \times 10^{6} \mathrm{ft}^{-1}$

- Some runs are repeated at $\mathrm{Re} / \mathrm{L}=8 \times 10^{6} \mathrm{ft}^{-1}$ to determine whether tho data actually correlate with $\operatorname{Re}_{k}$ at low Re ( say $1.5 \times 10^{6} \mathrm{ft}^{-1}$ ) and high Re ( say Re/L $=14 \times 10^{6} \mathrm{ft}^{-1}$ )

- Tunnel test conditions are compared with Ilight in figure 11-1. $R e_{k \max }$ can be simulated even though $\mathrm{k} / \mathrm{r}_{\mathrm{n}}$ is too large iflight 0.1 , tunnel 0.6 )

other points that will be incorporated include:

- Include runs without grit and with standard transition strips for flight data estimation)

- Repeat runs with new roughness application

- While the bulk of the runs will have roughness on wing/tail/nose, in a few cases isolate the relative contributicns of wing, tail and nose as in the Grumman and NASA test series.

Instrumentation will include standard six component force and moments. The accuracy of the LTPT baiance is adequate. Flow visualization: tufts on video. It would be extremely useful to provide transition visualization.

\subsubsection{Analysis and Comparisons with Data}

It wouid be very useful to carry out, in parallel with the experiment, a study similar to that of Ref. 25, using single infinite-cylinder bourdary layer theory together $w^{2}$ a the pressure distribution predicted from Ref. io.

\subsubsection{Analysis of Experimental Data and Extrapolation to Flight} To overcome the characteristic inismatch between tunnel and flight Reynolds number (see figure 130) we anticipate using the 'plateau' procedure. This 


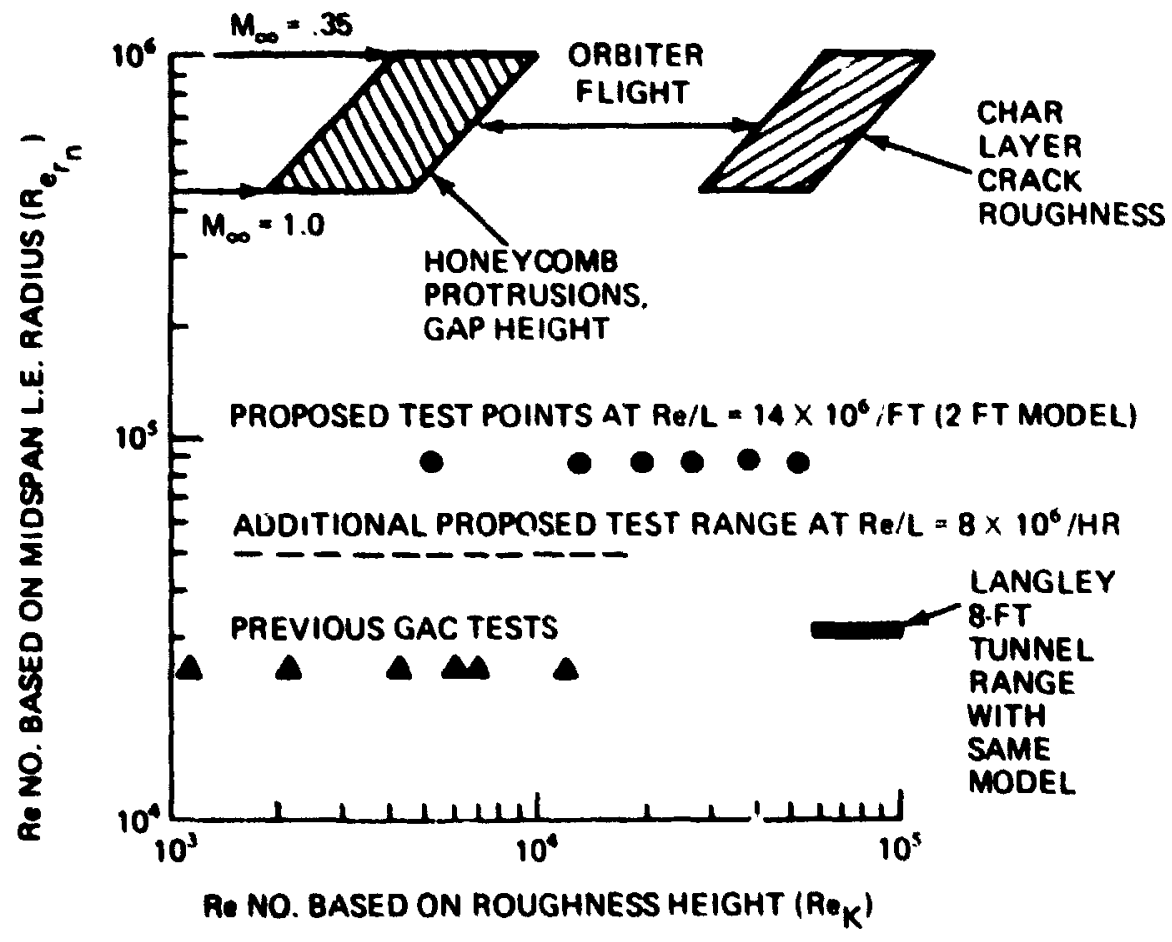

Figure 130 Proposed Tunnel Tests And Flight Conditons 
procedure, or other possibilities, such as comperiscns of aerodynamic characteristics at same $\mathrm{Re}_{k}$ but wrong $\mathrm{k} / \mathrm{r}_{\mathrm{n}}$, should be at least partially checked with the data obtained. Effort should be devoted to this task, especially for the extrapolation of $c_{\text {Imax }}$ ' but it is not easy to describe what should be tried.

11.3.5 Conclusions on Aerodynamic Performance Degradation and Recommendations for Ablative Leading-Edge Design

This is a repeat of the study of Sections 4.3 and 4.5 for $c_{18} c_{n B}(L / D) \max$ and $c_{\text {Imax }}$. In particular the results will be a new estimate of the $\Delta c_{1 \beta}$ $\Delta c_{u \beta} \Delta L / D \max$ and $\Delta c_{\mathrm{Imax}}$ for the roughness and reunion of the $3560 \mathrm{HF}$ and Mod 7 He ablators. 
12. REFERENCEC

1 Tillian, D. I., and Roscoe, T. J., "Thermal Evaluation Tests of Ablator and Wood Wodels of the :ISL $: 5 \mathrm{~K}$ Shuttle irbiter Wing Tip Leading Edge in the USC $10 \mathrm{MW}$ Arc-Heated Tunnel," NASA US: Memorandum ES5/7-15(0) /171 (M), July 21, 1970.

Z Graham, J., et at., "Ablative Leading Edge Design Concepts for the Shuttle Orbiter," NASA Space Shuttle Technology Conference, Volume II, Structures and Materials, NASA TMX-2273 (1971), pp. 195-231.

3 Johannesen, B., "Post-Test Report of the Low Speed Force Test on the 1/25 Scale GAC H33 Orbiter Model in the Grumman 7 x 10 Low Speed lunnel," GWTT 300, Nov. 1971.

4 Johannesen, B., "Post-Test Report of the Low Speed Force Test on the 1/25 Scale GAC H33 Orbiter Model in the Grumman $7 \times 10$ Low Speed Tunnel," GWTT 304, March 1972.

5 Niblock, G. A., Reeder, J. C. and Huneidi, F., "Four Space Shuttle Wing Leading Edge Concepts," American Institute of Aeronautics and Astronautics, Paper No. 73-738, 1973.

6 (Anon.) "Space Shu',tle Program," NASA Manned Space Center, RFP No. 9BC-421-67-2-40P, 1972, pp. 1-7 and 1-8.

7 Forcht, B. A., "Development of a Fail-Safe Design Oxidation-Resistant Reinforced Carbon System for the Wing L.E. of a Space Shuttle Vehicle," ITV Vought System Division, VSC Report T143-5R-30008, June 1973.

8 Moss, H., "Value of a Pound," Grumman Aerospace Corp., Shuttle Frogram Memorandum B35-13N:C-86, Jan. 26, 1972. 
9 Moss, H., "Parallel Burn SRM Value of a Pound," Gruman Aerospace Corp., Shuttle Program Memorandum B35-40M0-72005, March 23, 1972.

10 "Current (1973) Values Used in Space Tug Studies," private communication from B. Frumkin, Grumman Aerospace Corp.

11 (Anon.) "KSC Space Shuttle Processing Study, Prelininary Planning Baseline Operational Flow," NASA Document (unnumbered), March 1973.

12 DaForno, G. and Peinemann, M., "Some Effects of Ablative Leading Edge Roughness Upon Low Speed Aerodynamic Characteristics of Shuttle Orbiters," presented at LRC Ablation Technology Symposium, Nov. 1971.

13 Pyle, J. S. and Montoya, L.C., "Effect of Roughness of Simulated Ablated Material on Low-Speed Performance Characteristics of a Lifting Body Vehicle," NASA TMX-1810, 1969 (CONEIDENTIAL).

I4 Decker, J. P., "Some Effects of Ablation Surface Roughness on the Aerodyramic Characteristics of a Reentry Vehicle at Low Subsonic Speeds," NASA TMX-2318, 1969 (CONFIDENTIAL).

15 Decker, J. P. and Abel, I., "Some Effects of Ablation Surface Roughness on the Aerodynamic Characteristics of a Reentry Vehicle at Mach Numbers from 0.30 to $1.00, "$ NASA TMSX-205C, 1971 (CONFIDENTIAL).

16 Pyle; J. S., Ash, "Performance Characteristics of the Lifting Body Vehicle," NASA TMX-2101, 1970

17 Minutes of the NASA/DOD Space Shuttle Aerothermodynamic/Configureation Working Group Meeting, March $9 \& 10,1972$.

18 Personal communication of J. Graham (Avco) to G. DaForno (Grumman), Nov. 1971. 
19 Personal communication of H. Chandler to G. DaForno, Nov. 1971

20 Letter by I. Graham (Avio) to $\mathrm{h}$. Wolter (Grumman), GACSS/NWG/3 dated ian. 26, 2971.

21 McVey, D. F., Auerbach, I., and $\because c B r i d e, ~ D . ~ D .$, "Some Observations on the Influence of Graphite :iicrostructure on Ablation Ferformance," AIAA Paper No. 70-155, 1070 .

22 Rogers, E. W. and Hall, I. M., "Investigation at Transonic Speeds of the Performance or Various Distributed Roughness Bands Used to Cause Boundary Layer Transition Near the Leading Edge of a Cropped Delta Half Wing," ARC CP 481, 1960 .

23 Decker, J. P. and Ware, G. M., "Effects of Roughness on Aerodynamic Characteristics of Grumman H33 Orbiter at $N=0.25$," DMS-DR-2139, NASA/ LRC, April 1972.

$24 a$ Schlichting, H., "Boundary Layer Theory," Pergamon Press, 1955.

$24 \mathrm{~b}$ Droblenkov, V. F., "The Turbulent Boundary Layer on a Rough Curvilinear Surface," NASA TM 1440, 1958, (Translated from Izv. Akad. Nauk SSSR Ot1. Tekhi. Nauk No. 8, 1955, p. 1721). 
Tani, I., "Low-Speed Flows Involving Bubble Separation," in Kuechemann, D. and Stern, :., (eds). Progress in Acronautical Sciences, Vol. 5, pp. T0103. Pergamon, 1964.

26 Grumman video-tapes of tuft studies taken during GWrs 304.

27 Abbutt, I.H., and Doenhoff, A. E., "Theory of Wing Sections," Dover, 2959. Treon, S. T. and Steinle, F. h., ictstetter, W. R., and Hagerman, I, R., "Data Correlation from Investigations of a high Subsonic Speed Transport Aircraft Model in Three Major Transonic Wind Tunnels," AIAA Paper No. $69-794,1969$. Carlucci, F. T., "Data Report for Third Series of Tests on the 1/25-Scale GAC Orbiter Model HS3 in the GAC Low Speed Wind Tunnel," GhTM 292, 1971.

WeIsh, W. E., Starner, K. E., Leeds, D. H,, and Slaughter, J. I., "Low Density Ablation Materials Survey," Grumman Aerospace Corp., TDR-669 $(6240-10)-5$, SSD-TR-66-35.

31 Welsh, W. E. and Slaughter, J., "Plasma Arc Tests of Carbon-Phenolic Materials for Lifting Reentry Vehicle Applications," Gruman Aerospace Corp. TDR-669 (5250-40)-1. Meltzer, J., Rossof, J., and Slaughter, J., "Structure and Materials Aspects of the PRIME FIIght Test Vehicle," AIAA/ASME Tth Structures and Materials Conference, Cocoa Beach, Fla., April 1966. 

Gemini Ablative Heatshield, "J. Spacecraft, Vol. 3, No. 10, Oct. 1966.

34 (Anon.) "Spece Shuttle Materials Property summary Report," AVSD-0478/70CR, Oct. 1970, prepared for Grumman Aerospace Corp.

35 Grindle, S. I. and Todd, J. P., "Materials Evaluation for Lifting Reentry Applications," Plesmadyme Corp., TR AML-TR-65-144, May 1965.

36 (Anion.) "Prime Lifting Body Spacecraft - A Collection of Papers," Air Force Report No. SAMSO-IR-68-111.

37 (Anon.) "Information About Space Material," Dow-Corning Co. Bulletin 61-051, June 1971. Tr.smas, H. K. and Recesso. J. V., "Ablative Compcsites for Lifting Reentry Thermal Protection, "AVSSD-0081-68-RR, 1968. Watman, H., "Criteria and Performance Charts for Assessing Reentry Glider Horizontal Landability," Grumman Aerospace Corp. AD Rept. No. ADR 01-0764.1, Sept. 1964.

40 Chin, J., Moore, K. and Domas, D., "Results of a Preliminary Flying Quadities Analysis of the O4OA Orbiter," Shuttle Program Memo B36-172MO-24, Jan. 1972.

41 Krepski, R. E., "Design 619 Orbiter - Estimated Aerodynamic Data," Gruman Aerospace Corp. IOM B36-156MO-72-016, May 26, 1972. Jung, W. G. and Krepski, R. E., "Analysis of the First Series of Subsonic Wind Tunnel Tests of the Grumman Design 469 Delta Wing Orbiter at the Grumman Low Speed Wind Tunnel (GWTT 308)," Grumman Aerospace Corp. IOM B36-156M0-72-002, May 3, 1972. 
43 Martorella, K. F. "Orbiter Desirn 6l9 Flyine qualities," Gruman Aerospace Corp. IOM B36-156M-72-023, June $7,1972$.

44 Chin, I., Moore, K. and Domas, D., "Results of a Preliminary Plying Qualities Analysis of the OLOA Orbiter," Shuttle Fropram Memo B36-1T24024, Jan. 1972.

45 Tillian, D. J. and Roscce, T. T., "Thermal Evaluation Tests of Ablator and Wood Models of the MSC 35K Shuttle Orbiter Wing Tip Leading Edge in the MSC 10 NW ArC-Heated Tunnel," Enclosure to Memorandum ES5/7-15(0)/ $171(M)$, NASA, MSC, 1970 . McDonnell-Douglas Corp.," Space Shuttle Phase B Study System Extension," Final Report, Part II, Vol. I, Technical Report, System and Orbiter, MDC EO 558, p. B.3-25, March 15, 1972.

47 Seiferth, R. W., "Ablative Heatshields Design for Space Shuttle," MASA CR-132,282 (1973).

48 Dolan, C. M., "Study for Development of Elastomeric Thermal Shield Naterials," NASA CR-186.

49 Price, A. B., "Design Report: Thermal Protection System X-15A-2," NASA CR-82003, Jan. 1968.

Symiy, E. D., and Pears, C. D., "Properties of Ablation and Insulation Materials" ( 3 volumes), NASA CR-111912, June 1971. Thomas, H. K., and Recesso, J. V., "Ablative Composites for Lifting Reentry Thermal Protection," AFM-TR-67-270, July 1968 (Part II), April 1970 (Part III). 
Weber, G. A., Ronthaler, ‥, : : I'Connor, :. J., "Low-Density Heat-

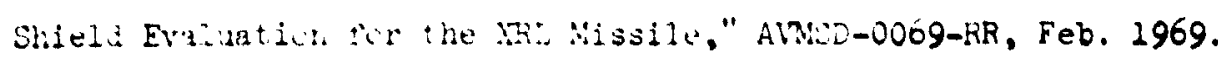
Welsh, W. E. and Starner, K. E., "Low Density Ablation Materials Survey," Grumman Aerospace Corp. Report DD-669 (6.240-10)-5, Jan. 1966.

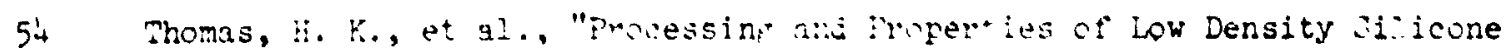
Ablator Mod i," AlSSD-0380-67-RM," Oct. 1967.

55 Grumman Aerospace Corp., "Shuttle System Evaluation and Selection,"

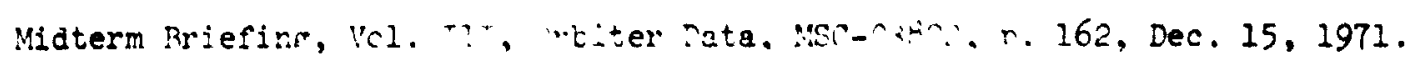

56 Private communication from S. Tompkins, Thermal Protection Branch, NASA Langley Research Center.

57 Neltzer, J., Slaughter, J., and Sallis, D., "PRIME Vehicle Heat Protection System Froceedings of Asset/Advarced Iifting Reentry Technology Symposium," Dec. 1965.

58 Lockheed Iorp., "AIterrate Space Shuttle Concepts Studies," LMSC A995887 ACS 186, Nov. 3, 1971.

59 Mecown, U. W., Davis, R. M., "Radiative vs Ablative Heatshield Concepts for Manned Entry Vechicles,. J. Spacecraft Rockets, 2., 1967, pp. 725-731. 
60 Moodie, D. M., "Apollo Heatshield Block II," Final Thermodynamics Report, Vol. I, Summary Doc. AVSSD - 0095-67-CR, April 15, 1967, Avco* Systems Division.

61 Deriugin, V., et.al., "Thermal-Structural Combined Loads Fesign Criteria Study," NASA CR-2102, Oct. 1972.

62 (Anon.) "Structural Design Criteria Applicable to a Space Shuttle," NASA SP-8057, Jan. 1971.

63 Thomas, H. K., et al., "Processing and Properties of Low Density Silicone Ablator Mod 7, Avco Systems Div., Report AVSSD - 0380-67 - RM, Oct. 1367.

64 Thomas, H. K., et al., "Ablative Composites for Lifting Reentry Thermal Protection," Report AFML-TR-67-270, Part I, Sept. 1967.

65 Nagler, R.G., et al., "A Light-weight 6.5-ft Aeroshell for an Early Mars Probe Mission," JPL TR 32-1325, Sept. 1968.

66 Hess, T., et al., "Final Report for RSI TPS Development Program," Report GE-EYP-012, General Electric Co., Phila., Pa., May 1972.

67 Dietrich, R.W., "Design Tests: Iosd/Deflection Test for Candidate Seals Design," Avco Memo SS-RWD-40, Avco Systems Div., May 18, 1972.

68 Gasser, G., and Moodie, M., "Apollo Heatshield Block II, "Final Thermodynamics Report, Vol. VI, Ablator Analysis, AVSSD - 0095-67-CR, April 15, 1967, Avco Systems Div.

69 Herb. R. B., et al., "Apollo TPS Development," American Irstitute of Aeronautics and Astronautiss, Paper 68-1142, 1968.

70 Mosher, D. A., "I. E. Seal Tests," Avco SD Memo F360-73-DAM-44, Avco Systems Div., Jan. 9,1973. 
71 Hoercher, H. and Feeman, R., "Evnluation of jardidate L. E. Nose Region Seals," Avco TR-K500-73-HEH-RF-85, Avco Systems Division, Apri1 2, 1973. Movies of ROVERS Arc Run N. 623-1, 2, 2, and 624-1, 2, A.co systems Div.

73 Private communication from D. Mosher (Avco) to P. Roy (Avco) Nov. 1972.

74 Buttram, R. J., "Space Shuttle TPS," Iockheed Corp., Vol. I, Final Report, IMSC-D152738, Jan. 1972.

Winkler, H. B. et al., "A Feasibility Study of an Experiment for Determining the Properties of the Nars Atmosphere," Final Report, Vol. III, Subsystem and Technical Analysis, Book II, Mechanics and Design, NASA CR-73,005, 1966, pp. 6-9. Boppe, C., Unpublished Grumman - Neumann Wing-Body Computer Code, 1970. Tillian, D. J. and Rosese, T. J., "Thermal Evaluation Tests of Abletor and Wood Models of the MSC $25 \mathrm{~K}$ Shuttle Orbiter Wing Tip Leading Edge in the MSC $10 \mathrm{MW}$ Arc-Heated Tunnel" 